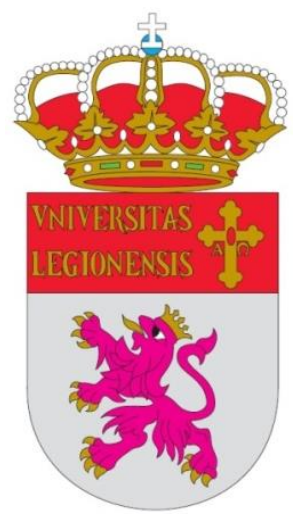

UNIVERSIDAD DE LEÓN

Comunidad@Buenas Prácticas de Seguridad, Salud y Calidad de Vida en el trabajo INIAV

"Factores críticos de éxito"

Comunidade@boas práticas segurança, saúde e qualidade de vida no trabalho INIAV

"Fatores críticos de sucesso"

Programa de Doctorado titulado "Salud Discapacidad, Dependencia y Bienestar"

Tutor: Dr. D. Jesús Angel Seco Calvo

Directores: Dr. D. Jesús Angel Seco Calvo

Doutora Casimira Flor da Costa Santos

Dr. D. Óscar Seco Calvo

Tesis Doctoral presentada para obtener el grado de Doctora por la Universidad León

Élia Cristina de Sousa Figueiredo

León, 2019 


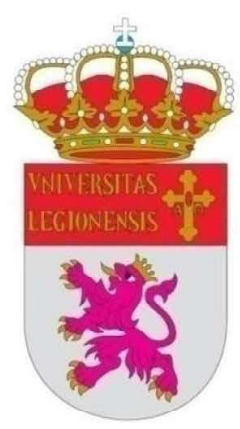

\section{INFORME DEL DIRECTOR DE LA TESIS}

(Art. 11.3 del R.D. 56/2005)

El Dr. D. Jesús Angel Seco Calvo, como Director 1 de la Tesis Doctoral titulada

\section{Comunidad @ Buenas Prácticas de Seguridad, Salud y Calidad de Vida en el trabajo}

\section{INIAV}

"Factores críticos de éxito"

Realizada por Doña Élia Cristina de Sousa Figueiredo en el Programa de Doctorado Salud, Discapacidad, Dependencia y Bienestar de la Universidad de León, informa favorablemente el depósito de la misma, dado que reúne las condiciones necesarias para su defensa.

Lo que firmo, para dar cumplimiento al art. 11.3 del R.D. 56/2005, en León a de de 2019.

Dr. Jesús Seco Calvo

Firmado por SECO CALVO JESUS - 07865930E el día 28/10/2019 con un certificado emitido por AC FNMT Usuarios

1 Si la Tesis está dirigida por más de un Director tienen que constar los datos de cada uno y han de firmar todos ellos. 


\section{INFORME DEL DIRECTOR DE LA TESIS}

(Art. 11.3 del R.D. 56/2005)

E2 Doutora Casimira Flor da Costa Santos, como Director 2 de la Tesis Doctoral titulada

\section{Comunidad@Buenas Prácticas de Seguridad, Salud y Calidad de Vida en el trabajo INIAV}

"Factores críticos de éxito"

Realizada por Doña Élia Cristina de Sousa Figueiredo en el Programa de Doctorado Salud, Discapacidad, Dependencia y Bienestar de la Universidad de León, informa favorablemente el depósito de la misma, dado que reúne las condiciones necesarias para su defensa.

Lo que firmo, para dar cumplimiento al art. 11.3 del R.D. 56/2005, en León a de de 2019.

Dra. Casimira Flor Santos

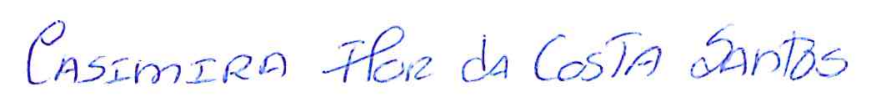

2 Si la Tesis está dirigida por más de un Director tienen que constar los datos de cada uno y han de firmar todos ellos. 


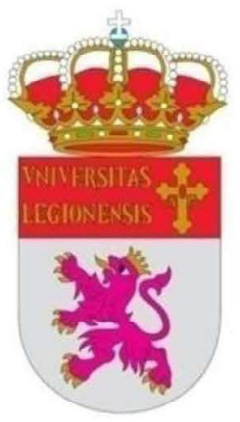

INFORME DEL DIRECTOR DE LA TESIS

(Art. 11.3 del R.D. 56/2005)

E3 Prof. Dr. Óscar Seco Calvo, como Director 2 de la Tesis Doctoral titulada Comunidad@Buenas Prácticas de Seguridad, Salud y Calidad de Vida en cl trabajo INIAV

"Factores críticos de éxito"

Realizada por Doña Élia Cristina de Sousa Figueiredo en el Programa de Doctorado Salud, Discapacidad, Dependencia y Bienestar de la Universidad de León, informa favorablemente el depósito de la misma, dado que reúne las condiciones necesarias para su defensa.

Lo que firmo, para dar cumplimiento al art. 11.3 del R.D. 56/2005, en León a de Firmado por SECO CALUQ 20\$CAR - DNI 07989559A el día 28/10/2019 con un certificado emitido por AC Administración Pública

Dr. Óscar Seco Calvo

2 Si la Tesis está dirigida por más de un Director tienen que constar los datos de cada uno y han de firmar todos ellos. 


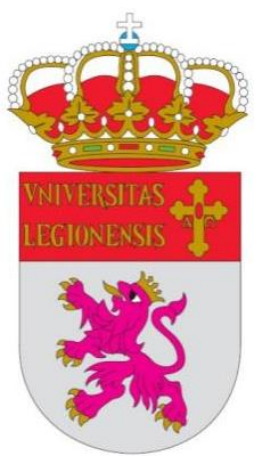

\section{ADMISIÓN A TRÁMITE DE LA TESIS DOCTORAL}

El órgano responsable del programa de doctorado en Salud, Discapacidad, Dependencia y Bienestar, regulado por el R.D. 99/2011 en su reunión celebrada el día de , ha acordado dar su conformidad a la admisión a trámite de lectura de la Tesis Doctoral titulada: "Comunidad @ Buenas Prácticas de Seguridad, Salud y Calidad de Vida en el trabajo INIAV - "Factores críticos de éxito" dirigida por los Dr. D. Jesús Angel Seco Calvo y Doutora Casimira Flor da Costa Santos y Dr. D. Óscar Seco Calvo, elaborada por Doña Élia Cristina de Sousa Figueiredo y cuyo título en inglés es el siguiente Community@Good Practices of Safety, Health and Quality of Life at Work INIAV - "Critical factors of success"

Lo que firmo en León a de de 2019.

El Secretario,

Fdo.: Má Nélida Fernández Martínez $\mathrm{V}^{\mathrm{o}} \mathrm{B}^{\mathrm{o}}$

El Presidente de la Comisión Académica,

Fdo.: Dr. Jesús Seco Calvo 


\section{Agradecimentos}

Sentida gratidão.

Ao meu sempre Professor Doutor Serafín de Abajo Olea, que iniciou este processo comigo e me deu o apoio possível e a sua amizade.

Ao meu diretor de tese Professor Doutor Jesús Angel Seco Calvo, por me ter aceite e reintegrado neste programa de doutoramento, após o meu primeiro programa de doutoramento ter sido extinto e também pelo apoio na conclusão da dissertação da tese.

À minha orientadora e diretora de tese Doutora Casimira Flor da Costa Santos, a verdadeira, a amiga, a sempre presente e que nunca permitiu que eu desistisse, que fez com que eu acreditasse nas minhas capacidades e que tudo seria possível com esforço e dedicação, que me amparou ao longo deste vasto percurso e espero que me acompanhe p'la vida.

À Professora Doutora Rosário Cabrita os ensinamentos na temática Gestão do Conhecimento.

À Dra Cláudia Sánchez Lara e Dr. António Neto o apoio na tradução e correção dos documentos em Espanhol.

Ao Grupo de Animadores de Prevenção do INIAV /Oeiras e Polo de Santarém todo o trabalho desenvolvido e apoio para que o mesmo chegasse a bom porto.

À minha querida amiga Margarida Pombo.

Ao Paulo Varanda as horas de paciência e apoio na formatação e revisão do trabalho final.

Aos meus pais e ao meu filho Tomás, por serem e por estarem na minha vida! 
Doctorado en Salud, Discapacidad, Dependencia y Bienestar

“A gratidão é a virtude das almas nobres"

Esopo

2

Comunidad@Buenas Prácticas de Seguridad, Salud e Calidad de Vida en el trabajo INIAV

"Factores críticos de éxito" 


\section{Índice Geral}

Índice de Ilustrações........................................................................................................................... 10

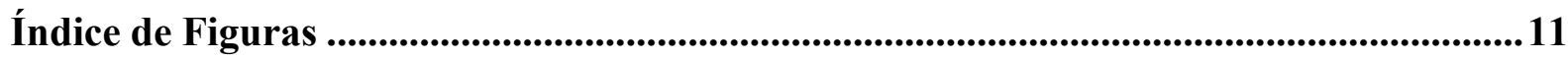

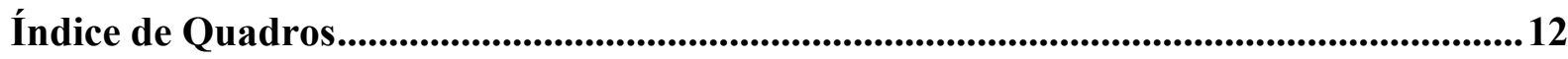

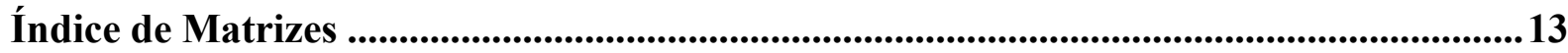

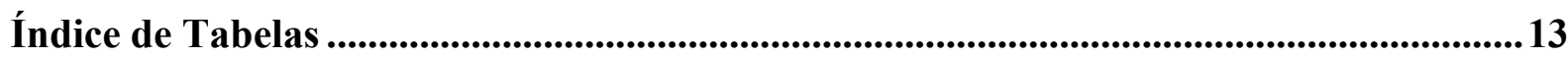

Índice de Gráficos.................................................................................................................................... 13

Siglas/Abreviaturas ...................................................................................................................... 14

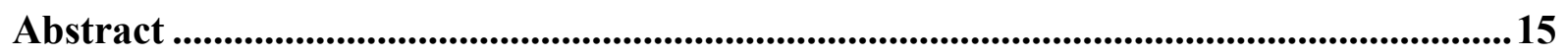

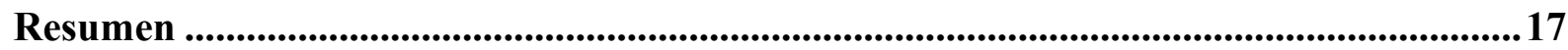

Resumo …..................................................................................................................................... 19

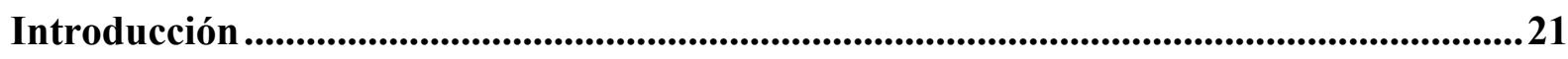

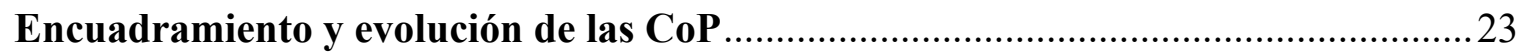

El aprendizaje individual para el aprendizaje colaborativo ………….....................28

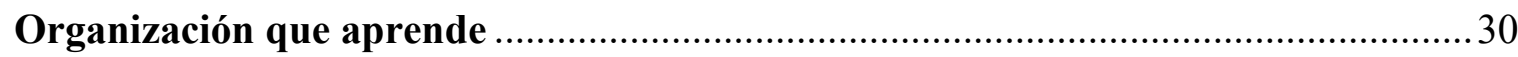

Organizaciones basadas en el conocimiento …………………...................................... 31

Comunidad de práctica como enfoque para la gestión del conocimiento ………….....32

Factores condicionantes al intercambio de conocimiento dentro de las Comunidades 34

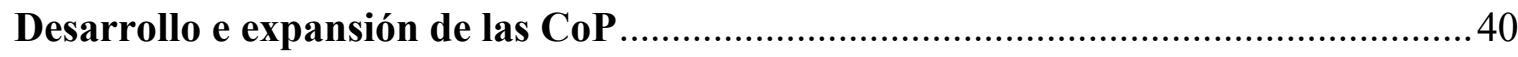

Dimensiones de análisis de los factores críticos de éxito para el mantenimiento de las

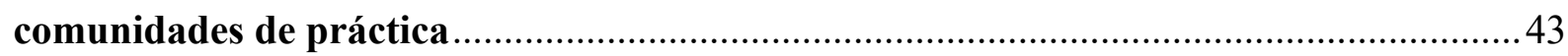

De la Expansión de la CoP a su Desaparición ..........................................................4 


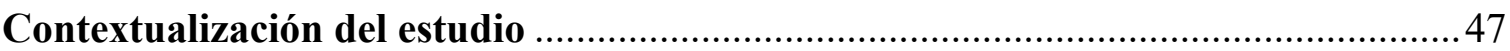

Este trabajo se fundamenta en el estudio de 3 tópicos esenciales: ......................... 47

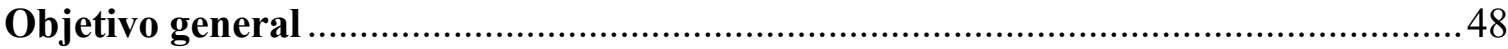

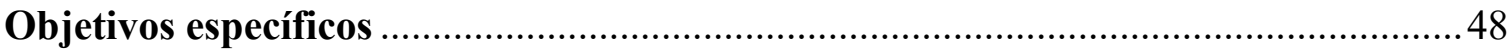

Identificación del problema de nuestro trabajo de investigación .............................. 48

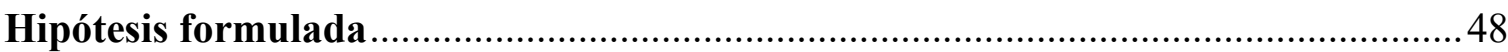

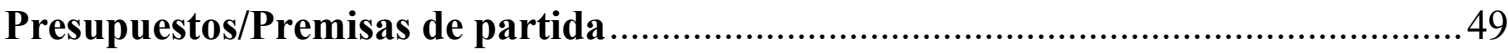

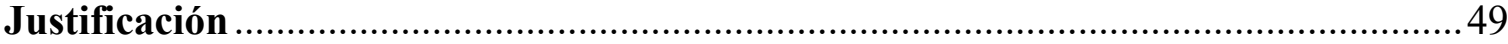

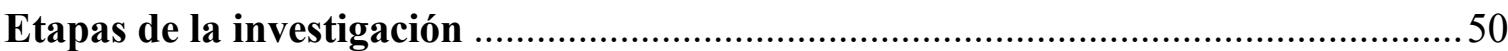

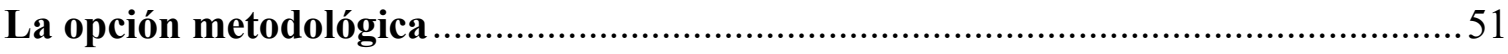

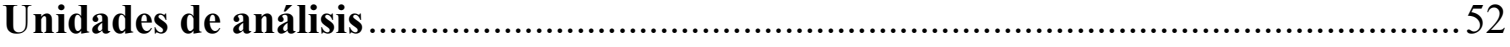

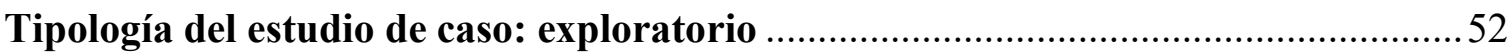

La recoja y análisis de la información en estudios de caso ....................................5 52

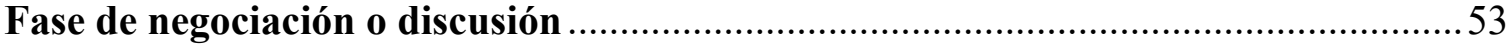

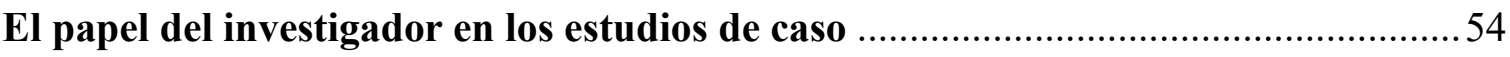

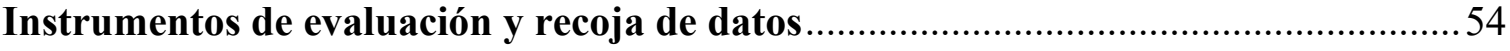

Los participantes y el contexto de la Investigación ..................................................55

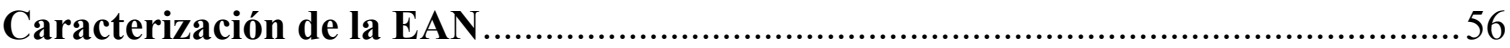

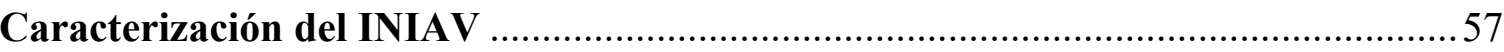

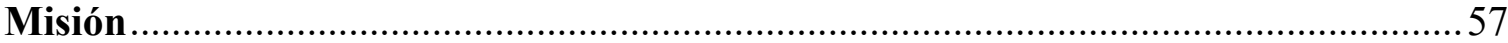

Los participantes, el contexto de la investigación y las características de la muestra58

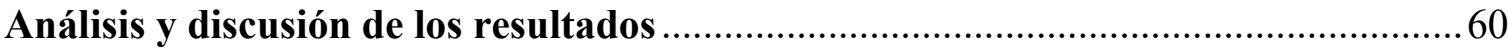

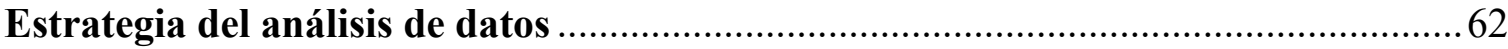

Análisis de la Encuesta en soporte de papel aplicado en una acción presencial...............91

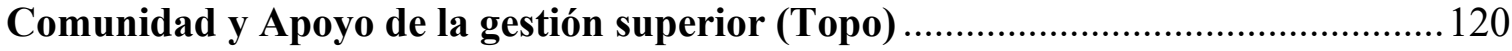

Conclusiones y propuesta de próximos trabajos................................................. 136

Capítulo 1 ......................................................................................................................................... 138

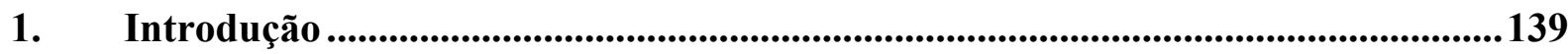

4

Comunidad@Buenas Prácticas de Seguridad, Salud e Calidad de Vida en el trabajo INIAV

"Factores críticos de éxito" 
1.1. Premissas de que partimos para a investigação......................................................141

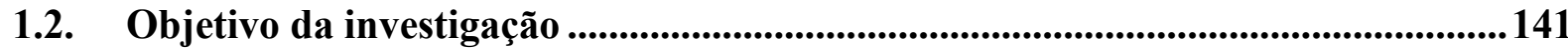

1.3. Identificação do problema da investigação .......................................................141

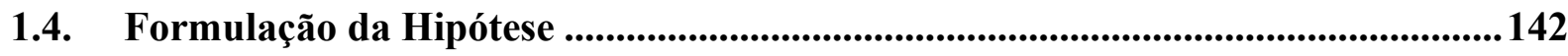

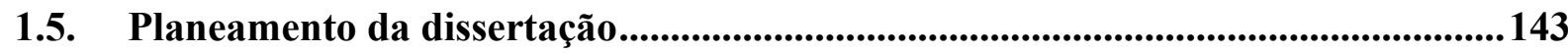

Capítulo 2 ...................................................................................................................................... 145

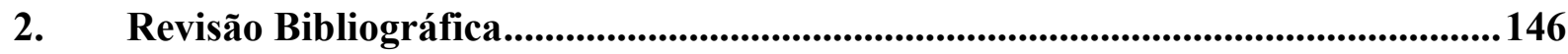

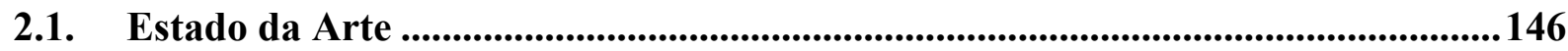

2.2. Da aprendizagem individual para a aprendizagem colaborativa .......................... 149

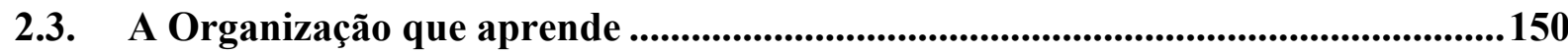

2.4. Organizações baseadas em conhecimento ..................................................151

2.5. Comunidade de Prática como abordagem para a Gestão do Conhecimento.......152

2.6. Organização de uma Comunidade de Prática .................................................. 155

2.7. Da Expansão da CoP ao Desaparecimento ........................................................... 155

2.8. Caraterísticas das Comunidades de Prática ................................................... 157

2.9. O papel do capital social nas Comunidades de Prática...........................................160

2.10. Enquadramento e evolução das CoP ........................................................................ 162

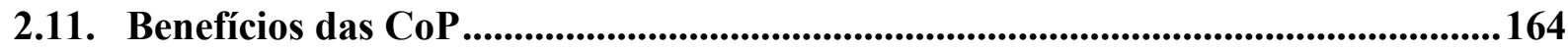

2.12. Fatores condicionantes à partilha de conhecimento dentro das Comunidades ... 164

2.12.1. Papeis dos membros da Comunidade de Prática ..............................................172

2.12.2. Papel do moderador/ Líder ..................................................................173 
2.12.3. Participação de especialistas .........................................................................................174

2.13. Criação, Estrutura e Desenvolvimento das CoP.........................................................174

2.14. Fatores Críticos de Sucesso....................................................................................178

2.15. Comunidades Virtuais de Prática | CoPV ....................................................................... 179

2.15.1. Vantagens na adoção de uma Wiki ..............................................................................180

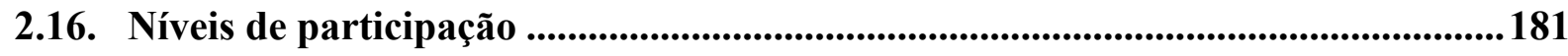

2.16.1. Ativos periféricos ..........................................................................................................182

2.16.2. Participação de especialistas ..........................................................................................183

2.17. Condução de eventos presenciais ...................................................................................183

2.18. Dimensões de análise dos fatores críticos de sucesso para a manutenção das comunidades de prática .......................................................................................................................184

2.18.1. Dimensão Organizacional .............................................................................................184

2.18.2. Dimensão Individual................................................................................................ 185

2.18.3. Dimensão Liderança ....................................................................................................... 187

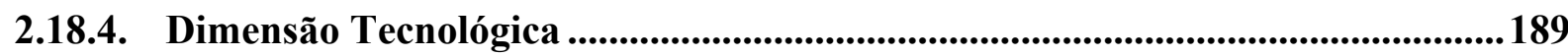

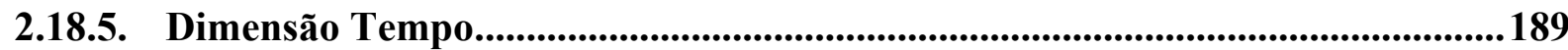

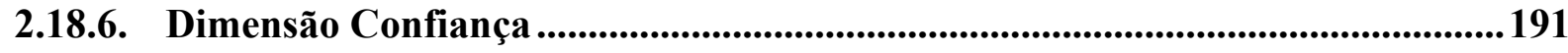

2.19. Estímulo ao desenvolvimento das CoP ........................................................................197

2.20. Ciclo de Vida das Comunidades de Prática ..................................................................200

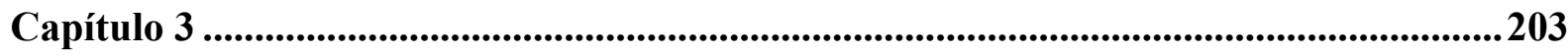

3. A opção metodológica....................................................................................................204

6

Comunidad@Buenas Prácticas de Seguridad, Salud e Calidad de Vida en el trabajo INIAV

"Factores críticos de éxito" 


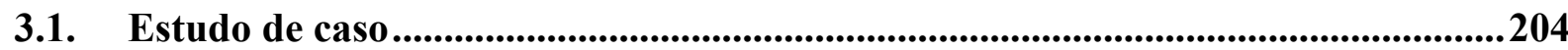

3.2. Funcionamento e sobrevivência da CoP Boas Práticas SST e Qualidade de Vida204

3.2.1. Estratégia metodológica do estudo..................................................................204

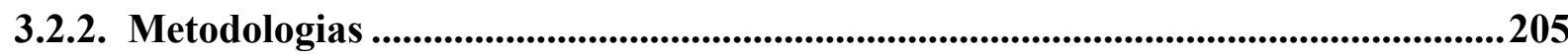

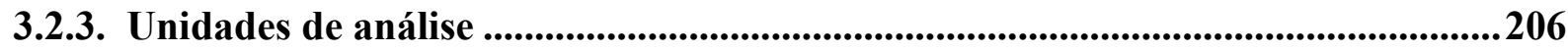

3.2.4. Tipologia do estudo de caso: exploratório ...................................................207

3.2.5. A recolha e análise da informação em estudos de caso ........................................207

3.2.6. Fase de negociação ..........................................................................................................208

3.2.7. O papel do investigador nos estudos de caso...........................................................208

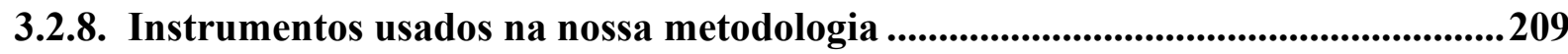

3.2.9. Os participantes e o contexto da Investigação ...............................................209

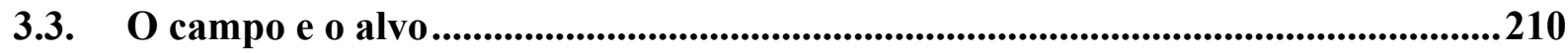

3.4. Caraterização das Organizações do estudo.....................................................210

Capítulo 4 ................................................................................................................................. 215

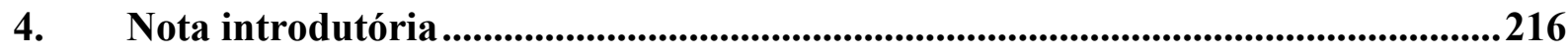

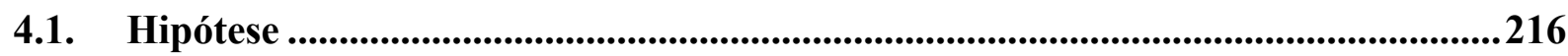

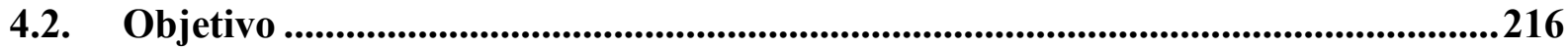

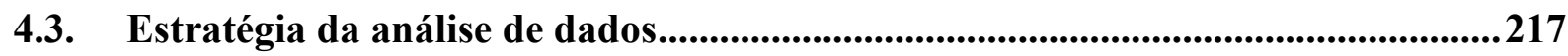

4.3.1. Utilização de Múltiplas Fontes de Evidência ............................................................. 217

4.4. Análise do Inquérito em suporte de papel aplicado numa ação presencial .........248

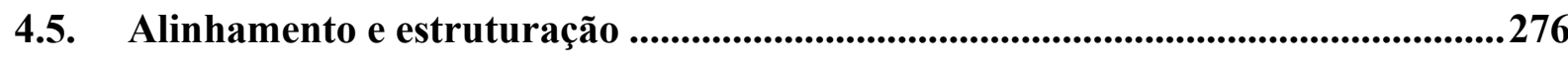

7

Comunidad@Buenas Prácticas de Seguridad, Salud e Calidad de Vida en el trabajo INIAV

"Factores críticos de éxito" 


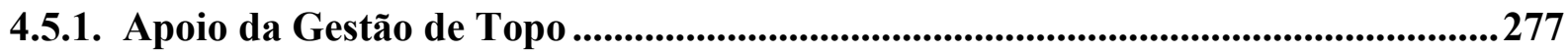

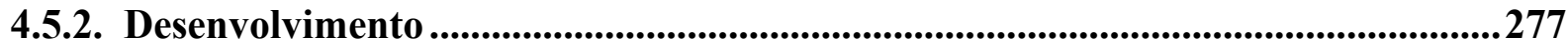

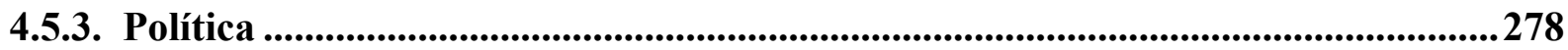

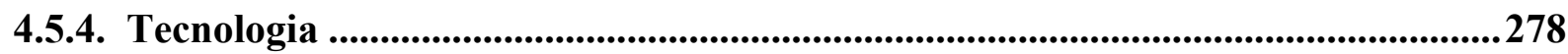

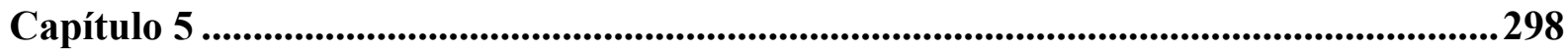

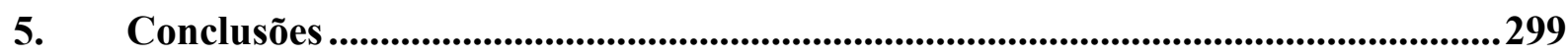

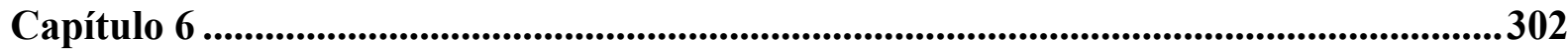

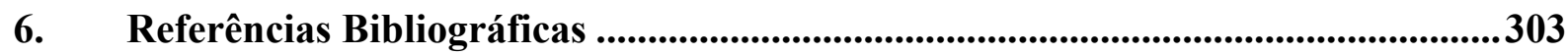




\section{Anexos al Grupo A | Instrumentos de evaluación}

AI: Guión de entrevista semiestructurada con el coordinador de la comunidad embrionaria (CoPGAPEAN)

AII: Guión de entrevista semiestructurada con la comunidad embrionaria (CoPGAPEAN)

AIII: Tipología de documentos para analizar en CoPGAPEAN

AIV: Surveys online 2012

AV: encuestas 2-8-10-12 "En línea"

\section{Anexos al Grupo B | Análisis de los instrumentos}

BI: Análisis de contenido de entrevista semiestructurada del coordinador de la Comunidad de Prácticas CoPGAPEAN y CoPSSQVTINIAV

BII: Análisis de contenido de entrevista semiestructurada con los miembros de la COPGAPEAN

BIII: Análisis de documentos $\mid$ Actas de las reuniones, productos preparados y interacciones por la CoPGAPEAN

BIV: Tratamiento de resultados encuestas en línea 2012

BV: Análisis de la consulta aplicada en una acción in situ

BVI: ICOS

9

Comunidad@Buenas Prácticas de Seguridad, Salud e Calidad de Vida en el trabajo INIAV

"Factores críticos de éxito" 


\section{Índice de Ilustrações}

Ilustração 1 - Fluxograma da dissertação...................................................146

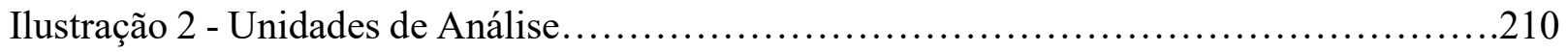

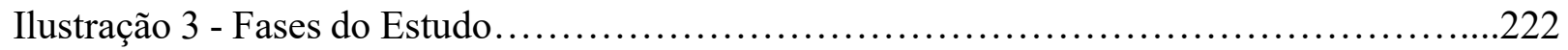

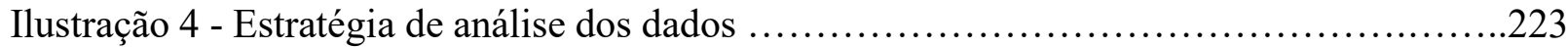

Ilustração 5 - Avaliação da Cultura Organizacional e de Segurança - ICOS (CIS/ISCTE) ....224

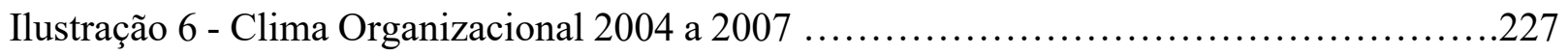

Ilustração 7 - Desenvolvimento da Confiança/Clima facilitador positivo $2004-2008$........228

Ilustração 8 - Ação Presencial realizada em 2006 -Seminário ...............................229

Ilustração 9 - Fases de mudança Organizacional e influência na CoPGAPEAN..................243

Ilustração 10 - Ferramenta de Trabalho Colaborativo 2012 ......................................244

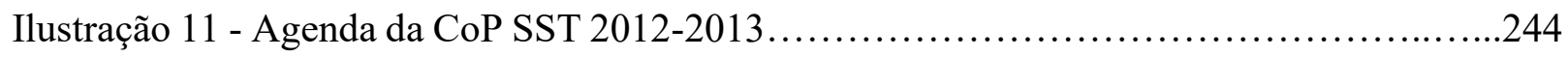

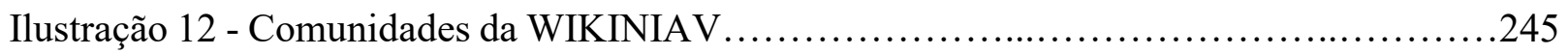

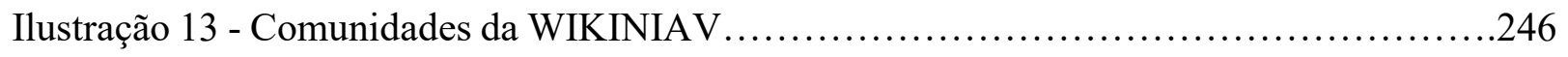

Ilustração 14- Combinação mais escolhida questão 2 Surveys online.............................249

Ilustração 15 - Combinação mais escolhida questão n ${ }^{\circ} 8$ Surveys online ..........................250

Ilustração 16 - Contribuição dos elementos da prática para o resultado.......................254

Ilustração 17 - Contribuição dos elementos da prática apoio da gestão de topo para o resultado257

Ilustração 18 - Contribuição dos elementos da prática apoio desenvolvimento para o resultado258

Ilustração 19 - Contribuição dos elementos da prática apoio desenvolvimento para o resultado259

Ilustração 20 - Contribuição dos elementos da prática apoio | Política para o resultado .........260

Ilustração 21 - Contribuição dos elementos da prática apoio desenvolvimento para o resultado |

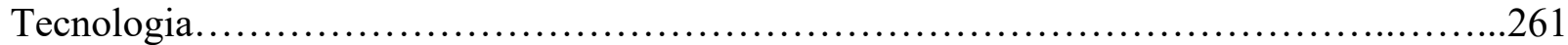

Ilustração 22 - Contribuição dos elementos da prática apoio desenvolvimento para o resultado |

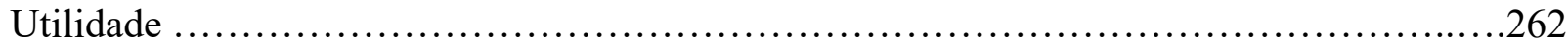

Ilustração 23 - Práticas essenciais para o resultado confiança (2009-2014) ..................263

Ilustração 24 - Práticas essenciais para o resultado Contribuição (2009-2014) .................264

Ilustração 25 - Práticas essenciais para o resultado Sentimento de Pertença (2009-2014) .....265

10

Comunidad@Buenas Prácticas de Seguridad, Salud e Calidad de Vida en el trabajo INIAV

"Factores críticos de éxito" 


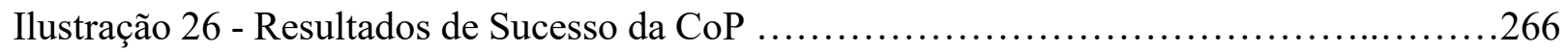

Ilustração 27- Constructo de resultados de sucesso para a manutenção da CoPGAPEAN e sua

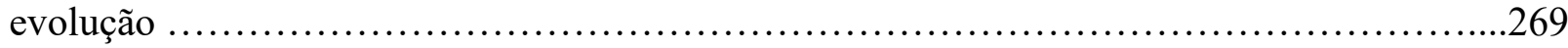

Ilustração 28 - Fases de Desenvolvimento da CoP no INIAV ................................271

Ilustração 29 - Influência Positiva da Gestão de Topo 2004-2008_.............................281

Ilustração 30 - Influencia positiva da Coordenação da CoP 2008-2014 .........................281

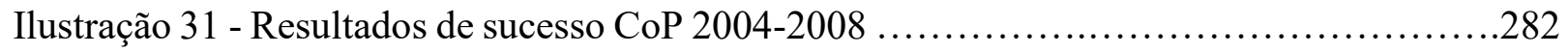

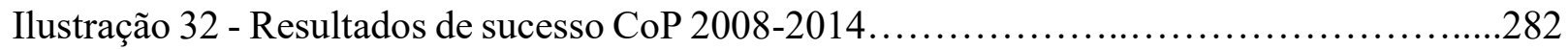

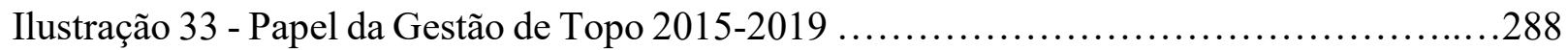

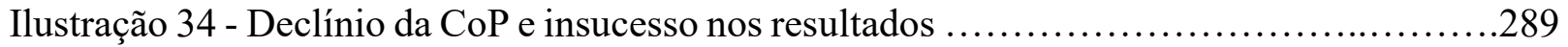

Ilustração 35 - Estratégia do Projeto Cultura de Segurança .......................................291

Ilustração 36 -Envolvimento da Gestão de Topo da EAN ....................................292

Ilustração 37 - Organizações envolvidas no projeto | O papel de cada um no projeto..............293

Ilustração 38 - Diagnóstico da Cultura de Segurança e saúde......................................2294

Ilustração 39 - Envolvimento e suporte da Gestão de Topo e Chefias intermédias ................295

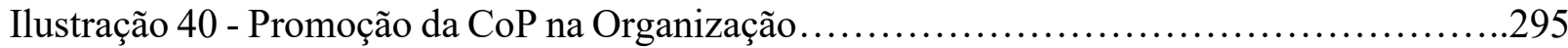

Ilustração 41 - Disponibilização de recursos para os membros da CoP ..........................296

Ilustração 42 - Recursos cedidos pela Gestão de Topo à estrutura da CoP ........................296

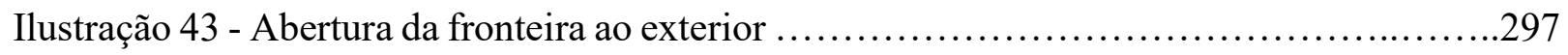

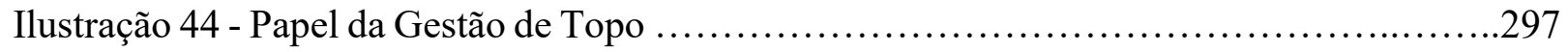

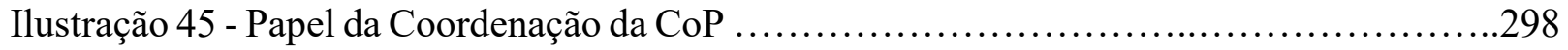

Ilustração 46 - Caminhos Estratégicos da Gestão de Topo nos diferentes períodos ..............299

\section{Índice de Figuras}

Figura 1 - Estágios de desenvolvimento das Comunidades de Prática .........................204

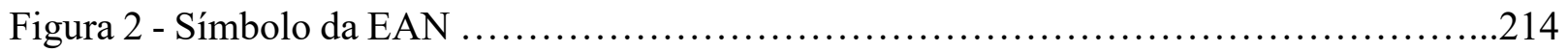

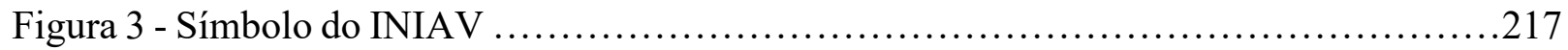

Figura 4 - O INIAV sua localização e dispersão geográfica em Portugal ......................218 
Figura 5 - Seminário EAN/INA cultura de Segurança e Saúde no Trabalho ..................229

Figura 6 - Partilha do estudo desenvolvido com outras Organizações . .....................231

Figura 7 - Partilha de conhecimento: Confiança, Utilidade, Sentimento de Pertença ...........236

Figura 8 - Documentos partilhados pelos facilitadores da $\mathrm{CoP}$ em reuniões alargadas com a Gestão de Topo e chefias (2004-2008). Comunicação face to face ..........................237

Figura 9 - Formação do Grupo facilitador de mudanças face a SST ........................238

Figura 10 - Envolvimento interno e Facilitação forte aumentando a confiança dos membros da

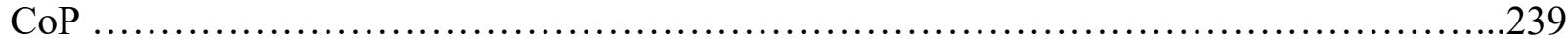

Figura 11 - Cultura Positiva e Facilitadora ...........................................239

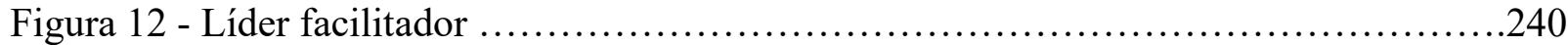

Figura 13 - Envolvimento e cedência de tempo e infraestruturas para o funcionamento da

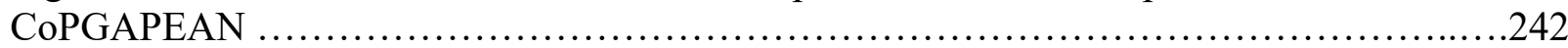

Figura 14 - Apresentação Pública da CoP virtual CoPSSQVTINIAV (2009-2014) ..........243

Figura 15 - Extrato da Resolução do Conselho de Ministros n. ${ }^{\circ}$ 28/2019 ...................273

\section{Índice de Quadros}

Quadro 1 - Descrição de cada um dos papéis dos membros da Comunidade ..................176

Quadro 2 - Síntese dos fatores críticos de sucesso (FCS) à manutenção das CoP e suas dimensões

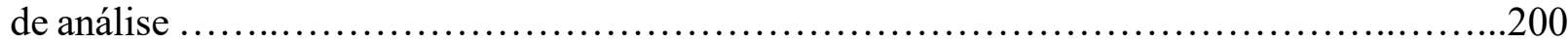

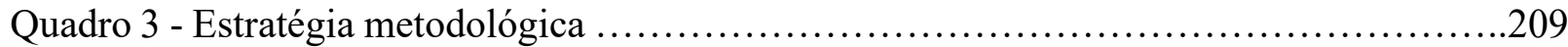

Quadro 4 - Instrumentos da Metodologia .............................................213

Quadro 5 - Desenvolvimento da Confiança CoPGAPEAN ................................228

Quadro 6 - Resultados de sucesso da CoPGAPEAN ....................................230

Quadro 7 - Práticas essenciais que reforçou o resultado do sucesso da CoPGAPEAN .......233

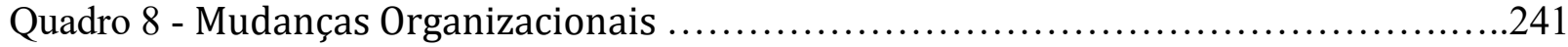

Quadro 9 - Apreciação do inquérito da Ação Presencial .................................252

Quadro 10 - Significado do constructo dos resultados alcançados pela CoP de 2004 a 2014 ..268

12

Comunidad@Buenas Prácticas de Seguridad, Salud e Calidad de Vida en el trabajo INIAV

"Factores críticos de éxito" 


\section{Índice de Matrizes}

Matriz 1 - Elementos essenciais das Práticas (Política | Coordenação da CoP | Tecnologia

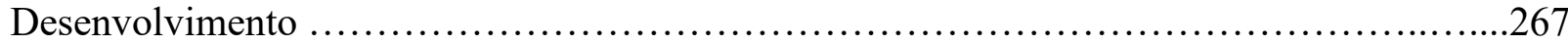

Matriz 2 - Elementos da prática x parâmetros individuais de cada prática ......................274

Matriz 3- Parâmetros individuais de cada prática (Política | Coordenação da CoP | Tecnologia |

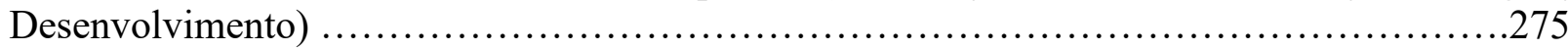

Matriz 4 - Práticas essenciais X resultados de sucesso da CoPGAPEAN e sua transformação CoP

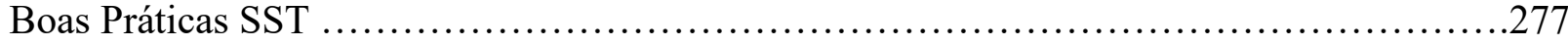

Matriz 5 - Práticas essenciais não implementadas em 2015-2019 que resultaram em insucesso da

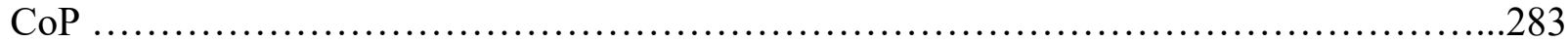

Matriz 6 - Elementos da prática x parâmetros individuais de cada prática ....................284

Matriz 7 - Elementos da prática x parâmetros individuais de cada prática ......................286

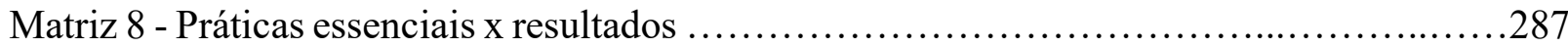

\section{Índice de Tabelas}

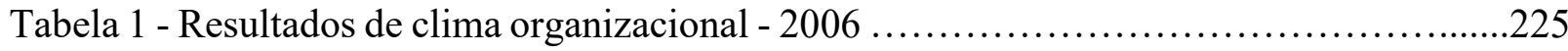

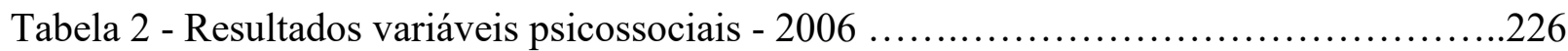

Tabela 3 - Caraterização da Amostra por sexo e por Carreira Profissional .......................247

\section{Índice de Gráficos}

Gráfico 1 - Apresentação gráfica Distribuição da amostra ...................................248

Gráfico 2 - Representação gráfica da distribuição da amostra por carreiras ....................248

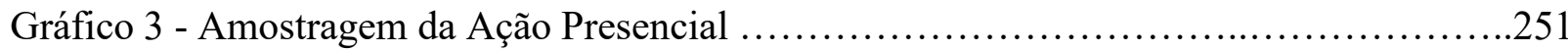




\section{Siglas/Abreviaturas}

- ACT: Autoridade para as Condições do Trabalho

- $\quad$ AP: Administração Pública

- APO: Asian Productivy Organization

- CoP: Comunidade de Prática

- $\quad$ CoPV: Comunidade de Prática Virtual

- $\quad$ CIKM: Canadian Institute of Knowledge Management

- $\quad$ CMC: Comunicação mediada por computador

- $\quad$ EaD: Educação à Distância

- $\quad$ FCS: Fatores críticos de sucesso

- $\quad$ GC: Gestão do Conhecimento

- $\quad$ INA: Instituto Nacional de Administração

- INIAV: Instituto Nacional de Investigação Agrária e Veterinária

- INRB: Instituto Nacional de Recursos Biológicos

- ITecn: Infraestrutura tecnológica

- ISCTE: Instituto Superior de Ciências do Trabalho e da Empresa

- $\quad$ TIC: Tecnologias de informação e comunicação

- $\quad$ NHS :(National Library for Health)

- $\quad$ SciELO: Scientific Electronic Library Online

- $\quad$ SHST: Segurança, Higiene e Saúde no Trabalho

- $\quad$ SST: Segurança e Saúde no Trabalho

- WIKINIAV: Ferramenta de trabalho colaborativo do INIAV

- HSST: Higiene, Salud y Securidad en el Trabajo 


\section{Abstract}

The communities of practice have been recognized as a structure that allows to create, share and apply knowledge in organizations, assisting in this way the implementation of strategies outlined when properly directed. Communities of Practice show a versatile and stimulating configuration capable of creating, transferring, retaining and using knowledge, while providing the organization that continues to learn. The great challenge is to make traditional, static, bureaucratic, verticalorganizing, routine-based organizations with individualistic work cultures evolve into organizations that learn. For (Gairín, J. S., 2000), the path towards the organizations that learn is based on a growing autonomy and collaboration among its members: organizations that privilege collaborative learning in a context of organizational autonomy raise the True communities of practice. With this work, we seek to study an organization in which communities of virtual practices are already present and specifically we focus on the community of sharing good SST practices and quality of life at work. The objective of our work consisted in analyzing the critical elements of the essential practices for the success and survival of this community, assuming that without the work developed by $\mathrm{CoP}$ Prevention animators who formed the 1st presential Community of knowledge sharing in this domain the virtual CoP community for sharing good SST practices and quality of life was achieved. The hypothesis formulated for our investigation has been validated and we elect as essential practices to ensure successful results and the correct functioning and survival of the community of good SST practices and quality of life at work, having as elements essential of these practices: culture, alignment and structuring, support of the organization's top management, strong leader/coordination, development, policy and technology. These are the essential practices that have derived from successful results for the CoP and these results are trust; The sense of belonging; The usefulness and the contribution that developed in the period in which the CoP embryoniccommunity of practice of the preventive animators was formed and which remained until its transformation into the community of mixed practice (Virtual and Presential) the community of Good practices of INIAV. Our study was exploratory and analyzed a community of practice in the field of occupational safety and Health in an agrarian research organization in the Portuguese public sector for a period of 15 years from its birth to its decline that coincides with a change of leadership 
of the organization that does not value collaborative work and declines the functioning of the collaborative work platform at a time when the conditions for continuity were created. The practice of involvement of the top management is with involvement and support, flexibility of activities, promotion of $\mathrm{CoP}$ and availability of resources is a facilitator factor or will be inhibitor even if the leadership of the CoP is strong and that the culture of sharing is Positive if it is not the will of the Organization's management the community dies slowly if it is already formed or will never be born because it is not top management priority.

Keywords: communities of practice; CoP; Essential practices; Inhibitory practices; Collaborative work; SST; Knowledge sharing; CoPV 


\section{Resumen}

Las comunidades de práctica se han sido reconocidas como una estructura que permite crear, compartir y aplicar conocimientos en la organización, asistiendo de esta manera a la implementación de estrategias esbozadas cuando se dirigen adecuadamente. Las comunidades de práctica muestran una configuración versátil y estimulante capaz de crear, transferir, retener y utilizar el conocimiento, al tiempo que proporciona la organización que sigue aprender. El gran desafío es hacer que las organizaciones tradicionales, estáticas, burocráticas, de organización vertical y basadas en las rutinas con culturas de trabajo individualistas evolucionen en organizaciones que aprenden. Para (Gairín, J. S., 2000), el camino hacia las organizaciones que aprenden se basa en una creciente autonomía y colaboración entre sus miembros: las organizaciones que privilegian el aprendizaje colaborativo en un contexto de autonomía organizativa elevan la verdaderas Comunidades de Práctica. Con este trabajo, buscamos estudiar una organización en la que las comunidades de prácticas virtuales ya están presentes y específicamente nos centramos en la comunidad de compartir buenas prácticas de SST y calidad de vida en el trabajo. El objetivo de nuestro trabajo consistió en analizar los elementos críticos de las prácticas esenciales para el éxito y la supervivencia de la comunidad de buenas prácticas de SST y la calidad de vida en el trabajo, suponiendo que sin el trabajo desarrollado por la CoP (Animadores de Prevención) que formaron la $1^{\mathrm{a}}$ comunidad presencial de intercambio de conocimientos en este ámbito, se logró la comunidad virtual de CoP para compartir buenas prácticas de SST y calidad de vida. La hipótesis formulada para nuestra investigación ha sido validada y elegimos como prácticas esenciales para asegurar resultados exitosos y el correcto funcionamiento y supervivencia de la comunidad de buenas prácticas de SST y calidad de vida en el trabajo, teniendo como elementos esenciales de estas prácticas: cultura, alineamiento y estructuración, apoyo de la alta dirección de la organización, fuerte líder/coordinación, desarrollo, política y tecnología. Estas son las prácticas esenciales que han derivado de resultados exitosos para la $\mathrm{CoP}$ y estos resultados son de confianza; El sentimiento de pertenencia; La utilidad y la contribución que se desarrollaron en el período en el que se formó la Comunidad embrionaria de la $\mathrm{CoP}$ de la práctica de los animadores preventivos y que permaneció hasta su transformación en la comunidad de la práctica mixta (virtual y presencial) la comunidad de 
Buenas Prácticas de INIAV. Nuestro estudio fue exploratorio y analizó una comunidad de práctica en el campo de la seguridad y la salud en el trabajo en una organización de investigación agraria en el sector público portugués por un período de 15 años desde su nacimiento hasta su declive que coincide con un cambio de liderazgo de la organización que ha dejado de valorar el trabajo colaborativo y rechaza el funcionamiento de la plataforma de trabajo colaborativo en un momento en que se crearon las condiciones para la continuidad. La práctica de la participación de la alta dirección es con la participación y el apoyo, la flexibilidad de las actividades, la promoción de la CoP y la disponibilización de recursos es un factor facilitador o será inhibidor, aunque el liderazgo de la CoP sea fuerte y que la cultura de compartir sea positiva si acaso no sea de la voluntad de la organización la comunidad se muere lentamente si ya estuviera formada o nunca nacerá pues no será prioridad de la gestión de arriba.

Palabras claves: Comunidades de Práctica; CoP; Prácticas esenciales; Prácticas inhibitorias; Trabajo colaborativo; SST; Intercambio de conocimientos; CoPV 


\section{Resumo}

As comunidades de prática têm sido reconhecidas como uma estrutura que permite criar, partilhar e aplicar conhecimento nas organizações, auxiliando desta forma a implementação das estratégias delineadas quando corretamente direcionadas. As comunidades de prática mostram-se uma configuração versátil e estimulante capaz de criar, transferir, reter e usar o conhecimento, ao mesmo tempo que proporciona à organização que continue a aprender. O grande desafio, consiste em fazer com que as organizações tradicionais, estáticas, burocráticas, de organização vertical, sustentadas na rotina, com culturas de trabalho individualistas, evoluam para organizações que aprendem. Para (Gairín, J. S., 2000), o caminho em direção às organizações que aprendem assenta numa crescente autonomia e colaboração entre os seus membros: as organizações que privilegiam uma aprendizagem colaborativa num contexto de autonomia organizacional elevam-se a verdadeiras comunidades de prática. Com o presente trabalho, procuramos estudar uma organização em que as comunidades de prática virtuais já estão presentes e especificamente vamo-nos centrar na Comunidade de Partilha de Boas Práticas SST e Qualidade de Vida no Trabalho. O objetivo do nosso trabalho consistiu em analisar os elementos críticos das práticas essenciais para o sucesso e sobrevivência da referida comunidade, partindo do pressuposto que sem o trabalho desenvolvido pela CoP (Animadores de Prevenção) que formou a $1^{\text {a }}$ Comunidade presencial de partilha de conhecimento neste domínio, a CoP virtual, Comunidade de Partilha de Boas Práticas SST e Qualidade de Vida foi atingido. A hipótese formulada para a nossa investigação foi validada e elegemos como Práticas Essenciais para garantir resultados de sucesso e o correto funcionamento e sobrevivência da comunidade de Boas Práticas SST e Qualidade de Vida no Trabalho tendo como elementos essenciais dessas práticas: a Cultura, Alinhamento e Estruturação, Apoio da Gestão de Topo da Organização, Líder/Coordenação forte, Desenvolvimento, Política e Tecnologia. São estas as práticas essenciais que derivaram em resultados de sucesso para a $\mathrm{CoP}$ e esses resultados são a Confiança; o Sentimento de Pertença; a Utilidade e a Contribuição que se desenvolveram no período em que se formou a $\mathrm{CoP}$ embrionária-Comunidade de Prática dos Animadores de Prevenção e que se mantiveram até à sua transformação em Comunidade de Prática Mista (Virtual e Presencial) a Comunidade de Partilha de Boas Práticas SST do INIAV.O nosso estudo foi exploratório e fez a 
analise de uma Comunidade de Pratica no Domínio da Segurança e Saúde no Trabalho numa Organização de Investigação Agrária do setor público português durante um período de 15 anos desde o seu nascimento ao seu declínio que coincide com uma mudança de Liderança da Organização que deixou de valorizar o trabalho colaborativo e declina o funcionamento da plataforma de trabalho colaborativo num momento em que estavam criadas as condições para a continuidade. A Prática de envolvimento da Gestão de topo, com envolvimento e suporte, flexibilização das atividades, promoção da CoP e disponibilização de recursos é um fator facilitador ou será inibidor mesmo que a liderança da CoP seja forte e que a Cultura de Partilha seja positiva se não for da vontade da Gestão da Organização a Comunidade morre lentamente se já estiver formada ou nunca nascerá pois não será prioridade da Gestão de Topo.

Palavras-chave: Comunidades de Prática; CoP; Práticas essenciais; Práticas inibidoras; Trabalho colaborativo; SST; Partilha de conhecimento; CoPV 


\section{Introducción}

Frente al escenario actual de intensas modificaciones y frente a la necesidad imprescindible de mantener las organizaciones, las Comunidades de Práctica $(\mathrm{CoP})$ se destacan como una alternativa muy interesante para la creación y diseminación del conocimiento organizacional, sean éstas virtuales o presenciales. Para (Chu, M.T.; Khosla, R., 2008), las CoP aumentan las competencias esenciales de la organización, dinamizan el aprendizaje y la innovación, proporcionan una mayor eficiencia en las rutinas de trabajo y optimizan la capacidad de respuesta a los problemas internos y externos de la institución. En la misma perspectiva, (Wenger, E.; Trayner, B.; Laat, M., 2011) afirman que las Comunidades también pueden ser vistas como un mecanismo de ayuda, ya que a través de ellas las personas unen fuerzas para enfrentar los desafíos individuales y colectivos. Las Comunidades de Práctica son herramientas promisorias de intercambio y creación de conocimiento en las organizaciones, sobre todo en aquellas intensivas en este activo intangible. Así según (Wenger, E., 1998a), son importantes para el buen funcionamiento de cualquier organización, siendo crucial para las Organizaciones que reconocen el conocimiento como un bien esencial.

Según el escenario que se presenta, el conocimiento de los factores críticos de éxito para mantener las Comunidades representa un aliado a su gestión. De esta manera, su surgimiento se transforma en una herramienta de gestión, tanto para las organizaciones como para los miembros de las Comunidades.

El concepto de comunidades de práctica $(\mathrm{CoP})$ fue utilizado por primera vez por (Lave, J.; Wenger, E., 1991) en la perspectiva de que el conocimiento y el aprendizaje ocurren a través de las interacciones sociales y, se percibe como parte de una construcción colectiva. Para los autores, lo definieron como un "...conjunto de relaciones que se establecen entre personas, actividades y el mundo (el medio), a lo largo del tiempo y en relación con otras comunidades de práctica". Étienne Wenger, además de precursor en los estudios sobre las CoP, es considerado su mayor referencia.

El concepto adoptado en el presente trabajo de investigación ha sido muy referenciado en los trabajos académicos, y fue acuñado por (Wenger, E.; Mcdermott, R.; Snyder, W. M., 2002a): "un 
grupo de personas que comparten una preocupación, un conjunto de problemas, una pasión sobre un tema y que profundizan sus conocimientos y experiencias, interactuando regularmente". Estas personas no trabajan necesariamente juntas todos los días, pero, se encuentran porque agregan valor en sus interacciones. Como pasan algún tiempo, juntas, comparten información, insights y consejos. Se ayudan unas a otras a resolver problemas, discuten situaciones, aspiraciones y necesidades. Pueden tener puntos de vista en común, exploran ideas y acciones, así como sondean los límites, crean herramientas, padrones, manuales y otros documentos o simplemente pueden desarrollar una tácita comprensión de lo que se comparte. Pero acumulan conocimiento, haciéndose informalmente la frontera (del conocimiento) por el valor que agregan al aprendizaje que encuentran juntos.

La convivencia entre los miembros de una comunidad, incluso el establecimiento de lazos de afinidad, se define a partir de pactos sociales o padrones de relación. Estos padrones de relaciones son construidos y profundizados por el capital social que se desarrolla en el grupo.

Para (Hall, H., 2001b), el papel del capital social es extremadamente importante para delimitar la naturaleza, el grado, las barreras y el papel de los premios recibidos para el incremento del intercambio de conocimiento. Torsvik (2000) argumenta que la confianza es condición para la construcción del capital social y su desarrollo. El autor considera que el capital social es uno de los resultados del desarrollo de la confianza dentro de una red de relaciones.

El trabajo de investigación desarrollado por (Flor, C., 2015) destaca un aspecto relevante para la utilización del concepto de capital social, que pasa por la discusión sobre la intervención de las organizaciones en la formación y sustentación de las Comunidades de Práctica. En lo que se refiere a este tema, (Dudley, R.G., 2004) puede ser creado, y cómo sería ese proceso. Esas cuestiones son relevantes, según el autor, pues, una vez establecido el capital social, es auto reforzado con su potencial, promoviendo una estrategia de intervención en las organizaciones. Esta estrategia de intervención sería posible a través de tres dimensiones del capital social, identificadas por (Nahapiet, J.; Ghoshal, S., 1998). Los autores caracterizan las tres dimensiones como: estructural, relacional y cognitiva. 
La dimensión estructural, que se refiere a la formación de redes informales que habilitan la identificación de un individuo por el otro, como recursos potenciales en la red, incluyendo lazos fuertes (contactos regulares y frecuentes) y débiles (contactos menos frecuentes). La dimensión relacional que se refiere a la dinámica interpersonal de los individuos dentro de la red. Esta dimensión reconoce que el capital social se desarrolla y se fomenta cuando los individuos creen en la reciprocidad de las acciones individuales y que los demás cumplen con las obligaciones que les competen. Se tratan de cuestiones de confianza, compartiendo normas y valores, obligaciones, expectativas e identificaciones, críticas para el desarrollo del capital social. Por último, la dimensión cognitiva, que se refiere a la necesidad de contexto y de lenguaje comunes para la construcción del capital social. Para esa dimensión, la construcción de un contexto común es posible por medio de la utilización de artefactos e historias comunes. Los autores (Nahapiet, J.; Ghoshal, S., 1998) argumentan que las dimensiones interfieren en variables que miden la creación y el intercambio del conocimiento. Estas variables son: Acceso a ocasiones para intercambiar activos provenientes del proceso de intercambio del conocimiento; Anticipación del valor a través del intercambio de esos activos; Motivación de los individuos para compartir estos activos y la habilidad de la organización para ajustarse, de acuerdo con las necesidades externas.

\section{Encuadramiento y evolución de las CoP}

Las $\mathrm{CoP}$ permiten acceder y aumentar el conocimiento y las competencias profesionales, traduciéndose en un valor inmediato para los profesionales. La pertenencia a una comunidad constituye una oportunidad para que sus miembros se desarrollen profesionalmente (Gamble, P. R. \& Blackwell, J., 2001), ya que les permite acceder a recursos y especialistas a los que difícilmente accede si no pertenecen a esa comunidad (Wenger, Etienne, 2000a), (Wenger, Etienne, 2000b).

Una estrategia de gestión del conocimiento basada en las Comunidades de Práctica, segundo (Wenger, Etienne, 2000a), consiste en siete pasos: 
-Asignar las necesidades de conocimiento de la organización, para entender qué conocimientos son críticos para el negocio, que aún no se están aprovechando adecuadamente y qué competencias la organización desea desarrollar;

-Encontrar a las comunidades que tengan un potencial de compromiso y descubrir en torno de cuáles prácticas las personas podrían comprometerse e identificarse;

-Desarrollar comunidades, ayudar a las comunidades claves a desarrollar su máximo potencial; -Conectar a través de las fronteras, las Comunidades no existen aisladas necesitan intercambios, tanto interna como externamente a la organización. Es necesario negociar cómo las comunidades y la organización pueden contribuir una con la otra;

-Sentimiento de pertenencia, acontece en varios niveles, es la forma en que la organización nutre el imaginario de las personas y crea oportunidades de participación.

Las Comunidades de Práctica no reúnen a las personas socialmente para que se sienten mejor en el ambiente de trabajo, pero la oportunidad es de estar ligando las identidades profesionales directamente al funcionamiento actual de la organización.

Para que las organizaciones puedan aprovechar esta conexión debe dar soporte sin asfixiar a las comunidades, sólo iluminar su camino para que se involucren y se dediquen, desdoblar esta estrategia de conocimiento por ondas de transformación organizacional, en un proceso continuo (Wenger, Etienne, 2000b).

McDermott (2000) incluye en la definición de Comunidades de Práctica el aspecto de la virtualidad. Para este autor, la Comunidad Virtual de Práctica es más que un simple grupo trabajando a distancia, y debe ser considerada como un grupo con una misión común, debiendo entregar un producto, basado en intercambios de información, regulares y mutuas. La definición de comunidades de prácticas permite, pero no asume, intencionalidad, es decir, el aprendizaje puede ser la razón por la que un grupo de gente se une o como resultado de las interacciones de los miembros.

No de todo lo que se considere una "comunidad" puede considerarse que se va a derivar un conocimiento compartido, este tiene que tener tres características: 


\section{El dominio}

Una comunidad de práctica no es simplemente un club de amigos o un grupo de personas, tiene que tener una identidad definida que se crea a través de un interés compartido. Por lo tanto, la pertenencia implica un compromiso con el dominio y la tenencia de una competencia que distingue a los miembros de otras personas. Fuera de la comunidad puede que el dominio no sea considerado como “experiencia”, por ejemplo, una pandilla juvenil puede haber desarrollado varias formas de lidiar con su dominio: sobrevivir en la calle y tener una cierta identidad para vivir. Valoran su conocimiento puesto en común y aprenden unos con los otros, aunque pocas personas (o quizás ninguna) fuera del grupo valoren o reconozcan esta experiencia.

\section{La comunidad}

Al perseguir su interés en un dominio, los miembros participan en actividades y discusiones conjuntas, se ayudan mutuamente y comparten información. Así, construyen relaciones que los llevan a aprender entre ellos y se preocupan por seguir adelante juntos. Poseer el mismo trabajo o la misma titulación no constituye una comunidad de prácticas, a menos que los miembros interactúen y aprendan juntos. Hay que matizar que las interacciones de los miembros no tienen que ser diarias, pero sí lo suficientemente sólidas y válidas para que les permita avanzar.

\section{La práctica}

Una comunidad de práctica no es meramente una de interés, sino que son capaces, en su variedad, de desarrollar un repertorio compartido de recursos: experiencias, historias, herramientas, formas de abordar problemas recurrentes, en resumen, una práctica compartida. En el caso de las escuelas de formación, esto lleva tiempo y una interacción sostenida entre alumnos y profesor.

Si bien toda comunidad de prácticas tiene que tener los tres elementos: dominio, comunidad y práctica, existe toda una variedad de formas y tamaños. Algunas son locales y otras traspasan fronteras, algunas se suelen reunir cara a cara, aunque la mayoría lo hace de forma on-line. También hay comunidades reconocidas formalmente y cuentan incluso con presupuestos, mientras otras son totalmente informales. Este tipo de organización ha existido desde que los seres humanos han tenido 
la capacidad de aprender en grupo, es decir, desde siempre. También tienen su propia pirámide organizativa, con miembros centrales y otros periféricos, y con gente que viene y se va de forma más o menos constante. De hecho, las comunidades de práctica están en todas partes. Pueden tener un cariz familiar y pasar más desapercibidas; sin embargo, cuando se les da un nombre y se enfoca, se torna a una perspectiva que puede ayudar a comprender mejor el mundo. En particular, permite ver más allá de estructuras formales más obvias, como las organizaciones, aulas o países y percibir construcciones definidas por el compromiso en la práctica y el aprendizaje, informar que está asociada a ella.

¿Dónde se aplica este concepto? El concepto de comunidades de prácticas se pueda aplicar en negocios, diseño organizativo, gobierno, educación, asociaciones profesionales, proyectos de desarrollo y vida cívica. Este concepto de CoP se ha vuelto esencial en varios ámbitos científicos, en particular en la Gestión del Conocimiento, el Aprendizaje Organizacional, las Ciencias de la Educación y las Ciencias de la Información (Cox, Andrew, 2005).Sus aplicaciones prácticas transvasan el mundo empresarial encontrándose éstas en contextos organizacionales tan distintos como: gestión de cuidados de salud (ej. (Schenkel, A e Teigland, R., 2008)); planeamiento social, agricultura, etc. (ej. (Kranendonk, R.P. e Kersten, P.H., 2007)); colaboración en investigación científica (e-science) (ej. (Farooq, Muhammad et al., 2008)); y en los más diversificados dominios de la educación (ej. (Wenger, E.; Mcdermott, R.; Snyder, W. M., 2002a) y de la formación especializada en los puestos de trabajo (ej. (Doak S. \& Assimakopoulos, D., 2007); (Fuller, A.; Hodkinson, P.; Unwin, L., 2005)).

En las organizaciones no es fácil hacer que el conocimiento traspase las fronteras de los grupos de trabajo, equipos y departamentos. En este sentido, la contribución de las comunidades se extiende hasta el fortalecimiento de los lazos entre los individuos pertenecientes al mismo grupo profesional, así como también extendiendo la red a un grupo más vasto. La presencia en la comunidad es siempre un acto voluntario motivado por la necesidad que los individuos sienten de discutir sus actividades con el objetivo de adquirir más conocimiento (Ardichvili, A.; Page, V. \& Wentling, T., 2003); (Zboralski, K.; Gemuenden, H. G. \& Letti, C., 2004) para mejorar el desempeño de sus funciones (o actividades) (Gamble, P. R. \& Blackwell, J., 2001). La inexistencia de relaciones de poder 
impuestas, surgen naturalmente y generalmente están asociadas al dominio sobre las "materias" de varios miembros (Cox, Andrew, 2005), siendo relevante la inclusión de una diversidad de tipos de miembros, desde los principiantes hasta los peritos de renombre.

Los autores (Mendes, L.; Urbina, L.M.S., 2015), subrayan que las CoP se centran en el intercambio de conocimientos, en el ejercicio del aprendizaje conjunto y se organizan para estimular los procesos de aprendizaje y difusión de los conocimientos que ocurren informalmente. Los mismos autores destacan, que hay el compromiso de los miembros con la ayuda mutua y el aprendizaje colectivo; resaltan el alto nivel de integración entre sus miembros y recuerdan que la CoP sobrepasa las fronteras departamentales e incluso organizacionales. Los autores (Morales, A.H.; Macías, R.C.F., 2013), añaden la ausencia de jerarquía en las CoP, siendo que la posición de cada participante es flexible y dinámica dependiendo de la participación en las actividades de la comunidad. En el trabajo (Cyrino, M.C.C.T.; J.G., Estevam, 2016), observa aspectos como el respecto, la confianza, el desafío, la negociación de significados y la valoración de las singularidades y prácticas profesionales. La autora apunta que esas características y peculiaridades de las CoP forman un suelo fértil para el desarrollo de la identidad profesional.

No obstante, con la globalización de las economías los individuos que eventualmente participaban en CoP presenciales dejaron de tener espacios y oportunidades para interactuar personalmente con facilidad (Kiesler, S. \& Cummings, J. N., 2002). Así, las CoP soportadas por tecnologías comenzaron a reemplazar las Comunidades en las que sus miembros se encontraban personalmente, en la medida en que las CoP ponen a disposición de sus miembros el "espacio" y las condiciones necesarias para interactuar, aun cuando están geográficamente dispersos y separados por diferentes husos horarios (Orlikowski, W. J., 2002).

Estas estructuras sociales ya son realidad en muchas organizaciones, los casos más explorados por la literatura son: Xerox, Banco Mundial y British Petroleum. En Portugal, las iniciativas son todavía escasas, es un tema que tiene gran potencial para ser trabajado por las organizaciones portuguesas. Sin embargo, este tipo de arreglo no es estimulado y en la mayoría de las veces ni es percibido por las estructuras formales. En algunos casos, los gestores no tienen claro la diferencia entre lo que es una verdadera Comunidad de Práctica y el otro tipo de arreglo colectivo como: equipos de trabajo 
o redes de relación informal. En otras palabras, "en muchos casos, se percibe que la vivencia en grupos es indiscriminadamente tratada como un relato de Comunidades de Práctica" (Lave, Conferencia de clausura, 2004).

Lo cierto es que el concepto ha sido adoptado más fácilmente por las personas de negocios debido al reconocimiento de que el conocimiento es un activo crítico que debe gerenciarse estratégicamente. Los esfuerzos iniciales de gestionar este conocimiento en los sistemas de información tuvieron resultados decepcionantes.

Así que las comunidades de práctica proporcionaron un nuevo enfoque que se centró en las personas y en las estructuras sociales que les permiten aprender unos con los otros. Hoy en día no existe casi ninguna organización, con un tamaño razonable, que no tenga alguna forma de iniciativa de una comunidad de práctica.

Una serie de características explican esa corriente de interés en esta organización como vehículo para desarrollar capacidades estratégicas en las diferentes Organizaciones:

-Permiten a los profesionales asumir la responsabilidad colectiva de gestionar el conocimiento que necesitan entendiendo que, dada la estructura adecuada, están en la mejor posición para hacerlo. -Las comunidades entre los profesionales crean un vínculo directo entre el aprendizaje y el rendimiento porque las mismas personas participan en comunidades de práctica, en equipos y en unidades con dispersión geográfica.

-Los profesionales pueden abordar los aspectos tácticos y dinámicos de la creación y el intercambio de conocimientos, así como los aspectos más explícitos.

-Las comunidades no están limitadas por estructuras formales, sino que crean conexiones entre personas a través de límites organizativos y geográficos.

\section{El aprendizaje individual para el aprendizaje colaborativo}

Al hablar en condiciones y desafíos de emergencia de las comunidades virtuales de práctica (CoPV) no se puede dejar de encuadrar en el contexto actual de cambio, relacionada con las nuevas necesidades de aprendizaje de la sociedad de la información, se basa en el reconocimiento cada vez 
más importante del aprendizaje colaborativo como forma superior de aprendizaje. La colaboración no pone en cuestión la autoformación, mientras que la capacidad de cada uno aprender por sí misma, parte del principio de que cualquier profesional es capaz de iniciar y dirigir sus procesos de aprendizaje y formación.

La cultura de colaboración (presencial o virtual) está muy relacionada con el trabajo en equipo, lo que exige nuevas destrezas sociales. De este modo, contribuir a su formación implica a la persona, pero también a su relación con el otro, el grupo, la organización, la institución, el contexto (Bernard, P., 1999).

El intercambio de conocimientos y experiencias entre colegas ("aprender juntos") puede ser uno de los medios más enriquecedores y con mayor incidencia en el desarrollo profesional (Bolivar, A., 2000a).

La actividad colaborativa presupone la construcción de una realidad compartida, vinculada a una dinámica relacional, donde son fundamentales los procesos reflexivos, de resolución de problemas y de control del aprendizaje. El aprendizaje colaborativo, a pesar de estar en un nivel de exigencia superior al aprendizaje individual, no se puede separar de ésta en la medida en que el autoaprendizaje es el soporte del aprendizaje colaborativo.

Según (Levan, S. K., 2004), el trabajo colaborativo designa una modalidad de acción que ultrapasa la acción individual y se inscribe explícitamente en una dinámica de acción colectiva, o sea que puede considerarse que el trabajo colaborativo es el resultado de una actividad social entre varios agentes para conseguir un resultado.

Trabajar con los otros no es una práctica evidente. El trabajo colaborativo es una forma de organización deliberada, compleja, que se construye en la inteligencia de acción de manera de realizar un encadenamiento de actividades que implican la participación de varios actores operando en red. En este emprendimiento, la motivación, la comunicación y la interacción están en la base de un trabajo colaborativo eficaz (Levan, S. K., 2004). Para ello, es necesario movilizar las competencias individuales y colectivas colaborativas. 
La adquisición de estas competencias, tanto a nivel individual como colectivo, exige tiempo (Levan, S. K., 2004). Esta disposición se consigue a través de la participación activa de todos los miembros del grupo, para realizar las tareas y alcanzar objetivos comunes.

De esta manera, resulta cada vez más evidente que la integración de estas "tecnologías corporativas" transporta consigo una profunda revisión de las organizaciones.

\section{Organización que aprende}

Las organizaciones que aprenden están formadas por personas que expanden continuamente su capacidad para crear los resultados que desean, donde se estimulan patrones de comportamiento nuevos y amplios, la aspiración colectiva gana libertad, y las personas se ejercitan continuamente en aprender juntos. Estas organizaciones sólo pueden construirse cuando entendemos que el mundo no está hecho de fuerzas separadas y que en el mundo de hoy la capacidad de aprender continua y rápidamente es la única ventaja competitiva sostenible.

El concepto de organización que aprende, como forma de adaptación a un contexto cambiante, expresa la idea de un proceso en transformación progresiva, una aspiración, un camino hacia un objetivo, que requiere un cambio continuo o una autotransformación, y no un proceso producto final. El gran desafío consiste en que las organizaciones tradicionales, estáticas, burocráticas, de organización vertical, basadas en la rutina, con culturas de trabajo individualistas, evolucionan hacia organizaciones que aprenden.

Para (Gairín, J. S., 2000), el camino hacia las organizaciones que aprenden se basa en una creciente autonomía y colaboración entre sus miembros: las organizaciones que privilegian un aprendizaje colaborativo en un contexto de autonomía organizacional se elevan a verdaderas comunidades de práctica. Hay también, de esta forma, una aproximación del concepto de organización que aprende al concepto de comunidad de práctica, teniendo en cuenta sus fundamentos en la teoría social del aprendizaje, en lo que se refiere al aprendizaje a partir de la práctica y en la construcción colectiva de significados. Internalizar el cambio en la cultura de trabajo es uno de los aspectos claves para el 
éxito organizacional, pero requiere (transformación o reconversión) de la organización, sobre la base de una profunda metamorfosis de las mentalidades y comportamientos.

Los autores (Snyder, W. M.; Cummings, T. G., 1998) realizaron una síntesis de la relación entre el aprendizaje individual y el aprendizaje organizacional: los individuos aprenden en las organizaciones, pero este aprendizaje puede o no contribuir para el aprendizaje organizacional.

El aprendizaje es organizacional en la medida en que: se lleva a cabo para lograr los propósitos de organización; es compartida o distribuida entre los miembros de la organización (grupos); los resultados del aprendizaje se incorporan en sistemas, estructura y cultura organizacionales.

\section{Organizaciones basadas en el conocimiento}

Las organizaciones basadas en el conocimiento tienen en sus cuadros altamente cualificados, trabajadores del conocimiento, cuyo papel es esencialmente el de solucionar problemas. En este contexto, los grupos de trabajo deben buscar y explorar ejemplos de las mejores prácticas, mejorar su eficacia y eficiencia, y contribuir para un aprendizaje organizacional global, con visibilidad para todos los actores.

Los grupos de trabajo en las organizaciones basadas en el conocimiento necesitan gestionar dinámicamente sus calificaciones, crear mecanismos para descubrir nuevas ideas e innovaciones e identificar fuentes de información. El desafío para todas las organizaciones, pero para las organizaciones basadas en el conocimiento en particular, es manejar su conocimiento de forma efectiva.

A partir del trabajo de (Macintosh, A., 1997), sobre la gestión de recursos del conocimiento organizacional, un conjunto de obstáculos para una mayor productividad y desempeño en organizaciones basadas en conocimiento fue identificado:

- La mayoría de los RH pierden mucho de su tiempo buscando la información que necesita.

- El saber hacer esencial está sólo disponible en la mente de algunas personas.

31

Comunidad@Buenas Prácticas de Seguridad, Salud e Calidad de Vida en el trabajo INIAV

"Factores críticos de éxito" 
- Información valiosa está disimulada en numerosos conjuntos de datos y documentos.

- Errores costosos se repiten debido a la no consideración de experiencias anteriores.

- Retrasos, productos y servicios con poca calidad resultan de un insuficiente flujo de información entre los diversos agentes organizacionales

En base a estos argumentos, (Dieng, R. et al., 1998) un conjunto de motivaciones que justifica la construcción de una Memoria Organizacional:

-Evitar la pérdida de inteligencia corporativa (o capital intelectual) cuando un especialista deja la Organización.

-Explorar y reutilizar la experiencia adquirida en los proyectos pasados para evitar la repetición de errores.

-Mejorar la circulación y comunicación de la información en la organización.

-Integrar el saber hacer a partir de diferentes partes de la organización.

-Mejorar el proceso de aprendizaje individual y organizacional.

La definición de una plataforma de trabajo colaborativa para el desarrollo de Comunidades de Práctica $(\mathrm{CoP})$ podrá minimizar y resolver parte de los problemas antes mencionados.

Las CoP podrán ser desarrolladas y fomentadas, formando parte integrante de la estrategia organizacional, como forma de estimular el compartir el conocimiento.

\section{Comunidad de práctica como enfoque para la gestión del conocimiento}

Siendo las CoP uno de los enfoques posibles de la Gestión del Conocimiento, al realizarse un trabajo de reparto entre los elementos de los grupos que las componen se da la transformación del conocimiento ya existente en nuevo, acabando ellas mismas por estar en la base de nuevas redes de conocimiento que se van generando (Vasconcelos, J. et al., 2005). Así, las CoP son intrínsecas a la existencia del propio conocimiento (Lave, J.; Wenger, E., 1991).

Las CoP surgen de las relaciones informales que se establecen en las organizaciones. A partir del momento en que se empiezan a estructurar y que empiezan a ser un instrumento de intercambio de 
conocimiento acaban por transformarse, lentamente, en grupos formales, pasando del conocimiento tácito al explícito. Las Comunidades de Práctica pueden ser constituidas presencial o virtualmente. Muchas veces, no necesitan restringirse a la comunicación virtual, pudiendo ser complementadas por encuentros y reuniones de sus miembros.

En el contexto de la gestión del conocimiento, la cultura favorable a compartir experiencias, a partir de la CoP, puede viabilizar mejores prácticas en las organizaciones, haciéndose atractiva al aprendizaje colaborativo. Por lo tanto, corresponde a la organización incentivar la creación de las $\mathrm{CoP}$, cultivando su mantenimiento y buscando, permanentemente, medios para diseminación orgánica de conocimientos prácticos articulados con la política y las estrategias organizacionales.

Las comunidades de práctica son estrategias para la construcción del conocimiento que pueden ocurrir naturalmente en las relaciones sociales en los ambientes de trabajo. (Lahti, S.; Moilanen, R., 2004), el conocimiento tácito es uno de los puntos fuertes de los colaboradores más viejos y experimentados, presentando la capacidad de interpretar información relativa a la cual no existe regla formal de procesamiento. Hay un gran potencial en el conocimiento en su forma tácita.

Compartir el conocimiento tácito entre colaboradores más jóvenes y mayores es uno de los principales desafíos de la gestión. Los autores (Lahti, S.; Moilanen, R., 2004) refieren en su estudio que el aprendizaje que ocurre entre colaboradores más jóvenes y mayores aumenta las competencias individuales y libera conocimiento tácito individual para la utilización de toda la organización.

La transformación del conocimiento tácito, para que éste pueda ser registrado de forma a contener información suficiente para posibilitar la diseminación de los beneficios en la organización (MCelroy, M.W., 2003).

En el trabajo de investigación desarrollado por (Flor, C., 2015) se menciona que el conocimiento tácito es uno de los puntos fuertes de los colaboradores más viejos y experimentados, presentando la capacidad de interpretar información relativa a la cual no existe regla formal de procesamiento. Flor (2015) explicita que el gran problema de Organizaciones detentadoras de conocimiento es la salida de trabajadores poseedores de mucho conocimiento tácito que no pasó a explícito. 


\section{Factores condicionantes al intercambio de conocimiento dentro de las Comunidades}

Aunque no es el objetivo de este trabajo discutir la "Gestión del Conocimiento" tampoco cuestionar el enfoque que el área de tecnología de la información da al término, sino adoptar la lógica de que el conocimiento es un activo estratégico a ser gestionado y que las Comunidades de La práctica puede y/o debe ser el tejido social del conocimiento. Por más que la organización establezca procesos eficientes, si las personas que están involucradas en el día a día de la organización no participan efectivamente, resulta muy complicado alcanzar una cultura de compartir el conocimiento. Algunos autores ven la imposibilidad de gestionar "algo tan orgánicamente diverso y dinámico como el conocimiento humano" (Albrecht, Karl, 2004). Lo que está dentro de las posibilidades de la organización es gestionar las condiciones, haciendo el ambiente favorable al aprendizaje. En esta línea, la propuesta es gestionar la "cultura del conocimiento". Esta gestión seguirá proporcionando la continuidad de una Comunidad de Prácticas que se desarrolle en la Organización.

El intercambio de conocimiento dentro de las CoP y CoPV está condicionada por diversos factores que la pueden potenciar / facilitar o constreñir. A través de la gestión del conocimiento, la organización amplía su visión sobre el papel de las personas en la creación de estrategias competitivas más consistentes, pues el conocimiento está directamente ligado a las personas y consiste en activos individuales y colectivos y debe ser construido de acuerdo con la relevancia de los objetivos organizacionales (Castro, S.A.; Cazarini, E.W., 2005). (Campos, R.L.; Barbosa, F.V, 2001) es importante saber cómo se adquirió el conocimiento, y cómo puede ser utilizado, teniendo como base tres factores: tiempo, espacio y el reconocimiento de la necesidad del mantenimiento, con foco en alcanzar resultados positivos en la organización.

Este proceso está compuesto por factores inhibidores que son aquellos que pueden dificultar o impedir, tanto el compartir y la gestión del conocimiento. Estos factores inhibidores, según (Robbins, S. P., 2004), se encuentran en los tres niveles de conocimiento: individual, grupal y organizacional. A nivel del individuo, el autor enumeró la expectativa, los valores, las actitudes, la percepción, la personalidad, la emoción, los sentimientos, la disposición y la motivación. A nivel 
del grupo, los factores inhibidores pueden surgir de interacciones estratificadas, estilo de liderazgo, confianza y clima psicológico.

En la esfera de la organización, las políticas y prácticas de recursos humanos se caracterizan como factores que pueden inhibir la gestión del conocimiento. Para Riege (2005) los factores inhibidores organizacionales son: falta de claridad en la integración entre la estrategia y el modelo de gestión del conocimiento; poco espacio para compartir; sistema ineficiente de reconocimiento y recompensa para estimular la motivación que lleve al compartir; y el ambiente físico inadecuado.

El proceso de gestión del conocimiento también está impregnado por factores que contribuyen al éxito de los procesos de creación, diseminación y utilización del conocimiento. Estos factores, basados (Terra, J. C. C., 2000) se encuentran interconectados en las siguientes dimensiones: estrategia y alta administración; sistemas de información y comunicación; cultura de la organización; organización y procesos de trabajo; políticas y prácticas para la gestión de recursos humanos; y la evaluación del resultado. El liderazgo es uno de los factores facilitadores para la diseminación del conocimiento, pues el compartir resultará dentro de la comunidad y corrobora el estímulo a la motivación para la transmisión de ese conocimiento.

Confianza - Para que una comunidad de práctica tenga éxito, además de la necesaria participación, la confianza es un elemento fundamental (Preece, Jenny, 2000); (Wenger, E.; Mcdermott, R.; Snyder, W. M., 2002a). Por norma a los individuos no les gusta compartir lo que saben sin recibir nada en cambio, con miedo de perder el poder que consideran que el conocimiento les puede traer, privilegiando de esta forma el interés individual en perjuicio del interés colectivo. En efecto, el conocimiento puede no llegar donde es necesario. La principal condición para el trabajo en grupo es la confianza mutua que los miembros del grupo desarrollan. Los autores (Wenger, E.; Mcdermott, R.; Snyder, W. M., 2002a), (Kuan, Y.; Gonzales, R.; Olson, S., 2003) alegan que el compartir conocimiento tácito, que permite la construcción de conocimiento colectivo, es posible sólo mediante el crecimiento de la confianza entre los miembros del grupo. De esta forma, el desarrollo de las comunidades, originadas a partir de grupos informales que comparten valores y objetivos similares, permite la conquista de esa confianza, de forma casi natural, pero también es posible que esa confianza se desarrolle a partir de la convivencia de un grupo formalmente constituido. 
Un ambiente de confianza y de apertura, sin ambigüedades de lenguaje diferente entre individuos, es fundamental para desbloquear el conocimiento, pues sin ello, los individuos no sólo no se entienden como tampoco confían unos en otros (Davenport, Thomas H.; Prusak, Laurence, 1998).

En la Cultura organizacional la participación de los colaboradores está condicionado por factores culturales (Davenport, T. H.; Prusak, L., 2003). Entre los que pueden facilitar este comportamiento se encuentra la confianza (sólo en un ambiente de confianza es que todos aportarán su conocimiento, sin miedo a consecuencias negativas); la visión y los objetivos organizacionales (éstos permiten desarrollar un sentimiento de implicación y de apetencia para la contribución entre los colaboradores (Kim, S.; Lee, H., 2005), valores, lenguaje y marcos de referencia comunes (Davenport, T. H.; Prusak, L., 2003), (Sharratt, M.; Usoro, A., 2003) "estructuras de oportunidad" que constituyen ocasiones propicias y beneficios obtenidos por compartir conocimiento dentro de las comunidades (Krogh, G. V. \& Grand, S., 2002). Considerando que en una organización existen intereses diversos y distribuidos, cada miembro procurará establecer relaciones más cercanas con aquellos que comparten los mismos, en el caso de las comunidades virtuales en Internet, concluyeron, además, la existencia de obstáculos a la comunicación que van más allá de los existentes en la comunicación presencial, que se destacan el sentimiento de aislamiento, la pérdida de la riqueza existente en la comunicación no el verbal y, a menudo, las dificultades en la utilización de la tecnología, factores introducidos por la utilización de ésta como medio de soporte a la comunidad. Para que las barreras al compartir y la creación de conocimiento nuevo sean superadas es esencial que las organizaciones motiven a sus colaboradores para actos de compartir y de colaboración y que los recompensen por los mismos (Ardichvili, A.; Page, V. \& Wentling, T., 2003); (Chung, L. H., 2001); (Hall, H., 2001b).

Otros factores que condicionan negativamente la inclusión de los colaboradores pueden estar relacionados con la falta de tiempo y de locales para que los individuos se encuentren; la falta de reconocimiento de estatuto y/o la concesión de recompensas a quien posee y el conocimiento y la intolerancia a los errores y a la necesidad de ayuda (Davenport, T. H.; Prusak, L., 2003).

El intercambio de conocimiento dentro de las CoP e CoPV (Comunidades de Práctica Virtuales) está condicionado por diversos factores que lo pueden potenciar/facilitar o constreñir. Estos pueden ser de naturaleza individual o colectiva, siendo que en la primera categoría se incluyen los 
designados factores intrínsecos y en la segunda los extrínsecos, colectivos, tecnológicos o los relacionados con factores organizacionales tales como la cultura, la estructura o la tecnología.

Colectivos - Se refieren a factores de naturaleza contextual. Por ejemplo, si el grupo en el cual los individuos están integrados (organización) no permite el desarrollo de sentimientos de confianza (Roberts, Joanne, 2006), estos tienden a no compartir su conocimiento y a tener recelos en el momento de colocar cuestiones, porque consideran que su conocimiento no tiene interés para la comunidad. No obstante, cuanto "mayor sea la confianza que los miembros tienen entre sí, más reducidos serán los costos sociales del intercambio de conocimiento”, (Krogh, G. V.; Grand, S., 2002), ya que, sin confianza, los miembros de una comunidad pueden tener reluctancia de compartir su conocimiento.

La presencia de una relación de confianza entre los individuos indica una gran predisposición para intercambiar una comprensión mutua, construida con base en un contexto social y cultural compartido. Para que una comunidad de práctica tenga éxito, además de la necesaria participación, la confianza es un elemento fundamental (Preece, Jenny, 2000); (Wenger, E.; Mcdermott, R.; Snyder, W. M., 2002a). En general, a los individuos no les gusta compartir lo que saben sin recibir nada en cambio, por miedo de perder el poder que consideran que el conocimiento les puede traer, privilegiando de esta manera el interés individual en detrimento del interés colectivo. Como consecuencia, el conocimiento podrá no llegar a donde es necesario.

Cultura organizacional - La inclusión de los colaboradores está condicionada por factores culturales (Davenport, T. H.; Prusak, L., 2003).

Entre los factores que pueden facilitar ese comportamiento se encuentran la confianza : solo en un ambiente de confianza es que todos contribuirán con su conocimiento, sin miedo de consecuencias negativas; la visión y los objetivos organizacionales :estos permiten desarrollar un sentimiento de inclusión y de apetencia o anhelo de contribuir entre los colaboradores (Kim, S.; Lee, H., 2005); valores, lenguaje y cuadros de referencia comunes (Davenport, T. H.; Prusak, L., 2003); (Sharratt, M.; Usoro, A., 2003); estructuras de oportunidad que constituyen ocasiones propicias y 
beneficios obtenidos por intercambiar conocimiento dentro de las comunidades (Krogh, G. V.; Grand, S., 2002).

Estructura organizacional - La estructura organizacional influye en las actitudes de intercambio de conocimiento de los colaboradores (Kim, S.; Lee, H., 2005). De acuerdo con (Chung, L. H., 2001), estructuras organizacionales más burocráticas y centralizadas tienden a reprimir la creación de conocimiento mientras que las flexibles y descentralizadas pueden alentar el intercambio de conocimiento, especialmente el tácito, en virtud de permitir una mayor interacción entre las personas.

Factores tecnológicos - La utilización de tecnología como medio de soporte de la comunidad tiene impacto en la manera como los miembros se involucran en el intercambio y creación del conocimiento. En lo que concierne a las desventajas en la utilización de la tecnología como soporte es necesario destacar la pérdida de la riqueza del medio de comunicación, o sea el valor asociado al lenguaje no verbal (pistas/ rituales), esenciales al intercambio del conocimiento tácito como lo refieren (Krogh, G. V.; Grand, S., 2002). Por el contrario, presenta como ventaja principal el hecho de posibilitar el acceso a un número más amplio de personas aumentando de esta manera las probabilidades de respuesta, de colaboración en la resolución de problemas, de creación de conocimiento y acceso a un mayor número de recursos de información (Sharratt, M.; Usoro, A., 2003). Tecnologías colaborativas tales como el correo electrónico, los boletines electrónicos, los fórums y los chats facilitan el desarrollo de las CoP, cuyos miembros se encuentran distantes unos de otros temporal y geográficamente (Wang, Y. et al., 2007).

Las Comunidades de Práctica y la tecnología, uno de los obstáculos que se presentan para la creación de una CoP es la preocupación por la necesidad de inversión en tecnología. En primer lugar, es importante observar las posibilidades de comunicación e interacción de las redes de relaciones de Internet que dispone de herramientas colaborativas gratuitas que posibilitan la formación de pequeñas redes, como los foros, blogs, micro blogs, wikis, chats, e-mails. Así, no se hacen necesarias altas inversiones, grandes portales. 
Por otro lado, (Silva, H.F.N.; Arboit, A.E.; Garcia, A.K.; Rigoni, C.F., 2012), enfatizan que el desarrollo de CoP no depende obligatoriamente de tecnología. Según la autora, la tecnología actúa como un importante facilitador para la interacción entre los participantes de una comunidad, pero no consiste en un elemento determinante para su constitución. Su investigación con los Tribunales de cuentas en Brasil, demostró además la efectividad de los eventos y foros, como forma de compartir, pudiendo contribuir a la constitución de CoP.

La utilización de tecnología como medio de soporte a la comunidad tiene impacto en la forma en que los miembros se involucran en el compartir y la creación del conocimiento. En lo que concierne a las desventajas en la utilización de la tecnología como soporte hay que resaltar la pérdida de la riqueza del medio de comunicación, es decir el valor asociado al lenguaje no verbal (consejos/ rituales), esenciales para la partilla del conocimiento tácito, como lo refieren (Krogh, G. V. \& Grand, S., 2002). Por el contrario, presenta como ventaja principal el hecho de posibilitar el acceso a un número ampliado de personas aumentando de esta forma las probabilidades de respuesta, de colaboración en la resolución de problemas, de creación de conocimiento y acceso a un número mayor de recursos de información (Sharratt, M.; Usoro, A., 2003).

McDermott (2000) incluye en la definición de Comunidades de Práctica el aspecto de la virtualidad. Para este autor, la Comunidad Virtual de Práctica es más que un simple grupo trabajando a distancia, y debe ser considerada como un grupo con una misión común, debiendo entregar un producto, basado en intercambios de información, regulares y mutuas.

La colaboración y las comunidades virtuales con soporte en la tecnología tal vez contengan el germen de una verdadera revolución cultural (Taurisson, A., 2003). Este autor destaca que "elles pourraient modifier notrerapport à l'espace, et même au temps, et sembleraient jouer avec la frontière du réel et de l'imaginaire, tout en étant porteuses de nouvelles relation sociales” (p 3). Así, en lo que se refiere a las TIC, se asiste a lo que podemos llamar un desplazamiento del énfasis colocado en la I (de información) para un predominio cada vez mayor de la $\mathrm{C}$ (de comunicación). 


\section{Desarrollo e expansión de las CoP}

Para conseguir un buen desempeño, las CoP necesitan del apoyo y del incentivo de la Dirección (Wenger, E.; Snyder, W. M., 2001) confirman esta idea al aclarar que las CoP "aunque sean autoorganizadas y por lo tanto resistentes a la supervisión y a la interferencia, requieren esfuerzos de la gestión para desarrollarlas e integrarlas en la organización. Solo así pueden ser completamente impulsadas".

Las Comunidades de Práctica no pueden ser cultivadas de la misma forma que se desarrollan estructuras organizacionales tradicionales. Más que planificar, dirigir y organizar sus actividades, diseñar y desarrollar comunidades de práctica implica obtener y alentar gradualmente la participación de individuos con talento y capacidades para generar e implementar ideas innovadoras. Las CoP no se confunden con departamentos formales ya que normalmente se componen de personas que se involucra voluntariamente en una comunidad. También no se confunden con cualquier red informal, pues la mayoría carece de dominio ligado a una práctica. Para desarrollar y estimular la dinámica de las Comunidades de Práctica hay que estar atento a los siguientes puntos:

-Legitimar la participación de los miembros: las Organizaciones pueden reservar un tiempo (diario, semanal, mensual, etc.) para que los miembros participen en las actividades comunitarias. Otro aspecto es la creación de un lugar para que ocurra;

-Negociar el contexto estratégico: las Organizaciones deben tener un sentido claro de cómo el conocimiento está vinculado a las estrategias de negocio y usarlo para despertar en las Comunidades su propio valor estratégico. Este proceso implica una negociación que trabaja en dos sentidos: incluye la comprehensión de lo que es conocimiento y, por lo tanto, qué prácticas una determinada actividad exige; por otro lado, clama por la atención sobre lo que las CoP traen como posibles direcciones estratégicas, conocimiento retirado de la práctica diaria;

-Establecer sintonía con prácticas existentes en la Organización: generalmente el conocimiento que las Organizaciones necesitan ya está presente dentro de las mismas. Así, promover la formación de Comunidades de Práctica que aprovechen ese potencial es un punto de partida muy interesante. 
La existencia de una $\mathrm{CoP}$ necesita de la participación y de la inclusión o compromiso de determinadas personas que compartan o que estén interesadas por un determinado asunto. Esta inclusión no puede ser forzada, apenas estimulada. (Wenger, E.; Mcdermott, R.; Snyder, W. M., 2002a) sugiere que las motivaciones para participar en una comunidad pueden variar de miembro para miembro y pueden surgir del valor que se le reconoce, por relaciones personales ya establecidas o por la oportunidad de mejorar su saber. La vitalidad de una comunidad depende de la existencia de actividades diversificadas y suficientemente desafiantes para el conjunto de miembros.

En el proceso de creación y desarrollo de la $\mathrm{CoP}$ es necesario designar un coordinador responsable, ya sea a través de la creación de un departamento específico o del nombramiento de una persona responsable. Como la creación de la CoP necesita, como mínimo, de la existencia de determinados grupos formales sobre los cuales serán consolidadas sus bases, la primera función del coordinador es la realización de un levantamiento de datos o mapa de estos grupos dentro de la Organización. En esta etapa es necesario que el coordinador explique lo que es una $\mathrm{CoP}$, que beneficios pueden obtenerse a través de ella y la importancia del compromiso de todos para el éxito de la misma. Esta explicación debe realizarse de una manera no ilusoria, para no provocar futuras frustraciones y consecuente desmotivación de los involucrados.

Los autores (Wenger, E.; Snyder, W. M., 2001) afirman que las CoP necesitan de determinadas acciones para sostener su desarrollo. O sea, proporcionar la infraestructura necesaria para el desarrollo de la $\mathrm{CoP}$, dejando a su disposición los recursos necesarios para la realización de sus actividades y dándoles una mayor legitimidad.

Otra etapa importante es que la organización deberá recompensar a los integrantes de las comunidades, ya sea con incentivos monetarios, como gratificaciones o premios, o a través de otras motivaciones. El intercambio de experiencias debe ser considerado por la organización como una función de sus integrantes. La organización debe intentar medir los resultados obtenidos mediante la implantación de la CoP. Esta no es una actividad fácil, ya que los resultados además de aparecer a largo plazo, no son fáciles de entender. 
El último paso es divulgar los resultados obtenidos para toda la organización. Esta actividad permitirá mantener la motivación de los que participan activamente y motivará a los demás que no están involucrados a participar en las CoP.

En lo que se refiere a la participación de los miembros, (Wenger, E.; Mcdermott, R.; Snyder, W. M., 2002a) señalan tres niveles que se pueden encontrar:

$1^{\circ}$ grupo: Núcleo - pequeño número de personas (de $10 \%$ a $15 \%$ del total) que participan activamente en las discusiones. Identifican temas, promueven encuentros, ayudan al coordinador, asumen el liderazgo, o sea, movilizan la Comunidad en la tarea del aprendizaje;

$2^{\circ}$ grupo: Activo - está también constituido por un grupo pequeño de individuos (de $15 \%$ a $20 \%$ ) que asisten regularmente a las reuniones y participan en algunos fórums, no obstante, sin la regularidad e intensidad del núcleo;

$3^{\circ}$ grupo: Periférico - está formado por la mayoría de los integrantes de la Comunidad. Raramente participan, razón por la cual están al margen de las discusiones y se limitan a observar las interacciones entre los miembros del núcleo y del activo.

Los participantes transitan entre los tres grupos presentados, no obstante (Wenger, Etienne, 2000b) indican un cuarto grupo, que está fuera de los tres niveles principales, rodeando la Comunidad e interesándose por ella, éstos son los clientes y las CoP (Wenger, E.; Snyder, W. M., 2001) que comparten el mismo dominio.

McDermott (2000) afirma que las Comunidades de Práctica son herramientas poderosas para el intercambio de conocimiento tácito, ya que este reside en las relaciones interpersonales. Sugiere cuatro dimensiones de dificultades para mantener las Comunidades:

Desafíos a la gestión: Para evidenciar que las Comunidades son importantes para el desarrollo organizacional, es interesante que el dominio gire en torno de temas centrales al negocio de la empresa, dado que los resultados serán impactantes para la organización; Las Comunidades necesitan de un miembro que sea respetado por los demás, de modo de actuar como coordinador. Al mismo tiempo, este debe tener conocimiento técnico sobre el dominio, pero sobre todo habilidad

42

Comunidad@Buenas Prácticas de Seguridad, Salud e Calidad de Vida en el trabajo INIAV

"Factores críticos de éxito" 
para conectar las personas y garantizar que los integrantes reservan tiempo para participar de las actividades de la Comunidad. Cultura corporativa que permita la creación y el mantenimiento de las CoP.

Desafíos a la comunidad: Mantener la energía de la Comunidad involucra personas que tengan elevado conocimiento sobre el dominio con el objetivo de proporcionar legitimidad a la CoP. Crear espacios en los que los individuos puedan tener contacto cara a cara y obtener el apoyo de la organización, que es relevante para mantener la Comunidad.

Desafío técnico: La tecnología colaborativa de la Comunidad tiene que ser fácil de manipular y ser comprensible para todos los miembros.

Desafío individual: Producir un sentimiento de seguridad con la finalidad de que los participantes compartan sus ideas/dudas/percepciones con los otros. Finalmente, uno de los aspectos aglutinantes de una Comunidad, que ayuda a establecer su identidad, es el conocimiento compartido en su interior.

\section{Dimensiones de análisis de los factores críticos de éxito para el mantenimiento de las comunidades de práctica}

La dimensión organizativa, para (Scarso \& Bolisani, 2008), se refiere a la estructura de la Comunidad, a los papeles de los miembros, a los mecanismos fundamentales de funcionamiento ya la relación de la CoP con el resto de la organización. Deberá preocuparse por cuestiones como: la relación entre la estructura jerárquica existente y la transferencia de poder a la línea de gestión en virtud de la CoP; definición de cómo las Comunidades pueden coexistir con las estructuras ya presentes, sobre todo cuando se consideran "parte del sistema"; opción en cuanto al tipo de gestión: local o centralizada por el modelo global de la organización; conflicto de prioridad en las actividades de los miembros (como colaboradores de la institución y como integrantes de las CoP); mecanismos de gobernanza de las Comunidades; y, finalmente, el papel del liderazgo. (Scarso \& Bolisani, 2008) 
destacan que las CoP no responden bien al control riguroso del estilo gestión tradicional y que ese modo puede bloquear las contribuciones espontáneas de los miembros. La transversalidad proporcionada por la $\mathrm{CoP}$ entre las distintas unidades de la organización puede generar conflictos en virtud de la estructura jerárquica organizacional. El desarrollo de una Comunidad a veces exige la transferencia de poder a la línea de gestión, y esto puede ser percibido como un elemento para la competencia interna en la organización.

La cuestión de cómo las $\mathrm{CoP}$ pueden coexistir con las estructuras presentes en la organización es crítica, especialmente cuando se asume una configuración formal y se reconocen como una "parte del sistema" (Wenger, E.; Mcdermott, R.; Snyder, W. M., 2002a). Las CoP con gestión central crean una práctica común y facilitan la adhesión de los miembros, ya que las que tienen gestión local proporcionan una mejor delimitación del foco y actúan en cuestiones específicas de interés de los participantes.

Zboralski (2009) defiende que compartir experiencias en Comunidades es una opción de cuño personal, es decir, cada individuo escoge con quien desea compartir su conocimiento. Así, la decisión de interactuar con otros miembros se convierte en un proceso complejo, pues los intereses y las motivaciones varían en gran medida de persona a persona. Esta autora también sostiene la idea de que la participación en Comunidades de Práctica se basa en contribuciones voluntarias - lo que transforma la motivación de los miembros en un factor determinante para las interacciones en la CoP. Este punto clave, aun utilizando las ideas de la investigadora, proviene de fuentes diversas, tales como: interés en el tema del dominio, beneficios en virtud de la adquisición de nuevos conocimientos, construcción de una red de contactos y voluntad de aumentar el status dentro de la organización. Visualización de ascenso profesional motivó a los miembros a participar en las Comunidades.

Según (McDermott, R., 2000), que también trata de la dimensión individual, uno de los elementos clave para fomentar la participación en las Comunidades es conseguir crear un sentimiento de seguridad que los miembros compartan sus ideas / dudas / percepciones con los demás participantes. En la perspectiva del autor, la confianza existente en las relaciones que componen la estructura comunitaria es esencial para que el conocimiento y las prácticas sean compartidos En el trabajo de 
(Cruz, C. C. P.; Motta, C. L. R.; Santoro, F. M.; Elia, M., 2009) la falta de confianza sobre la base del conocimiento desalienta las personas a contribuir con contenidos para su consolidación.

La ausencia de confianza en los contenidos de una base del conocimiento desalienta a las personas a consultarla. La falta de confianza en el conocimiento que se ha compartido puede provocar el abandono de los miembros de una Comunidad de Prácticas (Majewski, G.; Usoro, A.; Khan, I., 2011). La confianza establece la percepción de los participantes de la comunidad de que ésta pueda proporcionar conocimiento en entornos virtuales. La confianza está asociada con la percepción de los participantes de la comunidad de que recibirán conocimientos en el entorno virtual (Thomas, A. U.; Fried, G. P.; Johnson, P.; Stilwell, B. J., 2013).

Las CoP propician el intercambio de documentos útiles a la rutina de trabajo (Curran, J. A.; Murphy, A. L.; Abidi, S. S. R.; Sinclair, D.; McGrath, P. J., 2009). La falta de tiempo fue reportada como un obstáculo a la participación en las actividades de CoPV. (Pemberton, J.; Mavin, S.; Stalker, B., 2007). En términos de comunicación en línea, el tiempo también es un Factor Crítico de Éxito (FCS), al considerar que la escritura (para las posturas de las preguntas y respuestas) es un proceso largo, si se compara con la comunicación verbal, desalentando a algunos miembros su participación en la CoP.

A lo largo del tiempo, el interés por la CoP puede disminuir, sobre todo si se alía a otros factores, tales como: si la participación es voluntaria o formalmente institucionalizada, o aún está vinculada a la perspectiva de progresión funcional o sólo por la motivación de aprender.

El papel del líder es fundamental para la calidad de las interacciones en las comunidades. Es lo que afirma (Zboralski, Katja, 2009) apoyado en estudios de (Wenger, E., 1998a). Los dirigentes pueden ser considerados como facilitadores, lo que implica actuar en varios frentes con el objetivo de promover el buen progreso de la comunidad, y así tratar de ayudar en la construcción de la confianza, la cohesión y un clima positivo para las comunicaciones. Zboralski (2009), afirma que la presencia de un líder fuerte, que tiene una influencia efectiva, es el principal factor para la calidad de las interacciones entre los miembros. El carácter cualitativo mencionado por el autor se basa en la importancia y la usabilidad del conocimiento compartido, que se incrementan en virtud del nivel de inserción e influencia del líder en la CoP. 
Segundo (Pemberton, J.; Mavin, S.; Stalker, B., 2007), las comunidades sin líderes se convierten en grupos fragmentados $\mathrm{y}$, en un breve espacio de tiempo, se pierden y rara vez sobreviven. Sin embargo, para los autores, el gran desafío es medir el grado de interferencia del líder, que transita en el umbral peligroso entre la orientación y la autoridad, en la dinámica de la comunidad.

El apoyo de la organización (recursos) influyó en la frecuencia de las interacciones de los miembros en las Comunidades. La demostración pública, por parte de los gestores, de la importancia de las actividades de las CoP para la organización fomentó las participaciones apoyo de la organización a la Comunidad "fue capturado por cuatro ítems: conciencia de la importancia de los trabajos comunitarios a la organización; proporcionar recursos (tiempo para dedicarse a las actividades, espacio físico para las reuniones, infraestructura técnica, cultura organizacional de compartir el conocimiento); hablar positivamente a otros sobre las actividades del grupo; y apoyo del supervisor directo a sus comandados a participar en las $\mathrm{CoP}$.

\section{De la Expansión de la CoP a su Desaparición}

Las $\mathrm{CoP}$ emergen frecuentemente en el contexto de organizaciones o redes profesionales en las que las personas ya están involucradas en una práctica profesional común. En el transcurso de su ciclo de vida, las CoP evolucionan en sus prácticas o desarrollan nuevas, a través de discusiones y de la exploración de conocimiento interno y externo.

La evolución de las CoP puede llevar no sólo a su expansión, en relación al tema, a la práctica ya sus miembros, así como a su desaparición (Wenger, E.; Mcdermott, R.; Snyder, W. M., 2002a)

Así, la continuidad de las CoP está relacionada con la posibilidad de que sus miembros se identifiquen con los demás miembros, con el tema y con la práctica. A medida que se identifican con la comunidad, asumen roles/identidades dentro de la comunidad, como colaboradores, líderes o simplemente como observadores (lurkers).

Este proceso de identificación depende de la trayectoria del aprendizaje que las prácticas individuales y colectivas adquieren, lo que implica considerar las experiencias pasadas y futuras de los participantes, las relaciones entre ellos y el uso de herramientas de tecnología que interfieren en esas relaciones.

46

Comunidad@Buenas Prácticas de Seguridad, Salud e Calidad de Vida en el trabajo INIAV

"Factores críticos de éxito" 


\section{Contextualización del estudio}

Nuestro estudio incide en una Comunidad que tiene una historia de 15 años (2004-2019) y que se presenta en la figura 3. Comienza precisamente con un pequeño grupo que comparte la pasión que los une en la forma de una pequeña comunidad presencial, la única forma que existía de comunicación online a través de los miembros era el email del grupo. La organización del estudio pasó en estos quince años por grandes transformaciones que luego mencionaremos, pero esta pequeña Comunidad dio origen a la gran Comunidad que hoy podemos buscar y encontrar en internet, siempre con enfoque en el área de la Prevención, Salud y Calidad de Vida de los Trabajadores.

El Instituto Nacional de Investigação Agrária e Veterinária (INIAV) pasó por un intenso proceso de alteración organizacional, escisión y fusión (figura 4).

Es una organización muy dispersa en términos geográficos, pretendiendo la Comunidad de intercambio de Buenas Prácticas SST y Calidad de Vida en el trabajo ultrapasar las fronteras geográficas y continuar compartiendo el conocimiento en la temática de la Prevención de riesgos laborales, que es transversal a todas las actividades del INIAV y aprovechar toda la actividad desarrollada por la Comunidad del Grupo de Animadores de Prevención (CoPGAPEAN) desarrollada en el Polo donde en este momento funciona la sede del INIAV.

Las Comunidades de Práctica constituyen un espacio privilegiado de interacción entre sus miembros, promoviendo el aprendizaje y el intercambio de conocimiento, siendo este último una condición crítica de éxito para la promoción de la innovación. Así, se revela crucial comprender los factores organizacionales que podrán condicionar este intercambio, inhibiéndolo o potenciándolo.

\section{Este trabajo se fundamenta en el estudio de 3 tópicos esenciales:}

El primero se refiere al estudio y recurso a bibliografía sobre el asunto de factores de éxito de otras Comunidades ya estudiadas. 
- El segundo al análisis de todo el recorrido de formación de la Comunidad a lo largo de quince años.

- El tercero a analizar los factores que favorecen la sobrevivencia de la comunidad y sus transformaciones.

\section{Objetivo general}

Este trabajo tiene como objetivo general analizar los elementos de la práctica que conducen a la obtención de resultados facilitadores o inhibidores de la supervivencia de la comunidad de compartir Buenas Prácticas SHST y sus transformaciones.

\section{Objetivos específicos}

-Alcanzar los objetivos definidos por la CoP de Buenas Prácticas SST y Calidad de Vida dos trabajadores;

-Intercambio de saberes y experiencias en el dominio de la SST y de Buenas Prácticas en la Prevención de riesgos laborales.

\section{Identificación del problema de nuestro trabajo de investigación}

¿Cuáles son las prácticas esenciales para el establecimiento, funcionamiento y mantenimiento de la Comunidad de Buenas Prácticas SST y Calidad de Vida del INIAV?

\section{Hipótesis formulada}

Formulamos una hipótesis para nuestra investigación y elegimos como Prácticas Esenciales para garantizar resultados de éxito y el correcto funcionamiento y supervivencia de la comunidad de Buenas Prácticas SST y la Calidad de Vida en el Trabajo tomando como elementos esenciales de esas prácticas: la Cultura, alineamiento y estructuración, Apoyo de la Gestión de la Organización, Líder/Coordinación fuerte, Desarrollo, Política y Tecnología. 
Es un estudio exploratorio sobre la comunidad virtual de práctica en el campo de la Prevención. Para tratar de responder a la pregunta de investigación se planteó varios aspectos de las comunidades virtuales de práctica en la bibliografía.

\section{Presupuestos/Premisas de partida}

Sin el trabajo desarrollado por el Grupo de Animadores de Prevención que formó la $1^{\mathrm{a}}$ Comunidad presencial de intercambio de conocimiento en este dominio la CoP virtual de la WIKINIAV no se habría desarrollado;

Añadir elementos de este grupo en la Comunidad Virtual;

Las interacciones solo tendrán éxito si son mixtas. Elección de eventos presenciales además de los virtuales;

La Comunidad deberá abrir fronteras al exterior, partiendo de la premisa que el intercambio de Buenas prácticas entre Organizaciones, favorece el cambio de comportamientos y actitudes frente a la Prevención;

Elección de moderadores con formación adecuada y con creencia en el desafío;

Cautivar el Liderazgo de la Organización en todo el proceso.

\section{Justificación}

La Comunidad de intercambio de Buenas prácticas SST y Calidad de Vida dos trabajadores, tal como otras Comunidades nació de una pasión de un pequeño grupo, el Grupo de Animadores de Prevención que la originó y pasó por varias fases de desarrollo y entusiasmo.

Paso para una nueva dinámica, la virtual, y en una nueva Organización, el nuevo INIAV. La dispersión geográfica es grande, la diversidad de las culturas de la fusión es también grande, por lo que esta es una gran oportunidad de aproximación a través del trabajo colaborativo.

Con el presente trabajo, pretendemos estudiar una Organización en la que las comunidades de

prácticas virtuales ya estén presentes y específicamente nos centraremos en la Comunidad de intercambio de Buenas Prácticas SST y Calidad de Vida en el Trabajo. 
Este trabajo acompañó todo el proceso de nacimiento y fases del ciclo de vida de la Comunidad, aprovechando los instrumentos aplicados por la investigadora que participó en el desarrollo de la WIKINIAV y siguiendo su trabajo durante todo el proceso.

\section{Etapas de la investigación}

Identificación del problema de la investigación

Revisión bibliográfica

Planeamiento de la metodología

Acompañamiento y discusión del diagnóstico con la otra investigadora

Análisis Documental de la Comunidad Presencial

Acompañamiento del proyecto virtual

Búsqueda | Pesquisa

Recolección de informaciones

Análisis de las cuestiones que fueron introducidas en los instrumentos utilizados y que sirvieron para nuestro estudio

Dinámica de la Comunidad SST

Análisis de la fase virtual y presencial 
Conclusión y redacción

\section{La opción metodológica}

\section{Estudio de caso}

Nuestra opción en este estudio fue la de un estudio de caso que acompañó simultáneamente el mismo caso en dos vertientes, siendo que una de ellas estudió la implementación de una herramienta innovadora en la gestión del conocimiento de la Comunidad de Buenas Prácticas SST en el INIAV, teniendo el investigador un papel activo y participativo (Flor, C., 2015) que implicó la presencia de la investigadora en los acontecimientos, y nuestra investigación pasó para un papel más pasivo de observación sin interacción directa con el público al que estaba dirigida. No obstante, para que no hubiera superposición de aplicación de instrumentos de diagnóstico, ya que corríamos el riesgo de cansar al público, dialogamos con la investigadora del primer proyecto de manera de incluir en los instrumentos de diagnóstico cualitativos y cuantitativos cuestiones que nos interesaban para validar los factores de la hipótesis que formulamos.

En este trabajo de investigación seguimos el ejemplo de (Yin, R., 1993), (Yin, R., 2005) y (Flick, U., 2004), que destacan la importancia de utilizar, en algunos métodos de investigación, simultáneamente datos cualitativos y cuantitativos. La utilización de datos cualitativos y cuantitativos en la misma investigación tiene como finalidad ver estas dos metodologías como complementarias y no como opuestas o rivales. (Yin, R., 2005) también aborda esta cuestión destacando que los estudios de caso son una estrategia abarcadora y pueden incluir las evidencias cuantitativas. Según este autor, la estrategia de estudio de caso, al ser una estrategia abarcadora, no se debe confundir con investigación cualitativa, ya que existe una gran e importante área común entre la investigación cualitativa y cuantitativa.

El problema de la generalización en la investigación cualitativa consiste en el hecho de hacerse siempre para determinados contextos (Flick, U., 2004). Pero la cuestión debe ponerse más en términos de transferibilidad para otros contextos. 


\section{Unidades de análisis}

La definición de la unidad de análisis está relacionada también con la forma como se definen las cuestiones iniciales de investigación.

Cuando queremos analizar una realidad, podemos considerar esa realidad de forma global, como una totalidad única, o podemos considerarla como constituida por una serie de unidades, cuya caracterización peculiar exige un trabajo diferenciado (Rodríguez, G. G.; Flores, J. G.; Jiménez, E. $G, 1999$ ). Cada unidad de análisis requiere una estrategia diferente de recoja de datos (Yin, R., 2005).

Elegimos como primera Unidad de análisis la Comunidad presencial de intercambio de conocimiento sobre Buenas Prácticas SHST del Grupo de animadores de Prevención de la EAN (CoPGAPEAN).

La segunda Unidad de análisis fue la CoPSSQVT

\section{Tipología del estudio de caso: exploratorio}

En nuestro caso tuvimos dos (2) estudios de caso aplicados al mismo contexto Organizacional y no dos estudios de caso en Organizaciones diferentes. El primer estudio (Flor, C., 2015) dio origen a nuestra hipótesis y a los factores críticos elegidos, siendo un estudio exploratorio ya que procuramos dar énfasis al descubrimiento de prácticas que pudieran formular nuevas ideas y comprender el fenómeno.

\section{La recoja y análisis de la información en estudios de caso}

Parece consensual que deben ser el caso y su contexto, así como el problema, las proposiciones y respectivas cuestiones que orientarán todo nuestro estudio. De acuerdo con (Fragoso, A., 2004), el investigador debe asegurar que los métodos y técnicas de recolección de información son utilizados 
de forma suficiente y pertinente. Para eso, el investigador debe recoger y organizar datos de diversas fuentes y de forma sistemática (Dooley, L. M., 2002)

\section{Fase de negociación o discusión}

En nuestro estudio intentamos entender como todo sucedió antes del surgimiento de la WIKINIAV, para eso tuvimos que buscar junto al investigador y a la Organización que tipo de Comunidad existía, que es lo que sucedió para que diera origen a una Comunidad dentro de una Organización del sector público virtual.

Nuestra recoja de datos tuvo inicio el año en que se formó la Comunidad del Grupo de animadores de Prevención en el año 2004, hasta el año 2014.

Fue necesario direccionar todo nuestro trabajo conjuntamente con el otro investigador, para que no hubiera sobrecarga de cuestionarios y entrevistas, ya que nos arriesgábamos a no obtener respuestas. En este sentido hubo consenso y se aplicaron varios instrumentos con gran alcance para que consiguiéramos obtener los datos que necesitábamos para ambos estudios. El cuestionario online que fue aplicado al Universo del INIAV se fundamentó en otro cuestionario aplicado en otro estudio y la investigadora del estudio que acompañaba solicitó la correspondiente autorización al investigador Paulo Sérgio de Oliveira para que se replicara el cuestionario en Portugal y se adecuara a nuestro público. El cuestionario fue validado en varias fases ya explicitadas en el estudio (Flor, C., 2015). Los resultados se compartieron entre los dos equipos de investigación en un ambiente de cordialidad.

También fue necesario pedir autorización para consultar documentos que nos aclararan todo el recorrido del GAP para la construcción del archivo (Portefólio).

La ventaja más importante para el uso de fuentes múltiples de evidencia es el desarrollo de líneas convergentes de investigación como proceso de triangulación de datos (Yin, R., 2005). 


\section{El papel del investigador en los estudios de caso}

Las estrategias positivistas crearon la idea del observador neutro, sin influencia sobre el objeto de investigación. En este sentido, se puede captar una realidad objetiva, en la medida en que se considera que puede ser eliminada la subjetividad a través de una relación distante del observador/investigador.

Nuestro papel en esta investigación fue de investigador no participante, limitándonos a observar todos los acontecimientos. La relación más próxima que existía era con el otro investigador del mismo estudio de caso, pero con otra línea de investigación.

\section{Instrumentos de evaluación y recoja de datos}

La diseño e implementación del estudio envolvió la utilización de una vasta diversidad de herramientas, así como también, la construcción de algunos instrumentos para la recoja de datos, trabajando siempre conjuntamente con el otro investigador. Esta situación resultó de las cuestiones de la investigación que nos propusimos contestar y de la metodología adoptada, y representa una vertiente más cualitativa derivada de nuestra necesidad de entender cuáles son los factores críticos de éxito para la supervivencia de la Comunidad de Buenas Prácticas SST y la Calidad de Vida en el trabajo.

\section{Diario}

Análisis Documental de la Comunidad de Animadores de Prevención (acceso a todos los documentos del GAP)

Análisis de las categorías Fórum SST; categoría GC-CoP intercambio de Buenas Prácticas SST; Categoría SST

Análisis de los contenidos de las cuestiones de las entrevistas que estaban relacionadas con nuestro trabajo

Análisis de las cuestiones colocadas en los cuestionarios relacionadas con nuestro trabajo Análisis del contenido de la entrevista con el Gestor de la plataforma INA y con la Moderadora Global de la Comunidad 
Doctorado en Salud, Discapacidad, Dependencia y Bienestar

\section{Los participantes y el contexto de la Investigación}

De acuerdo con (Hill, M. M.; Hill, A., 2002) la naturaleza y la dimensión del Universo son definidas por el objetivo de la investigación.

El objetivo de nuestro trabajo de investigación pasa por analizar los factores que son críticos para el éxito y supervivencia de la Comunidad de Buenas Prácticas SST y alcanzar los objetivos fijados por la Comunidad que son: intercambio de saberes y experiencias en el dominio de la SST, Buenas prácticas en la Prevención de riesgos laborales y calidad de vida en el trabajo.

Nuestra investigación es de índole más cualitativa y por ese motivo utilizamos una muestra de menor dimensión. En nuestro caso, al acompañar el estudio (Flor, C., 2015) fue la muestra elegida por la investigadora por conveniencia ya que los individuos están próximos del contexto de la investigación, contemplando todas las carreras profesionales, lo que fue ventajoso ya que el GAP (Grupo de Animadores de Prevención) también tenía su sede en el Polo Oeiras. La interpretación de los datos fue mucho más fácil por el hecho de ser un espacio común.

Antes de elegir la muestra por conveniencia, la primera investigadora (Flor, C., 2015) hizo un diagnóstico al Universo INIAV aplicando un cuestionario online en el que también fueron compartidas cuestiones que nos interesaban. Este cuestionario ya había sido aplicado por Paulo Sérgio de Oliveira y se le solicitó autorización para hacer uno nuevo y adecuarlo a nuestro estudio, como documenta el estudio da referida autora.

Nuestro estudio tuvo 2 fases diferentes, una iniciada con la Comunidad Presencial (GAP) teniendo acceso al proceso Documental de esa Comunidad y otra acompañando el estudio de (Flor, C., 2015) de 2012 a 2014. Tuvimos también como elemento facilitador el hecho de que esta investigadora era también uno de los elementos facilitadores del GAP. El primer estudio se basó en la EAN (Estação Agronómica Nacional) y el segundo en el INIAV (Instituto Nacional de Investigação Agrária e Veterinária). 
Doctorado en Salud, Discapacidad, Dependencia y Bienestar

\section{Caracterización de la EAN}

La Estação Agronómica Nacional (EAN) pertenece al Instituto Nacional de Investigação Agrária e Pescas (INIAP). El Instituto Nacional de Investigação Agrária e Pescas (INIAP) es un Laboratorio del Estado integrado en el Ministerio de Agricultura, de Desarrollo Rural y de las Pescas (MADRP), que tiene como función realizar acciones de investigación, experimentación y demostración necesarias para el refuerzo de las filas o líneas productivas agrícola y forestal, incluyendo la mejoría de la producción y la defensa del patrimonio genético vegetal y animal. Creado en 1974 como INIA, organismo integrador de todas las unidades de investigación del Ministerio de Agricultura, y en 2002 fundiéndose con el IPIMAR.

El estudio fue realizado en el ámbito del Programa Sabáticas del Instituto Nacional de Administração (INA) en la EAN y con la participación del Director de la EAN se formó la primera Comunidad de intercambio de Conocimiento y Buenas prácticas en la AP (Administración Pública) presencial, como lo prueban los documentos presentados en el Anexo A e B de este trabajo.

El primer paso consistió en hacer un diagnóstico de la Cultura Organizacional y de la Seguridad en colaboración con el ISCTE (Instituto Superior de Ciencias del Trabajo) a través de una metodología mixta con entrevistas semiestructuradas a una muestra por conveniencia de la EAN y aplicando el ICOS (Inquérito de Clima Organizacional e de Segurança con la colaboración del ISCTE). Después de este diagnóstico se evaluó cual era la prioridad de intervención al nivel de la Cultura de Seguridad y se formó una Comunidad de 13 funcionarios que serían formados (formación continua) para el cambio. En 2004 se inició el proceso formativo del grupo y en 2005 el grupo inició un gran trabajo de campo compartiendo conocimientos tanto dentro de la Organización como con otras Organizaciones de la AP, como lo demuestran varios documentos presentados en los Anexos A e B. 
Doctorado en Salud, Discapacidad, Dependencia y Bienestar

\section{El segundo estudio se realizó en el INIAV}

\section{Caracterización del INIAV}

El Instituto Nacional de Investigação Agrária e Veterinária (INIAV) es un Laboratorio de Estado integrado en el Ministerio de Agricultura. El INIAV fue creado en 2012 a partir del antiguo Instituto Nacional dos Recursos Biológicos I.P. (INRB). Las atribuciones relacionadas con la investigación agraria (del L-INIA) y veterinaria (del L-LNIV) del ex-INRB fueron asignadas al INIAV, y las relativas a las áreas de la pesca y acuicultura al Instituto Português do Mar e da Atmosfera, I. P. (IPMA).

\section{Misión}

El INIAV tiene por misión la concretización de la política científica y la realización de investigación de soporte de las políticas públicas, en defensa de los intereses nacionales y con el propósito de continuar y profundizar las políticas comunes de la Unión Europea. Brinda apoyo técnico y científico a la Tutela a través de la elaboración de pareceres, la creación de grupos de trabajo, y la elaboración y el análisis crítico de documentos.

El INIAV tiene Laboratorios Nacionales de Referencia para enfermedades animales, seguridad alimentaria y para enfermedades y plagas vegetales. Los investigadores y técnicos superiores de estos Laboratorios Nacionales de Referencia poseen un gran know-how en las áreas de la sanidad animal y vegetal, así como también en la seguridad alimentaria, por lo que brindan asesoría al Gobierno y a las Autoridades Nacionales siempre que es necesario.

El INIAV tiene un papel central en el dominio de la promoción y conservación de los recursos genéticos nacionales en las áreas animal y vegetal, mediante la creación y el mantenimiento de colecciones vivas y de bancos nacionales de Germoplasma 


\section{Los participantes, el contexto de la investigación y las características de la muestra}

De acuerdo con (Hill, M. M.; Hill, A., 2002), la naturaleza y la dimensión del universo son definidas por el objetivo de la investigación. En las investigaciones de índole más cualitativa, normalmente se privilegia la utilización de muestras de menor dimensión. En este caso, el estudio incidió sobre el Instituto Nacional de Investigação Agrária e Veterinária, que es un Instituto que está geográficamente disperso. La muestra seleccionada incidió por conveniencia en la elección de funcionarios del INIAV, situados en el Centro de investigación de Oeiras y corresponde a 35\% del Universo INIAV. Su elección recayó sobre diferentes carreras profesionales (Dirección superior de $1^{\mathrm{o}}$ grado, Dirección superior de $2^{\circ}$ grado, la carrera de investigación, la carrera de Técnico superior, la carrera de Técnico profesional de laboratorio y la carrera de Asistente administrativo, Informático, Docente Universitario). La muestra contempló los géneros masculino y femenino de diferentes edades. Se trató de un estudio exploratorio, cuyos resultados no son generalizados a un grupo más amplio de personas, no obstante, permitió obtener algunas recomendaciones para estudios posteriores. Nuestra opción estuvo relacionada con la ventaja de que este tipo de muestra es simple de organizar y poco costosa, ya que no teníamos como objetivo de este estudio la generalización de los resultados. Respetamos los criterios de representatividad y de imparcialidad y seguimos los mismos criterios del estudio que se realizaba en paralelo.

En el primer estudio, realizamos un análisis documental exhaustivo sobre todos los aspectos que caracterizan el Grupo de animadores de Prevención de la ENA, la Comunidad embrionaria para el proceso de cambio de actitud frente a la prevención de riesgos laborales que pasamos resumidamente a describirlos y que están documentados en los ANEXOS BI;BII;BIII;BVI.

- Historia del GAP (Comunidad del grupo de Animadores de Prevención);

- Mensajes elaborados por el GAP en encuentros presenciales, tanto en grupos numerosos en auditorio (150 personas) como en grupos más pequeños (16 personas);

- Elaboración de productos del GAP;

- Guías de Buenas Prácticas;

- Fichas técnicas;

- Cartillas / folletos; 
- Dinamización de Seminarios: internos, con el objetivo de incluir jefes de jerarquías elevadas e intermedias y colegas; externos, con el objetivo de compartir las experiencias vividas en la organización;

- La inclusión del Coordinador del grupo en todas las fases del proceso;

- La inclusión de los líderes en todas las fases del proceso.

La recoja de datos fue Documental, con autorización del primer investigador del estudio de caso. Tuvimos acceso a las fichas técnicas, Guías y Manuales de Buenas prácticas y a las cartillas/folletos que fueron elaborados en el primer estudio como se documenta en el (ANEXO BIII). Visualizamos también algunos vídeos del primer estudio para comprender mejor la importancia de este grupo como catalizador de la comunidad que se formó. Realizamos una entrevista semiestructurada a la coordinadora del grupo (ANEXO BII). El análisis del contenido de la entrevista nos permitió verificar que este estudio fue catalizador del proceso de cambio, que adherieron al estudio profesionales técnicos de laboratorio, que hubo una inversión formativa en el grupo y un gran compromiso por parte de los jefes de la alta jerarquía, que apoyó siempre todas las acciones premiando el trabajo del grupo.

Con la salida de los jefes/líderes de la Organización hubo una ruptura, una falta de confianza en la continuidad, y en ese momento la Coordinadora del grupo reanalizó la estrategia y se percató de que no tenía las herramientas necesarias para dar continuidad con entusiasmo. Para hacer frente a esta situación se formó, adquirió conocimientos y posteriormente fue invitada a dirigir la $1^{\mathrm{a}}$ comunidad virtual para la Administración Portuguesa. Desde esta posición, facilitó la formación de más elementos del grupo como facilitadores de la Comunidad Virtual de intercambio de Buenas Prácticas SHST en las comunidades@ina. El grupo abrió sus fronteras siendo invitado por otro Organismo de la AP para dinamizar una comunidad en el ámbito de la prevención. Esta fue una Comunidad dirigida por el INA (Instituto Nacional de Administração).

Colocamos algunas cuestiones al gestor de esta Comunidad, como consta en el (ANEXO AII), y reparamos en la importancia de un moderador activo y facilitadores del GAP. Esta fue una de las Comunidades más activas del INA, como lo demuestra la entrevista. 
Aquí es necesario considerar el papel del moderador Global y enérgico de la Comunidad.

El $2^{\circ}$ estudio de caso nació con el cambio del INA donde ya estaba instalada la CoP de Buenas Prácticas SST y en ese momento la Moderadora del grupo recurrió a un informático del INRB (Instituto Nacional de Recursos Biológicos) para saber en relación a la posibilidad de crear una herramienta que permitiera el trabajo de la Comunidad virtualmente (el Ingo Nuno Silva). El INRB estaba viviendo momentos difíciles y con una herramienta sin costos comenzamos a dar pasos con la finalidad de verificar esta posibilidad (herramienta Joomla), pasando por una fase experimental.

El INRB sufrió una nueva transformación y en el proceso de cambio de Dirección la Directora dejó aprobado el nuevo proyecto y pasó el testimonio a la nueva Dirección del INIAV, que abrió las puertas al proyecto de la WIKINIAV, pasando así la plataforma por una fase experimental seguida de una operacional con éxito.

Para lograr incluir a todos los colegas y como la SST es un área transversal a todas las actividades del Instituto, se crearon varias categorías con la finalidad de que nacieran varias comunidades temáticas del dominio del INIAV, compartiendo el saber de la SST con todas, ya que era común y transversal. Nuestra función consistió en analizar dentro de la WIKINIAV los acontecimientos relacionados con la SST y la Calidad de Vida del trabajador. Negociamos con la investigadora del $1^{\mathrm{o}}$ estudio la posibilidad de integrar cuestiones importantes y como facilitadora del proceso trabajamos lado al lado para ganar tiempo, sin cansar a los trabajadores con más cuestionarios y entrevistas.

\section{Análisis y discusión de los resultados}

Presentamos una reflexión sobre el análisis e interpretación de los datos recurriendo a la triangulación metodológica. La triangulación combinó métodos y recoja de datos cualitativos y cuantitativos (entrevistas, cuestionarios, documentos, observaciones y notas de campo), así como también diferentes métodos de análisis de datos (análisis del contenido de las entrevistas, análisis combinatorio, análisis de cuadros de observación). El objetivo consistió en contribuir para una mejor comprehensión del problema estudiado. 
Con la triangulación pretendimos validar los resultados recurriendo a diferentes métodos. Adaptamos nuestro análisis al realizado por el estudio que se estaba a llevando a cabo en paralelo (Flor, C., 2015).

Con el objetivo de encontrar las respuestas a la cuestión que se planteó al inicio de nuestra investigación, el desafío fue: Analizar los elementos de las prácticas esenciales que conducen a la obtención de resultados facilitadores o inhibidores de la supervivencia de la comunidad de compartir Buenas Prácticas SST y la Calidad de Vida en el Trabajo ( CoPSSQVT ) y sus transformaciones.

Formulamos una hipótesis para nuestra investigación y elegimos como prácticas esenciales para garantizar resultados de éxito y el correcto funcionamiento y supervivencia de la comunidad de Buenas Prácticas SST y la Calidad de Vida ( CoPSSQVT )en el Trabajo tomando como elementos esenciales de esas prácticas: la Cultura, alineamiento y estructuración, Apoyo de la Gestión de la Organización, Líder/Coordinación fuerte, Desarrollo, Política y Tecnología.

Para alcanzar el objetivo de nuestro trabajo que consistió en analizar los elementos críticos de las prácticas esenciales para el éxito y supervivencia de la Comunidad de Buenas Prácticas SST y Calidad de Vida en el Trabajo y partiendo del presupuesto que sin el trabajo desarrollado por la CoP Animadores de Prevención (CoPGAPEAN) que se formó la $1^{\mathrm{a}}$ Comunidad presencial de intercambio de conocimiento en este ámbito la $\mathrm{CoP}$ virtual Comunidad de compartir de Buenas prácticas SST y Calidad de Vida de WIKINIAV no se habría desarrollado, de ahí nuestra necesidad de analizar 2 estudios de caso aplicados al mismo contexto organizacional y no dos estudios de caso en organizaciones diferentes.

Como hemos dicho anteriormente, optamos por un estudio exploratorio.

La necesidad de gestionar todo nuestro trabajo en conjunto con otro investigador, pues hemos optado por analizar la formación de la Comunidad embrionaria y seguir su ciclo de vida hasta la fase de transformación y continuidad iniciando nuestro análisis en 2004 y terminando en 2019 que corresponde a un período de tiempo de 15 años.

En ese sentido hubo consenso y nosotros analizamos varios instrumentos con una gran cobertura para que pudiéramos obtener los datos que necesitábamos. 


\section{Estrategia del análisis de datos}

Utilización de Fuentes Múltiples de Evidencia: La ventaja más importante para el uso de fuentes múltiples de evidencia es el desarrollo de líneas convergentes de investigación, como proceso de triangulación de datos.

Nuestro papel en esta investigación fue de investigador no participante, limitándonos a observar todos los acontecimientos y la relación más cercana que existía era con el otro investigador del mismo estudio de caso, pero con otra línea de investigación.

Siendo nuestra investigación de índole más cualitativa y por eso utilizamos una muestra de menor tamaño, de acuerdo con (Hill, M. M.; Hill, A., 2002) la naturaleza y la dimensión del Universo son definidos por el objetivo de la investigación. En nuestro caso al acompañar el estudio (Flor, C., 2015) fue la muestra elegida por la investigadora por conveniencia pues los individuos están cerca del contexto de investigación, contemplando todas las carreras profesionales, lo que para nosotros fue ventajoso pues la Comunidad embrionaria (CoPGAPEAN) también se basó en el Polo Oeiras y para la interpretación de los datos fue mucho más fácil el espacio ser común.

Nuestro estudio tuvo 2 fases distintas, una iniciada con la formación Comunidad Presencial (2004 a 2008) y la otra el análisis en el período de 2009 a 2019 (ilustración 3).

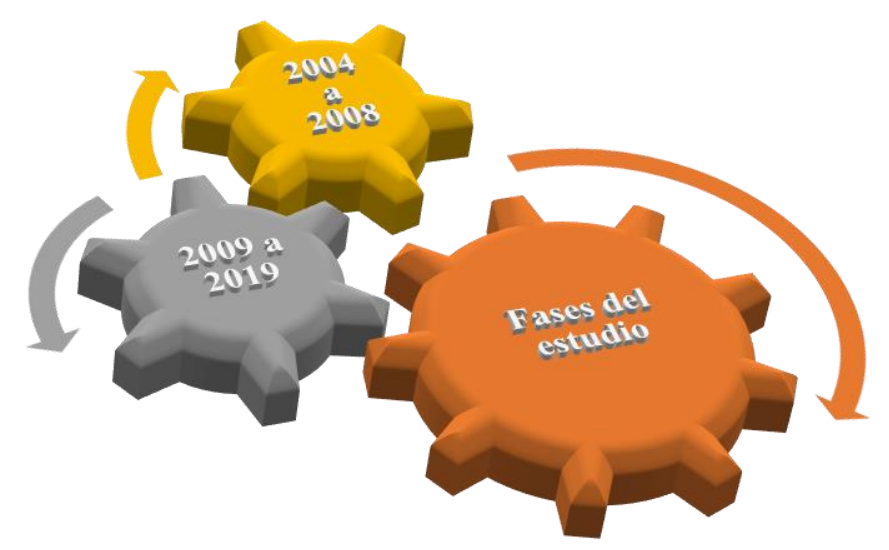

Ilustración 3 - Fases del estudio

Fuente: Desarrollo propio 
Las dos fases del estudio tuvieron lugar en el mismo lugar (Pólo Oeiras ) y lo que marcó la gran diferencia en el seguimiento del estudio fueron los grandes cambios organizativos y también una comunidad que dura un período muy largo de 2004 a 2014 y en este intervalo va de una comunidad En persona (2004-2008) y mixto, es decir, en persona y componente virtual, de (2004 a 2014), también analizamos el período de (2015-2019) para tratar de entender por qué en este período la disminución de la actividad colaborativa en el campo de la seguridad y la salud.

Nuestra apuesta fue contactar los miembros facilitadores y la Coordinadora de la CoPGAPEAN teniendo acceso al proceso Documental de esa Comunidad para el análisis de datos. Aplicamos herramientas de evaluación de datos, una entrevista semiestructurada con el Coordinador de los miembros de la comunidad de la COP y otros facilitadores (ANEXO AI y AII) y se realizó un análisis de contenido de los mismos en (ANEXO BI y BII).

Esta Comunidad nace en la EAN (Estación Agronómica Nacional) que pertenecía al INIAP en 2005 una de las estaciones experimentales la Estación Agronómica Nacional (EAN) perteneciente al Instituto Nacional de Investigación Agraria y Pesca (INIAP).

También se analizaron varios tipos de documentos: libro de actas de reuniones; Documentos formales de la dirección; Documentos de eventos presenciales; Folletos; Carteles y Fichas técnicas. La ventaja más importante para el uso de fuentes múltiples de evidencia es el desarrollo de líneas convergentes de investigación, como proceso de triangulación de datos (Yin, R., 2005). 


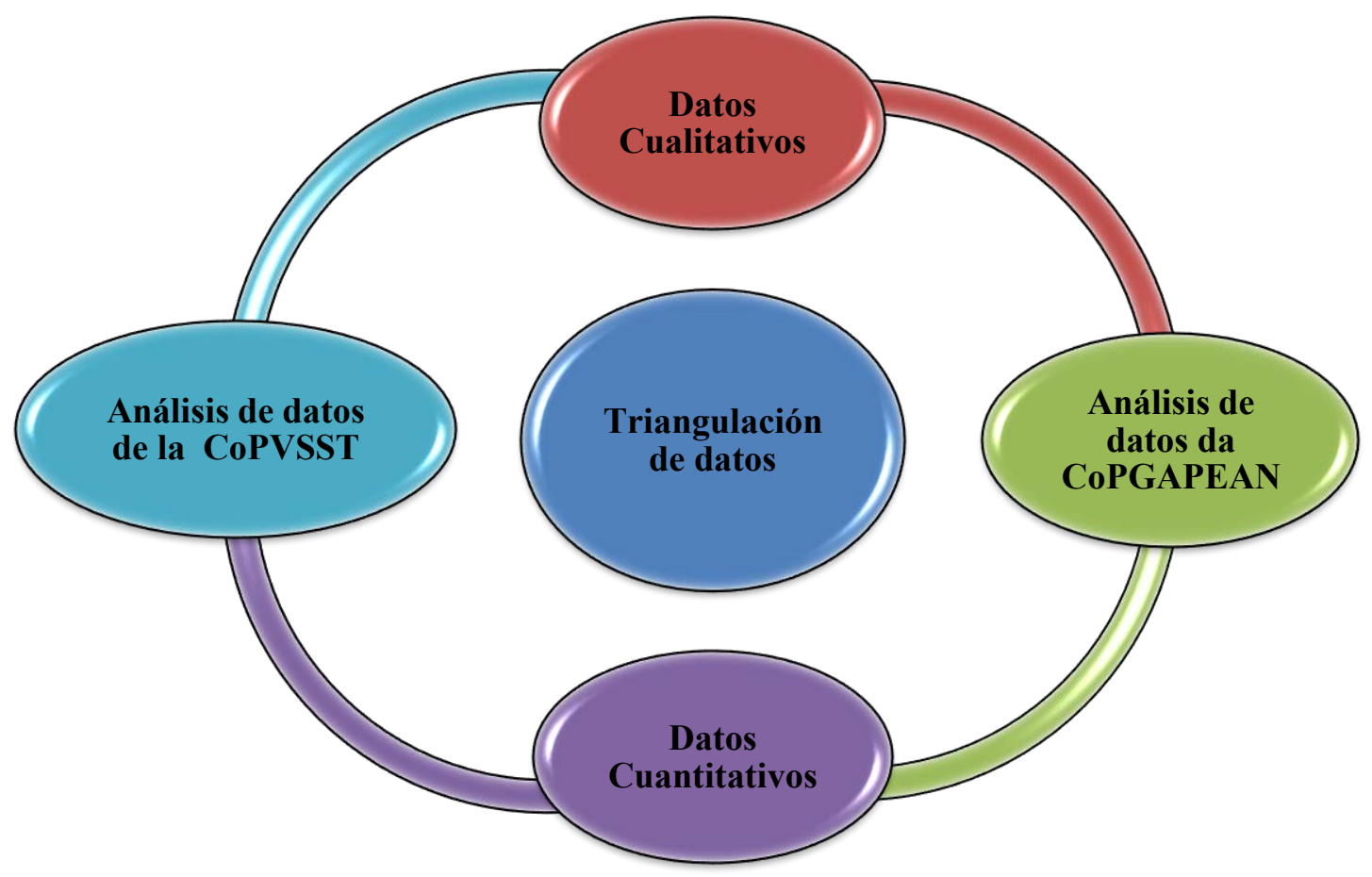

Ilustración 4 - Estrategia de análisis de datos

Fuente: Desarrollo propio

Uno de los datos de nuestro análisis revela un punto crucial al inicio del proyecto (2004 a 2008) la implicación de la Gestión de Topo y como consecuencia de esta participación como estrategia para el éxito en un plan de intervención, la Gestión de Topo de la Organización pide un diagnóstico de la Cultura Organizacional y de la Seguridad haciendo una alianza con el CIS/ISCTE (Centro de Investigación Social del Instituto Superior Ciencias del Trabajo y de la Empresa). 


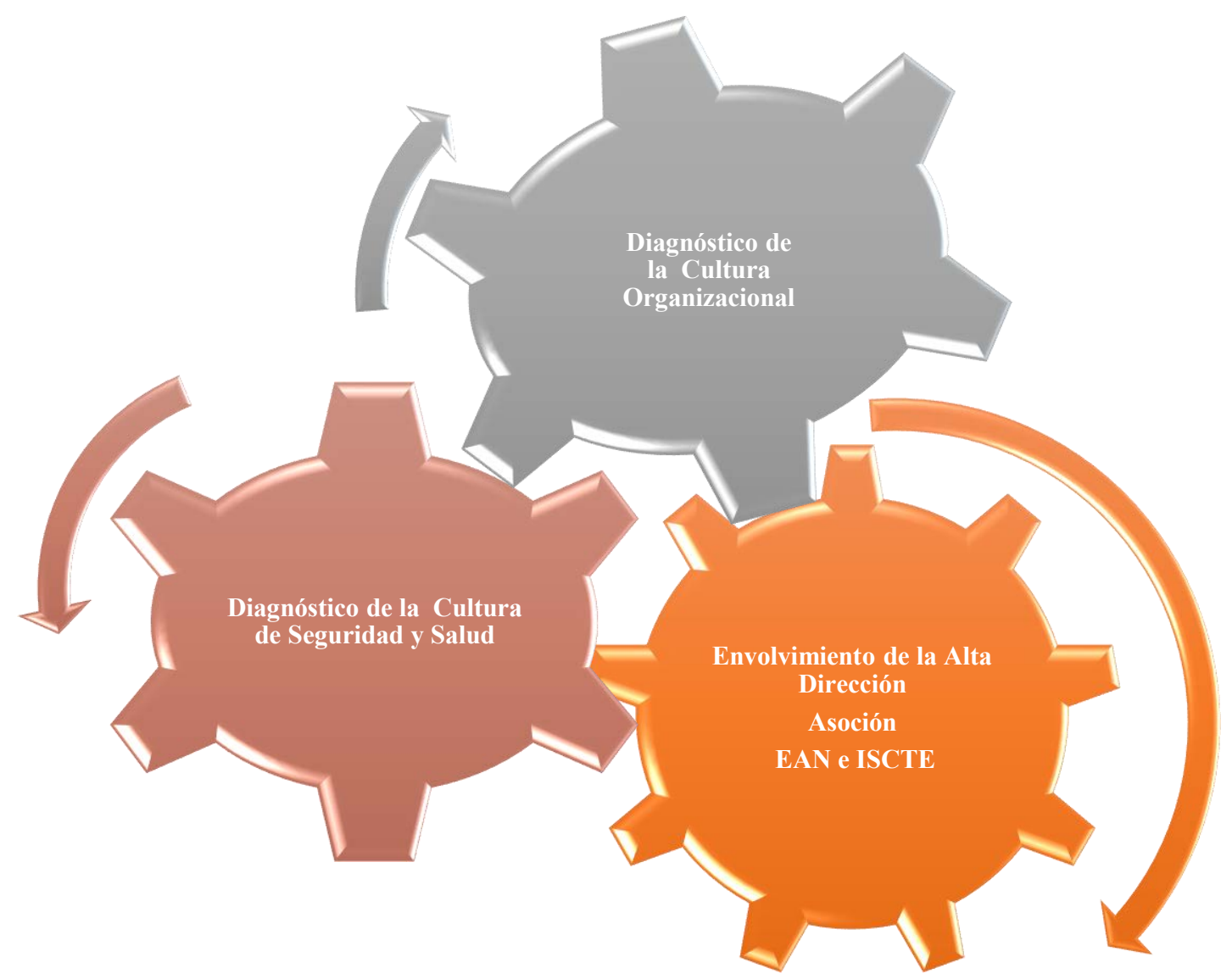

Ilustración 5 - Diagnóstico de la Cultura Organizacional y de Seguridad - ICOS (CIS/ISCTE)

Fuente: Desarrollo propio

Después del diagnóstico se evaluó cuál era la prioridad de intervención a nivel de la Cultura de Seguridad y se formó una Comunidad de quince funcionarios que tuvieron acceso a un programa de formación / entrenamiento para el cambio. En 2004 inició el proceso formativo del grupo y en 2005 el grupo inició un gran trabajo de campo compartiendo conocimientos tanto dentro de la Organización como con otras Organizaciones de la AP. Fue crucial preparar para el cambio y el líder de la Organización tuvo un papel preponderante, apoyando al grupo en todas las fases y envolviéndose él mismo en las acciones.

El Clima organizacional fue evaluado al inicio del proyecto estando la Comunidad de los Animadores de Prevención (CoPGAPEAN) a dar sus primeros pasos en la construcción de un 
sentimiento de pertenencia y confianza mutua, estableciendo una asociación con el Centro de Investigación Social del ISCTE que a través de sus instrumentos de evaluación y aplicando un cuestionario (Silva, S. ICOS, 2006) nos dieron la posibilidad de hacer una evaluación de la Cultura Organizacional y de la Seguridad a pedido del Dirigente máximo de la Organización debido a la necesidad de que en un proceso de intervención tengamos la compatibilización de la Cultura Organizacional y de la seguridad. En este estudio, un total de 121 individuos (Oeiras) respondieron al cuestionario.

Resultados de clima organizacional (2005-2006)

\section{Variables Organizacionales}

\begin{tabular}{|l|r|r|r|r|r|}
\hline & $\mathrm{N}$ & Mínimo & Máximo & Média & \multicolumn{1}{c|}{$\begin{array}{c}\text { Desvio- } \\
\text { padrão }\end{array}$} \\
\hline Objetivos & 111 & 1,33 & 7,00 & 5,0450 & 1,33370 \\
Inovação & 108 & 1,00 & 7,00 & 4,6537 & 1,32456 \\
Apoio & 107 & 1,00 & 6,80 & 4,7402 & 1,37778 \\
Regras & 109 & 2,00 & 7,00 & 4,9235 & 1,16943 \\
\hline
\end{tabular}

Escala: $1=$ nada importante ou nada frequente; 7 = muitissimo importante ou muitissimo frequente

Tabla 1 - Variables Organizacionales Psicosociales

Fuente: (Silva, Silvia; Tavares, Susana, 2006) - Documento consultado (ANEXO BVI)

ICOS 2006: El clima organizacional es evaluado a través del modelo de los valores contrastantes y verificamos que los valores se sitúan por encima del punto medio de la escala al nivel de los objetivos, innovación, apoyo y reglas, lo que significa un clima positivo. Los trabajadores comparten la percepción de que la organización valoriza más los objetivos y las reglas revelando los resultados (Tabla 1- analisys documental) de la existencia de una preocupación en definir una misión y objetivos claros para la organización.

En cuanto a las variables psico-sociales estudiadas que se encuentran en la (tabla 2) las medias, desviaciones estándar y valores mínimos y máximos observados en una escala de concordancia podemos recoger datos muy favorables para la implementación de cambios. Verificamos una identificación positiva con la organización y con la profesión, una implicación afectiva (analisys documental ). También verificamos que el valor medio presentado en la relación trabajo-familia es 
favorable, hay también un valor medio positivo en relación al ajuste persona-trabajo (tabla 2) análisys Documental (ANEXO BVI) .

\begin{tabular}{|c|c|c|c|c|c|}
\hline VARIAVVEIS ESTUDADAS & $\mathrm{N}$ & Mínimo & Máximo & Média & $\begin{array}{l}\text { Desvio- } \\
\text { padrão }\end{array}$ \\
\hline IMAGEM ORGANIZACIONAL & & & & & \\
\hline Imagem percebida & 106 & 1,00 & 7,00 & 3,9198 & 1,19749 \\
\hline Prestígio percebido & 98 & 1,00 & 7,00 & 4,1388 & 1,09973 \\
\hline $\begin{array}{l}\text { INTERDEPENDENCIA NO EXERCICIO DA } \\
\text { FUNÇÄO }\end{array}$ & & & & & \\
\hline Interdependência recíproca & 107 & 1,00 & 6,75 & 4,5210 & 1,22095 \\
\hline $\begin{array}{l}\text { PERCEPÇÄO DE SUPORTE NO LOCAL DE } \\
\text { TRABALHO }\end{array}$ & & & & & \\
\hline Perceção de suporte organizacional & 103 & 1,00 & 6,38 & 3,6735 & 1,30154 \\
\hline $\begin{array}{l}\text { Perceção de suporte em relação aos colegas } \\
\text { IDENTIFICAÇÄO }\end{array}$ & 107 & 1,75 & 7,00 & 4,7722 & 1,25328 \\
\hline Identificação com a organização & 107 & 2,00 & 7,00 & 5,0748 & 1,27221 \\
\hline Identificação com a profissão & 110 & 1,00 & 7,00 & 5,3782 & 1,05286 \\
\hline $\begin{array}{l}\text { IMPLICAÇAAO ORGANIZACIONAL } \\
\text { Implicaçâo afetiva }\end{array}$ & 111 & 1.00 & 7.00 & 4.8198 & 1.32509 \\
\hline Implicação normativa & 105 & 1,00 & 7,00 & 4,0643 & 1,34942 \\
\hline Implicação continuidade & 102 & 1,00 & 6,75 & 3,4975 & 1,31701 \\
\hline $\begin{array}{l}\text { CONFLITO ENTRE O TRABALHO E A } \\
\text { FAMILIA }\end{array}$ & & & & & \\
\hline conflite trabalho-família & 107 & 1,00 & 6,25 & 2.9486 & 1,20618 \\
\hline $\begin{array}{l}\text { conflite família-trabalho } \\
\text { AJUSTAMENTO DO INDIVIDUO }\end{array}$ & 104 & 1,00 & 4,75 & 2,1082 &, 93785 \\
\hline Ajustamento pessoa-organização & 104 & 1,00 & 7,00 & 3,8654 & 1,46334 \\
\hline $\begin{array}{l}\text { Ajustamento pessoa-trabalho } \\
\text { ATITUDE FACE A MUDANÇA }\end{array}$ & 109 & 1,00 & 7,00 & 4,9778 & 1,15290 \\
\hline $\begin{array}{l}\text { Atribuição situacional das consequências da } \\
\text { mudança }\end{array}$ & 108 & 1,33 & 7,00 & 3,5000 & 1,27399 \\
\hline Pessimismo relativamente à mudança & 107 & 1,00 & 7,00 & 3,2033 & 1,17669 \\
\hline $\begin{array}{l}\text { COMPORTAMENTOS DE CIDADANIA } \\
\text { ORGANIZACIONAL }\end{array}$ & & & & & \\
\hline Dedicação ao trabalho & 112 & 3,00 & 7,00 & 5,9487 &, 78710 \\
\hline Dedicação ao trabalho extra-horário & 106 & 1,00 & 7,00 & 4,2075 & 1,45384 \\
\hline INTENÇÄO DE SAIDA & & & & & \\
\hline Intenção de turnover & 112 & 1 & 7 & 2.0804 & 1.55898 \\
\hline
\end{tabular}

$5=$ Concordo em parte; $6=$ Concordo bastante $; 7=$ Concordo totalmente

Tabla 2 - Variables Organizacionales Psicosociales

Fuente: (Silva, Silvia; Tavares, Susana, 2006)- Documento consultado (ANEXO BVI)

Al nivel de comportamientos de ciudadanía organizacional tenemos un valor positivo en relación a la dedicación al trabajo y un valor positivo en relación a la continuidad en la organización.

También verificamos que el valor medio presentado en la relación trabajo-familia es favorable, hay también un valor medio positivo en relación al ajuste persona-trabajo (tabla 2). Al nivel de

67

Comunidad@Buenas Prácticas de Seguridad, Salud e Calidad de Vida en el trabajo INIAV

"Factores críticos de éxito" 
comportamientos de ciudadanía organizacional tenemos un valor positivo en relación a la dedicación al trabajo y un valor positivo en relación a la continuidad en la organización.

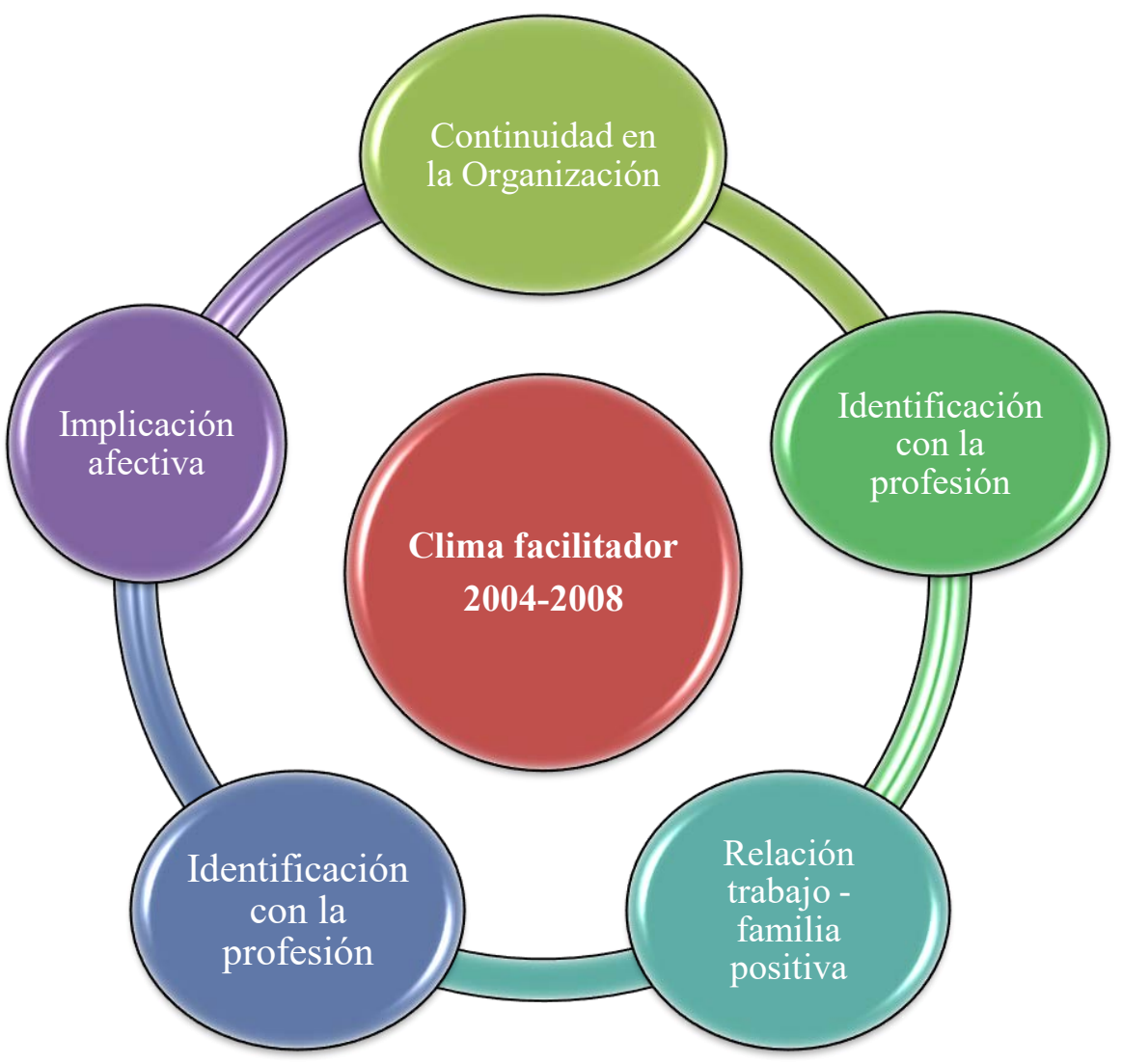

Ilustración 6 - Clima Organizacional 2004 a 2008

Fuente: Desarrollo propio

En este período de intervención tenemos un clima organizacional facilitador de la implementación de cambios y mucha apertura a proyectos innovadores.

Tenemos una Gestión de Topo involucrada en un proyecto para la Administración Pública y facilitando el desarrollo del mismo en su organización.

En este período hubo el desarrollo de la confianza (Cuadro 5) y los elementos de la práctica más destacados para este resultado fueron el Estímulo de la Organización para que sus colaboradores compartan el conocimiento en el Dominio de la Comunidad en estudio (SHST). 
Resultado

\section{Confianza}

Hay un fuerte sentimiento de confianza entre los miembros de la CoP

Cuadro 5 - Desarrollo de la confianza CoPGAPEAN

Fuente: Desarrollo propio

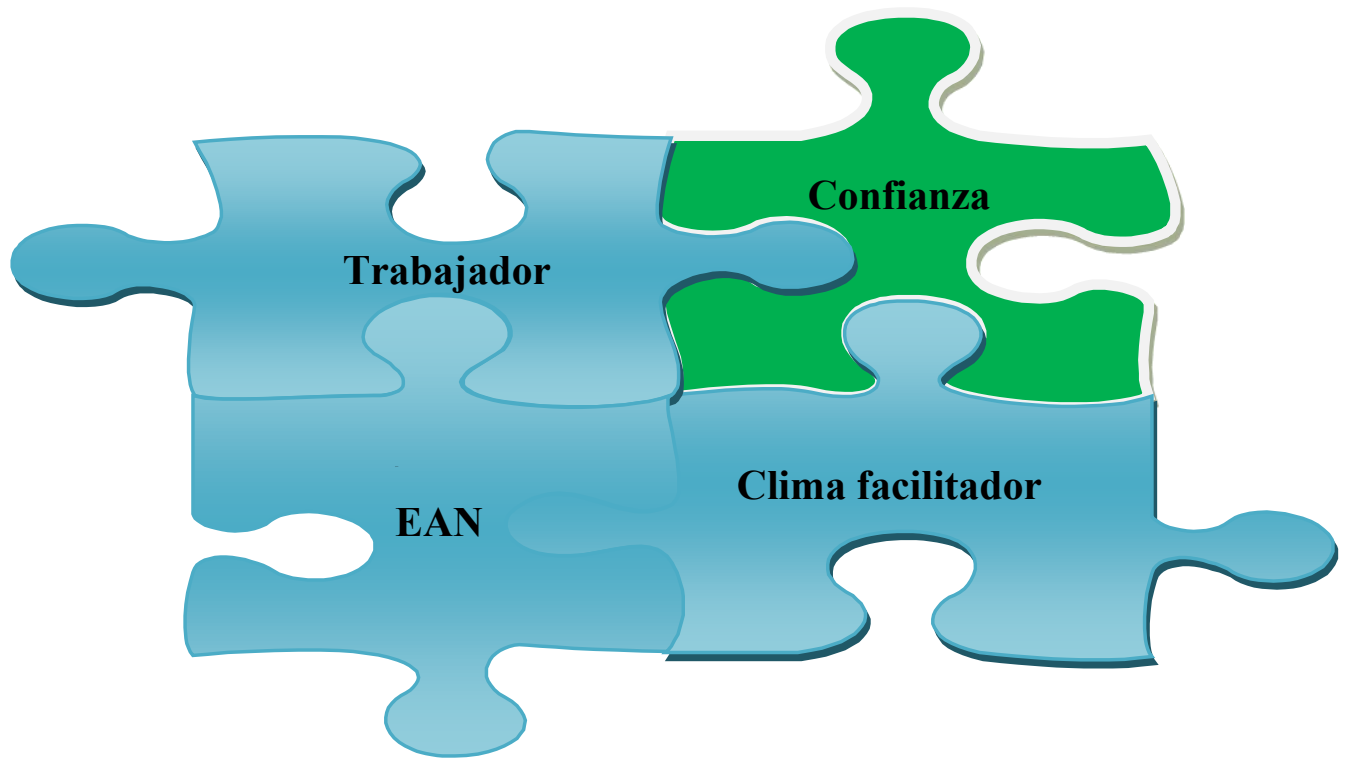

Ilustración 7 - Desarrollo de la confianza CoPGAPEAN

Fuente: Desarrollo propio

Este sentimiento de confianza se evidencia como resultado y fue alimentado por prácticas esenciales (Ilustración 8; Figura 5) tales como: el establecimiento de objetivos a corto y medio plazo, así como la definición de métodos de interacción evidenciados en los documentos por nosotros consultados (Actas y registro de eventos realizados por la $\mathrm{CoP}$ ). 


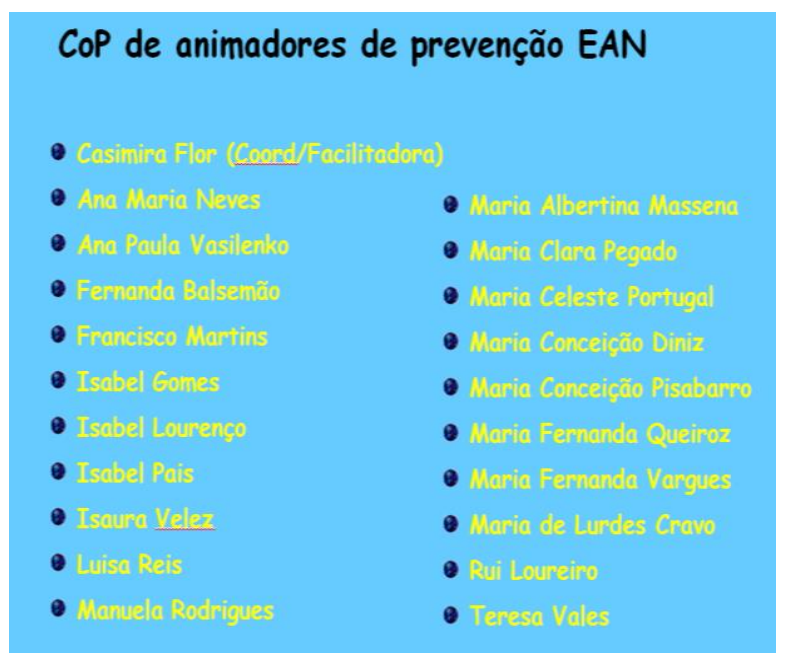

$\mathrm{Na}$ sequência das entrevistas e dos Inquéritos de Cultura Organizacional e Segurança, feitos na EAN o grupo alvo de técnicos de laboratório iniciou um longo e motivante percurso que esperamos, tenha continuidade.

Ilustración 8 - Acción Presencial realizada en 2006 - Seminario

Fuente: Desarrollo propio

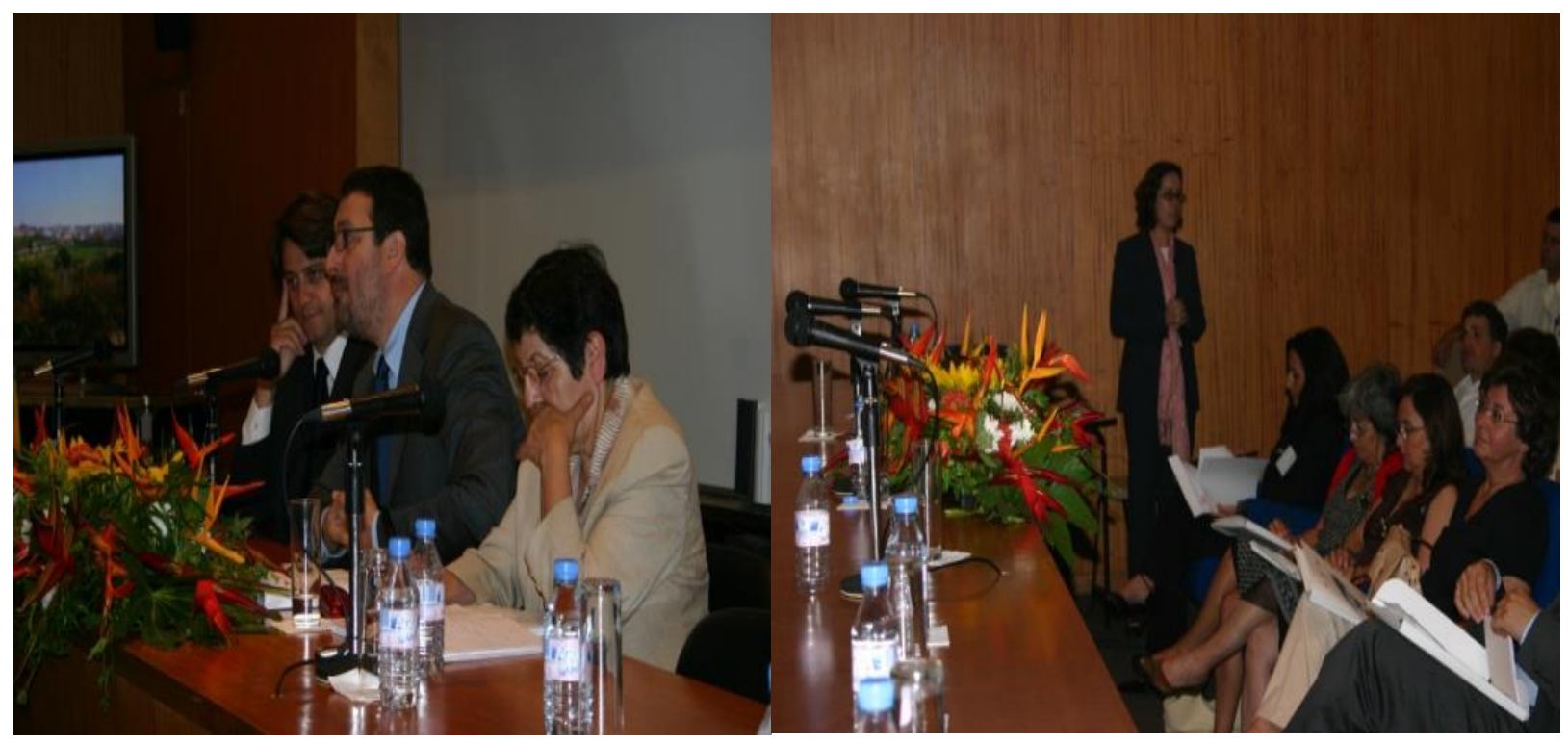

Figura 5 - Acción Presencial realizada en 2006 - Seminario

Fuente: Desarrollo propio

Comunidad@Buenas Prácticas de Seguridad, Salud e Calidad de Vida en el trabajo INIAV

"Factores críticos de éxito" 
Estímulo de la Gestión de Topo para que sus colaboradores compartan el conocimiento en el dominio de la seguridad y la salud en el trabajo.

\begin{tabular}{c|c|}
\cline { 2 - 2 } Resultado & Hay un fuerte sentimiento de confianza entre los miembros de la CoP \\
\hline Confianza & $\begin{array}{l}\text { Participación e interés en los eventos relacionados con el dominio de } \\
\text { la CoP }\end{array}$ \\
\hline Utilidade & $\begin{array}{l}\text { El participante ve a CoP como un instrumento para mejorar los } \\
\text { conocimientos en el dominio. }\end{array}$ \\
\hline $\begin{array}{c}\text { Sentimiento de } \\
\text { Pertenencia }\end{array}$ & Participación individual del miembro con la CoP \\
\cline { 2 - 2 } &
\end{tabular}

Cuadro 6 - Dinámico del CoPGAPEAN

Fuente: Desarrollo propio

También se definieron los moderadores de la CoP (ilustración 8), en los diversos momentos del recorrido, estando explícito en la observación que hicimos al libro de actas que fue cíclica el paso en la moderación siendo asegurada por todos los miembros de la Comunidad, gestionada por la líder de la CoPGAPEAN y alentada por el Gestión de Topo.

Las reuniones de dinámica colaborativa se realizaron en las infraestructuras de la Estación Agronómica Nacional (EAN), teniendo la gestión de arriba concedido tiempo para las actividades comunitarias, compatibilizando las actividades normales de trabajo con las de la CoP, así como disponibilidad los recursos físicos (salas) y materiales para el desarrollo de las actividades colaborativas.

La Gestión de Topo también promovió internamente las actividades de la CoPGAPEAN estableciendo el puente con gerencias intermedias y reconociendo la importancia de las actividades de la CoPGAP en la EAN, teniendo el cuidado de estimular el intercambio de conocimiento y dio 
la libertad para expresar las ideas y contribuir al cambio de comportamiento y actitudes frente a la prevención de riesgos laborales.

En las reuniones se ha elaborado un plan de actividades y tareas distribuidas por los diferentes miembros (observación de las actas de todas las reuniones). En el período se realizó el mayor número de encuentros presenciales y la dinámica resultó en un aumento de la confianza, sentimiento de pertenencia y utilidad en CoPGAPEAN.

Además de las reuniones del grupo embrión, hubo eventos en los cuáles ha participado y organizado en la EAN con la apertura de su frontera al exterior (como ejemplo presentado en la figura 6).

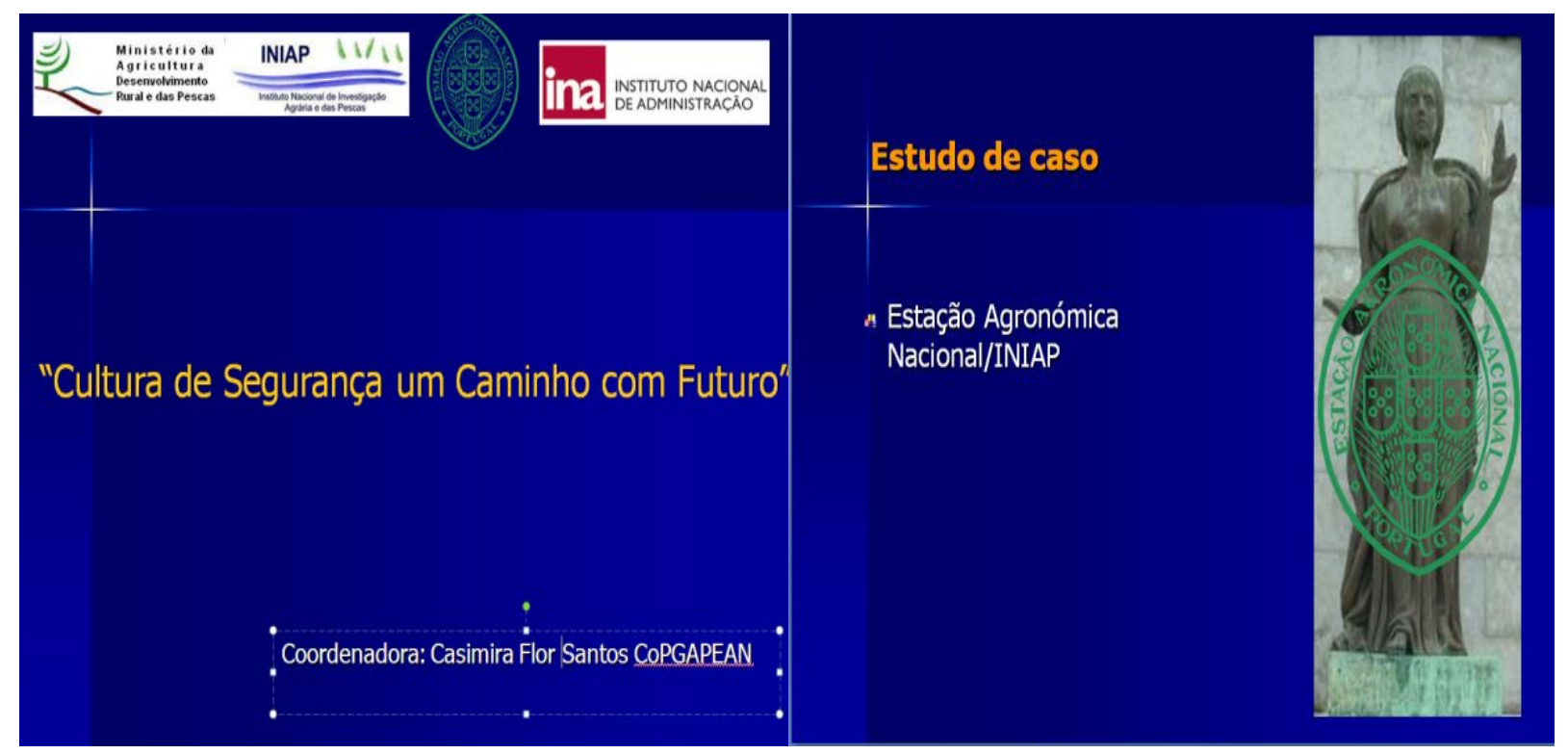

Figura 6 - Partilla del estudio desarrollado con otras Organizaciones

Fuente: Desarrollo propio

A CoPGAPEAN desarrolló prácticas esenciales para la obtención de resultados de éxitos, conforme cuadro que se presenta: 


\begin{tabular}{|c|c|c|}
\hline Documentos Observados & Elementos de prácticas & Refuerzo \\
\hline $\begin{array}{l}\text { Actas de la reunión } \\
106 / 10 / 2005 \\
11 / 10 / 2005 \\
12 / 10 / 2005 \\
19 / 10 / 2005 \\
26 / 10 / 2005 \\
27 / 10 / 2005 \\
09 / 11 / 2005 \\
16 / 11 / 2005 \\
23 / 11 / 2005 \\
30 / 11 / 2005 \\
07 / 12 / 2005 \\
16 / 12 / 2005 \\
04 / 01 / 2006 \\
18 / 01 / 2006 \\
25 / 01 / 2006 \\
01 / 02 / 2006 \\
15 / 02 / 2006 \\
20 / 02 / 2006 \\
01 / 03 / 2006 \\
08 / 03 / 2006 \\
15 / 03 / 2006 \\
18 / 03 / 2006 \\
12 / 04 / 2006 \\
19 / 04 / 2006 \\
10 / 05 / 2006 \\
17 / 05 / 2006 \\
24 / 05 / 2006 \\
02 / 06 / 2006 \\
14 / 06 / 2006 \\
19 / 06 / 2006 \\
27 / 06 / 2006 \\
27 / 06 / 2006 \\
04 / 07 / 2006 \\
19 / 07 / 2006 \\
12 / 07 / 2006 \\
20 / 07 / 2006 \\
25 / 07 / 2006 \\
02 / 08 / 2006\end{array}$ & $\begin{array}{l}\text { Alineación y estructuración } \\
\text { Definición de métodos de interacción entre los } \\
\text { participantes; } \\
\text { Establecimiento de objetivos a corto y medio plazo; } \\
\text { Definición de una estructura rotativa entre los } 13 \\
\text { elementos del Grupo nuclear CoPGAPEAN ( } 3 \text { elementos } \\
\text { para facilitar las reuniones boca arriba); } \\
\text { Periodicidad de las reuniones semanales; } \\
\text { Apoyo de liderazgo; } \\
\text { Alta dirección de participación y apoyo; } \\
\text { Tiempo de fácil para las actividades de la CoP (1 día por } \\
\text { semana para reunirse); } \\
\text { Disponibilidad de recursos (salas de reuniones); } \\
\text { Cultura; } \\
\text { Estímulo de la organización para que las personas } \\
\text { compartan conocimientos; } \\
\text { Transparencia de la información generada por CoP; } \\
\text { Reconocimiento de la organización de la utilidad y retorno } \\
\text { de CoPGAPEAN; } \\
\text { Política; } \\
\text { Facilitar el entorno de intercambio de conocimientos; } \\
\text { Coordinación de la CoP; } \\
\text { Miembro del facilitador de la CoP y experto en el ámbito } \\
\text { y en la dinámica colaborativa; } \\
\text { Reconocimiento formal dentro de la organización; } \\
\text { Desarrollo de actividades que promuevan las interacciones } \\
\text { en el grupo; } \\
\text { Política; } \\
\text { Libertad de expresión de ideas; } \\
\text { Facilitar el entorno de intercambio de conocimientos }\end{array}$ & $\begin{array}{l}\text { Sentimiento de Pertenencia } \\
\text { Utilidad } \\
\text { Confianza }\end{array}$ \\
\hline $\begin{array}{l}25 / 09 / 2006 \\
11 / 10 / 2006 \\
24 / 10 / 2006 \\
25 / 10 / 2006 \\
09 / 11 / 2006 \\
16 / 11 / 2006 \\
22 / 11 / 2006 \\
23 / 11 / 2006 \\
29 / 11 / 2006 \\
05 / 12 / 2006 \\
13 / 12 / 2006 \\
18 / 12 / 2006\end{array}$ & $\begin{array}{l}\text { Alineación y estructuración; } \\
\text { Definición de métodos de interacción entre los } \\
\text { participantes; } \\
\text { Establecimiento de objetivos a corto y medio plazo } \\
\text { Definición de una estructura rotativa entre los } 13 \\
\text { elementos del Grupo Nuclear CoPGAPEAN ( } 3 \text { elementos } \\
\text { para facilitar las reuniones enfrentados) } \\
\text { Periodicidad de las reuniones semanales; } \\
\text { Apoyo de liderazgo; } \\
\text { Alta dirección de participación y apoyo; } \\
\text { Tiempo de fácil para las actividades de la CoP (1 día por } \\
\text { semana para reunirse); }\end{array}$ & $\begin{array}{l}\text { Confianza y sentimiento de } \\
\text { pertenencia }\end{array}$ \\
\hline
\end{tabular}

Comunidad@Buenas Prácticas de Seguridad, Salud e Calidad de Vida en el trabajo INIAV

"Factores críticos de éxito" 


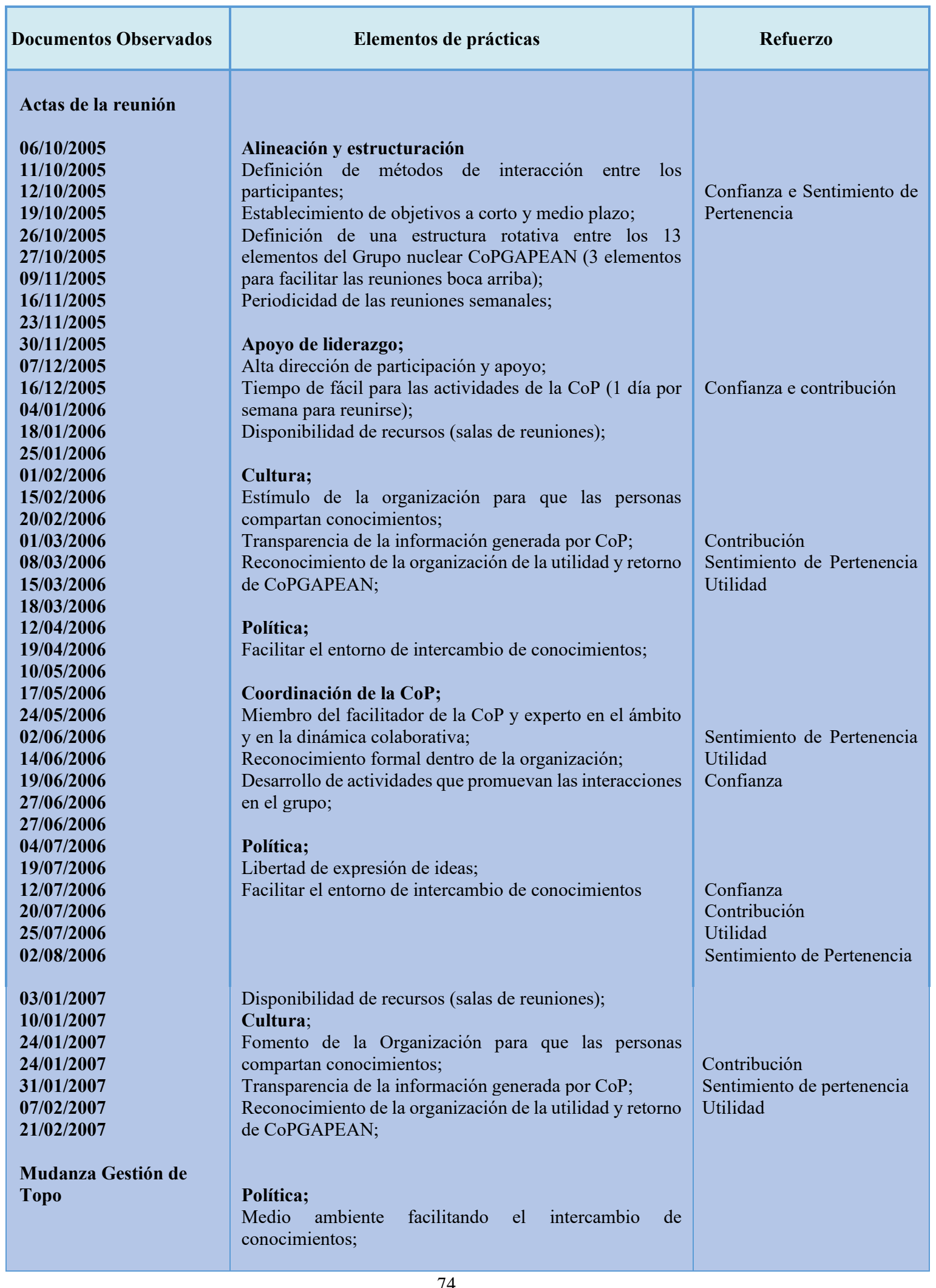

Comunidad@Buenas Prácticas de Seguridad, Salud e Calidad de Vida en el trabajo INIAV

"Factores críticos de éxito" 


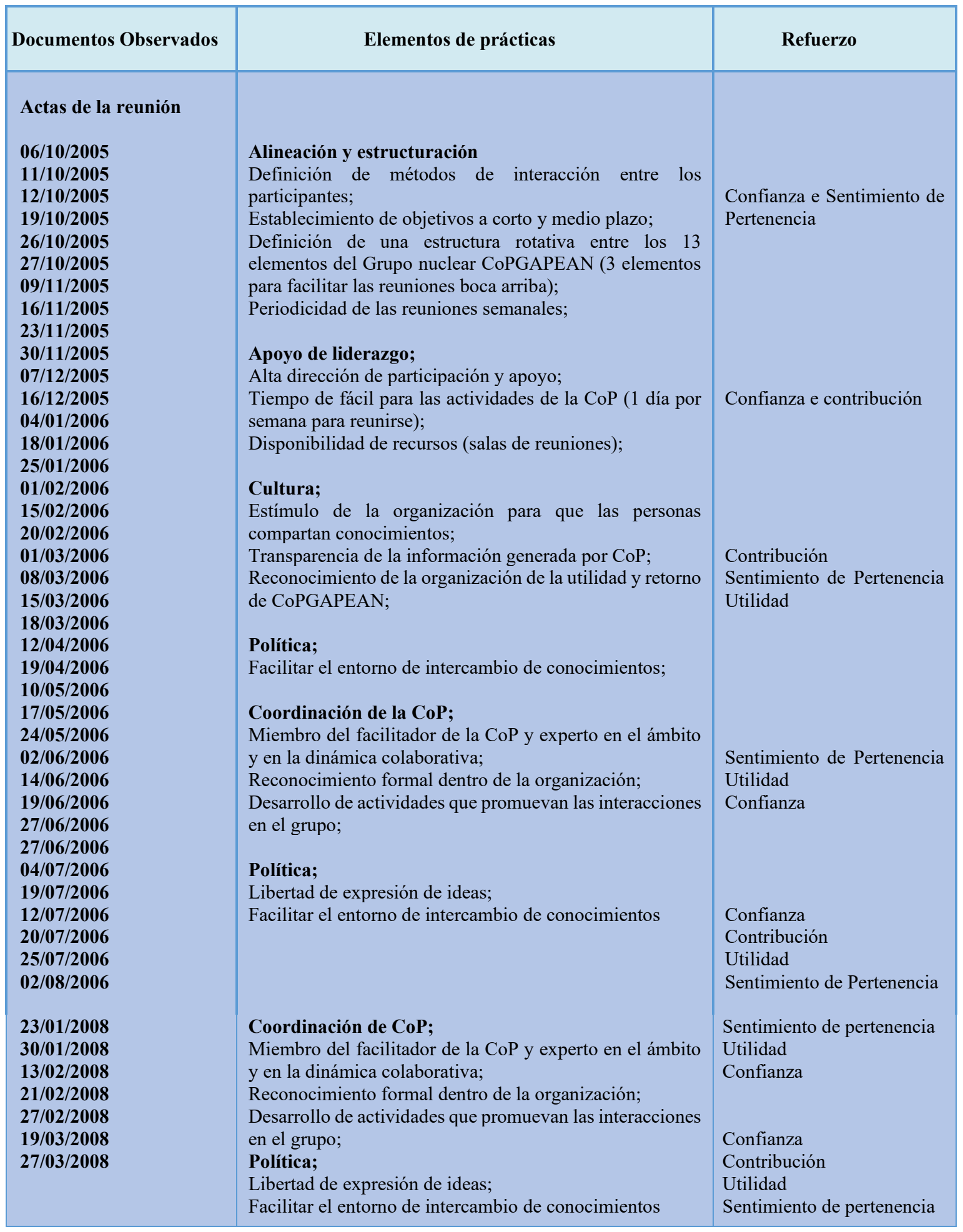

Cuadro 7 - Prácticas esenciales que reforzaron el resultado de éxito de CoPGAPEAN

Fuente: Desarrollo propio

75

Comunidad@Buenas Prácticas de Seguridad, Salud e Calidad de Vida en el trabajo INIAV

"Factores críticos de éxito" 
Cuando los tres elementos, dominio, comunidad y práctica funcionan en armonía, éstos crean una $\mathrm{CoP}$, una estructura de conocimiento ideal para asumir responsabilidades para un efectivo desarrollo y partilla del conocimiento.

En la Práctica de Alineamiento y Estructuración se definieron estrategias y planes de acción para la obtención de los objetivos de la CoPGAPEAN.

La Comunidad es el elemento central de la CoP, formada por un grupo de personas que interactuaron entre sí regularmente, en actividades conjuntas y de interés común, construyendo relaciones pautadas en la confianza. Estas personas con interés en el ámbito de la SHST al compartir su conocimiento, aprendieron juntas, desarrollando la responsabilidad y el compromiso de participación en el grupo de animadores de prevención.

Además Alineamiento y Estructuración de la tenemos la práctica esencial Apoyo del Liderazgo / Gestión de Topo que hicieron con que el resultado de confianza se mostrase esencial para aumentar un fuerte sentimiento de confianza entre los miembros de la CoP y que se caracteriza por el Apoyo de la Gestión de Topo.

La necesidad de legitimar la participación de los miembros reservando un tiempo (diario, semanal, mensual, etc.) para que los miembros participen en las actividades de la CoPGAPEAN.

Otro aspecto interesante en el apoyo de la Gestión de Topo fue la creación de un lugar para que las actividades sucedieran (figura 5).

Un punto de partida muy interesante de la gestión superior fue la preocupación por establecer una sintonía con prácticas existentes en la organización, sabiendo que el conocimiento que la organización necesita ya está presente dentro de ella, hay que sacarle partido promoviendo la formación de Comunidades de Práctica que aprovechen ese potencial.

También en la parte de la Gestión superior hubo la preocupación en alinear los sistemas de reconocimiento a la $\mathrm{CoP}$.

El reconocimiento y las recompensas no fueron olvidados a los que participaron y una forma interesante fue incluir, en la evaluación del desempeño, aspectos que valoraron la participación de los funcionarios en actividades comunitarias. 
Proporcionar soporte: a pesar de que la $\mathrm{CoP}$ es autosuficiente, pero se ha beneficiado de algunos recursos, tales como: expertos externos a la organización y las instalaciones.

El establecimiento de una atmósfera abierta a la Gestión del Conocimiento que incluyó la creación de la Comunidad, apalancamiento la conciencia de la necesidad de compartir conocimiento en la organización, así como la voluntad de interactuar en la CoP. Además de la atmósfera, según (Zboralski, Katja, 2009), los recursos cedidos por la organización también integran el contexto favorable a la participación de los miembros. En sus consideraciones sobre la influencia del apoyo organizacional en las CoP (Zboralski, Katja, 2009), afirma que el apoyo de la organización ha sido de gran importancia para el éxito de las iniciativas en el contexto de la gestión del conocimiento. Os autores (Scarso, E.; Bolisani, E., 2008) mencionan ejemplos de recompensas no financieras que son efectivas en lo que se refiere al incentivo a la participación en Comunidades, tales como: reconocimiento público, por parte de la organización, de que los miembros de las CoP son especialistas en ese dominio; y motivación personal.

En el trabajo desarrollado por (Flor, C., 2015) la investigadora valida en su estudio de investigación los incentivos que la alta Dirección en su estudio usó para dar ánimo a CoPGAPEAN y que siguieron la lógica del estudio de (Scarso, E.; Bolisani, E., 2008) el reconocimiento público, la motivación personal y el reconocimiento de competencias permitiendo que los participantes en la CoP pudieran compartir en sus seminarios y talleres su conocimiento. También verificamos que la práctica esencial cultura de la Organización reveló Buenas Prácticas en el intercambio del conocimiento en el ámbito de la Prevención, siendo el estímulo y el fortalecimiento de la Organización para compartir el conocimiento en el ámbito de la Seguridad y Salud en el Trabajo.

Se presenta la Práctica de Apoyo de la alta Dirección con elementos esenciales de la misma tales como: cómo el reconocimiento público de la Organización se refleja en utilidad de la CoPGAPEAN promoviendo públicamente la CoP y una Cultura favorable al compartir con el elemento esencial de práctica acentuado en la transparencia de las informaciones generadas por la CoP de los animadores de Prevención.

La dimensión cultural presenta un factor crítico de éxito mencionado por (Scarso, E.; Bolisani, E., 2008), la proximidad cultural entre los miembros facilita la diseminación del conocimiento entre los 
participantes de las CoP. En nuestro análisis concluimos que para la CoPGAPEAN el saber no es sólo una cuestión individual, es también una cuestión de intercambio, de aprender través del otro, de su experiencia.

En la práctica cultural acentuamos el estímulo de la Organización para que las personas compartan el conocimiento y el reconocimiento de la Organización de la importancia, utilidad y retorno de la COPGAPEAN.

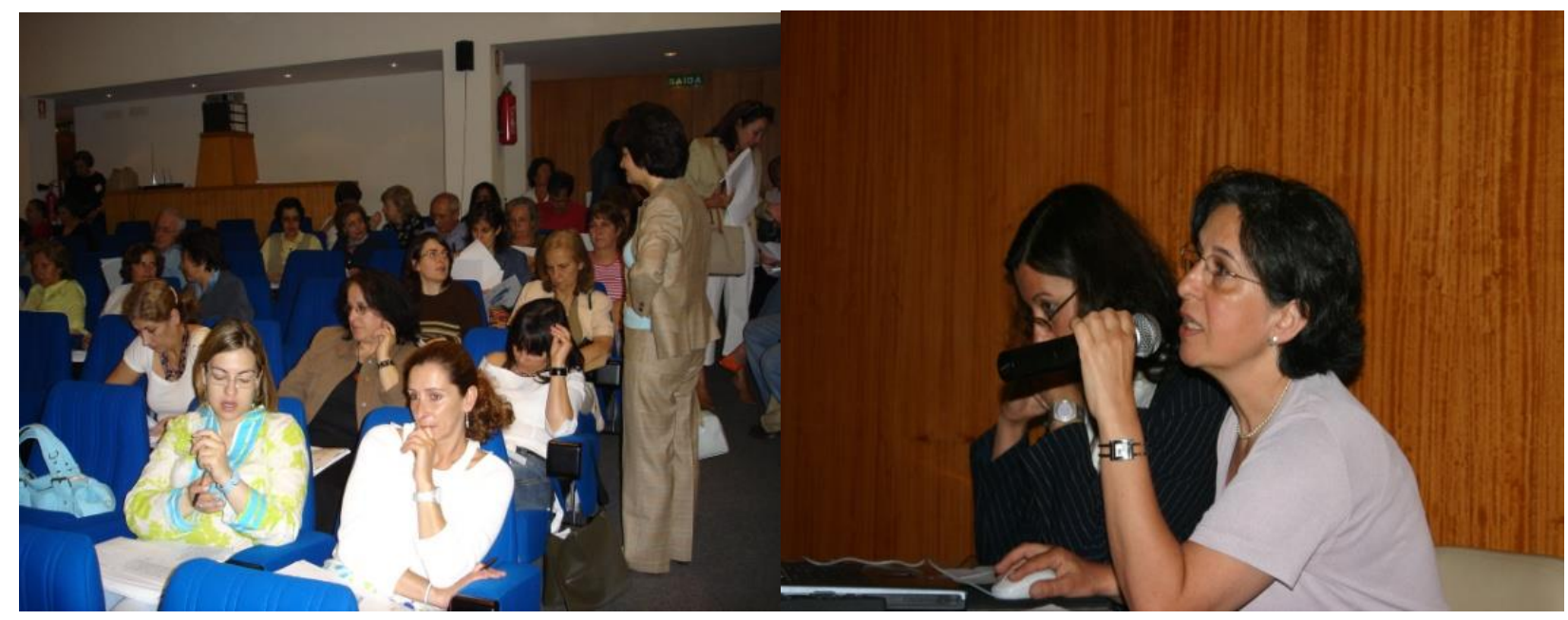

Figura 7 - Intercambio de conocimientos: Confianza | Utilidad | Sentimiento de Pertenencia Fuente: Desarrollo propio

Esta comunidad posibilitó además de la experiencia individual la interacción entre diferentes grupos profesionales, fomentó interacciones y relaciones basadas en el respeto mutuo y la confianza, alentando la disposición a compartir ideas todas estas acciones se encuadran en la práctica esencial para que los resultados evolucionen hacia el éxito y esta práctica está relacionada con el desarrollo de la CoP.

También hubo una gran inversión en la formación / entrenamiento de los miembros de la comunidad de los animadores de prevención y la existencia y permanencia de una coordinación fuerte. El dominio se refiere a la Seguridad y Salud en el Trabajo y siendo el foco en el reparto de Buenas Prácticas SST el área de conocimiento en torno a la cual se construyó la comunidad y creó una identidad. La apuesta en este ámbito legitimó a la comunidad por la afirmación de los objetivos y 
valores de los miembros y otros stakeholders. Las prácticas esenciales se desarrollaron para que la confianza formara parte de la Comunidad y la implicación de las Jefaturas intermedias además de la Gestión de Topo fueron cruciales en el proceso. Hubo un ambiente de libertad para expresar ideas y facilitar el compartir el conocimiento una política y una cultura abierta al trabajo colaborativo (figura 8).
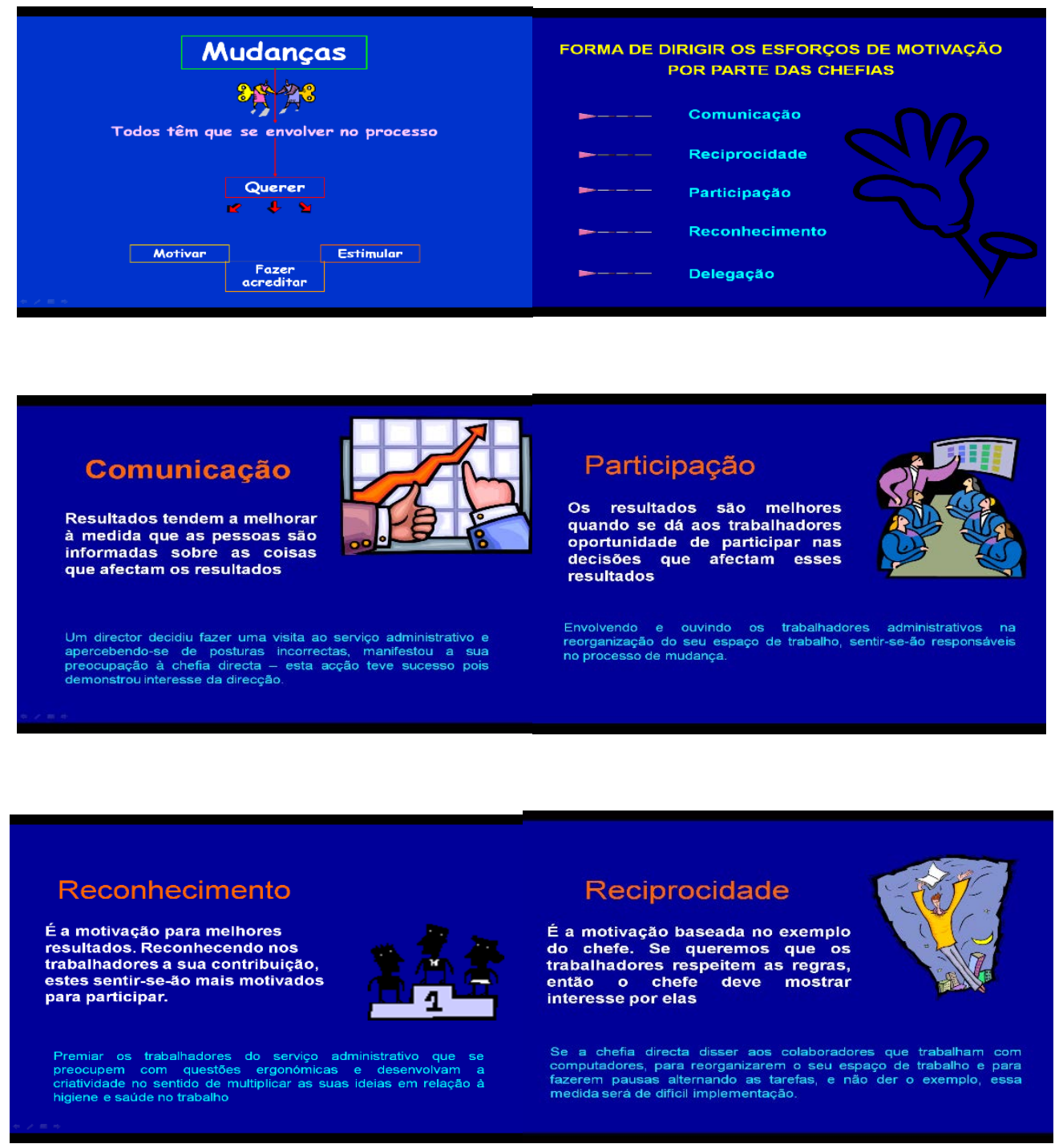

Figura 8 - Documentos por los facilitadores de la CoP en reuniones amplias con la Gestión de Topo y Jefes intermedios (20042008). Comunicación cara a cara

Fuente: Desarrollo propio 
Por el análisis documental comprobamos que fue muy importante para la Comunidad perdurar en el tiempo la existencia de un líder / coordinador fuerte e implicado en la dinámica además de ser un experto en el ámbito como práctica esencial.

Se diseñaron y desarrollaron actividades de interacción personal para aumentar el nivel de confianza de este grupo de personas, la coordinadora estableció puentes con especialista para proporcionar formación y entrenamiento en el ámbito de la SHST, así como en todo el proceso luchó para que la gestión de arriba valorizara el manejo el trabajo y la dedicación de estos miembros del grupo para que en la evaluación de rendimiento se tenga en cuenta este parámetro.

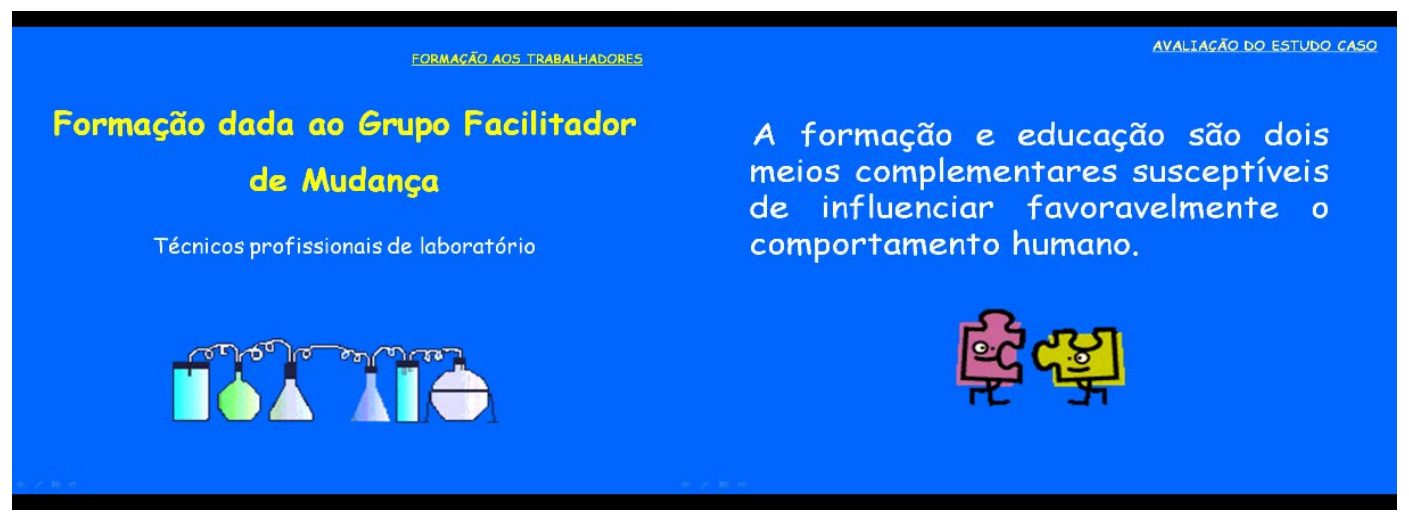

Figura 9 - Formación del Grupo facilitador de cambios frente a la SST

Fuente: Desarrollo propio

Las evidencias de cada uno de los elementos que justifica la acción de la Gestión de la Comunidad aumentaron el nivel de confianza de los funcionarios que se asociaron a la Comunidad. Zboralski, (2009), afirma que es competencia de la organización velar para que la Comunidad tenga un miembro que sea respetado por los demás, actuando como coordinador y que tenga conocimiento técnico en el ámbito, pero sobre todo habilidad para conectar a las personas. 


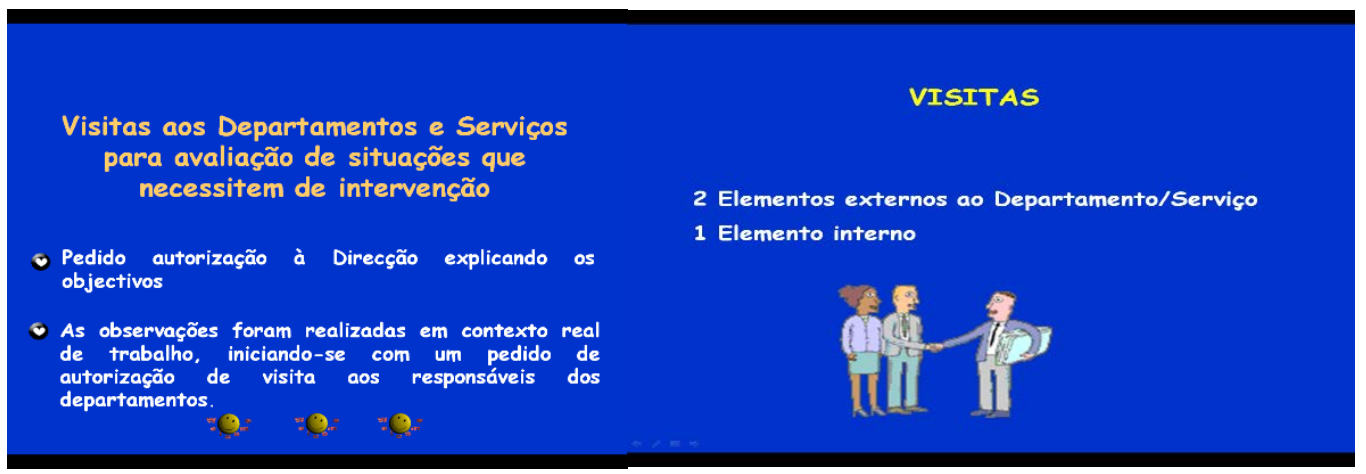

Figura 10 - Involucramiento interno y facilitación fuerte aumento la confianza de los miembros de la CoP

Fuente: Desarrollo propio

El resultado de la práctica esencial de apoyo de un líder fuerte en la Comunidad dará un resultado positivo en la confianza. En los diversos documentos por nosotros observados el ambiente facilitador de la partilla del conocimiento, la libertad para expresar ideas y la apertura a la entrada de nuevos miembros formó parte de la política como se evidencia en los documentos observados lo que provocó un aumento de la confianza (Figura 10) como resultado de la práctica relacionada con la Política de la Organización.

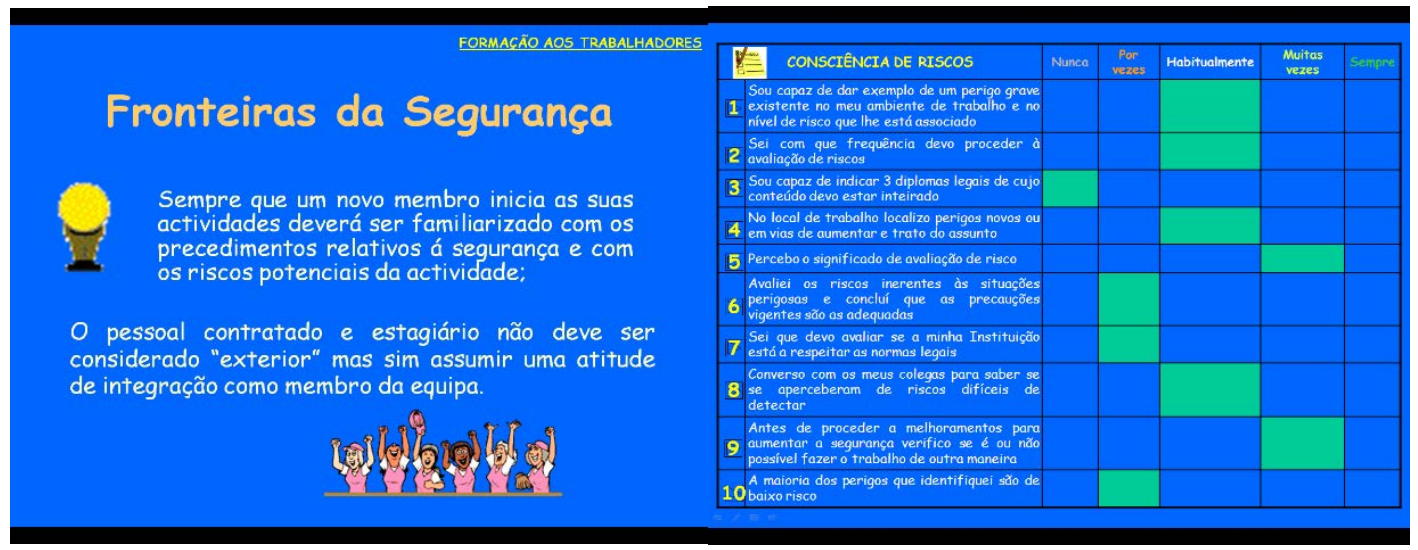

Figura 11 - Cultura positiva y facilitadora

Fuente: Desarrollo propio

La confianza como uno de los resultados para el éxito de la CoP en el intervalo de tiempo entre 2009 y 2014. 
El gran desafío fue que la CoP logró apoyo a nivel tecnológico pasando a una Comunidad mixta con las dos vertientes la presencial y la virtual. El período en que se desarrolló el proyecto estuvo marcado por varios cambios organizacionales.

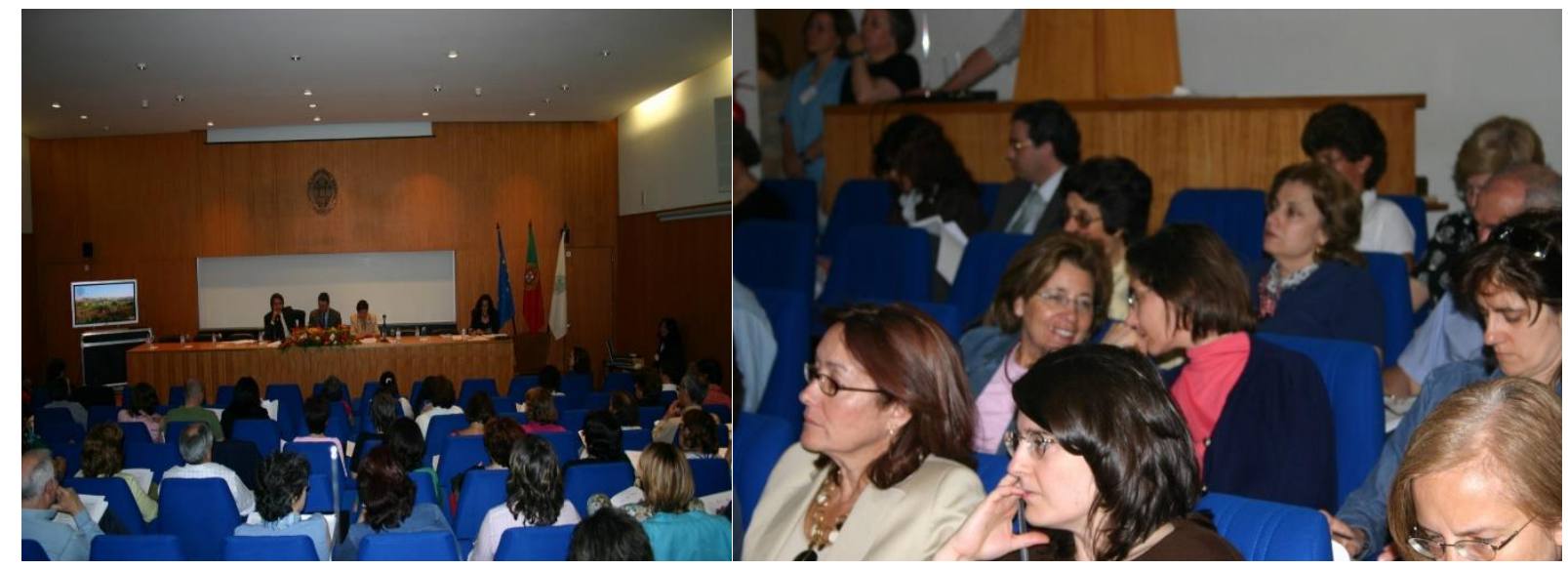

Figura 12 - Líder facilitador

Fuente: Desarrollo propio

Los cambios inevitables, que ocurrieron en la práctica, en los miembros que compusieron la CoP, en las tecnologías y en las relaciones con la organización, se movieron con energía.

Por la observación del (cuadro 7) pudimos concluir que la dinámica presencial fue acentuada en 2005 y mediados de 2007, cuando el Liderazgo de la Organización cambió, después con la entrada de un nuevo liderazgo se mantuvo, pero con encuentros más espaciados.

Podemos afirmar que el liderazgo de 2005 a principios de 2007 posibilitó 55 encuentros presenciales de reuniones de la CoP y entre 2007-2008 la energía disminuyó en términos de dinámica y mucha incertidumbre en la Organización habiendo observado 7 encuentros.

Este período está marcado por un Líder Organizacional que facilita el intercambio de conocimiento en el ámbito de la Seguridad y la Salud en el trabajo, después de este liderazgo se enfrentan a otros 3 líderes de la Organización y corrimos el riesgo de que el proyecto no tuviese continuidad. El mantenimiento de la energía que vitaliza esa estructura requiere de atención y conservación, para poder sostener a la $\mathrm{CoP}$ y aquí el Coordinador de la $\mathrm{CoP}$ es la figura central en el proceso pues que la participación y el compromiso de los miembros disminuyeron en esta fase de 
incertidumbres, pero la comunidad continuó como centro de conocimiento, a través de los contactos personales existentes y de la práctica compartida. El papel del Coordinador es idéntico al de la enzima en las reacciones químicas (Flor, C., 2015), esta figura tendrá que establecer nuevos puentes con las nuevas Direcciones de la Organización para que la CoP no se extinga, los años clave de cambio de Liderazgo Organizacional fueron: 2008-2012 y 2015.

\begin{tabular}{|c|}
\hline Historia (2002-2019) \\
\hline $\begin{array}{l}\text { En 2002, el INIA y el Instituto de Investigación de la Pesca y del Mar } \\
\text { (IPIMAR), a través de un proceso de fusión, pasan a integrar el } \\
\text { Instituto Nacional de Investigación Agraria y de la Pesca (INIAP) }\end{array}$ \\
\hline $\begin{array}{l}\text { En } 2006 \text { se creó el Instituto Nacional de Recursos Biológicos (INRB, } \\
\text { IP), como resultado de la fusión del INIAP con el Laboratorio } \\
\text { Nacional de Investigación Veterinaria (LNIV), de la integración de } \\
\text { las atribuciones, en el ámbito de la investigación, Dirección General } \\
\text { de Protección de Cultivos (DGPC) y la integración del Banco } \\
\text { Portugués de Germoplasma Vegetal }\end{array}$ \\
\hline $\begin{array}{l}\text { En } 2012 \text { se ha creado el Instituto Nacional de Investigación Agraria } \\
\text { y Veterinaria (INIAV I.P.) con las atribuciones relacionadas con la } \\
\text { investigación agraria y veterinaria del INRB. }\end{array}$ \\
\hline
\end{tabular}

Cuadro 8 - Historia 2002 a 2019

Fuente: Desarrollo propio

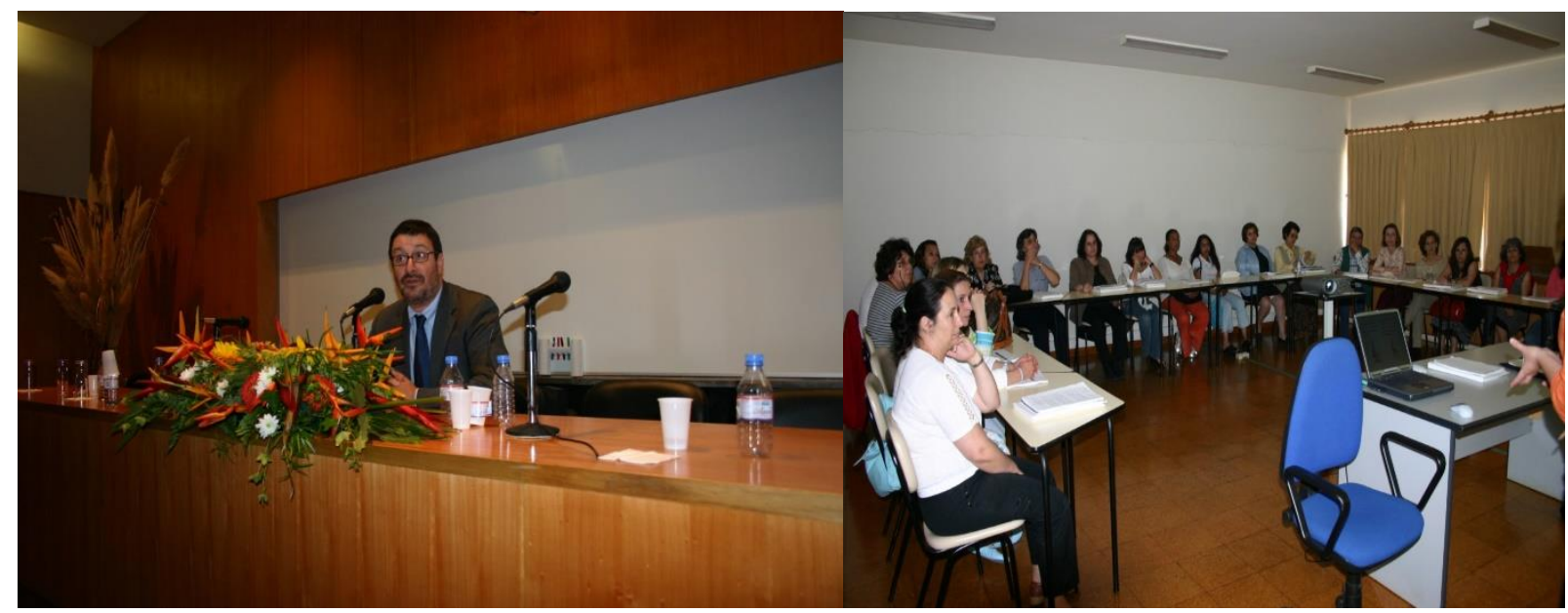

Figura 13 - Participación y cedencia de tiempo e infraestructuras para el funcionamiento de la CoPGAPEAN Fuente: Desarrollo propio 
Así, la organización debe intervenir en el momento en que se encuentre entre la decisión de evolucionar hacia otros dominios o dejar que la comunidad se extinga. Es muy importante analizar lo que sucede en estos períodos de cambio y cuáles los factores críticos paran la continuidad del trabajo colaborativo.

El año 2008 estuvo marcado por un nuevo líder organizacional que dio la continuidad al trabajo iniciado por la COPGAPEAN manteniéndose la misma dinámica y aquí el papel del coordinador de la $\mathrm{CoP}$ en el gran desafío, en esta fase de grandes cambios organizacionales fue el mantenimiento del ritmo y la supervivencia de la CoP. En 2009 hay la posibilidad de en asociación una vez más con el INA entrando en la dinámica virtual y en la apuesta de entrenamiento de facilitadores para el desarrollo de una CoP mixta.
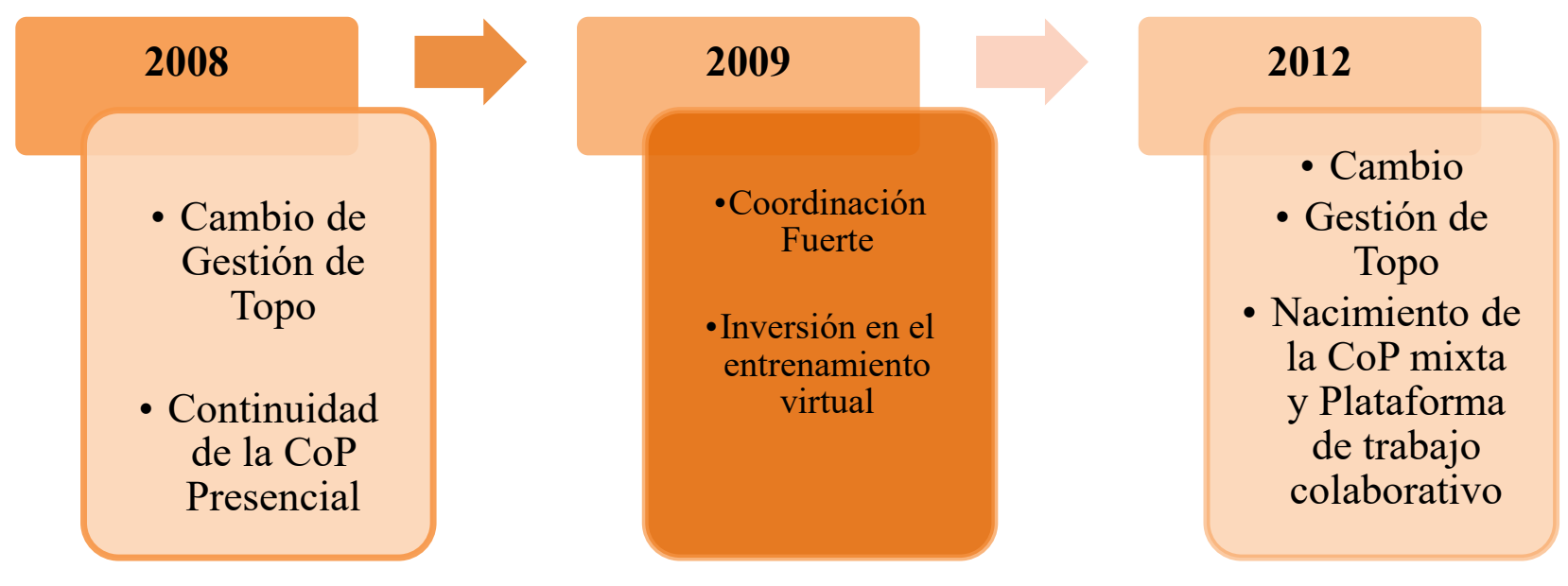

Ilustración 9 - Fases de cambio organizacional e influencia en la CoPGAPEAN

Fuente: Desarrollo propio

La CoPGAPEAN en 2012 se transforma en una Comunidad con una nueva dinámica virtual, sin embargo, continúa la dinámica Presencial pues que forma parte de la Cultura de la organización encuentros presenciales ensancha también sus fronteras cautivando otras temáticas del Dominio del INIAV como muestra la( ilustración 9 y 10) la plataforma de WIKINIAV. 
A Comunidade WIKINIAV alberga outras Comunidades temáticas:

A $1^{\text {a }}$ Comunidade de Partilha de Boas Práticas SHST já uma comunidade em fase de sustentação, pois teve a sua origem antes do nascimento da WIKINIAV. Esta comunidade é transversal a todas as atividades e áreas temáticas do Instituto e por isso mesmo se destaca como uma categoria específica na barra de categorias principal;

Na categoria Gestão do Conhecimento (GC) - estão todas as fichas das Comunidades que ao longo do projeto foram aparecendo, estando ainda na fase potencial (fase inicial de formação da Comunidade temática - nasceram pelo apelo que as temáticas tiveram em termos de interesse e impacto no público alvo e fases em que se encontram:

- Comunidade de saberes e sabores da pêra rocha - Fase Potencial.

- Comunidade de partilha de saberes das plantas melíferas - Fase Potencial-1 ${ }^{a}$ fase.

- Comunidade de partilha de saberes e sabores do azeite e azeitona; Fase Potencial $1^{\text {a }}$ fase.

- Comunidade de partilha de saberes das mulheres na Agricultura; Fase de potencial $2^{\mathrm{a}}$ fase.

- Comunidade de partilha de Boas práticas SHST; Fase de Maturidade $-3^{a}$ Fase.

- Comunidade de partilha de saberes do figo da índia. Fase de crescimento-4ªse.

- Comunidade de resolução de problemas entre moderadores de Wikiniav: Fase de Maturidade $-3^{a}$ Fase.

La práctica referente a la tecnología se evidencia aquí como facilitadora y da nueva vida y ánimo a la continuidad y supervivencia de la COPGAPEAN que en 2012 gana su propia plataforma de trabajo colaborativo en el INIAV teniendo apoyo de la nueva Dirección que apostó en el proyecto ampliando la posibilidad de este proyecto piloto de incentivar la creación de nuevas CoP en la Organización.

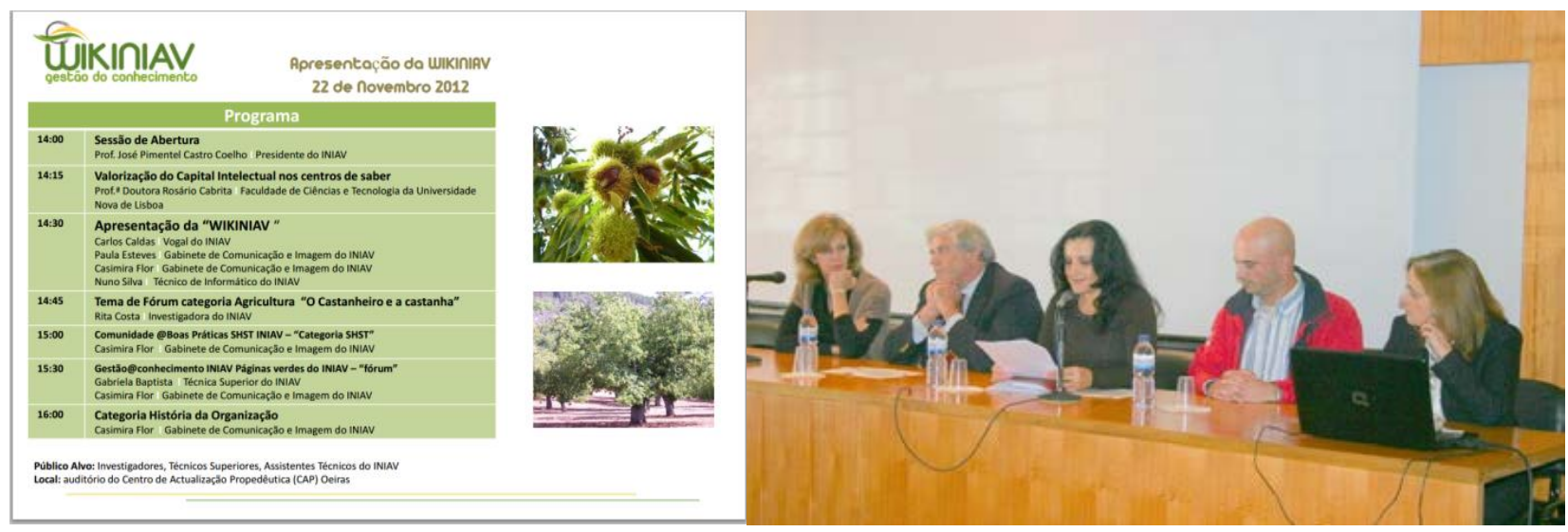

Figura 14 - Presentación Pública de la CoP Virtual CoPSSQVTINIAV (2009-2014)

Fuente: Desarrollo propio

Comunidad@Buenas Prácticas de Seguridad, Salud e Calidad de Vida en el trabajo INIAV

"Factores críticos de éxito" 
Ferramenta de apoio ao trabalho colaborativo

WIKINIAV é uma tecnologia de servidor colaborativo, "open source", que possibilita aos seus utilizadores terem acesso, procurar e editar artigo num ambiente em tempo real e participarem num fórum. Este servidor são é uma ferramenta crítica para coordenar documentos, bancos de dados e projetos colaborativos de forma efetiva e eficiente. Diferentemente de muitas outras alternativas, uma Wiki suporta atributos e estruturas definidos pelos seus utilizadores de foma flexível. É fácil de usar, de acordo com as tecnologias e padröes correntes, e requer muito pouco investimento tanto em hardware como em software e treino.

Link de acesso: http://wiki.iniav.pt/

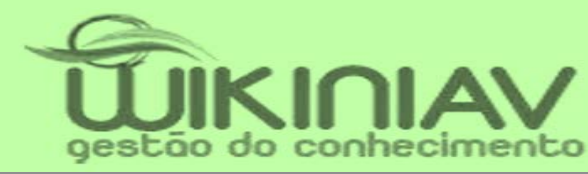

Ilustración 10 - Herramienta de trabajo colaborativo 2012

Fuente: Desarrollo propio

Agenda 2012-2013:

- Proposta da CoP pelo GT de Desenvolvimento Organizacional e Inovação-Junho de 2012.

- Reuniões com facilitadores.

- Apresentação Pública 22 de Novembro de 2012.

- Work shop s temáticos presenciais.

- Junho 2013-Encontro de membros.

Descrição da Comunidade: A Comunidade nasce com um grupo de técnicos especialistas neste domínio do INIAV.

Objectivos da Comunidade: Partilha de saberes e experiências no domínioSHST Boas práticas na prevenção de riscos laborais e qualidade de vida no trabalho.

Tags (Palavras-Chave): Acidentes, SHST, Prevenção, boas práticas, saúde, segurança e trabalho

Duração: Ilimitada.

Ilustración 11 - Agenda de la CoPSST 2012-2013

Fuente: Desarrollo propio

Comunidad@Buenas Prácticas de Seguridad, Salud e Calidad de Vida en el trabajo INIAV

"Factores críticos de éxito" 


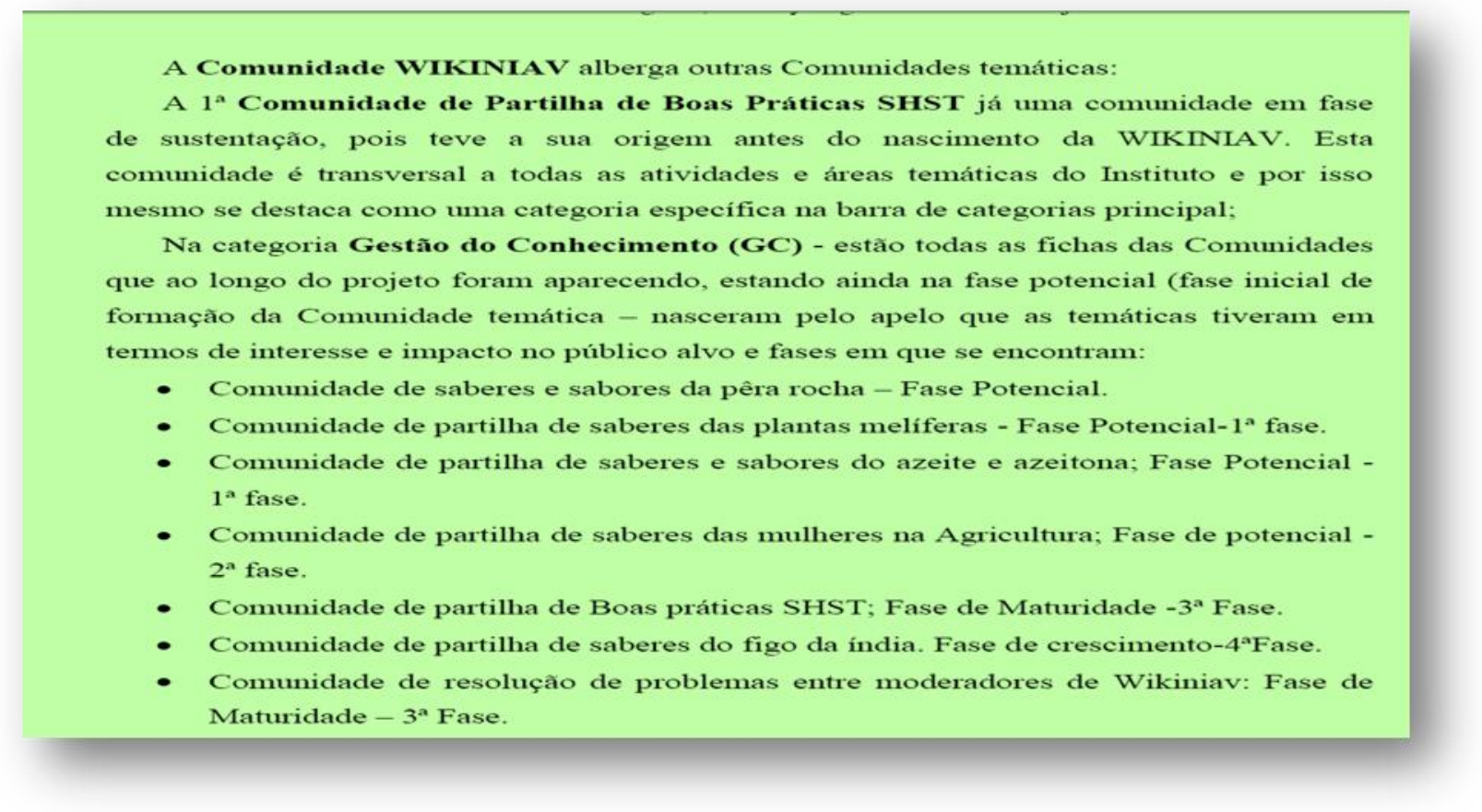

Ilustración 12 - Comunidades del WIKINIAV

Fuente: Desarrollo propio

Tal como podemos observar en la ilustración 13 tenemos 7 Comunidades que nacieron de la dinámica de la transformación de la Comunidad CoPGAPEAN, la plataforma de trabajo colaborativo apoyara no sólo la CoP del dominio de la SHST, sino también otras CoP del ámbito de la Agricultura. El trabajo desarrollado por la CoPGAPEAN para compartir las Buenas Prácticas SHST ya está en una fase de madurez.

La Confianza, el sentimiento de pertenencia, la Contribución y la Utilidad ya son resultados de prácticas de esta CoP que crecen debido al apoyo de la Gestión de Topo. Además de todo el apoyo a nivel de infraestructuras, de la flexibilidad de horas para el trabajo comunitario hay una apuesta a nivel tecnológico que es un marco positivo en el ciclo de vida de la dinámica colaborativa en el INIAV.

La herramienta de trabajo colaborativo de WIKINIAV tiene como atajos creados: Dominios transversales al conocimiento del Instituto: SHST; Historia Organizacional; Agricultura y Medio Ambiente; GC; Foro; eventos. 
La participación en esta plataforma implica siempre una invitación por los moderadores responsables de la temática en discusión su registro en WIKINIAV pasa siempre por el administrador de la plataforma (Nuno Silva-administrador) e información a Casimira Flor (Coordinadora / Facilitadora) que hace la verificación del nuevo registro.

Esta herramienta fue creada y administrada por un Ingeniero informático que en colaboración con la coordinadora del proyecto adecuó la herramienta a las necesidades del mismo, pasando por un período experimental de prueba y sólo después para el operativo.

\section{Comunidad de Buenas Prácticas de Seguridad, Salud y Calidad de Vida en el Trabajo}

Dominio: Salud y seguridad.

Práctica: compartir experiencias, conocimientos y difusión de buenas prácticas en el ámbito del SHST y la calidad de vida en el trabajo.

\section{Análisis combinatorio del cuestionario aplicado en el segundo estudio (2012).}

\section{Caracterización de muestra}

Dados da amostra
\begin{tabular}{|l|l|}
\hline $\begin{array}{l}\text { Contabilização } \\
\text { por sexo: }\end{array}$ & \\
\hline I. Feminine & 138 \\
\hline 2. Masculine & $\mathbf{5 7}$ \\
\hline Total & 195 \\
\hline
\end{tabular}

\begin{tabular}{|l|l|}
\hline $\begin{array}{l}\text { Contabilização } \\
\text { por carreira }\end{array}$ & $\mathbf{2 5}$ \\
\hline 1 Assistente Técnico & $\mathbf{2}$ \\
\hline $\begin{array}{l}\text { 2Investigação } \\
\text { (Assistente de) }\end{array}$ & $\mathbf{3}$ \\
\hline $\begin{array}{l}\text { 3Investigador } \\
\text { (Bolseiro) }\end{array}$ & $\mathbf{7 2}$ \\
\hline $\begin{array}{l}\text { 4Investigador } \\
\text { Auxiliar }\end{array}$ & $\mathbf{3}$ \\
\hline $\begin{array}{l}\text { 5Investigador } \\
\text { Principal }\end{array}$ & $\mathbf{3}$ \\
\hline $\begin{array}{l}\text { 6Técnico } \\
\text { Informática }\end{array}$ & $\mathbf{8 0}$ \\
\hline $\begin{array}{l}\text { 7 Técnico Superior } \\
\text { 8 Omisso }\end{array}$ & 6 \\
\hline Total & 194 \\
\hline
\end{tabular}

Tabla 3 - Caracterización de la muestra por sexo y por carrera profesional

Fuente: Desarrollo propio 


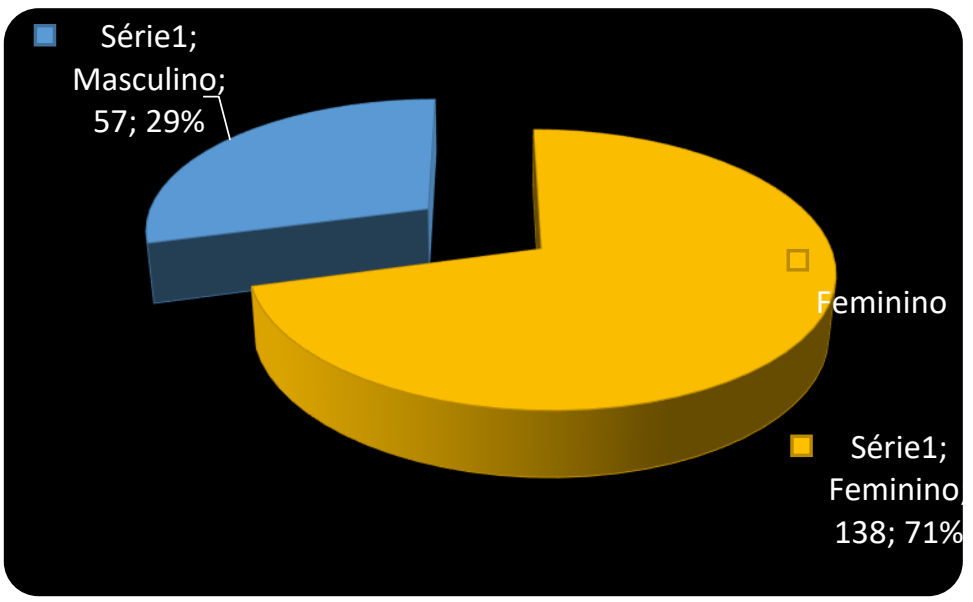

Gráfico 1 - Presentación gráfica | Distribución de la muestra por género

Fuente: Desarrollo propio

Como podemos observar en el (gráfico1) presentado el sexo femenino representa cerca del 70,8\% de la muestra de funcionarios participantes. Siendo las carreras de Técnico Superior e Investigador Auxiliar mayoritarias en el INIAV(Gráfico 2).

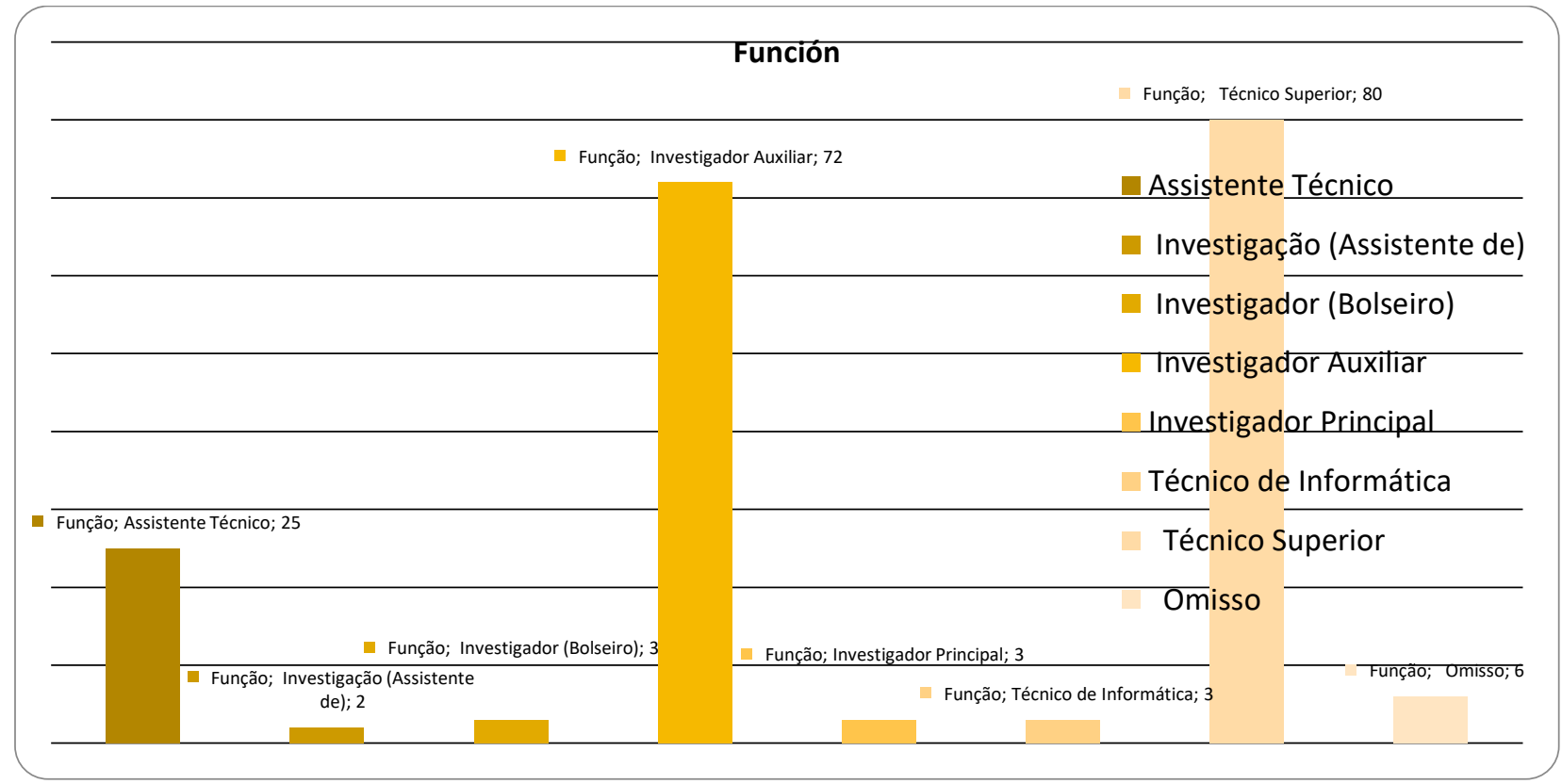

Gráfico 2 - Presentación gráfica | Distribución de la muestra por categoría profesional

Fuente: Desarrollo propio

Comunidad@Buenas Prácticas de Seguridad, Salud e Calidad de Vida en el trabajo INIAV

"Factores críticos de éxito" 
Después de la recoja de los datos tratados por SPSS. Las cuestiones que hemos analizado: 2 y 8 (ANEXO BIV) El cuestionario voluntario lanzado por correo electrónico a los empleados del INIAV, tuvimos un feedback de respuestas en un total del 27,3\%, siendo el 19,6\% del sexo femenino y el $8,1 \%$ del sexo masculino. También quisimos percibir en términos de carrera profesional como si presentaban el porcentaje de respuestas y en un total de adhesión del 27,6\% pudimos también verificar que las carreras de Investigación y Técnica Superior tuvieron mayor porcentaje de adhesión al cuestionario.

El análisis estadístico realizado fue un análisis combinatorio que mostró las combinaciones con el mayor número de casos.

Se presenta el análisis de la cuestión 2 del cuestionario en línea, siendo las combinaciones y el número de casos ocurridos referentes a la cuestión que planteamos a los empleados (Pregunta n. ${ }^{o}$ 2: cuando necesitaban de una información relacionada al área de trabajo / especialización en la forma que buscan encontrar el conocimiento necesario para la resolución del problema).

Por el análisis combinatorio ocurrió el número de casos y la combinación más escogida fue:

3-4-2 con 49 número de casos:

3-Conversan con Personas de su Equipo - 4-Se apoyan en Documentación Técnica -2-Conversan con personas de otras Organizaciones.

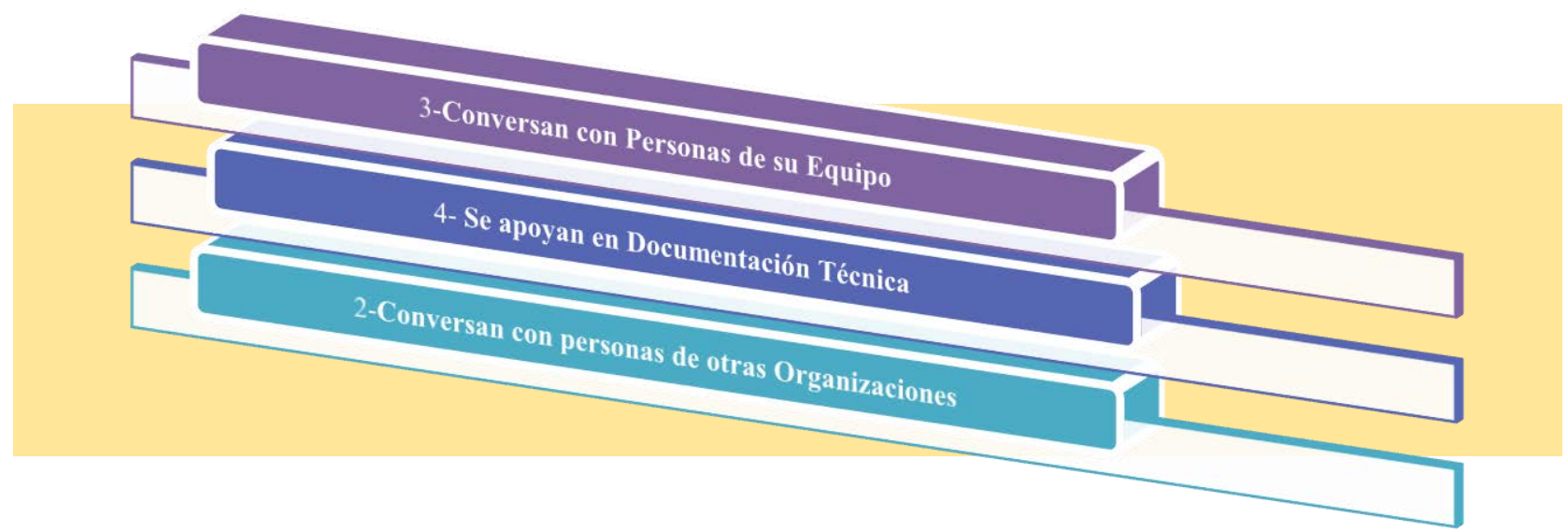

Ilustración 14 - Combinación más elegida cuestión 2 | Surveys Online

Fuente: Desarrollo propio

90

Comunidad@Buenas Prácticas de Seguridad, Salud e Calidad de Vida en el trabajo INIAV

"Factores críticos de éxito" 
En la cuestión n. ${ }^{\circ} 8$ (ANEXO BIV) hemos intentado saber cuáles son los factores que más contribuyen para el intercambio de información por parte de los funcionarios y las combinaciones que encontramos que están relacionadas con el grado de importancia / relevancia dada por la muestra y el análisis combinada resultó en una combinación de 29 con mayor número de casos. 1-Ambiente relajado, 2-Confianza, 3-Para su aprendizaje; 4-Voluntad de ser útil;

Teniendo en cuenta el mayor número de casos ocurridos, la combinación elegida fue:

2.Confianza - 4. Voluntad de ser útil - 3. Para su aprendizaje -1. Ambiente relajado

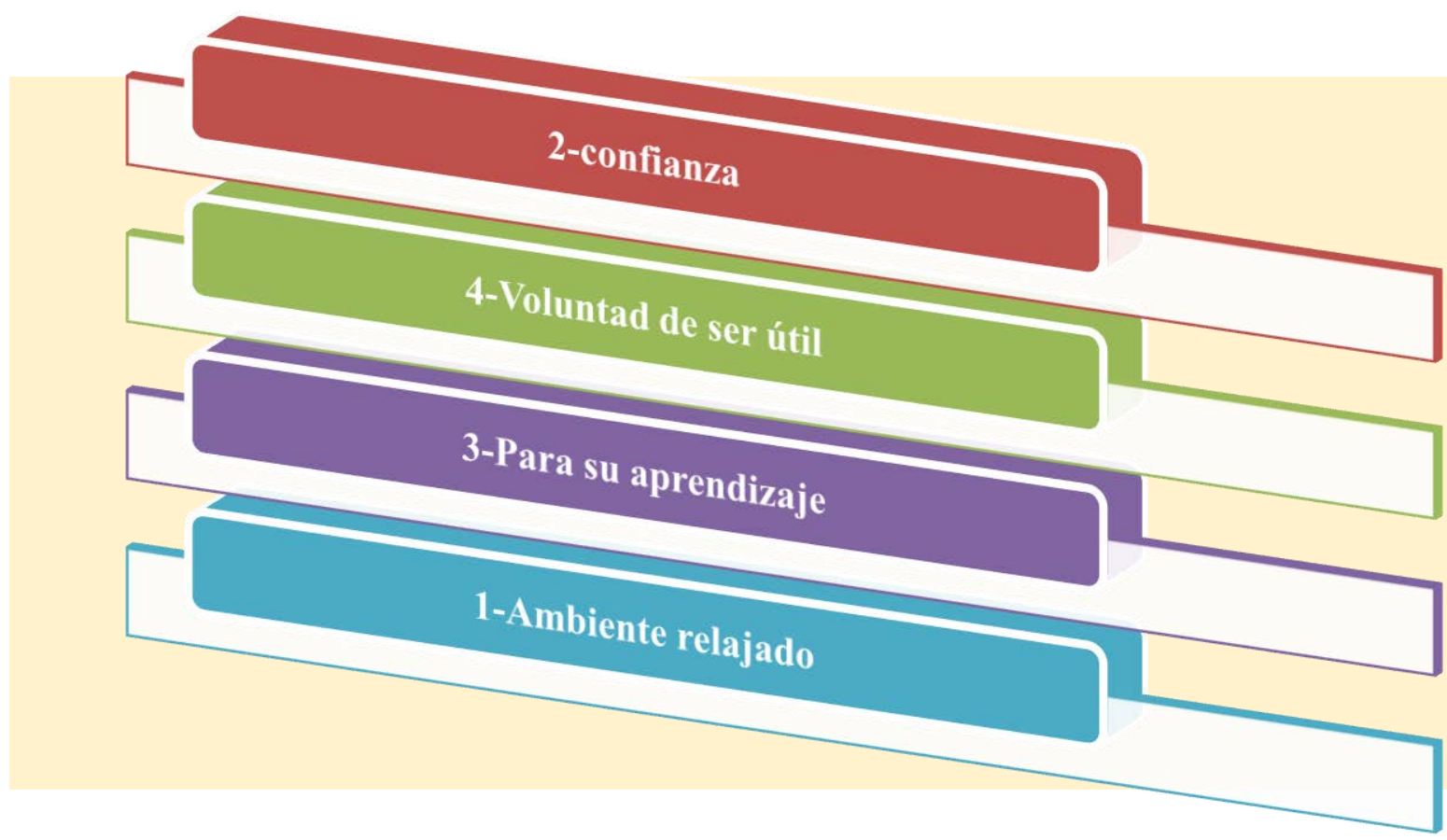

Ilustración 15 - Combinación más elegida cuestión | Surveys Online

Fuente: Desarrollo propio

\section{Análisis de la Encuesta en soporte de papel aplicado en una acción presencial}

El tercero instrumiento de evaluación fue una encuesta aplicada en una acción presencial de WIKINIAV aplicado en el período experimental. (ANEXO BV). 
La encuesta fue distribuida en el inicio de la acción en formato de papel y recogida a la salida del auditorio.

Participaron en esta acción un total de 62 funcionarios del Polo Oeiras que correspondió al 25\% de la muestra elegida por conveniencia, respondieron 45 funcionarios correspondiendo a 67,7\% de los participantes cuestionados en la acción y 17 no entregaron la encuesta correspondiendo a $27,4 \%$ de los presentes en la acción.

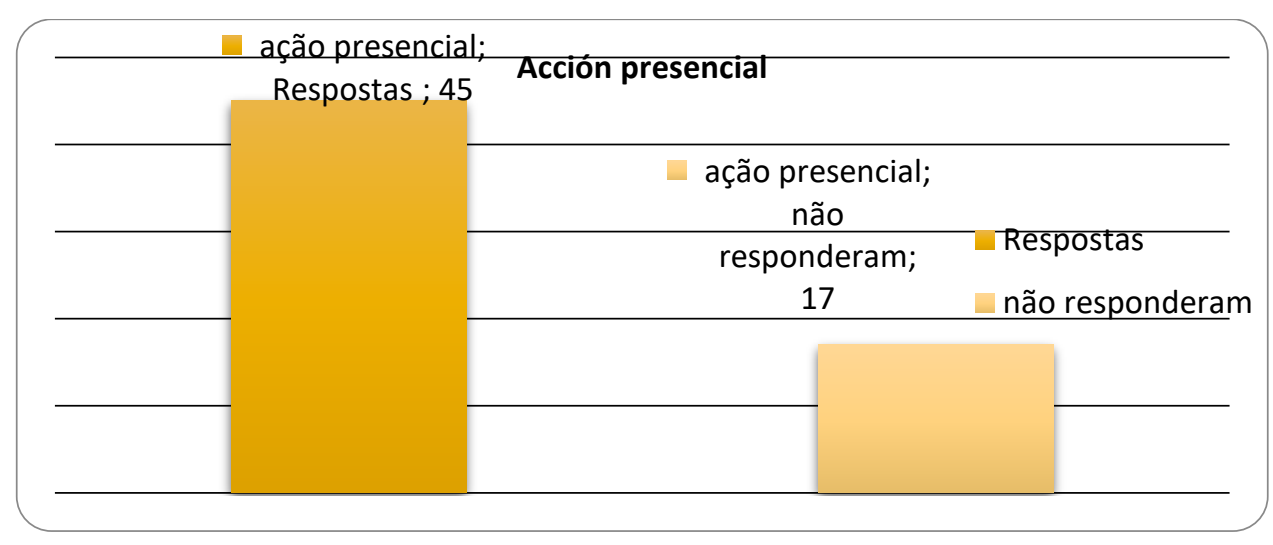

Gráfico 3 - Muestreo en soporte de papel aplicado en una acción presencial

Fuente: Desarrollo propio

A continuación, haremos la apreciación global de cada una de las respuestas a la investigación que figura en el (ANEXO BV). Se analizaron las preguntas n. ${ }^{\circ}$ 2-3-6-9. En el análisis de la pregunta n. ${ }^{\circ}$ 2 del cuestionario presencial conseguimos percibir que la perspectiva de los funcionarios que contestaron 72,5\% creó que la apuesta en el desarrollo de Comunidades de Práctica en el INIAV, la plataforma de trabajo colaborativo para el desarrollo de Comunidades de Práctica $(\mathrm{CoP})$ podrá minimizar y resolver parte de los problemas relacionados con la pérdida de tiempo en la búsqueda de información, la pérdida del conocimiento tácito, la diseminación valiosa de la información estar por muchos documentos y la gestión del error. La pregunta $n .^{\circ} 3$ cuando se les inquirió si les gustaría ser miembros de una Comunidad de Práctica que compartiera conocimientos sobre un tema de prevención de riesgos laborales, el $62 \%$ de los empleados respondieron positivamente.

92

Comunidad@Buenas Prácticas de Seguridad, Salud e Calidad de Vida en el trabajo INIAV

"Factores críticos de éxito" 
También analizamos los resultados de la pregunta n. 6 para que podamos percibir si la herramienta de trabajo colaborativo era del agrado de los empleados cuestionados.

Verificamos por el análisis de las respuestas que el 78\% de los funcionarios que participaron en la acción les ha gustado el formato de la presentación de esta herramienta de apoyo de trabajo colaborativo.

La mayoría de los empleados (78\%) que asistieron a la acción, manifestaron su voluntad de tener una acción de entrenamiento sobre la herramienta WIKINIAV, después de haber analizado las respuestas a la pregunta $n .^{\circ} 9$.

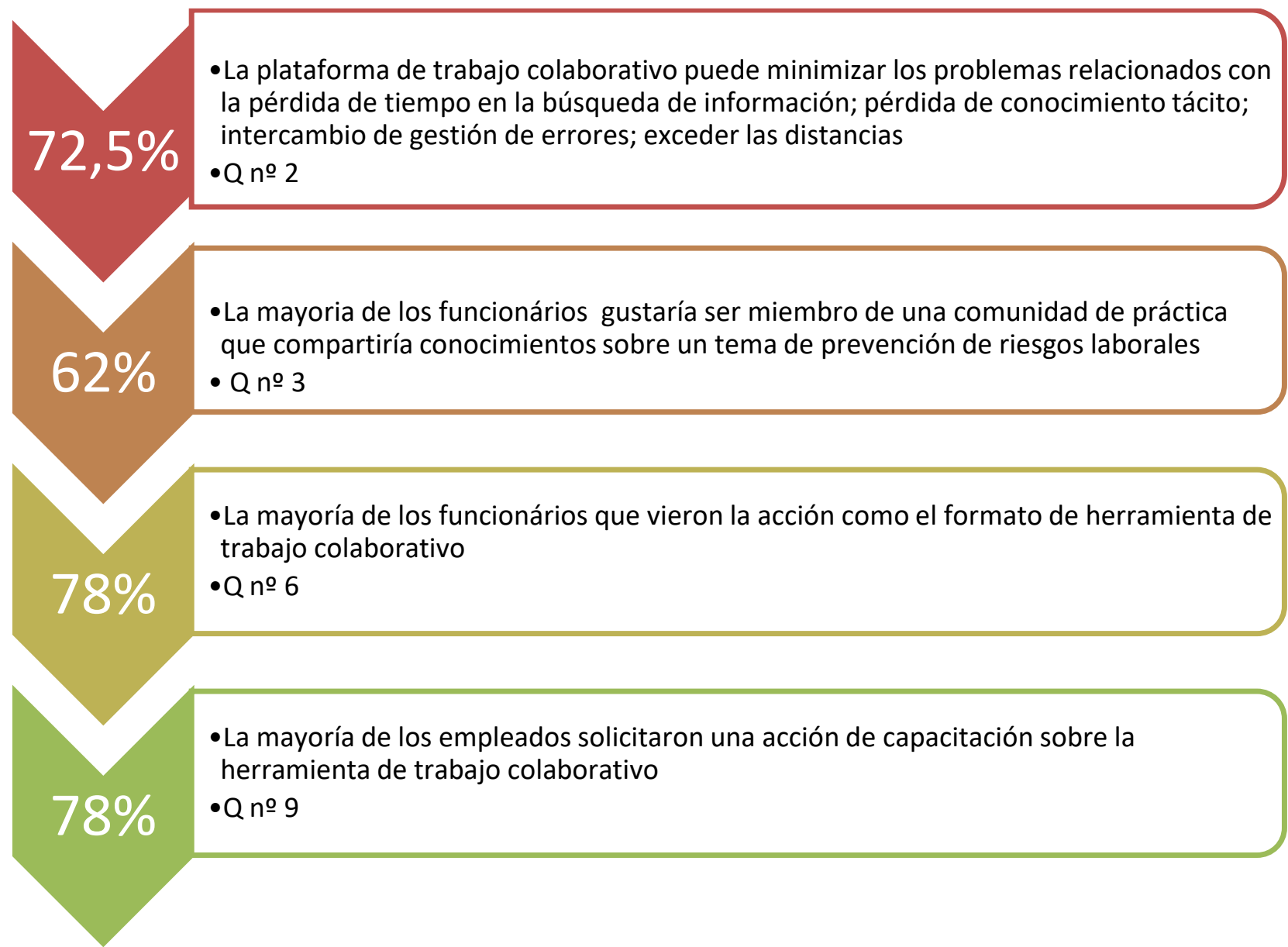

Cuadro 9 - Evaluación de la encuesta de la acción de cara

Fuente: Desarrollo propio 
El siguiente análisis muestra los elementos de la Práctica de Alineamiento y Estructuración de CoP que influirá en los resultados para su éxito y funcionamiento.

El primer período por nosotros analizado va de 2004 a 2012, un período de 8 años.

En las Prácticas Esenciales de la Alineamiento y la Estructuración de la CoP se definieron objetivos a corto y medio plazo para el desarrollo de la CoP y el establecimiento de Políticas de flexibilización para los cambios propuestos por la CoPGAPEAN, el establecimiento de normas para la creación y desarrollo de la CoP, la definición de métodos de interacción entre los participantes, fue definida la estructura de la $\mathrm{CoP}$, se expuso el foco de la $\mathrm{CoP}$ y se definieron estrategias para alcanzar sus objetivos.

Después de la consulta de varios documentos que explicitaban las evidencias construimos el (cuadro 9) presentado repartiendo en cajas y cada una tiene un elemento de la práctica correspondiente a las prácticas esenciales y puntuamos en términos de evidencias en una Escala de evaluación cada uno de los elementos que justificaban esta práctica de (1Muy málo - 2Málo -3 Razonable-4oBueno 5Muy bueno) para alcanzar los resultados esenciales para el éxito de la CoPGAPEAN.

La evaluación pasó por un grupo de 3 examinadores siendo los 3 especialistas en el dominio y en la dinámica de la CoP.

El puntaje se muestra en cada cuadro que define el elemento esencial de práctica y conduce a un resultado exitoso: CF-Confianza; CT- Contribución; SP-Sentido de Pertenencia; U-Utilidad.

Se evaluaron la alineación y estructuración, el apoyo de la alta dirección, la cultura, el desarrollo y la coordinación de CoPGAPEAN, así como la política y la tecnología al aplicar las herramientas de evaluación. 


\section{Práctica esencial: alineación y estructuración 2004-2014}
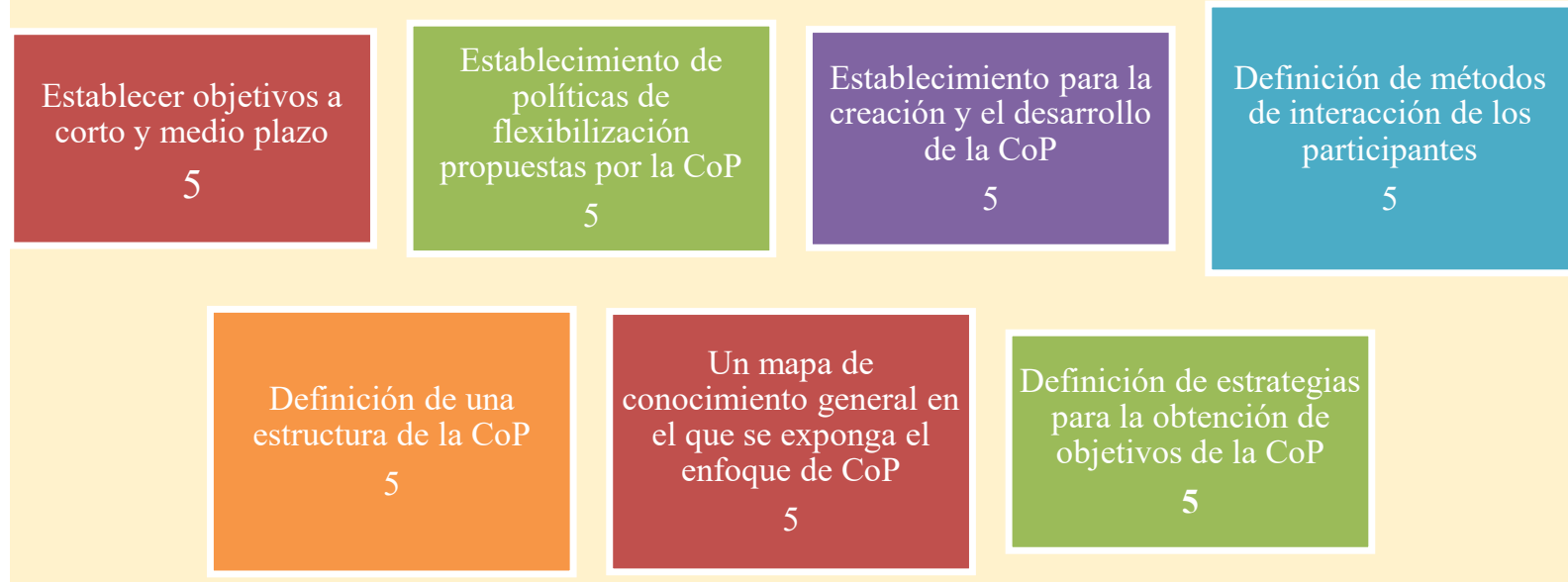

Escala de calificación: 1Muy malo | 2Má | 3razonable | 4bueno | 5 muy bueno

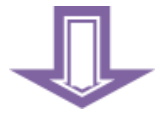

\section{Resultados de éxito: CF-Confianza | CT-contribución | SP-Sentimiento de Pertenencia | U-Utilidad}

Ilustración 16 - Contribución de los elementos de la práctica alineación y estructuración al resultado de éxito

Fuente: Desarrollo propio

En una escala de evaluación se puntuó el valor del alineamiento y la estructuración y 5 Muy bien, podemos concluir que fueron los elementos de la práctica del Alineamiento y Estructuración mencionados los responsables por el éxito de los resultados: Confianza; Contribución; Sentimiento de Pertenencia y Utilidad.

El análisis en esta categoría implica las siguientes dimensiones: alineamiento de las necesidades tales como (problemas y temas comunes, experiencia de los miembros y herramientas), los métodos de interacción con la identificación de los objetivos de compartir el conocimiento del dominio de la CoP, alineación con la Organización y la participación de la gestión superior.

En el análisis del (ilustración 16), en que expusimos los elementos de la Práctica referente a la Estructuración y Alineamiento de la CoP que conducirán a los resultados de éxito como el desarrollo de la Confianza de la Contribución, Sentimiento de Pertenencia y Utilidad, se desarrolló la práctica 
de alineación y estructuración (ilustración 16), teniendo en cuenta en esta práctica el establecimiento de políticas de flexibilización propuestas por la CoP; se definieron los métodos de interacción de los participantes que entre 2004 y 2008 fueron por encima de todas las interacciones síncronas en el aula y auditorio y 2009 a 2012 interacciones mixtas síncronas y asíncronas en aula, auditorio y plataforma de trabajo colaborativo, otro elemento a evidenciar en el resultado de la encuesta la confianza fue la construcción de un mapa con el enfoque explícito de la CoP.

Para el resultado de la Contribución (CT), crucial para el mantenimiento de la CoP se establecieron objetivos a corto y a medio plazo y políticas de flexibilización propuestas por la CoP; también se establecieron normas para el desarrollo y funcionamiento de la CoP; se definieron los métodos a adoptar para la interacción; se definió una estructura para la CoP (administradores, facilitadores, Líder, gestor de contenidos); se explicitó el enfoque de la CoP y se definieron estrategias y planes de acción para alcanzar los objetivos.

En la ilustración 16 están representados los elementos de la Práctica Estructuración y alineamiento que evidenciaron también una gran importancia en el desarrollo de la Confianza (CF) y son ellos:

- establecimiento de Políticas de Flexibilización propuestas por la CoP,

- la definición de métodos de interacción y de la estructura de la CoP

- y la demostración del foco de la CoP.

También se observa en la (ilustración 16) que para el alcancé del Sentimiento de Pertenencia se han desarrollado varios elementos de la Práctica de la Estructuración y Alineamiento que fueron cruciales para el resultado de la $\mathrm{CoP}$ tales como: el establecimiento de objetivos a corto y a medio plazo, el establecimiento de políticas de flexibilización de propuestas presentadas por la CoP y de creación de normas para el funcionamiento de la misma, la definición de la estructura y de los medios de interacción de la CoP, así como la definición de estrategias para alcanzar los objetivos propuestos por la CoP.

Para alcanzar el resultado referente a la Utilidad señalamos los elementos de la práctica más importantes que lo justifican tales como:

- trazar objetivos a corto y medio plazo,

- proponer políticas de flexibilización para propuestas de la CoP,

- la definición de las interacciones y de la estructura de la CoP, 
- así como la definición de estrategias para el alcance de los objetivos.

Podemos concluir que para el alcance de los resultados que consideramos esenciales para el Desarrollo y Mantenimiento de la CoP en estudio -Confianza, Contribución, Sentimiento de Pertenencia, Utilidad -la Práctica de Alineamiento es esencial para que se alcancen exitosamente estos resultados. Otra Práctica Esencial para que haya resultados de éxito en el Mantenimiento y Desarrollo de la CoP.

Apoyo de la Gestión de Topo tiene como objetivo el apoyo incondicional de la Gestión superior de la Organización para su desarrollo siendo consideradas dos dimensiones:

- la participación de la gestión superior

- y su compromiso.

Práctica esencial: Apoyo a la gestión Top 2004 - 2014
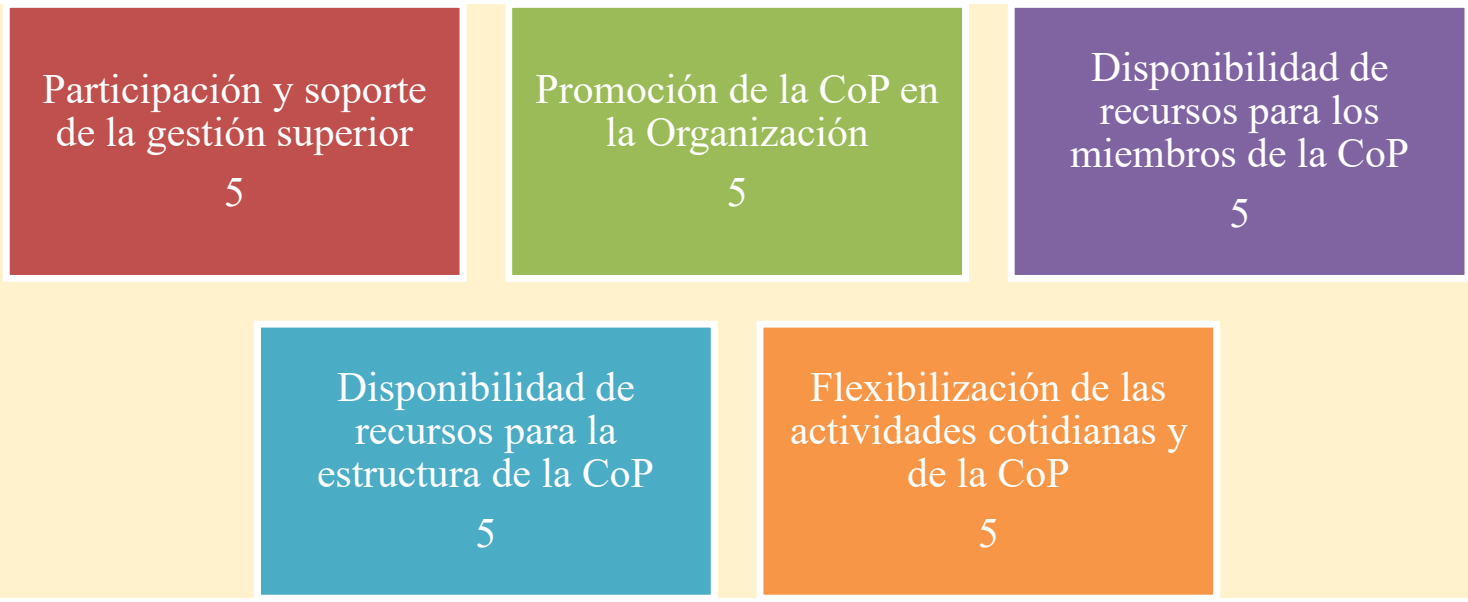

Escala de calificación: 1Muy malo | 2Má | 3razonable | 4bueno | 5 muy bueno

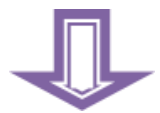

\section{Resultados de éxito: CF-Confianza | CT-contribución | SP-Sentimiento de Pertenencia | U-Utilidad}

Ilustración 17 - Contribución de los elementos de la práctica apoyo de la gestión de topo para el resultado de éxito Fuente: Desarrollo propio 
En una Escala de evaluación se puntuó el valor del apoyo de la gestión a la CoP y 5 Muy bueno. Podemos concluir que fueron los elementos de la práctica Gestión de Topo mencionados los responsables para el éxito de los resultados: Confianza; contribución; Sentimiento de Pertenencia y Utilidad.

\section{Práctica esencial: desarrollo 2004-2014}
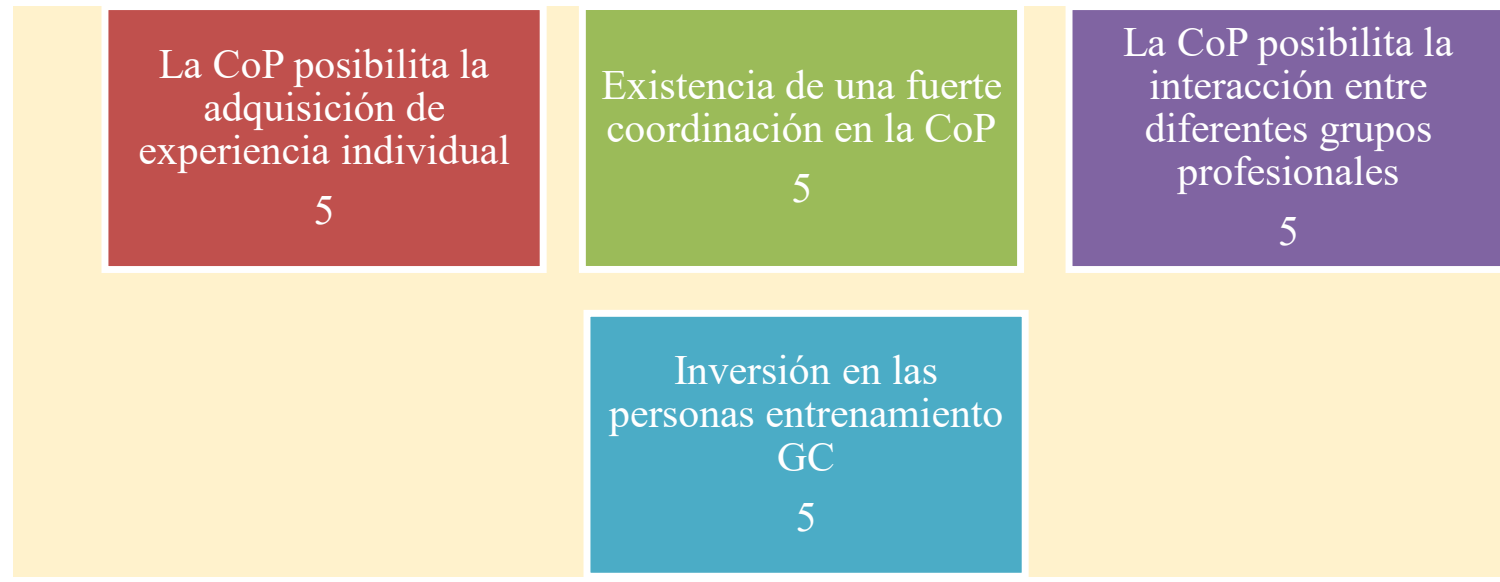

Escala de calificación: 1Muy malo | 2Má | 3razonable | 4bueno | 5 muy bueno

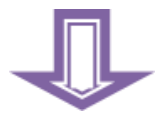

\section{Resultados de éxito: CF-Confianza | CT-contribución | SP-Sentimiento de Pertenencia | U-Utilidad}

Ilustración 18 - Contribución de los elementos de la práctica apoyo desarrollo para resultado de éxito

Fuente: Desarrollo propio

En una Escala de evaluación se puntuó el valor de la alineamiento y estructuración y 5 Muy bien podemos concluir que los elementos de la práctica mencionados son los responsables para el éxito de los resultados: Confianza; Contribución; Sentimiento de Pertenencia y Utilidad. Los elementos de la practica Desarrollo: Adquisición de experiencia individual; existencia de una fuerte coordinación; interacción entre diferentes grupos profesionales e inversión en las personas fueran los responsables por los resultados de éxito. 
También fue muy importante una coordinación fuerte y muy implicada en la dinámica y además especializada en el ámbito.

\section{Práctica principal: Gestión de CoP 2004 - 2014}
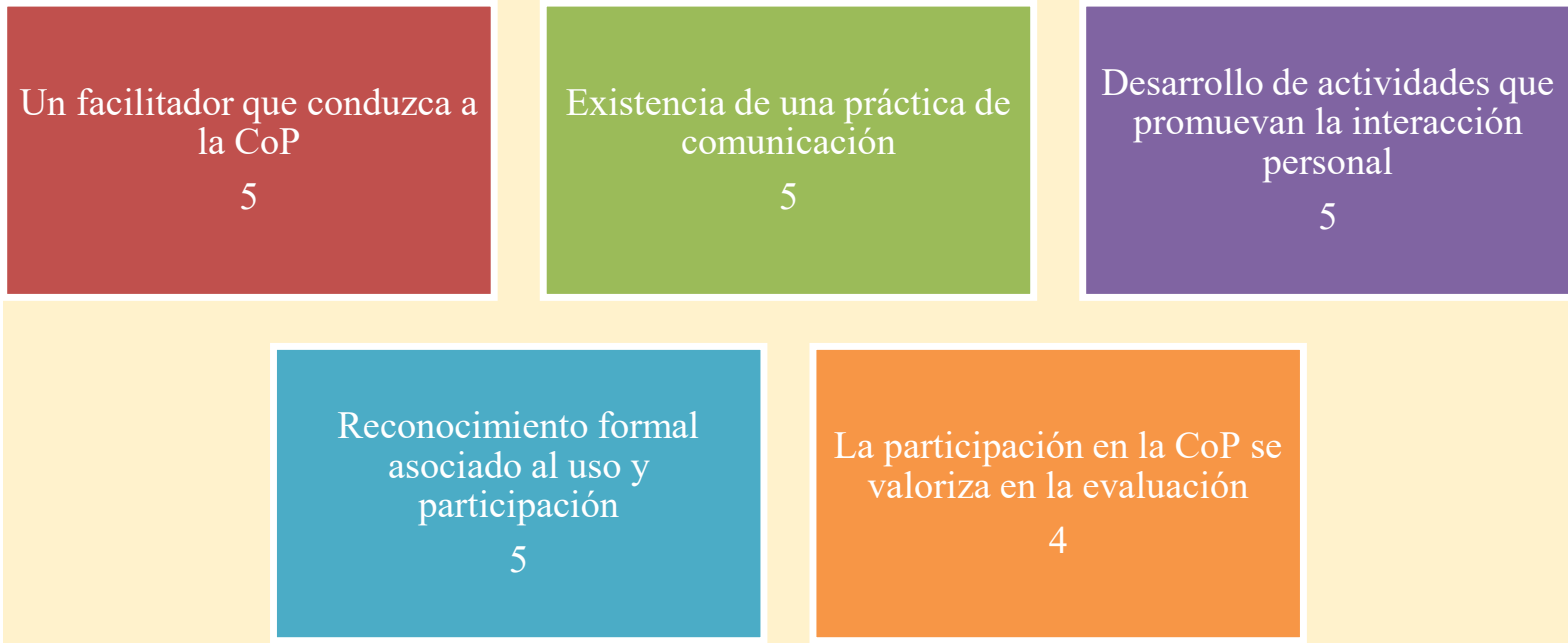

Escala de calificación: 1Muy malo | 2Má | 3razonable | 4bueno | 5 muy bueno

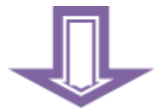

\section{Resultados de éxito: CF-Confianza | CT-contribución | SP-Sentimiento de Pertenencia | U-Utilidad}

\footnotetext{
Ilustración 19 - Contribución de los elementos de la práctica gestión fuerte para el resultado de éxito

Fuente: Desarrollo propio
}

En una escala de evaluación se puntuó el valor de la Gestión de la CoP $(4,8)$ Muy bueno pudendo concluir que fueron los elementos de la práctica mencionados los responsables por el éxito de los resultados: Confianza; contribución; Sentimiento de Pertenencia y Utilidad.

Los elementos : facilitador que conduzca la $\mathrm{CoP}$; existencia de una práctica de comunicación; desarrollo de actividades que promuevan la interacción-reconocimiento formal; participación fueran cruciales para los resultados de éxito. 


\section{Papel del Moderador Global}

El Moderador Global es el responsable por invitar miembros, recibir y validar pedidos, y comunicar al gestor la aceptación de los mismos para que sea creada una palabra clave.

El Moderador Global es responsable también por invitar especialistas para moderar fórums y facilitar el trabajo de los mismos en la dinámica colaborativa. También es responsable en prestar atención y alertar a los especialistas en relación a las preguntas que llevan mucho tiempo sin respuesta. Como ejemplo, en el Fórum SST, la moderadora Global es la Especialista responsable por el mismo, lo que facilita el buen funcionamiento. Este papel muchas veces fue compartido con el coordinador de la plataforma que facilitaba el intercambio de conocimiento y de todo lo que se relaciona con la temática de la SST. La moderadora fue premiada con Karma: 13 - Este es un número de premio debido a su grado de esfuerzo.

Administrador del Site | Moderador Global - modera y facilita toda la plataforma | Moderador modera sólo su área de especialidad.

\section{Gestor de la plataforma}

La plataforma tiene un Administrador que controla los pedidos de acceso. Siempre se envían correos electrónicos para la Coordinadora de la plataforma para saber si autoriza la entrada de un nuevo miembro y se da la posibilidad de que los moderadores de cada tópico realicen el pedido de miembros externos.

Este especialista tuvo como responsabilidad la gestión informática de la herramienta, la concesión de señas de acceso y la resolución de problemas relacionados con el funcionamiento de la misma. El papel o rol de apoyo técnico fue desarrollado por el administrador de la herramienta, que aseguró la entrada de miembros y el acceso y la seguridad de la herramienta. La coordinadora filtraba las

preguntas y las enviaba para los especialistas, optimizando de esta manera el tiempo. Se facultaron herramientas que apoyaron y facilitaron la comunicación y la interacción entre los miembros de la Comunidad y de los miembros con los contenidos disponibles en la plataforma. Las interacciones 
sincrónicas se dieron mayoritariamente con la Moderadora Global responsable por la categoría de la SHST.

Práctica esencial: política 2004 - 2014

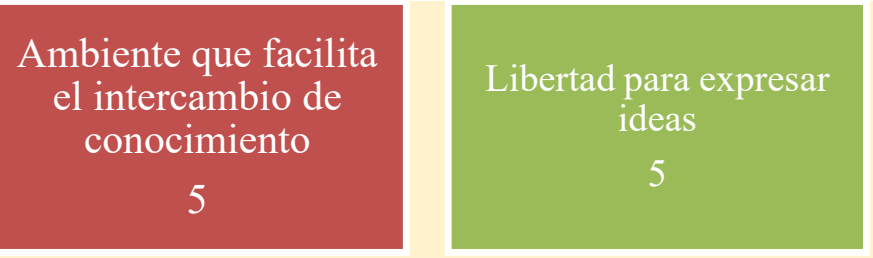

Procedimiento

facilitador de registro

de entrada de nuevos

miembros

5

Escala de calificación: 1Muy malo | 2Má | 3razonable | 4bueno | 5 muy bueno

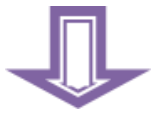

\section{Resultados de éxito: CF-Confianza | CT-contribución | SP-Sentimiento de Pertenencia | U-Utilidad}

Ilustración 20 - Contribución de los elementos de la práctica apoyo Política para el resultado de éxito

Fuente: Desarrollo propio

En una escala de evaluación se puntuó el valor de la Política 5 Muy bueno pudendo concluir que fueron los elementos de la práctica mencionados (Ambiente facilitador- libertad -procedimiento facilitador de entrada de nuevos miembros) los responsables por el éxito de los resultados: Confianza; contribución; Sentimiento de Pertenencia y Utilidad. 
Práctica esencial: Tecnología $2004-2014$
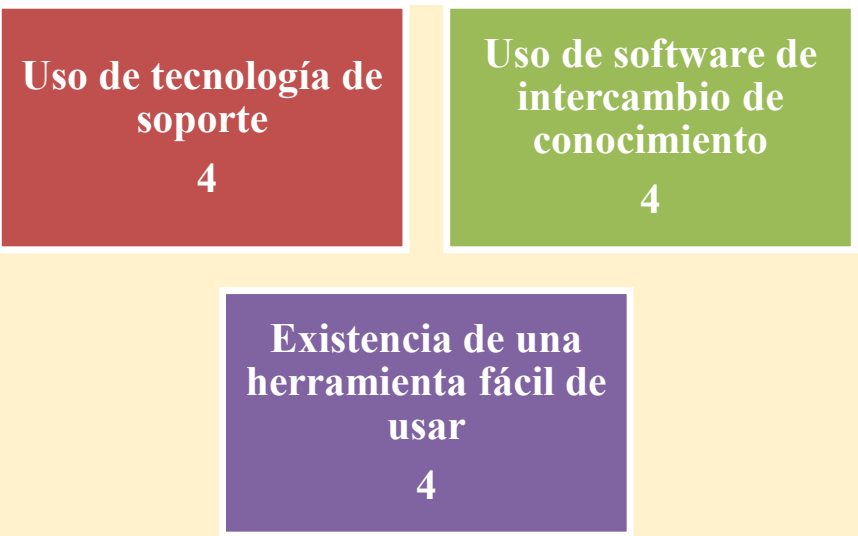

Escala de calificación: 1Muy malo | 2Má | 3razonable | 4bueno | 5 muy bueno

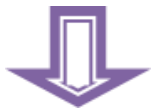

\section{Resultados de éxito: CF-Confianza | CT-contribución | SP-Sentimiento de Pertenencia | U-Utilidad}

Ilustración 21 - Contribución de los elementos de la práctica apoyo Política para el resultado de éxito

Fuente: Desarrollo propio

En una escala de evaluación se puntuó el valor de la Tecnología 4 de buena podemos concluir que fueron los elementos de la práctica mencionados a responsables por el éxito de los resultados: Confianza; contribución; Sentimiento de Pertenencia y Utilidad.

El formato de la plataforma de trabajo colaborativo fue una de nuestras preocupaciones y a partir del análisis de las respuestas al cuestionario (pregunta $n^{\circ} 6$ ) verificamos que el 78\% de los funcionarios que participaron les custó el formato de presentación de esta herramienta de apoyo al trabajo colaborativo. 


\section{Práctica esencial: Cultura 2004 - 2014}
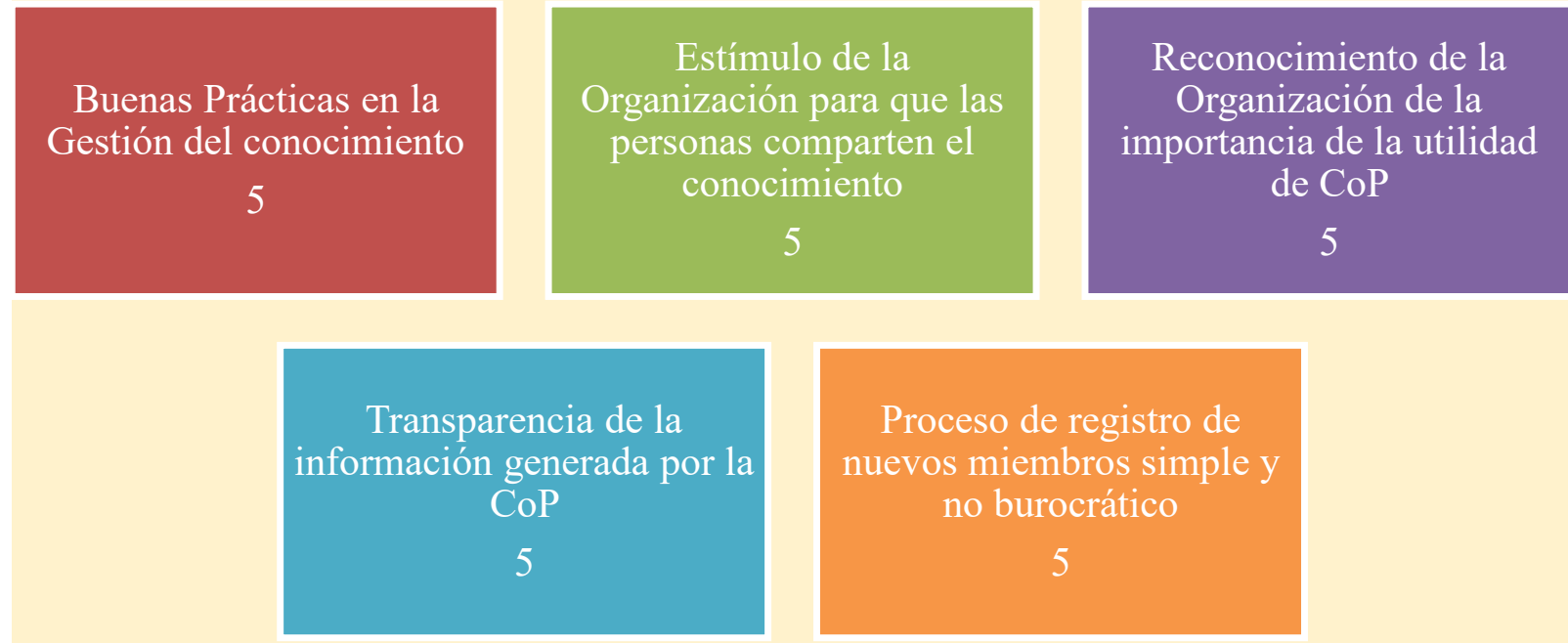

Escala de calificación: 1Muy malo | 2Má | 3razonable | 4bueno | 5 muy bueno

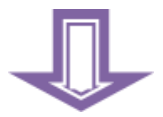

\section{Resultados de éxito: CF-Confianza | CT-contribución | SP-Sentimiento de Pertenencia | U-Utilidad}

Ilustración 22 - Contribución de los elementos de la práctica apoyo Cultura para el resultado de éxito

Fuente: Desarrollo propio

En una escala de evaluación se puntuó el valor de la Cultura 5 de muy bueno pudendo concluir que fueron los elementos de la práctica mencionados los responsables por el éxito de los resultados: Confianza; contribución; Sentimiento de Pertenencia y Utilidad, elementos como :estimulo de la organización de la importancia de la utilidad de la CoP; la transparencia de la información; buenas prácticas de gestión del conocimiento y proceso de registro de nuevos miembros no burocrático fueran responsables pelo éxito en resultados Confianza; Contribución; Sentimiento de Pertenencia y Utilidad.

Como se evidencia en la (ilustración 23), la Confianza es el resultado de las diferentes prácticas relacionadas con: Alineamiento, apoyo de la gestión superior, la cultura el desarrollo, el liderazgo 
de la CoP la política y la tecnología que entra en este intervalo de tiempo como una herramienta más que la CoP tuvo a su disposición. Se promovieron debates e intercambio de ideas presenciales y virtuales, hubo libertad para expresar ideas sin juicios de valor y reconocimiento formal asociados al trabajo colaborativo, entrenamientos relacionados con la gestión del conocimiento en el dominio, transparencia de las informaciones apoyadas siempre por la Gestión de Topo y por la Coordinación de la CoP.

\section{Confianza (2004-2014)}

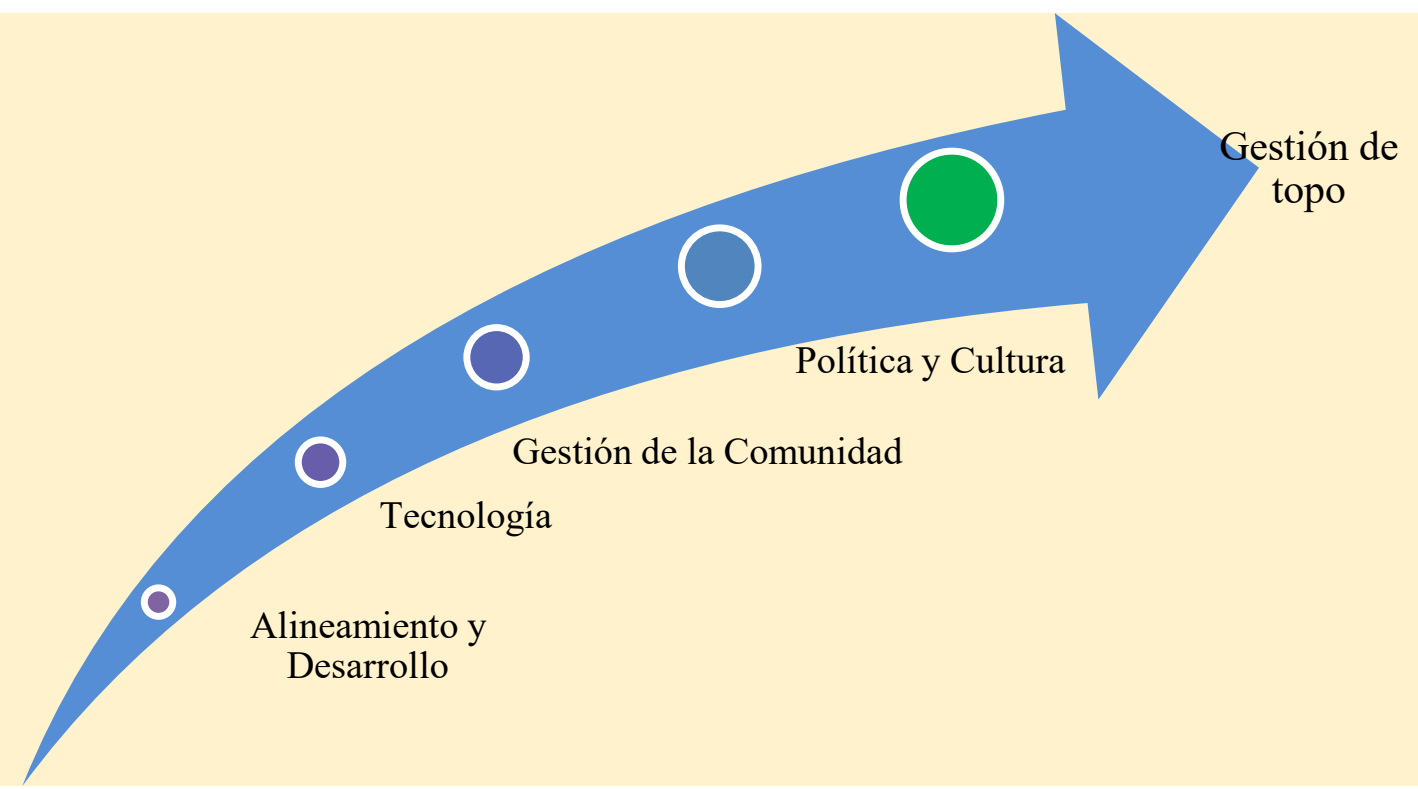

Ilustración 23 - Prácticas esenciales para el resultado de la confianza (2009-2014)

Fuente: Desarrollo propio

En esta fase del ciclo de vida la Organización atravesó un período de grandes cambios y fusiones lo que podría ser perturbador pues la gestión anterior que en 2009 ya no se encontraba en la Organización y que fue la palanca de toda la dinámica podría ser motivo para que la actividad declinara y el final de la $\mathrm{CoP}$ estuviese muy cerca, pero esto no se verificó porque la siguiente gestión recibió el testimonio para la continuidad y fue facilitadora, aquí la importancia de una fuerte coordinación fue decisiva para que la Comunidad diera seguimiento a toda la dinámica que da 
continuidad a la confianza existente entre los miembros de la comunidad y entre la Comunidad y la Organización.

La participación, el interés y la implicación en los eventos relacionados con la CoP;

La definición de estrategias y planes de acción para la obtención de los objetivos;

La participación y facilitación de la gestión superior;

La exposición de los beneficios de las partes interesadas de la Comunidad;

La CoP posibilitó la interacción entre diferentes grupos profesionales;

Hubo libertad para expresar ideas y se promovieron debates y encuentros presenciales y virtuales. El estímulo de la Organización para que las personas compartieran el conocimiento se han dado grandes contribuciones como elementos que justificaron las prácticas esenciales para un buen funcionamiento de la CoP y que resultaron en el Resultado del Éxito al que llamamos Contribución.

\section{Contribución (2004-2014)}

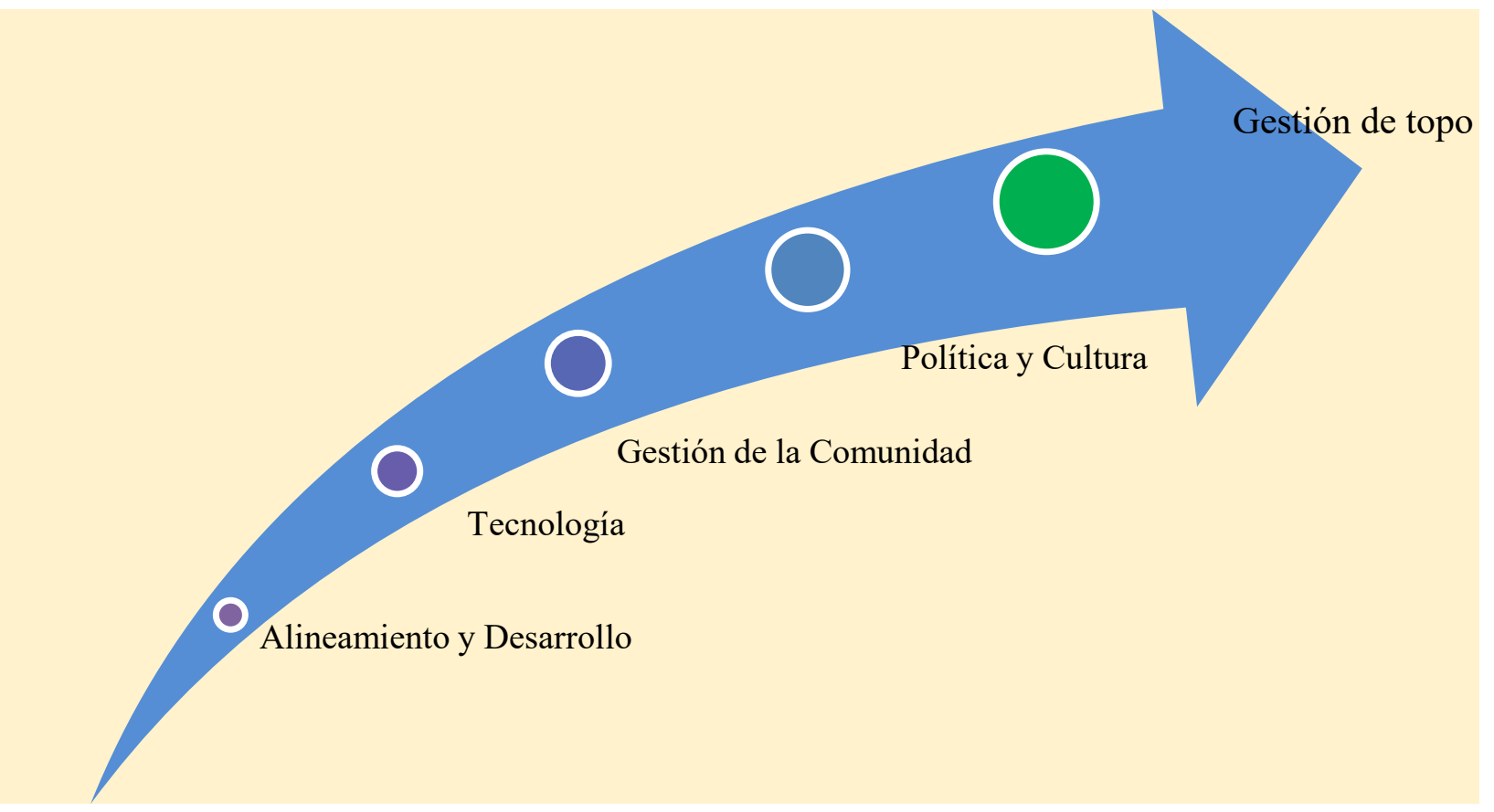

Ilustración 24 - Prácticas esenciales para el resultado Contribución (2009-2014)

Fuente: Desarrollo propio 


\section{Sentimiento de Pertenencia}

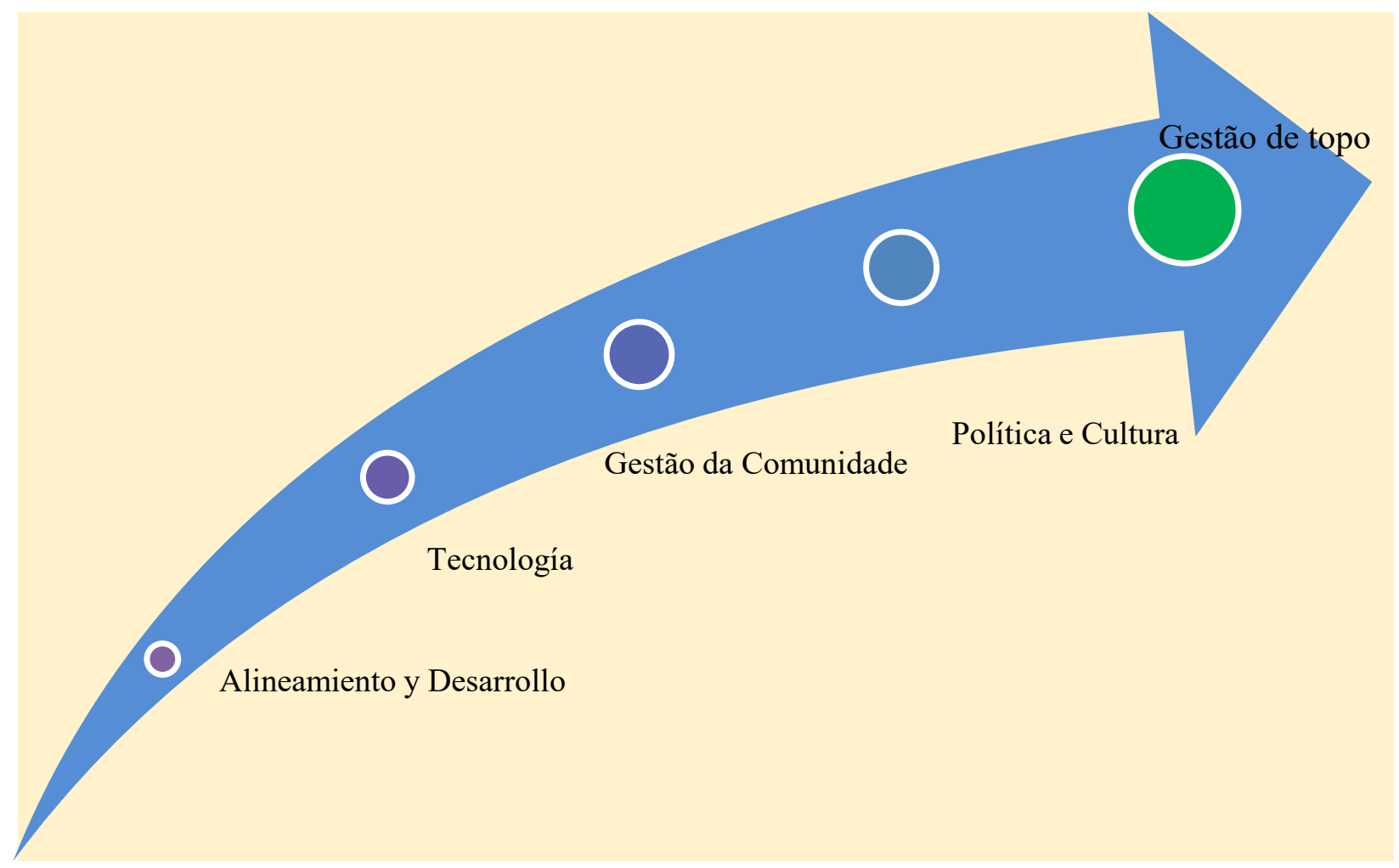

Ilustración 25 - Prácticas esenciales para el resultado Sentimiento de Pertenencia (2009-2014)

Fuente: Desarrollo propio

Lo mismo ha sucedido con el resultado Sentimiento de Pertenencia en que se definieron métodos de interacción entre los participantes de la $\mathrm{CoP}$, hubo Flexibilización de la Gestión superior para posibilitar la integración entre la actividad de la CoP y el trabajo diario. También hubo la aclaración de los beneficios prestados a los stakeholders, así como el estímulo por parte de la Organización para que las personas compartan el conocimiento.

Todas estas prácticas esenciales culminaron en resultado de éxito en lo que se refiere al Sentimiento de pertenencia, la inversión en el entrenamiento de las personas y el apoyo continuado. Un ambiente facilitador de la partilla, participación, promoción de encuentros presenciales y virtuales. Para lograr alcanzar el resultado Utilidad se establecieron objetivos a corto y medio plazo, la CoP fue promovida por la Gestión de Topo, el Liderazgo de la Comunidad fue Proactiva, hubo 
demostración de los beneficios de la CoP, una cultura de compartir el conocimiento, una inversión en el mercado, entrenamiento de las personas y apoyo continuado, un entorno facilitador del compartir promoviendo debates e intercambio de ideas.

Analizando el período comprendido entre 2015-2019 nos hemos debatido con un grave problema para la CoP y que estuvo relacionado con la Práctica esencial de la Gestión superior. En la evaluación que hicimos es inexistente en esta fase y la evaluación dada ha sido 1 muy mála.

No hubo implicación - ni flexibilización de las actividades-ni Promoción - Se cerraron los recursos para los miembros y para la estructura. No haremos análisis de los otros elementos y prácticas esenciales pues el fracaso de la CoP dependía de la práctica esencial de la gestión superior haber fallado en este período

\section{Práctica esencial: Gestión de Topo 2015 - 2019}
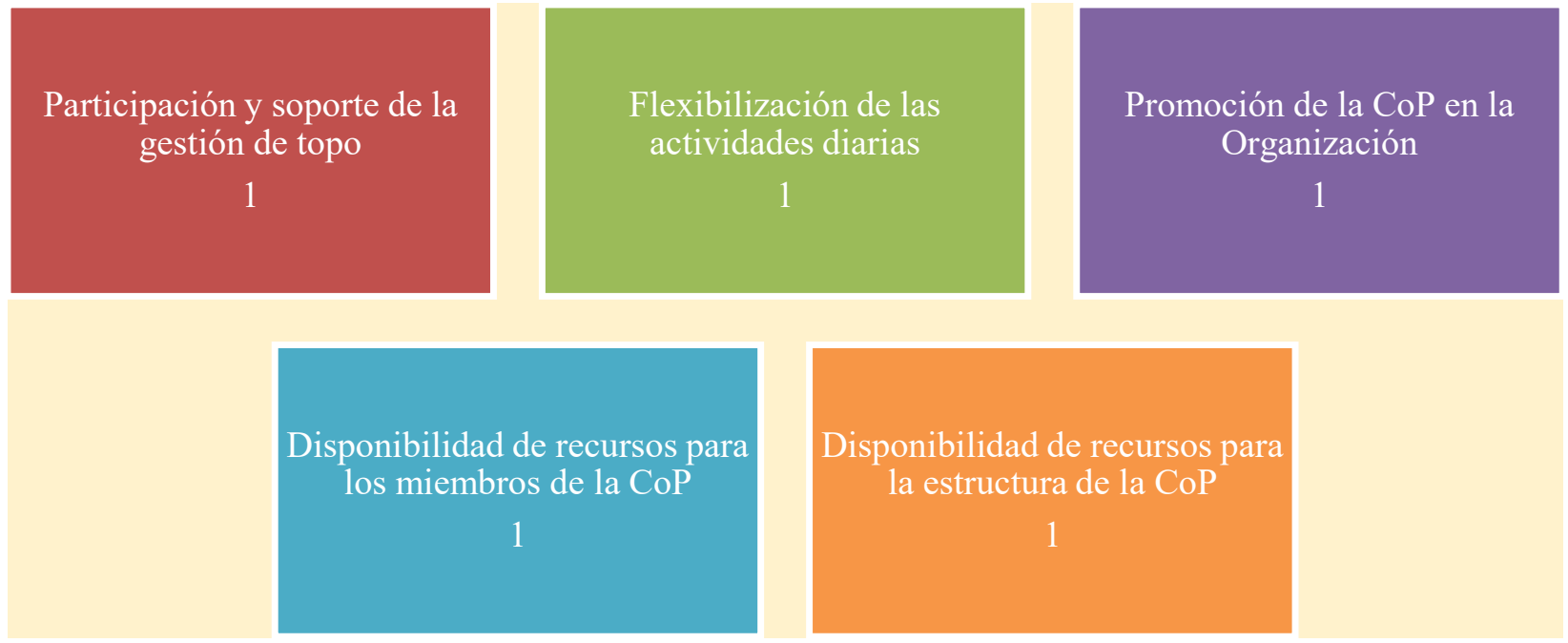

Escala de calificación: 1Muy malo | 2Má | 3razonable | 4bueno | 5 muy bueno

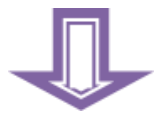

Resultados de éxito: CF-Confianza | CT-contribución | SP-Sentimiento de Pertenencia | U-Utilidad

Ilustración 26- Resultados de fracaso de la CoP

Fuente: Desarrollo propio 
Tenemos una cultura y política de intercambio de conocimiento negativo en la Organización. No hubo incentivo durante este período: Buenas prácticas en GC; Estímulo de la Organización para que las personas comparten el conocimiento; reconocimiento de la Organización de la importancia de la utilidad de la $\mathrm{CoP}$; transparencia de la información y proceso de registro de nuevos miembros.

A continuación, presentamos matrices de análisis y cruce de nuestros análisis y haremos primero el análisis de los intervalos de tiempo 2004 a 2008 y de 2009 a 2015 que fueron 2 períodos marcados por cambios en la Gestión de topo y Organizaciones pero que fueron facilitadoras al desarrollo del trabajo colaborativo.

Matrices de análisis: Elementos de la práctica x Prácticas

\begin{tabular}{|c|c|c|c|c|}
\hline & Política & Coordenación & Tecnología & Desarrollo \\
\hline \multicolumn{5}{|l|}{ Elementos de la práctica } \\
\hline \multicolumn{5}{|l|}{ Existencia de una práctica de comunicación } \\
\hline \multicolumn{5}{|l|}{ Un facilitador o líder que dirige la CoP } \\
\hline \multicolumn{5}{|c|}{$\begin{array}{l}\text { Desarrollo de actividades que promuevan la interacción } \\
\text { personal }\end{array}$} \\
\hline \multicolumn{5}{|c|}{ Reconocimiento formal asociado con el uso y la participación } \\
\hline \multicolumn{5}{|l|}{ La participación en la CoP es parte de la evaluación } \\
\hline \multicolumn{5}{|c|}{ Apoyo en la integración e implicación de nuevos miembros } \\
\hline \multicolumn{5}{|c|}{ La CoP permite la adquisición de experiencia individual } \\
\hline \multicolumn{5}{|c|}{$\begin{array}{l}\text { La CoP permite la interacción entre diferentes grupos } \\
\text { profesionales }\end{array}$} \\
\hline \multicolumn{5}{|l|}{ La existencia de una fuerte coordinación en la CoP } \\
\hline \multicolumn{5}{|l|}{ Inversión en formación de personas GC } \\
\hline \multicolumn{5}{|l|}{ Facilitar el entorno de intercambio de conocimientos } \\
\hline \multicolumn{5}{|l|}{ Libertad para expresar ideas } \\
\hline \multicolumn{5}{|c|}{ Proceso de facilitación del registro de nuevos miembros } \\
\hline \multicolumn{5}{|l|}{ Uso de la tecnología de soporte } \\
\hline La existencia de una herramienta fácil de usar & & & & \\
\hline
\end{tabular}

Matriz 1 - Elementos de la práctica x Prácticas CoP de 2004 a 2014

Fuente: Desarrollo propio 
Se elegieron los colores verdes para señalar las prácticas facilitadoras del intercambio de conocimiento en la $\mathrm{CoP}$, el rojo para las inhibidoras del intercambio de conocimiento y el naranja el color de transición en que las prácticas son moderadas, pero en el sentimiento del crecimiento del reparto. En el análisis de la matriz 1 en que cruzamos los elementos esenciales para las prácticas Alineamiento y estructuración - Apoyo de la Dirección y Cultura se enfrentan con un refuerzo facilitador a las prácticas que van a dar resultados de éxito que se validarán en una matriz de cruce con los resultados Confianza-contribución - el sentimiento de Pertenencia y Utilidad.

\begin{tabular}{|c|l|}
\hline $\begin{array}{c}\text { Resultado } \\
\mathbf{2 0 0 4} \text { a } 2014\end{array}$ & \multicolumn{1}{c|}{ Definición } \\
\hline Utilidad & $\begin{array}{l}\text { Los Miembros creen en la utilidad y eficacia de la CoP por sí } \\
\text { mismos }\end{array}$ \\
\hline Confianza & Hay un fuerte sentido de confianza entre los miembros de la CoP \\
\hline Sentimiento de & $\begin{array}{l}\text { Los Miembros se relacionan entre sí fuera de la CoP y tienen un } \\
\text { fuerte sentido de pertenencia a la CoP }\end{array}$ \\
\hline Pertenencia & $\begin{array}{l}\text { Los miembros de la CoP participan en la comunidad de manera } \\
\text { continua y sistemática. }\end{array}$ \\
\hline
\end{tabular}

Cuadro 10 - Resultados de éxito y su significado

Fuente: Desarrollo propio

Podemos concluir que las prácticas esenciales analizadas en las matrices $n^{\circ} 1$ y 2 ayudaron a obtener resultados facilitadores (cuadro 10) al buen funcionamiento de la CoP.

Analizando el significado de cada uno de los constructos del resultado podremos afirmar que hubo un fuerte sentimiento de confianza entre los miembros de la CoP, también verificamos que los miembros de la CoP creían en la utilidad y en la efectividad de la CoP y un fuerte sentimiento de pertenencia con una participación continua y sistemática tal como evidencian los análisis de los 
Documentos que observamos y los miembros de la $\mathrm{CoP}$ participaran en la comunidad de una manera continua.

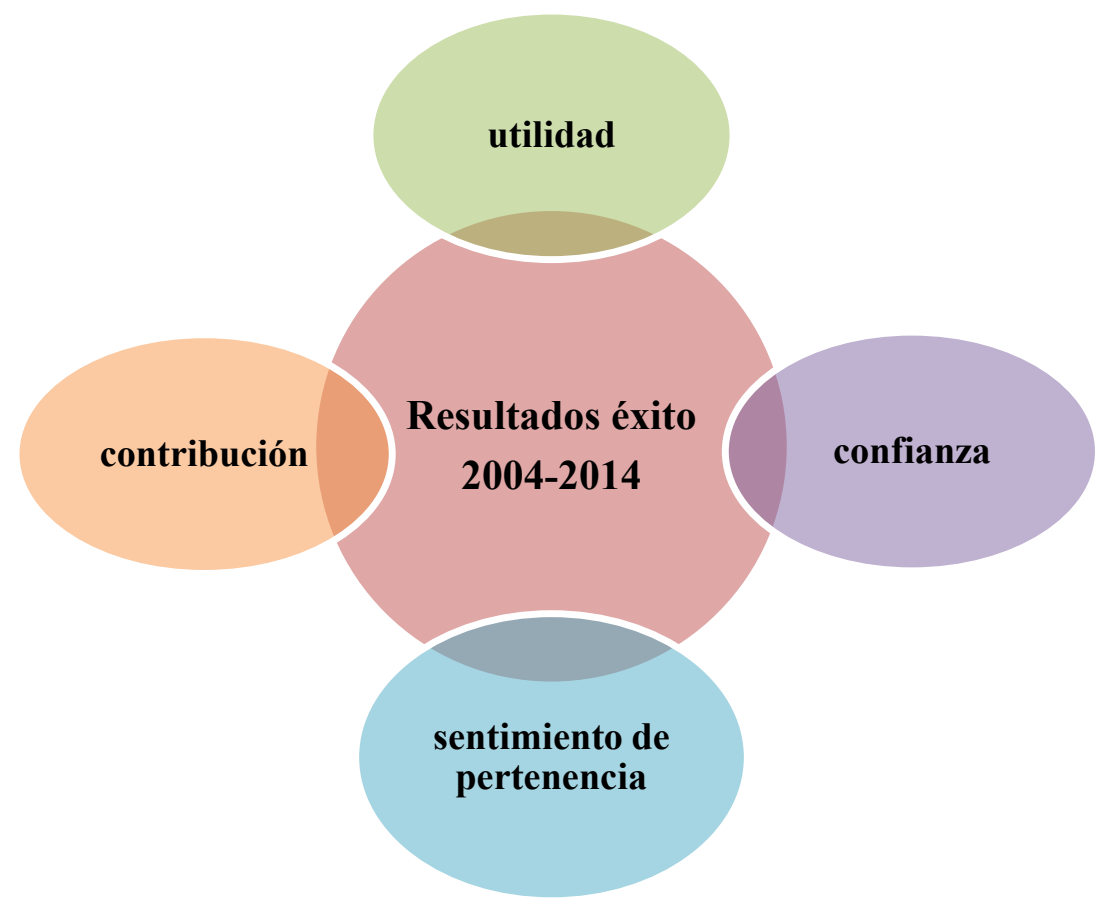

Ilustración 27 resultados de éxito para el mantenimiento de la CoPGAPEAN y su evolución (2004-2014).

Fuente: Desarrollo propio

Analizando la (matriz 1) que evidencia las aportes de los elementos esenciales que llevarán al constructo de la práctica esencial para que a continuación se puedan analizar los resultados de éxito o inhibidores en la vida de la $\mathrm{CoP}$ siendo que para que la estructura y alineamiento resultaran en una práctica esencial para un buen resultado de la $\mathrm{CoP}$ fue diseñada pensando en su evolución, habiendo una definición clara de los objetivos de la CoP como evidencia los documentos que representa los principios seguidos por la Comunidad.

También se definió la estructura de la CoP (moderadores -administrador - Gestor / coordinador). Se definieron estrategias y planes de acción para el logro de los objetivos como se evidencia en los Principios definidos para el soporte y desarrollo de la CoP .

La CoP fue presentada públicamente por la nueva dirección con una mejora significativa aprovechando la evolución de las tecnologías de Información y Comunicación, con el recurso a 
WIKINIAV una tecnología de servidor colaborativo "open source" que posibilitó a los usuarios acceder, buscar un artículo y editar un artículo en tiempo real y participar en un forúm.

Esta herramienta es fácil de usar y requiere de muy poca inversión tanto en hardware como en software, en el entrenamiento. Según (Serrano, A.; Fialho, C., 2003), los tres principales desafíos de la GC son:

- Construir una infraestructura que permita la creación / obtención y el uso del conocimiento;

- Fomentar una cultura que estimule la partilla del conocimiento;

- Administrar resultados

Añade que el cambio organizacional, enmarcado por la misión, identidad y ética de la organización, puede ocurrir al nivel de tres dominios:

- Actividades;

- Estructura;

- Comportamiento organizacional.

El establecimiento de una atmósfera amigable con la Gestión del Conocimiento - GC, aumenta la conciencia de la necesidad de compartir conocimiento en la organización, así como la voluntad de interactuar. Los recursos cedidos por la organización también integran el contexto favorable a la participación de los miembros, y este apoyo es revelado, por ejemplo, por la aceptación de la Gestión de Topo al ceder tiempo para la realización de las reuniones, por la valorización pública de los beneficios que la Comunidad ha traído a la organización, por la liberación de recursos (que pueden ser revertidos en recompensas o incluso destinados a financiar su participación en congresos, talleres), entre otros. La participación de expertos en el ámbito de la comunidad fue resaltada por Wenger (Neves, Ana, 2018), (Preece, Jenny, 2000) y (Wenger, Etienne; Mcdermott, R.; Snyder, W. M., 2002a).Los expertos contestan cuestiones específicas, dan consejos, ayudan a dar legitimidad a la comunidad y atraen a otras personas clave para la comunidad.

Por el análisis de varios Documentos y también de acciones que asistimos podremos decir que la COP embrionaria del trabajo Colaborativo en la temática de la Seguridad y la Salud en el Trabajo tiene su fase Potencial y de crecimiento teniendo el Apoyo Incondicional de la Gestión de Topo, un liderazgo fuerte en la Comunidad y un experto en el ámbito, una Cultura Positiva que se caracterizó 
por la valorización del intercambio de conocimientos en el ámbito de la Prevención de riesgos laborales.

\section{Fases de desarrollo de las CoP de la WIKINIAV}

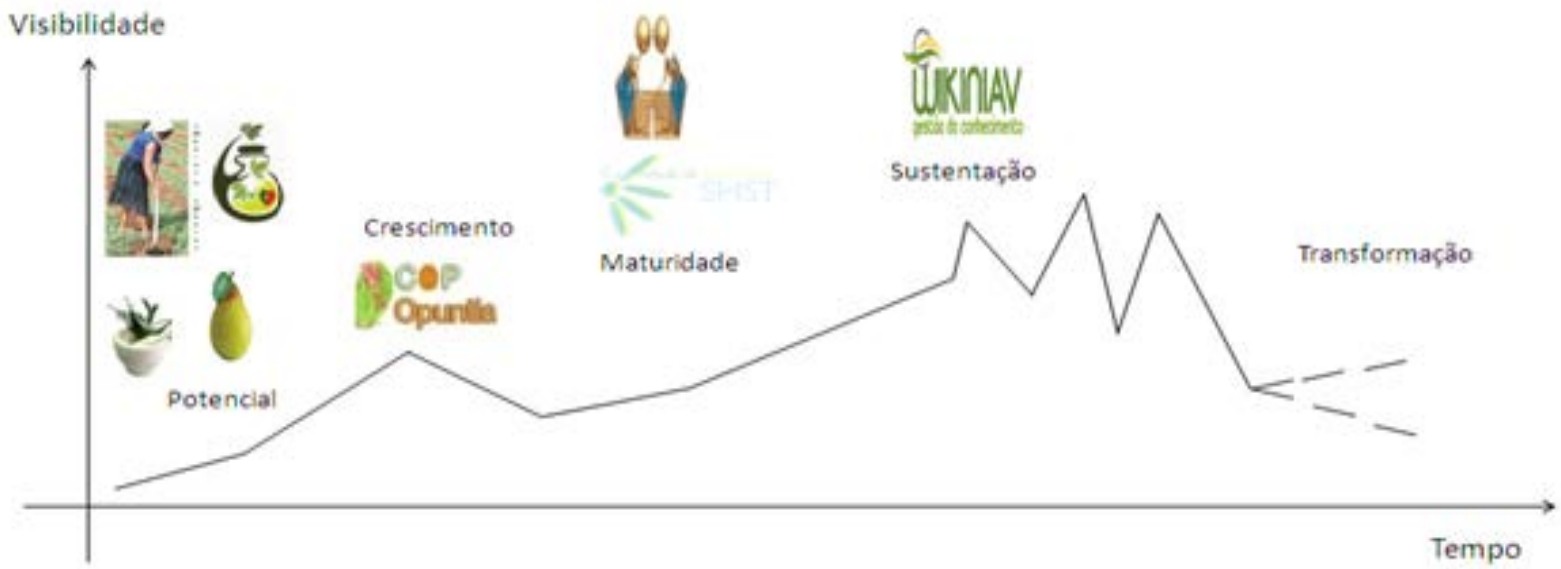

Ilustración 13 - Fases de desarrollo de las CoP de la WIKINIAV

Fuente: (Flor, C., 2015)

Se puede observar (ilustración 13) que la gran Comunidad WIKINIAV alberga 7 Comunidades en varias fases de desarrollo:

Fase 1 - En la fase inicial o potencial, la Comunidad es lanzada oficialmente y provoca la entrada de nuevos miembros

Comunidad de intercambio de Saberes y Sabores de la Aceituna y del Aceite Portugués

Comunidad de intercambio de Saberes y Sabores de las Mujeres en la Agricultura

Comunidad de intercambio de Saberes y Sabores de la Pera Roca

Comunidad de intercambio de conocimiento sobre Plantas Melíferas, Aromáticas y Medicinales.

\section{Fase 2-En la fase de crecimiento}

Comunidad de intercambio de Saberes del Higo de la India

\section{Fase 3 - En la fase de madurez}


Comunidad de intercambio de Buenas Prácticas SHST

Comunidad de resolución de problemas entre moderadores de la WIKINIAV

\section{Fase 4 - En la fase de sustentación}

Comunidad de intercambio de conocimiento WIKINIAV

\section{Fase 5 - Fase de transformación}

De 2008 a 2011 esta Comunidad pasó por la fase de madurez y sostenimiento y apesar de los cambios organizacionales y de la Organización pasar por un período muy complicado la Comunidad permanece.

En 2012 la CoPGAPEAN entra en una nueva dinámica y se transforma, hay un nuevo cambio en las jerarquías de primer nivel y se da la posibilidad de invertir en una plataforma de trabajo colaborativo, la CoP amplía sus fronteras y promueve la apertura de otras Comunidades en el ámbito de actuación del Instituto y en el período de 2012 a 2014 es un período muy favorable al trabajo de la Comunidad de compartir Buenas Prácticas SST. En 2015 debido a nuevos cambios en la Gestión de Topo encontramos una Administración de Topo inhibidora y la Comunidad entra en una fase de desarrollo

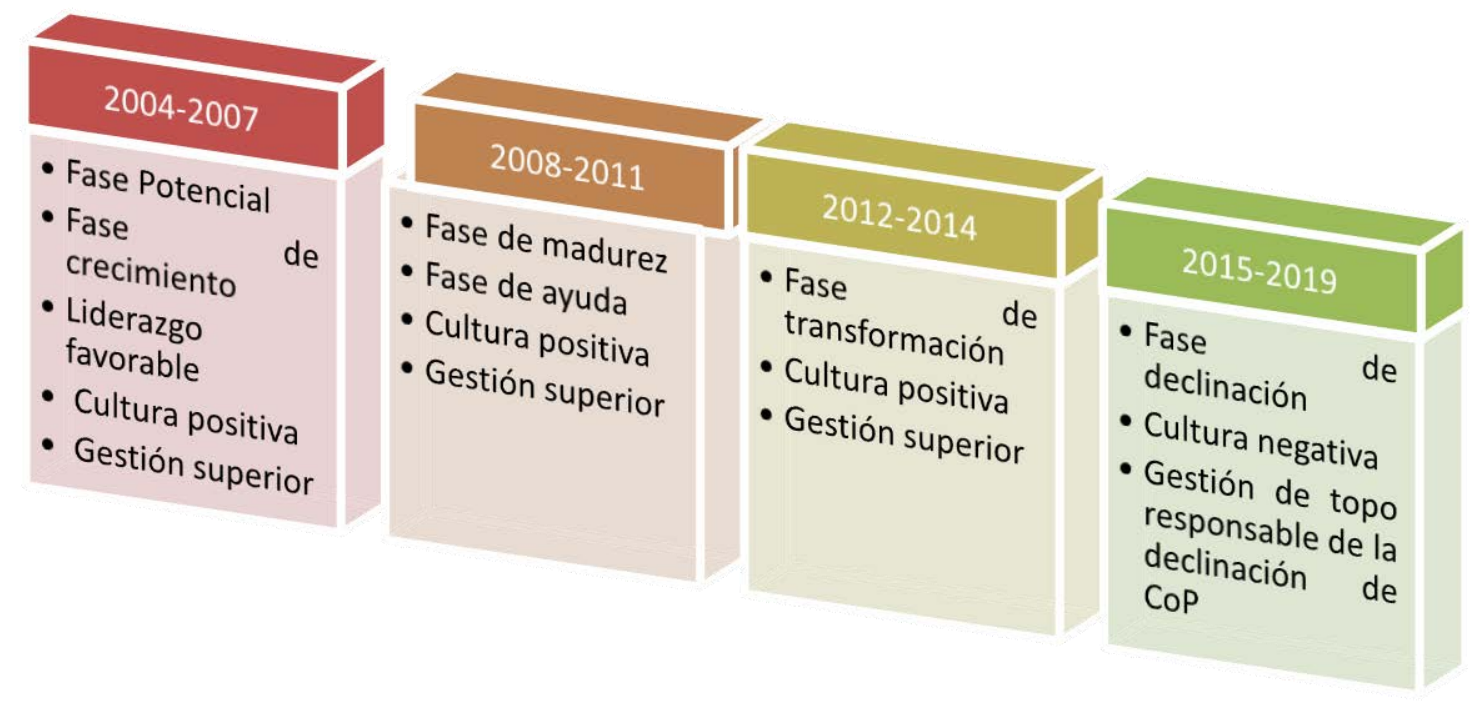

Ilustración 28 - Fases de desarrollo de las CoP

Fuente: Desarrollo propio 
La principal disminución observada en nuestro análisis se centra en (2015-2019), y no existe un clima organizacional positivo para compartir en el campo de la prevención de riesgos laborales. de los empleados / empleados de la organización renacen en la organización, la Comunidad que se forma ha perdido su espíritu. Sin embargo, en términos legislativos a principios del año 2019 salió una legislación centrada en la administración pública y aquí está nuestra esperanza.

El XXI Gobierno Constitucional asumió el compromiso de revalorizar el trabajo en funciones públicas y de fortalecer la Administración, en el marco de la reforma agraria, Público, promoviendo su eficiencia y sostenibilidad y proporcionando condiciones de trabajo dignas para sus profesionales.

De acuerdo con la ley presupuestaria estatal de 2019 , en su artículo n. ${ }^{\circ} 24^{\circ}$, el gobierno desarrolla una red colaborativa en la gestión pública, que apoya la implantación de sistemas de salud y seguridad en el trabajo en la administración pública, prevalencia de un enfoque preventivo y gestión integrada de riesgos profesionales - A través de la transferencia de conocimientos y el intercambio de buenas prácticas. "

Implementar servicios de SST de referencia en toda la AP, de forma colaborativa; Capacitar los servicios públicos para la implementación y funcionamiento de los servicios SST; Punto 3-Crear una red colaborativa (Red) con el objetivo principal de promover y reforzar la aplicación del régimen legal de SST en la Administración Pública hasta el final de 2020, a través de la implementación del Plan de Acción.

Analizando el extracto presentado en la( ilustración 28), podremos decir que todo el trabajo en dos proyectos de investigación que apuestan en el intercambio de conocimientos en colaboración y formato innovador de comunidades de práctica sirven ciertamente para apoyar un proyecto de gran envergadura para la Administración Pública portuguesa y ver la transformación de la CoP de buenas prácticas compartir SST en una CoP ampliada a toda la AP. 


\section{PRESIDÊNCIA DO CONSELHO DE MINISTROS}

\section{Resolução do Conselho de Ministros n. ${ }^{\circ}$ 28/2019}

O XXI Governo Constitucional assumiu o compromisso de revalorizar o trabalho em funções públicas e de fortalecer a Administração Pública, promovendo a sua eficiência e sustentabilidade e proporcionando condições de trabalho dignas para os seus profissionais.

As boas condições de trabalho, nas suas componentes físicas, organizacionais e psicossociais, são essenciais para a satisfação dos trabalhadores e para a promoção da segurança, saúde e bem-estar no trabalho, influenciando de forma inequívoca os seus desempenhos.

2 - Determinar que o Plano SST-AP tem como objetivo geral operacionalizar o regime legal de Segurança e Saúde no Trabalho (SST) na Administração Pública (AP) até final de 2020 e como objetivos específicos:

a) Implementar serviços de SST de referência em toda a AP, de forma colaborativa;

b) Capacitar os serviços públicos para a implementação e funcionamento de serviços SST,

c) Executar planos de segurança e saúde ocupacionais para a AP nas diferentes áreas governativas;

d) Desenvolver, testar e replicar medidas inovadoras no domínio da SST.

3 - Criar uma rede colaborativa (Rede) com o objetivo principal de promover e reforçar a aplicação do regime legal de SST na Administração Pública até ao final de 2020, através da implementação do Plano de Ação.

4 - Determinar que a Rede é coordenada pelo membro do Governo responsável pela área do Emprego Público, em articulação com os membros do Governo responsáveis pelas áreas do emprego e da saúde.

5 - Determinar que integram a Rede:

a) $\mathrm{O}$ inspetor-geral da Autoridade para as Condições do Trabalho;

b) O diretor-geral da Direção-Geral da Saúde;

c) O diretor-geral da Direção-Geral da Administração e do Emprego Público (DGAEP);

d) O diretor-geral da Direção-Geral da Qualificação dos Trabalhadores em Funções Públicas;

Figura 15 - Normas legislativas de 2019

Fuente: Diário da República Portuguesa 
Doctorado en Salud, Discapacidad, Dependencia y Bienestar

\begin{tabular}{|c|c|c|c|}
\hline 2009-2014 & Alineación & Soporte de dirección & Cultura \\
\hline \multicolumn{4}{|l|}{ Objetivos a corto o medio plazo } \\
\hline \multicolumn{4}{|l|}{ Creación y desarrollo de la CoP } \\
\hline \multicolumn{4}{|l|}{$\begin{array}{l}\text { Definición de métodos de interacción de } \\
\text { CoP }\end{array}$} \\
\hline \multicolumn{4}{|l|}{ Definición de la estructura de la CoP } \\
\hline \multicolumn{4}{|l|}{$\begin{array}{l}\text { Definición de estrategias y planes de } \\
\text { acción para alcanzar los objetivos de la } \\
\text { CoP }\end{array}$} \\
\hline \multicolumn{4}{|l|}{ Presentación pública de la CoP } \\
\hline \multicolumn{4}{|l|}{ Apoyo y participación de la dirección } \\
\hline \multicolumn{4}{|l|}{$\begin{array}{l}\text { Actividades diarias y de flexibilización } \\
\text { de la CoP }\end{array}$} \\
\hline \multicolumn{4}{|l|}{ Promoción de la CoP en la organización } \\
\hline \multicolumn{4}{|l|}{$\begin{array}{l}\text { Disponibilidad de recursos para los } \\
\text { miembros de la CoP }\end{array}$} \\
\hline \multicolumn{4}{|l|}{$\begin{array}{l}\text { Disponibilidad de recursos para la } \\
\text { estructura del CoP }\end{array}$} \\
\hline \multicolumn{4}{|l|}{$\begin{array}{l}\text { Mejores prácticas en la gestión del } \\
\text { conocimiento }\end{array}$} \\
\hline \multicolumn{4}{|l|}{$\begin{array}{l}\text { Estímulo de la organización para que las } \\
\text { personas compartan conocimientos }\end{array}$} \\
\hline \multicolumn{4}{|l|}{$\begin{array}{l}\text { Reconocimiento por la organización de } \\
\text { la importancia de la utilidad de la CoP }\end{array}$} \\
\hline $\begin{array}{l}\text { Transparencia de la información } \\
\text { generada por la CoP }\end{array}$ & & & \\
\hline
\end{tabular}

\section{Refuerzo facilitador}

Matriz 2 - Elementos de la práctica x parámetros individuales de cada práctica 2009 a 2014

Fuente: Desarrollo propio 
Doctorado en Salud, Discapacidad, Dependencia y Bienestar

\begin{tabular}{|c|c|c|c|c|}
\hline Prácticas 2009-2014 & Política & $\begin{array}{l}\text { Coordinación } \\
\text { CoP }\end{array}$ & Tecnología & Desarrollo \\
\hline \multicolumn{5}{|l|}{ Existencia de una práctica de comunicación } \\
\hline \multicolumn{5}{|l|}{ Un facilitador o líder que conduzca a CoP } \\
\hline \multicolumn{5}{|l|}{$\begin{array}{l}\text { Las actividades de desarrollo promueven la } \\
\text { interacción personal }\end{array}$} \\
\hline \multicolumn{5}{|l|}{$\begin{array}{l}\text { Reconocimiento formal del uso y la } \\
\text { participación }\end{array}$} \\
\hline \multicolumn{5}{|l|}{$\begin{array}{l}\text { Participación en la evaluación de la CoP de los } \\
\text { empleados }\end{array}$} \\
\hline \multicolumn{5}{|l|}{$\begin{array}{l}\text { Apoyo en la integración e implicación de } \\
\text { nuevos miembros }\end{array}$} \\
\hline \multicolumn{5}{|l|}{$\begin{array}{l}\text { El CoP permite la adquisición de experiencia } \\
\text { individual }\end{array}$} \\
\hline \multicolumn{5}{|l|}{$\begin{array}{l}\text { CoP permite la interacción entre diferentes } \\
\text { grupos profesionales }\end{array}$} \\
\hline \multicolumn{5}{|l|}{$\begin{array}{l}\text { La existencia de una fuerte coordinación en la } \\
\text { CoP }\end{array}$} \\
\hline \multicolumn{5}{|l|}{ Inversión en formación de personas GC } \\
\hline \multicolumn{5}{|l|}{$\begin{array}{l}\text { Facilitar el entorno de intercambio de } \\
\text { conocimientos }\end{array}$} \\
\hline \multicolumn{5}{|l|}{ libertad de expresar ideas } \\
\hline \multicolumn{5}{|l|}{$\begin{array}{l}\text { Proceso de facilitador regulatorio para nuevos } \\
\text { miembros }\end{array}$} \\
\hline \multicolumn{5}{|l|}{ Uso de la tecnología de soporte } \\
\hline \multicolumn{5}{|l|}{ Uso del software de uso compartido de GC } \\
\hline Fácil de usar existencia de herramientas & & & & \\
\hline
\end{tabular}

reforço facilitador

Matriz 3 - Parámetros individuales de cada práctica (Política, Coordinación de la CoP, Tecnología, Desarrollo) refuerzo facilitador

Fuente: Desarrollo propio 
La construcción de las (matrices 2 y 3 )nos permitió tener la percepción del refuerzo positivo de los elementos de cada práctica, siguiendo estos elementos responsables del éxito o el fracaso de cada una de las prácticas consideradas esenciales y en la línea horizontal las prácticas esenciales para el refuerzo positivo. Cuando cruzamos esta información marcamos el refuerzo positivo en verde. Aquí tenemos un proceso de análisis cualitativo pero muy fácil para comprender qué salió bien o mal y para qué apostamos. CoP no pierdas el ritmo. Hemos preparado la(matriz 2) para que podamos comprender fácilmente el refuerzo facilitador de los elementos de cada una de las prácticas que son esenciales para obtener resultados éxito, por lo que la (matriz de 2) que se cruza con los elementos / acciones que fueron responsables del refuerzo positivo: Alineamiento y estructuración; Apoyo de la alta dirección y cultura de la Organización. En la práctica relacionada con el alineamiento/ estructuración, hemos observado un refuerzo facilitador debido al desarrollo de elementos / acciones cruciales, tales como: establecimiento de objetivos a corto y mediano plazo, definición de métodos de interacción; definición de la estructura de la CoP, presentación pública de la CoP y la definición de estrategias y planes de acción para lograr los objetivos. Con respecto a la alta dirección / apoyo de la gerencia, el refuerzo fue positivo y se relacionó con acciones tales como: participación y participación y presentación pública de la $\mathrm{CoP}$, dos recursos disponibles para los miembros y la estructura de la CoP. Por el análisis de la ( matriz 3) matriz podemos concluir que hubo un ambiente facilitador de la partilla del conocimiento, libertad para expresar ideas y un proceso facilitador de registro de nuevos miembros que quisieran entrar en la dinámica. También hubo interacciones entre diferentes grupos profesionales. La existencia de Un facilitador / Líder fuerte y comprometido con la dinámica de facilitación y entrenamiento de los miembros de la CoP fue facilitador de los resultados presentados en la tabla siguiente aumentando la confianza entre los miembros, el sentimiento de Pertenencia a la Utilidad y haciendo con que los miembros contribuyesen cada vez más. En el parámetro de la Práctica del Desarrollo observamos que el saber no es sólo una cuestión individual, es también una cuestión de intercambio, de aprendizado con los demás o de uno con otro, de su experiencia. Esta comunidad posibilitó además de la experiencia individual la interacción entre diferentes grupos profesionales, fomentó interacciones y relaciones basadas en el respeto mutuo y la confianza, alentando la disposición a compartir ideas. También hubo una gran inversión en el entrenamiento 


\section{de los miembros de la comunidad de los animadores de prevención y la existencia y permanencia} de una coordinación fuerte.

\begin{tabular}{|c|c|c|c|c|}
\hline 2005-2014 & Confianza & Contribución & $\begin{array}{l}\text { Sentimiento de } \\
\text { Pertenencia }\end{array}$ & Utilidad \\
\hline $\begin{array}{l}\text { Alineación de } \\
\text { estructuración }\end{array}$ & $\begin{array}{c}\text { Definición de métodos de } \\
\text { interacción entre los participantes } \\
\text { de la CoP }\end{array}$ & $\begin{array}{l}\text { Definición de estrategias } \\
\text { y planes de acción para } \\
\text { alcanzar los objetivos de } \\
\text { la CoP }\end{array}$ & $\begin{array}{c}\text { Definición de } \\
\text { métodos de interacción entre } \\
\text { los participantes de la CoP }\end{array}$ & $\begin{array}{c}\text { Establecer objetivos a } \\
\text { corto y largo plazo }\end{array}$ \\
\hline $\begin{array}{l}\text { Apoyo al } \\
\text { liderazgo }\end{array}$ & $\begin{array}{l}\text { Apoyo y participación de la } \\
\text { dirección }\end{array}$ & $\begin{array}{l}\text { Disponibilidad de } \\
\quad \text { Recursos }\end{array}$ & $\begin{array}{c}\text { Flexibilización de las } \\
\text { actividades y actividades } \\
\text { diarias de la CoP }\end{array}$ & $\begin{array}{c}\text { Promoción de la CoP } \\
\text { por la Dirección }\end{array}$ \\
\hline Evaluación & $\begin{array}{l}\text { Existencia de herramientas que } \\
\text { ha permitido la retroalimentación } \\
\text { de los miembros sobre la } \mathrm{CoP}\end{array}$ & $\begin{array}{c}\text { Exposición de los } \\
\text { beneficios de éxito } \\
\text { proporcionados a las } \\
\text { partes interesadas de la } \\
\text { CoP }\end{array}$ & $\begin{array}{l}\text { Exposición de beneficios e } \\
\text { historias de éxito } \\
\text { proporcionadas a las partes } \\
\text { interesadas de la CoP }\end{array}$ & $\begin{array}{c}\text { Exposición de } \\
\text { beneficios e historias } \\
\text { de éxito } \\
\text { proporcionadas a los } \\
\text { stackeholders de la } \\
\text { CoP }\end{array}$ \\
\hline Cultura & $\begin{array}{l}\text { Estímulo de la organización para } \\
\text { que los empleados compartan sus } \\
\text { conocimientos }\end{array}$ & $\begin{array}{l}\text { Reconocimiento de la } \\
\text { Organización y } \\
\text { importancia de la CoP }\end{array}$ & $\begin{array}{l}\text { Estímulo de la organización } \\
\text { para que los empleados } \\
\text { compartieran conocimientos }\end{array}$ & $\begin{array}{c}\text { Estímulo } \\
\text { organizacional para } \\
\text { partilla de } \\
\text { conocimientos }\end{array}$ \\
\hline Desarrollo & $\begin{array}{l}\text { Existencia y permanencia de un } \\
\text { facilitador fuerte }\end{array}$ & $\begin{array}{c}\text { La CoP permite la } \\
\text { interacción de diferentes } \\
\text { GP }\end{array}$ & $\begin{array}{c}\text { Inversión en } \\
\text { personas/formación GC }\end{array}$ & $\begin{array}{c}\text { Inversión en } \\
\text { personas/formación } \\
\text { GC }\end{array}$ \\
\hline $\begin{array}{l}\text { Gestión de la } \\
\text { CoP }\end{array}$ & $\begin{array}{c}\text { Facilitador/líder que llevó a cabo } \\
\text { un buen progreso de la CoP }\end{array}$ & $\begin{array}{c}\text { Existencia de una } \\
\text { práctica de } \\
\text { comunicación en la CoP }\end{array}$ & $\begin{array}{l}\text { Desarrollo de actividades } \\
\text { para la interacción } \\
\text { personal de la CoP }\end{array}$ & $\begin{array}{l}\text { Desarrollo de la } \\
\text { formación y apoyo } \\
\text { continuo }\end{array}$ \\
\hline Política & $\begin{array}{c}\text { Medio ambiente facilitando la } \\
\text { participación de la CG }\end{array}$ & $\begin{array}{l}\text { Liberdade para } \\
\text { expressar las ideias sin } \\
\text { juicio de valor }\end{array}$ & $\begin{array}{c}\text { Ambiente que } \\
\text { facilitara la partilla GC }\end{array}$ & $\begin{array}{c}\text { Ambiente que } \\
\text { facilitara la partilla } \\
\text { GC }\end{array}$ \\
\hline Tecnología & $\begin{array}{l}\text { Uso de infraestructuras y } \\
\text { herramientas de GC }\end{array}$ & $\begin{array}{l}\text { Utilización de tecnología } \\
\text { de soporte }\end{array}$ & $\begin{array}{l}\text { Uso de un software de } \\
\text { intercambio de archivos }\end{array}$ & $\begin{array}{l}\text { Promoción de debates } \\
\text { e intercambio de } \\
\text { ideas/participación }\end{array}$ \\
\hline
\end{tabular}

Matriz 4 - Matriz de Prácticas que refuerza los resultados de Éxito

Fuente: Desarrollo propio

Comunidad@Buenas Prácticas de Seguridad, Salud e Calidad de Vida en el trabajo INIAV 
El análisis de las (matrices 2 y 3) nos lleva al análisis de la (matriz 4) que cruza los resultados con las prácticas que ayudaron fuertemente en el mantenimiento de la vida de la CoP. En la intersección entre las prácticas esenciales para obtener resultados éxito, podemos leer el elemento / acción de la práctica que ayudó a los resultados favorables para el intercambio de conocimientos en el dominio de la Comunidad, siendo estos resultados (Confianza, Contribución, Sentimiento de pertenencia, Utilidad. Estas matrices resultaron del análisis realizado en el anexo (BI; BII; BIII; BIV; BIV; BVI)

\section{Comunidad y Apoyo de la gestión superior (Topo)}

Hubo implicación y compromiso de la gestión superior en las diferentes fases de la CoP de otra forma este proyecto no tendría piernas para andar. La implicación de la Gestión superior se ha revelado en varios niveles(ilustración 29). Quier sea en la explicitación de los beneficios del compartir el conocimiento y buenas prácticas en la prevención de riesgos laborales, como en el compromiso con la implementación del proyecto.

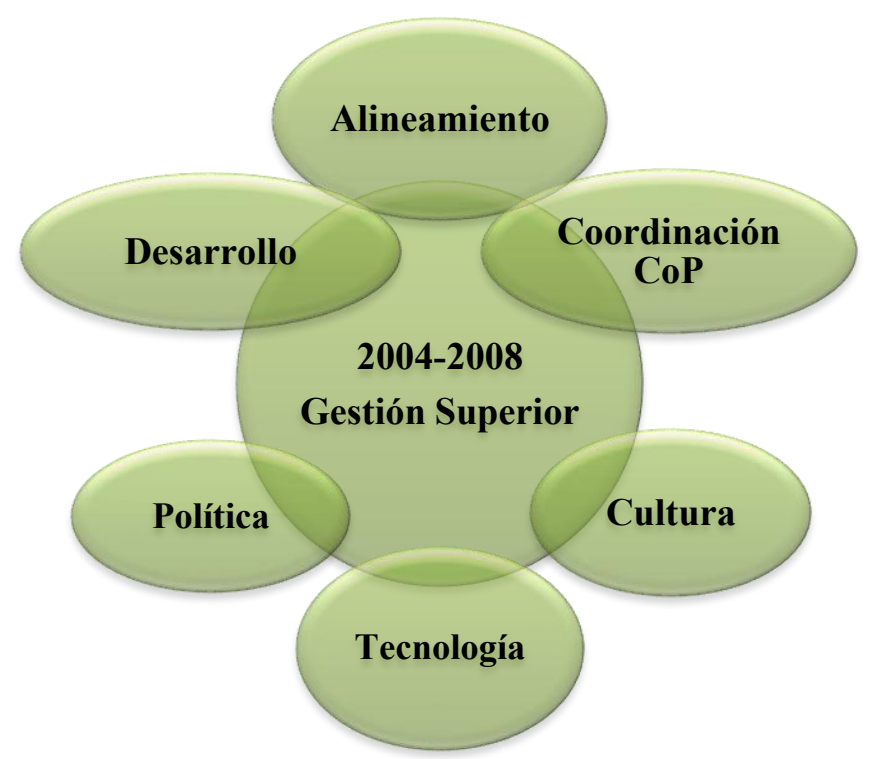

lustración 29 - Influencia Positiva de la Gestión de Topo 2004-2008

Fuente: Desarrollo propio

Comunidad@Buenas Prácticas de Seguridad, Salud e Calidad de Vida en el trabajo INIAV

"Factores críticos de éxito" 


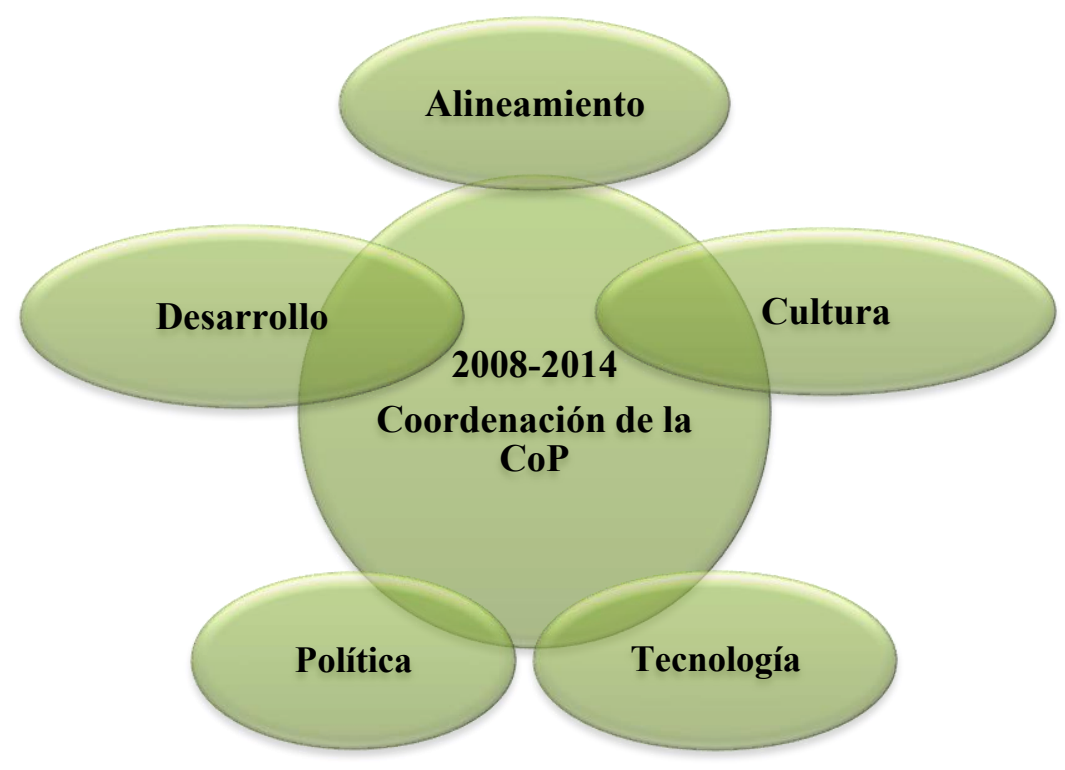

Ilustración 30 - Influencia positiva de la Coordinación de la CoP 2008-2014

Fuente: Desarrollo propio

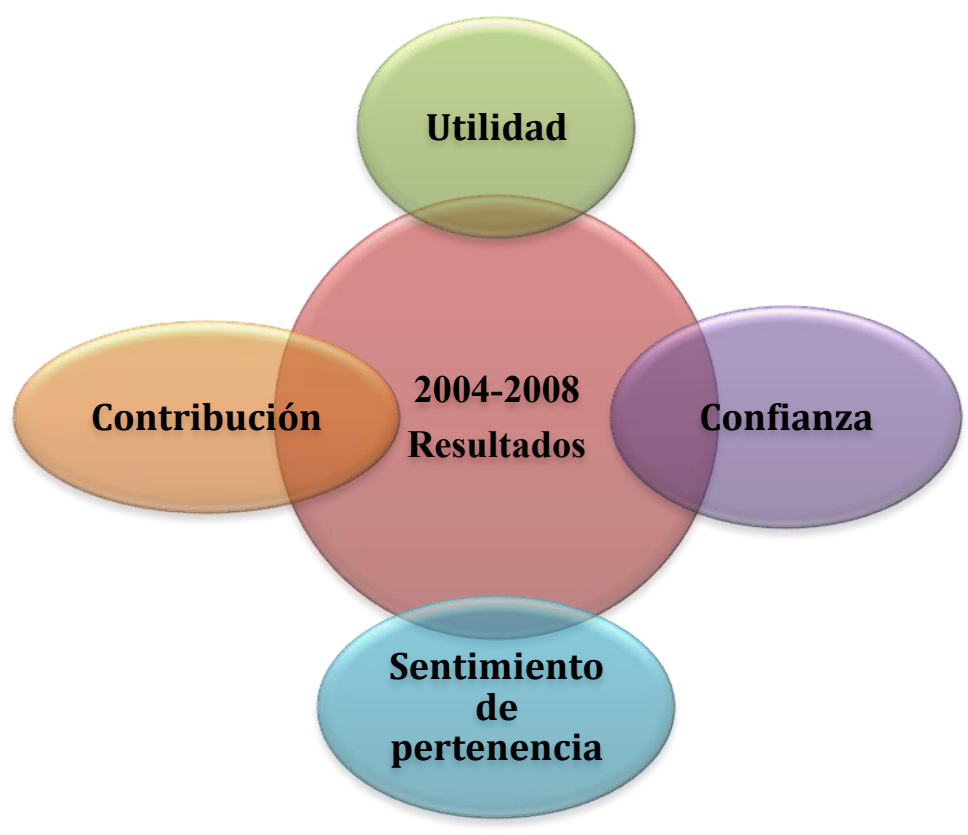

Ilustración 31- Resultados de éxito de CoP 2004-2008

Fuente: Desarrollo propio

Comunidad@Buenas Prácticas de Seguridad, Salud e Calidad de Vida en el trabajo INIAV "Factores críticos de éxito" 


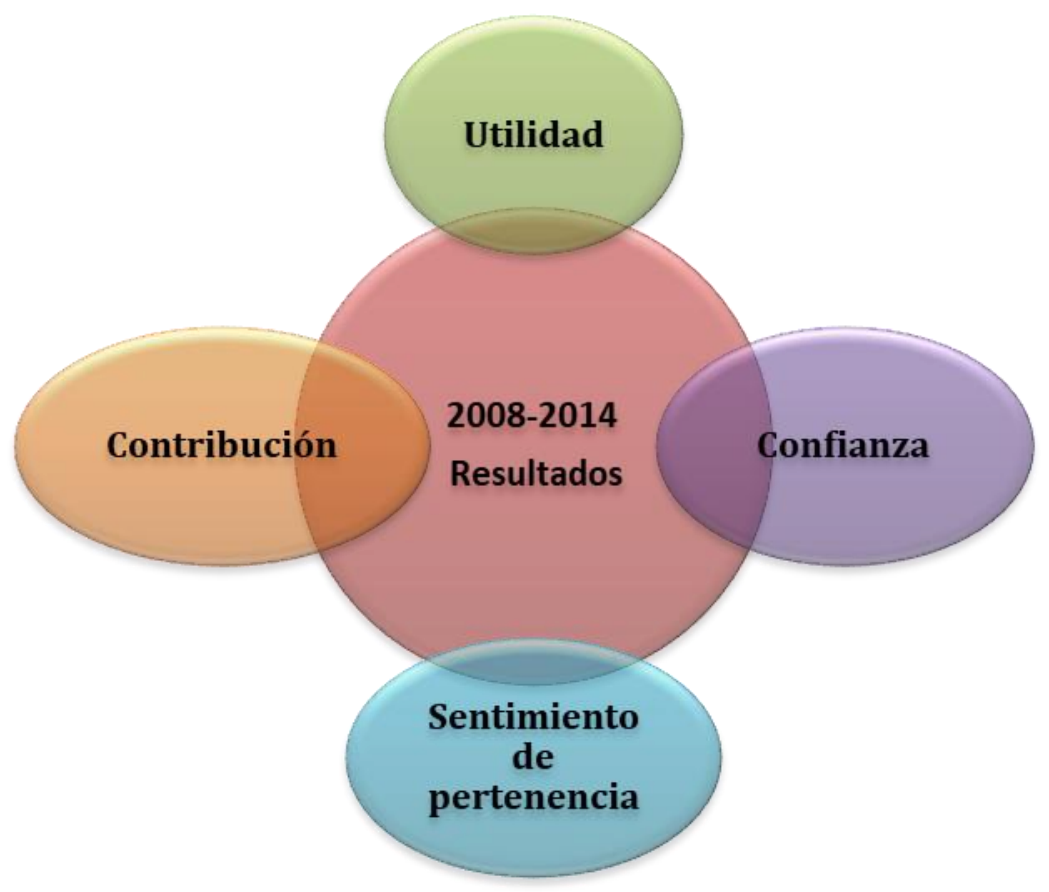

Ilustración 32 - Resultados de éxito CoP 2008-2014

Fuente: Desarrollo propio 
Doctorado en Salud, Discapacidad, Dependencia y Bienestar

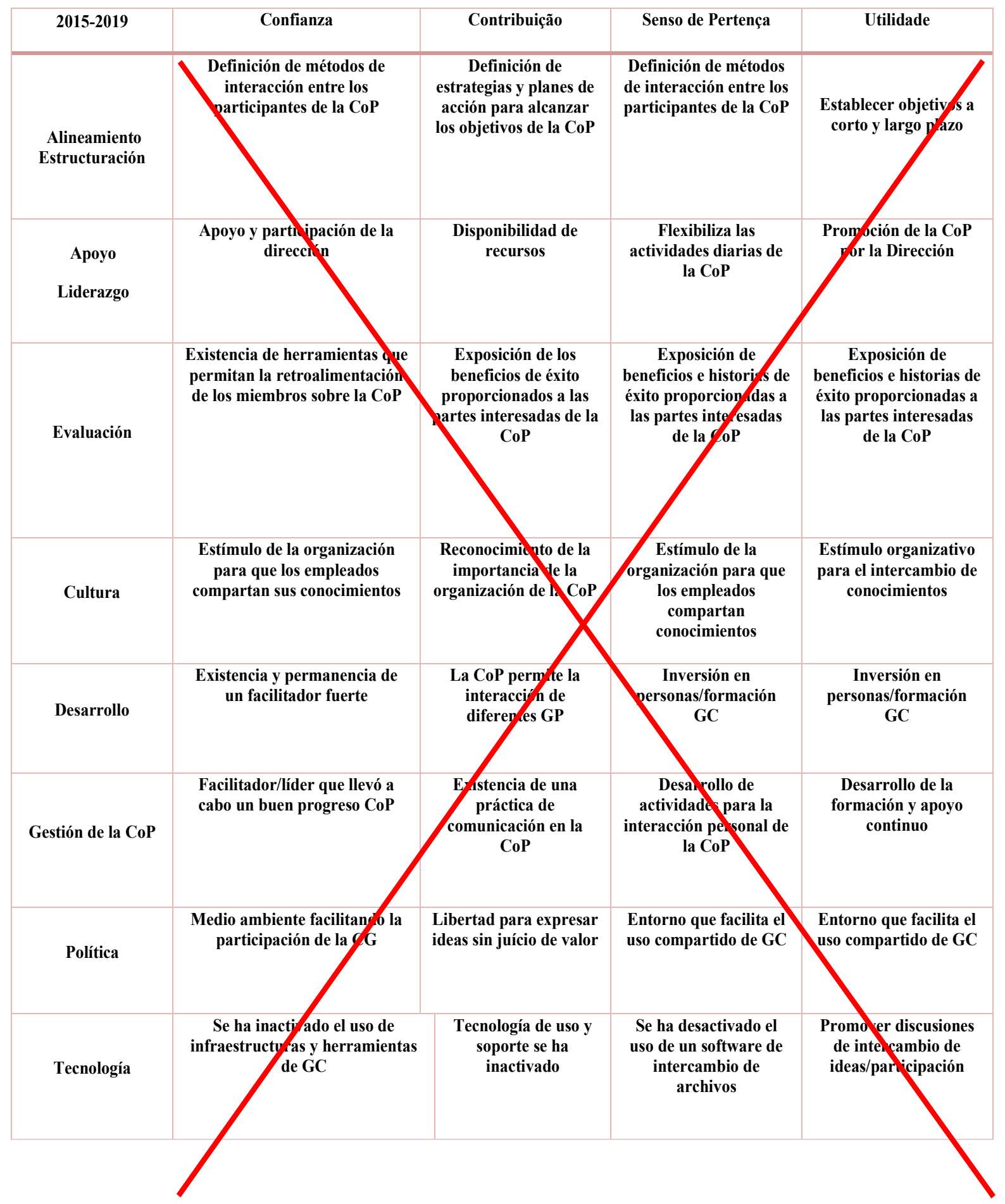

Matriz 5 - Prácticas esenciales no implementadas en 2015 - 2019 que resultaron en el fracaso de la CoP

Fuente: Desarrollo Propio

Comunidad@Buenas Prácticas de Seguridad, Salud e Calidad de Vida en el trabajo INIAV

"Factores críticos de éxito" 
Analizando la matriz 5, podemos ver que nos enfrentamos a un período en el que las prácticas esenciales de intercambio de conocimientos en el contexto de SST no existían, lo que quiero decir en resultados no exitosos del trabajo colaborativo. Zboralski (2009), en sus consideraciones sobre la influencia del apoyo organizacional en las CoP, afirma que el amparo de la organización es de gran importancia para el éxito de las iniciativas en el contexto de la gestión del conocimiento.

\begin{tabular}{|c|c|c|c|}
\hline 2015-2019 & Alineación & $\begin{array}{l}\text { Soporte de } \\
\text { dirección }\end{array}$ & Cultura \\
\hline \multicolumn{4}{|l|}{ Objetivos a corto o medio plazo } \\
\hline \multicolumn{4}{|l|}{ Creación y desarrollo de la CoP } \\
\hline \multicolumn{4}{|l|}{ Definición de métodos de interacción de CoP } \\
\hline \multicolumn{4}{|l|}{$\begin{array}{l}\text { Definición de la estructura del CoP (administradores, } \\
\text { moderadores, líderes) }\end{array}$} \\
\hline \multicolumn{4}{|l|}{$\begin{array}{l}\text { Definición de estrategias y planes de acción para alcanzar los } \\
\text { objetivos de la CoP }\end{array}$} \\
\hline \multicolumn{4}{|l|}{ Presentación pública de la CoP } \\
\hline \multicolumn{4}{|l|}{ Apoyo y participación de la dirección } \\
\hline \multicolumn{4}{|l|}{ Actividades diarias y de flexibilización de la CoP } \\
\hline \multicolumn{4}{|l|}{ Promoción de la CoP en la organización } \\
\hline \multicolumn{4}{|l|}{ Disponibilidad de recursos para los miembros de la CoP } \\
\hline \multicolumn{4}{|l|}{ Disponibilidad de recursos para la estructura de la CoP } \\
\hline \multicolumn{4}{|l|}{ Mejores prácticas en la gestión del conocimiento } \\
\hline \multicolumn{4}{|l|}{$\begin{array}{l}\text { Estímulo de la organización para que las personas compartan } \\
\text { conocimientos }\end{array}$} \\
\hline \multicolumn{4}{|l|}{$\begin{array}{l}\text { Reconocimiento de la organización de la importancia de la utilidad } \\
\text { de la CoP }\end{array}$} \\
\hline Transparencia de la información generada por la CoP & & & \\
\hline
\end{tabular}

\section{Refuerzo Facilitador}

Matriz 6 - Elementos de la práctica x parámetros individuales de cada práctica

Fuente: Desarrollo propio
Refuerzo moderado

El establecimiento de un ambiente amigable con la Gestión del Conocimiento - GC, incluyendo la creación de Comunidades, aumenta la conciencia de la necesidad de compartir conocimiento en una organización, así como la voluntad de interactuar en las CoP. 
Además de la atmósfera, según (Zboralski, Katja, 2009), los recursos cedidos por la organización también integran el contexto favorable a la participación de los miembros, y este apoyo es revelado, por ejemplo, por la anuencia de la gerencia al ceder tiempo para la realización de las reuniones, por la valorización pública de los beneficios que la Comunidad ha aportado a la organización, cedencia de recursos. Ninguna de estas prácticas se ha evidenciado entre 2015 y 2019.

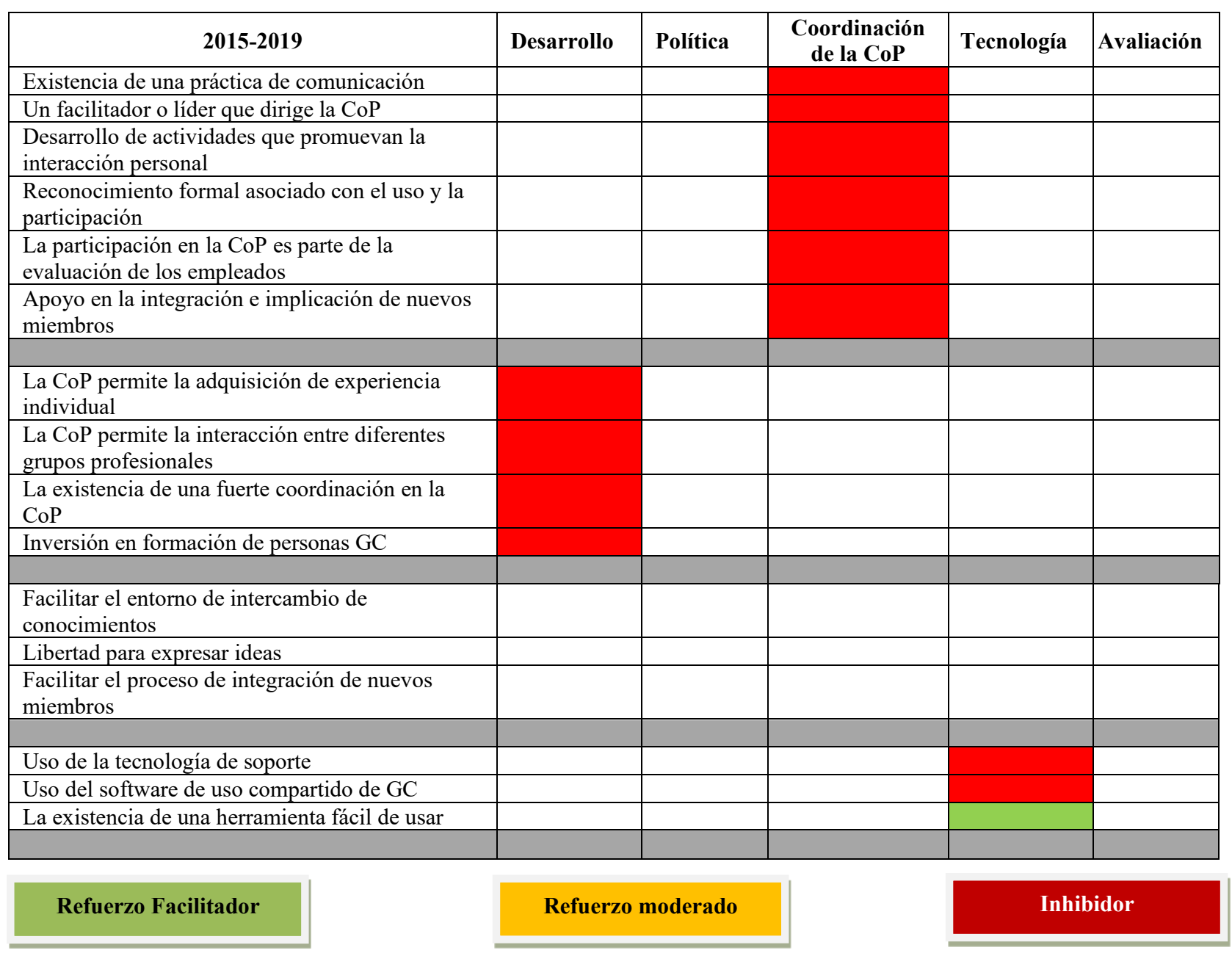

Matriz 7 - Elementos de la práctica x parámetros individuales de cada práctica

Fuente: Desarrollo propio

Por el análisis de las matrices 5 y 6 podemos concluir que los resultados en el período de (2015 a 2019) que podrían resultar en éxito para la Comunidad de Práctica de partilla de conocimientos en el ámbito de la seguridad y la salud en el trabajo como la Confianza-Contribución- Sentimiento de 
Pertenencia y Utilidad -no se verificaron lo que llevó al declive de la CoP, siendo el principal elemento de la práctica responsable de esta situación el hecho de haber fallado el apoyo de la gestión superior de la organización, esta práctica es crucial para que todas las demás pueden entrar en la dinámica de partilla Hubo una reversión de la cultura y la política, aunque la fase en que la tecnología estaba en el auge, en términos organizacionales no hubo la posibilidad de que cualquier CoP creciera o se mantuviera si la Gestión de Topo no fuera abierta y apoyara el trabajo colaborativo.

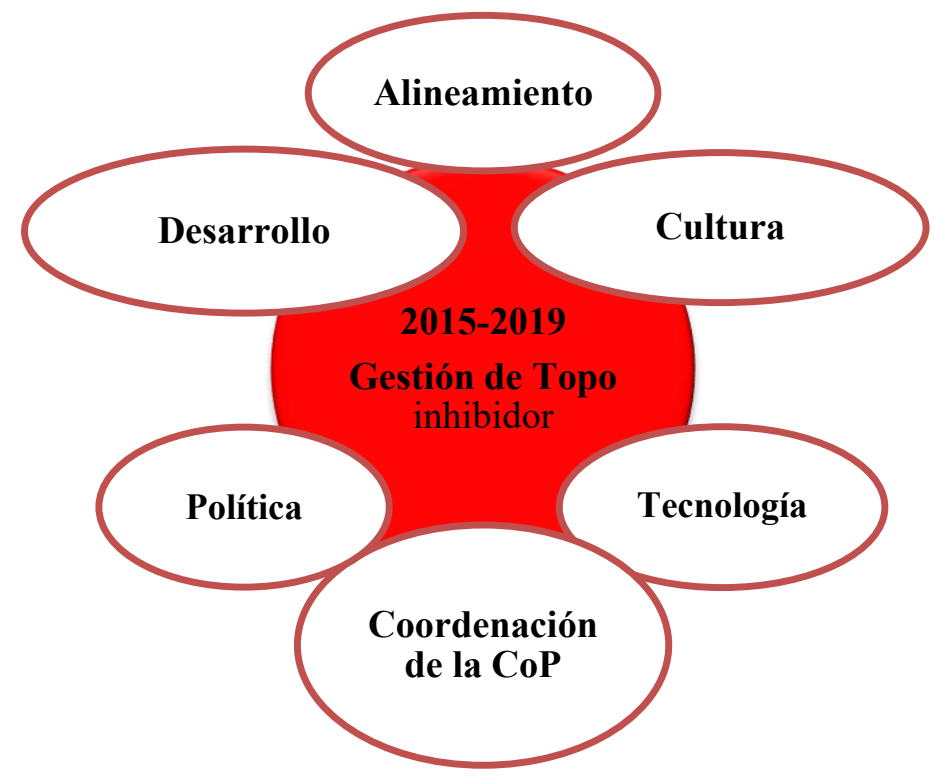

Ilustración 33 - Función de gestión superior 2015-2019

Fuente: Desarrollo propio

Analizando la (Ilustración 33), podemos concluir que no se desarrollaron en este período las prácticas esencias para dar origen a resultados que evidenciaran el buen funcionamiento y continuidad de la CoP. Los miembros de la CoP no se sintieron dispuestos a compartir sus conocimientos, no mostraron interés en la realización de eventos de la CoP, tampoco hubo participación individual con la $\mathrm{CoP}$ y no consideraron útil mejorar sus conocimientos y todo ello porque la Gestión de Topo fue inhibidora y resistente al trabajo colaborativo. 


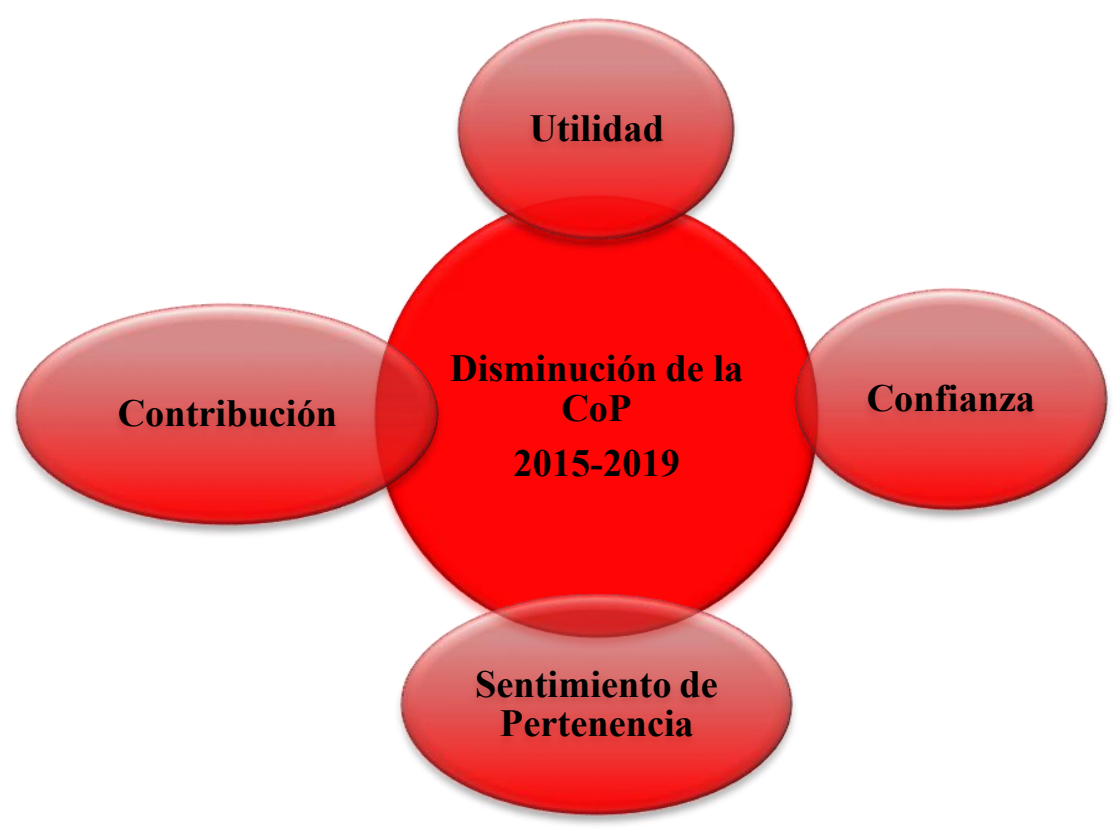

Ilustración 34 - Disminución de la CoP y resultados fallidos

Fuente: Desarrollo propio

Incluir el hábito de participar en la Comunidad de Prácticas en la rutina del trabajo implica un cambio de cultura. Una vez que la utilización de la Comunidad de Prácticas implica cambio de cultura, creación y mantenimiento de una infraestructura de soporte y dedicación parcial de la rutina de trabajo de la organización, la obtención y el mantenimiento del patrocinio es un factor crítico de éxito (Rosa Neto, J. R.; Vilanova, L.O. et al., 2006).

En el período entre 2015 y 2019 nos encontramos con un retroceso en el cambio de cultura de partilla, el hábito que existía fue bloqueado y que es crítico, este bloqueo es de la responsabilidad de la Gestión de Topo. La Organización de nuestro estudio se enfrenta al problema del envejecimiento de sus colaboradores y salida para la jubilación siendo también crítico todo el conocimiento tácito que se pierde con la salida de los mismos, pero la Gestión de Topo no considera eso relevante. La estructura organizacional influye en las actitudes de compartir el conocimiento de los colaboradores (Kim, S.; Lee, H., 2005). De acuerdo con (Chung, L. H., 2001), las estructuras organizativas más burocráticas y centralizadas tienden a reprimir la creación de conocimiento mientras que las flexibles y descentralizadas pueden alentar la partilla del conocimiento, 
especialmente el tácito en virtud de permitir una mayor interacción entre las personas. Según (Lahti, S.; Moilanen, R., 2004) el conocimiento tácito es uno de los puntos fuertes de los colaboradores más viejos y experimentados, presentando la capacidad de interpretar información relativa a la cual no existe regla formal de procesamiento. Hay un gran potencial en el conocimiento en su forma tácita. Compartir el conocimiento tácito entre colaboradores más jóvenes y mayores es uno de los principales desafíos de la gestión. (Lahti, S.; Moilanen, R., 2004) refieren en su estudio que el aprendizaje que ocurre entre colaboradores más jóvenes y mayores aumenta las competencias individuales y libera conocimiento tácito individual para la utilización de toda la organización. En las matrices 6 y 7 podemos observar la intercepción de los elementos de práctica / acciones que no existían y que inhibían las prácticas esenciales para obtener resultados éxito.

La elección de esta organización estuvo relacionada con la diversidad de actividades profesionales: Administrativa; Laboratorios (químicos) biológicos. Actividades de campo (Agricultura) y actividades de mantenimiento. En la ilustración 35 presentamos el esquema de nuestro análisis sobre (¿Cómo, cuándo y dónde nació la CoPGAPEAN)

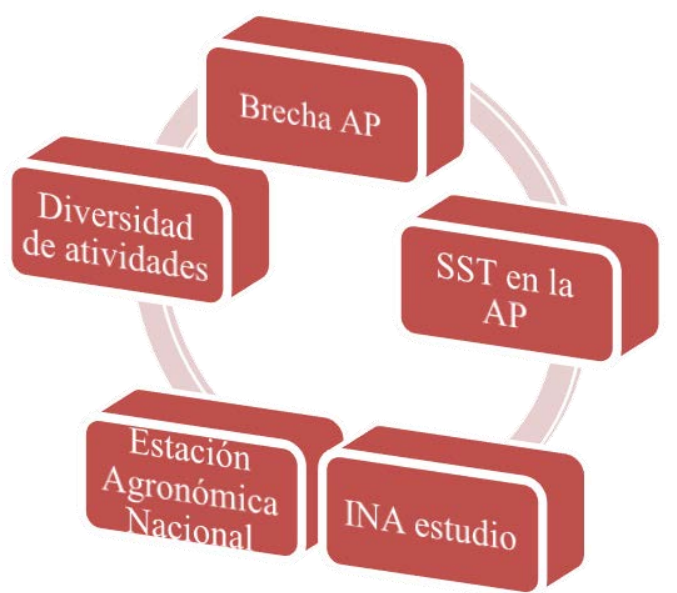

Ilustración 35 - Estrategia de Proyectos de Cultura de Seguridad

Fuente: Desarrollo propio

Después de escogida la Organización para realizar el estudio, el siguiente paso implicaría la gestión superior de la organización en estudio. Sin la implicación de la gestión de arriba el proyecto al 
principio no tendría piernas para caminar. A partir del momento en que la gestión de arriba acepta que el proyecto se desarrolle en la organización también decide involucrarse en la dinámica (Ilustración 36).

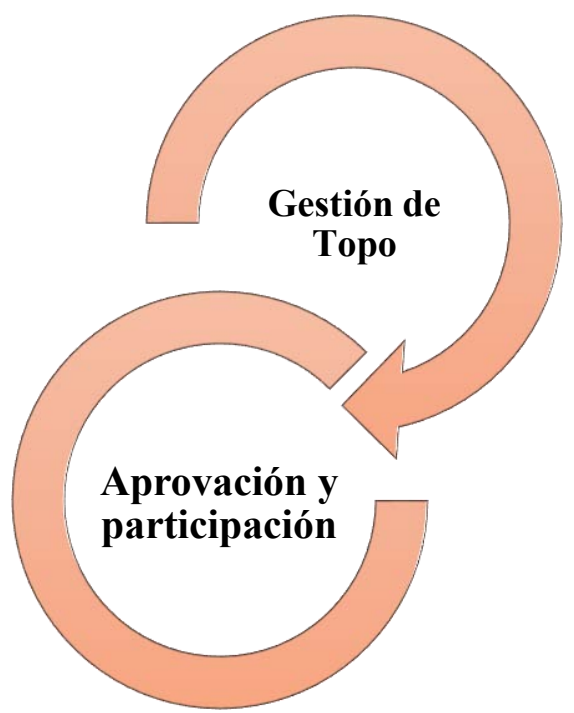

Ilustración 36 - Envolvimiento de la Gestión de Topo da EAN

Fuente: Desarrollo propio

Las organizaciones que participaron en el proyecto fueron el INA (Instituto Nacional de Administración), la EAN (Estación Agronómica Nacional) en toda la fase del proyecto y el CIS / ISCTE en la fase de diagnóstico tal como se muestra en la Ilustración 37.

INA: Departamento de Investigación y Desarrollo en el ámbito del Programa Sabáticas para la AP aprueba y apoya el proyecto en la temática de la HSST, recientemente alterada la nomenclatura para SST.

EAN: La organización donde se realiza el estudio fue una organización del sector público con diversidad de actividades profesionales, tenía todo lo que el proyecto necesitaba.

ISCTE: El centro de investigación social del ISCTE (Instituto Universitario de Lisboa) colaboraron en la aplicación de las herramientas de diagnóstico de la cultura de seguridad y de organización 
Sin estas alianzas el proyecto no tendría éxito. El INA al aprobar un proyecto en esta temática desencadena una gran preocupación para la implementación del sistema de Gestión de Prevención de Riesgos Laborales en la AP.
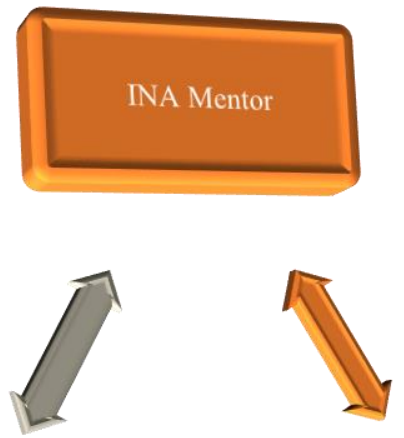

ISCTE Apoyo en el

diagnóstico

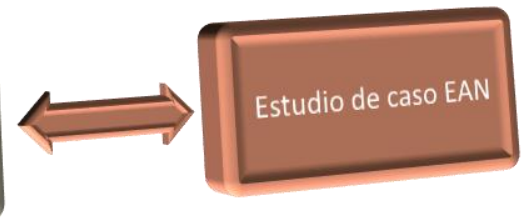

Ilustración 37 - Organizaciones involucradas no proyecto

Fuente: Desarrollo propio

Sin estas alianzas el proyecto no tendría éxito. El INA al aprobar un proyecto en esta temática desencadenó una gran preocupación para la implementación del sistema de Gestión de Prevención de Riesgos Laborales en la AP. Después de la participación del gestor de la organización, hicimos una alianza con el ISCTE, pues en el CIS Investigación Social) ya existían instrumentos de diagnóstico de la Cultura de Seguridad y Organizacional que serían facilitadores para un proceso de intervención después del análisis de los instrumentos aplicados compatibilizaron la Cultura de Seguridad y Organizacional.

Después del diagnóstico realizado a través de la metodología Qualiquantitativa (Entrevistas semiestructuradas y la encuesta ICOS (Encuesta de Cultura Organizacional y Seguridad) tuvimos 
acceso a la realidad de la situación y logramos, involucrando la gestión de arriba, percibir cuales son los grupos más favorables al cambio.

Así se percibía que tanto la gestión superior como la gestión intermedia sería asociada al proyecto, así como el grupo técnico-profesional tal como podemos observar en el esquema presentado en la (Ilustración 38).

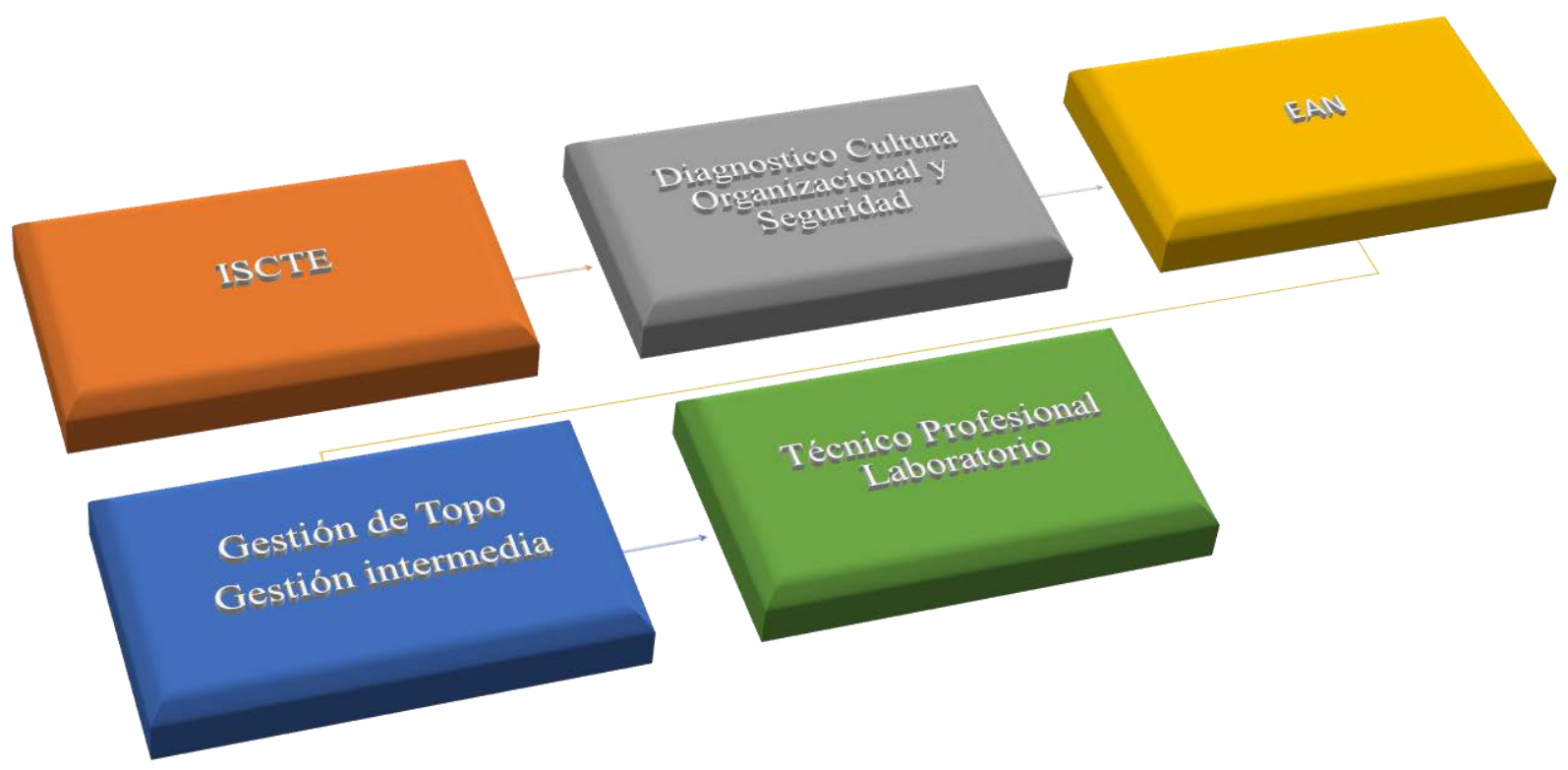

Ilustración 38 - Diagnóstico de la cultura de la salud y la seguridad

Fuente: Desarrollo propio

La gestión superior con todos los riesgos que podrían surgir de la aceptación de un proyecto de éstos en su organización, asumió correr los riesgos a favor del cambio y la relación con los jefes intermedios era muy favorable (ilustración 39).

En relación a todos los grupos profesionales, los técnicos profesionales de laboratorio son los que más vibraron con la temática. 


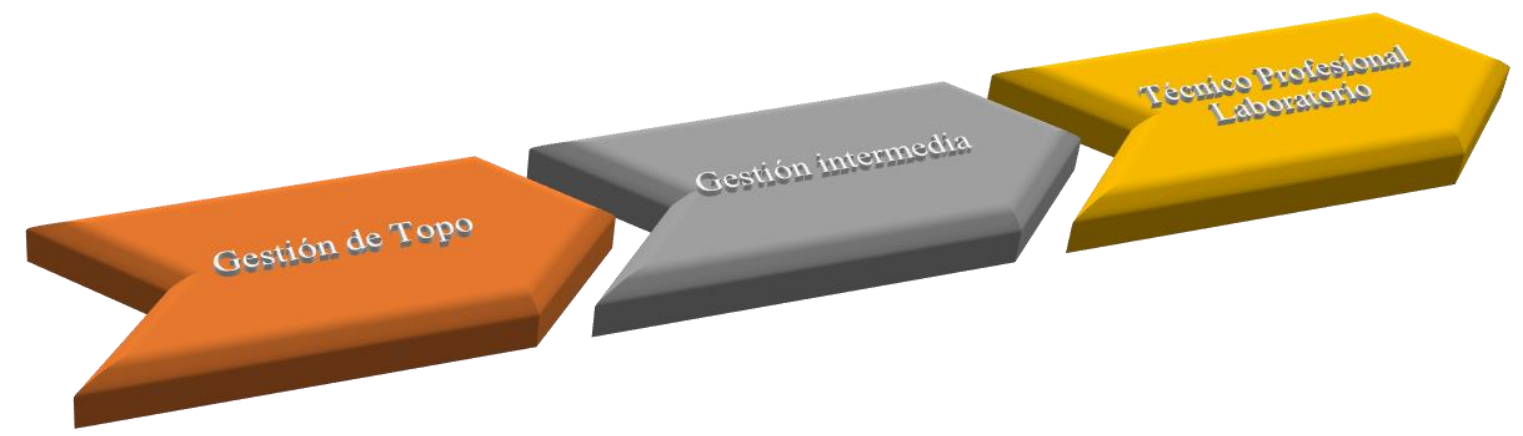

lustración 39 - Participación y apoyo de altos directivos y gestores intermedios

Fuente: Desarrollo propio

La estrategia fue involucrar a la Gestión superior en el cambio y el Director presentar públicamente el proyecto a todos los trabajadores como proyecto de la organización de y para el cambio frente a la prevención.

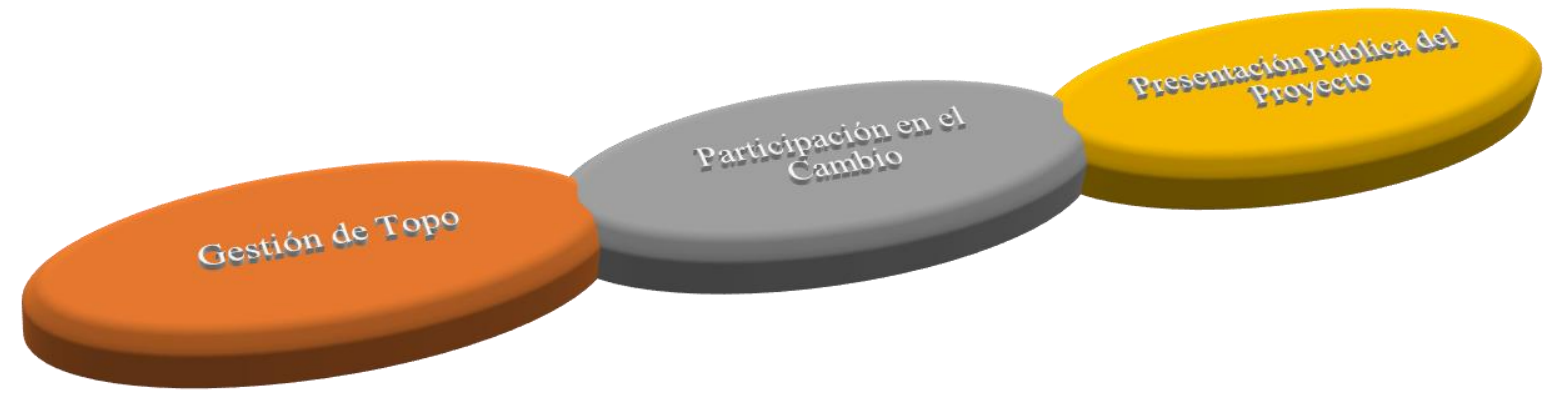

Ilustración 40 - Promoción de la CoP en la organización

Fuente: Desarrollo propio

En esta sesión de presentación el Director (ilustración 40) escogió el grupo facilitador y propuso de inmediato su formación en la temática de la Prevención de Riesgos Laborales el grupo técnicoprofesional de laboratorio. El grupo tuvo acceso a muchas horas de formación y el clima creado entre los elementos fue de confianza y mucha entrega a la temática. En el segundo semestre del año 2004 se organizaron como comunidad de partilla todo el conocimiento tanto formal como informal 
adquirido a lo largo del tiempo en que se encuentran tanto en el aula con formadores profesionales o en el terreno compartiendo su experiencia.

Nace la CoPGAPEAN, apoyada fuertemente y valorada por el gestor superior. Aquí fue muy importante la apertura de la Gestión de Topo, valorizando las actividades del grupo y creando condiciones para que la comunidad se desarrollara y mantuviera viva, en un tiempo que permitiese cambios efectivos en el comportamiento y actitudes de los colaboradores frente a la prevención.

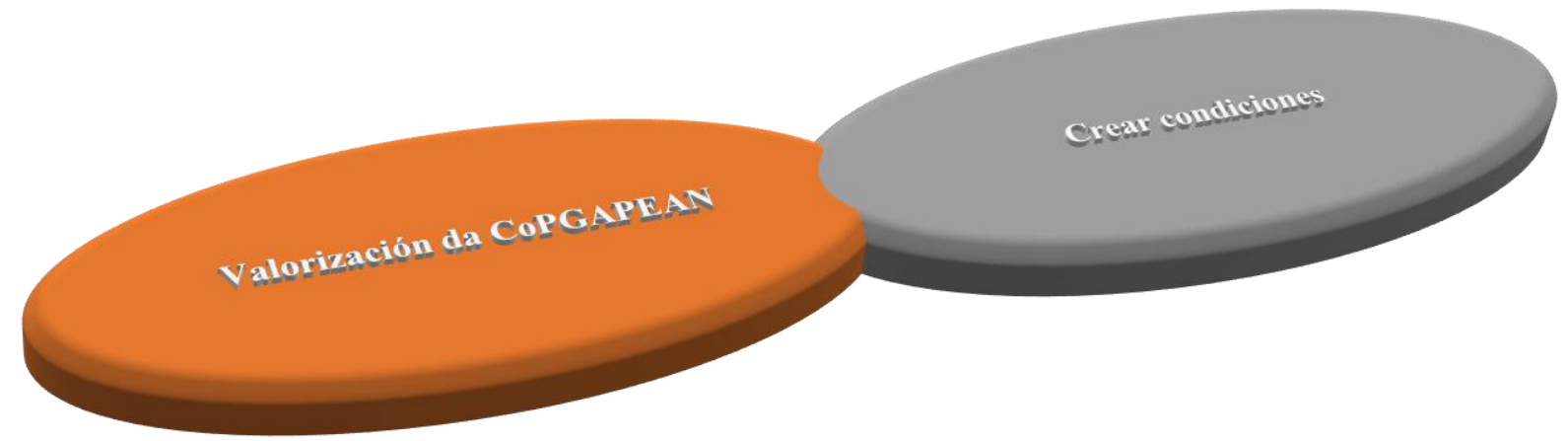

Ilustración 41 - Valorización da CoPGAPEAN

Fuente: Desarrollo propio

El líder de la organización apoya todas las iniciativas de esta comunidad embrionaria, cediendo tiempo para las actividades y apoyando las mismas. La cedencia de espacios de la organización, como aulas y auditorios para la realización de eventos y se involucra en la dinámica siempre que se le solicita valorizando el esfuerzo (ilustración 42).

El "combustible" no se agotó porque el líder siempre alimentaba al grupo, alentando y colaborando.

La comunidad se queda sin combustible para desempeñar su papel y, en última instancia, declarar. El coordinador comunitario era la enzima, el catalizador para que todo sucediera. 


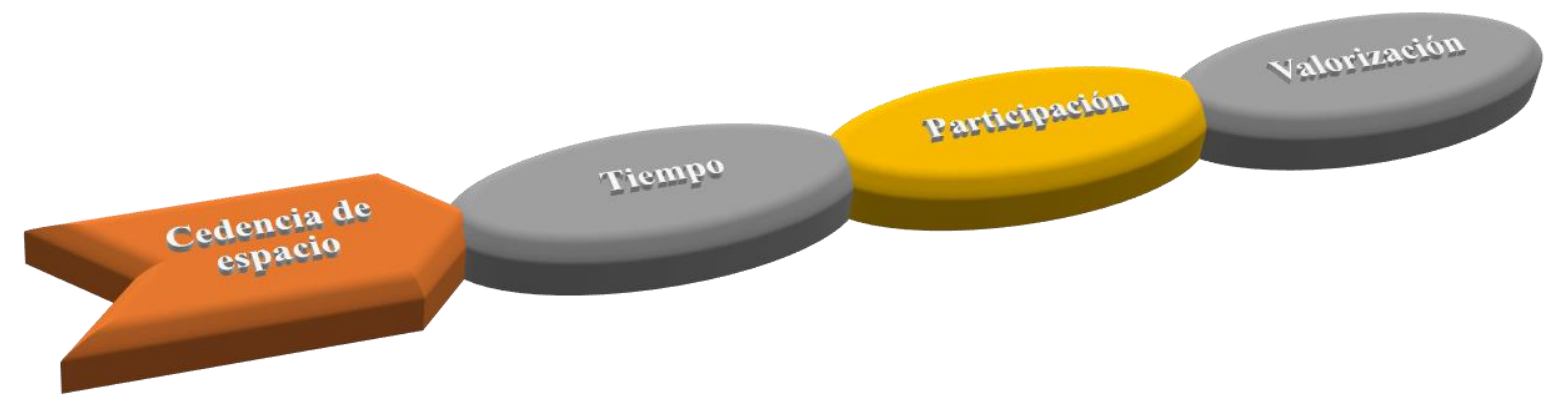

Ilustración 42 - Recursos proporcionados por la alta dirección a la estructura del CoP

Fuente: Desarrollo propio

El "combustible" no se agotó porque el líder alimentó siempre al grupo, incentivando y colaborando.

La comunidad se queda sin combustible para desempeñar su papel y acaba por declinar. La Coordinadora de la Comunidad fue la enzima, el catalizador para que todo sucediera.

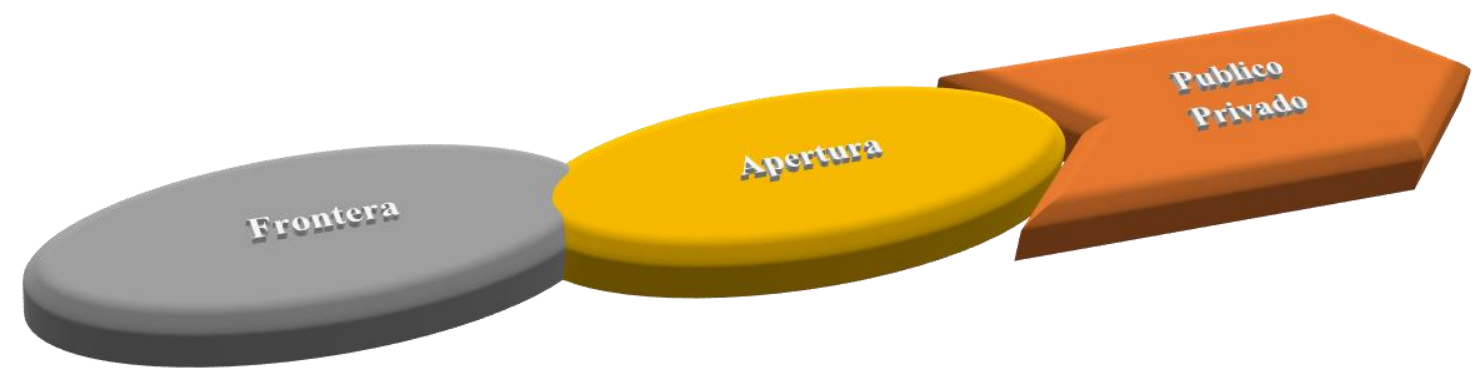

Ilustración 43 - Apertura de la frontera al exterior

Fuente: Desarrollo propio

La CoP se mantuvo activa incluso sin el líder organizacional, pero como prueba de su agradecimiento, un sentimiento que los mantenía unidos y aun luchando. En 2008, ya sin el líder organizacional, la CoPGAPEAN se mantuvo activa debido a su cohesión y en 2009 se transformó cuando tiene la oportunidad de la invitación del INA a transformarse en una CoP virtual. Si esta invitación no sucedía corría el riesgo de perderse. 2004 - 2005 - 2006 - 2007 - 2008 - 2009 -2010 En 2009 CoPGAPEAN se convierte en una comunidad mixta a través de la comunidad INA, se crea la comunidad de partilla de buenas prácticas de SHST. Los moderadores del grupo entraron en 
formación y se creó una nueva dinámica. Esta dinámica se mantuvo en esta plataforma hasta 2011.Una vez más los cambios en la AP, cambia servicios y la plataforma de soporte ha cerrado. La única posibilidad de continuidad era crear una herramienta de soporte para que esta dinámica no se perdiera. Y eso sucedió en el INRB con la creación de Wikiniav

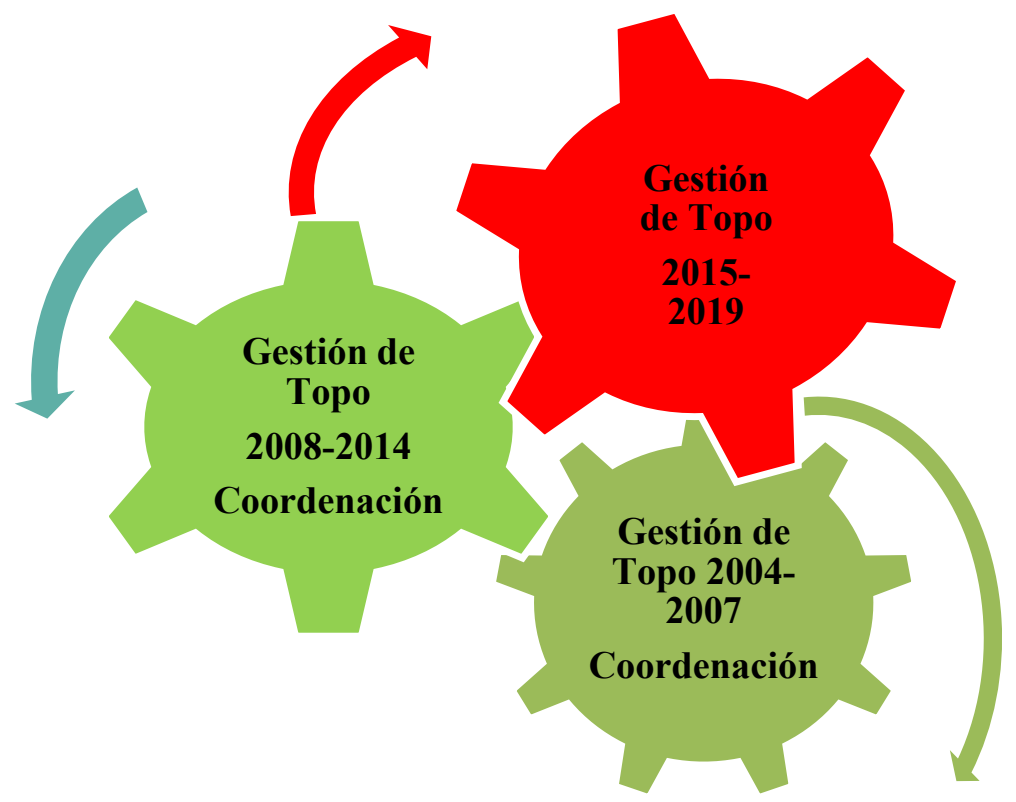

Ilustración 46 - Trabajo Colaborativo 2004-2019 Soporte de Alta Dirección

Fuente: Desarrollo propio

Como puede observar en (ilustración 46) presenta el éxito de la CoP que ha derivado de una estrategia de apuesta en el trabajo colaborativo entre 2004 y 2014 a pesar de varios cambios organizacionales, siendo apoyada también por un fuerte liderazgo de la CoP. A pesar de que en el período entre 2015-2014 se reunieron todas las condiciones para la continuidad de la CoP pues en términos tecnológicos la Organización se ha modernizado, así como el entrenamiento en la dinámica del trabajo colaborativo ya era del dominio y estudio de la Organización, concluimos que, sin el Apoyo de la Gestión de la Organización, la dinámica no iba a avanzar, aunque tuviera condiciones para ello porque la Gestión de topo había bloqueado. 


\section{Conclusiones y propuesta de próximos trabajos}

El objetivo de nuestro trabajo que consistió en analizar los elementos críticos de las prácticas esenciales para el éxito y la supervivencia de la Comunidad de Buenas Prácticas SST y la Calidad de Vida en el Trabajo y partiendo del presupuesto que sin el trabajo desarrollado por la CoP Animadores de Prevención que formó la $1^{\text {a }}$ Comunidad presencial de intercambio de conocimiento en este ámbito a la CoP virtual La comunidad de intercambio de buenas prácticas SST y la calidad de vida de WIKINIAV se ha alcanzado.

Como Prácticas indispensables: La participación y la participación de la gestión superior; La exposición de los beneficios de la CoP; Estímulo de la Organización para el intercambio de conocimiento; Definición de métodos de interacción (síncrona y asíncrona) Libertad de expresar idea; Medio ambiente que facilite el intercambio de conocimiento; Inversión en el entrenamiento y formación de los empleados

Como elementos críticos para la obtención de resultados de éxito para la Comunidad en estudio tenemos: El Alineamiento y la Estructuración; La Gestión de la Organización; la Facilitación / Liderazgo de la CoP; la cultura; Desarrollo; la política; la tecnología. Son éstas las prácticas esenciales que derivaron en resultados de éxito para la CoP y esos resultados son la Confianza; el Sentimiento de Pertenencia; la Utilidad y la contribución que se desarrollaron en el Período en que se formó la CoP embrionaria-Comunidad de Práctica de los Animadores de Prevención y que se mantuvieron hasta su transformación en Comunidad de Práctica Mixta (Virtual y Presencial) la Comunidad de Buenas Prácticas SST del INIAV.

El Período de declive de esta Comunidad coincide con un cambio de Liderazgo de la Organización que no valora el trabajo colaborativo y declina el funcionamiento de la plataforma WIKINIAV en un momento en que se crearon las condiciones para la continuidad. La Práctica de participación de la Gestión superior es con implicación y soporte, flexibilización de las actividades, promoción de la CoP y disponibilidad de recursos es un factor facilitador o será inhibidor, aunque el liderazgo de la CoP sea fuerte y que la Cultura de partilla sea positiva si no de la voluntad de la Gestión de la Organización la Comunidad muere lentamente si ya está formada o nunca nacerá pues no será prioridad de la Gestión de Topo. 
Sin embargo, podemos afirmar que todo el trabajo desarrollado en los dos proyectos de investigación que apostaron en el intercambio de conocimiento de forma colaborativa y en el formato innovador de las Comunidades de Práctica servirán sin duda de apoyo al gran proyecto para la administración pública portuguesa y veremos la transformación de la CoP para compartir buenas prácticas de SST en una CoP ampliada a todo el AP porque el XXI Gobierno Constitucional ha asumido el compromiso a principios de 2019 de revalorizar el trabajo en funciones públicas y fortalecer la administración pública, promoviendo su eficiencia y sostenibilidad y proporcionando condiciones de trabajo dignas para sus profesionales. Implementar los servicios SST de referencia en todo el AP, de forma colaborativa; autorizar los servicios públicos para la implementación y operación de los servicios de SST. En el punto 3-Crear una red de colaboración (red) con el objetivo principal de promover y reforzar la aplicación del régimen jurídico de la SST en la administración pública a finales de 2020, mediante la aplicación del plan de acción.

La hipótesis formulada para nuestra investigación ha sido validada y elegimos como prácticas esenciales para asegurar resultados éxito y el correcto funcionamiento y supervivencia de la comunidad de buenas prácticas de SST y calidad de vida en el trabajo: cultura, alineamiento y estructuración, apoyo a la alta dirección de la organización, fuerte líder/coordinación, desarrollo, política y tecnología.

Como propuesta de trabajo futuro y aprovechando la resolución del Consejo de Ministros, nos proponemos apoyar el proyecto de ejecución de los servicios de SST de referencia en todo el AP, de manera colaborativa; Capacitar a los servicios públicos y, sobre todo, a las organizaciones responsables por la implementación y operación de los servicios de SST. Las comunidades de práctica con comunicación síncrona y asíncrona y con una dinámica mixta, presencial y virtual son una herramienta innovadora para el intercambio de conocimientos en el campo de la prevención de riesgos laborales. También es urgente la formación de los principales facilitadores de la administración pública para que el trabajo en la plataforma sea posible. 
Doctorado en Salud, Discapacidad, Dependencia y Bienestar

\section{Capítulo 1} INTRODUÇÃO 


\section{Introdução}

$\mathrm{Na}$ atual conjuntura competitiva, cada vez mais os gestores responsáveis compreendem o valor da gestão do conhecimento como relevante fator de diferenciação, que quando gerido adequadamente, proporciona meios para alcançar vantagens competitivas.

As comunidades de prática têm sido reconhecidas como uma estrutura que permite criar, partilhar e aplicar conhecimento na organização, colaborando desta forma para a implementação das estratégias circunscrevidas quando corretamente direcionadas. As comunidades de prática apresentam-se como figura multifacetada e estimulante capaz de gerar, transferir, conservar e aplicar o conhecimento, ao mesmo tempo que proporciona à organização continuidade na aprendizagem. O enorme desafio, consiste em transformar as organizações tradicionais, estáticas, burocráticas, de organização vertical, sustentadas na rotina, com culturas de trabalho individualistas, evoluam para organizações que aprendem.

Para Gairin, J. S. (2000), o caminho em direção às organizações que aprendem assenta numa crescente autonomia e colaboração entre os seus membros: as organizações que privilegiam uma aprendizagem colaborativa num contexto de autonomia organizacional elevam-se a verdadeiras comunidades de prática. As organizações que aprendem necessitam de uma cultura onde todos os indivíduos, sem exceção, partilhem dos valores organizacionais.

Um clima de confiança e de respeito aceitável entre todos os intervenientes e aspetos como a mudança/adaptação, inovação e criatividade são fatores a ter em consideração, podendo então sublinhar que a aprendizagem organizacional é um fenómeno coletivo, dado que a organização só pode aprender através dos seus membros.

Neste âmbito o conceito de Comunidades de Prática (CoP) tem-se revelado como prática essencial de gestão do conhecimento, permitindo que o mesmo flua facilmente na Organização.

Com o presente trabalho, procuramos estudar uma organização em que as comunidades de prática virtuais já estão presentes e especificamente vamo-nos centrar na Comunidade de Partilha de Boas 
Práticas SST e Qualidade de Vida no Trabalho (Flor, C., 2015), para as quais são destinados recursos e esforço da instituição e de trabalhadores.

Este trabalho acompanhou todo o processo de nascimento e fases do ciclo de vida da Comunidade de Prática numa Instituição do Setor Público Português (Instituto Nacional de Investigação Agrária e Veterinária) pertencente ao Ministério da Agricultura, Florestas e Desenvolvimento Rural, tirando partido dos instrumentos aplicados pela investigadora que participou no desenvolvimento da WIKINIAV e seguindo o trabalho da mesma em todo o processo.

Este trabalho fundamenta-se no estudo de 3 tópicos fundamentais:

- O primeiro refere-se ao estudo e recurso a bibliografia sobre o assunto de fatores de sucesso de outras Comunidades já estudadas;

- O segundo a análise de todo o percurso de formação e transformação da Comunidade de Partilha de Boas Práticas em SHST ${ }^{4}$ ao longo de 15 anos;

- O terceiro, analisar as práticas essenciais que conduzam a resultados de sucesso da CoP.

A Comunidade de Boas Práticas SST e Qualidade de Vida tal como outras Comunidades nasceu de uma paixão de um pequeno grupo que a encetou e passou por várias fases de desenvolvimento e regozijo tendo como alavanca uma Comunidade embrionária, a Comunidade Presencial CoPGAPEAN (Comunidade de Prática do Grupo de Animadores de Prevenção da Estação Agronómica Nacional) estimulada e sustentada pela Gestão de Topo da Organização, na altura ainda Estação Agronómica Nacional e tendo também um líder especialista no domínio dentro da Comunidade.

Com o decorrer dos anos surgiu uma nova dinâmica, a virtual, também ela numa nova Organização o INIAV (Instituto Nacional de Investigação Agronómico e Veterinário). Neste Instituto a dispersão geográfica é grande, a multidiversidade das culturas da fusão é igualmente enorme, sendo esta a

\footnotetext{
${ }^{4} \mathrm{Na}$ atualidade, o termo SHST está em desuso, sendo aplicado, cada vez mais, em seu lugar, a sigla SST. Esta alteração surge do facto de ser constatado, por parte das autoridades na matéria, a ACT (Autoridade para as Condições de Trabalho) e Associações relacionadas com a SST, que se verifica um entendimento errado do termo Higiene, sendo sistematicamente confundido com as normais questões de higiene e não com as questões relacionadas com os agentes químicos, físicos ou biológicos existentes nos locais de trabalho. Neste contexto, a mais recente legislação que surgiu, a Lei n. ${ }^{\circ}$ 102/2009 de 10 de setembro, o Regime Jurídico da Promoção da Segurança e Saúde no Trabalho, já se refere unicamente a SST. Nesse sentido, e tendo em conta também as designações internacionais (AESST [Agência Europeia de Segurança e Saúde no Trabalho], OSHA [Occupational Safety and Health Administration], entre outras), ao longo deste trabalho aplicar-se-á já essa tendência de alteração de nomenclatura, passando a utilizar-se SST ao invés de SHST, sempre que não exigível por citações ou transcrições.
}

Comunidad@Buenas Prácticas de Seguridad, Salud e Calidad de Vida en el trabajo INIAV

"Factores críticos de éxito" 
oportunidade de aposta no trabalho colaborativo através do incentivo à participação na Comunidade de Prática.

\subsection{Premissas de que partimos para a investigação}

Sem o trabalho desenvolvido pela CoPGAPEAN que formou a $1^{\text {a }}$ Comunidade presencial de partilha de conhecimento neste domínio (Segurança, Higiene e Saúde no Trabalho - SHST, atualmente designado por Segurança e Saúde no Trabalho - SST) a CoP Virtual da WIKINIAV não se teria desenvolvido, sem as seguintes premissas:

- Envolvimento dos elementos deste grupo da CoPGAPEAN (Comunidade de Prática do Grupo de Animadores de Prevenção da Estação Agronómica Nacional).

- Interações de êxito são mistas: presenciais e virtuais.

- Escolha de Coordenação Forte com formação adequada e com crença no desafio.

- Apoio explícito da Gestão de Topo em todo o processo.

\subsection{Objetivo da investigação}

Analisar práticas indispensáveis na condução de resultados responsáveis pelo sucesso da Comunidade de Partilha de Boas Práticas de Segurança, Saúde e Qualidade de Vida no Trabalho do Instituto Nacional de Investigação Agrária e Veterinária (CoPSSQVTINIAV).

\subsection{Identificação do problema da investigação}

Quais são as práticas indispensáveis que poderão conduzir a resultados de sucesso na sobrevivência da CoPSSQVTINIAV? 
Doctorado en Salud, Discapacidad, Dependencia y Bienestar

\subsection{Formulação da Hipótese}

Para a nossa investigação e de forma a garantir a sobrevivência e o sucesso da CoP elegemos as seguintes práticas indispensáveis por resultados de sucesso da CoPSSQVTINIAV:

A1: Apoio da Gestão de Topo da Organização;

A2: Alinhamento e estruturação;

A3: Desenvolvimento;

A4: Política;

A5: Gestão da Comunidade;

A6: Cultura;

A7: Tecnologia; 


\subsection{Planeamento da dissertação}

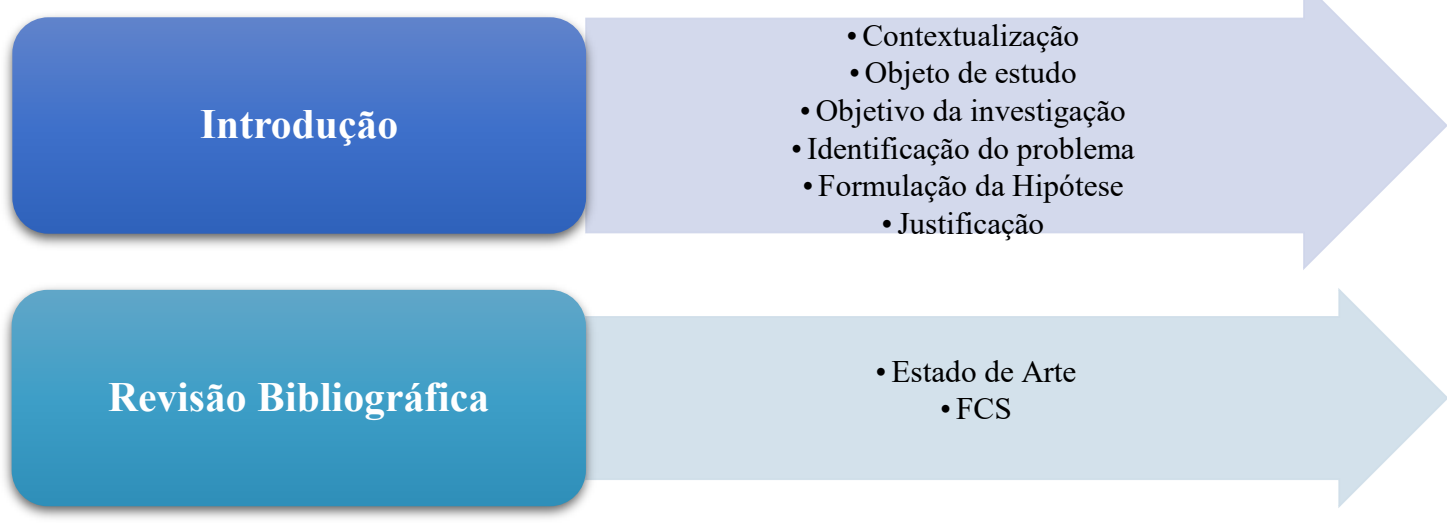

- Âmbito do estudo

Procedimentos

- Problema do estudo

Metodológicos

- Metodologia

- Caraterização da investigação

- Instrumentos aplicados

\section{Análise e Discussão de dados \\ - Apresentação \\ - Análise \\ - Discussão dos resultados \\ - Limitações do estudo}

- Caraterização da população em estudo

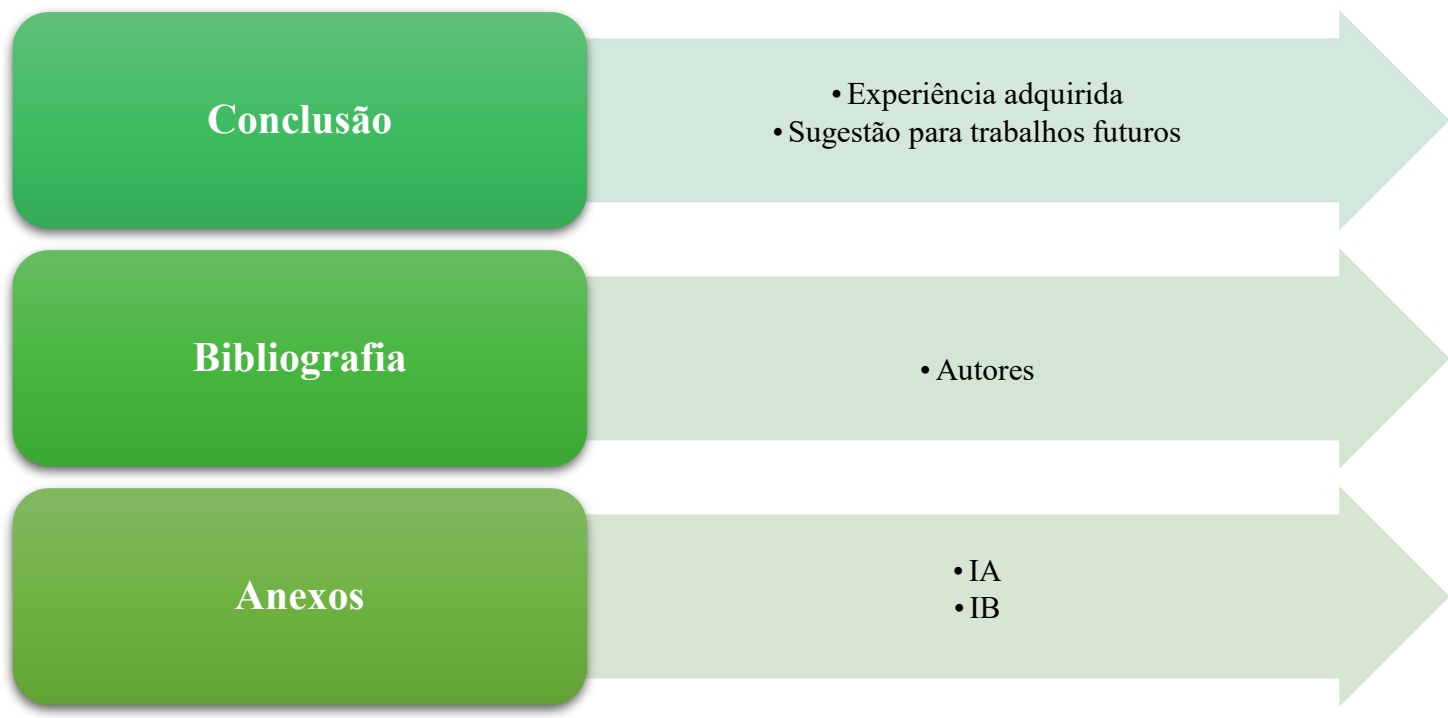

Ilustração 1 - Fluxograma da dissertação

Fonte: Elaboração própria

Comunidad@Buenas Prácticas de Seguridad, Salud e Calidad de Vida en el trabajo INIAV 
O trabalho desenvolve-se em seis capítulos, em que o primeiro capítulo, será o da Introdução, que fará o enquadramento geral das Comunidades de Prática e os seus fatores críticos de sucesso, os pressupostos, a fundamentação, objetivos, quer geral quer específicos, assim como a estrutura de desenvolvimento do trabalho.

O segundo capítulo é referente à revisão bibliográfica, abordará o estado de arte das comunidades de prática, o enquadramento e desenvolvimento das $\mathrm{CoP}$, dimensões de análise dos fatores críticos de sucesso para a manutenção das comunidades de prática. O terceiro capítulo aborda a metodologia aplicada na investigação. O quarto capítulo consiste em Análise e discussão de dados, com a aplicação de matrizes de avaliação. O quinto capítulo expõe as conclusões, encintando projetos futuros. Por último terminamos com bibliografia, onde estão presentes todos os autores que nos acompanham na elaboração deste trabalho. 
Doctorado en Salud, Discapacidad, Dependencia y Bienestar

Capítulo 2

$\underline{\text { REVISÃO BIBLIOGRÁFICA }}$ 


\section{Revisão Bibliográfica}

\subsection{Estado da Arte}

O conceito de comunidades de prática (CoP) foi introduzido no trabalho de Lave e Wenger em 1991, na perspetiva de que o conhecimento e a aprendizagem ocorrem através das interações sociais e, são percebidos como parte de uma construção coletiva. Para os autores, uma grande parte do processo de aprendizagem e da criação do conhecimento ocorre com ações práticas informais. Étienne Wenger, além de precursor nos estudos sobre as CoP, é considerado sua maior referência.

O conceito adotado no presente trabalho de investigação tem sido muito referenciado nos trabalhos académicos, e foi cunhado por (Wenger, Etienne; Mcdermott, R.; Snyder, W. M., 2002a): “um grupo de pessoas que partilham uma preocupação, um conjunto de problemas, uma paixão sobre um tema e que aprofundam seus conhecimentos e expertises, interagindo regularmente.

Este conceito de CoP tornou-se essencial em vários domínios científicos, nomeadamente, na Gestão do Conhecimento, na Aprendizagem Organizacional, nas Ciências da Educação e nas Ciências da Informação (Cox, Andrew, 2005).

Comunidades de Prática são grupos de pessoas que partilham um interesse, um problema em comum ou uma paixão sobre determinado assunto e que aprofundam o seu conhecimento e expertise nesta área através da interação contínua. Estas pessoas não trabalham necessariamente juntas todos os dias, mas, encontram-se porque agregam valor em suas interações. Como passam algum tempo, juntas, elas partilham informações, insights e conselhos. Ajudam-se umas as outras a resolver problemas, discutem situações, aspirações e necessidades. Ponderam pontos de vista em comum, exploram ideias e ações, assim como sondam os limites. Podem criar ferramentas, padrões, manuais e outros documentos ou podem simplesmente desenvolver uma tácita compreensão do que é compartilhado. Porém acumulam conhecimento, tornando-se informalmente a fronteira (do conhecimento) pelo valor que agregam à aprendizagem que encontram juntas. Este valor não é meramente instrumental para o seu trabalho resulta também na satisfação pessoal de conhecer colegas que compreendem as perspetivas uns dos outros e de pertencer a um interessante grupo de pessoas. Com o passar do tempo, desenvolvem uma perspetiva única sobre os seus assuntos bem 
como formam um corpo comum de conhecimento, práticas e teorias. Também desenvolvem relações pessoais e instituem formas de interação. Podem também desenvolver um senso comum de identidade, tornando-se então uma Comunidade de Prática (Wenger, Etienne; Mcdermott, R.; Snyder, W. M., 2002a).

As suas aplicações práticas transvazam o mundo empresarial, encontrando-se estas em contextos organizacionais tão distintos como: gestão de cuidados de saúde, (e.g. (Schenkel, A; Teigland, R., 2008); - planeamento social, agricultura, etc. (e.g. (Kranendonk, R.P.; Kersten, P.H., 2007)); colaboração em investigação científica (e-science) (e.g. [ (Farooq, Muhammad et al., 2008)]); ou ainda nos mais diversificados domínios da educação (e.g. [ (Wenger, Etienne; Mcdermott, R.; Snyder, W. M., 2002a)]); de formação especializada em posto de trabalho (e.g [ (Doak S. \& Assimakopoulos, D., 2007); (Fuller, A.; Hodkinson, P.; Unwin, L., 2005)]).

O conceito de Comunidades de Prática é bastante simples e antigo novo, é o fato das organizações utilizarem este recurso para melhorar sua performance.

Do exercício de partilhar experiências e práticas nasceu a Comunidade de Prática; uma estrutura flexível e autónoma que tem contribuído para direcionar estratégias organizacionais e criar novas linhas de negócios, solucionar problemas, promover a disseminação de melhores práticas, desenvolver habilidades dos funcionários e ajudar empresas a recrutarem e reterem talentos (Wenger, Etienne; Snyder, 2001).

Nas organizações, não é fácil fazer com que o conhecimento transponha as fronteiras dos grupos de trabalho, equipas e departamentos, nesse sentido o contributo das comunidades estende-se até ao fortalecimento dos laços entre os indivíduos pertencentes ao mesmo grupo profissional bem como alargando a rede a um grupo mais vasto.

A presença na comunidade é sempre um ato de iniciativa voluntária motivado pela necessidade que os indivíduos sentem em discutir a sua prática com o objetivo de adquirirem mais conhecimento (Ardichvili, A.; Page, V. \& Wentling, T., 2002); (Ardichvili, A.; Page, V. \& Wentling, T., 2003); (Zboralski, K.; Gemuenden, H. G. \& Letti, C., 2004)] para melhorarem o desempenho das suas funções (ou atividades) [ (Gamble, P. R. \& Blackwell, J., 2001); (Zboralski, K.; Gemuenden, H. G. 
\& Letti, C., 2004)] A não existência de relações de poder impostas - pelo contrário, estas surgem naturalmente e em regra estão associadas ao domínio sobre as "matérias" por vários membros (Cox, Andrew, 2005) sendo relevante a inclusão de uma diversidade de tipos de membros, desde os iniciados até a os especialistas.

Os autores (Mendes, L.; Urbina, L.M.S., 2015), salientam que as CoP têm o seu foco na partilha de conhecimentos, no exercício da aprendizagem conjunta e organizam-se para estimularem os processos de aprendizagem e difusão dos conhecimentos que ocorrem informalmente. Os mesmos autores destacam ainda, que há o comprometimento dos membros com a ajuda mútua e a aprendizagem coletiva; ressaltam o alto nível de integração entre os seus membros e lembram que a CoP ultrapassa as fronteiras departamentais e até mesmo organizacionais. (Morales, A.H.; Macías, R.C.F., 2013), acrescentam a ausência de hierarquia nas CoP, sendo que a posição de cada participante é flexível e dinâmica dependendo do envolvimento nas atividades da comunidade. (Cyrino, M.C.C.T.; J.G., Estevam, 2016), observa aspetos como o respeito, a confiança, desafio, a negociação de significados e a valorização das singularidades e práticas profissionais. A autora aponta que essas características e peculiaridades das CoP formam um solo fértil para o desenvolvimento da identidade profissional.

No entanto, com a globalização das economias os indivíduos que, eventualmente, participavam em CoP presenciais deixaram de dispor de local e oportunidades para interagirem pessoalmente (Kiesler, S. \& Cummings, J. N., 2002) com tanta facilidade.

Na procura de colaboradores de alto valor agregado á inteligência competitiva das organizações surgem as Comunidades de Prática, que estão a descobrir as suas possibilidades em Organizações de vanguarda que investem nesta nova fronteira organizacional. Estas estruturas sociais já são realidade em muitas organizações, os casos mais explorados pela literatura são: Xerox, Banco Mundial e British Petroleum. Em Portugal, as iniciativas ainda são escassas, trata-se de um tema que apresenta um grande potencial a ser trabalhado pelas Organizações Portuguesas. Contudo, este tipo de arranjo não é estimulado e na maioria das vezes nem é percebido pelas estruturas formais. Em alguns casos, os gestores não têm claro a diferença entre o que é uma verdadeira Comunidade de Prática e outro tipo de arranjo coletivo como: equipas de trabalho ou redes de relacionamento 
informal. Por outras palavras, "em muitos casos, percebe-se que a vivência em grupos é indiscriminadamente tratada como um relato de Comunidades de Prática” (Lave, J., 2004)

\subsection{Da aprendizagem individual para a aprendizagem colaborativa}

Ao falar em condições e desafios de emergência das comunidades virtuais de prática (CoPV) não se pode deixar de as enquadrar no contexto atual de mudança, relacionada com as novas necessidades de aprendizagem da sociedade da informação assenta no reconhecimento cada vez mais importante da aprendizagem colaborativa, como forma superior de aprendizagem. A colaboração não põe em causa a autoformação, enquanto capacidade de cada um aprender por si, parte do princípio de que qualquer profissional é capaz de iniciar e dirigir os seus processos de aprendizagem e formação.

A cultura de colaboração (presencial ou virtual) está muito relacionada com o trabalho em equipa, o que exige novas destrezas sociais. Deste modo, contribuir para a sua formação envolve a pessoa, mas também a sua relação com o outro, o grupo, a organização, a instituição, o contexto (Bernard, M., 1999).

O intercâmbio de conhecimentos e experiências entre colegas ("aprender juntos") pode ser um dos meios mais enriquecedores e com maior incidência no desenvolvimento profissional (Bolivar, M., 1999).

A atividade colaborativa pressupõe a construção de uma realidade partilhada, vinculada a uma dinâmica relacional, onde são fundamentais os processos reflexivos, de resolução de problemas e de controlo da aprendizagem.

A aprendizagem colaborativa, apesar de estar num nível de exigência superior à aprendizagem individual, não se pode separar desta na medida em que a autoaprendizagem é o suporte da aprendizagem colaborativa. 


\subsection{A Organização que aprende}

As organizações que aprendem são formadas por pessoas que expandem, continuamente, a sua capacidade de criar os resultados que desejam, onde se estimulam padrões de comportamento novos e abrangentes, a aspiração coletiva ganha liberdade, e as pessoas exercitam-se, continuamente, em aprender juntas. Essas organizações só podem ser construídas quando entendermos que o mundo não é feito de forças separadas e que, no mundo de hoje, a capacidade de aprender contínua e rapidamente é a única vantagem competitiva sustentável.

O conceito de organização que aprende, enquanto forma de adaptação a um contexto em mudança, expressa a ideia de um processo em transformação progressiva, uma aspiração, um caminho em direção a um objetivo, que requer uma mudança contínua ou uma autotransformação, e não um produto final.

O grande desafio consiste em fazer com que as organizações tradicionais, estáticas, burocráticas, de organização vertical, baseadas na rotina, com culturas de trabalho individualistas, evoluam para organizações que aprendem.

Para (Gairin, J. S., 2000), o caminho em direção às organizações que aprendem assenta numa crescente autonomia e colaboração entre os seus membros: as organizações que privilegiam uma aprendizagem colaborativa num contexto de autonomia organizacional elevam-se a verdadeiras comunidades de prática. Existe também, desta forma, uma aproximação do conceito de organização que aprende ao conceito de comunidade de prática, tendo em atenção os seus fundamentos na teoria social da aprendizagem, no que se refere à aprendizagem a partir da prática e na construção coletiva de significados. Internalizar a mudança na cultura de trabalho é um dos aspetos chave para o sucesso organizacional, mas, requer (transformação ou reconversão) da organização, com base numa profunda metamorfose das mentalidades e comportamentos.

A palavra "metanoia" significa mudança de mentalidade e talvez seja a denominação mais exata para descrever o que acontece numa organização que aprende.

Entender o significado de "metanoia" é entender o significado de aprendizagem, pois esse envolve uma alteração fundamental no processo de mudança mental. 
(Snyder, W.; Cummings, T., 1998) realizaram uma síntese da relação entre a aprendizagem individual e a aprendizagem organizacional: os indivíduos aprendem nas organizações, mas esta aprendizagem pode ou não contribuir para a aprendizagem organizacional.

A aprendizagem é organizacional na medida em que:

(1) é realizada para alcançar propósitos organizacionais;

(2) é partilhada ou distribuída entre os membros da organização (grupos);

(3) os resultados da aprendizagem são incorporados em sistemas, estrutura e cultura organizacionais.

\subsection{Organizações baseadas em conhecimento}

As organizações baseadas em Conhecimento têm nos seus quadros altamente qualificados, trabalhadores do conhecimento, cujo papel é essencialmente o de solucionar problemas.

Neste contexto, os grupos de trabalho têm de procurar e explorar exemplos das melhores práticas, melhorar a sua eficácia e eficiência, e contribuir para uma aprendizagem organizacional global, com visibilidade para todos os intervenientes.

Os grupos de trabalho nas organizações baseadas em conhecimento necessitam de gerir dinamicamente as suas qualificações, criar mecanismos para descobrir novas ideias e inovações, e identificar fontes de informação.

O desafio para todas as organizações, mas para as organizações baseadas em conhecimento em particular, é lidar com o seu conhecimento de forma efetiva.

A partir do trabalho de (Macintosh, A., 1997) sobre a gestão de recursos do conhecimento organizacional, um conjunto de entraves para uma maior produtividade e desempenho em organizações baseadas em conhecimento foi identificado: 
- A maioria dos RHs perde muito do seu tempo a procurar a informação que necessita.

- O saber fazer essencial está apenas disponível na mente de algumas pessoas.

- Informação valiosa está dissimulada em imensos conjuntos de dados e documentos.

- Erros dispendiosos são repetidos devido à não consideração de experiências anteriores.

- Atrasos, produtos e serviços com pouca qualidade resultam de um insuficiente fluxo de informação entre os diversos agentes organizacionais.

Baseado nestes argumentos, (Dieng, R. et Al., 1998) apresentaram um conjunto de motivações que justifica a construção de uma Memória Organizacional:

- Evitar a perda de inteligência corporativa (ou capital intelectual) quando um especialista deixa a Organização.

- Explorar e reutilizar a experiência adquirida nos projetos passados para evitar a repetição de erros.

- Melhorar a circulação e comunicação da informação na organização.

- Integrar o saber fazer a partir de diferentes partes da organização.

- Melhorar o processo de aprendizagem individual e organizacional.

A definição de uma plataforma de trabalho colaborativo para o desenvolvimento de Comunidades de Prática poderá minimizar e resolver parte dos problemas atrás referidos. As CoP poderão ser propositadamente desenvolvidas e fomentadas, fazendo parte integrante da estratégia organizacional, como forma de estimular a partilha de conhecimento.

\subsection{Comunidade de Prática como abordagem para a Gestão do Conhecimento}

Sendo as CoP uma das abordagens possíveis da Gestão do Conhecimento, ao realizar-se um trabalho de partilha entre os elementos dos grupos que as compõem dá-se a transformação do conhecimento já existente em novo, acabando elas próprias por estar na base de novas redes de conhecimento que se vão gerando (Vasconcelos, J. et Al., 2005). Assim, as CoP são intrínsecas à existência do próprio conhecimento (Lave, J.; Wenger, E., 1991). 
As CoP surgem dos relacionamentos informais que se estabelecem nas organizações. A partir do momento que se começam a estruturar e que começam a ser um instrumento de partilha de conhecimento acabam por se transformar, lentamente, em grupos formais, passando do conhecimento tácito ao explícito.

As Comunidades de Prática podem ser constituídas presencial ou virtualmente. Muitas vezes, não precisam se restringir à comunicação virtual, podendo ser complementadas por encontros e reuniões de seus membros.

No contexto da gestão do conhecimento, a cultura favorável á partilha de experiências, a partir da CoP, pode viabilizar melhores práticas nas organizações, tornando-se atraente à aprendizagem colaborativa. Cabe, pois, à organização incentivar a criação das $\mathrm{CoP}$, cultivando sua manutenção e procurando, permanentemente, meios para disseminação orgânica de conhecimentos práticos articulados com a política e as estratégias organizacionais.

Uma comunidade de prática CoP não é, simplesmente, uma comunidade de interesses. Compreendese por comunidade de interesses um grupo de pessoas que partilham algo, a CoP corresponde a uma comunidade de pessoas e nas relações de envolvimento intrínseco, que trabalham juntas, conversam entre si; trocam informações e opiniões; e são diretamente retroalimentados pelo entendimento mútuo, como uma questão de rotina.

As Comunidades de Prática costumam ser confundidas com equipas, redes ou grupos de tarefas. Diferentes destes, as Comunidades de Prática são tipicamente voluntárias, informais; emergem pela própria prática do trabalho, operam para além das hierarquias e dos limites organizacionais tradicionais e raramente são reconhecidas pelas organizações (McKeen, J. D.; Smith, H. A., 2002). Surge independente de um objetivo ou tarefa específica na organização (Kimble, C. Hildreth, P. M., 2004) e (Wenger, E., 2010).

As comunidades de prática são estratégias para a construção do conhecimento que podem ocorrer naturalmente nas relações sociais nos ambientes de trabalho.

Segundo (Lahti, S.; Moilanen, R., 2004), o conhecimento tácito é um dos pontos fortes dos colaboradores mais velhos e experientes, apresentando a capacidade de interpretar informação 
relativa à qual não existe regra formal de processamento. Existe um grande potencial no conhecimento na sua forma tácita.

Partilhar o conhecimento tácito entre colaboradores mais novos e mais velhos é um dos principais desafios da gestão. (Lahti, S.; Moilanen, R., 2004) referem no seu estudo que a aprendizagem que ocorre entre colaboradores mais novos e mais velhos aumenta as competências individuais e liberta conhecimento tácito individual para utilização de toda a organização.

Transformação do conhecimento tácito, para que este possa ser registado de forma a conter informação suficiente para possibilitar a disseminação dos benefícios na organização (MCelroy, M.W., 2003);

No trabalho de investigação desenvolvido por (Flor, C., 2015) é referido que o conhecimento tácito é um dos pontos fortes dos colaboradores mais velhos e experientes, apresentando a capacidade de interpretar informação relativa à qual não existe regra formal de processamento.

Neste trabalho de investigação (Flor, C., 2015) explicita que o grande problema de Organizações detentoras de conhecimento é a saída de trabalhadores detentores de muito conhecimento tácito que não passou a explícito.

Existe um grande potencial no conhecimento na sua forma tácita (Flor, C., 2015) partilhar sendo o Conhecimento tácito entre colaboradores mais novos e mais velhos é um dos principais desafios da gestão. As novas Tecnologias de Informação e Comunicação (TIC) proporcionaram um grande avanço nas CoP, pois os ambientes virtuais oferecem excelentes meios para a interação entre indivíduos. As CoP são facilitadoras do tácito.

Muitas vezes erra-se em focar a formação apenas na ferramenta a ser utilizada como suporte à metodologia, sem considerar a mesma no processo e nos aspetos humanos que envolvem a gestão do conhecimento.

Contudo, deve-se tomar cuidado com o excesso de informação para que os membros não percam o interesse. 


\subsection{Organização de uma Comunidade de Prática}

Para que uma Comunidade seja considerada uma Comunidade de Prática, é necessário que ela possua três dimensões fundamentais (Wenger, Etienne; Mcdermott, R.; Snyder, W. M., 2002a):

Domínio: essa dimensão define a área de conhecimento, sendo a base ou o alicerce sobre a qual a Comunidade se reúne, é através desse domínio partilhado que vai diferenciar os seus membros de outras pessoas.

Comunidade: é a dimensão que relaciona um grupo de pessoas que vai interagir entre si, aprendendo e construindo relações, assim desenvolvendo um sentimento de identidade e comprometimento com o grupo é através dessa interação que a Comunidade vai influenciar o pensamento dos indivíduos.

Prática: nesta dimensão, as ideias, ferramentas, habilidade, experiência e a perícia de fazer algo, num determinado domínio

Para se construir uma Comunidade de Prática é necessários estes três componentes e a ausência de um deles pode configurar um simples grupo de pessoas em torno de um objetivo comum, mas não pode ser denomina de Comunidade de Prática.

Todo o conceito de CoP refere-se a um sistema social de aprendizagem, abrangendo a dimensão social do processo de aprendizagem.

\subsection{Da Expansão da CoP ao Desaparecimento}

As CoP emergem frequentemente no contexto organizacional ou redes profissionais nas quais as pessoas já estão envolvidas em uma prática profissional comum.

No decorrer do seu ciclo de vida, as CoP evoluem nas suas práticas ou desenvolvem novas, através de discussões e da exploração de conhecimento interno e externo. 
A evolução das CoP pode levar não somente á sua expansão, em relação ao tema, à prática e aos seus membros, como também ao seu desaparecimento (Wenger, Etienne; Mcdermott, R.; Snyder, W. M., 2002a).

Assim, a continuidade das CoP está relacionada com a possibilidade dos seus membros se identificarem com os outros membros, com o tema e com a prática.

À medida que se identificam com a comunidade, assumem papéis/identidades dentro da comunidade, como colaboradores, líderes ou simplesmente como observadores (lurkers).

Esse processo de identificação depende da trajetória da aprendizagem que as práticas individuais e coletivas adquirem, o que envolve considerar as experiências passadas e futuras dos participantes, as relações entre eles e o uso de ferramentas de tecnologia que interferem nessas relações.

Wenger em (Wenger, E., 1998a) destaca a temporalidade e a liderança como elementos fundamentais na criação e sustentação das comunidades de prática. Para o autor, a temporalidade, ou seja, a duração das comunidades está diretamente associada à forma como as comunidades passam de um estágio a outro.

Nos vários estágios de desenvolvimento das comunidades de prática, os membros apresentam diferentes níveis de interação e desempenham diferentes tipos de atividades, sendo esses os fatores que podem contribuir para a continuidade das comunidades.

Outro ponto fundamental destacado por (Wenger, E., 1998a) é a liderança, pois a mesma promove o interesse e a motivação para o trabalho em grupo. (Lévy, Pierre, 1998) também enfatiza a importância da liderança nas comunidades de prática para a sua manutenção.

Este autor define o líder como um animador, ou seja, o líder tem o papel de auxiliar os membros a pesquisar, selecionar e organizar a informação. Um aspeto também importante para a manutenção das comunidades de prática e bem definido por (Henri, F.; Ludgren, K., 2000), é a coesão do grupo, essencial para a colaboração e para a aprendizagem dos membros da comunidade. (Olivieri, L. et. al., 2002); (Hernandes, C. A.; Fresneda, P. S., 2002) enfatizam que o desenvolvimento da confiança exerce papel de extrema relevância para a coesão do grupo. 


\subsection{Caraterísticas das Comunidades de Prática}

De acordo com (Christopoulos, T. P., 2008), há características em comum na maioria das comunidades de prática. designadamente:

- O carácter informal das $\mathrm{CoP}$ - as comunidades surgem naturalmente, de uma forma informal, sem serem controladas por mecanismos hierárquicos específicos (Cohendet, P.; Llerena, P., 2003);

- As visões sobre a aprendizagem - as $\mathrm{CoP}$ constituem o local privilegiado de aprendizagem, a qual decorre da resolução de problemas em conjunto, pelo grupo (Saint-Onge, H.; Wallace, D., 2003); (Tarmizi; Zigurs, 2006) as CoP disponibilizam, ainda, o local e o contexto para que esta aprendizagem ocorra (Saint-Onge, H.; Wallace, D., 2003); (Tarmizi; Zigurs, 2006)

- A presença na comunidade é sempre um ato de iniciativa voluntária motivado pela necessidade que os indivíduos sentem em discutir a sua prática com o objetivo de adquirirem mais conhecimento (Ardichvili, A.; Page, V. \& Wentling, T., 2003); (Zboralski, K.; Gemuenden, H. G. \& Letti, C., 2004) para melhorarem o desempenho das suas funções (ou atividades) (Gamble, P. R. \& Blackwell, J., 2001); (Zboralski, K.; Gemuenden, H. G. \& Letti, C., 2004);

- A auto-organização do sistema - o modo de funcionamento das CoP é definido pelos seus membros ao longo do ciclo de vida da comunidade (Brown, J.S.; Duguid, P., 2000); (Davenport, T. H.; Prusak, L., 2003); (Gongla, P.; Rizzuto, C.R., 2001); (Roberts, Joanne, 2006); (Wenger, E., 1998a); (Wenger, Etienne, 2000a); (Wenger, Etienne, 2000b); (Wenger, Etienne, 2004); (Wenger, Etienne; Snyder, 2001); (Wenger, Etienne; Mcdermott, R.; Snyder, W. M., 2002a).

- A disponibilização de uma dimensão temporal indeterminada - a sua duração depende do interesse dos seus membros em manter a comunidade "viva" (Brown, J.S.; Duguid, P., 1991); (Brown, J.S.; Duguid, P., 2001) ; (Saint-Onge, H.; Wallace, D., 2003); (Wenger, E., 1998a); 
- A não existência de relações de poder impostas - pelo contrário, estas surgem naturalmente e em regra estão associadas ao domínio sobre as "matérias" por vários membros (Cox, Andrew, 2005);

- A inclusão de uma diversidade de tipos de membros, desde os iniciados até aos peritos de renome.

O conceito de CoP tornou-se essencial em vários domínios científicos, nomeadamente, na Gestão do Conhecimento, na Aprendizagem Organizacional, nas Ciências da Educação e nas Ciências da Informação (Cox, Andrew, 2005).

Para (Chu, M. T.; Khosla, R., 2009), as CoP aumentam as competências essenciais da organização, dinamizam a aprendizagem e a inovação, proporcionam maior eficiência nas rotinas de trabalho e otimizam a capacidade de resposta aos problemas internos e externos à instituição. $\mathrm{Na}$ mesma perspetiva, (Wenger, E.; Trayner, B.; Laat, M., 2011) as Comunidades também podem ser vistas como um mecanismo de ajuda, pois é através das CoP que os trabalhadores unem forças para enfrentar os desafios individuais e coletivos nas organizações.

As suas aplicações práticas transvazam o mundo empresarial, encontrando-se estas em contextos organizacionais tão distintos como: gestão de cuidados de saúde (e.g. [ (Perrott, B.E., 2007); (Schenkel, A; Teigland, R., 2008)]); governance - planeamento social, agricultura, etc. (e.g. [ (Kranendonk, R.P.; Kersten, P.H., 2007)]); colaboração em investigação científica (e-science) (e.g. [ (Farooq, Muhammad et al., 2008)]); ou ainda nos mais diversificados domínios da educação (e.g. [ (Wenger, Etienne; Mcdermott, R.; Snyder, W. M., 2002a)]); de formação especializada em posto de trabalho (e.g[ (Doak S. \& Assimakopoulos, D., 2007); (Fuller, A.; Hodkinson, P.; Unwin, L., 2005)]).

Neste sentido, (Santos, N., 2005) afirma que as Comunidades de Prática são estruturas de significativa relevância nas organizações do conhecimento, e são vistas como as oficinas do capital humano e o lugar em que as coisas acontecem. Reconhecer sua existência e entender a oportunidade de incentivar o seu aparecimento é muito importante para a organização - considerando que, as Comunidades, colaboram na formação do capital humano. 
Apesar de representar uma estrutura informal, a CoP está ligada à Organização através do envolvimento dos seus membros, que são profissionais da Organização e que partilham, entre si, experiências e conhecimentos ligados ás suas práticas profissionais (Flor, C., 2015) Neste sentido, para além de trazer benefícios para os seus membros, as CoP criam uma série de benefícios para a Organização como um todo, podendo ser consideradas estruturas sociais eficazes para a aprendizagem Organizacional pela sua potencialidade de disseminar o conhecimento explícito e tácito. (Flor, C., 2015)

No livro Comunidades Virtuais: Como As Comunidades de Práticas na Internet Estão Mudando os Negócios, Teixeira Filho expõe que as principais atividades relacionadas com a Gestão do Conhecimento, em geral, são: partilhar o conhecimento internamente, atualizar o conhecimento, processar e aplicar o conhecimento para algum benefício organizacional, encontrar o conhecimento internamente, adquirir conhecimento externamente, reutilizar o conhecimento, criar novos conhecimentos e partilhar o conhecimento com a comunidade externa. Segundo o autor, as comunidades de prática podem ajudar em cada uma dessas ações (Teixeira Filho, Jayme, 2002).

Numa sociedade onde é cada vez mais requerida uma cultura de aprendizagem permanente, a construção social do conhecimento e a ideia de aprendizagem virtual parecem fazer emergir um novo paradigma, atribuindo cada vez mais importâncias às comunidades virtuais de prática e seus processos colaborativos nos quais se fundamentam.

Estes processos colaborativos, indissociáveis da aprendizagem em comunidade, relativizam a ideia de aprendizagem como processo individual ou mesmo inter individual, para passar a ser um processo partilhado e social. Contudo, apesar de reconhecida a sua importância, a emergência das comunidades de prática e respetivas dinâmicas de aprendizagem colaborativa, não são ainda um processo fácil na nossa cultura de trabalho e estrutura organizacional. Existem elementos da nossa cultura de trabalho e formas de funcionamento das instituições que limitam ou dificultam a criação destes novos ambientes virtuais de aprendizagem e de formação. 


\subsection{O papel do capital social nas Comunidades de Prática}

A convivência entre os membros de uma comunidade, inclusive o estabelecimento de laços de afinidade, é definida a partir de pactos sociais ou padrões de relacionamento. Esses padrões de relacionamento são construídos e aprofundados pelo capital social que é desenvolvido no grupo.

Para (Hall, H., 2001b), o papel do capital social é extremamente importante para delimitar a natureza, o grau, as barreiras e o papel dos prémios recebidos para o incremento da troca de conhecimento. (Torsvik, Gaute, 2000) argumenta que a confiança é condição para a construção do capital social e seu desenvolvimento.

O autor considera que o capital social é um dos resultados do desenvolvimento da confiança dentro de uma rede de relacionamentos.

Essa confiança pode ser baseada em:

1) Autointeresse, envolvendo ganhos mútuos, quando interações adicionais futuras são esperadas ou quando têm motivação pró-social,

2) Altruísmo,

3) Princípios,

4) Manutenção do status social.

Neste trabalho de investigação destaca-se um aspeto relevante para a utilização do conceito de capital social, que passa pela discussão sobre a intervenção das organizações na formação e sustentação das Comunidades de Prática. No que tange a esse assunto, (Dudley, R.G., 2004) questiona se o capital social pode ser criado, e como seria esse processo. Essas questões são relevantes, segundo o autor, pois, uma vez estabelecido o capital social, é autorreforçado com o seu potencial, promovendo uma estratégia de intervenção nas organizações. Essa estratégia de intervenção seria possível através de três dimensões do capital social, identificadas por (Nahapiet, J.; Ghoshal, S., 1998). Os autores caracterizam as três dimensões como: Estrutural; Relacional e Cognitiva. 
A dimensão estrutural, que se refere à formação de redes informais que capacitam a identificação de um indivíduo pelo outro, como recursos potenciais na rede, incluindo laços fortes (contatos regulares e frequentes) e fracos (contatos menos frequentes).

A dimensão relacional que diz respeito à dinâmica interpessoal dos indivíduos dentro da rede. Esta dimensão reconhece que o capital social é desenvolvido e fomentado quando indivíduos acreditam na reciprocidade das ações individuais e que os outros cumprirão as obrigações que lhes competem. Tratam-se aqui de questões de confiança, partilha de normas e valores, obrigações, expectativas e identificações, críticas para o desenvolvimento do capital social.

Por último, a dimensão cognitiva, que se refere à necessidade de contexto e de linguagem comuns para a construção do capital social. Para essa dimensão, a construção de um contexto comum é possível por meio da utilização de artefactos e histórias comuns.

(Nahapiet, J.; Ghoshal, S., 1998) argumentam que as dimensões interferem em variáveis que medeiam a criação e partilha do conhecimento.

Estas variáveis são:

- Acesso a ocasiões para trocar ativos provenientes do processo de troca do conhecimento;

- Antecipação do valor através da troca desses ativos;

- Motivação dos indivíduos para partilhar esses ativos;

- Habilidade da organização em se moldar, de acordo com necessidades externas.

Na dimensão Estrutural as comunidades permitem aos indivíduos estabelecer contatos com outros de fora da rede, o que favorece a procura de membros com habilidades diferentes das encontradas na rede.

Na dimensão relacional, as Comunidades de Prática permitem o desenvolvimento das interações interpessoais, necessárias para testar a confiança e o comprometimento dos membros, através da partilha do conhecimento. Desta forma, a comunidade cria seus próprios valores e normas, que são aceites pelos seus participantes. 
A dimensão cognitiva do capital social realiza-se pela criação de histórias, as quais permitem que os novos membros aprendam com os mais experientes, e possibilitam o desenvolvimento da memória da comunidade e sua perpetuação, mesmo depois dos membros que criaram a comunidade saiam.

A relevância deste tópico está ligada à importância das relações promovidas pelo desenvolvimento do capital social na definição de estratégias para a sobrevivência da comunidade, à medida que a mesma avança nos diversos estágios de seu ciclo de vida.

\subsection{Enquadramento e evolução das CoP}

As CoP permitem aceder e aumentar o conhecimento e as competências profissionais, traduzindose num valor imediato para os profissionais. A pertença a uma comunidade constitui uma oportunidade para os seus membros se desenvolverem profissionalmente (Gamble, P. R. \& Blackwell, J., 2001) uma vez que lhes permite ter acesso a recursos e especialistas aos quais dificilmente acederiam caso não pertencessem a essa comunidade (Wenger, Etienne, 2000a). (Wenger, Etienne, 2000b).

Uma estratégia de gestão do conhecimento baseada em Comunidades de Prática, segundo (Wenger, Etienne, 2000a), consiste em sete passos:

1. Mapear as necessidades de conhecimento da organização: Para entender quais conhecimentos são críticos para o negócio, quais ainda não estão a ser devidamente aproveitados e quais competências a organização deseja desenvolver;

2. Encontrar comunidades que tenham potencial de compromisso: Descobrir em torno de quais práticas as pessoas poderiam comprometer-se e identificar-se;

3. Desenvolver comunidades: Ajudar as comunidades-chave a desenvolver seu potencial máximo.

4. Conectar através das fronteiras: As Comunidades não existem isoladas precisam de trocas, tanto interna quanto externamente à Organização. É preciso negociar como comunidades e organização podem contribuir uma com a outra; 
5. Sentimento de pertencer: Acontece em vários níveis, é a forma como a organização nutre o imaginário das pessoas e cria oportunidades de participação;

6. Dirigir o negócio: As Comunidades de Prática não reúnem as pessoas socialmente para que se sintam melhor no ambiente de trabalho, mas a oportunidade é de estar a ligar as identidades profissionais diretamente ao funcionamento atual da organização. Para as organizações poderem tirar proveito desta conexão deve dar suporte sem asfixiar as comunidades, apenas iluminar o seu caminho para que se envolvam e se dediquem;

7.Aplique, avalie, reflita e renove: Crie o impulso.

Desdobrar esta estratégia de conhecimento por ondas de transformação organizacional, num processo contínuo. (Wenger, Etienne, 2000b). (McDermott, R., 1999) inclui na definição de Comunidades de Prática o aspeto da virtualidade. Para esse autor, a Comunidade Virtual de Prática é mais do que um simples grupo trabalhando à distância, e deve ser considerada como um grupo com uma missão comum, devendo entregar um produto, baseado em trocas de informação, regulares e mútuas.

Assim as CoP suportadas por tecnologia começaram como Comunidades em que os seus membros se encontravam pessoalmente, na medida em que as mesmas disponibilizam aos seus membros o "espaço" e as condições para interagirem mesmo quando distribuídos geograficamente e separados por diversos fusos horários (Orlikowski, W. J., 2002). De acordo com estes autores, o determinante é o domínio de conhecimento da $\mathrm{CoP}$, se é do interesse dos membros, se está relacionado com a sua prática diária e a forma de pertença, um ato voluntário. Assim, as CoP cujos membros interagem fundamentalmente através de tecnologias colaborativas, como forma de ultrapassarem as barreiras temporais e geográficas.

De acordo com (Dubé, L.; Bourhis, A. \& Jacob, R., 2006) os elementos a considerar na caraterização das CoPV constam de: Caraterísticas estruturantes nas quais se incluem os aspetos demográficos (orientação, espaço temporal, idade e nível de maturidade); O contexto organizacional (processo de criação das CoP, suas fronteiras, ambiente, grau de institucionalização formal e liderança); Caraterísticas de adesão (tamanho, dispersão geográfica, processo de seleção dos membros e sua 
adesão; Envolvimento e estabilidade, literacia digital, diversidade cultural) e Ambiente tecnológico (nível de dependência das TIC e disponibilidade).

\subsection{Benefícios das CoP}

(Terra, J. C. C.; Gordon, C., 2002) e i (Souza, E. G.; Nokata, L. E., 2011) identificam os seguintes benefícios para a organização advindos da utilização das CoP:

- Ajudam a dirigir a estratégia;

- Auxiliam na resolução de problemas;

- Transferem as melhores práticas;

- Desenvolvem habilidades profissionais;

- Contribuem para recrutar e reter talentos;

- Reduzem as barreiras culturais entre áreas funcionais; ajudam a reduzir custos.

- Promoção da aprendizagem e inovação organizacional;

- Possibilidade de melhorar o fluxo de informação, conhecimentos, práticas e experiências entre pessoas da mesma área de conhecimento ou que exercem a mesma função,

- Identificar novos conhecimentos,

- Mapear as competências individuais para melhor utilização,

- Promover a manutenção e renovação dos conhecimentos armazenados de forma a mantê-los atualizados e confiáveis,

- Otimizar o tempo reduzindo o retrabalho, facilitar e agilizar a partilha de boas práticas e lições aprendidas, superando os limites formais da organização

\subsection{Fatores condicionantes à partilha de conhecimento dentro das Comunidades}

Embora não seja o objetivo deste trabalho discutir a "Gestão do Conhecimento" tão pouco questionar o enfoque que a área de tecnologia da informação dá ao termo, mas sim adotar a lógica de que o conhecimento é um ativo estratégico a ser gerido e que as Comunidades de Prática podem 
e/ou devem ser o tecido social do conhecimento. Por mais que a organização estabeleça processos eficientes, se as pessoas que estão envolvidas no dia-a-dia da organização não participarem efetivamente, fica muito complicado atingir uma cultura de partilha do conhecimento. Alguns autores veem a impossibilidade de se gerir "algo tão organicamente diverso e dinâmico quanto o conhecimento humano" (Albrecht, Karl, 2004). O que está dentro das possibilidades da organização é gerir as condições, tornando o ambiente favorável à aprendizagem. Nesta linha, a proposta é gerir a "cultura do conhecimento". Esta gestão continua irá proporcionar a continuidade de uma Comunidade de Prática que se desenvolva na Organização.

A partilha de conhecimento dentro das CoP e CoPV é condicionada por diversos fatores que a podem potenciar/facilitar ou constranger.

Através da gestão do conhecimento, a organização amplia sua visão sobre o papel das pessoas na criação de estratégias competitivas mais consistentes, pois o conhecimento está diretamente ligado às pessoas e consiste em ativos individuais e coletivos e deve ser construído de acordo com a relevância dos objetivos organizacionais (Castro, S. A.; Cazarini, E. W., 2005). Segundo (Campos, R. L.; Barbosa, F. V., 2001) é importante saber como o conhecimento foi adquirido, e como ele poderá ser utilizado, tendo como base três fatores: tempo, espaço e reconhecimento da necessidade da manutenção, com foco em alcançar resultados positivos na organização.

Esse processo é composto por fatores inibidores que são aqueles que podem dificultar ou impedir, tanto o compartilhamento quanto a gestão do conhecimento.

Estes podem ser de natureza individual ou coletiva sendo que na primeira categoria se incluem os designados fatores intrínsecos e na segunda os extrínsecos, coletivos, tecnológicos ou, ainda, relacionados com fatores organizacionais tais como a cultura, a estrutura ou a tecnologia.

Esse processo é composto por fatores inibidores que são aqueles que podem dificultar ou impedir, tanto o compartilhamento quanto a gestão do conhecimento. Esses fatores inibidores, conforme (Robbins, S. P., 2004), encontram-se nos três níveis de conhecimento: individual, grupal e organizacional. 
Ao nível do indivíduo, o autor elencou a expectativa, os valores, as atitudes, a perceção, a personalidade, a emoção, os sentimentos, a disposição e a motivação. Ao nível do grupo, os fatores inibidores podem surgir de interações estratificadas, estilo de liderança, da confiança e do clima psicológico.

Na esfera da organização, as políticas e práticas de recursos humanos são caracterizadas como fatores que podem inibir a gestão do conhecimento. Para (Riege, A., 2005),os fatores inibidores organizacionais são: falta de clareza na integração entre a estratégia e o modelo de gestão do conhecimento; pouco espaço para compartilhamento; sistema ineficiente de reconhecimento e recompensa para estimular a motivação que leve ao compartilhamento; e ambiente físico inadequado.

Fatores Coletivos - Referem-se a fatores de natureza contextual. Por exemplo, se o grupo em que os indivíduos estão inseridos (organização) não permite o desenvolvimento de sentimentos de confiança (Roberts, Joanne, 2006), estes tendem a não partilharem o seu conhecimento e a terem receio de colocar questões por considerarem que o seu conhecimento não tem interesse para a comunidade; no entanto 'quanto maior a confiança que os membros tiverem entre si, mais reduzidos será os custos sociais da partilha de conhecimento' (Krogh, G. V. \& Grand, S., 2002) pois sem confiança, os membros de uma comunidade podem ter relutância em partilhar o seu conhecimento. A presença de uma relação de confiança entre os indivíduos indica uma grande predisposição para partilhar uma compreensão mútua, construída com base num contexto social e cultural partilhado. O processo de gestão do conhecimento também é permeado por fatores que contribuem para o sucesso dos processos de criação, disseminação e utilização do conhecimento. Esses fatores, com base em (Terra, J. C. C., 2000), encontram-se interligados nas seguintes dimensões: estratégia e alta administração; sistemas de informação e comunicação; cultura organizacional; organização e processos de trabalho; políticas e práticas para a gestão de recursos humanos; e avaliação do resultado. A liderança é um dos fatores facilitadores para a disseminação do conhecimento, pois, a partilha resultará respeito dentro da comunidade e corrobora o estímulo à motivação para a transmissão desse conhecimento. 
Confiança - Para que uma comunidade de prática tenha sucesso, além da necessária participação, a confiança é um elemento fundamental (Preece, Jenny, 2000); (Wenger, Etienne; Mcdermott, R.; Snyder, W. M., 2002a). Por norma os indivíduos não gostam de partilhar o que sabem sem receber nada em troca, com medo de perder o poder que consideram que o conhecimento lhes possa trazer, privilegiando desta forma o interesse individual em prejuízo do interesse coletivo. Como efeito, o conhecimento poderá não chegar onde é necessário. A principal condição para o trabalho em grupo é a confiança mútua que os membros do grupo desenvolvem. (Wenger, Etienne; Mcdermott, R.; Snyder, W. M., 2002a), (Kuan, Y.; Gonzales, R.; Olson, S., 2003) alegam que a partilha de conhecimento tácito, que permite a construção de conhecimento coletivo, é possível somente mediante o crescimento da confiança entre os membros do grupo. Dessa forma, o desenvolvimento das comunidades, originadas a partir de grupos informais que partilham valores e objetivos semelhantes, permite a conquista dessa confiança, de forma quase natural, mas também é possível que essa confiança se desenvolva a partir do convívio de um grupo formalmente constituído.

Um ambiente de confiança e de abertura, sem ambiguidades de linguagem diferente entre indivíduos é fundamental para desbloquear o conhecimento, pois sem isso, os indivíduos não só não se compreendem como também não confiam uns nos outros (Davenport, Thomas H.; Prusak, Laurence, 1998).

A confiança leva a níveis maiores de abertura entre os parceiros, facilitando uma transferência efetiva de conhecimento.

Fatores Extrínsecos (Hard) - Estes correspondem a recompensas, diretas ou indiretas, sendo que a motivação extrínseca resulta da avaliação custo/benefício que os colaboradores fazem ao decidirem envolverem-se ou não em atos de partilha e criação de conhecimento. (Hall, H.; Graham, D., 2004) Se a relação for positiva irão envolver-se nestes processos caso contrário, deixarão de o fazer (Kelley, H. H.; Thibaut, J., 1978).

Individuais - Fatores Intrínsecos (Soft) - Os indivíduos partilham conhecimento motivados por fatores relacionados com a sua personalidade, isto é, partilham o que sabem e ajudam na resolução dos problemas dos outros motivados pela satisfação de praticarem estes atos (Deci, E. L.; Ryan, R. M., 1975); (Krogh, G. V.; Grand, S., 2002) temos como exemplo destes fatores a tentativa de se 
colocar no lugar dos outros membros e atribui-lhes a designação genérica de 'care', i.e., uma norma social nas relações humanas que envolve as dimensões da confiança, empatia, disponibilização de ajuda e benevolência.

Estes fatores tendem a ser considerados como motivações de curto-prazo (Sharratt, M.; Usoro, A., 2003), importantes no momento de atração de novos membros para a comunidade, mas que a médiolongo prazo são mais prejudicais do que benéficos (Hall, H.; Graham, D., 2004).

De acordo com (Preece, Jenny, 2000), quando há confiança entre as pessoas, relacionamentos florescem, sem ela, enfraquecem. A maior parte das interações entre as pessoas ou organizações envolve algum grau de confiança e quanto maior for o risco associado a uma atividade, maior é o nível de confiança necessário.

(Preece, Jenny, 2000) expõe que a falta de indicadores físicos durante as conversas (e.g. gestos) leva a necessitar de um tempo maior no ambiente virtual para se construir confiança do que pessoalmente. Adicionalmente, a confiança virtual apresenta uma dicotomia: por um lado, as pessoas se sentem mais livres para expor detalhes pessoais, mas, por outro lado, a falta de contato real torna a confiança virtual frágil.

Na Cultura organizacional o envolvimento dos colaboradores é condicionado por fatores culturais (Davenport, T. H.; Prusak, L., 2003). Entre os que podem facilitar esse comportamento encontra-se a confiança (só num ambiente de confiança é que todos contribuirão com o seu conhecimento, sem medo de consequências negativas); a visão e os objetivos organizacionais (estes permitem desenvolver um sentimento de envolvimento e de apetência para contribuição entre os colaboradores (Kim, S.; Lee, H., 2005); valores, linguagem e quadros de referência comuns (Davenport, T. H.; Prusak, L., 2003); (Sharratt, M.; Usoro, A., 2003) 'estruturas de oportunidade’ que constituem ocasiões propícias e benefícios obtidos por partilhar conhecimento dentro de comunidades (Krogh, G. V. \& Grand, S., 2002). Considerando que numa organização existem interesses diversos e distribuídos, cada membro procurará estabelecer relações mais próximas com aqueles que partilham os mesmos interesses pois daí advém um maior benefício na partilha do conhecimento (Wellman, B.; Salaff, J.; Dimitrova, D.; Garton, L.; Gulia, M.; Haythornthwaite, C., 2000) no seu estudo sobre comunidades virtuais na Internet, concluíram, também, pela existência 
de obstáculos à comunicação que vão além dos existentes na comunicação presencial, dos quais se destacam o sentimento de isolamento, a perda da riqueza existente na comunicação não verbal e, frequentemente, as dificuldades na utilização da tecnologia, fatores estes introduzidos pela utilização desta como meio de suporte à comunidade.

Para que as barreiras à partilha e criação de conhecimento novo sejam ultrapassadas é essencial que as organizações motivem os seus colaboradores para atos de partilha e de colaboração e que os recompensem pelos mesmos. (Ardichvili, A.; Page, V. \& Wentling, T., 2003); (Chung, L. H., 2001); (Hall, H., 2001b).

Outros fatores que condicionam negativamente os envolvimentos dos colaboradores podem estar relacionados com a falta de tempo e de locais para que os indivíduos se encontrem; $\mathrm{O}$ não reconhecimento de estatuto e/ ou a atribuição de recompensas a quem detém o conhecimento e a intolerância ao erro e à necessidade de ajuda (Davenport, T. H.; Prusak, L., 2003).

Estrutura organizacional - A estrutura organizacional influencia as atitudes de partilha de conhecimento dos colaboradores (Kim, S.; Lee, H., 2005). De acordo com (Chung, L. H., 2001), estruturas organizacionais mais burocráticas e centralizadas tendem a reprimir a criação de conhecimento enquanto as flexíveis e descentralizadas podem encorajar a partilha de conhecimento, especialmente o tácito em virtude de permitirem uma maior interação entre as pessoas;

Os autores (Mendes, L.; Urbina, L.M.S., 2015), salientam que as CoP são focadas na partilha de conhecimentos, no exercício da aprendizagem conjunto e, são organizadas para estimularem os processos de aprendizagem e difusão dos conhecimentos que ocorrem informalmente. Os mesmos autores destacam ainda, que há o comprometimento dos membros com a ajuda mútua e a aprendizagem coletiva; ressaltam o alto nível de integração entre seus membros e lembram que a CoP ultrapassa as fronteiras departamentais e até mesmo organizacionais. (Morales, A.H.; Macías, R.C.F., 2013) , acrescentam a ausência de hierarquia nas CoP, sendo que a posição de cada participante é flexível e dinâmica dependendo do envolvimento nas atividades da comunidade. (Cyrino, M.C.C.T.; J.G., Estevam, 2016) , observa aspetos como o respeito, a confiança, desafio, a negociação de significados e a valorização das singularidades e práticas profissionais. A autora 
aponta que essas características e peculiaridades das CoP formam um solo fértil para o desenvolvimento da identidade profissional, tema de sua pesquisa.

As Comunidades de Prática e a tecnologia, um dos obstáculos que se apresentam para a criação de uma CoP é a preocupação com a necessidade de investimento em tecnologia. Primeiramente é importante observar as possibilidades de comunicação e interação das redes de relacionamento da internet que dispõe de ferramentas colaborativas gratuitas que possibilitam a formação de pequenas redes, como os fóruns, blogs, microblogs, wikis, chats, e-mails. Assim, não se faz necessário altos investimentos, grandes portais. Por outro lado, (Silva, H.F.N.; Arboit, A.E.; Garcia, A.K.; Rigoni, C.F., 2012), enfatizam que o desenvolvimento de CoP não depende obrigatoriamente de tecnologia. Segundo a autora, a tecnologia atua como um importante facilitador para interação entre os participantes de uma comunidade, mas não consiste em um elemento determinante para a sua constituição. A sua pesquisa com os Tribunais de contas no Brasil, demonstrou ainda a efetividade dos eventos e fóruns, como forma de partilha, podendo contribuir para a constituição de CoP.

A utilização de tecnologia como meio de suporte à comunidade tem impacto no modo como os membros se envolvem na partilha e criação do conhecimento.

No que concerne as desvantagens na utilização da tecnologia como suporte há a salientar a perda da riqueza do meio de comunicação, isto é o valor associado à linguagem não verbal (dicas/ rituais), essenciais à partilha de conhecimento tácito, como o referem (Krogh, G. V.; Grand, S., 2002) . Pelo contrário, apresenta como vantagem principal o facto de possibilitar o acesso a um número alargado de pessoas aumentando desta forma as probabilidades de resposta, de colaboração na resolução de problemas, de criação de conhecimento e acesso a um número maior de recursos de informação (Sharratt, M.; Usoro, A., 2003).

(McDermott, R., 1999) inclui na definição de Comunidades de Prática o aspeto da virtualidade. Para esse autor, a Comunidade Virtual de Prática é mais do que um simples grupo trabalhando à distância, e deve ser considerada como um grupo com uma missão comum, devendo entregar um produto, baseado em trocas de informação, regulares e mútuas. 
De facto, as tecnologias de informação desempenham um papel importante nas atividades das CoP. Tecnologias colaborativas tais como o correio eletrónico, as listservs, os boletins eletrónicos, os fora, os chats facilitam o desenvolvimento das $\mathrm{CoP}$ cujos membros se encontram distantes uns dos outros (temporal e geograficamente).

Para além disso, as CoP promovidas por tecnologias interativas online podem funcionar como uma estratégia para persuadir os membros de uma dada organização a adotarem a gestão do conhecimento (Wang, Y. et al., 2007).

A gestão das CoPV é caraterizada pela autogestão. Neste modelo, a existência de liderança exerce influência, sobre os demais membros, para a consecução de objetivos preestabelecidos. Dessa forma, o líder precisa conhecer plenamente o domínio da CoPV, uma vez que sua atividade é crucial para o crescimento e durabilidade da mesma (Ferraz, I.N.; Dornelas, J.S., 2017).

A vitalidade de uma comunidade depende da existência de atividades diversificadas e suficientemente desafiantes para o conjunto dos membros:

1. O perfil dos membros deve ser conhecido (exemplos: área de atuação profissional; a qual instituição o integrante está vinculado; quais os interesses comuns entre eles);

2. Definição clara dos objetivos da Comunidade (domínio);

3. Definir os critérios para a adesão dos membros, se houver (exemplos: área de formação profissional, um tipo de conhecimento, cargos específicos);

4. Estipular o critério de liderança da Comunidade (exemplo: haverá mudança de líder ao longo do tempo a fim de que cada instituição, por meio do membro, exerça este papel);

5. Planear os recursos financeiros necessários ao desenvolvimento das atividades (exemplo: valores destinados à viabilidade das reuniões presenciais, compra e manutenção dos equipamentos para as videoconferências, entre outros);

6. Programação dos encontros da Comunidade: frequência das interações (quinzenal, mensal, etc.); modo (virtual ou pessoalmente); duração dos encontros (tempo para as reuniões); formato (tópicos já definidos para a reunião, discussões abertas ou um com as duas formas). 


\subsubsection{Papeis dos membros da Comunidade de Prática}

\begin{tabular}{|c|c|}
\hline PAPEL & FUNÇÃO \\
\hline Coordenador & $\begin{array}{l}\text { Liderar a comunidade e estimular o seu crescimento. } \\
\text { Normalmente esse papel não é atribuído ao maior especialista } \\
\text { no assunto, pois geralmente ele não tem tempo para se envolver } \\
\text { na criação de comunidades, mas, é importante que ele conheça } \\
\text { o domínio da mesma. }\end{array}$ \\
\hline Moderador ou mediador & $\begin{array}{l}\text { Manter o ritmo da comunidade, sabendo o momento certo para } \\
\text { estimular os membros a participar, proporcionando maior } \\
\text { interação entre as pessoas. O seu perfil envolve não só domínio } \\
\text { sobre os temas e conhecimento do ambiente em que a } \\
\text { comunidade vai interagir, mas também habilidades } \\
\text { interpessoais e de negociação. Em alguns casos, também } \\
\text { desempenha o papel de coordenador. }\end{array}$ \\
\hline Suporte técnico & $\begin{array}{l}\text { Administrar a ferramenta na qual a comunidade se apoia para } \\
\text { as interações virtuais. Especialista (expert ou perito), função é } \\
\text { apoiar tecnicamente a comunidade. Normalmente não é o } \\
\text { moderador, mas a sua liderança e estímulo são importantes para } \\
\text { o sucesso do grupo. Sempre que possível deve ser o iniciador } \\
\text { das questões. }\end{array}$ \\
\hline $\begin{array}{l}\text { Facilitador de conhecimento } \\
\text { (knowledge brokers) }\end{array}$ & $\begin{array}{l}\text { Filtrar as perguntas e enviar para os especialistas naquele } \\
\text { assunto. Assim, cria um comprometimento maior com a } \\
\text { resposta, já que estes sabem que a pergunta é direcionada para } \\
\text { eles, além de otimizar o tempo de resposta, visto que as }\end{array}$ \\
\hline
\end{tabular}


Doctorado en Salud, Discapacidad, Dependencia y Bienestar

Bibliotecário

\subsubsection{Papel do moderador/ Líder}

O papel do moderador é bastante ressaltado na literatura, apontado como um papel crítico, e são expostas as principais funções e competências necessárias (Teixeira Filho, 2002).

(Wenger, Etienne; Mcdermott, R.; Snyder, W. M., 2002a) indicam um conjunto de funções executadas pelo moderador

- Identifica assuntos importantes no domínio da comunidade;

- Planeia e efetua a facilitação de eventos da comunidade;

- Liga membros da comunidade informalmente, cruzando fronteiras entre as unidades organizacionais;

- Fomenta o desenvolvimento de membros da comunidade;

- Gere a fronteira entre a comunidade e a organização formal, como equipas e outras unidades organizacionais;

- Ajuda a formular a prática, incluindo a base de conhecimento, lições aprendidas, melhores práticas, ferramentas e métodos, bem como eventos de aprendizagem;

- Avalia a saúde da comunidade e as contribuições dos membros e da organização.

173

Comunidad@Buenas Prácticas de Seguridad, Salud e Calidad de Vida en el trabajo INIAV

"Factores críticos de éxito" 
(Lévy, Pierre, 1998) refere-se ao líder como um animador, alguém cujo papel também consiste em auxiliar os membros a pesquisar, selecionar e organizar a informação. Ao mesmo tempo em que atua como motivador do processo de aprendizagem, o animador também integra e forma grupos para discussões, para pesquisas e execuções de tarefas.

\subsubsection{Participação de especialistas}

A participação de especialistas no domínio da comunidade foi ressaltada por Wenger.

(Neves, Ana, 2018), (Preece, Jenny, 2000) e (Wenger, Etienne; Mcdermott, R.; Snyder, W. M., 2002a). Os especialistas respondem questões específicas, dão conselhos, ajudam a dar legitimidade à comunidade e atraem outras pessoas chave para a comunidade.

\subsection{Criação, Estrutura e Desenvolvimento das CoP}

(Wenger, Etienne, 2004) define também três estruturas que são necessárias para integrar o trabalho das comunidades de prática na organização:

1. Estrutura de patrocínio, inclui empenho e apoio das organizações às comunidades através do seu patrocínio e publicitando as suas ideias e propostas criadas, para que desta forma as comunidades de prática consigam prosperar e ter impacto sobre as organizações.

2. Estrutura de reconhecimento, a participação ativa na comunidade deve ser incentivada pelo reconhecimento dos seus pares, mas também pela organização.

3. Estrutura de apoio, que proporcione pontos de encontro e de infraestruturas tecnológicas, bem como a designação de alguns papéis explícitos, com o tempo dedicado para a comunidade.

No processo de criação e desenvolvimento de CoP é designar um coordenador responsável, seja através da criação de um departamento específico ou da nomeação de uma pessoa responsável. 
Como a criação das CoP necessita, no mínimo, da existência de determinados grupos formais, sobre os quais suas bases serão consolidadas, a primeira função do coordenador é a realização do mapeamento destes grupos, dentro da Organização.

Nesta etapa é necessário que o coordenador explique o que é uma $\mathrm{CoP}$, quais os benefícios que podem ser obtidos através delas e a importância do envolvimento de todos para o sucesso da mesma. Esta explicação deve ser realizada de uma maneira não ilusória, para não provocar futuras frustrações e consequente desmotivação dos envolvidos.

Wenger et al (2001) afirmam que as CoP necessitam de determinadas ações para a sustentação de seu desenvolvimento. Deste modo, proporcionar infraestrutura necessária ao desenvolvimento da CoP, disponibilizando os recursos necessários para a realização de suas atividades, dando a elas uma maior legitimidade.

Outra etapa importante, quando a organização deverá recompensar os integrantes das comunidades, seja com incentivos monetários, como gratificações ou prémios, ou através de outras motivações.

A partilha das experiências deve ser considerada pela organização como uma função de seus integrantes.

A organização deve procurar medir os resultados obtidos pela implantação de CoP. Não é um a atividade fácil, pois os resultados para além de aparecerem a longo prazo, não são fáceis de serem percebidos. Um processo de se medir os resultados é ouvindo os depoimentos dos seus membros, reunindo as evidências empíricas de casos de sucessos, originados da partilha ou da criação de um determinado conhecimento pela CoP. O último passo é divulgar estes resultados obtidos para toda organização, esta atividade possibilitará a manutenção da motivação dos que participam ativamente e motivará os demais, que não estão envolvidos, a participarem nas CoP.

Uma comunidade de prática envolve muito mais do que o conhecimento técnico ou habilidade associada à obrigação de alguma tarefa. Os membros estão enredados num conjunto de relacionamentos ao longo do tempo (Lave, J.; Wenger, E., 1991) e comunidades se desenvolvem ao redor de coisas que interessam às pessoas (Wenger, E., 1998a). 
O fato de as Comunidades de Prática estarem organizadas em torno de alguma área de conhecimento e atividade em particular dá aos seus membros um sentimento de iniciativa conjunta e de identidade. Para uma comunidade de prática funcionar, precisa gerar e apropriar-se de um repertório de ideias, compromissos e lembranças compartilhados. A CoP também precisa desenvolver vários recursos, tais como ferramentas, documentos, rotinas, vocabulário e símbolos que de algum modo conduzem o conhecimento acumulado pela comunidade. Por outras palavras, tal iniciativa envolve prática e formas de fazer e abordar coisas que são compartilhadas para alguma extensão significativa entre os membros. Nas comunidades de prática as pessoas são movidas por um sentimento de propósito e por uma necessidade de conhecer o que os outros sabem, sendo definidas pelo conhecimento que geram, em vez da tarefa, característica que as distingue das equipas de trabalho. Além disso, a perenidade de uma comunidade é definida pelo valor que ela cria para seus membros e não pela conclusão de um projeto predeterminado.

Nas equipas de trabalho e de projetos, as metas são determinadas pelo gestor ou coordenador; enquanto na comunidade são negociadas entre os seus membros.

Cabe também ao líder das equipas de trabalho a escolha dos membros que desenvolverão o projeto; enquanto nas comunidades de prática, os componentes auto selecionam-se.

Por fim, cumpre destacar que as redes informais têm como objetivo colher e passar informações, inexistindo, como ocorre nas comunidades de prática, iniciativas conjuntas - tais como o desenvolvimento partilhado de ferramentas - que as mantenham unidas.

As redes informais são, em essência, um conjunto de relacionamentos, o que, por si, não as tornam uma comunidade de prática.

É exigido das comunidades um sentimento de missão, pois há algo que as pessoas querem concluir ou construir juntas e que nasce de seu repertório partilhado (Ipiranga, A.S.R.; Menezes, R.B.; Matos, J.L.L.; Maia, G.L.L., 2005).

As Comunidades de Prática não podem ser cultivadas da mesma forma que se desenvolvem estruturas organizacionais tradicionais. Mais do que planear, dirigir e organizar as suas atividades, desenhar e desenvolver comunidades de prática implica obter e encorajar gradualmente a 
participação de indivíduos com talento e capacidades para gerar e implementar ideias inovadoras. As CoP não se confundem com departamentos formais pois são normalmente constituídos por pessoas que se envolvem voluntariamente numa comunidade. Também não se confundem com qualquer rede informal, pois a maioria carece de domínio ligado a uma prática.

Para desenvolver e estimular a dinâmica das Comunidades de Prática há que estar atento(a) aos seguintes pontos:

- Legitimar a participação dos membros: as Organizações podem reservar um tempo (diário, semanal, mensal etc.) a fim de que os membros participem das atividades comunitárias. Outro aspeto é a criação de um local para que estas aconteçam.

- Negociar o contexto estratégico: as Organizações devem ter um sentido claro de como o conhecimento está ligado às estratégias de negócio e usá-lo para despertar, nas Comunidades, o seu próprio valor estratégico. Esse processo envolve uma negociação que trabalha em dois sentidos: inclui a compreensão do que é conhecimento e, portanto, quais práticas uma determinada atividade exige; por outro lado, clama pela atenção para o que as CoP trazem como possíveis direções estratégicas, conhecimento retirado da prática diária.

- Estabelecer sintonia com práticas existentes na Organização: geralmente o conhecimento que as Organizações necessitam já está presente dentro das mesmas. Assim, promover a formação de Comunidades de Prática que aproveitem esse potencial é um ponto de partida muito interessante.

- Alinhar os sistemas de reconhecimento às CoP: elementos do ambiente Organizacional podem favorecer ou inibir a formação de Comunidades (sistemas de recompensa, processos de trabalho, cultura corporativa, política da empresa, dentre outros). Por exemplo, remuneração e reconhecimento: esses são atribuídos de cima para baixo e podem ser interpretados como formas de manipular o comportamento e funcionamento de uma CoP. De outro modo, o reconhecimento e as recompensas não devem ser esquecidos aos que participam, e uma forma interessante é incluir, na avaliação de desempenho, aspetos que valorizem a participação dos funcionários em atividades comunitárias e de liderança. 
Doctorado en Salud, Discapacidad, Dependencia y Bienestar

- Fornecer suporte: os grupos mencionados são autossuficientes, contudo podem ser beneficiados por alguns recursos, tais como: peritos externos à Organização, viagens, instalações param as reuniões e Tecnologia de Comunicação.

\subsection{Fatores Críticos de Sucesso}

Os Fatores Críticos de Sucesso mais significativos poderão ser descritos da seguinte forma: Incluir o hábito de participar da Comunidade de Práticas na rotina da força de trabalho envolve uma mudança de cultura, que se torna mais crítica no que se refere à troca de experiências negativas; Dedicar um tempo para consultar e utilizar práticas criadas por outras pessoas também envolve uma mudança de processos organizacionais; Seleção de pessoas com perfil adequado para compor os papéis-chave da estruturação e implementação de uma Comunidade de Práticas, estas pessoas deverão ser reconhecidas corporativamente pelo excelente relacionamento interpessoal com seus pares e equipas, e pelo papel de formadores de opinião que exercem na sua área de atuação. Caso a Comunidade envolva atividades de validação de práticas, estas deverão ser realizadas por membros notoriamente reconhecidos na comunidade e que tenham experiência no assunto; Necessidade de criação e manutenção de uma estrutura para o planeamento, implementação e continuidade da Comunidade.

É fundamental que esta estrutura envolva pessoas desde a Direção até os responsáveis pelo treino e disseminação. Esta estrutura deverá ter a representatividade de diversas áreas da Organização: Gestão de Conhecimento, Processos, Recursos Humanos, Tecnologia de Informação e as áreas técnicas que serão o foco da Comunidade de Práticas; Obtenção do Patrocínio e comprometimento da alta e chefias intermédias.

Uma vez que a utilização da Comunidade de Práticas envolve mudança de cultura, criação e manutenção de uma infraestrutura de suporte e dedicação parcial da força de trabalho da organização, a obtenção e manutenção do patrocínio é um fator crítico de sucesso (Rosa Neto, J. R.; Vilanova, L.O. et al., 2006). 
A Comunidade é reconhecida como a estrutura social na qual o empreendedorismo é valorizado e a participação confere competência (Flor, C., 2015). Este ambiente age como uma incubadora, uma vez que consiste no local onde os indivíduos interagem e desenvolvem aptidões relevantes para otimizar as capacidades dos membros e da comunidade como um todo.

A identidade assume o papel de promotor do sentimento de pertença de um dado indivíduo na comunidade e através desta capacidade, o indivíduo sofre uma transformação de aprendiz para douto.

\subsection{Comunidades Virtuais de Prática | CoPV}

Segundo Wenger (2015), as novas tecnologias, como a internet, tem aumentado o alcance das interações. Entretanto, o aumento do fluxo de informações não elimina a necessidade de comunidade, logo, expandem-se as possibilidades para novos tipos de organização, por exemplo, a comunidade virtual de prática (CoPV), uma forma de fomentar a interação entre os pares e grupos para discussões e ações, visando o alcance de objetivos, anseios e atendimento de questões coletivas, pode ser realizada tanto em nível presencial quanto virtual. Verifica-se assim que as redes sociais virtuais constituem-se em importantes espaços nos quais as questões individuais podem ser identificadas e reconhecidas como coletivas, oferecendo melhores condições de ação das pessoas, principalmente se comparadas às ações individualizadas (Tavares, W.; Paula, A.P.P., 2015). Ferramentas que se vêm popularizando mais recentemente, como listas de discussão, fóruns, glossários compartilhados, pastas de documentos de referência, salas de bate-papo (chat) e facilidades de comunicação com vídeo e áudio (e.g. videoconferência), assim como ferramentas de uso mais antigo, como o telefone e fax, possibilitam a criação de espaços para interação entre as pessoas (Wenger, Etienne; Mcdermott, R.; Snyder, W. M., 2002a); (Nickols, Fred., 2000). De acordo com Wenger, McDermott e Snyder, o que possibilita que membros partilhem conhecimento não é a escolha de uma forma específica de comunicação (presencial em oposição à baseada na $W e b$, por exemplo), mas sim a existência de uma prática partilhada - um conjunto comum de situações,

problemas e perspetiva (Wenger, Etienne; Mcdermott, R.; Snyder, W. M., 2002a).Ainda de acordo 
com os autores citados, partilhar uma prática requer interação. Embora muitas comunidades comecem entre pessoas que trabalham no mesmo lugar ou morem próximas, a proximidade física não é uma necessidade. Muitas comunidades de prática são distribuídas em grandes distâncias).

\subsubsection{Vantagens na adoção de uma Wiki}

De acordo com o estudo da investigadora (Flor, C., 2015), passam por aproximações informais, oportunidades de construção de uma cultura de confiança, ganhos de tempo, formação de colaboradores, uso de outra tecnologia, viagens de colaboração de longas distâncias e na redução de e-mails.

As wikis permitem que os membros tenham maior controlo sobre a atividade que exercem dado o seu fácil uso, possibilitando ao mesmo tempo armazenar informações de membros com diferentes especializações.

A cultura de partilha de informação é incrementada fomentando a sensibilidade dos membros para comentar e anotar documentos para usufruto de membros de outras especializações. Ferramentas e técnicas, independentemente de quais sejam, não operam de forma isolada em programas de gestão do conhecimento, pois necessitam de apoio no ambiente da Organização. Segundo a National Library for Health (National Library for Health - NHS, 2005) os elementos-chave do ambiente são as pessoas, os processos e as tecnologias, os quais, por sua vez, atuam em duas frentes: como alavancas ou barreiras para a eficaz gestão do conhecimento.

Em síntese os fatores que afetam a implementação de iniciativas de GC segundo (Cabrita, M.R., 2009) são a liderança, cultura, medo, conhecimento e competências, integração organizacional, captação do conhecimento tácito, facilidade de utilização e envolvimento dos stakeholders e realização de benefícios.

O primeiro grupo é um núcleo central de pessoas que participa ativamente das discussões públicas da comunidade, que inclui o moderador da comunidade. Normalmente é um grupo pequeno, de 10 
a $15 \%$ do conjunto de pessoas da comunidade. O próximo grupo é o de membros ativos, que frequenta os eventos regularmente, participa ocasionalmente dos fóruns da comunidade, mas sem a regularidade ou a intensidade do grupo central.

O grupo de membros ativos também é pequeno, de 15 a $20 \%$ da comunidade. A porção maior da comunidade é de membros periféricos que raramente participam ( (Wenger, Etienne; Mcdermott, R.; Snyder, W. M., 2002a); (Preece, Jenny, 2000). Em inglês é usado o termo lurker (observador), um termo pejorativo (Preece, Jenny, 2000), para descrever alguém que observa o que está a acontecer, mas fica em silêncio.

Os observadores preferem ficar observar por diversas razões, tais como falta de tempo para contribuir mais ativamente ou timidez (Wenger, Etienne; Mcdermott, R.; Snyder, W. M., 2002a); (Preece, Jenny, 2000).

\subsection{Níveis de participação}

A presença na comunidade é sempre um ato de iniciativa voluntária motivado pela necessidade que os indivíduos sentem em discutir a sua prática com o objetivo de adquirirem mais conhecimento [ (Ardichvili, A.; Page, V. \& Wentling, T., 2003); (Zboralski, K.; Gemuenden, H. G. \& Letti, C., 2004)] para melhorarem o desempenho das suas funções (ou atividades) (Gamble, P. R. \& Blackwell, J., 2001).

Central: tem a seu cargo a liderança da comunidade, condução de projetos, lançamento de novos temas e desafios.

Ativo: encontram-se regularmente e têm uma participação efetiva no fórum de discussão.

Periférico: é composta pelos elementos novos na comunidade que vão observando e aprendendo. 


\subsubsection{Ativos periféricos}

Segundo, (Wenger, Etienne; Mcdermott, R.; Snyder, W. M., 2002a), os ativos periféricos acompanham os trabalhos da comunidade, podem ter conversas privadas sobre as discussões travadas, aprendem bastante e colocam o conhecimento adquirido em uso.

Para além dos três níveis de participação, há pessoas que não são participantes, mas têm interesse na comunidade, que incluem "vizinhos intelectuais" (Wenger, Etienne; Mcdermott, R.; Snyder, W. M., 2002a).

Os membros da comunidade movem-se entre esses níveis e chegam às pessoas externas podendo envolver-se com a comunidade por um tempo, pois as fronteiras são fluidas.

Segundo (Wenger, Etienne; Mcdermott, R.; Snyder, W. M., 2002a), a chave para uma boa participação numa comunidade e um grau de movimentação saudável entre os níveis é projetar atividades da comunidade que permitam que participantes de todos os níveis se sintam como membros efetivos.

Os autores citados salientam que a interação ocorre em espaços públicos (e.g. fóruns de discussão virtuais e eventos presenciais ou virtuais) e privados, que é o contato um a um entre membros da comunidade.

Essas duas dimensões estão relacionadas, pois, quando os relacionamentos entre os indivíduos são fortes, os eventos são mais ricos. Quando os participantes se conhecem bem, frequentemente vão aos eventos da comunidade com diversos propósitos, tais como: completar uma tarefa de um grupo pequeno, agradecer a alguém por uma ideia e encontrar alguém para ajudar a resolver um problema. A chave para projetar espaços da comunidade é orquestrar atividades tanto no espaço público como no privado que usem a força dos relacionamentos individuais para enriquecer os eventos e usem eventos para fortalecer os relacionamentos individuais (Wenger, Etienne; Mcdermott, R.; Snyder, W. M., 2002a). 


\subsubsection{Participação de especialistas}

A participação de especialistas no domínio da comunidade foi salientada por (Wenger, Etienne; Mcdermott, R.; Snyder, W. M., 2002a) (Neves, Ana, 2018), (Preece, Jenny, 2000). Os especialistas respondem questões específicas, dão conselhos, ajudam a dar legitimidade à comunidade e atraem outras pessoas chave para a comunidade.

De acordo com (Wenger, Etienne; Mcdermott, R.; Snyder, W. M., 2002a), o que possibilita que membros partilhem conhecimento não é a escolha de uma forma específica de comunicação (presencial em oposição à baseada na $W e b$, por exemplo), mas sim a existência de uma prática partilhada - um conjunto comum de situações, problemas e perspetivas. Ainda de acordo com os autores citados, partilhar uma prática requer interação. Embora muitas comunidades comecem entre pessoas que trabalham no mesmo lugar ou morem próximas, a proximidade física não é uma necessidade.

Segundo (Wenger, Etienne; Mcdermott, R.; Snyder, W. M., 2002a), se alguma interação presencial é absolutamente necessária em comunidades de prática virtuais e qual é o mínimo necessário ainda são questões em aberto. Entretanto, novas tecnologias e a necessidade de globalização.

Estão a fazer com que comunidades de prática virtuais rapidamente sejam a regra em vez de exceção. Partilhar conhecimento tácito requer interação e processos de aprendizado informais, como contar histórias (storytelling) e conversar (Wenger, Etienne; Mcdermott, R.; Snyder, W. M., 2002a).De acordo com os autores supracitados, as comunidades de prática estão na melhor posição para codificar conhecimento porque podem combinar os aspetos tácitos e explícitos do conhecimento.

\subsection{Condução de eventos presenciais}

Estes eventos servem para aumentar a confiança e a transferência de conhecimentos tácitos entre os membros, renovam o relacionamento entre as pessoas e ajudam a comunidade se tornar um ente presente nas vidas de seus componentes, que tendem a ser absorvidos pelos eventos do dia-a-dia. (Teixeira Filho, Jayme, 2002); (Davenport, Thomas H.; Prusak, Laurence, 1998); (Gongla, P.; 
Rizzuto, C.R., 2001); (Dixon, Nancy M., 2000) e (Wenger, Etienne; Mcdermott, R.; Snyder, W. M., 2002a).

"Nem só de interação virtual vive uma comunidade virtual. Pode ser útil organizar reuniões presenciais com certa periodicidade".

Eventos presenciais servem para:

a) aumentar a confiança entre os membros (Davenport, Thomas H.; Prusak, Laurence, 1998);

b) transferir conhecimentos tácitos entre os participantes da comunidade (Gongla, P.; Rizzuto, C.R., 2001);

c) renovar o relacionamento entre os membros (Dixon, Nancy M., 2000);

d) ajudar a comunidade a se tornar um ente presente nas vidas de seus componentes, que tendem a ser absorvidos pelos eventos do dia-a-dia (Wenger, Etienne; Mcdermott, R.; Snyder, W. M., 2002a).

\subsection{Dimensões de análise dos fatores críticos de sucesso para a manutenção das comunidades de prática}

\subsubsection{Dimensão Organizacional}

A dimensão organizacional, para (Scarso, E.; Bolisani, E., 2008), diz respeito à estrutura da Comunidade, aos papéis dos membros, aos mecanismos fundamentais de funcionamento e à relação da CoP com o restante da organização. Deverá preocupar-se com questões como: o relacionamento entre a estrutura hierárquica existente e a transferência de poder para a linha de gestão em virtude da CoP; definição de como as Comunidades podem coexistir com as estruturas já presentes, sobretudo quando consideradas "parte do sistema"; opção quanto ao tipo de gestão: local ou centralizada pelo modelo global da organização; conflito de prioridade nas atividades dos membros (como colaboradores da instituição e como integrantes das CoP); mecanismos de governança das Comunidades; e, por fim, o papel da liderança. 
(Scarso, E.; Bolisani, E., 2008) destacam que as CoP não respondem bem ao controle rigoroso do estilo gestão tradicional e que esse modo pode bloquear as contribuições espontâneas dos membros. Também sobre liderança, citam os estudos de (Bourhis, Dubé, \& Jacob, 2005), (Cargill, 2006) e (Von Wartburg, Rost, \& Teichert, 2006) para afirmar que ela é um ingrediente essencial nas CoP de sucesso, e que o papel do líder assume características especiais, baseadas em diretrizes como influência, respeito e estímulo intelectual.

Relacionamento com a estrutura existente. A transversalidade proporcionada pela CoP entre as distintas unidades da organização pode gerar conflitos em virtude da estrutura hierárquica organizacional. O desenvolvimento de uma Comunidade, por vezes, exige a transferência de poder para a linha de gestão, e isso pode ser percebido como um elemento para a competição interna na organização;

A questão de como as $\mathrm{CoP}$ podem coexistir com as estruturas presentes na organização é crítica, especialmente quando elas assumem uma configuração formal e são reconhecidas como uma "parte do sistema". (Wenger, Etienne; Mcdermott, R.; Snyder, W. M., 2002a)

Gestão local versus gestão centralizada. As $\mathrm{CoP}$ com gestão central criam uma prática comum e facilitam a adesão dos membros, já as que têm gestão local proporcionam uma melhor delimitação do foco e agem em questões específicas de interesse dos participantes (Ardichvili, A.; Maurer, M.; LI, W.; Wentling, T.; Stuedemann, R., 2006).

\subsubsection{Dimensão Individual}

(Zboralski, Katja, 2009) defende que partilhar experiências em Comunidades é uma opção de cunho pessoal, ou seja, cada indivíduo escolhe com quem deseja partilhar o seu conhecimento. Assim, a decisão de interagir com outros membros torna-se um processo complexo, pois os interesses e motivações variam, em grande medida, de pessoa para pessoa. Esta autora também sustenta a ideia de que a participação em Comunidades de Prática é baseada em contribuições voluntárias - o que transforma a motivação dos membros num fator determinante para as interações na CoP. Tal pontochave, ainda utilizando das ideias da pesquisadora, decorre de fontes diversas, tais como: interesse 
no tema do domínio, benefícios em virtude da aquisição de novos conhecimentos, construção de uma rede de contatos e vontade de aumentar o status dentro da organização.

A visualização de ascensão profissional motivou os membros a participarem das Comunidades. Segundo (McDermott, R., 2000), que também trata da dimensão individual, um dos elementoschave destinado a fomentar a participação em Comunidades é conseguir criar um sentimento de segurança que os membros partilhem suas ideias/dúvidas/perceções com os outros participantes.

Na perspetiva do autor, a confiança existente nas relações que compõem a estrutura comunitária é essencial a fim de que o conhecimento e as práticas sejam partilhados. (Cruz, C. C. P.; Motta, C. L. R.; Santoro, F. M.; Elia, M., 2009) A falta de confiança numa base do conhecimento desestimula as pessoas a contribuírem com conteúdos para a sua consolidação. A ausência de confiança nos conteúdos de uma base do conhecimento desestimula as pessoas a consultá-la.

A inexistência de confiança sobre o conhecimento que foi partilhado pode provocar o abandono dos membros de uma Comunidade de Prática. (Majewski, G.; Usoro, A.; Khan, I., 2011) A confiança estabelece a perceção dos participantes da comunidade de que esta possa fornecer conhecimento em ambientes virtuais.

A confiança está associada com a perceção dos participantes da comunidade de que receberão conhecimentos no ambiente virtual. (Thomas, A. U.; Fried, G. P.; Johnson, P.; Stilwell, B. J., 2013) As CoP propiciam a partilha de documentos úteis à rotina de trabalho. (Curran, J. A.; Murphy, A. L.; Abidi, S. S. R.; Sinclair, D.; McGrath, P. J., 2009)A falta de tempo foi relatada como um obstáculo à participação nas atividades da CoPV. (Pemberton, J.; Mavin, S.; Stalker, B., 2007).

Em termos de comunicação online, o tempo também é um FCS, ao considerar que a escrita (para as postagens das perguntas e respostas) é um processo demorado, se comparada à comunicação verbal, desestimulando alguns membros a sua participação na CoP. Ao longo do tempo, o interesse pela CoP pode diminuir, sobretudo se aliado a outros fatores, tais como: se a participação é voluntária ou formalmente institucionalizada, ou ainda se está vinculada à perspetiva de progressão funcional ou somente pela motivação de aprender. 
Os membros necessitam da segurança que seus poderes/status não serão perdidos em função de partilharem seus conhecimentos, sobretudo nos momentos de reestruturação ou de inovação nas empresas. Num estudo de (Zboralski, K., 2009) A expetativa de maior celeridade e de racionalização do trabalho influenciou positivamente para a participação dos membros; A perspetiva de criação ou de solidificação de uma rede de contatos dentro da organização impulsionou as participações dos indivíduos; A visualização de ascensão profissional motivou os membros a integrarem das CoP; Influência do líder -O fator "líder da comunidade" avaliou em que medida as atividades do líder podem influenciar na participação dos membros, e é constituído por: motivar os participantes; planeamento e organização da comunidade; treino e suporte; comunicação/informação; e conhecimento especializado sobre o domínio da CoP; o nível de conhecimento dos líderes sobre os domínios das CoP exercem forte impacto na qualidade das interações dos membros; os níveis de inserção e do poder de influenciar dos líderes auxiliaram no estabelecimento da frequência de participação das pessoas.

\subsubsection{Dimensão Liderança}

O papel do líder é central para a qualidade das interações em Comunidades. É o que afirma (Zboralski, K., 2009) apoiada em estudos de (Wenger, E., 1998a). Os líderes podem ser considerados como facilitadores, o que implica atuar em frentes diversas com o intuito de promover o bom andamento da Comunidade, e assim buscam auxiliar na construção da confiança, da coesão e de um clima positivo para as comunicações.

(Zboralski, K., 2009) afirma que a presença de um líder forte, que tenha influência efetiva, é o principal fator para a qualidade das interações entre os membros. O caráter qualitativo referido pela autora recai sobre a importância e usabilidade dos conhecimentos compartilhados, que são aumentadas em virtude do nível de inserção e influência do líder na CoP.

Segundo (Pemberton, J.; Mavin, S.; Stalker, B., 2007), Comunidades sem líderes tornam-se grupos fragmentados e, em um breve espaço de tempo, perdem-se, e raramente sobrevivem. No entanto, 
para os autores, o grande desafio é medir o grau de interferência do líder, que transita no perigoso limiar entre orientação e autoridade, na dinâmica da Comunidade.

As opiniões dos líderes devem pautar-se, sobretudo, no reflexo do entendimento do grupo quanto a um determinado assunto, o que proporciona o impacto positivo do líder na Comunidade, consoante afirmam (Pemberton, J.; Mavin, S.; Stalker, B., 2007).

Nessa perspetiva, eles alertam para o "impacto de energia" que a participação de um gestor da organização, ao exercer o papel do líder, pode acarretar de negativo à Comunidade - os membros podem sentir-se vigiados e, deste modo, minar seus intuitos de interação. As CoP precisam de um membro que seja respeitado pelos demais para atuar como coordenador. As CoP necessitam de forte envolvimento dos membros, assim como do líder, para seu sucesso

Segundo (Scarso, E.; Bolisani, E., 2008) os fatores críticos de sucesso basearam-se.

Liderança é um ingrediente essencial nas CoP de sucesso, sobretudo na fase inicial. O papel do líder assume características especiais - em comparação com a administração clássica, pautada na hierarquia e sistemas de recompensa -, baseadas em diretrizes como influência, respeito e estímulo intelectual (Von Wartburg, Rost, \& Teichert, 2006);

(Zboralski, K., 2009) No estudo, o autor reafirma um entendimento, já mencionado na literatura, que define as CoP como entidades semiformais em que a participação dos indivíduos é principalmente voluntária e ligada sobretudo a motivações pessoais intrínsecas. Assim, declara que intervenções forçadas por parte das organizações, com o propósito de proporcionar a adesão dos membros em Comunidades, correm sério risco de não obterem êxito - o papel organizacional deve restringir-se a facilitar/encorajar a participação, e não motivar, diante da própria natureza individual do elemento motivação.

A demonstração pública, por parte dos gestores, da importância das atividades das CoP para a organização fomentou as participações apoio da organização à Comunidade" foi capturado por quatro itens: consciência da importância dos trabalhos comunitários à organização; fornecer recursos (tempo a fim de se dedicar às atividades, espaço físico para as reuniões, infraestrutura técnica, cultura organizacional de compartilhamento do conhecimento); falar positivamente a outros 
sobre as atividades do grupo; e apoio do supervisor direto aos seus comandados a participarem das CoP.

\subsubsection{Dimensão Tecnológica}

Tecnologia (McDermott, R., 2000), (Loyarte, E.; Rivera, O., 2007), as ferramentas de tecnologia devem facilitar a dinâmica das atividades da $\mathrm{CoP}$ e não se constituírem em entraves à participação dos membros (Moreno, A., 2001). A tecnologia utilizada precisa ser compreendida/dominada pelos membros para que possam ter participação plena nas atividades da $\mathrm{CoP}$.

(Pemberton, J.; Mavin, S.; Stalker, B., 2007) Em termos de comunicação on-line, o tempo também é um fator crítico a considerar, ao considerar que a escrita (para as postagens das perguntas e respostas) é um processo demorado, se comparada à comunicação verbal, desestimulando alguns membros a sua participação na CoP.

(Scarso, E.; Bolisani, E., 2008) O tipo de suporte tecnológico varia largamente dependendo das características da $\mathrm{CoP}$, ou mesmo da fase do ciclo de vida em que se encontra. Uma infraestrutura tecnológica projetada de forma inadequada pode mesmo impedir o funcionamento de uma Comunidade.

Em CoP fortemente pautadas em TIC, a familiaridade com estas é fundamental para o bom andamento das atividades, e tal competência é especialmente relevante ao líder da CoP que pode auxiliar os demais membros na utilização desse tipo de tecnologia. $\mathrm{O}$ estabelecimento de um grupo de formadores, no espaço físico em que a CoPV aconteceu, minimizou as barreiras quanto às dúvidas e às deficiências para o acesso ao meio virtual.

\subsubsection{Dimensão Tempo}

(Pemberton, J.; Mavin, S.; Stalker, B., 2007), o estudo está estruturado com breve discussão da literatura sobre Comunidades de Prática e integrado nas experiências dos autores nas suas 
participações numa CoP, que possuía como domínio o interesse em investigações e publicações académicas.

A proposta do artigo é expor as dificuldades que uma Comunidade de Prática pode enfrentar nos processos de criação do conhecimento e aprendizagem.

O "efeito" do fator tempo pode ser segmentado da seguinte forma:

- Ao longo do tempo, o interesse pela CoP pode diminuir, sobretudo se aliado a outros fatores, tais como: se a participação é voluntária ou formalmente institucionalizada, ou ainda se está vinculada à perspetiva de progressão funcional ou somente à motivação de aprender;

- A saída de um membro-chave da organização, normalmente os fundadores ou organizadores da $\mathrm{CoP}$, pode conduzir a sua desintegração;

- Em termos de comunicação on-line, o tempo também é um FCS, ao considerar que a escrita (para as postagens das perguntas e respostas) é um processo demorado, se comparada à comunicação verbal, desestimulando alguns membros a sua participação na CoP; (Pemberton, J.; Mavin, S.; Stalker, B., 2007).

Referindo-se ao estímulo das Organizações às Comunidades (Flor, C., 2015) explicita o papel da mesma Legitimar a participação dos membros: as Organizações podem reservar um tempo (semanal, mensal) a fim de que os membros participem das atividades da Comunidade assim como a cedência de a criação de um local para que as interações aconteçam .A investigadora menciona a importância de a Organização beneficiar com alguns recursos, tais como: peritos externos à Organização, instalações para as reuniões e Tecnologia de Comunicação ou seja fornecer suporte através da prática e da aprendizagem significativa numa comunidade, os membros desenvolvem uma identidade, fomentada ao longo do tempo através do estabelecimento de atividades comuns e da partilha de conhecimento (Flor, C., 2015), num espírito de entreajuda. São estas interações que irão fundamentar a existência da comunidade em torno de um domínio de conhecimento e de uma prática específica, e do estabelecimento de relações entre os seus membros. O valor do indivíduo no seio das Comunidades de Prática é dado através da participação social, em particular desempenhando um papel ativo enquanto membro nas práticas da comunidade e construindo uma identidade em relação com a mesma (Flor, C., 2015). 
A descoberta de que há mais pessoas com objetivos e interesses comuns, que eventualmente estejam na posse de dados e opiniões que lhes permite aprender uns com os outros, faz crescer o sentimento de partilha e gerar entre esses indivíduos um maior interesse em manter essas interações. O principal papel de uma Organização nesta fase será o de identificar estes grupos que já sabem que conhecimento é importante partilhar e quais os problemas com que normalmente se deparam e ajuda-los a constituírem uma Comunidade de Prática (Flor, C., 2015).

Para se desenvolver uma Comunidade de Prática é necessário que esses interesses se transformem em algo útil para a Organização. O principal objetivo nesta fase é então promover a Comunidade em torno dos três elementos estruturais que caracterizam uma Comunidade de Prática: o domínio, a Comunidade e a Prática.

A dependência de um líder nesta primeira fase é notória. Alguém respeitado e bem relacionado na comunidade, com conhecimentos acerca do domínio, ajuda ao desenvolvimento da comunidade, mantendo-a focada no seu campo de ação e estimulando a colaboração e a participação dos membros (Flor, C., 2015).

\subsubsection{Dimensão Confiança}

(Majewiski, Grzegorz; Usoro, Abel; Khan, Imran, 2011) O objetivo do estudo é compreender o processo de disseminação do conhecimento em ambientes denominados como "mundos virtuais imersivos". Esses ambientes podem ser utilizados por Comunidades Virtuais de Prática e, segundo os autores, oferecem oportunidades mais ricas para o partilha, se comparados àqueles pautados puramente em textos.

De acordo com (Preece, Jenny, 2000), quando há confiança entre as pessoas, relacionamentos florescem, sem ela, enfraquecem. A maior parte das interações entre as pessoas ou organizações envolve algum grau de confiança e quanto maior for o risco associado a uma atividade, maior é o nível de confiança necessário. 
(Preece, Jenny, 2000) expõe que a falta de indicadores físicos durante as conversas (e.g. gestos) leva a necessitar de um tempo maior no ambiente virtual para se construir confiança do que pessoalmente. Adicionalmente, a confiança virtual apresenta uma dicotomia: por um lado, as pessoas se sentem mais livres para expor detalhes pessoais, mas, por outro lado, a falta de contato real torna a confiança virtual frágil.

A gestão do conhecimento baseia-se principalmente nos ativos intangíveis, e portanto, foca o individuo como fonte de conhecimentos a serem integrados estrategicamente aos produtos e serviços oferecidos pela Organização Este modelo de gestão se destaca por promover um diferencial competitivo para as organizações perante os desafios propostos pelo cenário atual, no qual as oportunidades vêm e vão à velocidade da luz (Hamel, Gary, 2001).

Para que as organizações prosperem ao longo do tempo nesse modelo de gestão, é fundamental promover continuamente a aprendizagem organizacional (Flor, C., 2015). A aprendizagem organizacional trabalha o conhecimento em duas dimensões intrinsecamente vinculadas: a explícita e a tácita. O conceito de aprendizagem organizacional pode ser entendido a partir de diferentes focos: foco na socialização da aprendizagem individual; no processo ou sistema; na cultura; na gestão do conhecimento; no desenvolvimento contínuo; e foco na criatividade e inovação. No trabalho de investigação desenvolvido por (Flor, C., 2015) é referido que o conhecimento tácito é um dos pontos fortes dos colaboradores mais velhos e experientes, apresentando a capacidade de interpretar informação relativa à qual não existe regra formal de processamento. Neste trabalho de investigação (Flor, C., 2015) explicita que o grande problema de organizações detentoras de conhecimento é a saída de trabalhadores detentores de muito conhecimento tácito que não passou a explícito. Existe um grande potencial no conhecimento na sua forma tácita (Flor, C., 2015) partilhar sendo o conhecimento tácito entre colaboradores mais novos e mais velhos é um dos principais desafios da gestão. As novas Tecnologias de Informação e Comunicação (TIC) proporcionaram um grande avanço nas $\mathrm{CoP}$, pois os ambientes virtuais oferecem excelentes meios para a interação entre indivíduos. As CoP são facilitadoras do tácito.

Relações de reciprocidade que existem no grupo. Esta consiste em dar e receber o conhecimento há momentos em que uma pessoa assume o papel de emissor e, em outros, de recetor do 
conhecimento. Neste movimento, consolida-se o sentimento de interdependência entre os membros, e a consciência comunitária surge. Assim, identificam-se mais fatores que seguem:

1. A reciprocidade é um dos elementos que auxiliam na geração de confiança;

2. As relações de reciprocidade estão associadas ao ato de fornecer conhecimento em ambientes virtuais;

3. A reciprocidade está associada ao impulso de se buscar conhecimento em espaços virtuais;

4. A confiança estabelece a perceção dos participantes de que a Comunidade possa fornecer conhecimento em ambientes virtuais;

5. A confiança está associada com a perceção dos participantes da Comunidade de que receberão conhecimentos no espaço virtual.

O sentimento de confiança em uma Comunidade é responsável pelo nível de aceitação/receção do conhecimento nela compartilhado - o recetor precisa confiar na experiência, credibilidade e reputação do emissor do conhecimento para incorporar o que por ele é compartilhado. A credibilidade das pessoas resulta na credibilidade da $\mathrm{CoP}$, isso significa que ela servirá como um referencial na busca de conhecimentos e soluções de problemas.

Segundo (Campos, R. L.; Barbosa, F. V., 2001) é importante saber como o conhecimento foi adquirido, e como ele poderá ser utilizado, tendo como base três fatores: tempo, espaço e reconhecimento da necessidade da manutenção, com foco em alcançar resultados positivos na organização. Esse processo é composto por fatores inibidores que são aqueles que podem dificultar ou impedir, tanto o compartilhamento quanto a gestão do conhecimento.

Esses fatores inibidores, conforme (Robbins, S. P., 2004), encontram-se nos três níveis de conhecimento: individual, grupal e organizacional. No nível do indivíduo, o autor elencou a expectativa, os valores, as atitudes, a perceção, a personalidade, a emoção, os sentimentos, a disposição e a motivação. No nível do grupo, os fatores inibidores podem surgir de interações estratificadas, estilo de liderança, da confiança e do clima psicológico. Na esfera da organização, as políticas e práticas de recursos humanos são caracterizadas como fatores que podem inibir a gestão do conhecimento. Para (Riege, A., 2005), os fatores inibidores organizacionais são: falta de clareza 
na integração entre a estratégia e o modelo de gestão do conhecimento; pouco espaço para compartilhamento; sistema ineficiente de reconhecimento e recompensa para estimular a motivação que leve ao compartilhamento; e ambiente físico inadequado.

A confiança é um fator essencial para a disseminação do conhecimento, deve ser estabelecida por meio de exemplos positivos e eventos que possam abalar essa relação devem ser considerados. Os fatores inibidores que foram considerados para realização deste estudo estão sistematizados no Quadro 2. Segundo (Gonçalo, C. R., 2005) a liderança é um dos fatores facilitadores para a disseminação do conhecimento, pois, o compartilhamento resulta no respeito dentro da equipe e corrobora o estímulo à motivação para a transmissão desse conhecimento. Observação assistemática o fato de se obter o conhecimento através de uma experiência casual, sem que se determine 'a priori' quais os aspetos relevantes a observar e que meios utilizar para observá-los.

\begin{tabular}{|c|c|c|}
\hline Dimensões & Fatores & Autores \\
\hline \multirow{3}{*}{ 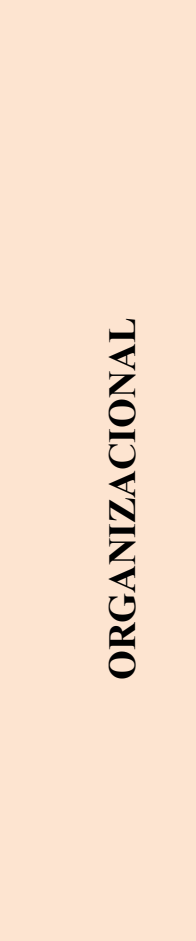 } & $\begin{array}{l}\text { A demonstração pública, por parte dos } \\
\text { gestores, da importância das atividades } \\
\text { das Comunidades para a organização } \\
\text { eleva a autoestima dos membros, o que } \\
\text { favorece a sua participação. }\end{array}$ & $\begin{array}{l}\text { (Loyarte, E.; Rivera, O., 2007); } \\
\text { (Zboralski, K., 2009) }\end{array}$ \\
\hline & $\begin{array}{l}\text { As organizações podem propor CoP aos } \\
\text { seus colaboradores, no entanto, não } \\
\text { devem impor critérios e processos } \\
\text { estruturados. A imposição de normas } \\
\text { retira da CoP a sua autodeterminação. }\end{array}$ & $\begin{array}{l}\text { (Loyarte, E.; Rivera, O., 2007); } \\
\text { (Pemberton, J.; Mavin, S.; Stalker, B., } \\
2007 \text { ) }\end{array}$ \\
\hline & $\begin{array}{l}\text { As CoP devem ser criadas em torno de } \\
\text { temas centrais ao sucesso do negócio da } \\
\text { organização. }\end{array}$ & $\begin{array}{l}\text { (McDermott, R., 2000); (Smits \& } \\
\text { Moor, 2004); (Loyarte, E.; Rivera, O., } \\
\text { 2007) }\end{array}$ \\
\hline
\end{tabular}




\begin{tabular}{|c|c|c|}
\hline & $\begin{array}{l}\text { Os membros necessitam de liberdade para } \\
\text { expressar suas opiniões e dúvidas. } \\
\text { Mecanismos de controle sob a CoP } \\
\text { baseados em autoridade impedem as } \\
\text { contribuições espontâneas. }\end{array}$ & $\begin{array}{l}\text { (Ardichvili, A.; Maurer, M.; LI, W.; } \\
\text { Wentling, T.; Stuedemann, R., 2006); } \\
\text { (Scarso, E.; Bolisani, E., 2008); } \\
\text { (Sherbino, et al., 2010) }\end{array}$ \\
\hline 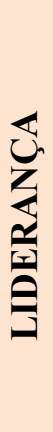 & $\begin{array}{l}\text { As CoP necessitam da presença de um } \\
\text { líder atuante para o seu sucesso. } \\
\text { Entre os principais requisitos para uma } \\
\text { Comunidade de Prática, está a presença do } \\
\text { líder ou animador, promovendo o } \\
\text { interesse e a motivação para seus } \\
\text { membros trabalharem juntos, como um } \\
\text { grupo. }\end{array}$ & $\begin{array}{l}\text { (McDermott, R., 2000); (Loyarte, E.; } \\
\text { Rivera, O., 2007); } \\
\text { (Scarso, E.; Bolisani, E., 2008) }\end{array}$ \\
\hline \multirow[b]{2}{*}{ 䆓 } & $\begin{array}{l}\text { Encontros face a face devem ser } \\
\text { comentados nas CoP. Tais interações são } \\
\text { fundamentais para a construção do } \\
\text { sentimento de confiança entre os } \\
\text { membros. }\end{array}$ & $\begin{array}{l}\text { (McDermott, R., 2000); (Sherbino, et } \\
\text { al., 2010) }\end{array}$ \\
\hline & $\begin{array}{l}\text { O suporte da organização é importante } \\
\text { para a manutenção da Comunidade. }\end{array}$ & $\begin{array}{l}\text { (McDermott, R., 2000); (Moreno, A., } \\
\text { 2001); (Loyarte, E.; Rivera, O., 2007); } \\
\text { (Scarso, E.; Bolisani, E., 2008); } \\
\text { (Zboralski, K., 2009); (Janke, et al., } \\
\text { 2012) }\end{array}$ \\
\hline
\end{tabular}




\begin{tabular}{|c|c|c|}
\hline \multirow{4}{*}{ 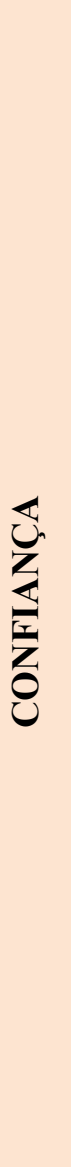 } & $\begin{array}{l}\text { Estabelecer de forma clara e objetiva o } \\
\text { domínio da CoP, para ciência dos } \\
\text { membros e da organização quanto ao seu } \\
\text { conteúdo. }\end{array}$ & $\begin{array}{l}\text { (Meeuwesen \& Berends, 2007); } \\
\text { (Scarso, E.; Bolisani, E., 2008); (Janke, } \\
\text { et al., 2012) }\end{array}$ \\
\hline & $\begin{array}{l}\text { A proximidade cultural entre os membros } \\
\text { facilita o compartilhamento do } \\
\text { conhecimento entre os membros das CoP. }\end{array}$ & $\begin{array}{l}\text { (Ardichvili, A.; Maurer, M.; LI, W.; } \\
\text { Wentling, T.; Stuedemann, R., 2006); } \\
\text { (Scarso, E.; Bolisani, E., 2008) }\end{array}$ \\
\hline & $\begin{array}{l}\text { A confiança está associada à perceção da } \\
\text { Comunidade em aceitar os conhecimentos } \\
\text { disponibilizados em uma base do } \\
\text { conhecimento. }\end{array}$ & $\begin{array}{l}\text { (Cruz, C. C. P.; Motta, C. L. R.; } \\
\text { Santoro, F. M.; Elia, M., 2009); } \\
\text { (Majewski, G.; Usoro, A.; Khan, I., } \\
\text { 2011) }\end{array}$ \\
\hline & $\begin{array}{l}\text { Estabelecimento de mecanismos que } \\
\text { assegurem aos membros a confiança sobre } \\
\text { a qualidade do conteúdo do conhecimento } \\
\text { compartilhado na CoP. }\end{array}$ & $\begin{array}{l}\text { (Scarso, E.; Bolisani, E., 2008); (Cruz, } \\
\text { C. C. P.; Motta, C. L. R.; Santoro, F. } \\
\text { M.; Elia, M., 2009) }\end{array}$ \\
\hline \multirow{2}{*}{$\begin{array}{l}\longleftarrow \\
0 \\
0 \\
0 \\
0 \\
\substack{0 \\
=}\end{array}$} & $\begin{array}{l}\text { As ferramentas de tecnologia da } \\
\text { informação e comunicação devem } \\
\text { facilitar a dinâmica das atividades das } \\
\text { CoP, e não se constituírem em entraves à } \\
\text { participação dos membros. }\end{array}$ & $\begin{array}{l}\text { (McDermott, R., 2000); (Loyarte, E.; } \\
\text { Rivera, O., 2007); (Scarso, E.; Bolisani, } \\
\text { E., 2008) }\end{array}$ \\
\hline & $\begin{array}{l}\text { A tecnologia utilizada precisa ser } \\
\text { compreendida/dominada para } \\
\text { participação plena dos membros nas } \\
\text { atividades da CoP. }\end{array}$ & $\begin{array}{l}\text { (Moreno, A., 2001); (Curran, J. A.; } \\
\text { Murphy, A. L.; Abidi, S. S. R.; Sinclair, } \\
\text { D.; McGrath, P. J., 2009) }\end{array}$ \\
\hline
\end{tabular}

Quadro 2 - Síntese dos fatores críticos de sucesso (FCS) à manutenção das CoP e suas dimensões de análise Fonte: Adaptação de (Rebelo, Waskow, Nunes, Selig, \& Nakayama, 2012) 


\subsection{Estímulo ao desenvolvimento das CoP}

Segundo (Wenger, Etienne, 2000a) devem existir espontaneamente ou pelo mero estímulo, e não imposição, das organizações. Referido autor alerta que, apesar de o surgimento, na maioria dos casos, ser natural, tal fato não implica que as instituições devam ficar neutras e sem participação em seu desenvolvimento. Para tanto, sugere que desenvolvê-las e estimulá-las incluem os seguintes pontos:

a) Legitimar a participação dos membros: as organizações podem reservar um tempo (diário, semanal, mensal etc.) a fim de que os membros participem das atividades comunitárias. Outro aspeto é a criação de um local para que estas aconteçam.

b) Negociar o contexto estratégico: as organizações devem ter um sentimento claro de como o conhecimento está ligado às estratégias de negócio e usá-lo para despertar, nas Comunidades, o seu próprio valor estratégico. Esse processo envolve uma negociação que trabalha em dois sentidos: inclui a compreensão do que é conhecimento e, portanto, quais práticas uma determinada atividade exige; por outro lado, clama pela atenção para o que as $\mathrm{CoP}$ trazem como possíveis direções estratégicas, conhecimento retirado da prática diária.

c) Estabelecer sintonia com práticas existentes na organização: geralmente o conhecimento que as organizações necessitam já está presente dentro delas. Assim, promover a formação de Comunidades de Prática que aproveitem esse potencial é um ponto de partida muito interessante.

d) Alinhar os sistemas de reconhecimento às CoP: elementos do ambiente organizacional podem favorecer ou inibir a formação de Comunidades (sistemas de recompensa, processos de trabalho, cultura corporativa, política da empresa, dentre outros). Por exemplo, remuneração e reconhecimento: esses são atribuídos de cima para baixo e podem ser interpretados como formas de manipular o comportamento e funcionamento de uma CoP. De outro modo, o reconhecimento e as recompensas não devem ser esquecidos aos que participam, e uma forma interessante é incluir, na avaliação de desempenho, aspetos que valorizem a participação dos funcionários em atividades comunitárias e de liderança. 
e) Fornecer suporte: os mencionados grupos são autossuficientes, contudo podem ser beneficiados por alguns recursos, tais como: peritos externos à organização, viagens, instalações para as reuniões e tecnologia de comunicação.

Zboralski, K. (2009), em suas considerações sobre a influência do apoio organizacional nas CoP, pauta-se em estudos de (Von Krogh, Georg, 1998) e (Hansen, M. T.; Nohria, N.; Tierney, T., 1999) com o intuito de afirmar que o amparo da organização tem sido de grande importância para o êxito das iniciativas no contexto da gestão do conhecimento.

O estabelecimento de uma atmosfera amigável à Gestão do Conhecimento - GC, incluindo a criação de Comunidades, aumenta a consciência da necessidade de se compartilhar conhecimento em uma organização, assim como a vontade em interagir nas CoP. Para além da atmosfera, segundo (Zboralski, K., 2009), os recursos cedidos pela organização também integram o contexto favorável à participação dos membros, e este apoio é revelado, por exemplo, pela anuência da gerência ao ceder tempo para a realização das reuniões, pela valorização pública dos benefícios que a Comunidade trouxe à organização, pela liberação de recursos (que podem ser revertidos em recompensas aos integrantes ou mesmo destinados a financiar a participação deles em congressos, workshops), entre outros.

(McDermott, R., 2000) trata dessa dimensão como “desafios à gestão" e aponta alguns elementos, classificando-os como de competência da organização, que são: evidenciar que as Comunidades são relevantes à instituição - tal intento pode ser facilitado se o domínio da Comunidade girar em torno de temas centrais ao negócio da empresa, pois os resultados serão, para esta, mais impactantes; garantir que as pessoas tenham tempo destinado a participar das atividades comunitárias; e proporcionar uma cultura corporativa que permita a criação e a manutenção das CoP.

(Scarso, E.; Bolisani, E., 2008) mencionam exemplos de recompensas não financeiras que são efetivas no que tange ao incentivo à participação em Comunidades, tais como: reconhecimento público, por parte da organização, de que os membros das CoP são especialistas naquele domínio; e motivação pessoal, ao se observar que as interações no ambiente comunitário trazem benefícios diretos às rotinas de trabalho. 
Outro aspeto inibidor é a presença de um membro que represente "os interesses" da organização junto ao grupo. Nessa situação, segundo (Pemberton, J.; Mavin, S.; Stalker, B., 2007), os participantes não se sentem livres a fim de expressar suas opiniões. E mais, caso seu futuro na organização pareça estar vinculado ao seu desempenho na Comunidade, o bloqueio torna-se ainda maior.

Os aludidos autores discutem ainda a presença na Comunidade de pessoas com status e autoridade elevados na organização. Indicam que indivíduos com esse perfil, em tese, dominam os debates nos quais participam, e que os colegas simplesmente concordam com eles, destacando, ao final, que situação congênere pode ser reproduzida em Comunidades. O impacto dessas participações resulta em pobreza na elaboração de encaminhamentos e decisões, e, em casos extremos, pode acarretar, inclusive, a rutura do grupo, em virtude da perceção dos membros que suas contribuições são marginalizadas ou simplesmente ignoradas.

(Loyarte, E.; Rivera, O., 2007) e (Zboralski, K., 2009) quando afirmam que a demonstração pública, por parte dos gestores, da relevância das atividades dos ambientes comunitários para a organização favorece as participações dos membros. Ainda (Loyarte, E.; Rivera, O., 2007) e (Pemberton, J.; Mavin, S.; Stalker, B., 2007) declaram que as organizações podem propor CoP aos seus colaboradores, no entanto não devem impor critérios e processos estruturados (Moreno, A., 2001) e (Pemberton, J.; Mavin, S.; Stalker, B., 2007) concordam que as informações sobre a Comunidade devem ser divulgadas dentro da instituição, como meio de não segregar possíveis interessados, e mesmo de evitar animosidade entre os não membros e os membros.

(Pemberton, J.; Mavin, S.; Stalker, B., 2007) O estudo é estruturado com breve discussão da literatura sobre Comunidades de Prática e é integrado às experiências dos autores em suas participações em uma $\mathrm{CoP}$, a qual possuía como domínio o interesse em pesquisas e publicações académicas.

A proposta do artigo é expor as dificuldades que uma Comunidade de Prática pode enfrentar nos processos de criação do conhecimento e aprendizagem. 


\subsection{Ciclo de Vida das Comunidades de Prática}

Cada fase do ciclo de vida de uma $\mathrm{CoP}$ apresenta características específicas que implicam cuidados próprios para promover um ambiente favorável e a aprendizagem coletiva. Para (Wenger, Etienne; Mcdermott, R.; Snyder, W. M., 2002a), as cinco fases do ciclo de vida de uma comunidade podem ser classificadas como: Inicial ou potencial, Crescimento, Maturidade, Sustentação e Transformação, explicitas na Figura 1.

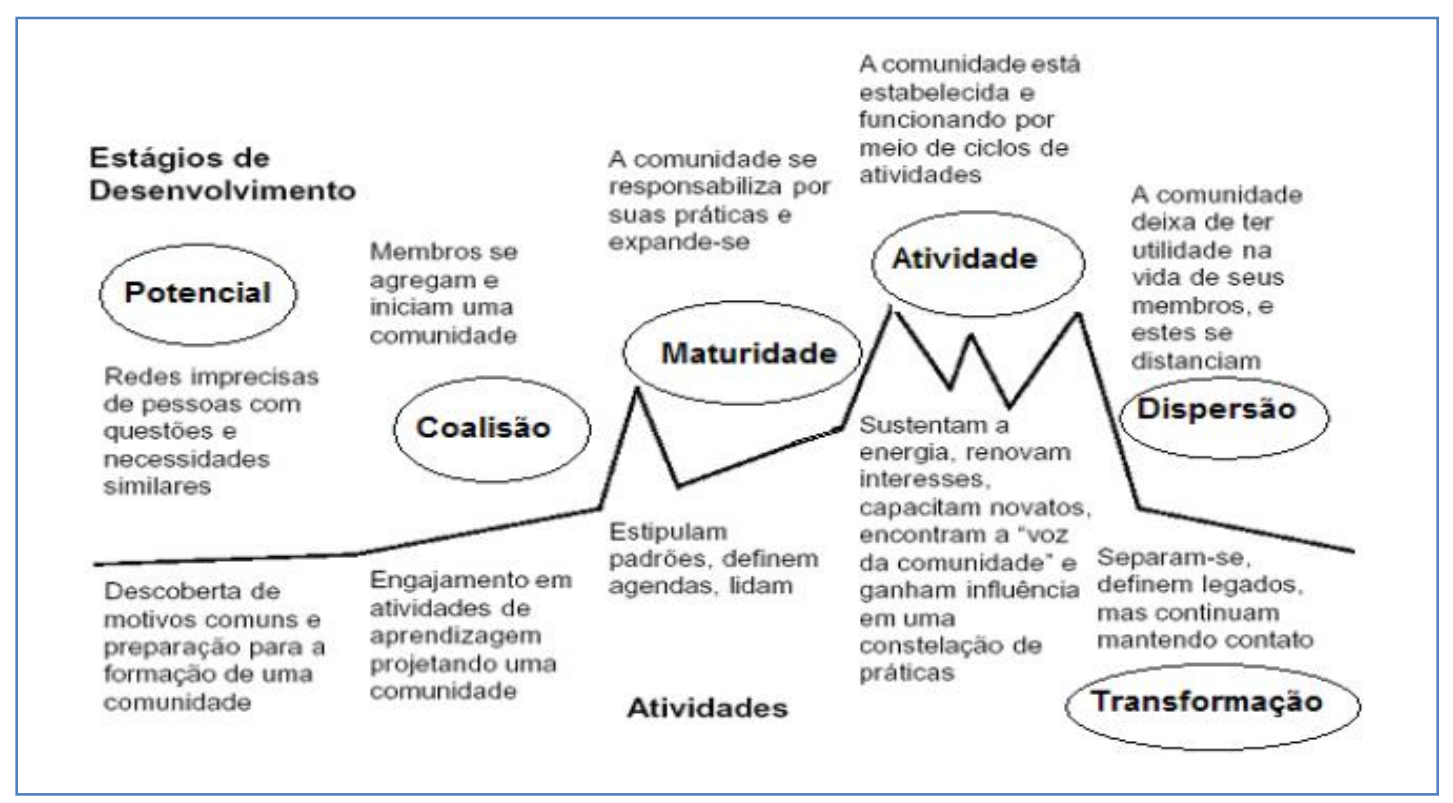

Figura 1 - Estágios de desenvolvimento das Comunidades de Prática

Adaptada de (Wenger, Etienne; Mcdermott, R.; Snyder, W. M., 2002a)

A manutenção e a evolução da comunidade, em seus diversos estágios de desenvolvimento, tornamse possíveis através da interação, colaboração e cooperação dos membros que exercem diferentes papéis (Nichani, M., 2001).

Após avaliar o comportamento dos membros, dentro de comunidades, o autor os classifica em:

- Conectores: pessoas que conhecem muitas outras e fazem conexões entre elas.

- Transferidores: pessoas que conectam pessoas com informações.

- Vendedores: eles alcançam os não convencidos, e os persuadem a aceitar as mudanças. 
Fase 1-Na fase inicial ou potencial, a comunidade é lançada oficialmente irá provocar a entrada de novos membros. A gestão deve mostrar os ganhos que a Organização e os participantes obtêm com a formação da comunidade.

As comunidades surgem como redes de pessoas que, independentemente de já se considerarem ou não como pertencentes a uma Comunidade de Prática, reúnem-se informalmente à volta de um tópico que consideram importante e partilham questões e necessidades semelhantes.

Fase 2 - Na fase de crescimento, a comunidade começa a tornar-se mais ativa, os membros começam a identificar e valorizar o seu envolvimento nas atividades de aprendizagem e as fronteiras da comunidade começam a ser definidas. Nesta fase deve-se negociar com a gestão o reconhecimento da comunidade e a sua relação com o contexto estratégico, para que possa obter o suporte necessário durante a sua existência.

A fragilidade deste estágio do ciclo de vida de uma Comunidade de Prática está no balanço entre o grau de confiança existente entre os membros e o valor que estes retiram. da sua participação e envolvimento na comunidade. É, assim, crucial nesta fase desenvolver atividades que permitam construir a confiança e a compreensão entre os indivíduos, desenvolvendo-lhes inclusive o hábito de se consultarem mutuamente.

É necessário que a Organização reconheça o papel da comunidade e a legitime, relacionando-a com o contexto estratégico e com assuntos importantes para a Organização.

Fase 3 - Na fase de maturidade, a comunidade ganha apoio e reconhecimento da Organização como um todo, começando a ter um crescimento sustentável do número de membros. A maturidade é encarada como a fase estável, em que já não é necessário grande suporte por parte da Organização para que as comunidades prossigam. Contudo, isso é um erro que pode inclusive por em causa a continuidade da comunidade.

A vida de uma Comunidade é complexa e, atingida a fase de maturidade, múltiplos fatores podem ameaçar novos membros trazem novas ideias e as necessidades da própria Organização modificam. Fase 4 - Na próxima fase sustentação, o grande desafio é manter o ritmo, passando por mudanças de membros, tecnologia e relações com a Organização. Neste momento, 
é importante mantê-la com ações para motivar os seus membros a continuar a participação de uma forma ativa. A energia de uma Comunidade nesta fase do seu ciclo de vida oscila entre picos mais altos ou mais baixos. Durante os períodos mais baixos, a comunidade precisa de ser rejuvenescida introduzindo novos tópicos ou recrutando novos líderes e novos membros para o grupo central da comunidade.

Fase 5 - Na fase de transformação, a Comunidade não é importante para os seus membros, mas é ainda reconhecida através das histórias, da preservação dos seus artefactos e da reunião de documentos que ressaltem a sua existência.

Ao longo da sua existência, uma comunidade enfrenta vários desafios no seu percurso, surgem novos interesses e novos relacionamentos se vão formando entre as pessoas.

O papel da Organização, nesta fase, é o de preservar a memória da Comunidade. A prática da Comunidade pode tornar-se comum, sem grande relevância ou os seus membros desenvolverem novos interesses e já não verem interesse ou valor para participarem. Perante estas situações, algumas Comunidades simplesmente desaparecem, ou então dividem-se, fundando outras comunidades. No entanto, estas transformações, ou o próprio desaparecimento são naturais e fazem parte do seu ciclo de vida de uma Comunidade de Prática.

Salientamos que todas as fases não têm um tempo definido de duração. Cada Comunidade desenvolve-se ao seu ritmo e apresenta características específicas de acordo com os membros que a compõem e relacionamentos e cultura que desenvolvem. 
Doctorado en Salud, Discapacidad, Dependencia y Bienestar

Capítulo 3

$\underline{\text { PROCEDIMENTOS METEDOLÓGICOS }}$ 


\section{A opção metodológica}

\subsection{Estudo de caso}

A nossa opção neste estudo foi a de um estudo de caso que acompanhou simultaneamente dois (2) estudos de caso aplicados a um contexto de mudanças organizacionais numa Organização de Investigação Agrária do setor público pertencente ao Ministério da Agricultura, Florestas e Desenvolvimento Rural.

No sentido de encontrar as respostas para a questão que foi levantada no início da nossa investigação o desafio foi:

Analisar quais os elementos da prática que levam à obtenção de resultados facilitadores ou inibidores da sobrevivência da Comunidade de Partilha de Boas Práticas SST e suas transformações

Para atingirmos o objetivo do nosso trabalho que consistiu em analisar os elementos críticos das práticas essenciais para o sucesso e sobrevivência da Comunidade de Boas Práticas SST e Qualidade de vida no trabalho e partindo do pressuposto que sem o trabalho desenvolvido pela CoP Animadores de Prevenção que formou a $1^{\text {a }}$ Comunidade Presencial de Partilha de conhecimento neste domínio a CoP virtual Comunidade de Partilha de Boas Práticas SST e Qualidade de Vida da WIKINIAV não se teria desenvolvido, daí a nossa necessidade de analisarmos dois (2) estudos de caso aplicados ao mesmo contexto Organizacional e não dois estudos de caso em Organizações diferentes.

\subsection{Funcionamento e sobrevivência da CoP Boas Práticas SST e Qualidade de Vida}

\subsubsection{Estratégia metodológica do estudo}


Análise da formação e transformações da Análise da formação e transformações da Comunidade do Grupo de Animadores de Prevenção da Estação Agronómica Nacional

\section{CoPGAPEAN}

\section{Resultados responsáveis pela sobrevivência ou não sobrevivência da CoP Boas Práticas SST e Qualidade de vida no INIAV}

(CoPSSQVTINAV)

Quadro 3 - Estratégia metodológica

Fonte: Elaboração própria

\subsubsection{Metodologias}

Seguimos neste trabalho de investigação o exemplo (Yin, R.K., 2005), (Yin, R., 1993) e (Flick, U., 2004), que salientam a relevância de utilizar, em alguns métodos de investigação, simultaneamente dados qualitativos e quantitativos.

A utilização de dados qualitativos e quantitativos, na mesma investigação, vai no sentido de olhar para estas metodologias como complementares e não como opostas ou rivais.

Também (Yin, R., 2005) aborda esta questão salientando que os estudos de caso são uma estratégia abrangente e podem incluir as evidências quantitativas.

Ainda segundo este autor, a estratégia de estudo de caso, ao ser uma estratégia abrangente, não se deve confundir com investigação qualitativa, pois existe uma grande e importante área comum entre a investigação qualitativa e quantitativa, no entanto a nossa opção foi de índole mais qualitativa. 


\subsubsection{Unidades de análise}

As Unidades de análise por nós selecionadas estão relacionadas com a questão da nossa investigação: Analisar quais os elementos da prática que levam à obtenção de resultados facilitadores ou inibidores da sobrevivência da Comunidade de Partilha de Boas Práticas SST e suas transformações.

Quando queremos analisar uma realidade, podemos considerar essa realidade de forma global, como uma totalidade única, ou então, podemos considerá-la como constituída por uma série de unidades, cuja peculiar caracterização exige um trabalho diferenciado (Rodríguez, G. G.; Flores, J. G.; Jiménez, E. G, 1999).

Cada unidade de análise requer uma estratégia diferente de recolha de dados (Yin, R.K., 2005).

Escolhemos como primeira Unidade de análise a Comunidade presencial de partilha de conhecimento sobre Boas Práticas SST do Grupo de animadores de Prevenção da EAN e como segunda Unidade de análise foi a Comunidade de Partilha de Boas Práticas SST desenvolvida já numa forma colaborativa mista tendo acesso à Plataforma de Trabalho colaborativo a Wikiniav.

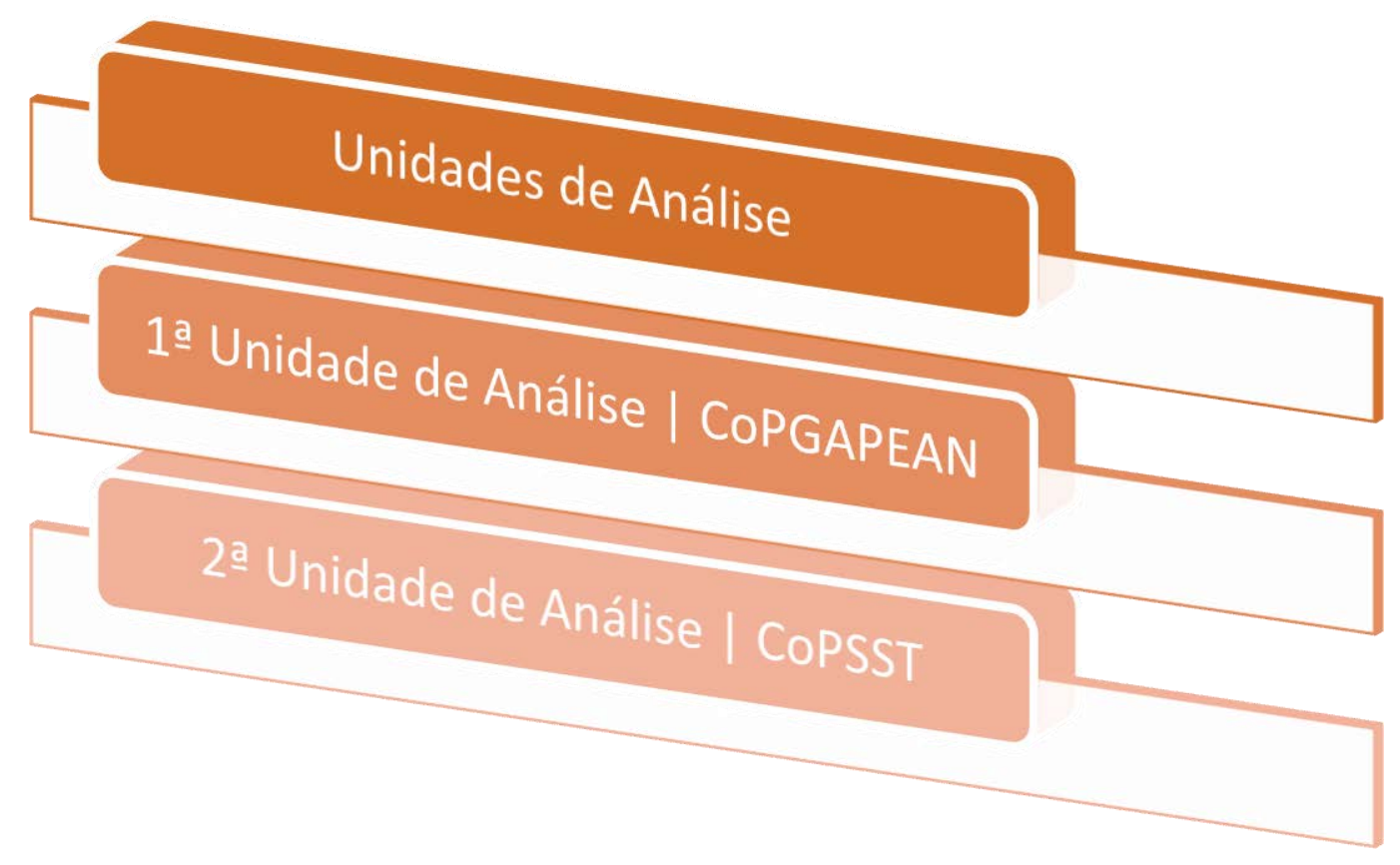

Ilustração 2 - Unidades de Análise

Fonte: Elaboração própria 


\subsubsection{Tipologia do estudo de caso: exploratório}

No nosso caso tivemos dois (2) estudos de caso aplicados ao mesmo contexto Organizacional e não dois estudos de caso em Organizações diferentes. O primeiro estudo (Flor, C., 2015) deu origem à nossa hipótese e práticas essenciais para o bom funcionamento e manutenção da Comunidade de Partilha Boas Práticas SST, sendo o nosso ainda um estudo exploratório pois procuramos dar ênfase à descoberta de práticas que possam formular novas ideias e compreender o fenómeno.

\subsubsection{A recolha e análise da informação em estudos de caso}

Parece consensual que devem ser o caso e o seu contexto, bem como o problema, as proposições e respetivas questões que orientarão todo o nosso estudo.

De acordo com (Fragoso, A., 2004) o investigador deve assegurar que os métodos e técnicas de recolha de informação são utilizados de informação suficiente e pertinente. Para isso, o investigador deve recolher e organizar dados de múltiplas fontes e de forma sistemática (Dooley, L. M., 2002). A nossa recolha inicia desde o ano em que se forma a Comunidade do Grupo de animadores de Prevenção ano 2004 até 2019. Houve a necessidade de pedirmos autorização para consulta de Documentos em arquivo da Comunidade embrionária (CoPGAPEAN) que nos esclarecessem todo o percurso e ciclo de vida da Comunidade que deu origem a toda a dinâmica de trabalho colaborativo. Foram inúmeros os Documentos a que tivemos acesso: atas de reuniões da CoP; eventos presenciais promovidos pela CoP (Seminários e Workshops; processo formativo/treino (Dossiers de formação),parcerias estabelecidas para a realização do projeto; documentos que provam o envolvimento da gestão de topo; Documentos de avaliação da Cultura Segurança e Organizacional; produtos elaborados pela CoP (Fichas técnicas, cartazes, guias de boas práticas, vídeos, tec).Construímos um guião que nos ajudou a agrupar a informação recolhida de acordo com o tipo de Documento observado para que a fase da análise fosse mais facilitada no processo da técnica da triangulação de dados.

Paralelamente e acompanhando um segundo estudo houve a necessidade de gerirmos todo o nosso trabalho em conjunto com o outro investigador para que não houvesse sobrecarga de inquéritos e entrevistas, pois corríamos o risco de não obtermos respostas. Nesse sentido houve consenso e foram aplicados vários instrumentos (qualitativos e quantitativos neste estudo aos quais tivemos 
acesso aos resultados e utilização dos mesmos) com grande abrangência para que conseguíssemos obter os dados que necessitávamos para ambos os estudos. A vantagem mais importante para a utilização de fontes múltiplas de evidência é desenvolvimento de linhas convergentes de investigação, enquanto processo de triangulação de dados (Yin, R.K., 2005).

\subsubsection{Fase de negociação}

No nosso estudo fomos tentados a perceber como tudo aconteceu antes do aparecimento da plataforma de trabalho colaborativo WIKINIAV tivemos por isso que procurar junto ao investigador e à Organização e estudo que tipo de Comunidade existia, o que aconteceu para que desse origem a uma Comunidade dentro de uma Organização do setor público virtual.

\subsubsection{O papel do investigador nos estudos de caso}

O nosso papel nesta investigação foi de investigador não participante, limitando-nos a observar todos os acontecimentos e a relação mais próxima que existia era com o outro investigador do mesmo estudo de caso, mas com outra linha de investigação. Foi observada a dinâmica de facilitação virtual e a dinâmica de facilitação presencial. Também observamos muito documentos que nos foram cedidos para análise. 


\subsubsection{Instrumentos usados na nossa metodologia}

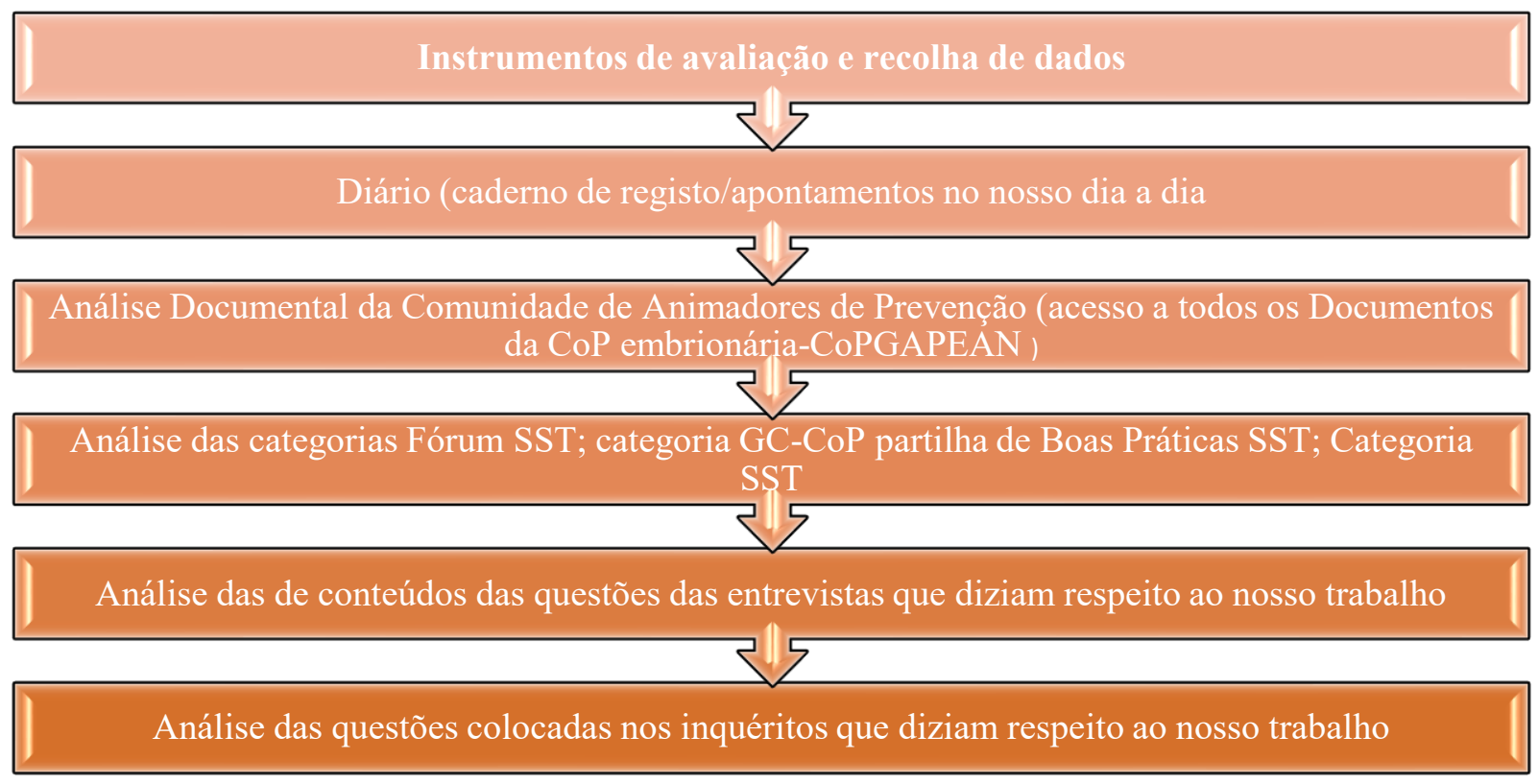

Quadro 4 - Instrumentos da Metodologia

Fonte: Elaboração Própria

\subsubsection{Os participantes e o contexto da Investigação}

De acordo com (Hill, M. M.; Hill, A., 2002) a natureza e a dimensão do Universo são definidas pelo objetivo da investigação. No sentido de encontrar as respostas para a questão que foi levantada no início da nossa investigação o desafio foi: Analisar quais os elementos da prática que levam à obtenção de resultados de facilitadores ou inibidores da sobrevivência da Comunidade de Partilha de Boas Práticas SST e suas transformações a opção do nosso trabalho de investigação é de índole mais qualitativa e por isso utilizamos uma amostra de menor dimensão. No nosso caso ao acompanharmos o estudo (Flor, C., 2015) foi a amostra escolhida pela investigadora por conveniência pois os indivíduos estão próximos do contexto de investigação, contemplando todas as carreiras profissionais, que para nós foi vantajoso pois a CoP dos Animadores de Prevenção também se sediou no Pólo Oeiras e é esta Comunidade a alavanca de todo o processo colaborativo na Organização. Para a interpretação dos dados foi muito mais fácil o espaço ser comum.

Para atingirmos o objetivo do nosso trabalho que consistiu em analisar os elementos críticos das práticas essenciais para o sucesso e sobrevivência da Comunidade de Boas Práticas SST e Qualidade de vida no trabalho e partindo do pressuposto que sem o trabalho desenvolvido pela 
CoP Animadores de Prevenção que formou a $1^{\circ}$ Comunidade presencial de partilha de conhecimento neste domínio a CoP virtual Comunidade de Partilha de Boas Práticas SST e Qualidade de Vida da WIKINIAV não se teria desenvolvido, daí a nossa necessidade de analisarmos 2 estudos de caso aplicados ao mesmo contexto Organizacional e não dois estudos de caso em Organizações diferentes. Como anteriormente dissemos optamos por um estudo exploratório. Houve por isso a necessidade de gerirmos todo o nosso trabalho em conjunto com o outo investigador pois optámos por analisar a formação da Comunidade embrionária e seguir o seu percurso de vida até à fase de transformação e continuidade iniciando a nossa análise em 2004 e terminando em 2019 que corresponde a um período de tempo de 15 anos. Nesse sentido houve consenso e aplicamos vários instrumentos com grande abrangência para que conseguíssemos obter os dados que necessitávamos para ambos os estudos.

\subsection{O campo e o alvo}

Embora neste estudo o foco da investigação esteja nos sujeitos, isso não significa, que não se reconheça a importância dos contextos em que a ação se desenvolve.

\subsection{Caraterização das Organizações do estudo}

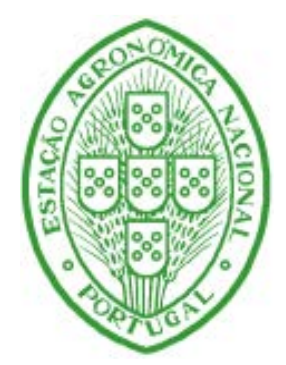

Figura 2 - Símbolo da EAN

Fonte: www.iniav.pt

A Estação Agronómica Nacional (EAN) pertencente ao Instituto Nacional de Investigação Agrária e Pescas (INIAP), um Laboratório do Estado, integrado no Ministério da Agricultura, do Desenvolvimento Rural e das Pescas (MADRP), incumbido de realizar ações de investigação, experimentação e demonstração necessárias ao reforço das fileiras produtivas agrícola e florestal, 
incluindo o melhoramento da produção e defesa do património genético vegetal animal. Criado em 1974 como INIA organismo integrador de todas as unidades de investigação do Ministério IPIMAR. INIAP engloba na atualidade, funcionalmente, as seguintes unidades orgânicas e respetivos departamentos:

\section{Estação Agronómica Nacional (EAN - Oeiras);}

Estação Florestal Nacional (EFN);

Estação Nacional de Fruticultura Vieira Natividade (ENFVN - Alcobaça);

Estação Nacional de Melhoramento de Plantas (ENMP - Elvas);

Estação Vitivinícola Nacional (EVN - Dois Portos);

Estação Zootécnica Nacional (EZN - Vale de Santarém);

Laboratório Químico Agrícola Rebelo da Silva (LQARS - Lisboa);

Instituto das Pescas e do Mar-I (PIMAR-Algés).

Missão e estratégia como organismo, cabendo-lhe fundamentalmente:

- Desenvolver atividades de investigação científica, desenvolvimento tecnológico e demonstração;

- Prestar apoio científico e assessoria tecnológica ao Governo;

- Definição de prioridades e estabelecimento dos programas de investigação e desenvolvimento;

- Reforço do processo de internacionalização;

- Desenvolvimento das ligações aos sectores produtivos das áreas agro-rural e das pescas e do mar - parcerias com entidades públicas e privadas;

-Implementação de sistemas de acompanhamento e avaliação das atividades de investigação e desenvolvimento;

-Criação e funcionamento de grupos dinamizadores em áreas horizontais;

\section{A História}


Fundada em 16 de Novembro de 1936 foi promulgado (Decreto Lei $\mathrm{n}^{\mathrm{o}} 27.207$ ) que criou a EAN, organismo de investigação científica de orientação e cooperação técnica dependente da Direção Geral dos Serviços Agrícolas à qual ficou a competir efetuar os estudos de investigação agronómica necessários à resolução dos problemas que respeitam ao desenvolvimento e defesa da produção agrícola, orientar os estudos de experimentação e ensaio a executar pelos organismos regionais, e fornecer elementos técnicos necessários para a elaboração e execução do plano de fomento e assistência técnica da referida direção geral.

Foi em modestas instalações anexas ao Mosteiro dos Jerónimos, com mobiliário rebuscado nos armazéns do património, índice da escassez de verbas que sempre travou o seu progresso onde se caldeou como alguém disse, o "espírito" da EAN.

Em 1941 foi transferida para a Quinta da Aldeia em Sacavém para edifício delineado para esse fim e onde ocupava pouco mais de 67 hectares. Compreendia no início 7 departamentos (citologia e genética, fitopatologia que incluía a entomologia, melhoramento de cereais e forragens, solos, química, sistemática, fitogeografia, pomologia. Este último departamento funcionou sempre em Alcobaça dando origem mais tarde à Estação Nacional de Fruticultura de Vieira da Natividade.

Por volta de 1950, a EAN foi forçada a procurar instalações a fim de que a quinta da aldeia, que ocupava fosse cedida para a indústria. A transferência da EAN para a Quinta do Marquês, em Oeiras demorou mais de uma década, mas a área de 130 hectares permitiu-lhe dispor de instalações mais amplas e campos experimentais mais extensos.

Como se tratava de uma zona menos poluída e mais aprazível levou a maioria do pessoal a fixarse nas proximidades.

O facto de dispor de uma grande área, permitiu junto a ela a instalação de outros organismos com atividades afins.

Com seu fundador toma posse em 23 de março de 1937 o professor António de Sousa Câmara iniciando-se uma nova era na investigação Agronómica em Portugal, insigne professor, investigador, doutrinador, orientador, criador de uma escola de cientistas agrários e delineador de uma metodologia que outros vieram mais tarde a decalcar para instituições semelhantes. Quem com ele lidou jamais poderá esquecer como era dotado da inteligência, da combatividade e do otimismo que caracterizam os grandes chefes. Os planos de trabalho da EAN publicados em 1939 demonstraram bem como esse homem tinha uma visão de futuro na resolução dos problemas fundamentais da agricultura Portuguesa. Em 1943 pública o livro "No caminho" no qual definiu 
os 4 pontos cardeais para a marcha da empresa Científica: a dedicação, a disciplina, a especialização e a Ação. Dos seus seguidores de renome Internacional temos Professores: Eng. ${ }^{\circ}$ Lopes da Fonseca Professor, Branquinho de Oliveira, Vieira da Natividade, José Contreiras, Pereira Amaro. A Estação perde autonomia, com a criação do Instituto Nacional de Investigação Agrária (INIA em 1974) a EAN é integrada neste instituto.

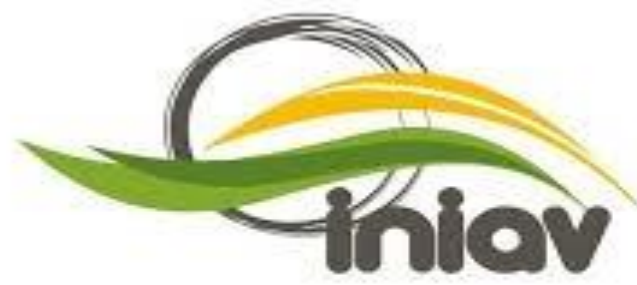

Instituto Nacional de

Investigaçāo Agrária e Veterinária, I.P.

Figura 3 - Símbolo do INIAV

Fonte: www.iniav.pt

\section{O segundo estudo realizou-se no Instituto Nacional de Investigação Agrária e Veterinária}

(INIAV) é um Laboratório do Estado, integrado no Ministério da Agricultura.

O INIAV foi criado em 2012, ficando com as atribuições relacionadas com a investigação agrária (do L-INIA) e veterinária (do L- LNIV) do antigo Instituto Nacional dos Recursos Biológicos I.P. (INRB), tendo as atribuições destas relativas às áreas das pescas e da aquicultura sido incorporadas no Instituto Português do Mar e da Atmosfera, I. P. (IPMA).

O INIAV detém os Laboratórios Nacionais de Referência para as doenças dos animais, para a segurança alimentar e para as doenças e pragas das plantas.

Os investigadores e técnicos superiores destes Laboratórios Nacionais de Referência tem grande know-how nas áreas da saúde animal e vegetal assim como da segurança alimentar, assessorando o governo e as Autoridades Nacionais nestas áreas sempre que necessário. O INIAV apoia os operadores das diversas fileiras com que se relaciona, nomeadamente, através do aconselhamento técnico-científico nos setores da produção agroflorestal, animal e das agroindústrias e outros serviços de várias naturezas a empresas e associações de agricultores e de criadores. 
Análises de alimentos, análise de terras e recomendações de fertilização, análises de águas, apoiam ao diagnóstico veterinário entre outros.

No INIAV - Polo Oeiras, encontra-se a sede do Instituto onde foi realizado o nosso segundo estudo.

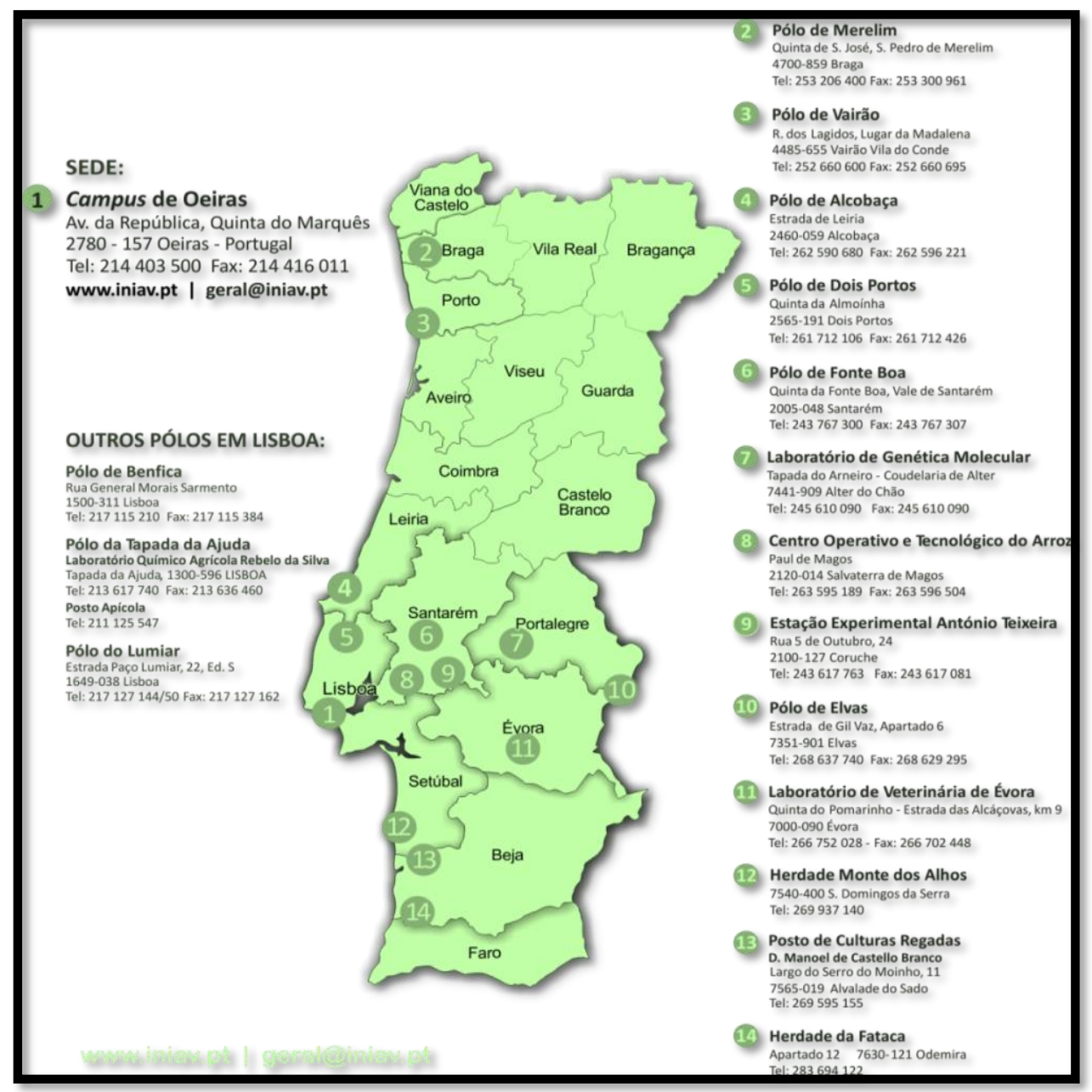

Figura 4 - O INIAV sua localização e dispersão geográfica em Portugal

Fonte: www.iniav.pt

O INIAV é um Instituto com uma dispersão geográfica muito grande estando os seus Pólos/unidades dispersos por todo o País como se pode observar no mapa acima apresentado.

Também devido à multidiversidade das organizações que resultaram do processo de fusão existindo uma cultura não uniforme no Instituto. 
Doctorado en Salud, Discapacidad, Dependencia y Bienestar

\section{Capítulo 4}

\section{ANÁLISE E DISCUSSÃO DE DADOS}




\section{Nota introdutória}

No sentido de encontrar as respostas para a questão que foi levantada no início da nossa investigação o desafio foi: Analisar quais os elementos da prática que levam à obtenção de resultados facilitadores ou inibidores da sobrevivência da Comunidade de Partilha de Boas Práticas SST e suas transformações.

\subsection{Hipótese}

Para a nossa investigação e elegemos como Práticas Essenciais para garantir resultados de sucesso e o correto funcionamento e sobrevivência da comunidade de Boas Práticas SST e Qualidade de vida no trabalho tendo como elementos essenciais dessas práticas: a Cultura, Alinhamento e estruturação, Apoio da Gestão de Topo da Organização, Líder /Coordenação forte, Desenvolvimento, Política e Tecnologia.

\subsection{Objetivo}

Para atingirmos o objetivo do nosso trabalho que consistiu em analisar os elementos críticos das práticas essenciais para o sucesso e sobrevivência da Comunidade de Boas Práticas SST e Qualidade de Vida no Trabalho e partindo do pressuposto que sem o trabalho desenvolvido pela $\mathrm{CoP}$ Animadores de Prevenção que formou a $1^{\text {a }}$ Comunidade presencial de partilha de conhecimento neste domínio a CoP virtual Comunidade de Partilha de Boas Práticas SST e Qualidade de Vida da WIKINIAV não se teria desenvolvido, daí a nossa necessidade de analisarmos dois (2) estudos de caso aplicados ao mesmo contexto organizacional e não dois estudos de caso em Organizações diferentes.

Precedentemente afirmámos optamos por um estudo exploratório. Subsistiu a necessidade de dirigirmos todo o nosso trabalho em conjunto com o outo investigador, pois escolhemos analisar a formação da Comunidade embrionária e seguir o seu ciclo de vida até à fase de transformação 
e continuidade iniciando a nossa investigação em 2004 e terminando em 2019 que corresponde a um período temporal de quinze (15) anos.

Nesse sentido houve consenso e aplicamos vários instrumentos com grande abrangência para que conseguíssemos obter os dados que necessitávamos para ambos os estudos.

\subsection{Estratégia da análise de dados}

\subsubsection{Utilização de Múltiplas Fontes de Evidência}

A vantagem mais importante para a utilização de fontes múltiplas de evidência é desenvolvimento de linhas convergentes de investigação, enquanto processo de triangulação de dados (Ilustração 4). O nosso papel nesta investigação foi de investigador não participante, limitando-nos a observar todos os acontecimentos e a relação mais próxima que existia era com o outro investigador do mesmo estudo de caso, mas com outra linha de investigação. Sendo a nossa investigação de índole mais qualitativa e por isso utilizamos uma amostra de menor dimensão, acordo com (Hill, M. M.; Hill, A., 2002) a natureza e a dimensão do universo são definidas pelo objetivo da investigação. No nosso caso ao acompanharmos o estudo (Flor, C., 2015) foi a amostra escolhida pela investigadora por conveniência pois os indivíduos estão próximos do contexto de investigação, contemplando todas as carreiras profissionais, o que para nós foi vantajoso pois a Comunidade embrionária (CoPGAPEAN) também se sediou no Pólo Oeiras e para a interpretação dos dados foi muito mais fácil o espaço ser comum. O nosso estudo teve duas fases distintas (Ilustração 3), um iniciado com a formação Comunidade Presencial (2004 a 2008) e outro a análise no período de 2009 a 2019. 


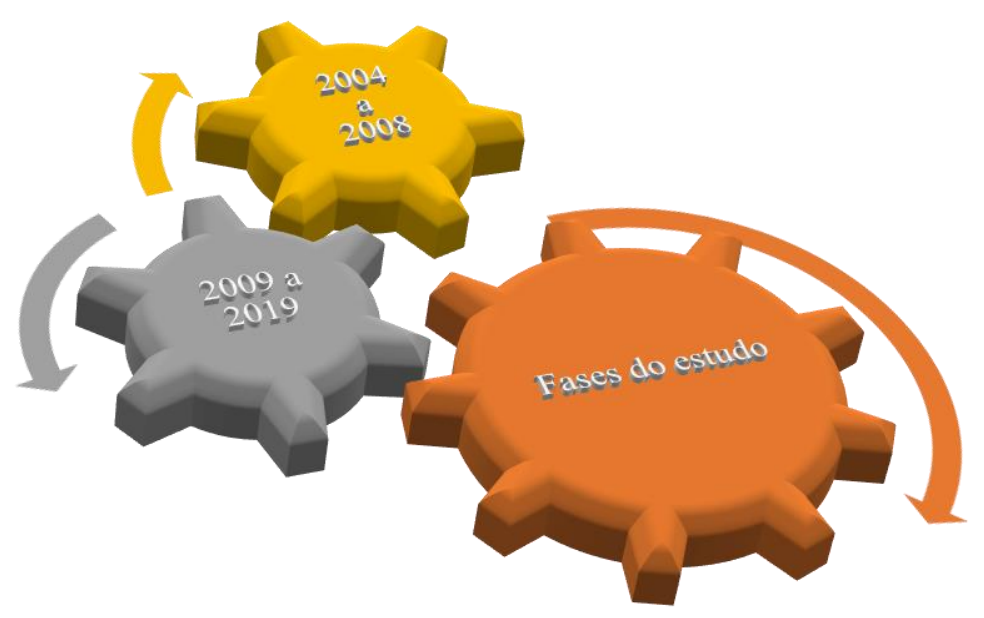

Ilustração 3 - Fases do Estudo

Fonte: Elaboração Própria

A nossa aposta foi contatar membros facilitadores da CoPGAPEAN e a Coordenadora da Comunidade.

Aplicamos os instrumentos de avaliação (ANEXO AI e AII), entrevistas semiestruturadas, uma entrevista individual (Guião no ANEXO AI) e uma entrevista em grupo a cinco (5) membros da comunidade embrionária (Guião no ANEXO AII). A análise de conteúdo destas entrevistas consta nos (ANEXOS BI e BII).

Construímos também um Guião para análise dos documentos da Comunidade embrionária, das mensagens elaboradas e das interações da CoPGAPEAN (ANEXO AIII), tendo após observação feito a análise de conteúdo dos mesmos (ANEXO BIII).

Foram analisados vários tipos de documentos: livro de atas de reuniões; documentos formais da direção; documentos de eventos presenciais; brochuras; cartazes; fichas técnicas. A vantagem mais importante para a utilização de fontes múltiplas de evidência é desenvolvimento de linhas 
convergentes de investigação, enquanto processo de triangulação de dados (Yin, R.K., 2005)

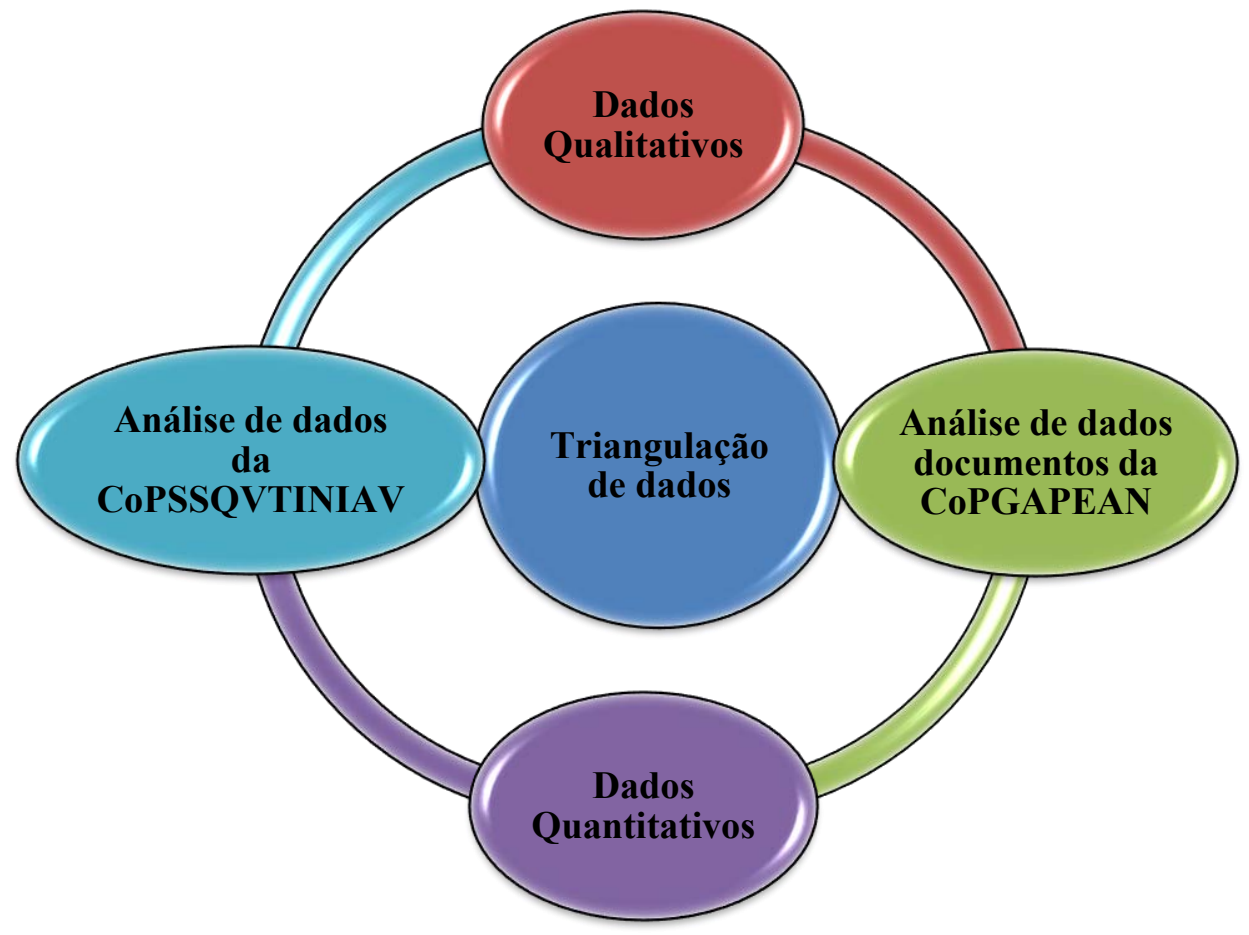

Ilustração 4 - Estratégia de análise dos dados

Fonte: Elaboração Própria

Utilizamos dados qualitativos derivados do acesso à nossa análise documental e também de entrevistas semiestruturadas da Comunidade embrionária (CoPGAPEAN), tivemos ainda acesso a um diagnóstico efetuado no nascimento da Comunidade embrionária (dados quantitativos) do questionário (diagnóstico da Cultura Organizacional de Segurança - ICOS). A evolução da CoPGAPEAN para uma CoP mista já com a componente virtual (CoPSSQVT) efetuamos o acompanhamento do estudo desenvolvido da implementação da mesma utilizando dados qualitativos e quantitativos. 0 método usado na análise de todos os dados recolhidos foi a triangulação dos dados, como nos mostra a Ilustração 4.

Um dado da nossa análise revela um ponto crucial no início do projeto (2004 a 2008) o envolvimento da Gestão de Topo e na sequência deste envolvimento como estratégia para o sucesso num plano de intervenção a Gestão de Topo da Organização pede um diagnóstico da 
Cultura Organizacional e de Segurança fazendo uma parceria com o CIS/ISCTE (Centro de Investigação Social do Instituto Superior de Ciências do Trabalho e da Empresa), como nos mostra a Ilustração 5 .

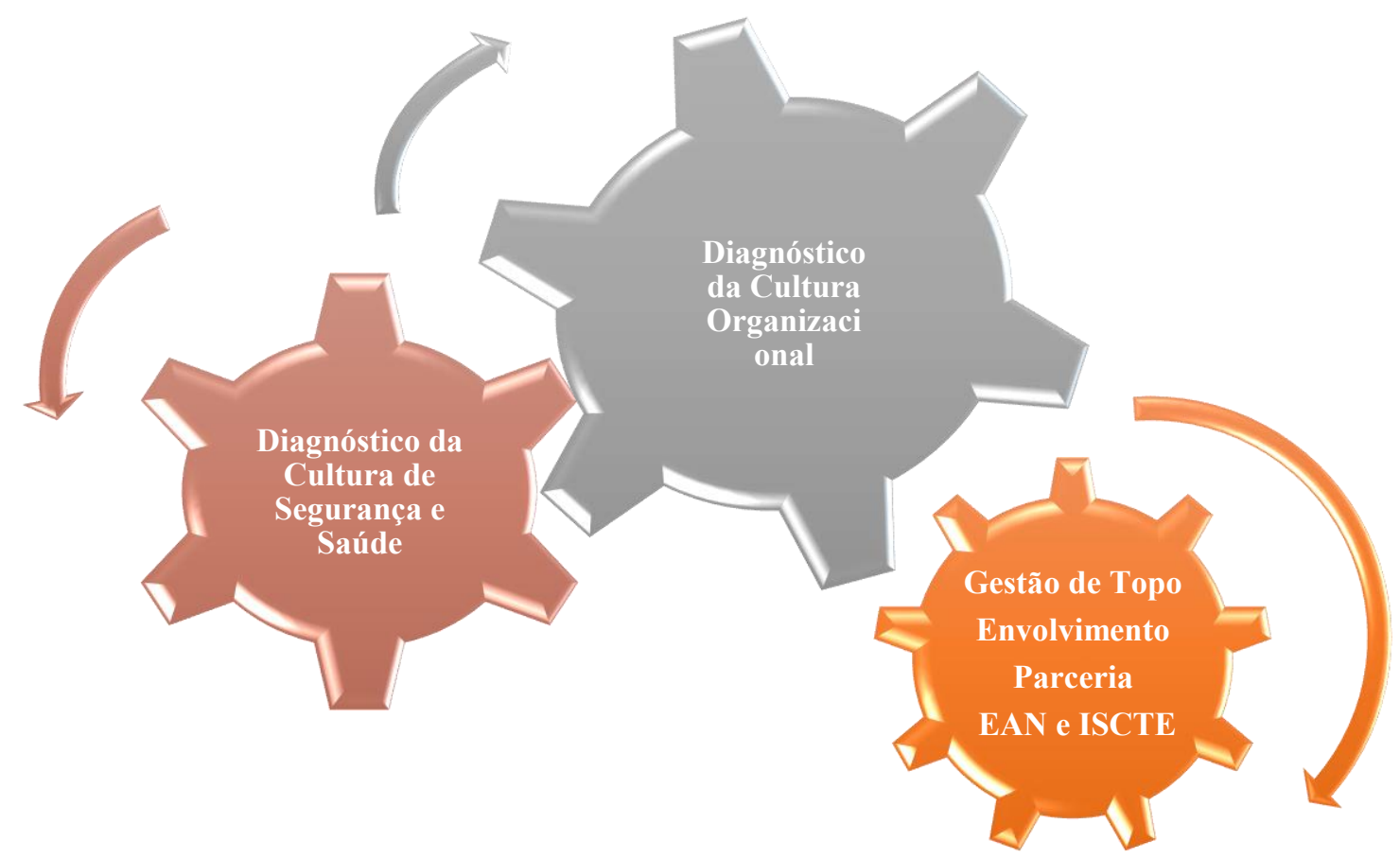

Ilustração 5 - Avaliação da Cultura Organizacional e de Segurança - ICOS (CIS/ISCTE)

Fonte: Elaboração Própria

Ressalta da nossa análise que o instrumento aplicado foi o ICOS (Inquérito da Cultura Organizacional e de Segurança), (Silva, Sílvia; Tavares, Susana, 2006) Inquérito de avaliação da Cultura Organizacional e de Segurança, uma metodologia mista com entrevistas semiestruturadas (ANEXO BIV) a uma amostra por conveniência da EAN (Estação Agronómica Nacional).

Após diagnóstico avaliou-se qual a prioridade de intervenção ao nível da Cultura de Segurança e formou-se uma Comunidade de quinze funcionários que tiveram acesso a um programa de formação/treino para a mudança. Em 2004 inicia o processo formativo do grupo e em 2005 o 
grupo inicia um grande trabalho de campo partilhando conhecimentos quer dentro da organização quer com outras organizações da Administração Pública como demonstram a análise de conteúdo das entrevistas semiestruturadas (ANEXO BI e BII) realizadas ao coordenador da CoP embrionária e aos membros da Comunidade. Da consulta do livro de atas (Quadro 7), assim como da análise de produtos elaborados e interações da CoPGAPEAN explicitadas no ANEXO BIII, conseguimos evidenciar o trabalho realizado pela CoPGAPEAN. Foi crucial preparar a cultura para a mudança e o líder da Organização teve papel preponderante, apoiando o grupo em todas as fases e envolvendo-se ele próprio nas ações.

O clima organizacional foi avaliado no início do projeto estando a Comunidade dos Animadores de Prevenção a dar os seus primeiros passos na construção de um sentimento de pertença e confiança mútua, sendo estabelecida uma parceria com o Centro de Investigação Social do ISCTE que através dos seus instrumentos de avaliação e aplicando um questionário (Silva, Sílvia; Tavares, Susana, 2006) nos facultaram a possibilidade de fazer uma avaliação da Cultura Organizacional e de Segurança a pedido do Dirigente máximo da Organização devido à necessidade de num processo de intervenção termos a compatibilização da Cultura Organizacional e de Segurança. Neste estudo, um total cento e vinte e um indivíduos responderam ao questionário.

ICOS 2006: Da consulta documental ao relatório de avaliação do clima organizacional, feito por investigadoras do ISCTE (Silva, Sílvia; Tavares, Suasana, 2006), o clima organizacional é avaliado através do modelo dos valores contrastantes e verificamos que os valores se situam todos acima do ponto médio da escala ao nível dos objetivos, inovação, apoio e regras, o que significa um clima positivo.

\begin{tabular}{|l|r|r|r|r|r|}
\hline & $\mathrm{N}$ & \multicolumn{1}{|c|}{ Minimo } & Máximo & \multicolumn{1}{c|}{ Média } & $\begin{array}{c}\text { Desvio- } \\
\text { padrão }\end{array}$ \\
\hline Objetivos & 111 & 1,33 & 7,00 & 5,0450 & 1,33370 \\
Inovação & 108 & 1,00 & 7,00 & 4,6537 & 1,32456 \\
Apoio & 107 & 1,00 & 6,80 & 4,7402 & 1,37778 \\
Regras & 109 & 2,00 & 7,00 & 4,9235 & 1,16943 \\
\hline
\end{tabular}

Tabela 1 - Resultados de clima organizacional-2006

Fonte: (Silva, Sílvia; Tavares, Susana, 2006) 
Os trabalhadores partilham a perceção de que a organização valoriza mais os objetivos e as regras revelando os resultados a existência de uma preocupação em definir uma missão e objetivos claros para a organização.

\begin{tabular}{|c|c|c|c|c|c|}
\hline VARIAVEIS ESTUDADAS & $\mathrm{N}$ & Mínimo & Máximo & Média & $\begin{array}{l}\text { Desvio- } \\
\text { padrão }\end{array}$ \\
\hline IMAGEM ORGANIZACIONAL & & & & & \\
\hline Imagem percebida & 106 & 1,00 & 7,00 & 3,9198 & 1,19749 \\
\hline Prestígio percebido & 98 & 1,00 & 7,00 & 4,1388 & 1,09973 \\
\hline $\begin{array}{l}\text { INTERDEPENDENCIA NO EXERCICIO DA } \\
\text { FUNÇÄO }\end{array}$ & & & & & \\
\hline Interdependência recíproca & 107 & 1,00 & 6,75 & 4,5210 & 1,22095 \\
\hline $\begin{array}{l}\text { PERCEPÇÄO DE SUPORTE NO LOCAL DE } \\
\text { TRABALHO }\end{array}$ & & & & & \\
\hline Perceção de suporte organizacional & 103 & 1,00 & 6,38 & 3,6735 & 1,30154 \\
\hline $\begin{array}{l}\text { Perceção de suporte em relação aos colegas } \\
\text { IDENTIFICAÇÄO }\end{array}$ & 107 & 1,75 & 7,00 & 4,7722 & 1,25328 \\
\hline Identificação com a organização & 107 & 2,00 & 7,00 & 5,0748 & 1,27221 \\
\hline $\begin{array}{l}\text { Identificação com a profissão } \\
\text { IMPLICACĀO ORGANIZACIONAL }\end{array}$ & 110 & 1,00 & 7,00 & 5,3782 & 1,05286 \\
\hline Implicação afetiva & 111 & 1,00 & 7,00 & 4,8198 & 1,32509 \\
\hline Implicação normativa & 105 & 1,00 & 7,00 & 4,0643 & 1,34942 \\
\hline Implicação continuidade & 102 & 1,00 & 6,75 & 3,4975 & 1,31701 \\
\hline $\begin{array}{l}\text { CONFLITO ENTRE O TRABALHO E A } \\
\text { FAMILIA }\end{array}$ & & & & & \\
\hline conflite trabalho-familia & 107 & 1,00 & 6,25 & 2.9486 & 1,20618 \\
\hline $\begin{array}{l}\text { conflite familia-trabalho } \\
\text { AJUSTAMENTO DO INDIVIDUO }\end{array}$ & 104 & 1,00 & 4,75 & 2,1082 &, 93785 \\
\hline Ajustamento pessoa-organização & 104 & 1,00 & 7,00 & 3,8654 & 1,46334 \\
\hline $\begin{array}{l}\text { Ajustamento pessoa-trabalho } \\
\text { ATITUDE FACE A MUDANCA }\end{array}$ & 109 & 1,00 & 7,00 & 4,9778 & 1,15290 \\
\hline $\begin{array}{l}\text { Atribuição situacional das consequências da } \\
\text { mudança }\end{array}$ & 108 & 1,33 & 7,00 & 3,5000 & 1,27399 \\
\hline Pessimismo relativamente à mudança & 107 & 1,00 & 7,00 & 3,2033 & 1,17669 \\
\hline $\begin{array}{l}\text { COMPORTAMENTOS DE CIDADANIA } \\
\text { ORGANIZACIONAL }\end{array}$ & & & & & \\
\hline Dedicação ao trabalho & 112 & 3,00 & 7,00 & 5,9487 &, 78710 \\
\hline Dedicação ao trabalho extra-horário & 106 & 1,00 & 7,00 & 4,2075 & 1,45384 \\
\hline INTENÇÄO DE SAIDA & & & & & \\
\hline Intenção de turnover & 112 & 1 & 7 & 2.0804 & 1.55898 \\
\hline
\end{tabular}

Tabela 2 - Resultados variáveis psicossociais -2006

Fonte: (Silva, Sílvia; Tavares, Susana, 2006)

ICOS- 2006: Relativamente às variáveis psicossociais estudadas que se encontram na Tabela 2 , que tivemos acesso por análise documental arquivada do estudo realizado em 2006 (ANEXO BVI), as médias, desvios padrão e valores mínimos e máximos observados numa escala de 222

Comunidad@Buenas Prácticas de Seguridad, Salud e Calidad de Vida en el trabajo INIAV

"Factores críticos de éxito" 
concordância podemos recolher dados muito favoráveis para a implementação de mudanças. Verificamos uma identificação positiva com a organização e com a profissão, uma implicação afetiva.

Também verificamos que o valor médio apresentado na relação trabalho-família é favorável, há também um valor médio positivo em relação ao ajustamento pessoa-trabalho. Ao nível de comportamentos de cidadania organizacional temos um valor positivo em relação à dedicação ao trabalho e um valor positivo em relação à continuidade na organização. Neste estudo, responderam 121 indivíduos responderam ao questionário.

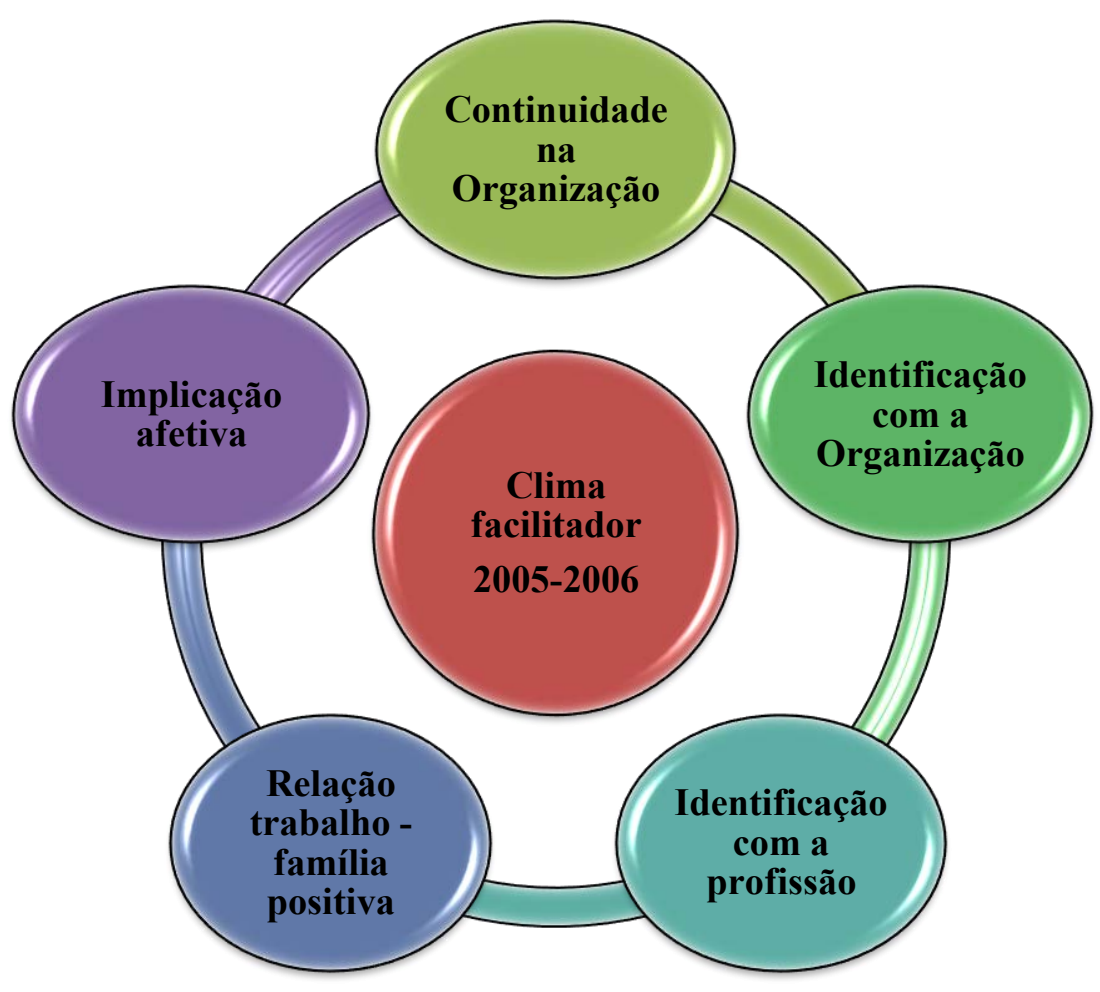

Ilustração 6- Clima Organizacional 2004 a 2007

Fonte: Elaboração Própria 
Neste Período de intervenção temos um Clima Organizacional facilitador, Ilustração 6, de implementação de mudanças e muita abertura a projetos inovadores. Temos uma Gestão de Topo envolvida num projeto para a Administração Pública e facilitando o desenvolvimento do mesmo na sua Organização. Esta prática desencadeou um resultado de sucesso, o desenvolvimento da Confiança.

Neste período houve um forte estímulo da Gestão de Topo para que os seus colaboradores partilhassem o conhecimento no domínio da SST, prática essencial que originou o desenvolvimento da confiança - um resultado de sucesso (Quadro 5).

Quadro 5 - Desenvolvimento da Confiança CoPGAPEAN

Fonte: Elaboração Própria

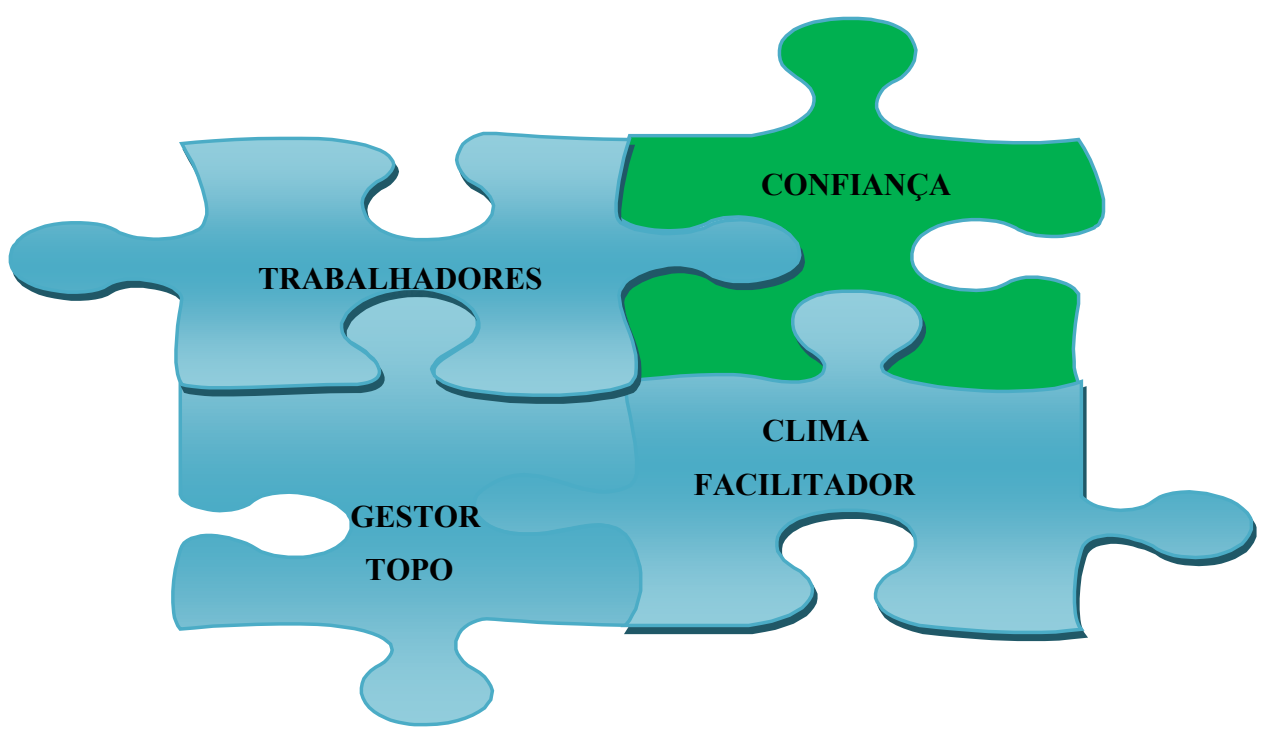

Ilustração 7 - Desenvolvimento da Confiança/Clima facilitador positivo 2004 -2008

Fonte: Elaboração Própria 
Este sentimento de confiança (Ilustração 7) evidencia-se como resultado e foi alimentado por práticas essenciais tais como: o estabelecimento de objetivos a curto e médio assim como a definição de métodos de interação evidenciados nos documentos por nós consultados (atas e registo de eventos realizados pela CoP - ANEXO BIII e Quadro 7)

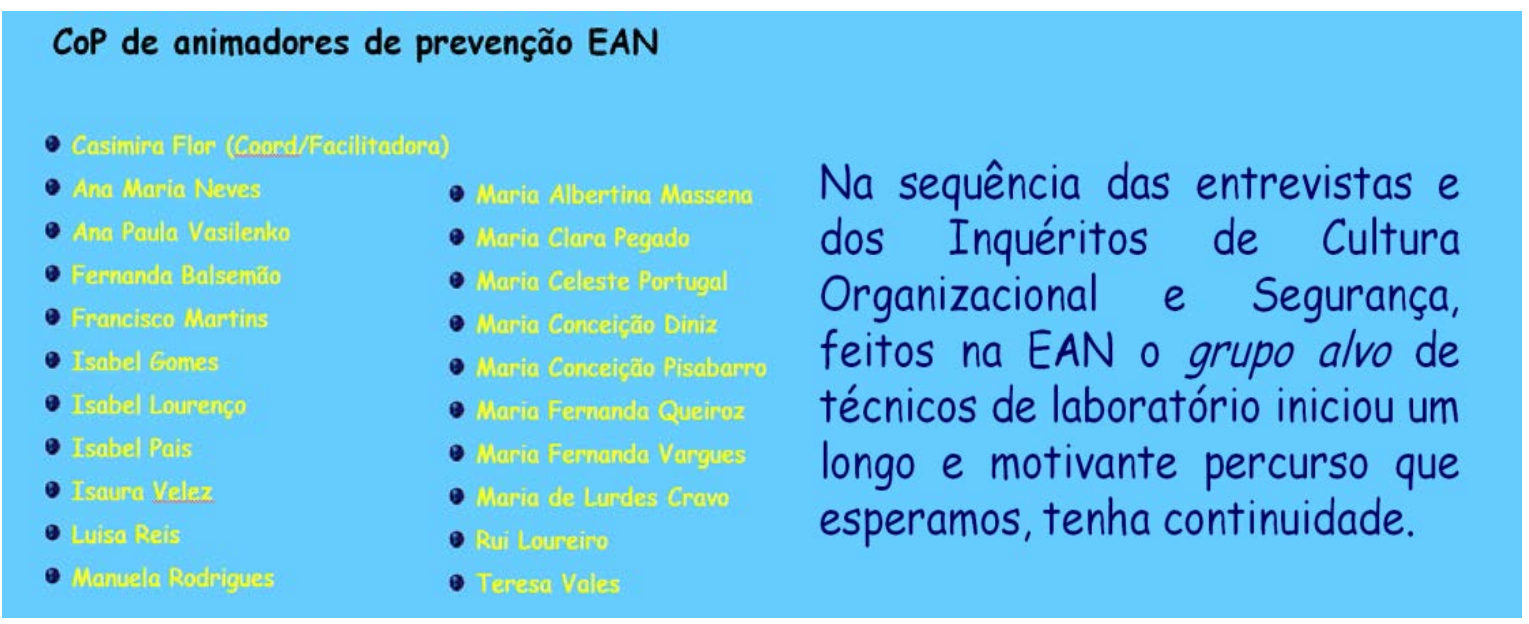

Ilustração 8 - Ação Presencial realizada em 2006 -Seminário

Fonte: Elaboração Própria

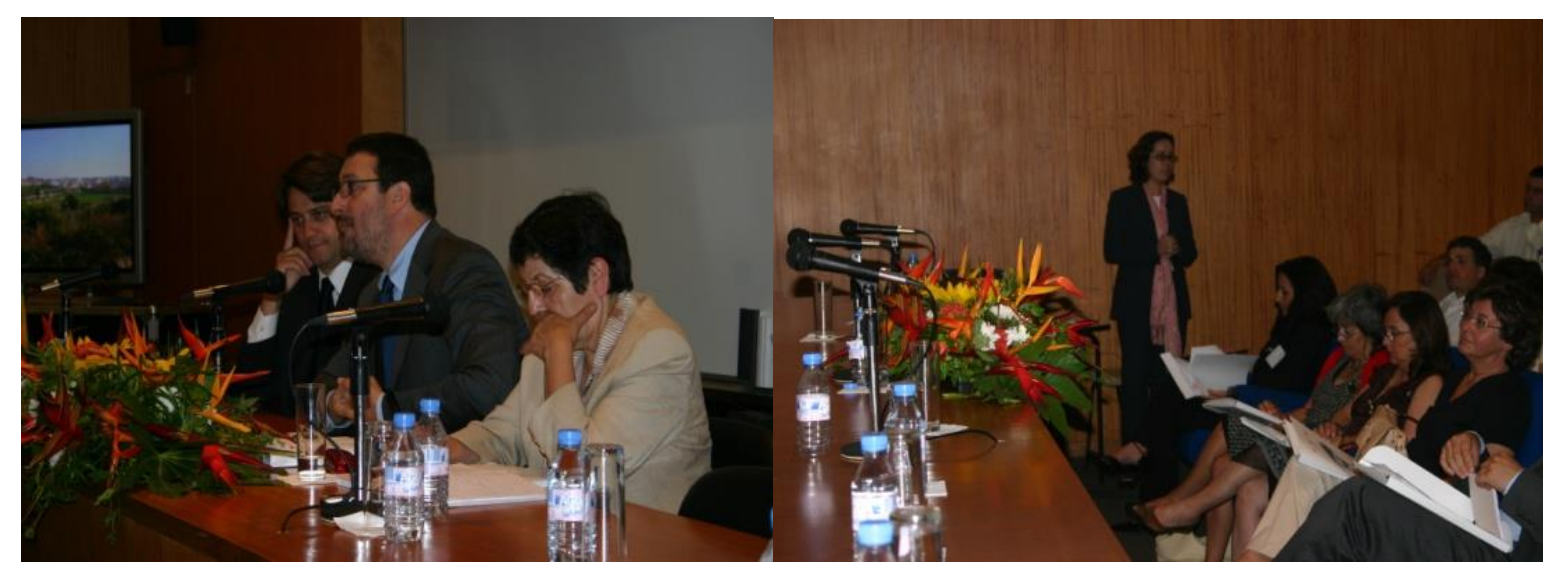

Figura 5 - Seminário EAN/INA cultura de Segurança e Saúde no Trabalho

Fonte: Elaboração Própria 
Doctorado en Salud, Discapacidad, Dependencia y Bienestar

\begin{tabular}{|l|l|}
\hline Resultado & $\begin{array}{l}\text { Estímulo da Gestão de Topo para que os seus colaboradores partilhassem o } \\
\text { conhecimento no Domínio da Segurança e Saúde no Trabalho }\end{array}$ \\
\cline { 2 - 2 } Confiança & Há um forte sentimento de confiança entre os membros da CoP \\
\hline \multirow{2}{*}{ Contribuição } & Participação e interesse nos eventos relacionados com o domínio da CoP \\
\cline { 2 - 2 } $\begin{array}{l}\text { Utilidade } \\
\text { Sentimento de } \\
\text { Pertença }\end{array}$ & $\begin{array}{l}\text { O participante vê a CoP como um instrumento para melhorar os conhecimentos } \\
\text { no Domínio. }\end{array}$ \\
\cline { 2 - 2 } & Envolvimento individual do membro com a CoP \\
\hline
\end{tabular}

Quadro 6 - Resultados de sucesso da CoPGAPEAN

Fonte: Elaboração Própria

Também foram definidos os moderadores da $\mathrm{CoP}$ nos vários momentos do percurso estando explícito na observação que fizemos ao livro de atas que foi cíclica a passagem na moderação sendo assegurada por todos os membros da Comunidade, gerida pela líder da CoPGAPEAN e incentivada pelo Gestor de Topo da Organização.

As reuniões de dinâmica colaborativa realizaram-se nas infraestruturas da Estação Agronómica Nacional, tendo a gestão de topo concedido tempo para as atividades comunitárias, compatibilizando as atividades normais de trabalho com as da CoP, assim como disponibilizando os recursos físicos (salas) e materiais para o desenvolvimento das atividades colaborativas.

A Gestão de Topo também promoveu internamente as atividades da CoPGAPEAN estabelecendo a ponte com Chefias intermédias e reconhecendo a importância das atividades da CoP na EAN, tendo o cuidado de estimular a partilha de conhecimento e deu liberdade para expressarem as ideias e contribuírem na mudança de comportamento e atitudes face à Prevenção de riscos laborais, (Figura 5). 
Nas reuniões foi elaborado um plano de atividades e tarefas distribuídas pelos diferentes membros (observação das atas de todas as reuniões), no período do Gestor de Topo facilitador realizou-se o maior número de encontros presenciais e a dinâmica resultou num aumento da confiança, contribuição, sentimento de pertença e utilidade na CoPGAPEAN.

Para além das reuniões do grupo embrião, houve eventos em que o grupo participou e organizou na EAN com a abertura da sua fronteira ao exterior (como exemplo apresentado na figura abaixo apresentada).
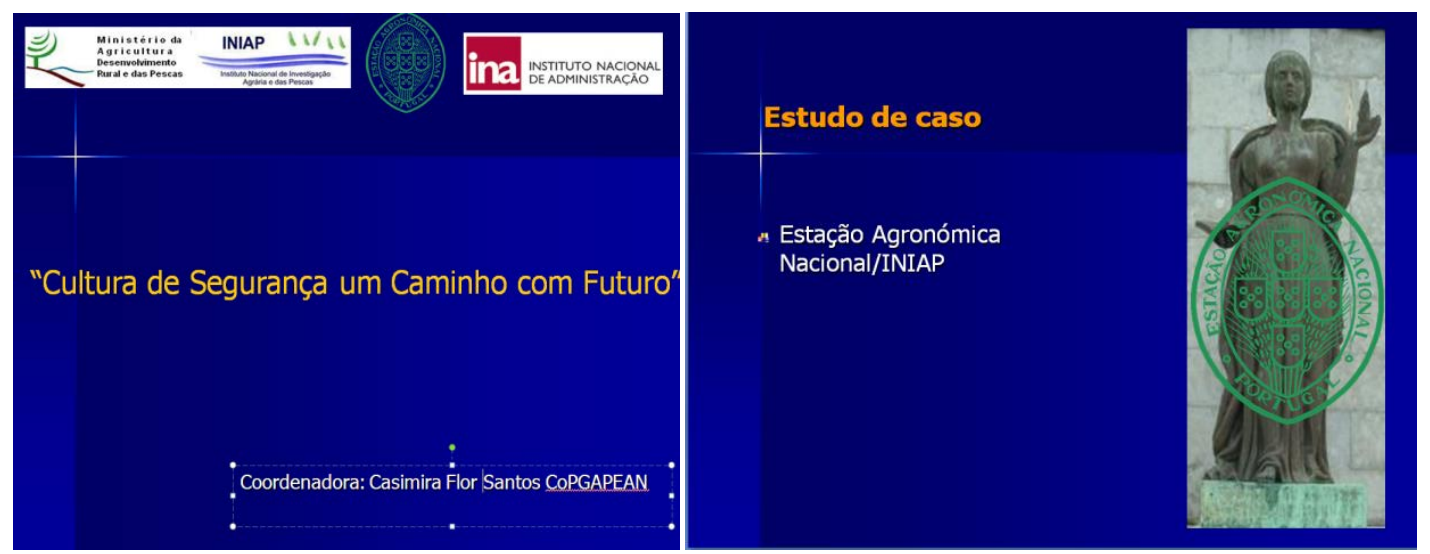

Figura 6 - Partilha do estudo desenvolvido com outras Organizações

Fonte: Elaboração Própria

Seguidamente apresentamos em formato de quadro resumo, práticas essenciais que reforçaram o resultado que evidenciou sucesso da CoPGAPEAN (Quadro 7) de 2005 a 2008. O documento observado para análise foi o livro de atas que consultamos desde 2005 a 2008, que nos dá a conhecer nas várias atas de reuniões efetuadas pelos membros da Comunidade a perceber quais as práticas essenciais para um bom resultado da CoPGAPEAN (Quadro 7). Como práticas referidas na coluna do centro temos o alinhamento e estruturação, o apoio da liderança, a cultura o desenvolvimento, a cultura, política e coordenação da $\mathrm{CoP}$, e em cada uma das práticas referidas foram evidenciadas os elementos da prática que reforçaram os resultados - confiança, sentimento de pertença, contribuição e utilidade que estão colocados na coluna da direita do Quadro 7. 
Doctorado en Salud, Discapacidad, Dependencia y Bienestar

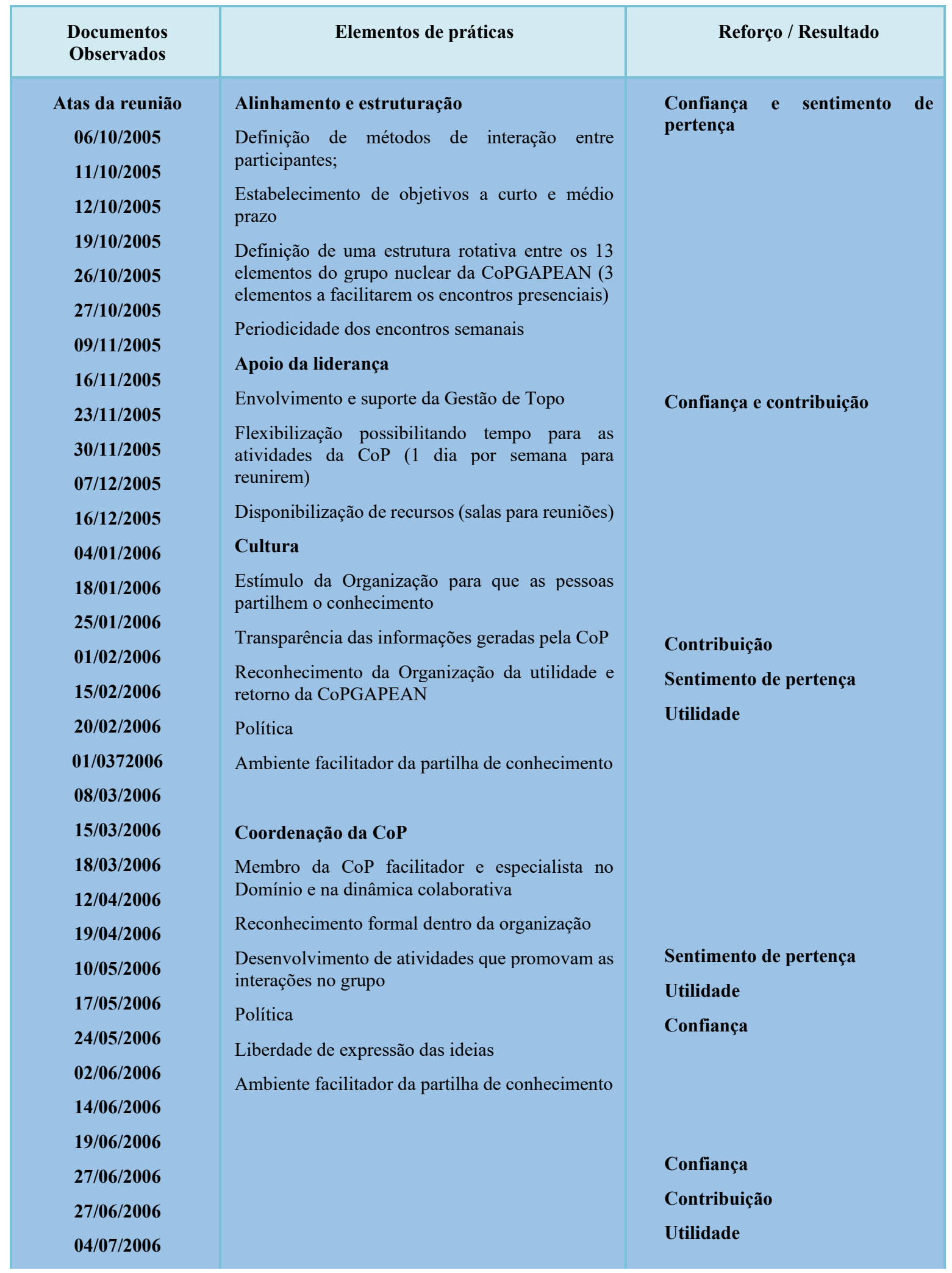

Comunidad@Buenas Prácticas de Seguridad, Salud e Calidad de Vida en el trabajo INIAV

"Factores críticos de éxito" 
Doctorado en Salud, Discapacidad, Dependencia y Bienestar

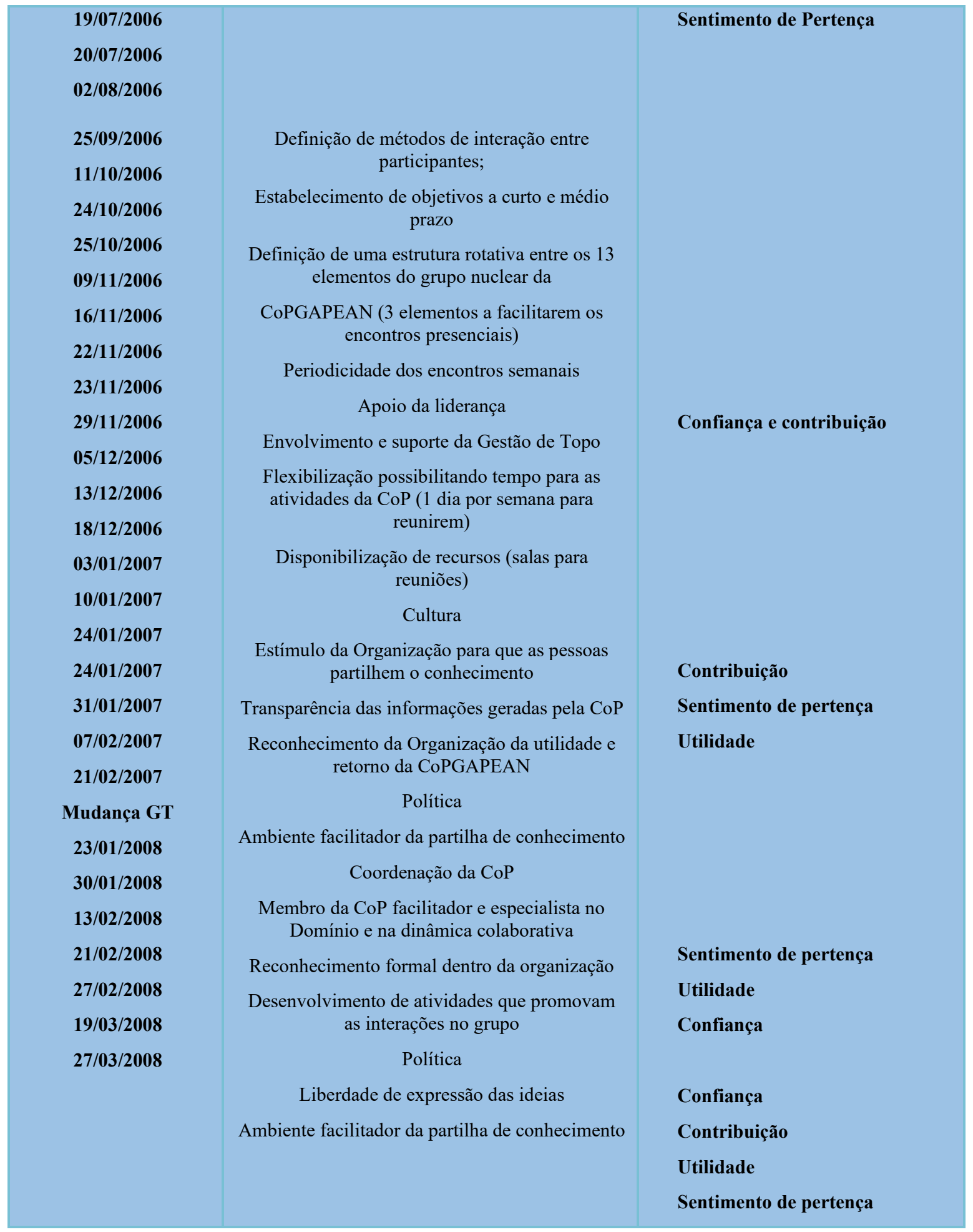

Quadro 7 - Práticas essenciais que reforçaram o resultado do sucesso da CoPGAPEAN

Fonte: Elaboração Própria

Comunidad@Buenas Prácticas de Seguridad, Salud e Calidad de Vida en el trabajo INIAV

"Factores críticos de éxito" 
A prática de alinhamento e estruturação foi crucial para o excelente desenvolvimento da Confiança. Quando os três elementos, domínio, comunidade e prática funcionam em harmonia, estes criam uma $\mathrm{CoP}$, uma estrutura de conhecimento ideal para assumir responsabilidades para um efetivo desenvolvimento e partilha de conhecimento.

Ainda na Prática de Alinhamento e estruturação foram definidos estratégias e planos de ação para a obtenção dos objetivos da CoPGAPEAN.

A Comunidade é o elemento central da CoP, formada por um grupo de pessoas que interagiram entre si regularmente, em atividades conjuntas e de interesse comum, construindo relações pautadas em confiança. Estas pessoas com interesse no domínio da SST ao partilhar o seu conhecimento, aprenderam juntas, desenvolvendo a responsabilidade e o compromisso de participação no grupo de animadores de prevenção.

Para além do alinhamento temos a prática essencial Apoio da Liderança / Gestão de Topo que fizeram com que a resultado confiança se mostrasse essencial para que aumentasse um forte sentimento de confiança entre os membros da $\mathrm{CoP}$ e que é caracterizado pelo Apoio da Gestão de Topo. A necessidade de legitimar a participação dos membros reservando um tempo (diário, semanal, mensal etc.) para que os membros participassem das atividades da COPGAPEAN. Outro aspeto interessante no apoio da Gestão de Topo foi a criação de um local para que as atividades acontecessem.

Um ponto de partida muito interessante da Gestão de Topo foi a preocupação de estabelecer sintonia com práticas existentes na organização e sabendo nós que o conhecimento que a organização necessita já está presente dentro dela, há que tirar partido disso promovendo a formação de Comunidades de Prática que aproveitem esse potencial.

Também da parte da Gestão de topo houve a preocupação em alinhar os sistemas de reconhecimento à $\mathrm{CoP}$.

O reconhecimento e as recompensas não foram esquecidos aos que participaram e uma forma interessante foi incluir, na avaliação de desempenho, aspetos que valorizaram a participação dos funcionários em atividades comunitárias. Fornecer suporte: apesar da CoP ser autossuficiente, 
contudo foi beneficiada por alguns recursos, tais como: peritos externos à organização, instalações param as reuniões e eventos de partilha.

O estabelecimento de uma atmosfera aberta à Gestão do Conhecimento - GC que incluiu criação da Comunidade, alavancou a consciência da necessidade de se partilhar conhecimento na organização, assim como a vontade em interagir na CoP. Para além da atmosfera, segundo (Zboralski, Katja, 2009), os recursos cedidos pela organização também integram o contexto favorável à participação dos membros. (Zboralski, Katja, 2009), nas suas considerações sobre a influência do apoio organizacional nas CoP, afirma que o apoio da organização tem sido de grande importância para o êxito das iniciativas no contexto da gestão do conhecimento. (Scarso, E.; Bolisani, E., 2008) mencionam exemplos de recompensas não financeiras que são efetivas no que tange ao incentivo à participação em Comunidades, tais como: reconhecimento público, por parte da organização, de que os membros das CoP são especialistas naquele domínio; e motivação pessoal. No trabalho desenvolvido por (Flor, C., 2015) a investigadora valida no seu estudo de investigação os incentivos que a Gestão de Topo no seu estudo usou para dar ânimo à CoPGAPEAN e que seguiram a lógica do estudo de (Scarso, E.; Bolisani, E., 2008) o reconhecimento público, motivação pessoal e o reconhecimento de competências permitindo que os participantes na CoP pudessem partilhar em Seminários e Workshops o seu conhecimento. Também verificamos verificar que a prática essencial Cultura da Organização revelou boas práticas na partilha de conhecimento no âmbito da Prevenção havendo estímulo e reforço da Organização para a partilha do conhecimento no domínio da Segurança e Saúde no Trabalho.

Apresenta-se a Prática de Apoio da Gestão de topo com elementos essenciais da mesma tais com: como o reconhecimento público da Organização se reflete em utilidade da CoPGAPEAN promovendo publicamente a CoP e uma Cultura favorável à partilha com o elemento essencial de prática acentuado na transparência das informações geradas pela $\mathrm{CoP}$ dos animadores de Prevenção. A dimensão cultural apresenta um fator crítico de sucesso mencionado item emerge (Scarso, E.; Bolisani, E., 2008), mencionaram a proximidade cultural entre os membros facilita a disseminação do conhecimento entre os participantes das CoP. Da análise do Quadro 7 que 
efetuámos concluímos que para a CoPGAPEAN o saber não é somente uma questão individual, é também uma questão de troca, de aprender com e através do outro, da sua experiência.

Ainda na Prática Cultura acentuamos o estímulo da Organização para que as pessoas partilhem o conhecimento e o reconhecimento da Organização da importância, utilidade e retorno da COPGAPEAN.
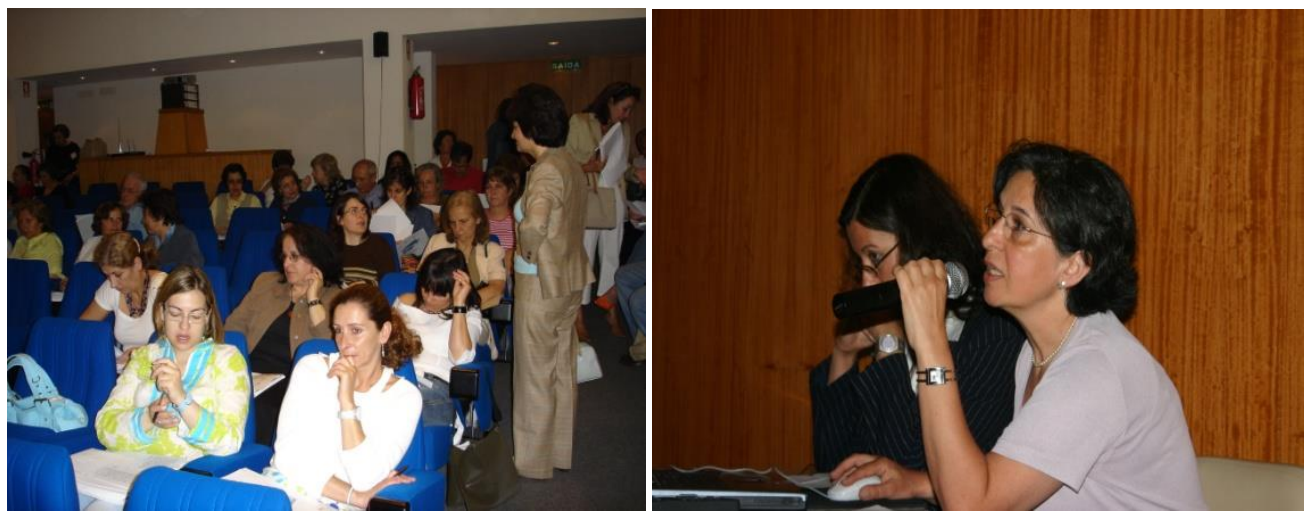

Figura 7 - Partilha de conhecimento: Confiança, Utilidade, Sentimento de Pertença Fonte: Elaboração Própria

Esta Comunidade possibilitou para além da experiência individual a interação entre diferentes grupos profissionais, representado na figura 7, também fomentou interações e relacionamentos baseados no respeito mútuo e na confiança, encorajando a disposição para partilhar ideias todas estas ações se enquadram na prática essencial para que os resultados evoluam no sentido do sucesso e essa prática está relacionada com o Desenvolvimento da CoP. Houve também um grande investimento no treino dos membros da comunidade dos animadores de prevenção e a existência e permanência de uma coordenação forte.

O domínio refere-se à Segurança e Saúde no Trabalho e sendo o foco na partilha de Boas Práticas SST a área de conhecimento em torno da qual se construiu a comunidade e criou uma identidade.

A aposta neste domínio legitimou a comunidade pela afirmação dos objetivos e valores dos membros e outros stakeholders. Práticas essenciais foram desenvolvidas para que a confiança 
fizesse parte da Comunidade e o envolvimento das Chefias intermédias para além da Gestão de Topo foram cruciais no processo (Figura 8). Houve um ambiente de liberdade para se expressarem ideias e facilitador da partilha do conhecimento uma Política e cultura aberta ao trabalho colaborativo.
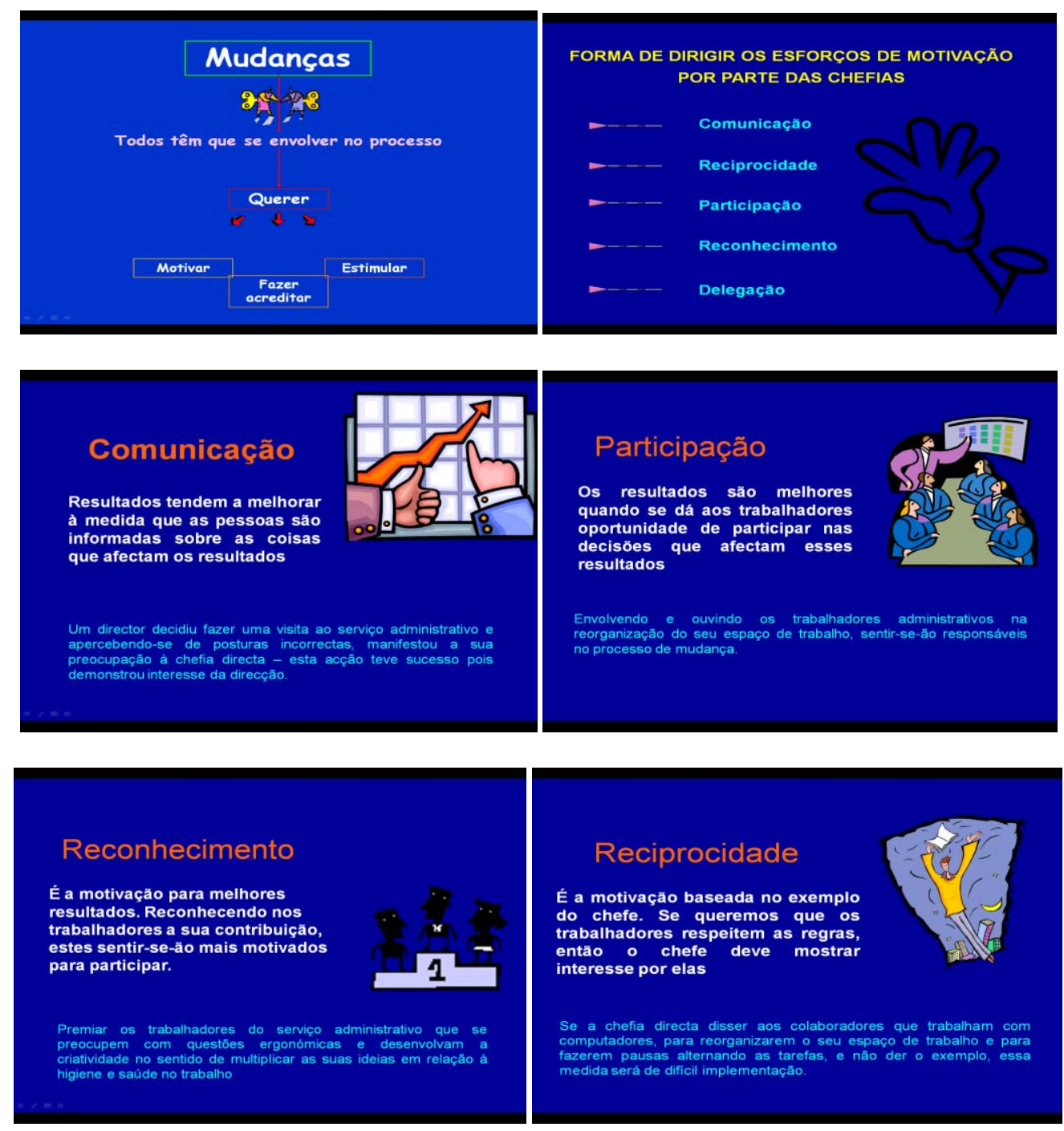

Figura 8- Documentos partilhados pelos facilitadores da CoP em reuniões alargadas com a Gestão de Topo e chefias (20042008). Comunicação face to face

Fonte: Elaboração Própria 
Pela análise documental verificamos que foi muito importante para a Comunidade perdurar no tempo a existência de um líder/coordenador forte e envolvido na dinâmica para além de ser especialista no domínio como prática essencial (ANEXO BIII). Foram planeadas e desenvolvidas atividades de interação pessoal como evidencia a Figura 10. Para se aumentar o nível de confiança deste grupo de pessoas, a coordenadora estabeleceu pontes com especialista para facultar formação e treino no domínio da SST assim como em todo o processo lutou para que a gestão de topo valorizasse o trabalho e dedicação destes membros do grupo no sentido de na avaliação de desempenho este parâmetro ser tido em conta.
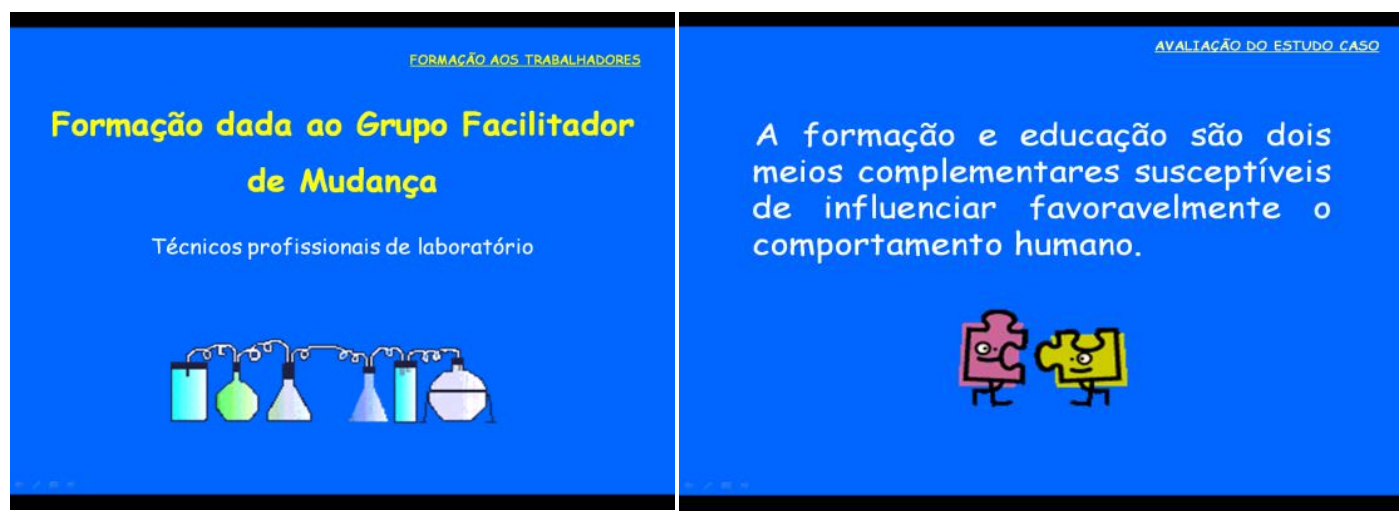

Figura 9 - Formação do Grupo facilitador de mudanças face a SST

Fonte: Elaboração Própria

As evidências de cada um dos elementos que justifica a ação da Gestão da Comunidade aumentaram o nível de confiança dos funcionários que se associaram à Comunidade. Zboralski, (2009), afirma que é de competência da organização zelar no sentido de que a Comunidade possua um membro que seja respeitado pelos demais, atuando como coordenador e que tenha conhecimento técnico no domínio, mas, sobretudo, habilidade para conectar as pessoas. 

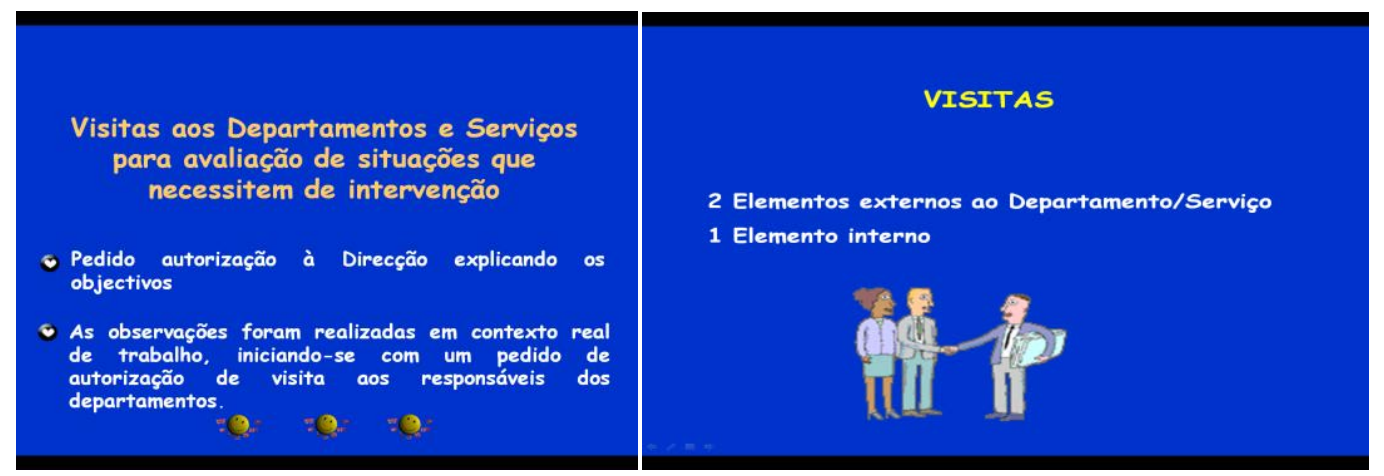

Figura 10 -Envolvimento interno e Facilitação forte aumentando a confiança dos membros da CoP

Fonte: Elaboração Própria

Como se evidencia na Figura 11 e em Quadro 7, o resultado da prática essencial de apoio de um líder forte na Comunidade dará um resultado positivo ao nível da confiança. Nos vários documentos por nós observados o ambiente facilitador da partilha de conhecimento, a liberdade para se expressarem ideias e a abertura á entrada de novos membros fez parte da política como se evidencia nos documentos observados (ANEXO BIII) o que provocou um aumento da confiança como resultado da prática relacionada com a Política da Organização.
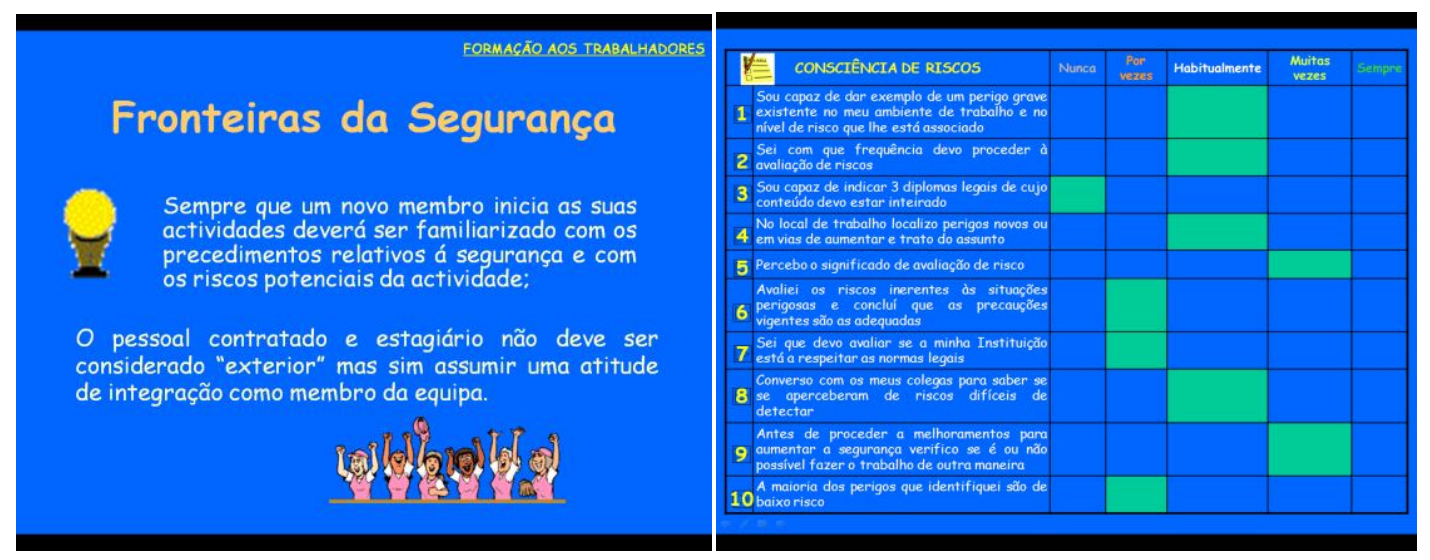

Figura 11 - Cultura Positiva e Facilitadora

Fonte: Elaboração Própria 
A confiança como um dos resultados para o sucesso da CoP no intervalo de tempo entre 2009 e 2014. O grande desafio foi a CoP ter conseguido apoio a nível tecnológico passando a uma Comunidade mista com as duas vertentes a presencial e a virtual. O período em que se desenvolve o projeto é marcado por várias mudanças Organizacionais como se evidencia na Figura 12.

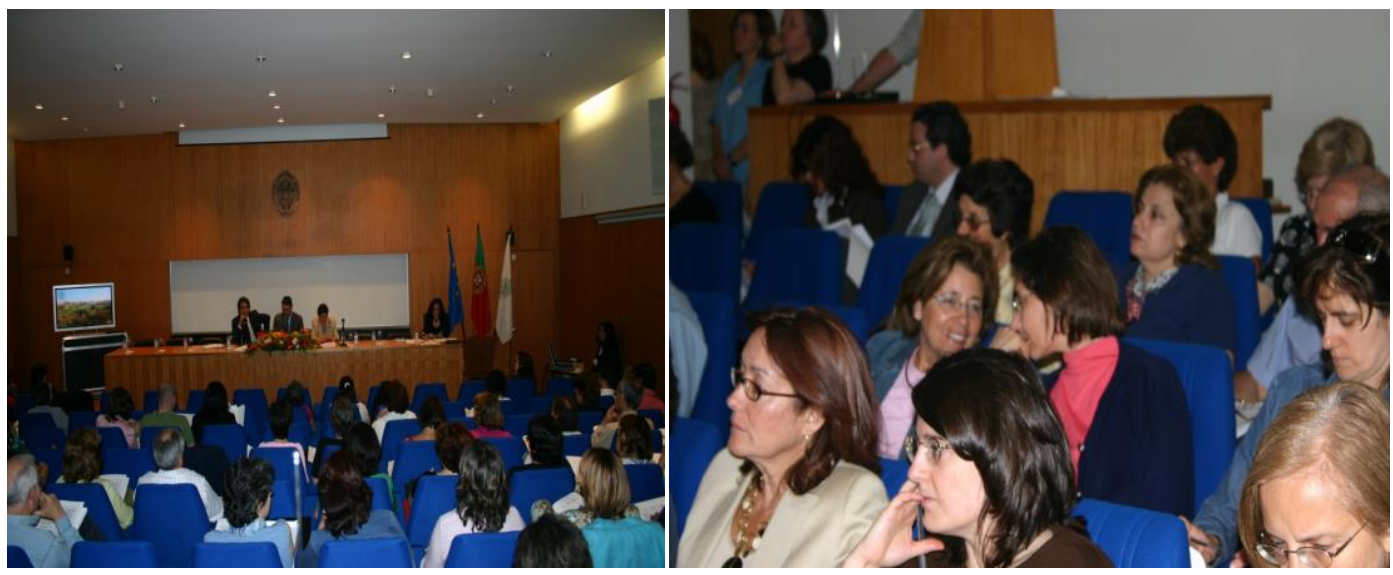

Figura 12 - Líder organizacional facilitador

Fonte: Elaboração Própria

Este período é marcado por um Líder Organizacional facilitador da partilha de conhecimento no âmbito da Segurança e Saúde no trabalho, após esta liderança somos confrontados com mais 3 líderes da Organização e corríamos o risco de o projeto não ter continuidade, (Figura 12).

Seguidamente apresentamos um quadro em que explicitamos as marcas das grandes mudanças organizacionais e que tiveram impacto no desenvolvimento do trabalho colaborativo, através do nascimento e desenvolvimento da Comunidade de Prática. 


\section{História (2002-2019)}

Em 2002, o INIA e o Instituto de Investigação das Pescas e do Mar

(IPIMAR), através de um processo de fusão, passam, a integrar o Instituto Nacional de Investigação Agrária e das Pescas (INIAP))

Em 2006 é criado o Instituto Nacional de Recursos Biológicos (INRB,

I.P.), em resultado da fusão do INIAP com o Laboratório Nacional de Investigação Veterinária (LNIV), da integração das atribuições, no domínio da investigação, da Direção Geral de Proteção de Culturas (DGPC) e da integração do Banco Português de Germoplasma Vegetal

Em 2012 é criado o Instituto Nacional de Investigação Agrária e Veterinária (INIAV I.P.) que fica com as atribuições relacionadas com a investigação agrária e veterinária do INRB.

Quadro 8 - Mudanças Organizacionais

Fonte: Elaboração Própria

As mudanças inevitáveis, que acontecem na prática, nos membros que compõem a CoP, nas tecnologias e nas relações com a organização, mexem com a energia.

A dinâmica presencial foi acentuada ente 2005 e meados de 2007, altura em que a Liderança da Organização muda, depois com a entrada de uma nova liderança mantem-se, mas com encontros mais espaçados. Podemos afirmar que a liderança de 2005 a início de 2007 possibilitou 55 encontros presenciais de reuniões da CoP e entre 2007-2008 a energia abrandou em termos de dinâmica e muita incerteza na Organização tendo observado 7 encontros. 

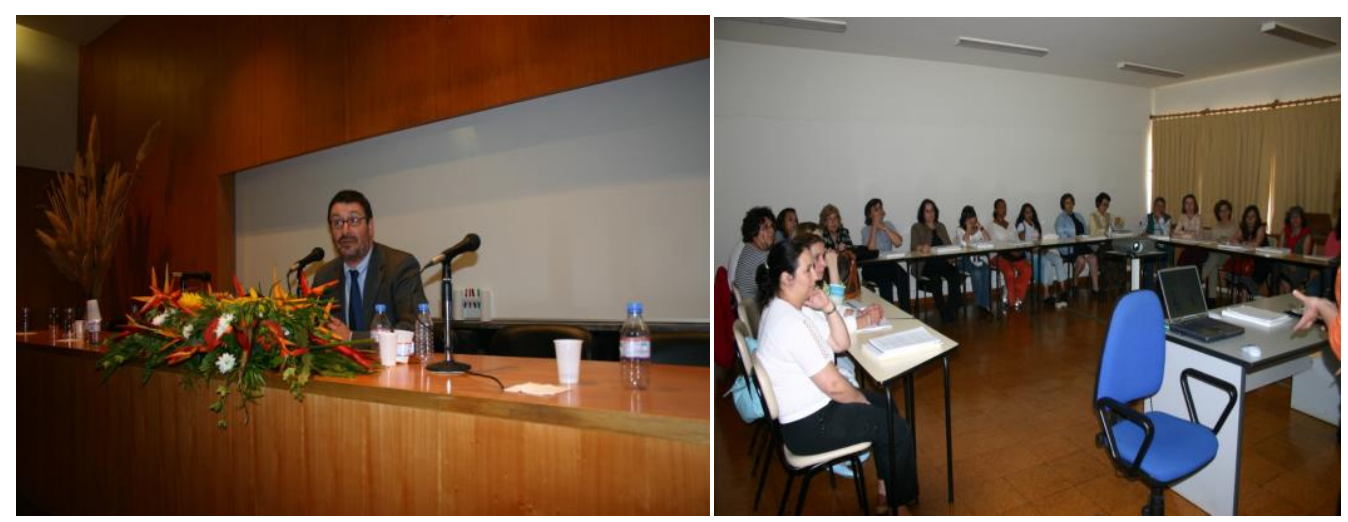

Figura 13 - Envolvimento e cedência de tempo e infraestruturas para o funcionamento da CoPGAPEAN Fonte: Elaboração Própria

A manutenção da energia que vitaliza essa estrutura requer atenção e conservação, para poder sustentar a CoP e aqui o Coordenador da CoP é a figura central no processo pois a participação e comprometimento dos membros diminuíram nesta fase de incertezas, mas a comunidade continuou como centro de conhecimento, através dos contatos pessoais existentes e da prática partilhada. O papel do Coordenador é idêntico ao da enzima nas reações químicas (Flor, C., 2015), esta figura (Figura 13) terá que estabelecer novas pontes com as novas Direções da Organização para que a CoP não se extinga, os anos chave de mudança de Liderança Organizacional foram: 2008-2012 e 2015. Assim, a organização deve intervir no momento em que se deparar entre a decisão de evoluir para outros domínios ou deixar que a comunidade se extinga. É muito importante analisarmos o que acontece nestes períodos de mudança e quais os fatores críticos param a continuidade do trabalho colaborativo.

O ano de 2008 é marcado por um novo líder Organizacional que dá continuidade ao trabalho iniciado pela COPGAPEAN mantendo-se a mesma dinâmica e aqui o papel do coordenador da CoP o grande desafio, nesta fase de grandes mudanças Organizacionais foi a manutenção do ritmo e a sobrevivência da CoP. Em 2009 há a possibilidade de em parceria mais uma vez com o INA entrarmos na dinâmica virtual e na aposta de treino de facilitadores para o desenvolvimento de uma CoP mista. Seguidamente apresentamos na Ilustração 9 as fases de mudança organizacional que influenciaram a CoPGAPEAN de 2008 a 2012. Em 2008 apesar 
da mudança da Gestão de Topo da organização, a dinâmica da CoP manteve-se e em 2009 devido à coordenação forte da CoP há um investimento em formação virtual que se consolida em 2012 ,com o nascimento da plataforma de trabalho colaborativo, como aposta e valorização de uma nova mudança de Gestão de Topo.
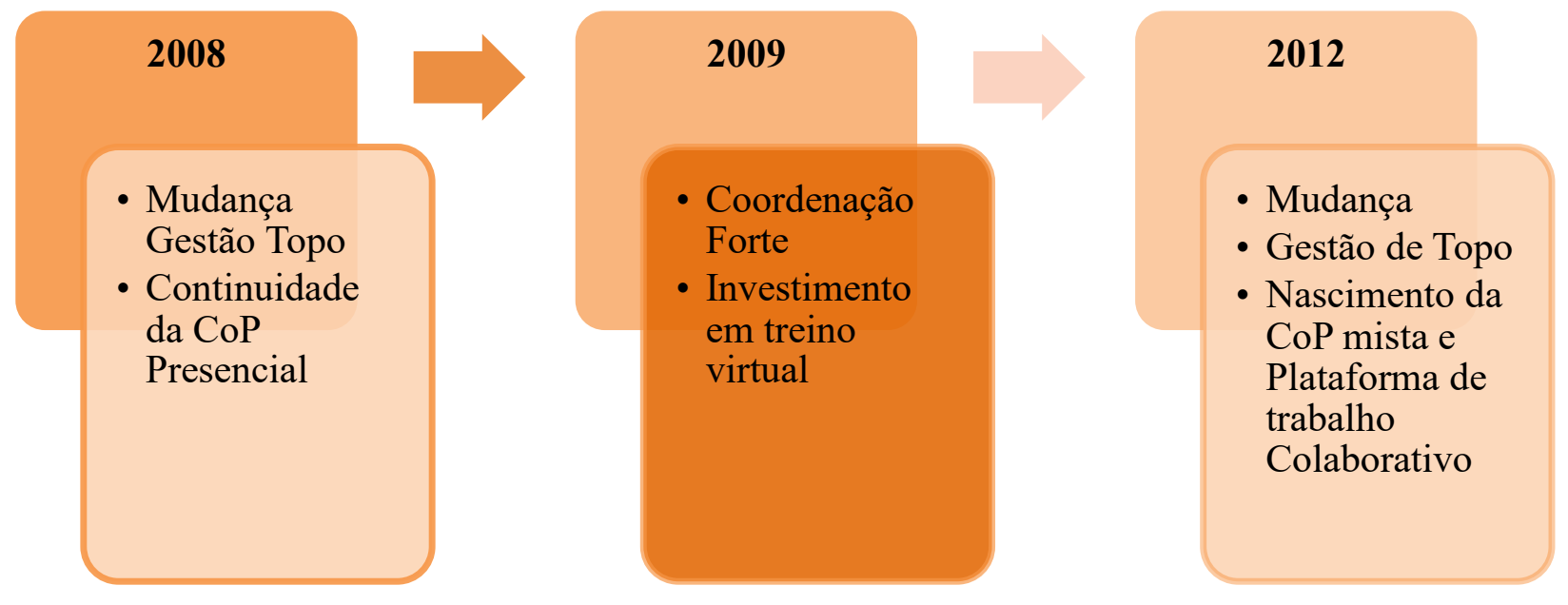

Ilustração 9 - Fases de mudança Organizacional e influência na CoPGAPEAN

Fonte: Elaboração Própria

A prática referente à tecnologia evidencia-se aqui como facilitadora e dá nova vida e ânimo à continuidade e sobrevivência da COPGAPEAN que em 2012 ganha a sua própria plataforma de trabalho colaborativo no INIAV tendo apoio da nova Direção que aposta no projeto alargando a possibilidade de este projeto piloto dar incentivo à criação de novas CoP na organização. 
Doctorado en Salud, Discapacidad, Dependencia y Bienestar

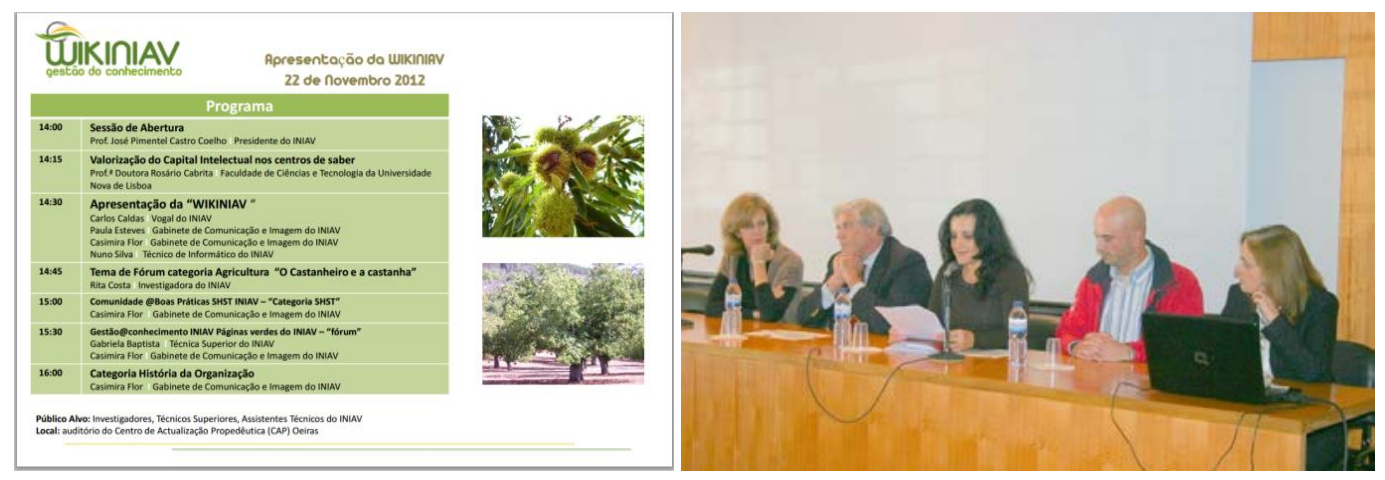

Figura 14 - Apresentação Pública da CoP virtual CoPSSQVTINIAV (2009-2014)

Fonte: Elaboração Própria

\section{Ferramenta de apoio ao trabalho colaborativo}

WIKINIAV é uma tecnologia de servidor colaborativo, "open source", que possibilita aos seus utilizadores terem acesso, procurar e editar artigo num ambiente em tempo real e participarem num fórum . Este servidor são é uma ferramenta crítica para coordenar documentos, bancos de dados e projetos colaborativos de forma efetiva e eficiente. Diferentemente de muitas outras alternativas, uma Wiki suporta atributos e estruturas definidos pelos seus utilizadores de forma flexível. É fácil de usar, de acordo com as tecnologias e padrões correntes, e requer muito pouco investimento tanto em hardware como em software e treino.

Link de acesso: http://wiki.iniav.pt/

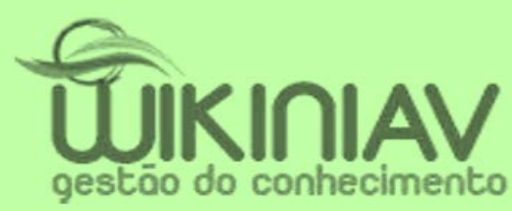

Ilustração 10 - Ferramenta de Trabalho Colaborativo 2012

Fonte: Elaboração Própria

Comunidad@Buenas Prácticas de Seguridad, Salud e Calidad de Vida en el trabajo INIAV

"Factores críticos de éxito" 
Agenda 2012-2013:

- Proposta da CoP pelo GT de Desenvolvimento Organizacional e Inovação-Junho de 2012.

- Reuniões com facilitadores.

- Apresentação Pública 22 de Novembro de 2012.

- Work shop s temáticos presenciais.

- Junho 2013-Encontro de membros.

Descrição da Comunidade: A Comunidade nasce com um grupo de técnicos especialistas neste domínio do INIAV.

Objectivos da Comunidade: Partilha de saberes e experiências no domínioSHST .Boas práticas na prevenção de riscos laborais e qualidade de vida no trabalho.

Tags (Palavras-Chave): Acidentes, SHST, Prevenção, boas práticas, saúde, segurança e trabalho

Duração: Ilimitada.

Ilustração 11 - Agenda da CoP SST 2012-2013

Fonte: Elaboração Própria

A CoPGAPEAN em 2012 transforma-se numa Comunidade com uma nova dinâmica a virtual, no entanto continua a dinâmica Presencial pois faz parte da Cultura da Organização encontros presenciais alarga também as suas fronteiras cativando outras temáticas do Domínio do INIAV como mostra as ilustrações 10,11 e 12 da plataforma da WIKINIAV. 
A Comunidade WIKINIAV alberga outras Comunidades temáticas:

A $1^{\text {a }}$ Comunidade de Partilha de Boas Práticas SHST já uma comunidade em fase de sustentação, pois teve a sua origem antes do nascimento da WIKINIAV. Esta comunidade é transversal a todas as atividades e áreas temáticas do Instituto e por isso mesmo se destaca como uma categoria específica na barra de categorias principal;

Na categoria Gestão do Conhecimento (GC) - estão todas as fichas das Comunidades que ao longo do projeto foram aparecendo, estando ainda na fase potencial (fase inicial de formação da Comunidade temática - nasceram pelo apelo que as temáticas tiveram em termos de interesse e impacto no público alvo e fases em que se encontram:

- Comunidade de saberes e sabores da pêra rocha - Fase Potencial.

- Comunidade de partilha de saberes das plantas melíferas - Fase Potencial- $1^{a}$ fase.

- Comunidade de partilha de saberes e sabores do azeite e azeitona; Fase Potencial $1^{\text {a }}$ fase.

- Comunidade de partilha de saberes das mulheres na Agricultura; Fase de potencial $2^{\mathrm{a}}$ fase.

- Comunidade de partilha de Boas práticas SHST; Fase de Maturidade $-3^{\mathrm{a}}$ Fase.

- Comunidade de partilha de saberes do figo da índia. Fase de crescimento-4aFase.

- Comunidade de resolução de problemas entre moderadores de Wikiniav: Fase de Maturidade $-3^{\mathbf{a}}$ Fase.

Ilustração 12 - Comunidades da WIKINIAV

Fonte: Elaboração Própria

Tal como poderemos observar na figura 12, temos 7 Comunidades que nascem na dinâmica da transformação da Comunidade CoPGAPEAN, esta CoP consegue que a plataforma de trabalho colaborativo dê apoio não só a CoP do domínio da SST como também outras CoP do domínio da Agricultura. Devido ao trabalho desenvolvido pela CoPGAPEAN a CoP de partilha de Boas Práticas SST já está numa fase de maturidade. A Confiança, o Sentimento de pertença, a Contribuição e Utilidade já são resultados de práticas desta $\mathrm{CoP}$ que crescem devido ao apoio da Gestão de Topo. Para além de todo o apoio a nível de infraestruturas, da flexibilidade de horas para o trabalho comunitário há uma aposta a nível tecnológico que é um marco positivo no ciclo de vida da dinâmica colaborativa no INIAV. 


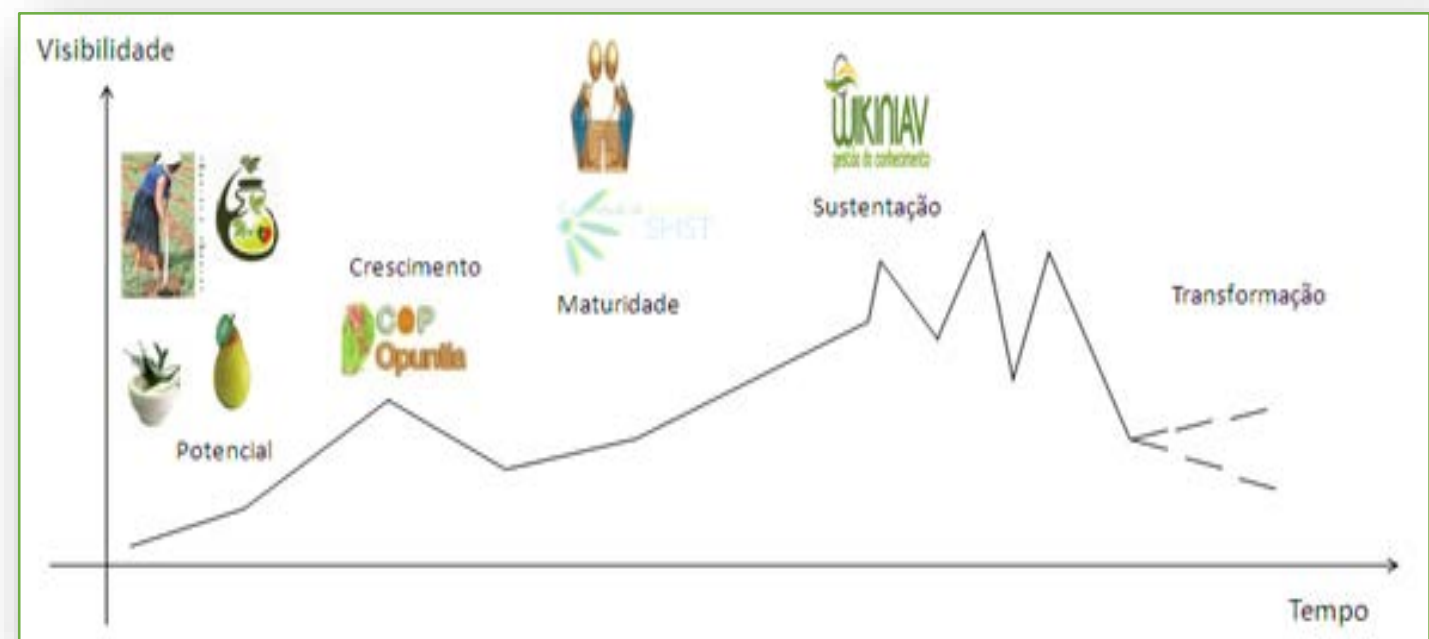

Ilustração 13 - Comunidades da WIKINIAV

Fonte (Flor,Santos.2015)

A ferramenta de trabalho colaborativo da WIKINIAV tem como categorias criadas: Domínios transversais ao conhecimento do Instituto: SST; História Organizacional; Agricultura e Ambiente; GC; Fórum; eventos.

A participação nesta plataforma envolve sempre um convite pelos moderadores responsáveis pela temática em discussão o seu registo na WIKINIAV passa sempre pelo administrador da plataforma (Nuno Silva-administrador) e informação a Casimira Flor (Coordenadora/Facilitadora) que faz a verificação do novo registo.

Esta ferramenta foi criada e administrada por um Engenheiro informático que em colaboração com a coordenadora de projeto adequou a ferramenta às necessidades do mesmo, passando por um período experimental de teste e só depois para o operacional.

Em 2012 já com a Comunidade Virtual Mista (CoPSSQVT) ativa, em parceria com outro trabalho de investigação que desenvolvia e apoiava o trabalho colaborativo no âmbito da SST, aproveitamos o estudo qualiquantitativo da investigadora para conseguirmos através dos instrumentos quantitativos (questionário online) e quantitativos (entrevista semiestruturadas) 
retirar dados para a nossa análise. Do questionário online aproveitamos os dados referentes às questões 2 e 8 (ANEXO BIV). Do inquérito de ação presencial em auditório as questões 2, 3, 6 e 9 (ANEXO BV) e as questões 2 e 8 do questionário surveys online. Já no final do nosso projeto e numa fase em que o trabalho e dinâmica da $\mathrm{CoP}$ se extinguiu aplicamos 2 entrevistas a membros da CoP.

As questões 2 e 8 do questionário surveys online foram:

- Questão n. ${ }^{\circ}$ 2: Quando necessitam de uma informação ligada à área de trabalho / especialização de que forma procuram encontrar o conhecimento necessário para a resolução do problema?

- Questão n. ${ }^{o}$ 8: Quais os fatores que mais contribuem para a partilha e informações por parte dos funcionários?

As questões 2, 3, 6 e 9 do inquérito da ação presencial foram:

- Questão n. ${ }^{\circ}$ 2: Na sua opinião a plataforma de trabalho colaborativo, poderá minimizar problemas relacionados com: a perda de tempo na procura da informação; a perda do conhecimento tácito e ultrapassar distâncias?

- Questão n. ${ }^{\text {3: }}$ Gosta de ser membro de uma Comunidade de Prática que partilha conhecimento sobre uma temática da prevenção de riscos laborais?

- Questão n. ${ }^{\circ}$ 6: Gosta do formato da ferramenta de trabalho colaborativo?

- Questão n. ${ }^{0}$ 9: Necessita de uma ação de treino/ formação na ferramenta de trabalho colaborativo?

Passaremos à análise das questões que nos servirão para na triangulação dos dados conseguirmos perceber quais as práticas essenciais para validar um resultado de sucesso da manutenção da CoP.

Foi aplicado no trabalho que se desenvolvia em paralelo um questionário online na plataforma surveys do INIAV sendo enviado por email. Responderam 195 trabalhadores num total de 703 trabalhadores distribuídos pelo País que corresponde a 27,7\% de respostas do Universo INIAV. O Pólo Oeiras onde se realizou o projeto representa 35\% do Universo INIAV. 


\section{Dados da amostra}

\begin{tabular}{|l|l|}
\hline $\begin{array}{l}\text { Contabilização } \\
\text { por sexo: }\end{array}$ & \\
\hline 1.Femining. & 138 \\
\hline 2 Masculine & 57 \\
\hline Total & 195 \\
\hline
\end{tabular}

\begin{tabular}{|l|l|}
\hline $\begin{array}{l}\text { Contabilização } \\
\text { por carreira }\end{array}$ & \\
\hline 1 Assistente Técnico & 25 \\
\hline $\begin{array}{l}\text { 2Investigação } \\
\text { (Assistente de) }\end{array}$ & 2 \\
\hline $\begin{array}{l}\text { 3Investigador } \\
\text { (Bolseiro) }\end{array}$ & 3 \\
\hline $\begin{array}{l}\text { 4Investigador } \\
\text { Auxiliar }\end{array}$ & $\mathbf{7 2}$ \\
\hline $\begin{array}{l}\text { 5Investigador } \\
\text { Principal }\end{array}$ & $\mathbf{3}$ \\
\hline $\begin{array}{l}\text { 6Técnico } \\
\text { Informática }\end{array}$ & $\mathbf{3}$ \\
\hline 7 Técnico Superior & $\mathbf{8 0}$ \\
\hline 8 Omisso & 6 \\
\hline Total & 194 \\
\hline
\end{tabular}

Tabela 3 -Caraterização da amostra por sexo e por carreira profissional

Fonte (Flor,Santos.2015)

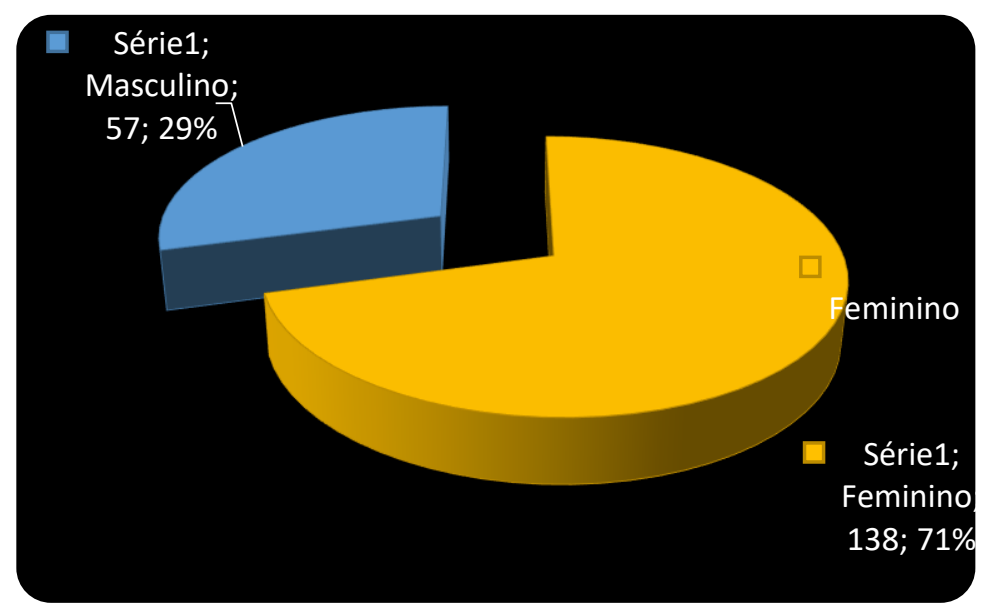

Gráfico 1-Apresentação gráfica Distribuição da amostra

Fonte: Elaboração Própria 
Tal como poderemos observar no gráfico 1 apresentado o sexo feminino representa cerca de $70,8 \%$ da amostra de funcionários respondentes. Sendo as carreiras de Técnico Superior e Investigador Auxiliar maioritárias no INIAV.

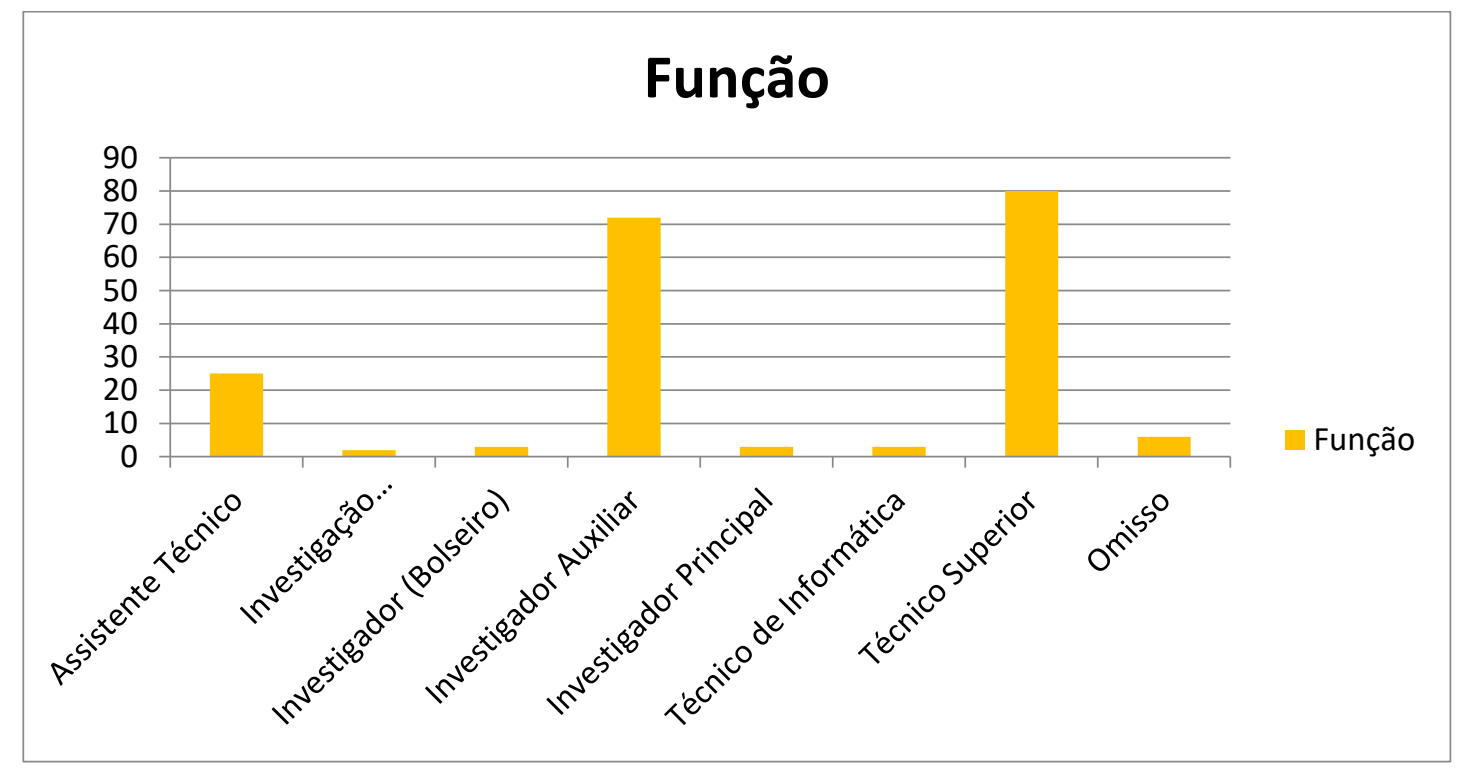

Gráfico 2- Representação gráfica da distribuição da amostra por carreiras

Fonte: Elaboração Própria

Após recolha os dados foram tratados por SPSS. As questões por nós analisadas deste instrumento aplicado (inquérito surveys online ANEXO IV) foram: 2 e a 8.

O questionário voluntário lançado por email para os funcionários do INIAV, tivemos um feedback de respostas num total de $27,3 \%$, sendo $19,6 \%$ do sexo feminino e $8,1 \%$ do sexo masculino.

Também quisemos perceber em termos de carreira profissional como se apresentavam a percentagem de respostas e num total de adesão de $27,6 \%$ podemos também verificar que as carreiras de Investigação e Técnica Superior tiveram maior percentagem de adesão ao questionário.

Apresentamos a análise da questão $\mathrm{n}^{0} 2$ do questionário online sendo as combinações e o número de casos ocorridos referentes à questão que colocámos aos funcionários (Questão $\mathrm{n}^{\mathrm{o}}$ 2: quando 246

Comunidad@Buenas Prácticas de Seguridad, Salud e Calidad de Vida en el trabajo INIAV

"Factores críticos de éxito" 
necessitam de uma informação ligada à área de trabalho / especialização de que forma procuram encontrar o conhecimento necessário para a resolução do problema).

Pela análise combinatória o número de casos ocorrido e a combinação mais escolhida foi: 3-42 com $49 n^{\text {o }}$ de casos: 3-Conversam com Pessoas da sua Equipa - 4-Apoiam-se em Documentação Técnica -2-Conversam com pessoas de outras Organizações, (Ilustração 15).

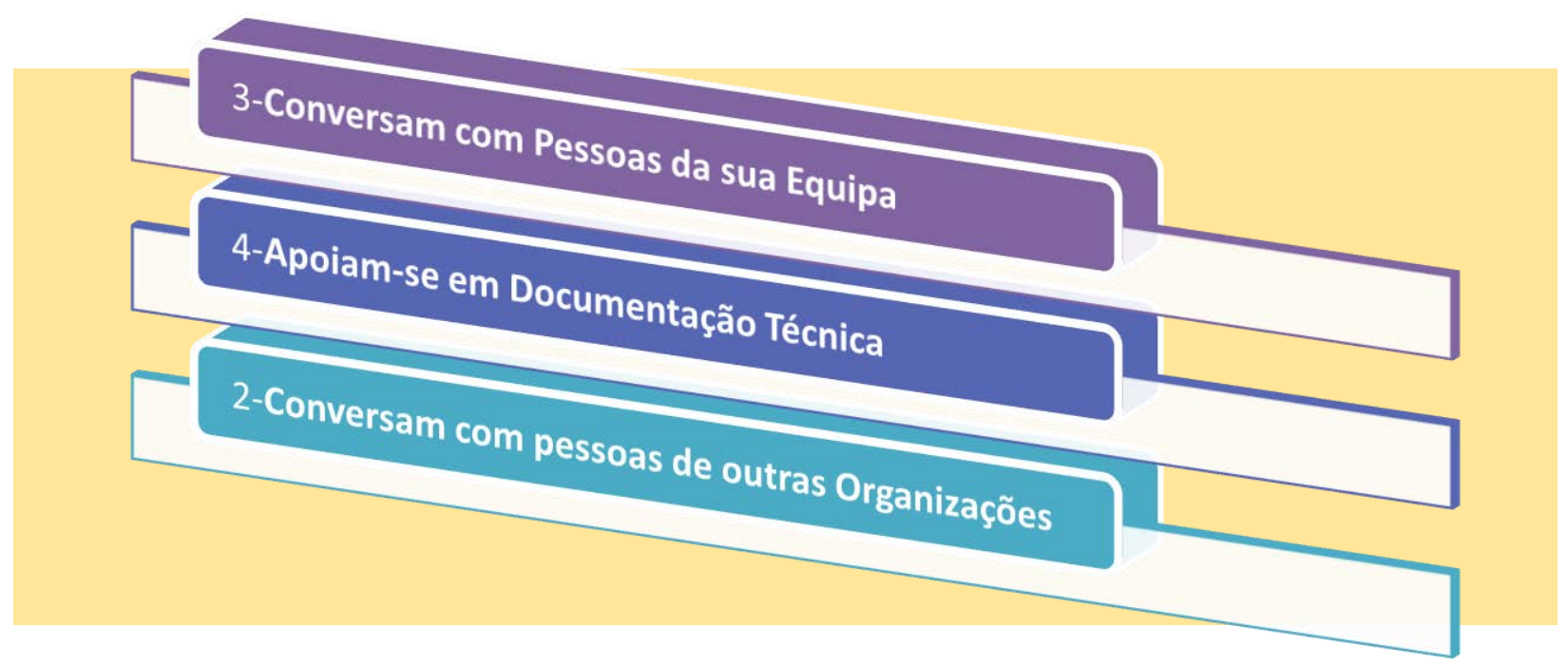

Ilustração 14- Combinação mais escolhida questão 2 Surveys online

Fonte: Elaboração Própria

Na questão $\mathbf{n}^{\mathbf{0}} \mathbf{8}$ do questionário online ANEXO BIV procurámos saber quais os fatores que mais contribuem para a partilha de informações por parte dos funcionários e as combinações que encontramos que estão relacionadas com o grau de importância/ relevância dada pela amostra e a análise combinatória resultou numa combinação de 29 com maior número de casos. 1-Ambiente descontraído;2-Confiança, 3-Para a sua aprendizagem; 4-Vontade de ser útil;

Tendo em conta o maior número de casos ocorridos a combinação escolhida foi:

2.Confiança - 4. Vontade de ser útil - 3. Para sua aprendizagem -1. Ambiente descontraído 


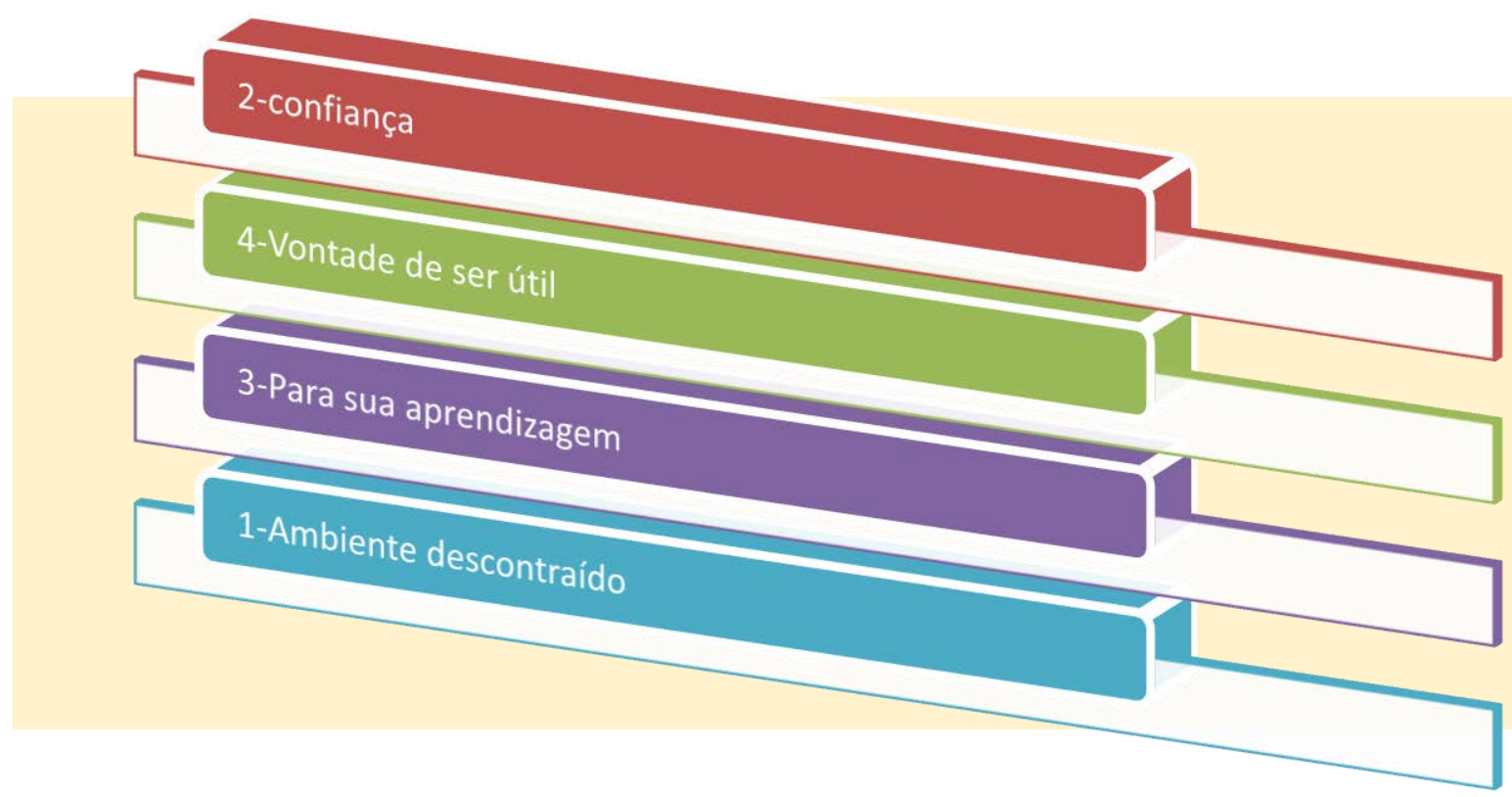

Ilustração 15 - Combinação mais escolhida questão $n^{\circ} 8$ Surveys online

Fonte: Elaboração Própria

\subsection{Análise do Inquérito em suporte de papel aplicado numa ação presencial}

Terceiro instrumento de avaliação um inquérito aplicado numa ação presencial da Wikiniav aplicado no período experimental. ANEXO BIV.

O inquérito foi distribuído no início da ação em formato de papel e recolhido à saída do auditório.

Participaram nesta ação um total de 62 funcionários do Pólo Oeiras que corresponde a $25 \%$ da amostra escolhida por conveniência, responderam 45 funcionários correspondendo a 67,7\% dos respondentes participantes na ação e 17 não entregaram o inquérito correspondendo a 27,4\% dos presentes na ação /Workshop. 


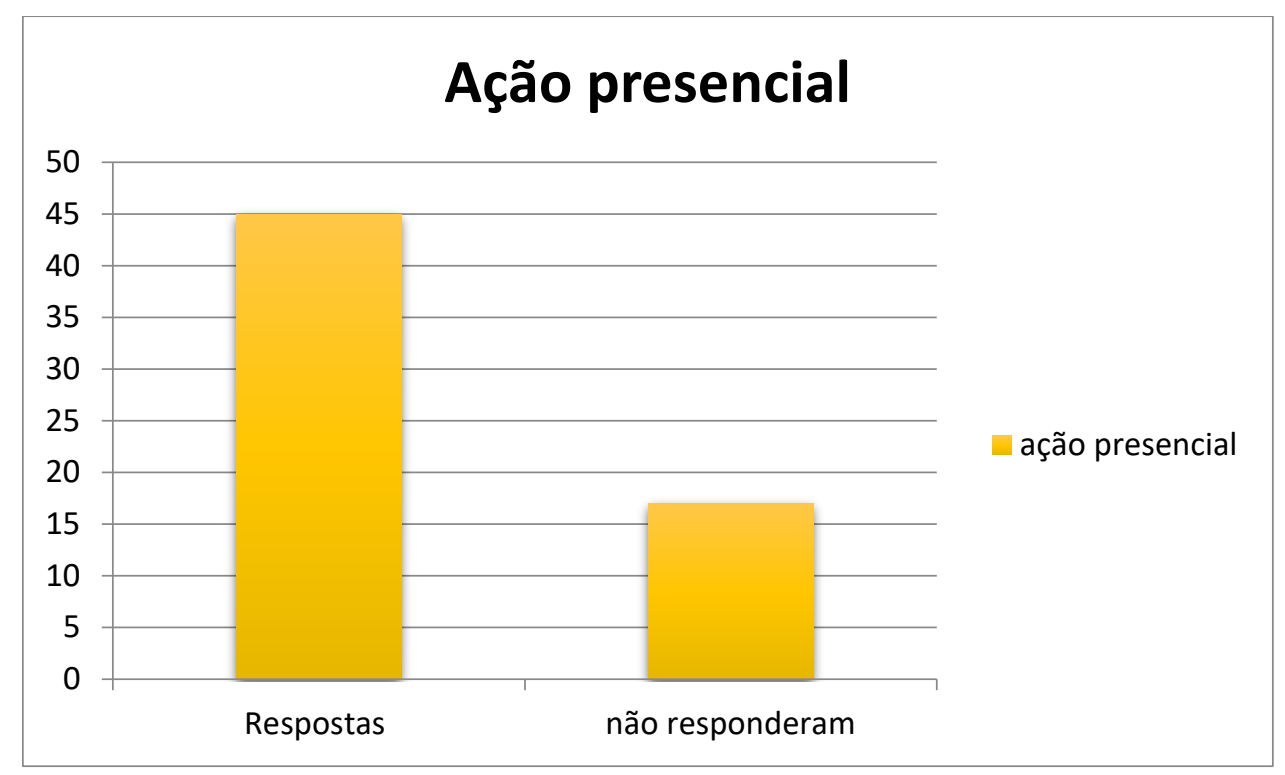

Gráfico 3 - Amostragem da Ação Presencial

Fonte: Elaboração Própria

Seguidamente faremos a apreciação global de cada uma das respostas ao inquérito que se encontra no Anexo BIII. Foram analisadas as questões na : 2-3-6-9

Analisando a questão $\mathbf{n}^{\mathbf{0}} \mathbf{2}$ do questionário presencial conseguimos percecionar que a perspetiva dos funcionários respondentes $72,5 \%$ acredita que a aposta no desenvolvimento de Comunidades de Prática no INIAV a plataforma de trabalho colaborativo para o desenvolvimento de Comunidades de Prática $(\mathrm{CoP})$ poderá minimizar e resolver parte dos problemas que estão relacionados com a perda de tempo na procura de informação, a perda de conhecimento tácito, informação valiosa estar disseminada por muitos documentos e a gestão do erro por não partilha. Questão no 3 quisemos perceber se os questionados gostariam de ser membros de uma Comunidade de Prática que partilhasse o conhecimento sobre uma temática da prevenção de riscos laborais, $62 \%$ dos funcionários respondeu positivamente.

Analisamos também os resultados da questão $\mathbf{n}^{\mathbf{0}} \mathbf{6}$ para conseguirmos perceber se a ferramenta de trabalho colaborativo era do agrado dos funcionários respondentes. Verificamos pela análise 
das respostas que 78\% dos funcionários que participaram na ação gosta do formato da apresentação desta ferramenta de apoio de trabalho colaborativo.

A maioria dos funcionários (78\%) que assistiram à ação, manifestou vontade de ter uma ação treino sobre a ferramenta WIKINIAV, após termos analisado as respostas da questão $\mathbf{n}^{0} 9$.

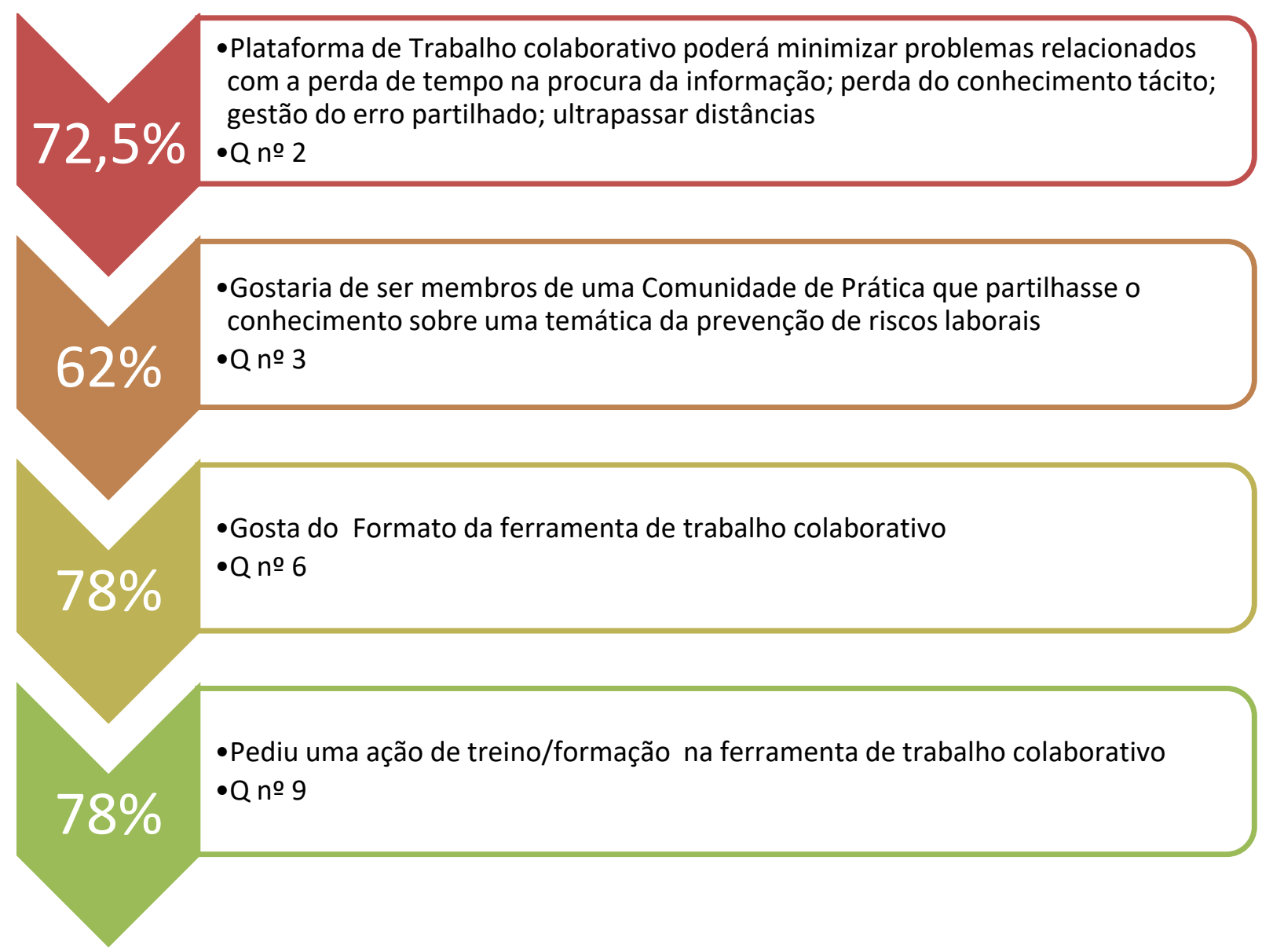

Quadro 9 - Apreciação do inquérito da Ação Presencial

Fonte: Elaboração Própria

A análise a seguir apresentada explicita os elementos da Prática de Alinhamento e Estruturação da $\mathrm{CoP}$ que irão ter influência nos resultados para o seu sucesso e funcionamento. $\mathrm{O} 1^{\mathrm{o}}$ período por nós analisado vai de 2004 a 2012, um período de 8 anos. 
Nas Práticas Essenciais do Alinhamento e da Estruturação da CoP foram definidos objetivos a curto e médio prazo para o desenvolvimento da CoP e, o estabelecimento de Políticas de flexibilização para mudanças propostas pela CoPGAPEAN, o estabelecimento de normas para a criação e desenvolvimento da $\mathrm{CoP}$, a definição de métodos de interação entre os participantes, foi definida a estrutura da $\mathrm{CoP}$, foi exposto o foco da $\mathrm{CoP}$ e definiram-se estratégias para alcançar os objetivos.

Após consulta de vários documentos que explicitavam as evidências construímos a ilustração 16 apresentada dividida em caixas e cada uma tem um elemento da prática que corresponde ao Alinhamento e Estruturação e pontuamos em termos de evidências numa Escala de avaliação, cada um dos elementos que justificavam esta prática de (1Muito má - 2Má-3Razoável-4Boa5Muito boa) para atingirmos os resultados essenciais para o sucesso da CoPGAPEAN.

A avaliação passou por um grupo de 3 avaliadores sendo os 3 especialistas no domínio e na dinâmica da CoP.

A pontuação é apresentada em cada caixa que define o elemento da prática essencial e que conduz a um resultado de sucesso: CF-Confiança; CT-Contribuição; SP-Sentimento de

\section{Pertença; U-Utilidade.}

Foram avaliados o Alinhamento e Estruturação, o Apoio da Gestão de Topo, a Cultura, o Desenvolvimento e a Coordenação da CoPGAPEAN, assim como a Política e Tecnologia e serão pontuados os elementos da prática de cada uma apresentando sempre as evidências qualitativas em anexo e também quando aplicados os instrumentos de avaliação. 


\section{Prática essencial: Alinhamento e estruturação 2004-2014}
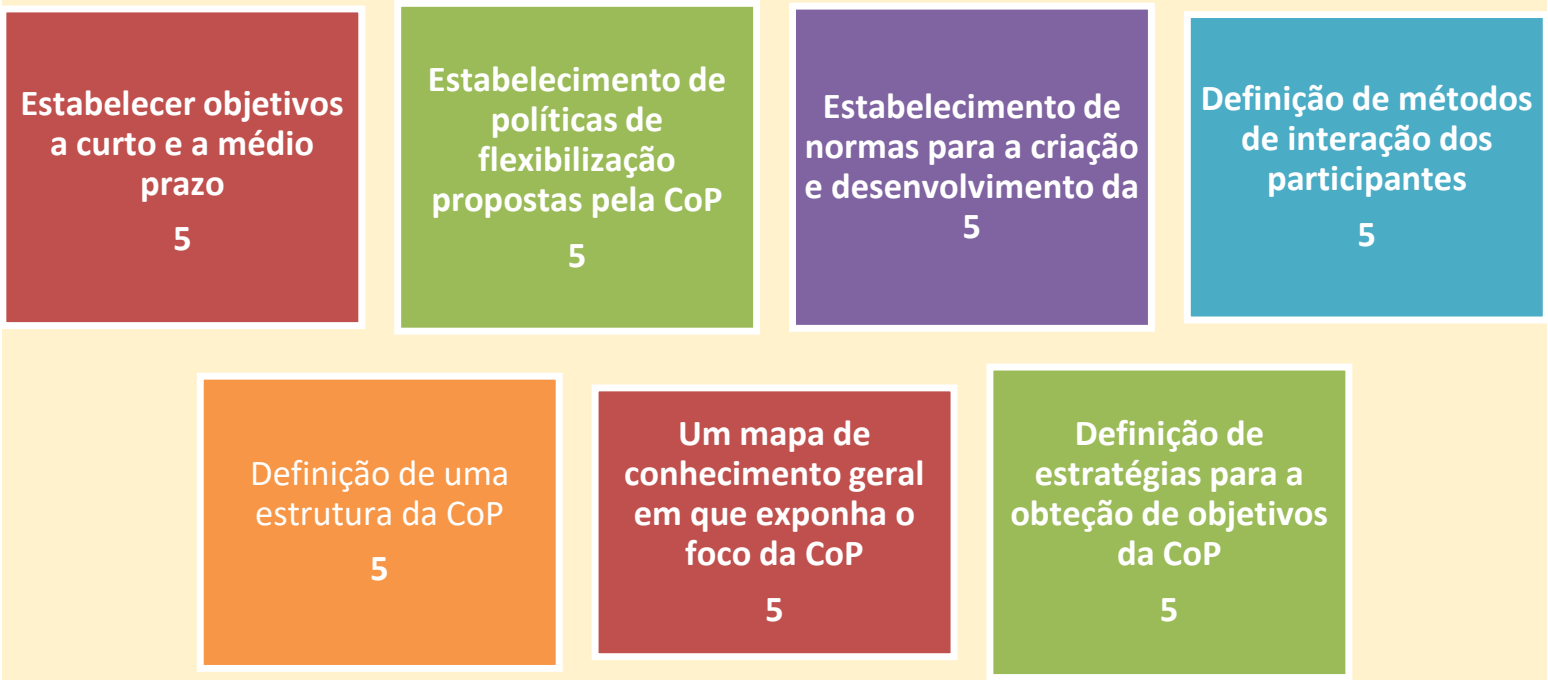

Escala de avaliação:1Muito má | 2Má | 3razoável | 4boa | 5muito boa

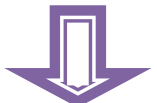

\section{Resultados de Sucesso: Confiança | Contribuição | Sentimento de Pertença | Utilidade}

Ilustração 16 - Contribuição dos elementos da prática alinhamento e estruturação para os resultados de sucesso

Fonte: Elaboração Própria

Numa escala de avaliação foi pontuado o valor do Alinhamento e estruturação, 5 Muito bom, podemos concluir que foram os elementos da prática do Alinhamento e Estruturação mencionados os responsáveis pelo sucesso dos resultados: Confiança; Contribuição; Sentimento de Pertença e Utilidade.

A análise nesta categoria envolve as seguintes dimensões: alinhamento das necessidades tais como (problemas e temas comuns, expertise dos membros, ferramentas), os métodos de interação a dentificação dos objetivos de partilha do conhecimento do Domínio da CoP, alinhamento com a Organização e envolvimento da Gestão de topo. 
Fazendo a análise da ilustração 16 em que explicitamos os elementos da Prática referente à Estruturação e Alinhamento da CoP que irão conduzir a resultados de sucesso como o desenvolvimento da Confiança da Contribuição, Sentimento de Pertença e Utilidade foi desenvolvida a prática de alinhamento e estruturação (ilustração 16) tendo impacto nesta prática o estabelecimento de políticas de flexibilização propostas pela $\mathrm{CoP}$; foram definidos os métodos de interação dos participantes que entre 2004 e 2008 foi acima de tudo interações síncronas em sala e auditório e 2009 a 2012 interações mistas síncronas e assíncronas, em sala ,auditório e plataforma de trabalho colaborativo, outro elemento a evidenciar no resultado da confiança foi a construção de um mapa com o foco da $\mathrm{CoP}$ explicito.

Para o resultado da Contribuição (CT), crucial para a manutenção da CoP foram estabelecidos objetivos a curto e a médio prazo e políticas de flexibilização propostas pela CoP; também foram estabelecidas normas para o desenvolvimento e funcionamento da $\mathrm{CoP}$; foram definidos quais os métodos a adotar para a interação; definiu-se uma estrutura para a CoP (administradores, facilitadores, Líder, gestor de conteúdos); explicitou-se o foco da $\mathrm{CoP}$ e foram definidas estratégias e planos de ação para atingir os objetivos.

Na ilustração 16 estão explícitos os elementos da Prática Estruturação e alinhamento que evidenciaram também uma grande importância no desenvolvimento da Confiança (CF) e são eles:

- estabelecimento de Políticas de Flexibilização propostas pela CoP,

- a definição de métodos de interação e da estrutura da CoP

- a explicitação do foco da CoP.

Também se observa na mesma ilustração, que para se atingir o Sentimento de Pertença foram desenvolvidos vários elementos da Prática da Estruturação e Alinhamento que foram cruciais para o resultado da CoP tais como: o estabelecimento de objetivos a curto e a médio prazo, o estabelecimento de políticas de flexibilização de propostas apresentadas pela CoP e de criação de normas para o funcionamento da mesma, a definição da estrutura e dos meios de interação da CoP, assim como a definição de estratégias para atingir os objetivos propostos pela CoP. 
Para se atingir o resultado referente à Utilidade assinalamos os elementos da prática mais importantes que o justificam tais como:

- traçar objetivos a curto e médio prazo,

- propor políticas de flexibilização para propostas da CoP,

- a definição das interações e da estrutura da CoP,

- assim como a definição de estratégias para atingir objetivos.

Poderemos assim concluir que para se atingirem os resultados que consideramos essenciais para o Desenvolvimento e Manutenção viva da CoP em estudo -Confiança, ContribuiçãoSentimento de Pertença-Utilidade - a Prática de Alinhamento é essencial para que se atinjam com sucesso estes resultados.

Outra Prática Essencial para que haja resultados de sucesso na Manutenção e Desenvolvimento da CoP Apoio da Gestão de Topo tem como objetivo o apoio incondicional da Gestão de topo da Organização para ao seu desenvolvimento sendo consideradas duas dimensões:

- o envolvimento da Gestão de topo

- o seu comprometimento. 


\section{Prática essencial: Apoio da Gestão Topo 2004 - 2014}
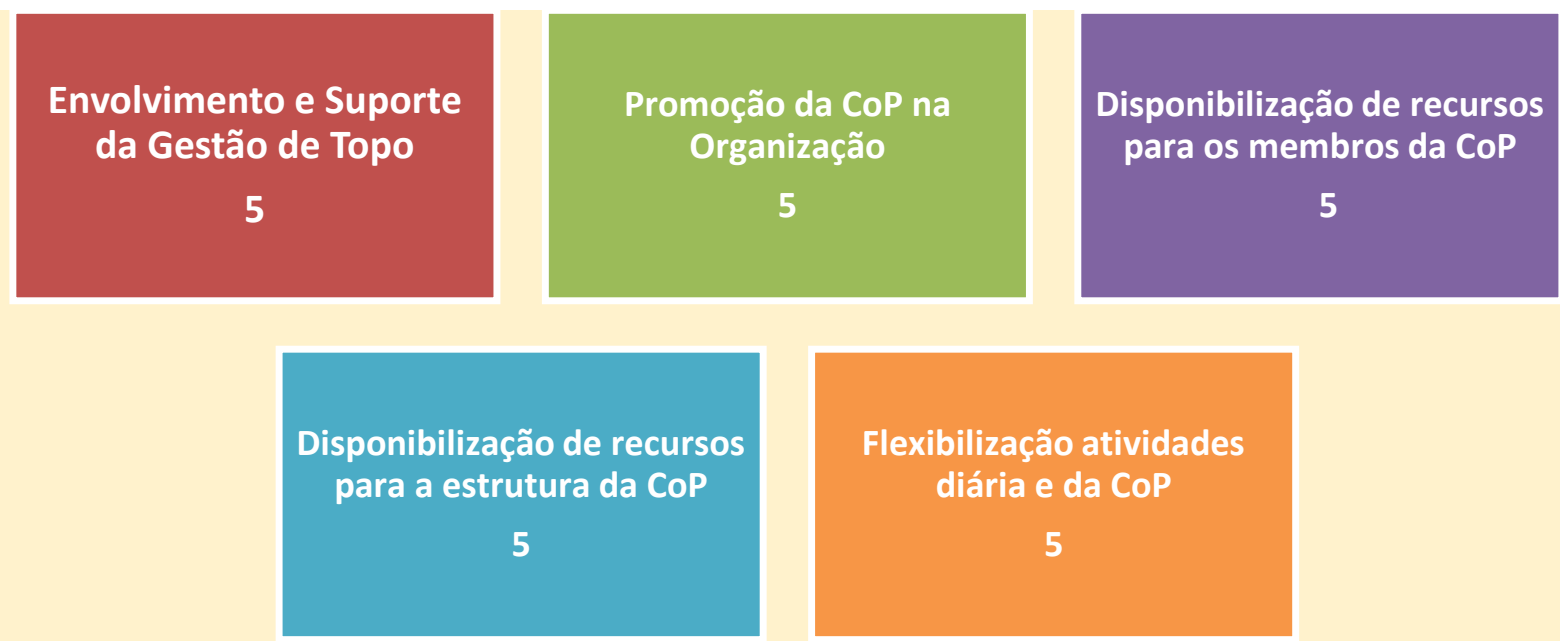

Escala de avaliação:1Muito má | 2Má | 3razoável | 4boa | 5muito boa

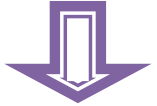

Resultados de Sucesso: Confiança | Contribuição | Sentimento de Pertença | Utilidade

Ilustração 17 - Contribuição dos elementos da prática apoio da gestão de topo para resultados de sucesso

Fonte: Elaboração Própria

Numa escala de avaliação foi pontuado o valor do apoio da gestão à CoP, 5 Muito bom, podemos concluir que foram os elementos da prática Gestão de Topo mencionados os responsáveis pelo sucesso dos resultados: Confiança; Contribuição; Sentimento de Pertença e Utilidade 


\section{Prática essencial: Desenvolvimento 2004 a 2014}
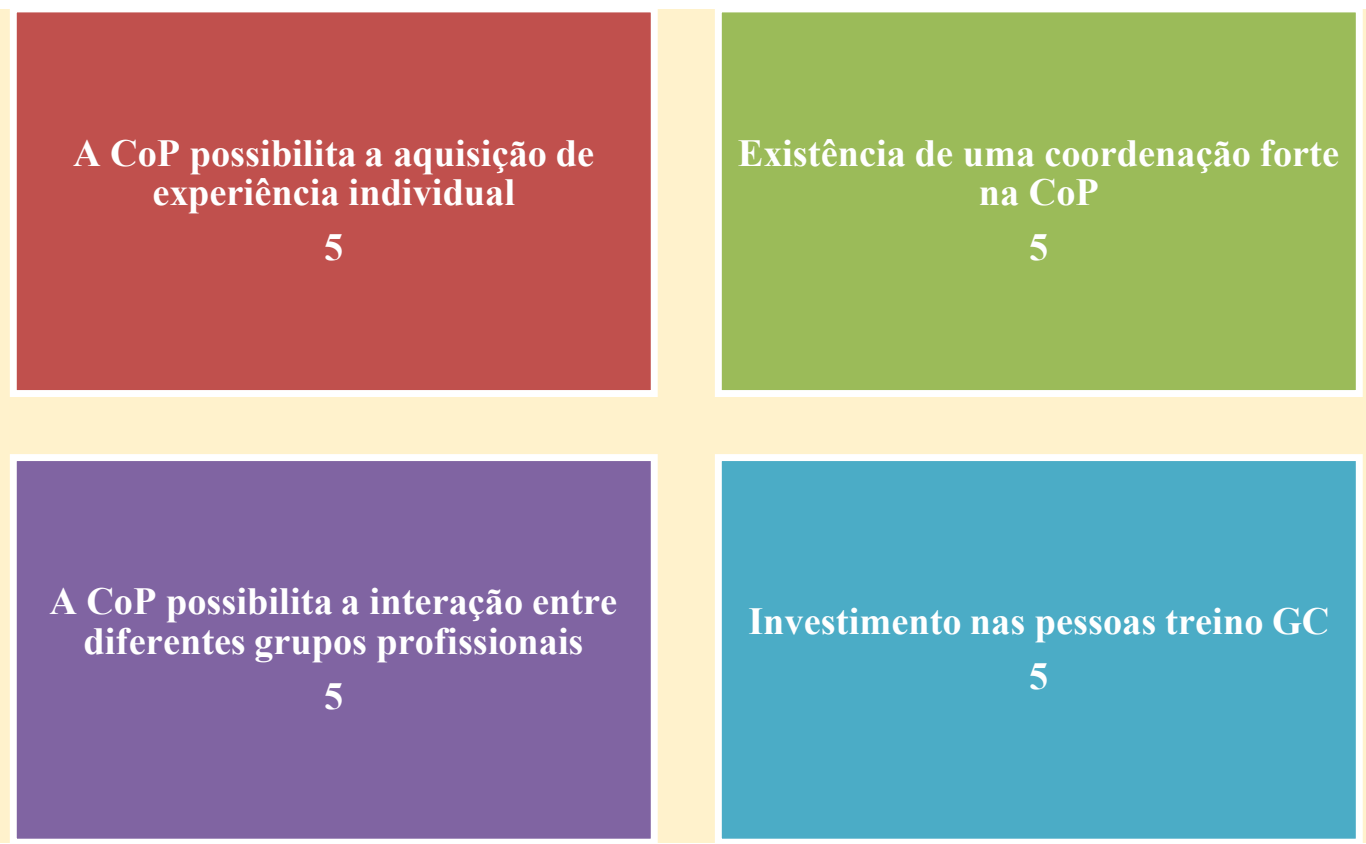

Escala de avaliação:1 Muito má | 2Má | 3razoável | 4boa | 5muito boa

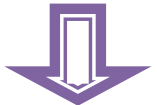

\section{Resultados de Sucesso: Confiança | Contribuição | Sentimento de Pertença | Utilidade}

Ilustração 18 - Contribuição dos elementos da prática de desenvolvimento para resultados de sucesso Fonte: Elaboração Própria

Numa escala de avaliação foi pontuado o valor do Alinhamento e estruturação, 5 Muito bom, podemos concluir que foram os elementos da prática mencionados os responsáveis pelo sucesso dos resultados: Confiança; Contribuição; Sentimento de Pertença e Utilidade.

Como podemos observar foram descritos os elementos da prática que conduziram a um resultado de sucesso da $\mathrm{CoP}$ a utilidade: $\mathrm{Na}$ fase de desenvolvimento foi muito importante o investimento no treino dos funcionários, a grande interação entre diferentes profissionais de diferentes carreiras do INIAV; também foi muito importante uma coordenação forte e muito envolvida na dinâmica e para além disso especialista no domínio. 


\section{Prática essencial: Gestão da CoP 2004 - 2014}
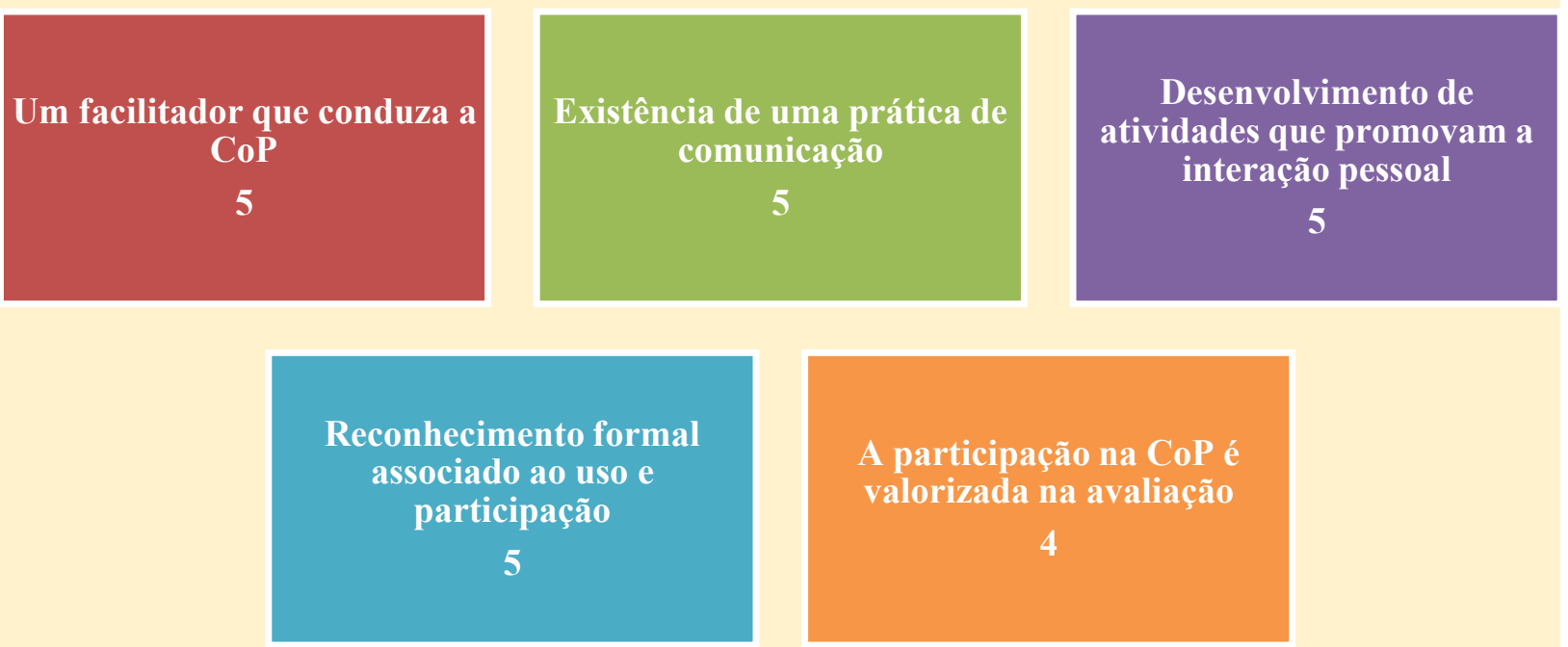

Escala de avaliação:1Muito má | 2Má | 3razoável | 4boa | 5muito boa

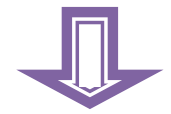

\section{Resultados de Sucesso: Confiança | Contribuição | Sentimento de Pertença | Utilidade \\ Ilustração 19 -Contribuição dos elementos da prática Gestão da CoP para os resultados de sucesso \\ Fonte: Elaboração Própria}

Numa escala de avaliação foi pontuado o valor da Gestão da CoP 4,8 Muito bom, podemos concluir que foram os elementos da prática mencionados os responsáveis pelo sucesso dos resultados: Confiança; Contribuição; Sentimento de Pertença e Utilidade. 


\section{Prática essencial: Política 2004 - 2014}
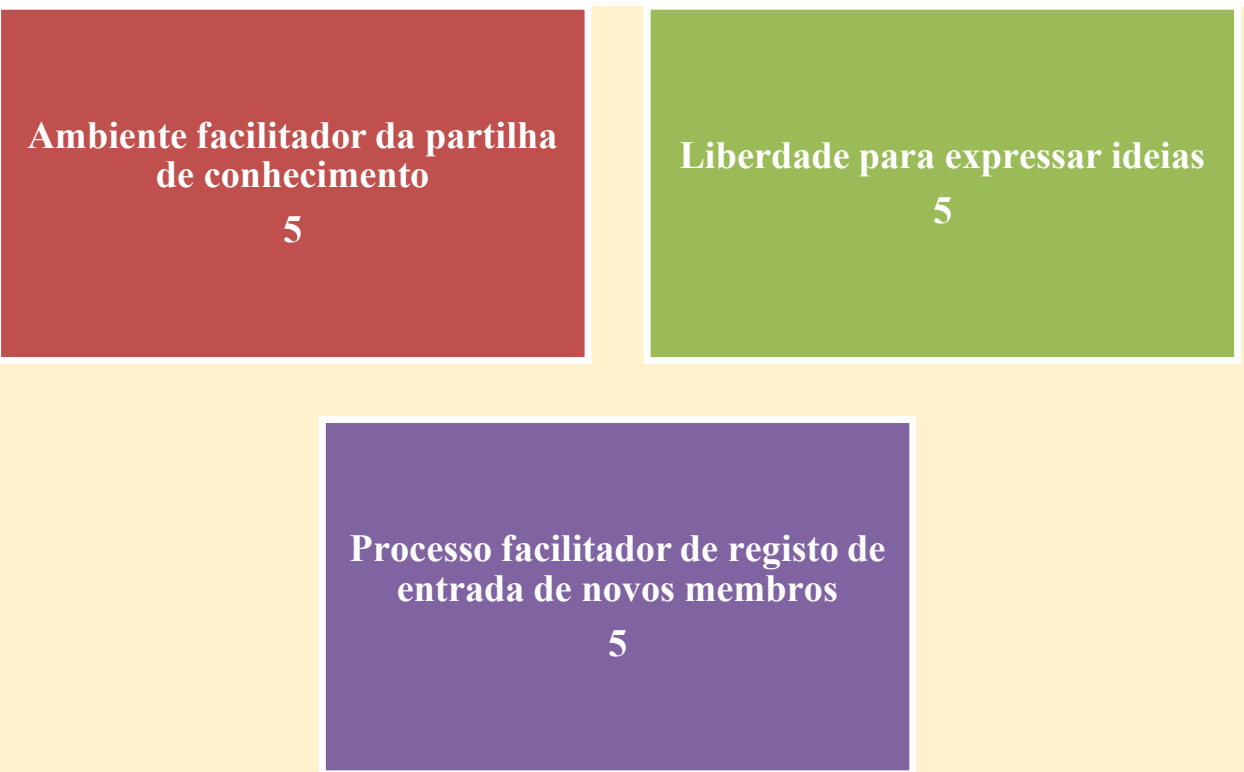

Escala de avaliação:1Muito má | 2Má | 3razoável | 4boa | 5muito boa

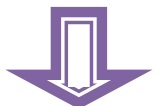

\section{Resultados de Sucesso: Confiança | Contribuição | Sentimento de Pertença | Utilidade}

Ilustração 20 - Contribuição dos elementos da prática Política para resultados de sucesso

Fonte: Elaboração Própria

Numa escala de avaliação foi pontuado o valor da Política, 5 Muito bom, podemos concluir que

foram os elementos da prática mencionados os responsáveis pelo sucesso dos resultados: Confiança; Contribuição; Sentimento de Pertença e Utilidade. 


\section{Prática essencial: Tecnologia 2004 - 2014}
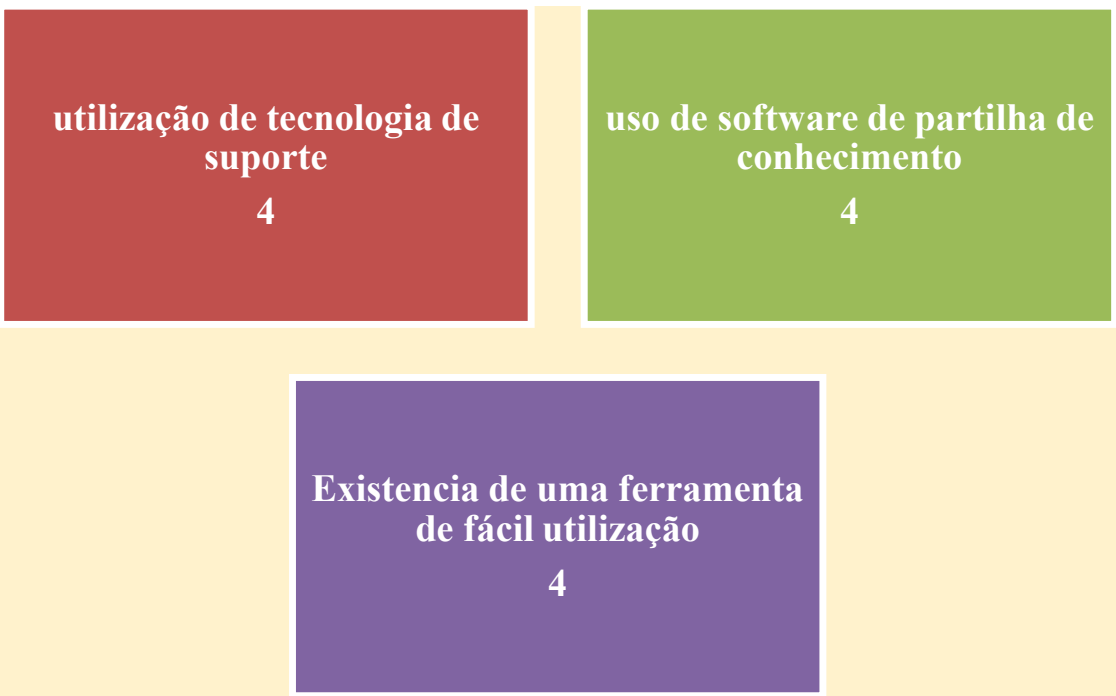

Escala de avaliação:1 Muito má | 2Má | 3razoável | 4boa | 5muito boa

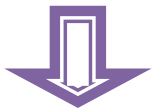

\section{Resultados de Sucesso: Confiança | Contribuição | Sentimento de Pertença | Utilidade}

Ilustração 21 - Contribuição dos elementos da prática Tecnologia para resultados de sucesso

Fonte: Elaboração Própria

Numa escala de avaliação foi pontuado o valor 4 Bom da Tecnologia, podemos concluir que

foram os elementos da prática mencionados os responsáveis pelo sucesso dos resultados: Confiança; Contribuição; Sentimento de Pertença e Utilidade. 


\section{Prática essencial: Cultura 2004 - 2014}
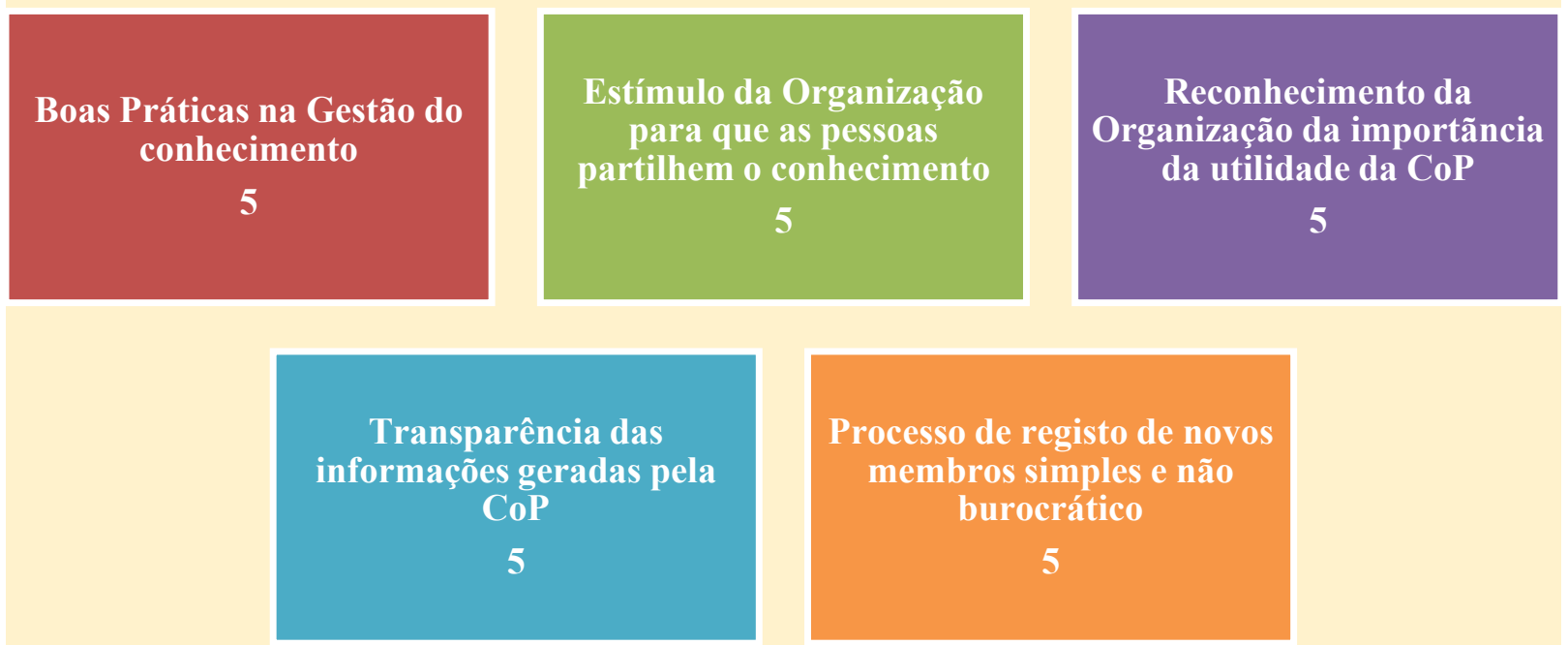

Escala de avaliação:1Muito má | 2Má | 3razoável | 4boa | 5muito boa

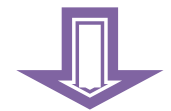

\section{Resultados de Sucesso: Confiança | Contribuição | Sentimento de Pertença | Utilidade}

Ilustração 22 - Contribuição dos elementos da prática Cultura para resultados de sucesso

Fonte: Elaboração Própria

Numa escala de avaliação foi pontuado o valor da Cultura, 5 Muito bom, podemos concluir que foram os elementos da prática mencionados os responsáveis pelo sucesso dos resultados: Confiança; Contribuição; Sentimento de Pertença e Utilidade.

Como se evidencia nas na ilustração 23 a Confiança é o resultado das diferentes práticas relacionadas com: alinhamento, apoio da gestão de topo, a cultura o desenvolvimento, a liderança da CoP a política e a tecnologia que entra neste intervalo de tempo como mais uma ferramenta que a $\mathrm{CoP}$ teve ao seu dispor. 
Promoveram-se debates e troca de ideias presenciais e virtuais, houve liberdade para expressar ideias sem juízos de valor e reconhecimento formal associado ao trabalho colaborativo, treinos relacionados com a gestão do conhecimento no domínio, transparência das informações apoiados sempre pela Gestão de Topo e pela Coordenação da CoP.

Confiança

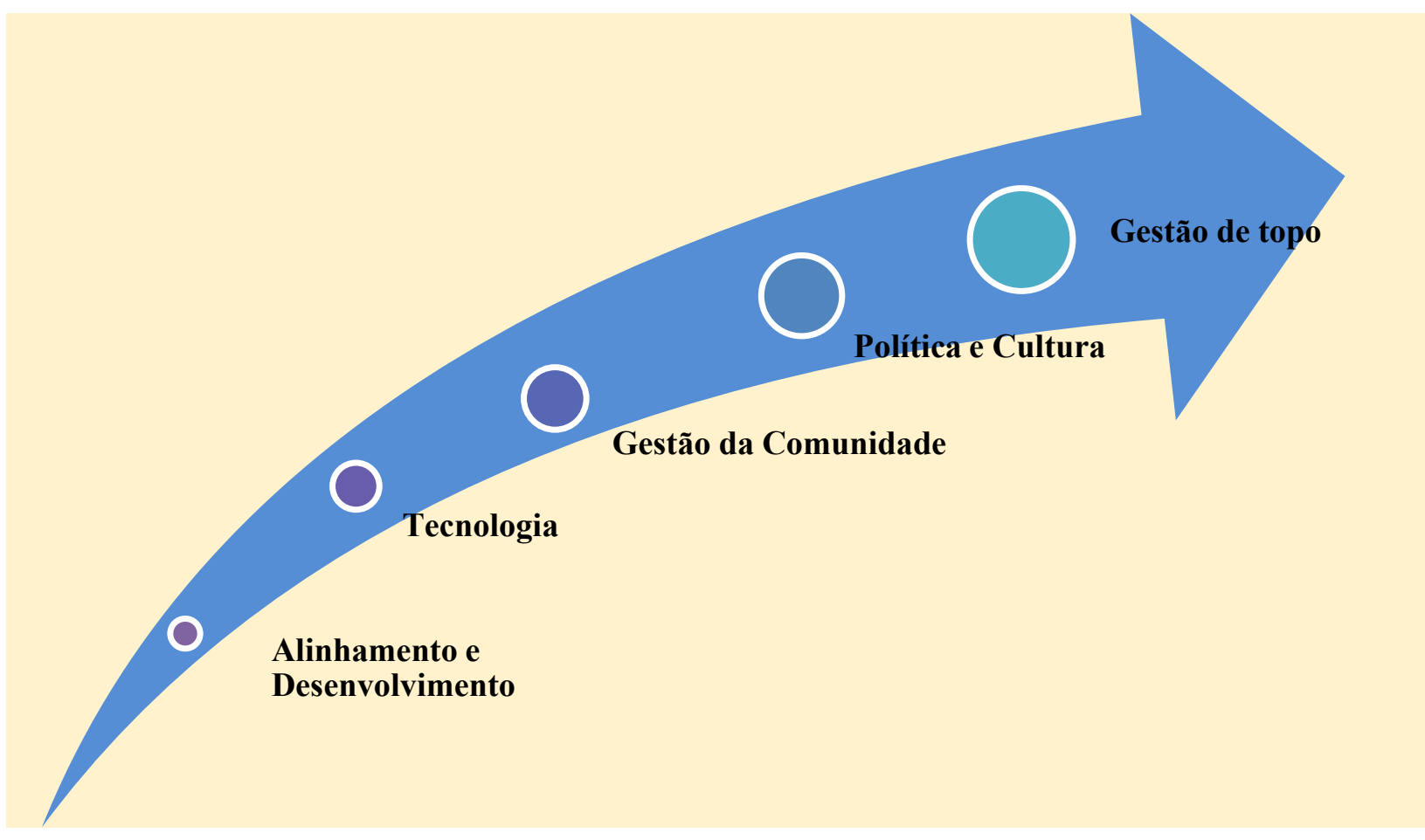

Ilustração 23 - Práticas essenciais para o resultado confiança (2009-2014)

Fonte: Elaboração Própria

Nesta fase do ciclo de vida a Organização atravessou um período de grandes mudanças e fusões o que poderia ser perturbador pois a gestão anterior que em 2009 já não se encontrava na Organização e que foi a alavanca de toda a dinâmica poderia ser motivo para que a atividade declinasse e o fim da $\mathrm{CoP}$ muito perto, mas isto não se verificou porque a Gestão de topo seguinte recebeu o testemunho para a continuidade e foi facilitadora, aqui a importância de uma coordenação forte foi decisiva para que a Comunidade desse seguimento a toda a dinâmica o 
que dá continuidade à confiança existente entre os membros da comunidade e entre a Comunidade e a Organização.

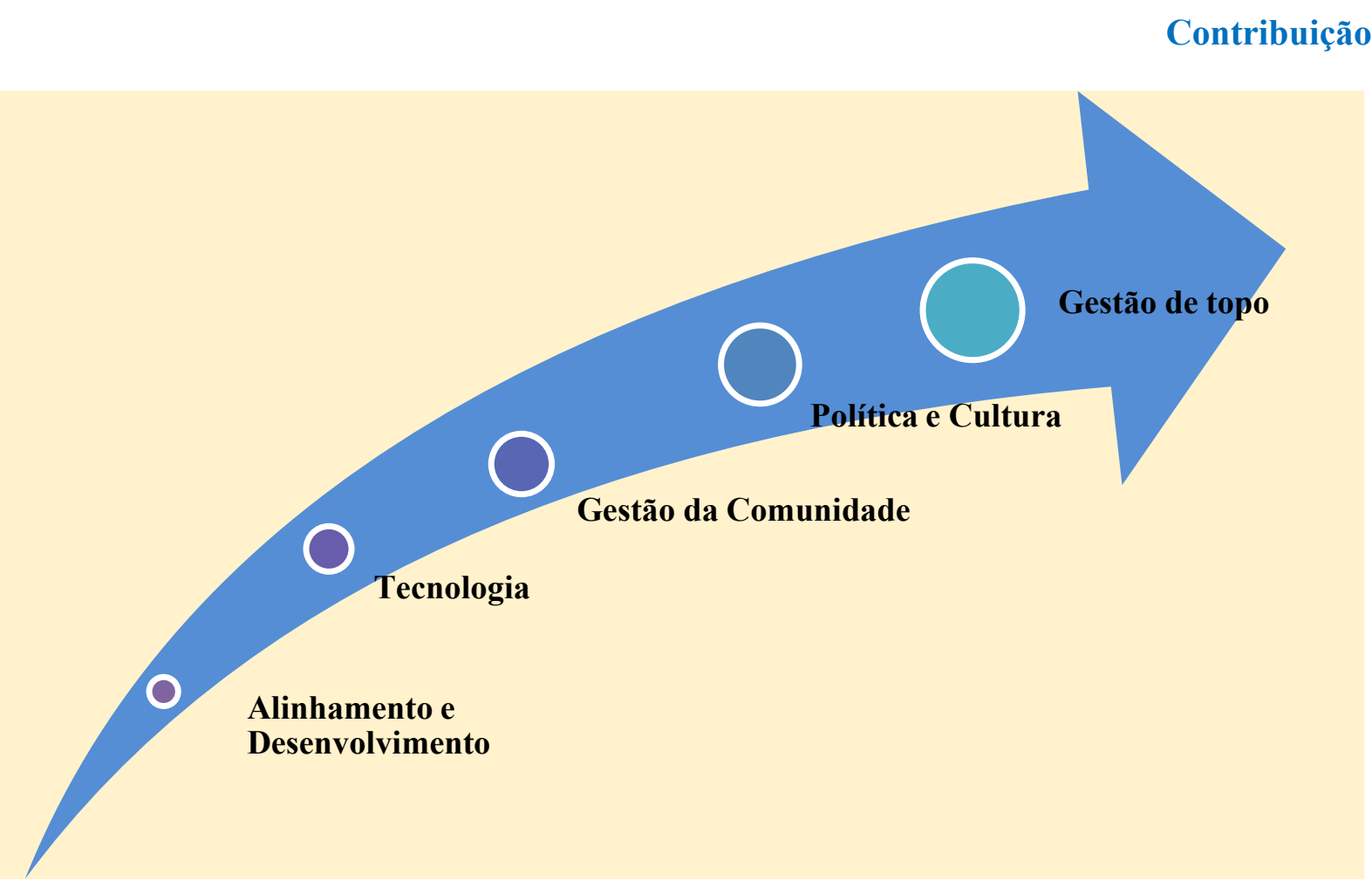

Ilustração 24 - Práticas essenciais para o resultado Contribuição (2009-2014)

Fonte: Elaboração Própria

A participação e interesse e envolvimento nos eventos relacionados com a CoP;

A definição de estratégias e planos de ação para a obtenção dos objetivos;

A participação e facilitação da Gestão de topo;

A exposição dos benefícios prestados aos stakeholders da Comunidade;

A CoP possibilitou a interação entre diferentes grupos profissionais; houve liberdade para se expressarem ideias e foram promovidos debates e encontros presenciais e virtuais. 
O estímulo da Organização para que as pessoas partilhem o conhecimento foram deram grandes contributos como elementos que justificaram as práticas essenciais para um bom funcionamento da CoP e que resultaram no Resultado de Sucesso ao qual chamamos de Contribuição.

O mesmo aconteceu para o resultado Sentimento de Pertença em que foram definidos métodos de interação entre os participantes da $\mathrm{CoP}$, houve flexibilização da Gestão de Topo para possibilitar a integração entre a atividade da $\mathrm{CoP}$ e o trabalho diário. Houve também a explicitação dos benefícios prestados aos stakeholders, assim como o estímulo por parte da Organização para as pessoas partilharem o conhecimento. Todas estas práticas essenciais culminaram no resultado de sucesso que se refere ao sentimento de pertença. Investimento no treino das pessoas e apoio continuado. Um ambiente facilitador da partilha, envolvimento, promoção de encontros presenciais e virtuais.

\section{Sentimento de Pertença e Utilidade}

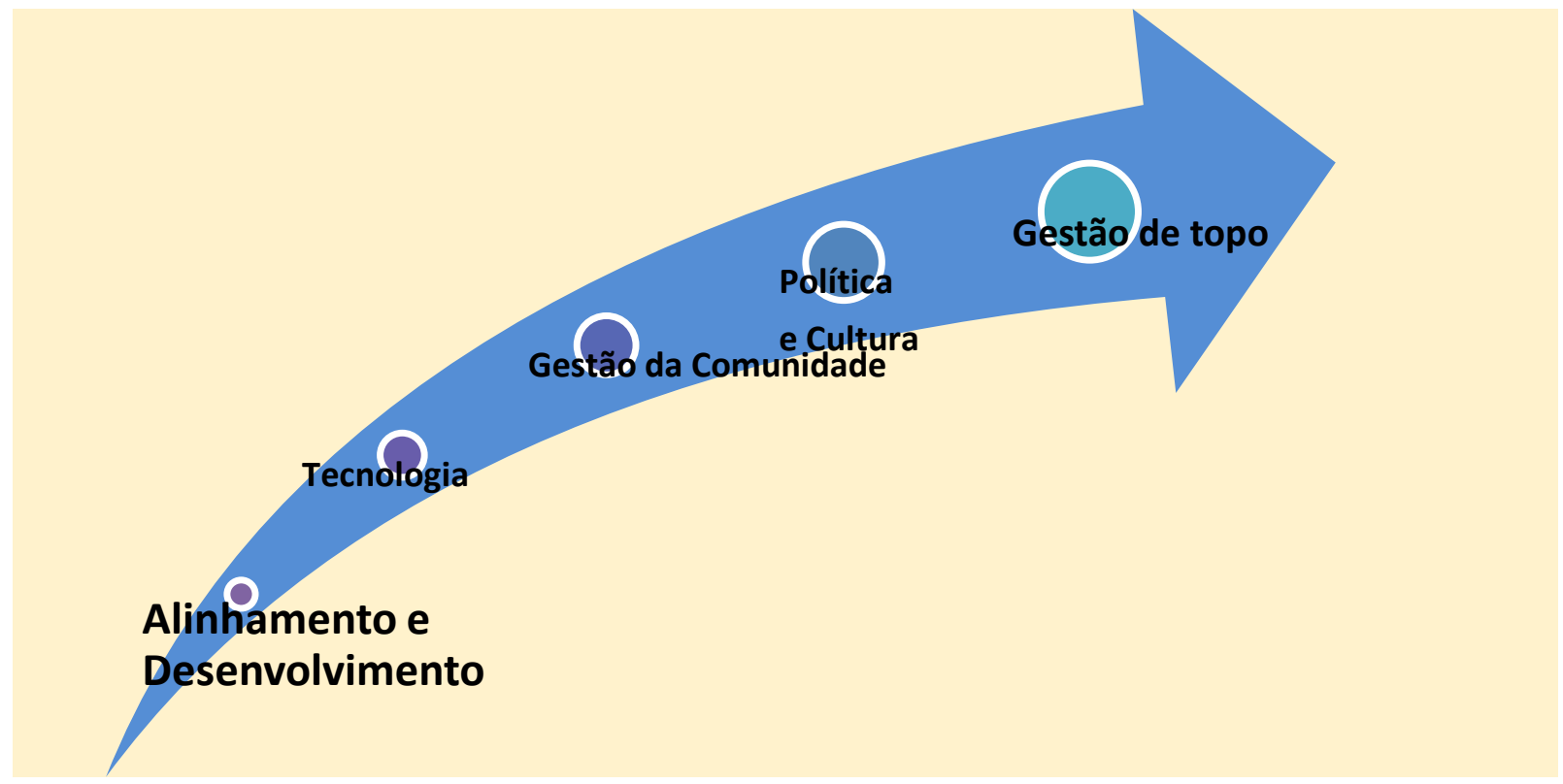

Ilustração 25 - Figura n. ${ }^{\circ}$ Práticas essenciais para o resultado Sentimento de Pertença (2009-2014)

Fonte: Elaboração Própria

Para se conseguir atingir o resultado Utilidade estabeleceram-se objetivos a curto e médio prazo, a CoP foi promovida pela Gestão de Topo, a Liderança da Comunidade foi Proativa, houve 
exposição dos benefícios da $\mathrm{CoP}$, uma cultura de partilha do conhecimento, um investimento no treino das pessoas e apoio continuado, um ambiente facilitador da partilha promovendo debates e troca de ideias

Analisando o período que corresponde a 2015-2019 confrontamo-nos com um problema grave para a CoP e que está relacionado com a Prática essencial da gestão de topo. Na avaliação que fizemos é inexistente nesta fase e a avaliação dada é 1 muito má.

Não houve envolvimento - nem flexibilização das atividades-nem Promoção - Fecharam-se os recursos para os membros e para a estrutura. Não faremos análises dos outros elementos e práticas essenciais pois o insucesso da CoP dependeu da prática essencial da Gestão de Topo ter falhado neste período

\section{Prática essencial: Gestão Topo 2015 - 2019}
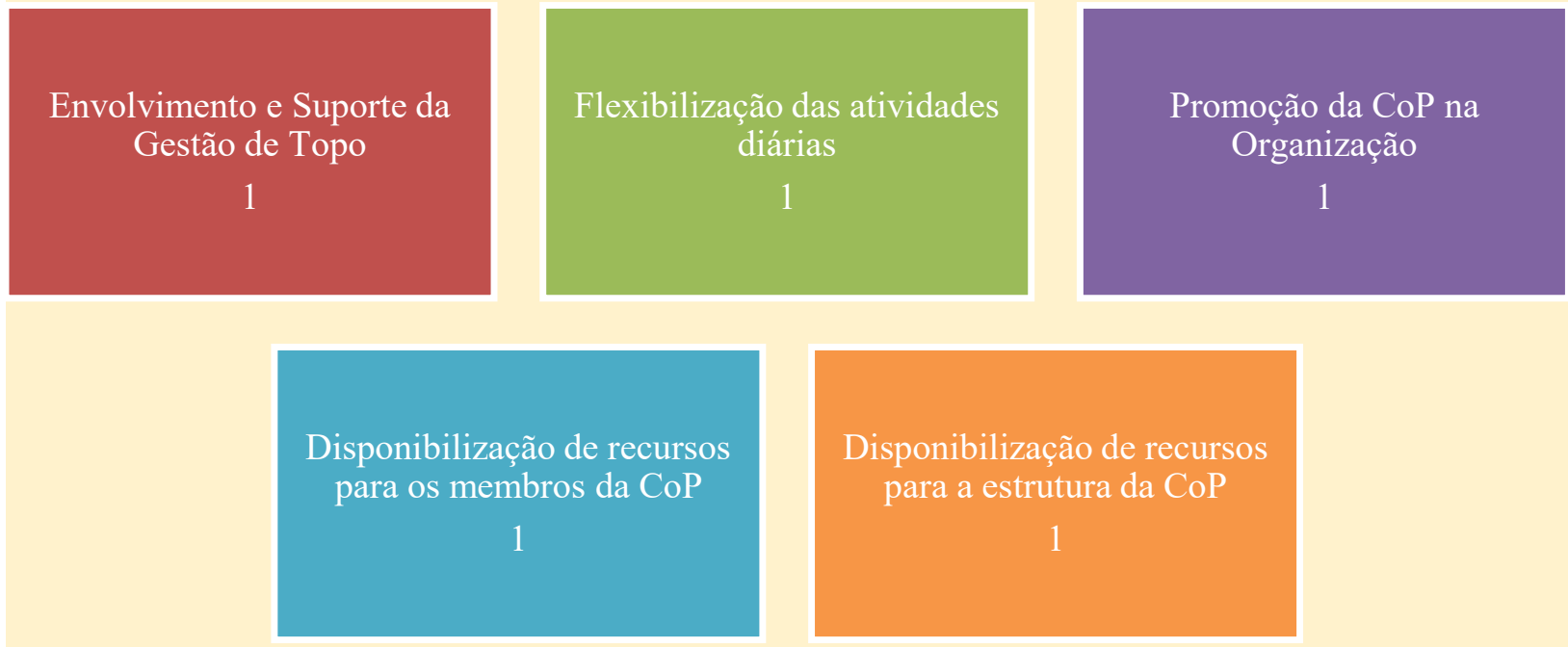

Escala de avaliação:1 Muito má | 2Má | 3razoável | 4boa | 5muito boa

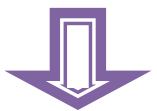

Resultados de Sucesso: Confiança | Contribuição | Sentimento de Pertença | Utilidade

Ilustração 26 - Resultados de Insucesso da CoP 
Fonte: Elaboração Própria

Temos uma Cultura e Política de partilha de conhecimento negativa na Organização.

Seguidamente apresentamos matrizes cruzamento de dados das nossas análises e faremos primeiro o estudo dos intervalos de tempo 2004 a 2008 e de 2009 a 2015 que foram dois períodos marcados por mudanças de gestão de topo e organizacionais, mas que foram facilitadoras ao desenvolvimento do trabalho colaborativo. Apresentamos de seguida uma matriz qualitativa de avaliação, que cruza os elementos da prática com a prática essencial.

\begin{tabular}{|c|c|c|c|c|}
\hline Elementos·da·Práticaø & Políticaa & Coordenaçãox & Tecnologia & Desenvolvimentod \\
\hline Existência'de'uma'prática'de'comunicação æa & $\alpha$ & & $\alpha$ & $\alpha$ \\
\hline Um facilitador'ou líder'que 'conduza' a $\cdot \mathrm{C} Q \mathrm{P} \alpha$ & $a$ & & $\alpha$ & $\alpha$ \\
\hline $\begin{array}{l}\text { Desenvolvimento'de'atividades 'que'promovam 'a' } \\
\text { interação'pessoala }\end{array}$ & $\alpha$ & & $\alpha$ & $\alpha$ \\
\hline Reconhecimento 'formal'associado'ao'uso'e participação 'a & $\alpha$ & & $\alpha$ & $\alpha$ \\
\hline A participação'na'CoP'faz parte'da avaliação' & $\alpha$ & & $\alpha$ & $a$ \\
\hline $\begin{array}{l}\text { Suporte'na 'integração'e'envolvimento 'de 'novos' } \\
\text { membrosa }\end{array}$ & $\alpha$ & $\alpha$ & $\alpha$ & \\
\hline A'CoP'possibilita'a 'aquisição'de 'experiência individuala & $\alpha$ & $\alpha$ & $\alpha$ & \\
\hline $\begin{array}{l}\text { A.CoP'possibilita' 'a 'interação'entre'diferentes 'grupos' } \\
\text { profissionaisa }\end{array}$ & $\alpha$ & $\alpha$ & $\alpha$ & \\
\hline Existência 'de'uma'coordenação forte 'na'CoPa & $a$ & $\alpha$ & $a$ & \\
\hline Investimento'nas 'pessoas treino $\cdot \mathrm{GCa}$ & $\alpha$ & $\alpha$ & $\alpha$ & ) \\
\hline Ambiente facilitador'da partilha'de'conhecimentoo & ) & $\alpha$ & $a$ & $a$ \\
\hline Liberdade'para'expressar'ideias' $\alpha$ & ) & $\alpha$ & $\alpha$ & $\alpha$ \\
\hline Processo facilitador'regulamentar'de'novos 'membrosa & ) & $\alpha$ & $\alpha$ & $\alpha$ \\
\hline Utilização'de·Tecnologia'de'suporteœ & $\alpha$ & $\alpha$ & & $\alpha$ \\
\hline Uso'de'Software'de'partilha'de'GCa & $a$ & $\alpha$ & & $a$ \\
\hline Existência de 'uma ferramenta fácil'utilização' $\alpha$ & $a$ & $\alpha$ & & $a$ \\
\hline
\end{tabular}

Reforço facilitador em transição -

Matriz 1 - Elementos das práticas vs prática essencial

Fonte: Elaboração Própria 
Foram escolhidas as cores verde para sinalizar as práticas facilitadoras da partilha de conhecimento na $\mathrm{CoP}$ e a vermelho as inibidoras da partilha de conhecimento e a laranja a cor de transição em que as práticas são moderadas, mas no sentido do crescimento da partilha.

Analisando a matriz $\mathrm{n}^{\mathrm{o}} 1$ em que cruzamos os elementos essenciais para as práticas Alinhamento e estruturação - Apoio da Direção e Cultura estamos confrontados com um reforço facilitador a Praticas que vão dar resultados de sucesso que serão validados numa matriz de cruzamento com os resultados Confiança-contribuição - sentimento de Pertença e Utilidade.

\begin{tabular}{|c|c|}
\hline $\begin{array}{l}\text { Resultado } \\
2004 \text { a } 2014\end{array}$ & Definição \\
\hline Utilidade & Membros acreditam na utilidade e na efetividade da CoP para si mesmos \\
\hline Confiança & Há um forte sentimento de confiança entre os membros da CoP \\
\hline $\begin{array}{l}\text { Sentimento } \\
\text { pertença }\end{array}$ & $\begin{array}{l}\text { Os membros relacionam-se entre si fora da CoP e possuem um forte sentimento de pertença } \\
\text { a CoP }\end{array}$ \\
\hline Contribuição & Os membros participam da Comunidade de uma maneira continua e sistemática \\
\hline
\end{tabular}

Quadro 10 - Significado do constructo dos resultados alcançados pela CoP de 2004 a 2014

Fonte: Elaboração Própria

Pelo quadro $n^{\circ} 10$ podemos concluir que as práticas essenciais analisadas nas matrizes $n^{\circ} 1$ e 2 , auxiliaram a obtenção de resultados facilitadores ao bom funcionamento da CoP.

Analisando o significado de cada um dos constructos do resultado poderemos afirmar que houve um forte sentimento de confiança entre os membros da CoP, também verificamos que os 
membros da CoP acreditavam na utilidade e na efetividade da CoP e um forte sentimento de pertença com uma participação continua e sistemática tal como evidenciam as análises dos documentos que observámos.

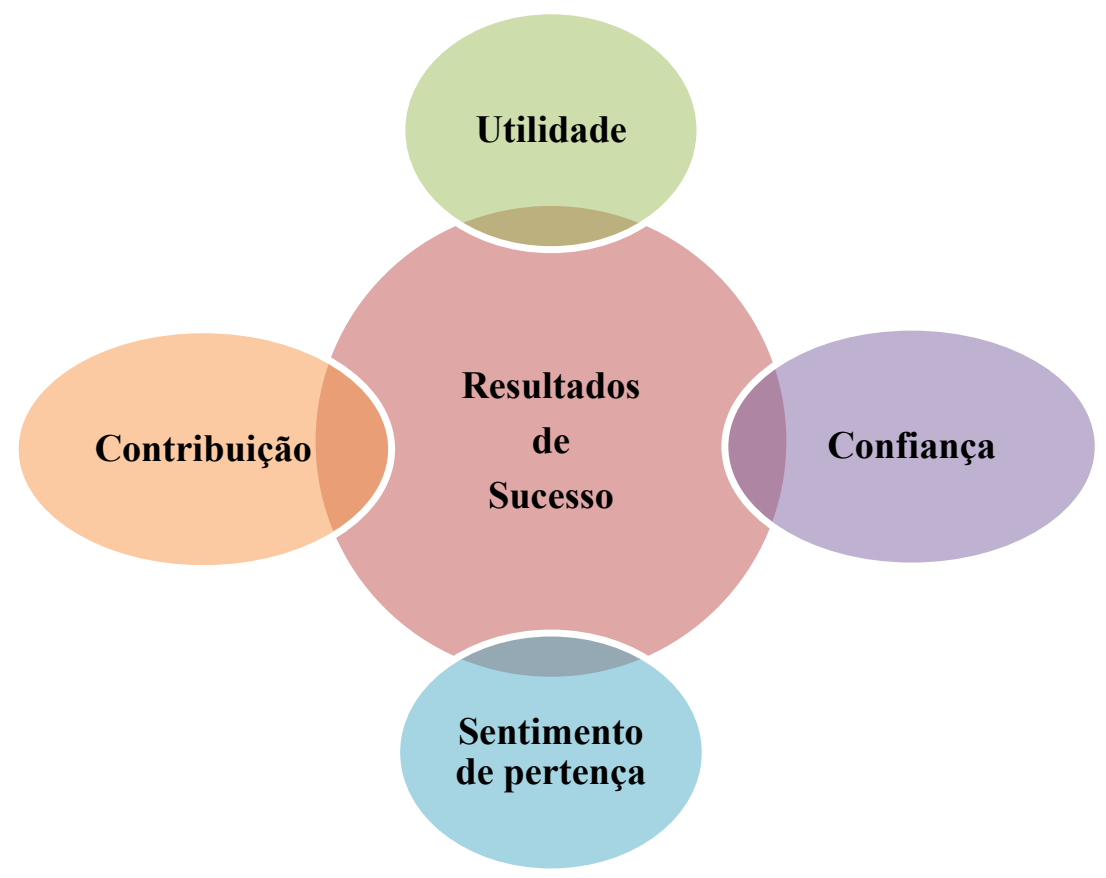

Ilustração 27- Constructo de resultados de sucesso para a manutenção da CoPGAPEAN e sua evolução.

Fonte: Elaboração própria

Analisando a matriz $\mathrm{n}^{\circ} 2$ que evidencia os contributos de elementos essenciais que levarão ao construto da prática essencial para que a seguir se possam analisar os resultados de sucesso ou inibidores na vida da $\mathrm{CoP}$ sendo que para que a estrutura e alinhamento resultassem numa prática essencial para um bom resultado a $\mathrm{CoP}$ foi desenhada pensando na sua evolução, havendo uma definição clara dos objetivos da CoP como evidencia os documentos analisados no ANEXO BIII que representa evidências e princípios da Comunidade. Foi também definida a estrutura da CoP (moderadores - administrador - gestor/coordenador). 
Definiram-se estratégias e planos de ação para o alcance dos objetivos como se evidencia nos Princípios definidos para o suporte e desenvolvimento da CoP no ANEXO AIII.

A CoP foi apresentada publicamente pela nova direção como evidencia o ANEXO BIII com uma melhoria significativa aproveitando a evolução das tecnologias de Informação e Comunicação, com o recurso à WIKINIAV uma tecnologia de servidor colaborativo "open source" que possibilitou aos utilizadores terem acesso, procurar um artigo e editar um artigo em tempo real e participarem num fórum.

Segundo Serrano (2005, pp. 124-127), os três principais desafios da GC são:

- Construir uma infraestrutura que permita a criação/obtenção e o uso do conhecimento;

- Fomentar uma cultura que estimule a partilha do conhecimento;

- Administrar resultados.

Acrescenta que a mudança organizacional, enquadrada pela missão, identidade e ética da organização, pode ocorrer ao nível de três domínios:

- Atividades;

- Estrutura;

- Comportamento organizacional.

O estabelecimento de uma atmosfera amigável à Gestão do Conhecimento - GC, aumenta a consciência da necessidade de se partilhar conhecimento na organização, assim como a vontade em interagir. Os recursos cedidos pela organização também integram o contexto favorável à participação dos membros, e este apoio é revelado, por exemplo, pela anuência da Gestão de Topo ao ceder tempo para a realização das reuniões, pela valorização pública dos benefícios que a Comunidade trouxe à organização, pela liberação de recursos (que podem ser revertidos em recompensas ou mesmo destinados a financiar a participação deles em congressos, workshops), entre outros.

A participação de especialistas no domínio da comunidade foi ressaltada por Wenger (NEVES, 2001), Preece (2000, p. 271) e Wenger, McDermott e Snyder (2002, p. 78-79). 
Os especialistas respondem questões específicas, dão conselhos, ajudam a dar legitimidade à comunidade e atraem outras pessoas chave para a comunidade.

Pela análise de vários documentos e também de ações que assistimos poderemos dizer que a COP embrionária do trabalho Colaborativo na temática da Segurança e Saúde no Trabalho tem a sua fase Potencial e de crescimento tendo o apoio incondicional da Gestão de Topo, uma liderança forte na Comunidade e especialista no domínio, uma cultura positiva que foi marcada pela valorização da partilha de conhecimento no domínio da Prevenção de riscos laborais. De 2008 a 2011 esta Comunidade passou pela fase de maturidade e sustentação e apesar das mudanças organizacionais e de a Organização passar por um período muito complicado a Comunidade permanece. Em 2012 a CoPGAPEAN entra numa nova dinâmica e transforma-se, há uma nova mudança nas hierarquias de topo e é dada a possibilidade de se investir numa plataforma de trabalho colaborativo , a CoP alarga as suas fronteiras e promove a abertura de outras Comunidades no domínio de atuação do Instituto e no período de 2012 a 2014 é um período muito favorável ao trabalho da Comunidade de Partilha de Boas Práticas SST. Em 2015 devido a novas mudanças na Gestão de Topo encontramos uma Gestão de Topo inibidora e a Comunidade entra numa fase de declínio. Volvidos 15 anos (2004 - 2019), após este primeiro estudo, vemos agora sair Resolução do Conselho de Ministros n. ${ }^{\circ}$ 28/2019. 


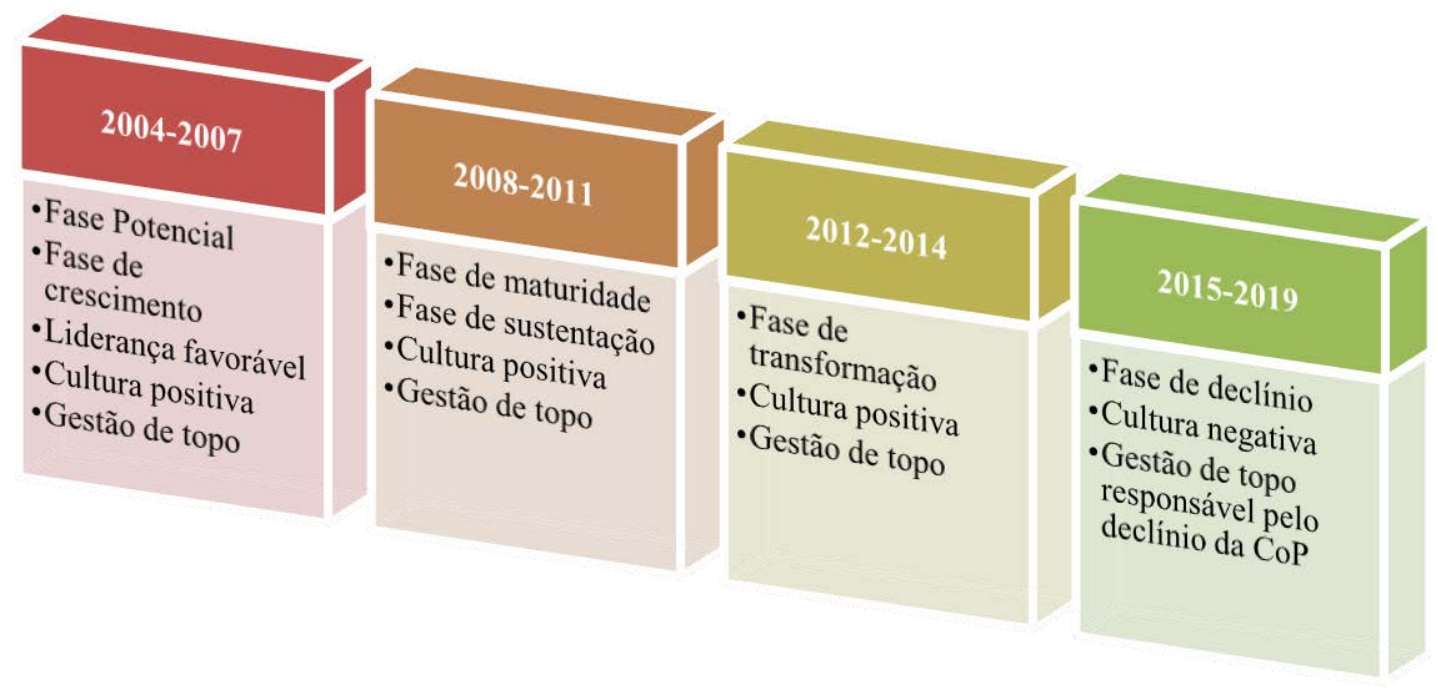

Ilustração 28 - Fases de Desenvolvimento da CoP no INIAV

Fonte: Elaboração Própria

O XXI Governo Constitucional assumiu o compromisso de revalorizar o trabalho em funções públicas e de fortalecer a Administração Pública, promovendo a sua eficiência e sustentabilidade e proporcionando condições de trabalho dignas para os seus profissionais.

De acordo coma lei do orçamento de estado para 2019, no seu art. $^{\circ} 24^{\circ}$, o governo desenvolve uma rede colaborativa na gestão pública, que apoia a implementação de sistemas de saúde e segurança ocupacional na administração pública, prevalência de uma abordagem preventiva e gestão integrada de riscos profissionais-através da transferência de conhecimentos e do intercâmbio de boas práticas. "

\section{Implementar serviços de SST de referência em toda a AP, de forma colaborativa; Capacitar} os serviços públicos para a implementação e funcionamento de serviços SST; Ponto 3-Criar uma rede colaborativa (Rede) com o objetivo principal de promover e reforçar a aplicação do regime legal de SST na Administração Pública até ao final de 2020, através da implementação do Plano de Ação. Analisando o extrato apresentado na figura 41, poderemos afirmar que todo o trabalho desenvolvido nos dois projetos de investigação que apostaram na partilha de conhecimento de forma colaborativa e no formato inovador das Comunidades de Prática 
servirão certamente de apoio ao grande projeto para a Administração Pública Portuguesa e veremos a transformação da CoP de Partilha de boas Práticas SST numa CoP alargada a toda a AP.

\section{PRESIDÊNCIA DO CONSELHO DE MINISTROS}

\section{Resolução do Conselho de Ministros n. ${ }^{\circ}$ 28/2019}

O XXI Governo Constitucional assumiu o compromisso de revalorizar o trabalho em funções públicas e de fortalecer a Administração Pública, promovendo a sua eficiência e sustentabilidade e proporcionando condições de trabalho dignas para os seus profissionais.

As boas condições de trabalho, nas suas componentes físicas, organizacionais e psicossociais, são essenciais para a satisfação dos trabalhadores e para a promoção da segurança, saúde e bem-estar no trabalho, influenciando de forma inequívoca os seus desempenhos.

2 - Determinar que o Plano SST-AP tem como objetivo geral operacionalizar o regime legal de Segurança e Saúde no Trabalho (SST) na Administração Pública (AP) até final de 2020 e como objetivos específicos:

a) Implementar serviços de SST de referência em toda a AP, de forma colaborativa;

b) Capacitar os serviços públicos para a implementação e funcionamento de serviços SST,

c) Executar planos de segurança e saúde ocupacionais para a AP nas diferentes áreas governativas;

d) Desenvolver, testar e replicar medidas inovadoras no domínio da SST.

3 - Criar uma rede colaborativa (Rede) com o objetivo principal de promover e reforçar a aplicação do regime legal de SST na Administração Pública até ao final de 2020, através da implementação do Plano de Ação.

4 - Determinar que a Rede é coordenada pelo membro do Governo responsável pela área do Emprego Público, em articulação com os membros do Governo responsáveis pelas áreas do emprego e da saúde.

5 - Determinar que integram a Rede:

a) $\mathrm{O}$ inspetor-geral da Autoridade para as Condições do Trabalho;

b) O diretor-geral da Direção-Geral da Saúde;

c) O diretor-geral da Direção-Geral da Administração e do Emprego Público (DGAEP);

d) O diretor-geral da Direção-Geral da Qualificação dos Trabalhadores em Funções Públicas;

Figura 15 - Extrato da Resolução Conselho de Ministros nº 28/2019

Fonte: Diário da República Portuguesa 
Doctorado en Salud, Discapacidad, Dependencia y Bienestar

\begin{tabular}{|c|c|c|c|}
\hline 2009-2014 & Alinhamento & Apoio Direção & Cultura \\
\hline Objetivos a curto ou médio prazo & & & \\
\hline Criação e desenvolvimento da CoP & & & \\
\hline Definição de métodos de interação da CoP & & & \\
\hline Definição da estrutura da CoP & & & \\
\hline $\begin{array}{l}\text { Definição de estratégias e planos de ação para o } \\
\text { alcance dos objetivos da CoP }\end{array}$ & & & \\
\hline Apresentação Pública da CoP & & & \\
\hline Envolvimento e suporte da Direção & & & \\
\hline Flexibilização atividades diária e da CoP & & & \\
\hline Promoção da CoP na Organização & & & \\
\hline $\begin{array}{l}\text { Disponibilização de recursos para os membros } \\
\text { da CoP }\end{array}$ & & & \\
\hline $\begin{array}{l}\text { Disponibilização de recursos para a estrutura da } \\
\text { CoP }\end{array}$ & & & \\
\hline Boas práticas na gestão de conhecimento & & & \\
\hline $\begin{array}{l}\text { Estímulo da Organização para que as pessoas } \\
\text { partilhem o conhecimento }\end{array}$ & & & \\
\hline $\begin{array}{l}\text { Reconhecimento da Organização da importância } \\
\text { da utilidade da CoP }\end{array}$ & & & \\
\hline $\begin{array}{l}\text { Transparência das informações geradas pela } \\
\text { CoP }\end{array}$ & & & \\
\hline
\end{tabular}

Matriz 2 - Elementos da prática x parâmetros individuais de cada prática

Fonte: Elaboração Própria

Comunidad@Buenas Prácticas de Seguridad, Salud e Calidad de Vida en el trabajo INIAV

"Factores críticos de éxito" 
Doctorado en Salud, Discapacidad, Dependencia y Bienestar

\begin{tabular}{|c|c|c|c|c|}
\hline Práticas 2009-20 & Política & $\begin{array}{c}\text { Coordenação } \\
\text { CoP }\end{array}$ & Tecnologia & Desenvolvimento \\
\hline Existência de uma prática de comunica & & & & \\
\hline Um facilitador ou líder que conduza a & & & & \\
\hline $\begin{array}{l}\text { Desenvolvimento atividades promovan } \\
\text { pessoal }\end{array}$ & & & & \\
\hline Reconhecimento formal ao uso e partic & & & & \\
\hline A participação na CoP da avaliação dos & & & & \\
\hline $\begin{array}{l}\text { Suporte na integração e envolviment } \\
\text { membros }\end{array}$ & & & & \\
\hline $\begin{array}{l}\text { A CoP possibilita a aquisição de } \\
\text { individual }\end{array}$ & & & & \\
\hline $\begin{array}{l}\text { A CoP possibilita a interação entre difer } \\
\text { profissionais }\end{array}$ & & & & \\
\hline Existência de uma coordenação forte na & & & & \\
\hline Investimento nas pessoas treino GC & & & & \\
\hline Ambiente facilitador da partilha conhec & & & & \\
\hline Liberdade expressar ideias & & & & \\
\hline Processo facilitador regular de novos $\mathrm{m}$ & & & & \\
\hline Utilização de Tecnologia de suporte & & & & \\
\hline Uso de Software de partilha de GC & & & & \\
\hline Existência ferramenta fácil utilização & & & & \\
\hline
\end{tabular}

Matriz 3- Parâmetros individuais de cada prática (Política | Coordenação da CoP | Tecnologia | Desenvolvimento)

Fonte: Elaboração própria

Comunidad@Buenas Prácticas de Seguridad, Salud e Calidad de Vida en el trabajo INIAV

"Factores críticos de éxito" 
Analisando a matriz $\mathrm{n}^{\mathrm{o}} 2$ que evidencia os contributos de elementos essenciais que levarão ao construto da prática essencial para que a seguir se possam analisar os resultados de sucesso ou inibidores na vida da $\mathrm{CoP}$

Pela análise da matriz $\mathrm{n}^{\mathrm{o}} 2$ poderemos concluir que houve um ambiente facilitador da partilha de conhecimento, liberdade para se expressarem ideias e um processo facilitador de registo de membros novos que quisessem entrar na dinâmica. Também houve interações entre diferentes grupos profissionais.

A existência de um facilitador /Líder forte e empenhado na dinâmica de facilitação e treino dos membros da CoP foi facilitador dos resultados apresentados na tabela seguinte aumentando a confiança entre os membros, o sentimento de Pertença a Utilidade e fazendo com que os membros contribuíssem cada vez mais.

No parâmetro da Prática do Desenvolvimento observámos que o saber não é somente uma questão individual, é também uma questão de troca, de aprender com e através do outro, da sua experiência. Esta Comunidade possibilitou para além da experiência individual a interação entre diferentes grupos profissionais, fomentou interações e relacionamentos baseados no respeito mútuo e na confiança, encorajando a disposição para partilhar ideias. Houve também um grande investimento no treino dos membros da comunidade dos animadores de prevenção e a existência e permanência de uma coordenação forte tal como já tínhamos mencionado anteriormente.

No período de 2009 a 2014 dá-se um grande salto positivo no ciclo de vida da CoPGAPEAN pois a Organização em estudo ( INIAV) aposta fortemente no uso de um software de partilha de conhecimento o que irá possibilitar para além dos encontros presenciais a possibilidade de estes profissionais se encontrarem virtualmente para além da possibilidade de transpor as fronteiras do campo onde o estudo se desenvolveu (campo Oeiras ).A análise da matriz $\mathrm{n}^{\mathrm{o}} 1$ leva-nos a análise das matrizes apresentadas $n .^{\circ} \mathrm{s} 2$ e 3 que cruzam os resultados com as práticas que auxiliaram fortemente na manutenção da vida da CoP. 


\begin{tabular}{|c|c|c|c|c|}
\hline 2005-2014 & Confiança & Contribuição & Sentimento de pertença & Utilidade \\
\hline $\begin{array}{l}\text { Alinhamento | } \\
\text { estruturação }\end{array}$ & $\begin{array}{l}\text { Definição de métodos } \\
\text { de interação entre } \\
\text { participantes da CoP }\end{array}$ & $\begin{array}{c}\text { Definição estratégias e } \\
\text { planos de ação para a } \\
\text { obtenção dos objetivos } \\
\text { da CoP }\end{array}$ & $\begin{array}{c}\text { Definição de métodos de } \\
\text { interação entre os } \\
\text { participantes da CoP }\end{array}$ & $\begin{array}{l}\text { Estabelecer objetivos a } \\
\text { curto e longo prazo }\end{array}$ \\
\hline Apoio | liderança & $\begin{array}{c}\text { Envolvimento e suporte } \\
\text { da Direção }\end{array}$ & $\begin{array}{c}\text { Disponibilização de } \\
\text { Recursos }\end{array}$ & $\begin{array}{l}\text { Flexibilizações atividades } \\
\text { diárias e atividade da CoP }\end{array}$ & $\begin{array}{c}\text { Promoção da CoP pela } \\
\text { Direção }\end{array}$ \\
\hline Avaliação & $\begin{array}{c}\text { Existência de } \\
\text { ferramentas que } \\
\text { possibilitem o feedback } \\
\text { dos membros sobre a } \\
\text { CoP }\end{array}$ & $\begin{array}{c}\text { Exposição dos } \\
\text { benefícios de sucesso } \\
\text { prestados aos } \\
\text { stakeholders da CoP }\end{array}$ & $\begin{array}{c}\text { Exposição dos benefícios } \\
\text { e histórias de sucesso } \\
\text { prestados aos } \\
\text { stakeholders da CoP }\end{array}$ & $\begin{array}{c}\text { Exposição dos benefícios e } \\
\text { histórias de sucesso } \\
\text { prestados aos stakeholders } \\
\text { da CoP }\end{array}$ \\
\hline Cult & $\begin{array}{c}\text { Estímulo } \\
\text { Organizacional para que } \\
\text { os funcionários } \\
\text { partilhem o seu } \\
\text { conhecimento }\end{array}$ & $\begin{array}{l}\text { Reconhecimento da } \\
\text { Organização da } \\
\text { importância das CoP }\end{array}$ & $\begin{array}{l}\text { Estímulo da Organização } \\
\text { para funcionários } \\
\text { partilhem conhecimento }\end{array}$ & $\begin{array}{l}\text { Estímulo Organizacional } \\
\text { aos funcionários para } \\
\text { partilhar conhecimento }\end{array}$ \\
\hline Desenvolvimento & $\begin{array}{c}\text { Existência e } \\
\text { permanência de um } \\
\text { facilitador forte }\end{array}$ & $\begin{array}{c}\text { A CoP possibilita a } \\
\text { interação de diferentes } \\
\text { GP }\end{array}$ & $\begin{array}{l}\text { Investimento nas } \\
\text { pessoas/treino GC }\end{array}$ & $\begin{array}{l}\text { Investimento nas } \\
\text { pessoas/treino GC }\end{array}$ \\
\hline Gestão da CoP & $\begin{array}{l}\text { Facilitador/líder que } \\
\text { conduziu um bom } \\
\text { andamento CoP }\end{array}$ & $\begin{array}{c}\text { Existência de uma } \\
\text { prática de comunicação } \\
\text { na CoP }\end{array}$ & $\begin{array}{c}\text { Desenvolvimento de } \\
\text { atividades para a } \\
\text { interação pessoal da CoP }\end{array}$ & $\begin{array}{l}\text { Desenvolvimento de treinos } \\
\text { e apoio continuado }\end{array}$ \\
\hline Política & $\begin{array}{c}\text { Ambiente facilitador da } \\
\text { partilha GC }\end{array}$ & $\begin{array}{l}\text { Liberdade para } \\
\text { expressar as ideias sem } \\
\text { juízo de valor }\end{array}$ & $\begin{array}{c}\text { Ambiente que facilite a } \\
\text { partilha GC }\end{array}$ & $\begin{array}{c}\text { Ambiente que facilite a } \\
\text { partilha GC }\end{array}$ \\
\hline Tecnologia & $\begin{array}{c}\text { Utilização } \\
\text { infraestruturas e } \\
\text { ferramentas de GC }\end{array}$ & $\begin{array}{l}\text { Utilização tecnologia } \\
\text { suporte }\end{array}$ & $\begin{array}{l}\text { Uso de um software de } \\
\text { partilha de arquivos }\end{array}$ & $\begin{array}{c}\text { Promover debates e troca de } \\
\text { ideias/envolvimento }\end{array}$ \\
\hline
\end{tabular}

Matriz 4- Práticas essenciais X resultados de sucesso da CoPGAPEAN e sua transformação CoP Boas Práticas SST

Fonte: Elaboração própria

Comunidad@Buenas Prácticas de Seguridad, Salud e Calidad de Vida en el trabajo INIAV

"Factores críticos de éxito" 
Passaremos também a analisar a entrevista semiestruturada realizada em 2016 a 5 membros da CoP da Organização em estudo a escolha dos membros envolveu 2 facilitadores, o líder da CoP e 2 membros passivos.

A entrevista realizou-se em sala, durou $1 \mathrm{~h}$ e foram destacados os parâmetros de avaliação que nos interessavam para conseguirmos compreender o fenómeno em estudo. Realizamos esta entrevista no segundo semestre do ano 2016, fase em que a dinâmica da Comunidade já estava num período muito complicado.

\subsection{Alinhamento e estruturação}

Os membros da CoP definiram objetivos e foram apresentados á Gestão de topo, tendo reunido em sala no CAP (Centro de Aprendizagem Propedêutico com a Alta Direção). Da reunião surgiu a proposta de apresentação pública da Comunidade em que iriam estar na abertura o Dirigente máximo da Organização.

Os métodos de interação dos participantes e reportando-nos ao ano 2005, foram interações em sala, em auditório, nos momentos de café e do chá e também por email foram definidos objetivos a curto e médio prazo da CoP. Ficou definida nesta reunião que após a apresentação Pública dos membros embrionários desta $\mathrm{CoP}$ estes elementos passariam por um processo de formação em sala com conteúdos programáticos relacionados com o Domínio da CoP .Definiu-se também que o período de formação seria presencial e em contexto real de trabalho para que se conseguissem implementar mudanças a curto prazo .Também se definiu alargar o horizonte dos

objetivos após o primeiro ano de dinâmica da CoP. Após 6 meses de formação os membros da CoP teriam como objetivo preparar um evento aberto e em parceria com outras Organizações do Sector Público (INA-IDICT) seria o segundo evento já aberto ao exterior. Programou-se também para além deste evento um trabalho ao nível da apresentação de matérias com mensagens de risco que seriam apresentados em forma de cartazes e brochuras no $1^{\mathrm{o}}$ evento aberto ao exterior. 


\subsubsection{Apoio da Gestão de Topo}

Houve envolvimento e comprometimento da gestão de topo nas diferentes fases da $\mathrm{CoP}$ de outra forma este projeto não teria pernas para andar. O envolvimento da Gestão de topo revelouse em vários níveis. Quer na explicitação dos benefícios da partilha de conhecimento e boas práticas na prevenção de riscos laborais, quer ao nível do comprometimento com a implementação do projeto.

A gestão de topo explicitou os benefícios e os sucessos prestados pela $\mathrm{CoP}$ em todos os momentos do ciclo de vida da CoPGAPEAN foram explicitados publicamente os benefícios resultantes do trabalho desenvolvido pela Comunidade, assim como dos sucessos da sua caminha intra e inter organizacional.

A Gestão de topo deu tempo aos funcionários para exercerem as atividades na $\mathrm{CoP}$, reuniu com as chefias intermédias no sentido os envolver neste processo e para que se gerisse de forma aos funcionários pudessem ter acesso a formação e tempo para desenvolverem todas as atividades em que estavam envolvidos.

A Cultura da Organização era aberta ao trabalho colaborativo. Antes da implementação no terreno do projeto da CoPGAPEAN e em parceria com o ISCTE/CIS o Dirigente da Organização pediu que se fizesse uma avaliação da Cultura Organizacional e de Segurança no sentido de após o período de diagnóstico e atendendo a compatibilização das duas se planeasse uma intervenção adequada.

No resultado do diagnóstico percecionou-se que os funcionários desta Organização eram colaborativos havendo um estímulo para a partilha de conhecimento.

A Organização estimulou os funcionários a partilharem o conhecimento cedendo infraestruturas de apoio aos encontros face a face e explicitando por escrito.

\subsubsection{Desenvolvimento}

Foi necessário para que se estabelecesse o sentimento de confiança entre os membros

Comunidad@Buenas Prácticas de Seguridad, Salud e Calidad de Vida en el trabajo INIAV

"Factores críticos de éxito" 
a nomeação de um líder da Comunidade ou coordenador e que tivesse competências relacionais e de facilitação que alavancou a partilha do conhecimento.

Esse Coordenador acompanhou e envolveu-se era o enzima facilitador de toda a dinâmica. Foram duas as figuras chave no processo, o diretor e a coordenadora assim como o investimento no período de treino / formação da CoP. Gestão da CoP que conduziu o bom andamento da dinâmica da $\mathrm{CoP}$ foi a líder da mesma havendo uma prática continua de partilha quer em encontros formais, quer informais.

\subsubsection{Política}

O ambiente criou confiança entre os membros, as suas ideias eram expressadas sem receios "Estávamos comprometidos com a mudança e o domínio da nossa CoP não permite receios" é o domínio da prevenção de riscos em atividades que lidam com o perigo diariamente.

\subsubsection{Tecnologia}

As infraestruturas e ferramentas foram facultadas “entre 2005 e 2008 tínhamos como ferramenta de Comunicação a correspondência eletrónica (assíncrona) e telefone (síncrona).

Em 2009 após um projeto de parceria com o INA tivemos a facilidade de aceder ao Comunidades@ina facilitadora da partilha de conhecimento e a partir de 2012 implementamos internamente a WIKINIAV (Flor, C., 2015).

As infraestruturas físicas cedidas foram salas e auditórios até 2015, a partir do $2^{\circ}$ semestre 2015 a COP deixou de ser importante para a gestão de topo da Organização e foi desativada. Nota a acrescentar pelos entrevistados que possa valorizar a entrevista: "sem dúvida depois de tudo o que partilhamos podemos concluir que por muita vontade, confiança e amor a camisola se a Gestão de Topo não se comprometer não há comunidade que perdure .Todos trabalhamos muito mas muito para que este projeto piloto tivesse continuidade e chegamos a um ponto que a vontade de um líder chega para terminar o nosso comprometimento, a confiança e o sentimento 
de pertença, mas estamos cá para no caso de mudarem de ideias darmos continuidade aquilo em que acreditamos".

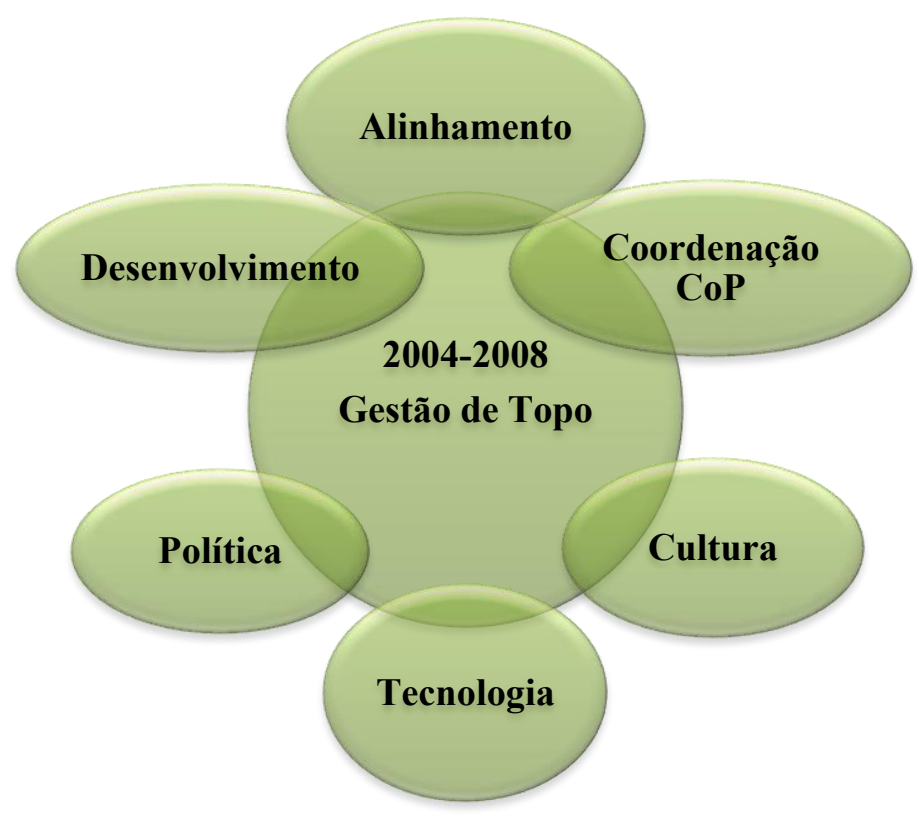

Ilustração 29 - Influência Positiva da Gestão de Topo 2004-2008

Fonte: Elaboração Própria

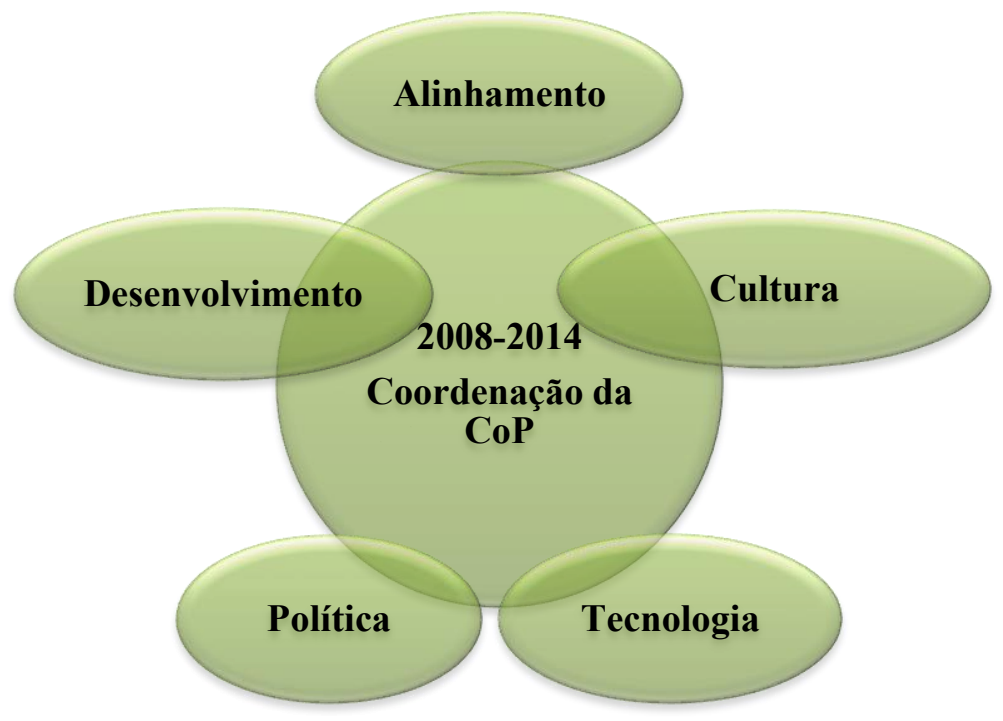

Ilustração 30 - Influencia positiva da Coordenação da CoP 2008-2014

Fonte: Elaboração Própria

Comunidad@Buenas Prácticas de Seguridad, Salud e Calidad de Vida en el trabajo INIAV

"Factores críticos de éxito" 


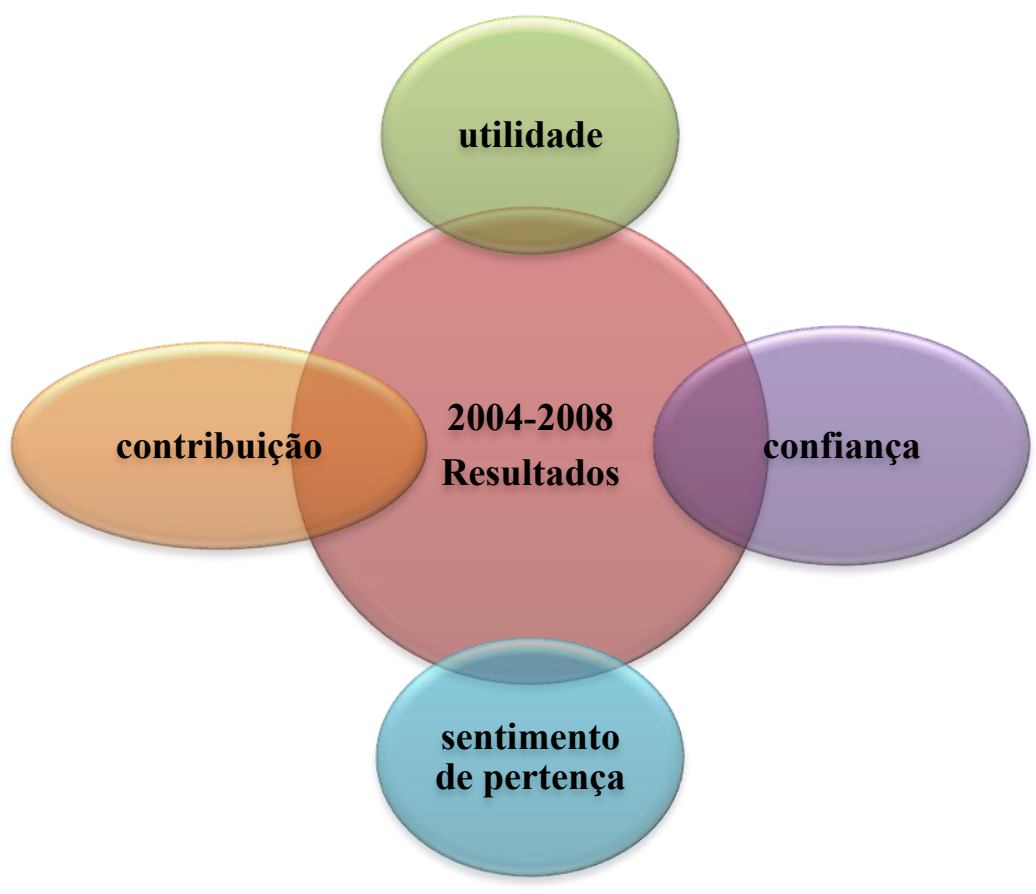

Ilustração 31 - Resultados de sucesso CoP 2004-2008

Fonte: Elaboração Própria

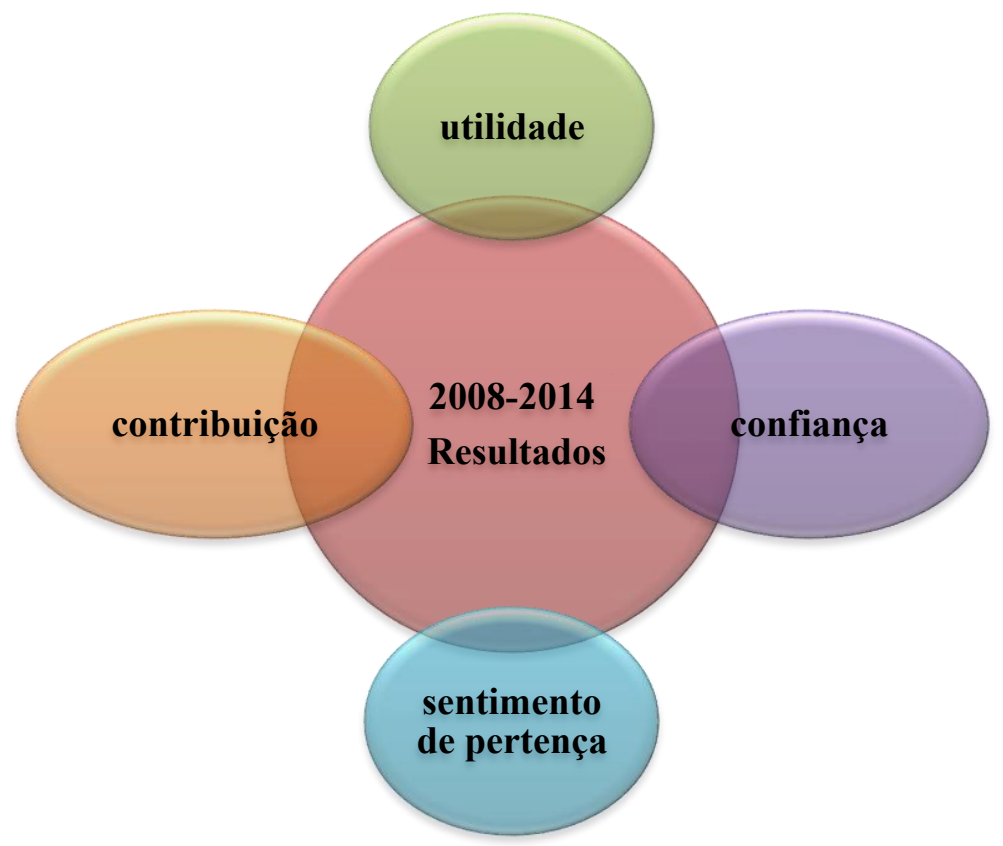

Ilustração 32 - Quadro nº: Resultados de sucesso CoP 2008-2014

Fonte: Elaboração Própria

Comunidad@Buenas Prácticas de Seguridad, Salud e Calidad de Vida en el trabajo INIAV

"Factores críticos de éxito" 


\begin{tabular}{|c|c|c|c|c|}
\hline 2015-2019 & Confiança & Contribuição & Sentimento de pertença & Utilidade \\
\hline $\begin{array}{l}\text { Alinhamento } \\
\text { estruturação }\end{array}$ & $\begin{array}{l}\text { Defi ição de métodos } \\
\text { de interação entre } \\
\text { participantes da CoP }\end{array}$ & $\begin{array}{c}\text { Definição estratégias } \\
\text { e planos de ação para } \\
\text { a obtenção dos } \\
\text { objetivos da CoP }\end{array}$ & $\begin{array}{l}\text { Definição de métodos } \\
\text { de interação entre os } \\
\text { participantes da CoP }\end{array}$ & $\begin{array}{l}\text { Estabelecer obj tivos } \\
\text { a curto e longo prazo }\end{array}$ \\
\hline $\begin{array}{c}\text { Apoio | } \\
\text { liderança }\end{array}$ & $\begin{array}{l}\text { Envolvimento e } \\
\text { suporte da Dire, }, \text { ão }\end{array}$ & $\begin{array}{c}\text { Disponibilização de } \\
\text { Recursos }\end{array}$ & $\begin{array}{c}\text { Flexibilizações e } \\
\text { atividades diárias da } \\
\text { CoP }\end{array}$ & $\begin{array}{l}\text { Pr moção da CoP } \\
\text { pela Direção }\end{array}$ \\
\hline Avaliação & $\begin{array}{c}\text { Existência de } \\
\text { ferramentas que } \\
\text { possibilitem o } \\
\text { feedback dos } \\
\text { membros sobre a CoP }\end{array}$ & $\begin{array}{l}\text { Exposição dos } \\
\text { be efícios de sucesso } \\
\text { prestados aos } \\
\text { stake olders da CoP }\end{array}$ & $\begin{array}{l}\text { Exposição dos } \\
\text { benefícios e história de } \\
\text { sucesso prestadoo aos } \\
\text { stakeholders da CoP }\end{array}$ & $\begin{array}{c}\text { Exposição dos } \\
\text { benefícios e histórias } \\
\text { de sucesso prestados } \\
\text { aos stakeholders da } \\
\text { CoP }\end{array}$ \\
\hline Cultura & $\begin{array}{c}\text { Estímulo da } \\
\text { Organização para que } \\
\text { os funcionários } \\
\text { partilhem } \\
\text { conhecimento }\end{array}$ & $\begin{array}{l}\text { Reconhecimento } \\
\text { Organização da } \\
\text { importância da Co }\end{array}$ & $\begin{array}{l}\text { ulo da } \\
\text { ação para } \\
\text { nários } \\
\text { harem } \\
\text { cimento }\end{array}$ & $\begin{array}{c}\text { Estímulo } \\
\text { Organizacional para } \\
\text { funcionários } \\
\text { partilharem } \\
\text { conhecimento }\end{array}$ \\
\hline $\begin{array}{c}\text { Desenvolviment } \\
\text { o }\end{array}$ & $\begin{array}{c}\text { Existência e } \\
\text { permanência de um } \\
\text { facilitador forte }\end{array}$ & $\begin{array}{l}\text { A CoP possibilita } \\
\text { interação de } \\
\text { diferentes \% }\end{array}$ & $\begin{array}{l}\text { nto nas } \\
\text { eino GC }\end{array}$ & $\begin{array}{l}\text { Investimento nas } \\
\text { pessoas/treino GC }\end{array}$ \\
\hline Gestão da CoP & $\begin{array}{l}\text { Facilitador/líder que } \\
\text { conduziu ao bom } \\
\text { andamento CoP }\end{array}$ & $\begin{array}{l}\text { Exist ncia de uma } \\
\text { prática de } \\
\text { co hunicação na CoP }\end{array}$ & $\begin{array}{c}\text { Desenvolvime to de } \\
\text { atividades part a } \\
\text { interação pessoal da } \\
\text { CoP }\end{array}$ & $\begin{array}{l}\text { Desenvolvimento de } \\
\text { treinos e apoio } \\
\text { continuado }\end{array}$ \\
\hline Política & $\begin{array}{c}\text { Ambiente facilitad or } \\
\text { da partilha G }\end{array}$ & $\begin{array}{l}\text { Liberdade para } \\
\text { expressar as ideias } \\
\text { sem juízo de valor }\end{array}$ & $\begin{array}{c}\text { Ambiente que facilite a } \\
\text { partilha GC }\end{array}$ & $\begin{array}{l}\text { lue facilite } \\
\text { lha GC }\end{array}$ \\
\hline Tecnologia & $\begin{array}{l}\text { Ulização infra } \\
\text { estruturas e } \\
\text { ferramentas de }\end{array}$ & $\begin{array}{l}\text { Utilização tecnologia } \\
\text { suporte-Foi inativada }\end{array}$ & $\begin{array}{c}\text { Uso de um software de } \\
\text { partilha de arquivos-Foi } \\
\text { inativada }\end{array}$ & $\begin{array}{c}\text { Promover dd bates } \\
\text { troca } \\
\text { ideias/envolvimento }\end{array}$ \\
\hline
\end{tabular}

Matriz 5 - Práticas essenciais não implementadas em 2015-2019 que resultaram em insucesso da CoP

Fonte: Elaboração Própria

Inibidor

Comunidad@Buenas Prácticas de Seguridad, Salud e Calidad de Vida en el trabajo INIAV

"Factores críticos de éxito" 


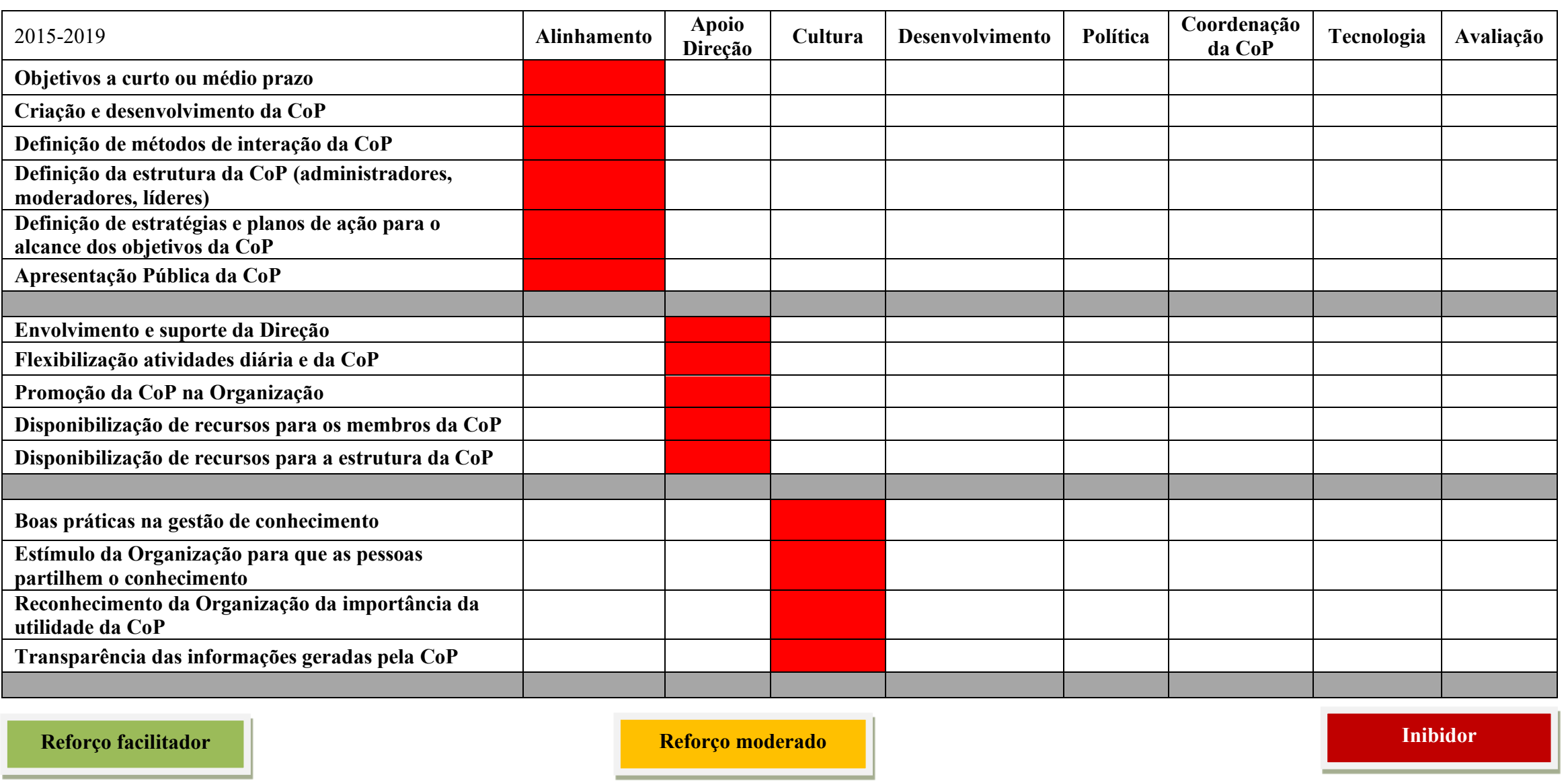

Matriz 6 - Elementos da prática x parâmetros individuais de cada prática Práticas

Fonte: Elaboração Própria 
Zboralski (2009), nas suas considerações sobre a influência do apoio organizacional nas CoP, afirma que o amparo da organização é de grande importância para o êxito das iniciativas no contexto da gestão do conhecimento.

O estabelecimento de uma atmosfera amigável à Gestão do Conhecimento - GC, incluindo a criação de Comunidades, aumenta a consciência da necessidade de se partilhar conhecimento em uma organização, assim como a vontade em interagir nas CoP.

Para além da atmosfera, segundo Zboralski (2009), os recursos cedidos pela organização também integram o contexto favorável à participação dos membros, e este apoio é revelado, por exemplo, pela anuência da gerência ao ceder tempo para a realização das reuniões, pela valorização pública dos benefícios que a Comunidade trouxe à organização, cedência de recursos. Nenhuma destas práticas foi evidenciada entre 2015 e 2019. 


\begin{tabular}{|c|c|c|c|c|c|c|c|c|}
\hline 2015-2019 & Alinhamento & $\begin{array}{c}\text { Apoio } \\
\text { Direção }\end{array}$ & Cultura & Desenvolvimento & Política & $\begin{array}{c}\text { Coordenação } \\
\text { da CoP }\end{array}$ & Tecnologia & Avaliação \\
\hline \multicolumn{9}{|l|}{ Existência de uma prática de comunicação } \\
\hline \multicolumn{9}{|l|}{ Um facilitador ou líder que conduza a CoP } \\
\hline \multicolumn{9}{|l|}{$\begin{array}{l}\text { Desenvolvimento de atividades que promovam a } \\
\text { interação pessoal }\end{array}$} \\
\hline \multicolumn{9}{|l|}{$\begin{array}{l}\text { Reconhecimento formal associado ao uso e } \\
\text { participação }\end{array}$} \\
\hline \multicolumn{9}{|l|}{$\begin{array}{l}\text { A participação na CoP faz parte da avaliação dos } \\
\text { funcionários }\end{array}$} \\
\hline \multicolumn{9}{|l|}{$\begin{array}{l}\text { Suporte na integração e envolvimento de novos } \\
\text { membros }\end{array}$} \\
\hline \multicolumn{9}{|l|}{$\begin{array}{l}\text { A CoP possibilita a aquisição de experiência } \\
\text { individual }\end{array}$} \\
\hline \multicolumn{9}{|l|}{$\begin{array}{l}\text { A CoP possibilita a interação entre diferentes } \\
\text { grupos profissionais }\end{array}$} \\
\hline \multicolumn{9}{|l|}{ Existência de uma coordenação forte na CoP } \\
\hline \multicolumn{9}{|l|}{ Investimento nas pessoas treino GC } \\
\hline & & & & & & & & \\
\hline \multicolumn{9}{|l|}{ Ambiente facilitador da partilha de conhecimento } \\
\hline \multicolumn{9}{|l|}{ Liberdade para expressar ideias } \\
\hline \multicolumn{9}{|l|}{ Processo facilitador de novos membros } \\
\hline & & & & & & & & \\
\hline \multicolumn{9}{|l|}{ Utilização de Tecnologia de suporte } \\
\hline \multicolumn{9}{|l|}{ Uso de Software de partilha de GC } \\
\hline \multicolumn{9}{|l|}{ Existência de uma ferramenta fácil utilização } \\
\hline & & & & & & & & \\
\hline Reforço facilitador & & ibidor & & & & & & \\
\hline
\end{tabular}

Matriz 7 - Elementos da prática x parâmetros individuais de cada prática

Fonte: Elaboração Própria 


\begin{tabular}{|c|c|c|c|c|}
\hline $\begin{array}{l}\text { Práticas essenciais } \\
2015-2019\end{array}$ & Confiança & Contribuição & Senso de pertença & Utilidade \\
\hline $\begin{array}{l}\text { Alinhamento e } \\
\text { estruturação }\end{array}$ & $\begin{array}{l}\text { Definição de } \\
\text { métodos de } \\
\text { interação entre } \\
\text { participantes da } \\
\text { CoP } \\
\end{array}$ & $\begin{array}{c}\text { Definição de } \\
\text { estratégias e planos } \\
\text { de ação para a } \\
\text { obtenção dos } \\
\text { objetivos da CoP }\end{array}$ & $\begin{array}{c}\text { Definição de } \\
\text { métodos de interação } \\
\text { entre os participantes } \\
\text { da CoP }\end{array}$ & $\begin{array}{l}\text { Estabelecer objetivos a curto e } \\
\text { longo prazo }\end{array}$ \\
\hline Apoio e liderança & $\begin{array}{l}\text { Envolvimento e } \\
\text { suporte da Direção }\end{array}$ & $\begin{array}{l}\text { Disponibilização de } \\
\text { Recursos }\end{array}$ & $\begin{array}{c}\text { Flexibilização } \\
\text { atividades diárias da } \\
\text { CoP }\end{array}$ & $\begin{array}{l}\text { Promoção da CoP pela } \\
\text { Direção }\end{array}$ \\
\hline Avaliação & $\begin{array}{c}\text { Existência de } \\
\text { ferramentas que } \\
\text { possibilitem o } \\
\text { feedback dos } \\
\text { membros sobre a } \\
\text { CoP }\end{array}$ & $\begin{array}{c}\text { Exposição dos } \\
\text { benefícios e } \\
\text { histórias de sucesso } \\
\text { prestados aos } \\
\text { stakeholders da CoP }\end{array}$ & $\begin{array}{c}\text { Exposição dos } \\
\text { benefícios e histórias } \\
\text { de sucesso prestados } \\
\text { aos stakeholders da } \\
\text { CoP }\end{array}$ & $\begin{array}{l}\text { Exposição dos benefícios e } \\
\text { histórias de sucesso prestados } \\
\text { aos stakeholders da CoP }\end{array}$ \\
\hline Cultura & $\begin{array}{c}\text { Estímulo da } \\
\text { Organização para } \\
\text { que os funcionários } \\
\text { partilhem o seu } \\
\text { conhecimento } \\
\end{array}$ & $\begin{array}{l}\text { Reconhecimento da } \\
\text { Organização da } \\
\text { importância da CoP }\end{array}$ & $\begin{array}{l}\text { Estímulo da } \\
\text { Organização para } \\
\text { que os funcionários } \\
\text { partilhem o seu } \\
\text { conhecimento } \\
\end{array}$ & $\begin{array}{c}\text { Estímulo da Organização } \\
\text { para que os funcionários } \\
\text { partilhem o seu conhecimento }\end{array}$ \\
\hline Desenvolvimento & $\begin{array}{l}\text { Existência e } \\
\text { permanência de um } \\
\text { facilitador forte }\end{array}$ & $\begin{array}{l}\text { A CoP possibilita a } \\
\text { interação de } \\
\text { diferentes grupos } \\
\text { profissionais } \\
\end{array}$ & $\begin{array}{l}\text { Investimento nas } \\
\text { pessoas/treino GC }\end{array}$ & $\begin{array}{l}\text { Investimento nas } \\
\text { pessoas/treino GC }\end{array}$ \\
\hline Gestão da CoP & $\begin{array}{l}\text { Facilitador/líder } \\
\text { que conduziu um } \\
\text { bom andamento } \\
\text { CoP }\end{array}$ & $\begin{array}{l}\text { Existência de uma } \\
\text { prática de } \\
\text { comunicação na } \\
\text { CoP }\end{array}$ & $\begin{array}{l}\text { Desenvolvimento de } \\
\text { atividades para a } \\
\text { interação pessoal e } \\
\text { desenvolvimento da } \\
\text { CoP }\end{array}$ & $\begin{array}{l}\text { Desenvolvimento de treinos e } \\
\text { apoio continuado }\end{array}$ \\
\hline Política & $\begin{array}{l}\text { Ambiente } \\
\text { facilitador da } \\
\text { partilha GC } \\
\end{array}$ & $\begin{array}{c}\text { Liberdade para } \\
\text { expressar as ideias } \\
\text { sem juízo de valor } \\
\end{array}$ & $\begin{array}{c}\text { Ambiente que } \\
\text { facilite a partilha GC }\end{array}$ & $\begin{array}{c}\text { Ambiente que facilite a } \\
\text { partilha GC }\end{array}$ \\
\hline Tecnologia & $\begin{array}{l}\text { Utilização de infra } \\
\text { estruturas e } \\
\text { ferramentas que } \\
\text { possibilitaram a } \\
\text { partilha de GC }\end{array}$ & $\begin{array}{l}\text { Utilização de } \\
\text { tecnologia de } \\
\text { suporte }\end{array}$ & $\begin{array}{l}\text { Uso de um software } \\
\text { de partilha de } \\
\text { arquivos }\end{array}$ & $\begin{array}{l}\text { Promover debates e troca de } \\
\text { ideias/envolvimento/encontros }\end{array}$ \\
\hline
\end{tabular}

\section{Reforço facilitador}

Matriz 8 - Práticas essenciais x resultados

Fonte: Elaboração Própria

Pela análise matriz acima apresentada (Matriz n $\left.{ }^{\circ} 8\right)$ poderemos concluir que os resultados no período de (2015 a 2019) que poderiam resultar em sucesso para a Comunidade de Prática de Partilha do conhecimento no domínio da Segurança e Saúde no trabalho como a Confiança -Contribuição -

Comunidad@Buenas Prácticas de Seguridad, Salud e Calidad de Vida en el trabajo INIAV

"Factores críticos de éxito" 
Sentimento de Pertença e Utilidade - não se verificaram o que levou ao declínio da CoP ,sendo o principal elemento da Prática responsável por esta situação o facto de ter falhado o Apoio da Gestão de Topo da Organização, esta prática é crucial para que todas as outras consigam entrar na dinâmica de Partilha. Houve uma reversão da Cultura e Política, mesmo sendo a fase em que a Tecnologia estava no auge. Em termos Organizacionais não há possibilidade de qualquer $\mathrm{CoP}$ crescer ou manter-se se a Gestão de Topo não for aberta e apoiar o trabalho colaborativo.

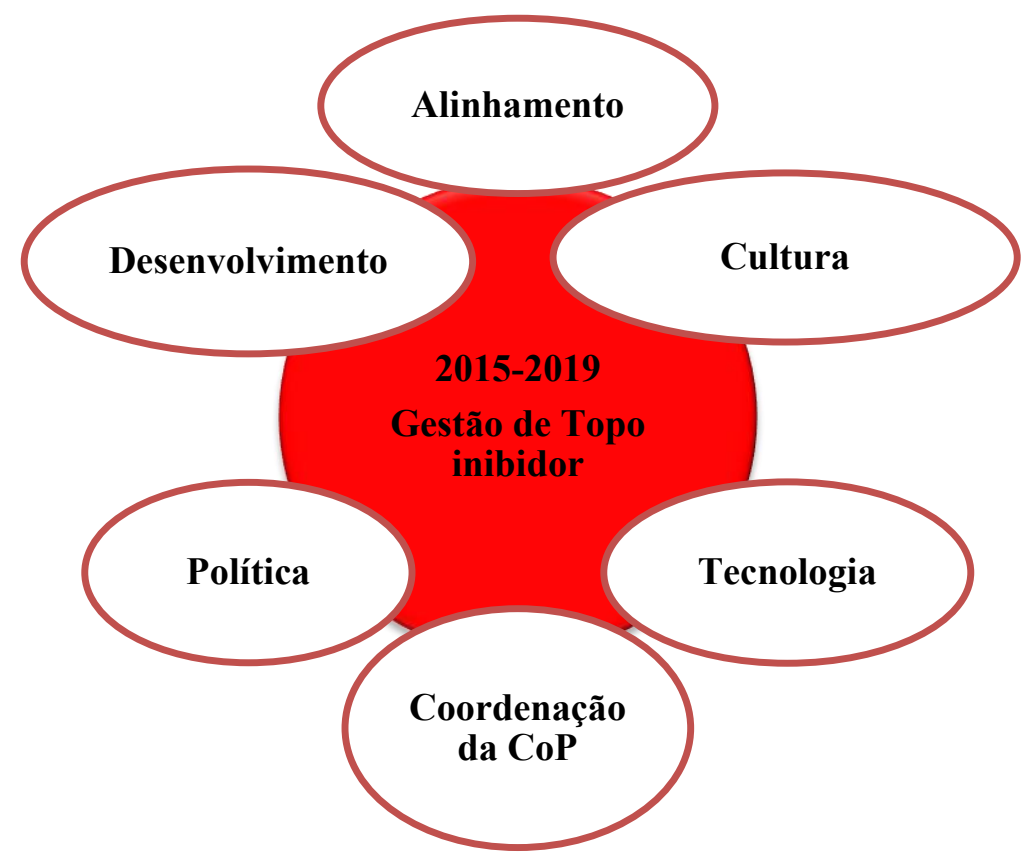

Ilustração 33 - Papel da Gestão de Topo 2015-2019

Fonte: Elaboração Própria 


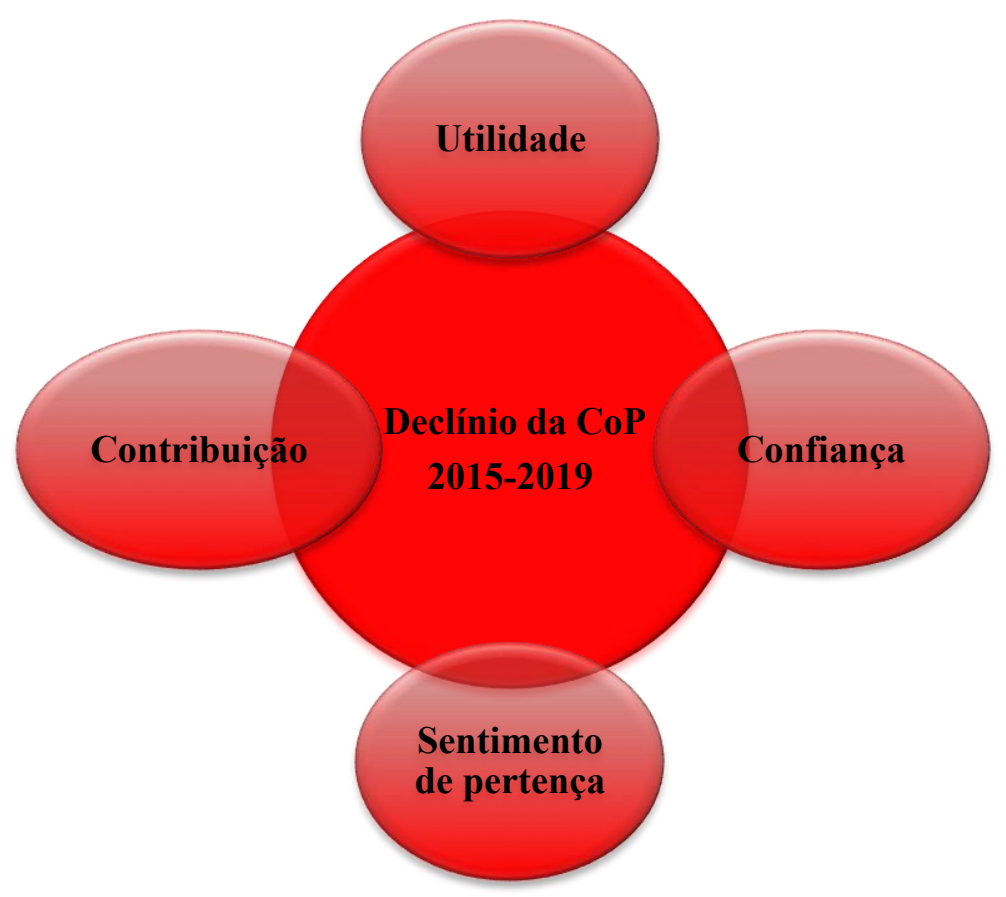

Ilustração 34 - Declínio da CoP e insucesso nos resultados

Fonte: Elaboração Própria

Analisando a ilustração 34 poderemos concluir que não foram desenvolvidos neste período as práticas essências para darem origem a resultados que evidenciassem o bom funcionamento e continuidade da $\mathrm{CoP}$. Os membros da $\mathrm{CoP}$ não se sentiram à vontade para partilhar o seu conhecimento, não mostraram interesse na realização de eventos da CoP, também não houve envolvimento individual com a $\mathrm{CoP}$ e não consideraram útil para melhorar o conhecimento e tudo isto porque a Gestão de Topo foi inibidora e resistente ao trabalho colaborativo.

Incluir o hábito de participar da Comunidade de Práticas na rotina do trabalho envolve uma mudança de cultura. Uma vez que, a utilização da Comunidade de Práticas envolve mudança de cultura, criação e manutenção de uma infraestrutura de suporte e dedicação parcial da rotina de trabalho da organização, a obtenção e manutenção do patrocínio é um fator crítico de sucesso (Rosa Neto \& Vilanova, 2006). 
No período entre 2015 e 2019 deparámo-nos com um retrocesso na mudança de cultura de partilha, o hábito que existia foi bloqueado e que é crítico, este bloqueio é da responsabilidade da Gestão de Topo. Segundo (Lahti \& Moilanen, 2004) o conhecimento tácito é um dos pontos fortes dos colaboradores mais velhos e experientes, apresentando a capacidade de interpretar informação relativa à qual não existe regra formal de processamento. Existe um grande potencial no conhecimento na sua forma tácita.

Partilhar o conhecimento tácito entre colaboradores mais novos e mais velhos é um dos principais desafios da gestão. Lahti e Moilanen referem no seu estudo que a aprendizagem que ocorre entre colaboradores mais novos e mais velhos aumenta as competências individuais e liberta conhecimento tácito individual para utilização de toda a organização.

A Organização do nosso estudo depara-se com o problema do envelhecimento dos seus colaboradores e saída para a aposentação sendo também crítico todo o conhecimento tácito que se perde com a saída dos mesmos, mas a Gestão de Topo não considera isso relevante. A estrutura organizacional influencia as atitudes de partilha de conhecimento dos colaboradores (Kim \& Lee, 2005). De acordo com (Chung, L. H., 2001), estruturas organizacionais mais burocráticas e centralizadas tendem a reprimir a criação de conhecimento enquanto as flexíveis e descentralizadas podem encorajar a partilha de conhecimento, especialmente o tácito em virtude de permitirem uma maior interação entre as pessoas. Outro instrumento por nós analisado foi a entrevista semiestruturada aplicada a Coordenadora /facilitadora líder da CoP ao longo de 15 anos.

Análise de conteúdo da entrevista realizada em 2019 à Coordenadora da Comunidade embrionária CoPGAPEAN. Atendendo a que Coordenadora da Comunidade de Prática dos Animadores de Prevenção, acompanhou e foi ativa em todo o estudo desde 2004 até 2019, entendemos que reunia o know how necessário para o desenvolvimento da nossa entrevista semiestruturada.

O objetivo da nossa entrevista foi perceber a história da Comunidade de Prática dos Animadores de Prevenção e a sua dinâmica colaborativa, bem como o seu ciclo de vida e os benefícios que trouxe para a Organização e também como lidou com as mudanças Organizacionais A CoPGAPEAN (Comunidade de Prática dos Animadores de Prevenção da Estação Agronómica nacional) nasce em 
2005. Inicia devido a uma lacuna na AP sobre a Gestão da Prevenção de Riscos Laborais integrada num projeto dinamizado pelo INA (Instituto Nacional de Administração).

Projeto com o tema "Cultura de Segurança - Um caminho com futuro na Administração Pública". A realização do estudo de caso foi numa organização do setor público a ex. Estação Agronómica Nacional (EAN) pertencente ao Ministério da Agricultura.

A escolha desta organização esteve relacionada com a diversidade de atividades profissionais: Administrativa; Laboratórios (químicos) biológicos. Atividades de campo (Agricultura) e atividades de manutenção. Na ilustração 35 apresentamos o esquema da nossa análise sobre (Como, quando e onde nasceu a CoPGAPEAN)

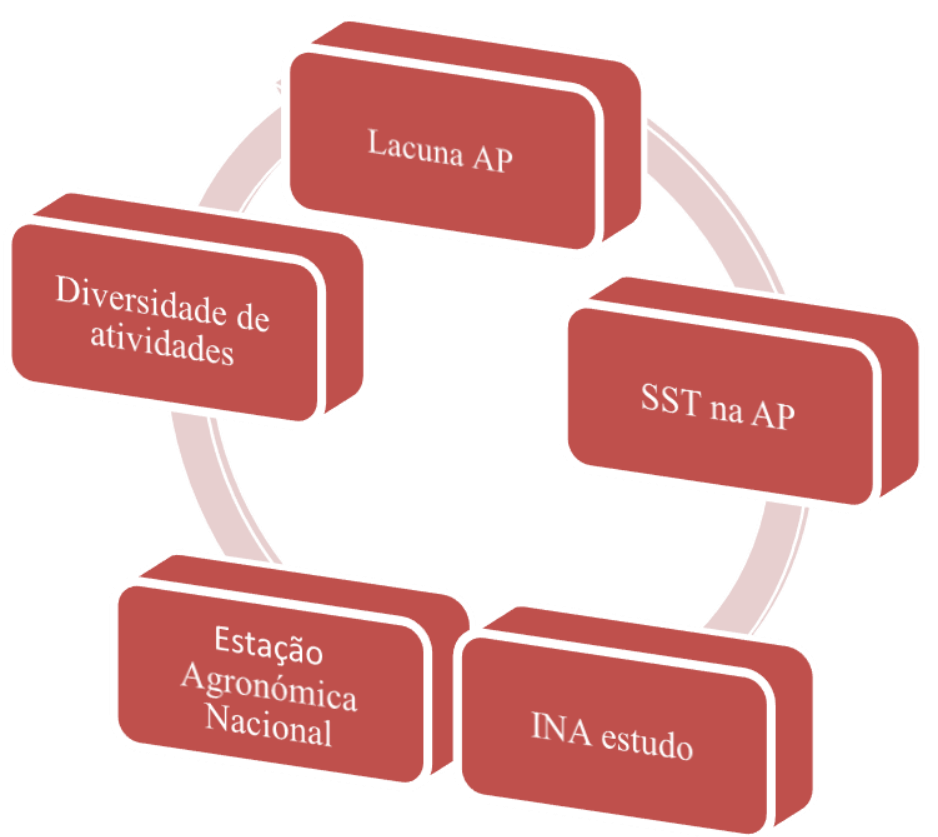

Ilustração 35 - Estratégia do Projeto Cultura de Segurança

Fonte: Elaboração Própria

Após escolhida a Organização para se realizar o estudo o passo seguinte seria envolver a gestão de topo da organização em estudo. Sem o envolvimento da gestão de topo o projeto à partida não teria 
pernas para andar. A partir do momento em que a gestão de topo aceita que o projeto se desenvolva na organização também decide envolver-se na dinâmica (ilustração 36).

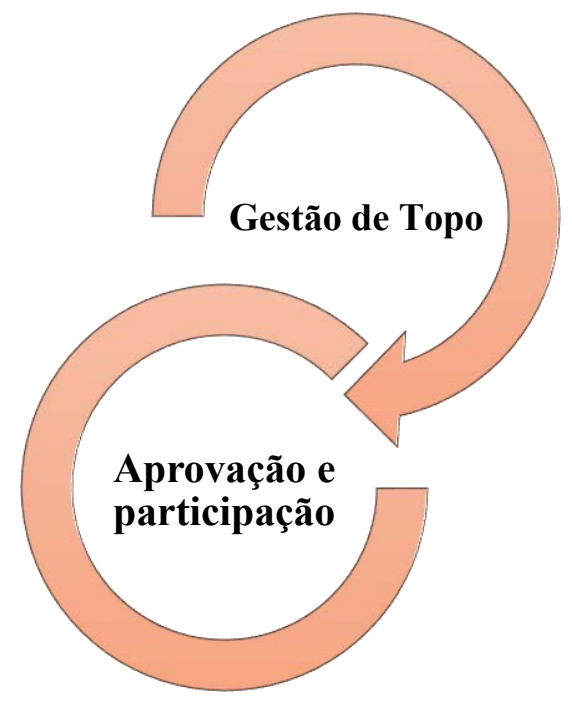

Ilustração 36 -Envolvimento da Gestão de Topo da EAN

Fonte: Elaboração Própria

As organizações que participaram no projeto foi o INA (Instituto Nacional de Administração), a EAN (Estação Agronómica Nacional) em toda a fase do projeto e o CIS/ISCTE na fase de diagnóstico tal como se apresenta na ilustração 36. 


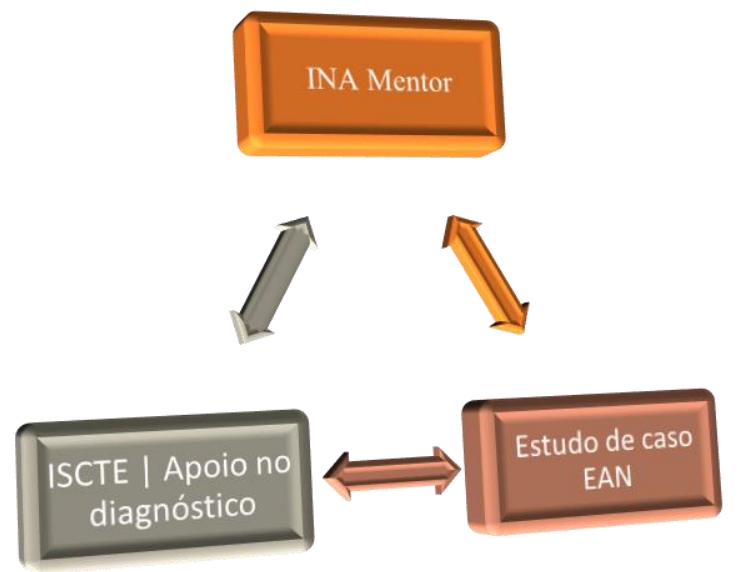

Ilustração 37 - Organizações envolvidas no projeto | O papel de cada um no projeto

Fonte: Elaboração Própria

INA: Departamento de Investigação e Desenvolvimento no âmbito do Programa sabáticas para a AP aprova e apoia o projeto na temática da HSST, recentemente alterada a nomenclatura para SST. EAN: A organização onde se realiza o estudo foi uma organização do setor público com diversidade de atividades profissionais, tinha tudo o que o projeto precisava.

ISCTE: O centro de investigação social do ISCTE (Instituto Universitário de Lisboa) colaborou aplicando instrumentos de diagnóstico da cultura de segurança e organizacional

Sem estas parcerias o projeto não teria sucesso. O INA ao aprovar um projeto nesta temática desencadeia uma grande preocupação para a implementação do sistema de Gestão de Prevenção de Riscos Laborais na AP.

Sem estas parcerias o projeto não teria sucesso. O INA ao aprovar um projeto nesta temática desencadeia uma grande preocupação para a implementação do sistema de Gestão de Prevenção de Riscos Laborais na AP. Após o envolvimento do gestor de topo da organização, fizemos uma parceria com o ISCTE, pois no CIS (Centro de Investigação Social) já existiam instrumentos de diagnóstico da Cultura de Segurança e Organizacional que seriam facilitadores para num processo de intervenção após análise dos instrumentos aplicados compatibilizaram a Cultura de Segurança e Organizacional. 
Após o diagnóstico feito através da metodologia Qualiquantitativa (Entrevistas semiestruturadas e o Inquérito ICOS (Inquérito de Cultura Organizacional e Segurança) tivemos acesso à realidade da situação e conseguimos, envolvendo a gestão de topo, percecionar qual/s os grupos mais favoráveis à mudança. Assim percecionamos quer a gestão de topo quer a gestão intermédia seria parceira no projeto assim o grupo técnico-profissional tal como podemos observar no esquema apresentado na

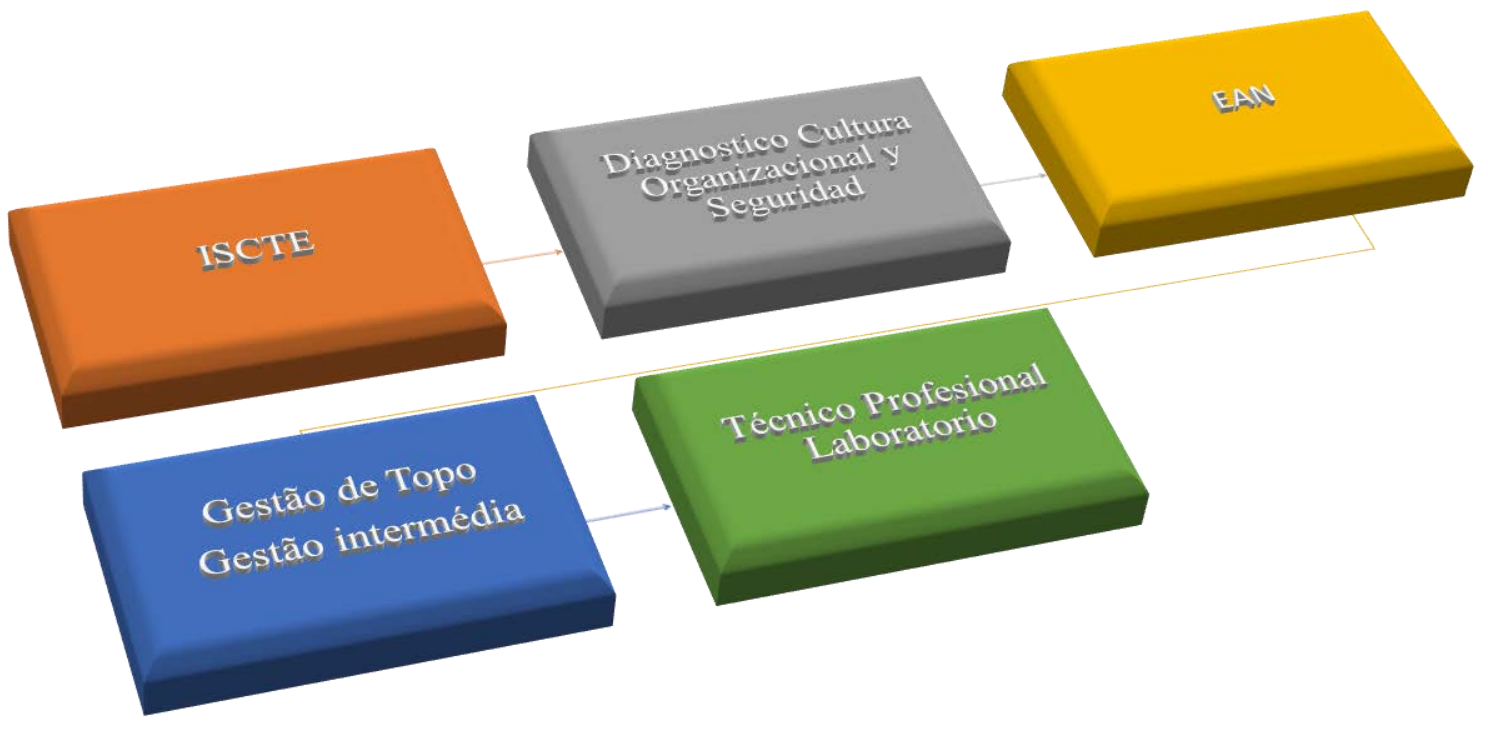

Ilustração 38 - Diagnóstico da Cultura de Segurança e saúde

Fonte: Elaboração Própria

A gestão de topo com todos os riscos que poderiam advir da aceitação de um projeto destes na sua organização, assumiu correr os riscos a favor da mudança e a relação com chefias intermédias era muito favorável. Em relação a todos os grupos profissionais, os técnicos profissionais de laboratório que mais vibraram com a temática. 


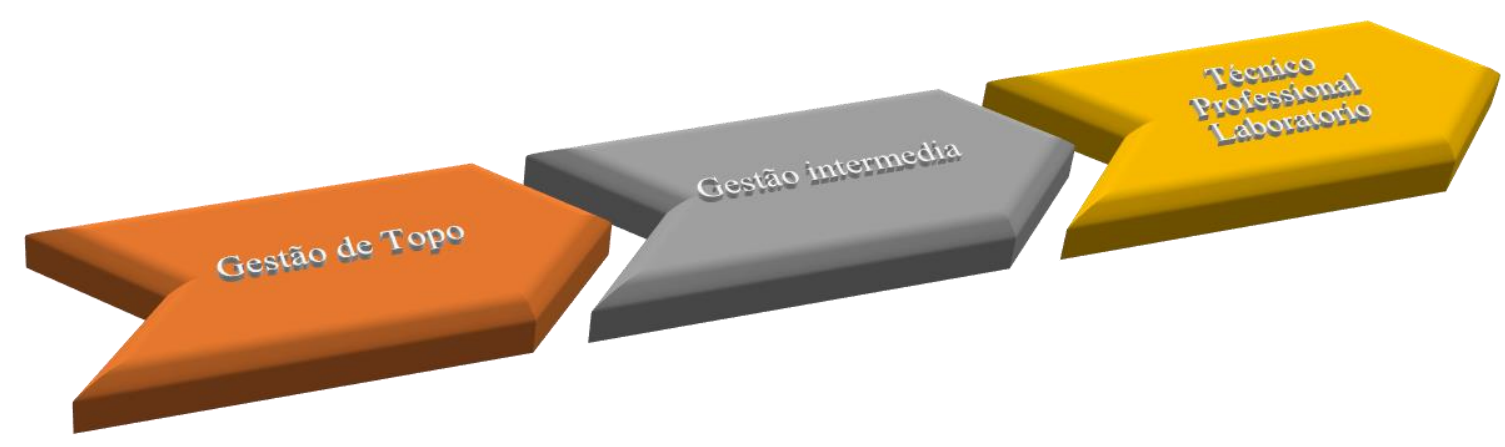

Ilustração 39 - Envolvimento e suporte da Gestão de Topo e Chefias intermédias

Fonte: Elaboração Própria

A estratégia foi envolver a Gestão de topo na mudança e o Diretor apresentar publicamente o projeto a todos os trabalhadores como projeto da organização de e para a mudança face a prevenção.

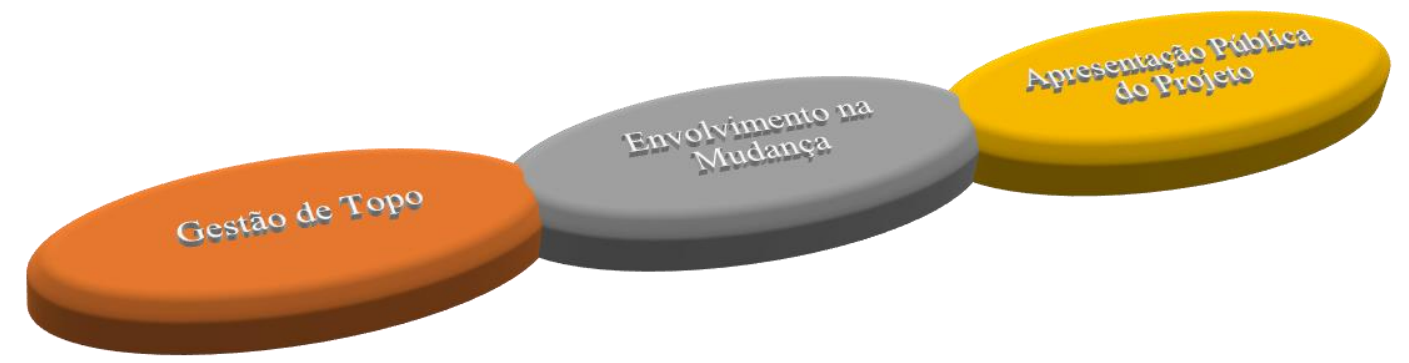

Ilustração 40 - Promoção da CoP na Organização

Fonte: Elaboração Própria

Nesta sessão de apresentação o Diretor escolheu o grupo facilitador e propôs de imediato a sua formação na temática da Prevenção de Riscos Laborais o grupo técnico-profissional de laboratório. O grupo tem acesso a muitas horas de formação e o clima criado entre os elementos é de confiança e muita entrega à temática. No segundo semestre do ano de 2004 organizaram-se como comunidade de partilha de todo o conhecimento quer formal quer informal adquirido ao longo do tempo em que se encontram quer em sala com formadores profissionais quer no terreno partilhando a sua experiência. 
Aqui foi muito importante a abertura da Gestão de Topo, valorizando as atividades do grupo e criando condições para que a comunidade se desenvolvesse e mantivesse viva, num tempo que permitisse mudanças efetivas no comportamento e atitudes dos colaboradores face à prevenção.

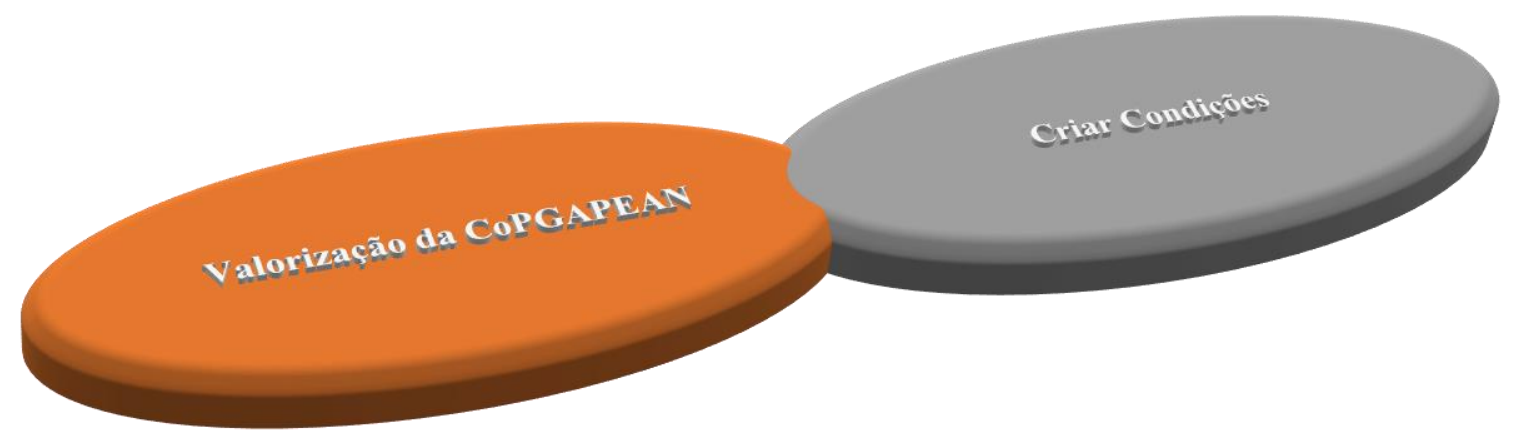

Ilustração 41 - Disponibilização de recursos para os membros da CoP

Fonte: Elaboração Própria

O líder da organização apoia todas as iniciativas desta comunidade embrionária, cedendo tempo para as atividades e apoiando as mesmas. Cedência de espaços da organização, como salas e auditórios para a realização de eventos e envolve-se na dinâmica sempre que é solicitado valorizando o esforço.

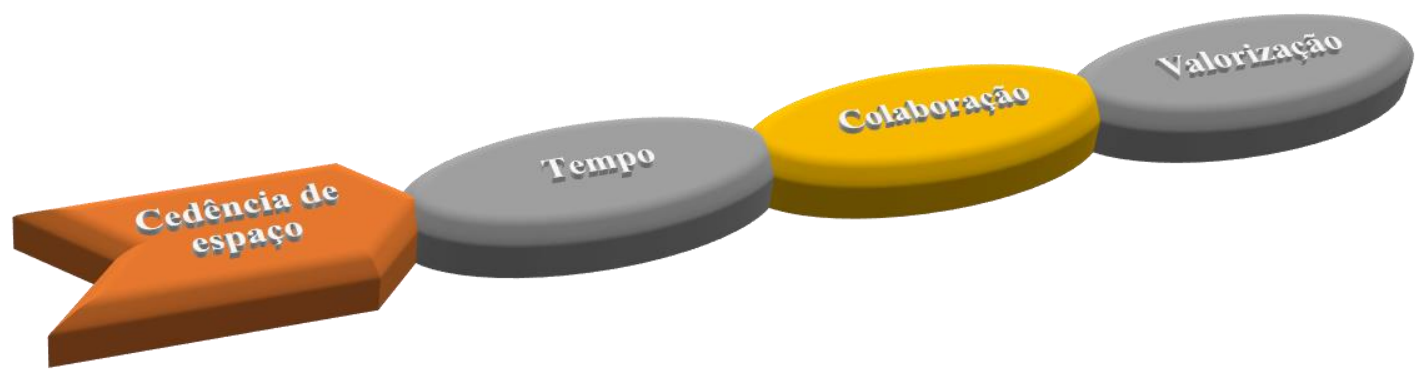

Ilustração 42 - Recursos cedidos pela Gestão de Topo à estrutura da CoP Fonte: Elaboração Própria

Eventos internos e externos: Seminários e Workshops

294

Comunidad@Buenas Prácticas de Seguridad, Salud e Calidad de Vida en el trabajo INIAV

"Factores críticos de éxito" 
A Comunidade abriu a fronteira a outras organizações do setor público e privado.

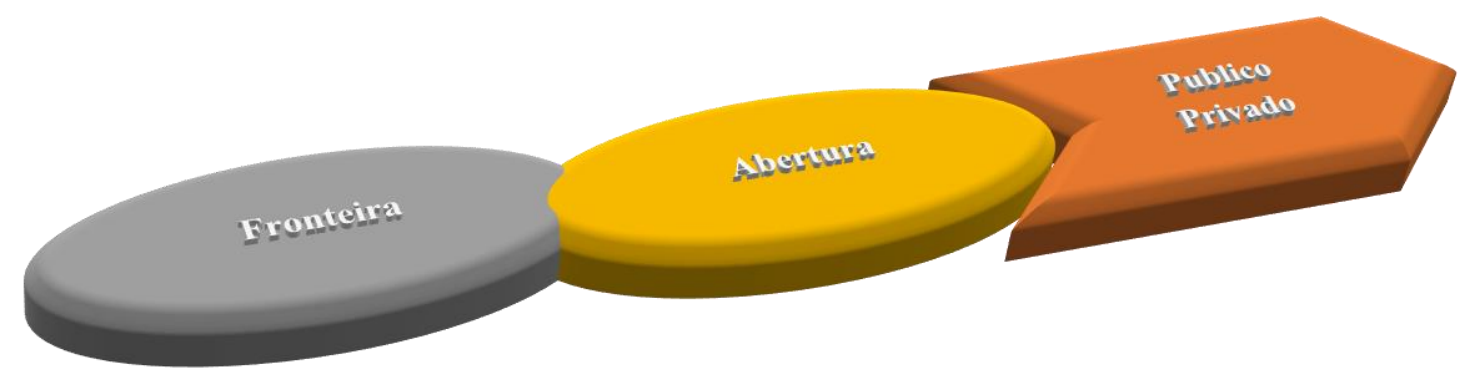

Ilustração 43 - Abertura da fronteira ao exterior

Fonte: Elaboração Própria

O "combustível" não se esgotou porque o líder alimentou sempre o grupo, incentivando e colaborando. A comunidade fica sem combustível para desempenhar o seu papel e acaba por declinar. A Coordenadora da Comunidade foi a enzima, o catalisador para que tudo acontecesse.

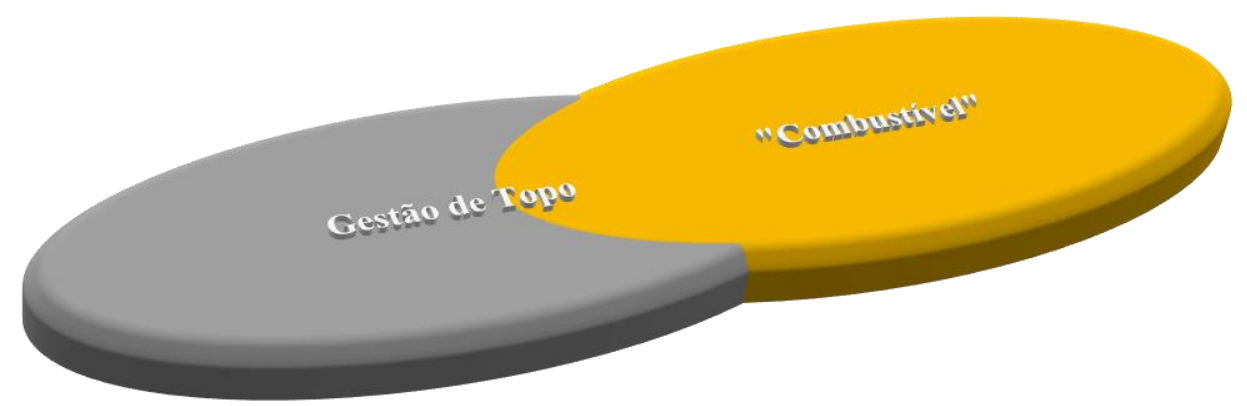

Ilustração 44 - Papel da Gestão de Topo

Fonte: Elaboração Própria 


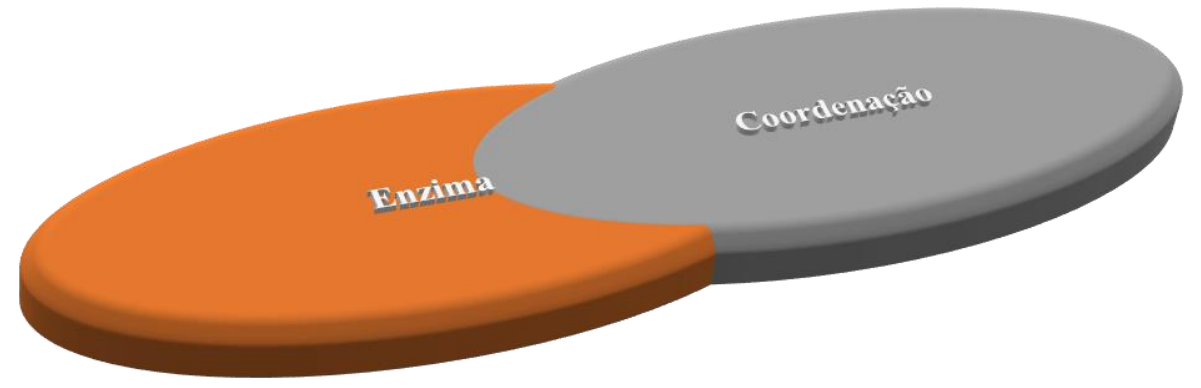

Ilustração 45 - Papel da Coordenação da CoP

Fonte: Elaboração Própria

A CoP manteve-se ativa mesmo sem o líder organizacional, mas como prova do seu agradecimento, um sentimento que os mantinha unidas e ainda lutando. E em 2008, já sem o líder organizacional a CoPGAP manteve-se ativa devido à sua coesão e em 2009 transformou-se quando tem a oportunidade de a convite do INA se transformar numa CoP virtual. Se este convite não acontecesse corria o risco de se perder.

$2004-2005-2006-2007-2008-2009-2010$

Em 2009 a CoPGAPEAN transforma-se numa Comunidade mista através da comunidade INA cria-se a Comunidade de Partilha de Boas Práticas de SST. Moderadores do grupo entraram em formação e criou-se uma nova dinâmica. Essa dinâmica manteve-se nesta plataforma até 2011. Mais uma vez as mudanças na AP, muda serviços e plataforma de suporte encerrou. A única possibilidade de continuidade era criar uma ferramenta de suporte para que esta dinâmica não se perdesse. E isso aconteceu no INRB com a criação da Wikiniav. 
Doctorado en Salud, Discapacidad, Dependencia y Bienestar

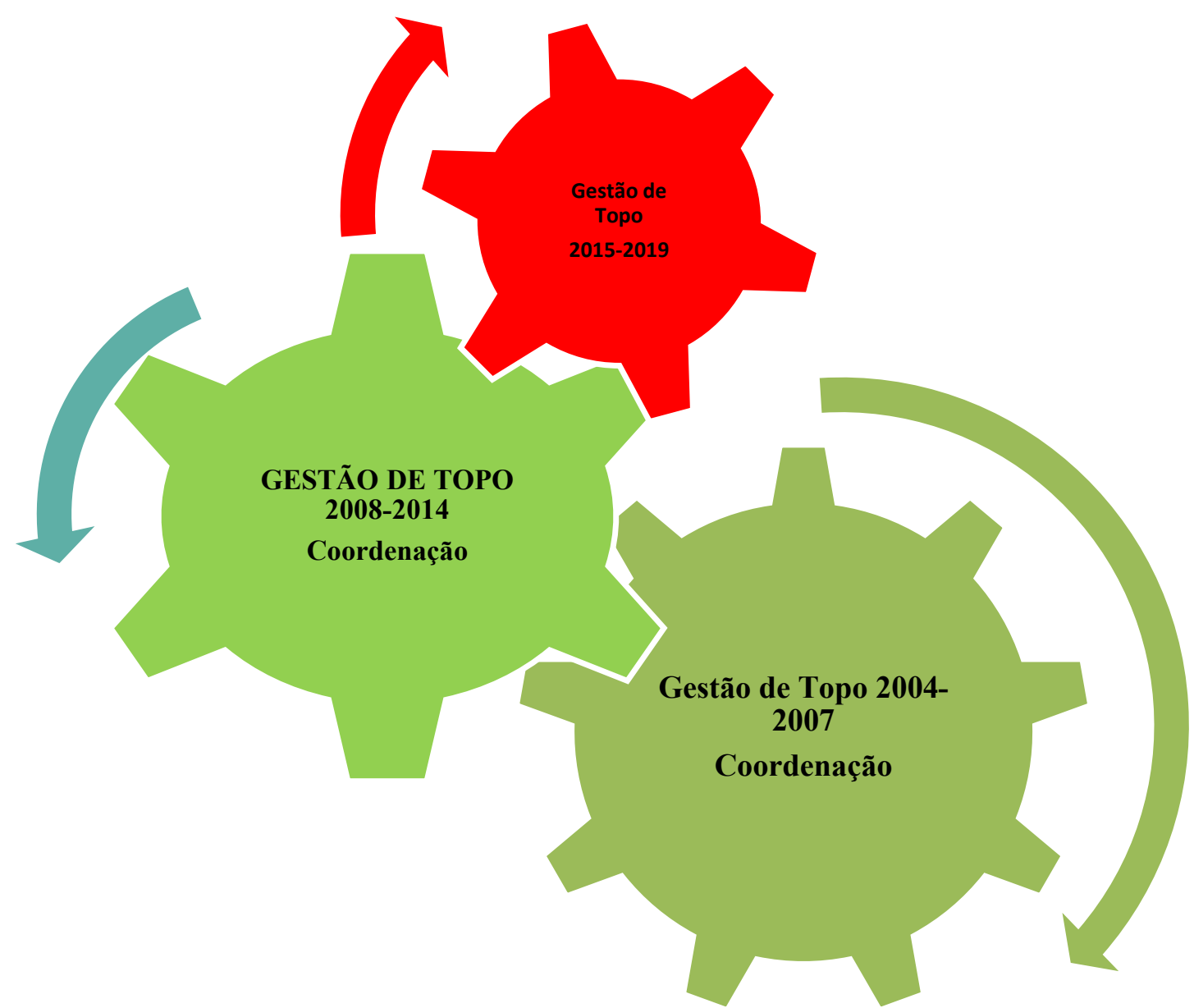

Ilustração 46 - Caminhos Estratégicos da Gestão de Topo nos diferentes períodos

Fonte: Elaboração Própria

Comunidad@Buenas Prácticas de Seguridad, Salud e Calidad de Vida en el trabajo INIAV

"Factores críticos de éxito" 
Doctorado en Salud, Discapacidad, Dependencia y Bienestar

Capítulo 5

CONCLUSÕES

298

Comunidad@Buenas Prácticas de Seguridad, Salud e Calidad de Vida en el trabajo INIAV

"Factores críticos de éxito" 


\section{Conclusões}

Como podemos avaliar por todos o desenvolvimento deste trabalho sucesso da $\mathrm{CoP}$ derivou de uma estratégia de aposta no trabalho colaborativo entre 2004 e 2014 apesar de várias mudanças Organizacionais, sendo suportada também por uma liderança forte da CoP. Apesar de no período entre 2014-2015 estarem reunidas todas as condições para a continuidade da CoP, atendendo a que em termos tecnológicos a Organização evolui, assim como em formação, estudo e dinâmica do trabalho colaborativo, era do domínio da Organização, concluímos que sem o Apoio da Gestão de Topo da Organização a dinâmica não prossegue mesmo reunindo todas as condições, contudo o fator inibidor é mais forte e acaba por vencer.

O objetivo do nosso trabalho consistiu em analisar os elementos críticos das práticas essenciais para o sucesso e sobrevivência da Comunidade de Boas Práticas SST e Qualidade de vida no trabalho e partindo do pressuposto que sem o trabalho desenvolvido pela CoP Animadores de Prevenção que formou a $1{ }^{\circ}$ Comunidade presencial de partilha de conhecimento neste domínio a CoP virtual Comunidade de Partilha de Boas Práticas SST e Qualidade de vida da WIKINIAV foi atingido.

Como Práticas indispensáveis: A Participação e envolvimento da Gestão de Topo; A Exposição dos benefícios da CoP; Estímulo da Organização para a partilha de conhecimento; Definição de métodos de interação (síncrona e assíncrona) Liberdade de expressar ideia; Ambiente que seja facilitador da partilha de conhecimento; Investimento no treino e formação dos funcionários.

Como elementos críticos para a obtenção de resultados de sucesso para a Comunidade em estudo temos: O Alinhamento e Estruturação; A Gestão de Topo da Organização; a Facilitação /Liderança da CoP; a Cultura; o Desenvolvimento; a Política; a Tecnologia. São estas as práticas essenciais que derivaram em resultados de sucesso para a CoP e esses resultados são a Confiança; o Sentimento de Pertença; a Utilidade e a Contribuição que se desenvolveram no período em que se formou a CoP embrionária - Comunidade de Prática dos Animadores de Prevenção e que se mantiveram até à sua transformação em Comunidade de Prática Mista (Virtual e Presencial) a Comunidade de Partilha de Boas Práticas SST do INIAV. 
O Período de declínio desta Comunidade coincide com uma mudança de Liderança da Organização que não valoriza o trabalho colaborativo e declina o funcionamento da plataforma WIKINIAV num momento em que estavam criadas as condições para a continuidade. A Prática de envolvimento da Gestão de topo com envolvimento e suporte, flexibilização das atividades, promoção da $\mathrm{CoP}$ e disponibilização de recursos é um fator facilitador ou será inibidor mesmo que a liderança da $\mathrm{CoP}$ seja forte e que a Cultura de partilha seja positiva se não for da vontade da Gestão da Organização a Comunidade "morre lentamente" se já estiver formada ou nunca nascerá pois não será prioridade da Gestão de Topo.

No entanto poderemos afirmar que todo o trabalho desenvolvido nos dois projetos de investigação que apostaram na partilha de conhecimento de forma colaborativa e no formato inovador das Comunidades de Prática servirão formalmente de apoio ao grande projeto para a Administração Pública Portuguesa e veremos a transformação da CoP de Partilha de boas Práticas SST numa CoP alargada a toda a AP, pois o XXI Governo Constitucional assumiu o compromisso no início de 2019 de revalorizar o trabalho em funções públicas e de fortalecer a Administração Pública, promovendo a sua eficiência e sustentabilidade e proporcionando condições de trabalho dignas para os seus profissionais. Implementar serviços de SST de referência em toda a AP, de forma colaborativa, capacitando os serviços públicos para a implementação e funcionamento de serviços de SST. Deverá ser criada uma rede colaborativa (Rede) com o objetivo principal de promover e reforçar a aplicação do regime legal de SST na Administração Pública até ao final de 2020, através da implementação do Plano de Ação.

A hipótese formulada para a nossa investigação foi validada e elegemos como Práticas Essenciais para garantir resultados de sucesso e a sobrevivência da comunidade de Boas Práticas SST e Qualidade de Vida no Trabalho alguns elementos essenciais dessas práticas: Cultura, Alinhamento e Estruturação, Apoio da Gestão de Topo da Organização, Líder /Coordenação forte, Desenvolvimento, Política e Tecnologia.

As Comunidades de Prática com Comunicação Síncrona e Assíncrona e com uma dinâmica mista, Presencial e Virtual são uma ferramenta inovadora para a partilha de conhecimento no domínio da 
Prevenção de Riscos laborais. A formação de facilitadores chave para a Administração Pública, também urge para que o trabalho na plataforma seja possível.

Como proposta de trabalho futuro e tirando partido da resolução do Conselho de Ministros propomos apoiar o projeto de Implementação serviços de SST de referência em toda a AP, de forma colaborativa; capacitando os serviços públicos e acima de tudo os responsáveis das Organizações para a implementação e funcionamento de serviços SST. 
Doctorado en Salud, Discapacidad, Dependencia y Bienestar

Capítulo 6 REFERÊNCIAS BIBLIOGRÁFICAS 
Doctorado en Salud, Discapacidad, Dependencia y Bienestar

\section{Referências Bibliográficas}

Albrecht, K. (2004). Um modelo de Inteligência Organizacional (44 ed., Vol. 3). São Paulo: HSM Management. Obtido em mai|Jun de 2004

Ardichvili, A., \& Page, V. \&. (2002). Motivation and barriers to participation in Virtual Knowledge-Sharing Communities of Practice. Proceedings of The Third European Conference on Orgabisational Knowledge, Learning and Capabilities (OKLC). Athens, Greece.

Ardichvili, A., \& Page, V. \&. (2003). Motivation and barriers to participation in virtual knowledge-sharing Communities of Practice (Vol. 7).

Ardichvili, A.; Maurer, M.; LI, W.; Wentling, T.; Stuedemann, R. (2006). Cultural influences on knowledge sharing through online communities of practice (1 ed., Vol. 10). Journal of Knowledge Management.

Bernard, M. (1999). Penser la mise a distance en formation. Paris: L'Hartmattan.

Bernard, P. (1999). La Cohésion sociale: critique d'un quasi-concept, lien Social et Politiques. RIAC.

Bolivar, A. (2000a). Los educativos como organizaciones que aprenden: promesa y realidades. Madrid: La Muralla.

Bolivar, M. (1999). Los centros educativos como organizaciones que aprenden. Madrid: La Muralla.

Bourhis, A., Dubé, L., \& Jacob, R. (2005). The Success of Virtual Communities of Practice: The Leadership Factor (1 ed., Vol. 3). The Electronic Journal of Knowledge Management.

Brown, J., \& Duguid, P. (1991). Organizational learning and communities of practice: Toward a unified view of working, learning and innovation (1 ed., Vol. 2). Organization Science.

Brown, J., \& Duguid, P. (2000). Balancing Act: How to Capture Knowledge Without Killing It (3 ed., Vol. 78 ). Harvard Business Review.

Brown, J., \& Duguid, P. (2001). Knowledge and Organization: A social practice perspective (2 ed., Vol. 12). Organization Science.

Brown, J.S.; Duguid, P. (1991). Organizational learning and communities of practice: Toward a unified view of working, learning and innovation (1 ed., Vol. 2). Organization Science.

Cabrita, M.R. (2009). Capital Intelectual e desempenho organizacional. LIDEL. doi:2009.978-972-757-618-0

303

Comunidad@Buenas Prácticas de Seguridad, Salud e Calidad de Vida en el trabajo INIAV

"Factores críticos de éxito" 
Doctorado en Salud, Discapacidad, Dependencia y Bienestar

Campos, R. L., \& Barbosa, F. V. (2001). Gestão do Conhecimento: o conhecimento como fonte de vantagem competitiva sustentável (Vol. 25). Campinas, SP Anais: ENANPAD - ANPAD.

Cargill, B. J. (2006). Leadership Issues within a Community of Practice. Australia: Swinburne University of Technology. doi:10.4018/978-1-59140-556-6.ch054

Castro, S.A.; Cazarini, E.W. (2005). Um modelo de mudança organizacional contínua através da gestão do conhecimento integrando tecnologia da informação e pessoas (4 ed., Vol. 1). Revista Gestão Industrial.

Christopoulos, T. P. (2008). A sustentação das comunidades virtuais de aprendizagem e de prática (Tese de Doutoramento ed.). São Paulo, Brasil: Escola de Administração de empresas da fundação Getúlio Vargas.

Chu, M. T., \& Khosla, R. (2009). Index evaluations and business strategies on communities of practice. (2 ed., Vol. 36). Expert Systems with Applications.

Chung, L. H. (2001). The Role of Management in Knowledge Transfer. Third Asian Pacific Interdisciplinary Research in Accounting Conference Adelaide, (pp. 15-17). South Australia.

Cohendet, P., \& Llerena, P. (2003). Routines and Incentives: The Role of Communities in the Firm. Industrial and Corporate Change. doi:10.1093/icc/12.2.271

Cox, A. (2005). What ate communities of pratice? A comparative review of four seminal works (6 ed., Vol. 31). Journal of Information Science. doi:10.1177/0165551505057016

Cruz, C. C. P.; Motta, C. L. R.; Santoro, F. M.; Elia, M. (2009). Applying reputation mechanisms in Communities of Practice: a case study (9 ed., Vol. 15). Journal of Universal Computer Science.

Curran, J. A.; Murphy, A. L.; Abidi, S. S. R.; Sinclair, D.; McGrath, P. J. (2009). Bridging the gap: knowledge seeking and sharing in a virtual community of emergency practice (3 ed., Vol. 32). Evaluation \& the Health Professions.

Cyrino, M.C.C.T.; J.G., Estevam. (2016). Mathematics Teachers' Professional Identity Development in Communities of Practice: Reifications of Proportional Reasoning Teaching. 30(54), pp. 165-187.

Davenport, T. H., \& Prusak, L. (2003). Conhecimento Empresarial: Como as organizações gerenciam o seu capital inteletual (Vol. 9). Rio de Janeiro: Editora Campus.

Davenport, Thomas H.; Prusak, Laurence. (1998). Working Knowledge: How Organizations Manage What They Know. Harvard Business School Press. doi:10.1145/348772.348775

Deci, E. L., \& Ryan, R. M. (1975). Intrinsic motivation. New York: Plenum Press. doi:10.1007/978-1-4613-4446-9 
Doctorado en Salud, Discapacidad, Dependencia y Bienestar

Dieng, R. e. (1998). Methods and Tools for Corporate Knowledge Management. KAW'98, Eleventh Workshop on Knowledge Acquisition, Modeling and Management. Canada.

Dixon, N. M. (2000). Common knowledge: How Companies Thrive by Sharing What They know. Boston: Harvard Business School Press.

Dixon, Nancy M. (2000). Common knowledge: How Companies Thrive by Sharing What They know. Boston: Harvard Business School Press.

Doak S. \& Assimakopoulos, D. (2007). How forensic scientists learn to investigate cases in practice (2 ed., Vol. 37). R\&D Management.

Dooley, L. M. (2002). Case Study Research and Theory Building (Vol. 4). Advances in Developing in Human Resources.

Dubé, L., \& Bourhis, A. \&. (2006). Towards a typology of virtual communities of practice (Vol. 1). Interdisciplinary Journal of Information, knowledge, and management.

Dudley, R.G. (2004). The Dynamic structure of social capital: how interpersonal connections create communitywide benefits. Conference: the International Conference of the System Dynamics Society.

Farooq, Muhammad et al. (2008). Seed pretreatment with hydrogen peroxide improves heat tolerance in maize at germination and seedling growth stages (Vol. 36). Austrália: Seed Science and Technology.

Ferraz, I., \& Dornelas, J. (Maio/agosto de 2017). Repertório compartilhado de recursos em comunidades virtuais de prática: um estudo dos mecanismos de interação, organização e controle em (C RIGS. 6(2).

Flick, U. (2004). Introducción a la investigación cualitativa. Madrid - Morata.

Flor, C. (2015). Gestión del conocimiento y comunidades de práctica: el camino de la innovación por la interacción "La Comunidad de Buenas Prácticas de la SST del INIAV. Léon: Universidad de Léon.

Fragoso, A. (2004). El estudio de casos en la investigación de educación de personas adultas. Valencia: Nau Llibres.

Fuller, A., Hodkinson, P., \& Unwin, L. (2005). Learning as peripheral participation in communities of practice: a reassessment of key concepts in workplace learning (1 ed., Vol. 31). British Educational Research Journal.

Gairin, J. S. (2000). Cambio de Cultura y Organizaciones que aprenden (Vol. 27). Educar.

Gamble, P. R. \& Blackwell, J. (2001). Knowledge Management - A State of the Art Guide First edition. London: British Library.

305

Comunidad@Buenas Prácticas de Seguridad, Salud e Calidad de Vida en el trabajo INIAV

"Factores críticos de éxito" 
Gonçalo, C. R. (2005). Barreiras Cognitivas: uma perspectiva decisiva para promover estratégias de conhecimento no desempenho da atividade organizacional da atividade organizacional (2 ed., Vol. 8). Produto e Produção. Obtido em junho de 2005

Gongla, P., \& Rizzuto, C. (2001). Evolving communities of practice: IBM Global Service (4 ed., Vol. 40). IBM Systems Journal.

Hall, H. (2001b). Social Exchange for knowledge exchange. Paper presented at the managing knowledge: Conversations and critiques. (pp. 10-11). Edinburg: University of Leicester Management Centre.

Hall, H., \& Graham, D. (2004). Creation and recreation: motivating collaboration to generate knowledge capital in online communities (Vol. 24). International Journal of Information Management .

Hamel, Gary. (jan/ Fev de 2001). A Era da Revolução. Obtido em 2016

Hansen, M. T.; Nohria, N.; Tierney, T. (1999). What's your strategy for managing knowledge? (2 ed., Vol. 77).

Henri, F., \& Ludgren, K. (2000). L'apprentissage collaborative: essai de definition. Telé-université.

Hernandes, C. A., \& Fresneda, P. S. (2002). Main critical success factors for the establishment and operation of virtula communities of practice. Brasilia, Brasil: Universidade Católica de Brasília (UCB) - Knowledge and it Management graduate program.

Hill, M. M.; Hill, A. (2002). Investigação por questionário (2 ed.). Edições Sílabo.

Ipiranga, A.S.R.; Menezes, R.B.; Matos, J.L.L.; Maia, G.L.L. (2005). Aprendizagem como ato de participação: a história de uma comunidade de prática (4 ed., Vol. 3). Cad. EBAPE.BR [online].

Janke, K. K., Seaba, H. H., Welage, L. S., Scott, S. A., Rabi, S. M., Kelley, K. A., \& Mason, H. L. (2012). Building a multi-institutional community of practice to foster assessment (4 ed., Vol. 76). American Journal Pharmaceutical Education.

Kelley, H. H., \& Thibaut, J. (1978). Interpersonal relations: A theory of interdependence. New York: Wiley.

Kiesler, S. \& Cummings, J. N. (2002). What do we know about promximity and distance in work groups? A legacy of research. In P. Hinds, \& S. Kiesler (eds), Distributed work (Cambridge, MA: MIT Press), 57-80.

Kim, S., \& Lee, H. (2005). Employee Knowledge Sharing Capabilities in Public \& Private Organizations: Does Organizational Context Matter? Proceedings of 38th Hawaii International Conference on System Sciences.

Kimble, C. H. (2004). Communities of practice: Going one step too far? Em P. 9. I'AIM (Ed.). Evry - France: Association Infromation and Management (AIM). Obtido em 10 de November de 2018

306

Comunidad@Buenas Prácticas de Seguridad, Salud e Calidad de Vida en el trabajo INIAV

"Factores críticos de éxito" 
Kranendonk, R.P. e Kersten, P.H. (2007). Midlife communities of practice: Experiences and alignment (7 ed., Vol. 50). American Behavioral Scientist.

Krogh, G. V. \& Grand, S. (2002). From economic theory toward a knowledge-based theory of the firm. New York: In Choo, C. W. e Bontis, N. (Eds.) The Strategic Management of Intellectual Capital and Organizational Knowledge: Oxford University Press.

Kuan, Y.; Gonzales, R.; Olson, S. (2003). Effects of information presentation on perceived reputation in virtual communities: A controlled experiment. TWENTY FOURTH INTERNATIONAL CONFERENCE ON INFORMATION SYSTEMS.

Lahti, S., \& Moilanen, R. (2004). Sharing of the tacit Knowledge - a chanllenge of managing young and aging employees. Finlandia: School of Business and Economics .

Lave, J. (2004). Palestra de encerramento. Organizational Knowledge, Learning, and Capabilities. Austria: The fifth European.

Lave, J., \& Wenger, E. (1991). Situated Learning - Legitimate Peripherical Participation (1º ed.). New York: Cambridge University Press.

Levan, S. K. (2004). Travail Collaboratif sur Internet. Concepts, méthodes et pratiques des plateaux projet. Pais: Vuilbert.

Lévy, Pierre. (1998). A inteligência coletiva. São Paulo: Loyola.

Loyarte, E.; Rivera, O. (2007). Communities of practice: a model for their cultivation (3 ed., Vol. 11). Journal of Knowledge Management.

Macintosh, A. (1997). Knowledge asset management (Vol. 20). Alring.

Majewski, G.; Usoro, A.; Khan, I. (2011). Knowledge sharing in immersive virtual communities of practice (1 ed., Vol. 41). VINE.

McDermott, R. (1999). Nurturing three dimensional communities of practice: How to get the most out of human networks. Knowledge Management Review Fall Edition.

McDermott, R. (2000). Critical success factors in building communities of practice. Knowledge Management Review (2 ed., Vol. 3). http://www.mcdermottconsulting.com/images/Articles/SME20-2010 20Critica20Success 20Factors.pdf> Acesso em6/02/2014.

McDermott, R. (2000). Desenvolvimento de comunidades como estágio natural. www.melcrum.com. 
Doctorado en Salud, Discapacidad, Dependencia y Bienestar

MCelroy, M. (2003). The New Knowledge Management. Complexity, Learning, and Sustainable Innovation. Butterworth Heinemann \& Knowledge Management Consortium International Press.

McKeen, J. D., \& Smith, H. A. (2002). New Developments in Practice II: Enterprise application integration, Communications of the assocition for Information Systems (31 ed., Vol. 8).

Meeuwesen, B., \& Berends, H. (2007). Creating communities of practices to manage technological knowledge: An evaluation study at Rolls-Royce. European Journal of Innovation Management. doi:10.1108/14601060710776743

Mendes, L.; Urbina, L.M.S. (2015). Análise sobre a Produção Acadêmica Brasileira em Comunidades de Prática (3 ed., Vol. 19). Curitiba: Rev. adm. contemp.

Morales, A., \& Macías, R. (2013). Caracterización de una comunidad de práctica orientada al uso de la matemática en la enseñanza de la ingeniería (62 ed., Vol. 13). Innovación Educativa.

Moreno, A. (2001). Enhancing knowledge exchange through Communities of Practice at the Inter-American Development Bank (8 ed., Vol. 53). Aslib Proceedings.

Nahapiet, J.; Ghoshal, S. (1998). Social Capital, Intellectual Capital, and the Organizational Advantage (2 ed., Vol. 23). The Academy of Management Review.

National Library for Health - NHS. (2005). ABC of knowledge management. Obtido em 28 de julho de 2012, de $<$ https://www.evidence.nhs.uk/search?q=ABC+of+Knowledge+Management $>$

Neves, A. (8 de novembro de 2018). Enttrevista concedida a 2001 de Wenger. Portal KMOL. Obtido de $:<$ http://www.kmol.online.pt/pessoas/WengerE/entrev_p.html

Nichani, M. (2001). Communities of practice at the core 4th October. http://www.elearningpost.com/elthemes/kmcore.asp. Obtido em 02 de maio de 2016

Nickols, F. (2000). Communities of Practice: Supporting Technologies. http://home.att.net/ discon/KM/CoPTechnology.htm>. Obtido em jan de 2017

Olivieri, L. e. (2002). O que são redes. Obtido de http://www.rits.org.br/redes_teste/rd_oqredes.cfm. Acesso em: 07 out. 2017

Orlikowski, W. J. (2002). Knowing in practice: Enacting a collective capability in distributed organizing (3 ed.,

Pemberton, J.; Mavin, S.; Stalker, B. (2007). Scratching beneath the surface of communities of (mal) practice (1 ed., Vol. 14). The Learning Organization.

308

Comunidad@Buenas Prácticas de Seguridad, Salud e Calidad de Vida en el trabajo INIAV

"Factores críticos de éxito" 
Doctorado en Salud, Discapacidad, Dependencia y Bienestar

Perrott, B. (2007). A strategic risk approach to knowledge management (Vol. 50). Business Horizons. doi:10.1016/j.bushor.2007.08.002

Preece, J., \& Maloney-Krichmar, D. (2003). Draft - Online Communities: Focusing on sociability and usability. (A. (. In J. Jacko and A. Sears, Ed.) NJ: Handbook of Human-Computer Interation, Lawrense Erlbaum Associates Inc. Publishers. Mahwah.

Preece, Jenny. (2000). Online Communities: Designing Usability, Supporting Sociability (9 ed., Vol. 100). Industrial Management \& Data Systems.

Rebelo, S., Waskow, L. B., Nunes, C. S., Selig, P. M., \& Nakayama, M. K. (2012). Barries to Implementation of Knowledge Management in Public Organizations. São Paulo: Anais do International Conference on Information Systems and Technology Management (CD).

Riege, A. (2005). Three-dozen knowledge-sharing barriers managers must consider (3 ed., Vol. 9). Journal of Knowledge Management.

Robbins, S. P. (2004). Fundamentos do comportamento organizacional (Vol. 7). São Paulo: Pearson Prentice Hall.

Roberts, Joanne. (2006). Limits to Communities of Practice. Journal of Management Studies.

Rodríguez, G. G.; Flores, J. G.; Jiménez, E. G. (1999). Metodología de la investigación. Málaga: Ediciones Aljibe.

Rosa Neto, J. R.; Vilanova, L.O. et al. (2006). Lições Aprendidas em Projetos de E\&P. II Seminário Internacional de Gerenciamento de Projetos da Petrobras. Salvador da Baia. Obtido em 05 a 07 de dezembro de 2006

Saint-Onge, H., \& Wallace, D. (2003). Leveraging Communities of Practice for Strategic Advantage. USA: Butterworth Heinemann.

Santos, N. (2005). Gestão do conhecimento organizacional. Florianóplis: Programa de Pós-Graduação em Engenharia e Gestão do Conhecimento.

Scarso, E.; Bolisani, E. (2008). Communities of practice as structures for managing knowledge in networked corporations (3 ed., Vol. 19). Journal of Manufacturing Technology Management.

Scarso, E.; Bolisani, E. (2008). The place of communities of practice in knowledge management studies: A critical review. Journal of Knowledge Management.

Schenkel, A e Teigland, R. (2008). Improved organizational performance through communities of practice (1 ed., Vol. 12). Journal of Knowlegde Management. 
Serrano, A.; Fialho, C. (2003). Gestão do conhecimento: O novo paradigma das organizações. Lisboa: FCA Editora Informática.

Sharratt, M., \& Usoro, A. (2003). Understanding Knowledge-Sharing in Online Communities of Practice (2 ed., Vol. 1). Electronic Journal on Knowledge Management.

Sherbino, J., Snell, L., Dath, D., Dojeiji, S., Abbott, C., \& Frank, J. R. (2010). A national clinician educator program: a model of an effective community of practice. doi:DOI: 10.3402/meo.v15i0.5356

Silva, H.F.N.; Arboit, A.E.; Garcia, A.K.; Rigoni, C.F. (2012). As contribuições relativas ao uso de eventos/fóruns para constituição de comunidades de práticas e expressão da inteligência coletiva: o caso da Bibliocontas (3 ed., Vol. 17). Perspectivas em Ciência da Informação.

Silva, Sílvia; Tavares, Susana. (2006). Avaliação da Cultura de Segurança e Bem Estar na EAN.

Smits, M., \& Moor, A. (2004). Effective Knowledge Management in Knowledge-Intensive Organizations. Proc. of the Fifth European Conference on Organizational Knowledge, Learning and Capabilities. Innsbruck, Austria.

Snyder, W. M.; Cummings, T. G. (1998). Organization Learning Disorders: Conceptual Model and Intervention Hypotheses (7 ed., Vol. 51). Boston, Massachusetts: Social Capital.

Snyder, W., \& Cummings, T. (1998). Organizational Learning Disorders: Conceptual Model and Intervenvention Hypotheses (7 ed., Vol. 51). Human Relations.

Souza, E. G., \& Nokata, L. E. (2011). Comunidade de práctica - Una enovation em la gestion dele conocimiento. Journal of Technology management \& Inovation.

Stake, R. E. (1999). Investigación con estudio de casos. Madrid: Morata.

Tarmizi, \& Zigurs. (2006). Virtual Technologies: Concepts, Methodologies, Tools, and Applications.

Taurisson, A. (2003). Reflexion générale. Le sens, l'inginierei et la mise en place des communautés virtualles d'apprentissage. In: Taurisson A. Sentini (Eds.), Pedagogies.net. L'essor des commuautés visrtualles d'apprendissage. Saint-Foy: Press de L'Université du Québec .

Tavares, W., \& Paula, A. (2015). Movimentos Sociais em Redes Sociais Virtuais: Possibilidades de Organização de Ações Coletivas no Ciberespaço. 4, pp. 213-234.

Teixeira Filho, Jayme. (2002). Comunidades Virtuais: Como As Comunidades de Práticas na Internet estão mudando os negócios. Rio de Janeiro: Ed. Senac.

310

Comunidad@Buenas Prácticas de Seguridad, Salud e Calidad de Vida en el trabajo INIAV

"Factores críticos de éxito" 
Teixeira, F. (2002). Condução de eventos presenciais.

Terra, J. C. C. (2000). Gestão do Conhecimento - O grande desafio organizacional. São Paulo: Negócio Editora.

Terra, J. C. C.; Gordon, C. (2002). Portais corporativos: a revolução na gestão do conhecimento. São Paulo: Negócio Editora.

Thomas, A. U.; Fried, G. P.; Johnson, P.; Stilwell, B. J. (2013). Sharing best practices through online communities of practice: a case study (Vol. 8). Human Resources for Health.

Torsvik, Gaute. (november de 2000). Social capital an economic development: a Plea for the mechanisms. 12, pp. 451-476.

Tucker, V. (2012). Facebooking in distance education constructing virtual communities of practice. Proceedings of TCC Worldwide Online Conference, (pp. 62-80). Hawaii.

Vasconcelos, J. et Al. (2005). Knowledge Management in Non-Governamental Organizations: A partnership for the future. International Conference on enterprise information systems. Miami-USA: USA Miami.

Vásquez. R. R., \&. A. (2003). Introducción a los estudios de casos. Los primeros contactos con la investigación etnográfica. Málaga: Ediciones Aljibe.

Von Krogh, Georg. (1998). Care in Knowledge Creation (3 ed., Vol. 40). Research article. doi:https://doi.org/10.2307\%2F41165947

Von Wartburg, I., Rost, K., \& Teichert, T. (2006). The creation of social and intellectual capital in virtual communities of practice: shaping social structure in virtual communities of practice (3 ed., Vol. 1). International Journal of Learning and Change.

Wang, Y. et al. (2007). Exploring the determinants of knowledge adoption in virtual communities: A social influence perspective.

Wellman, B., Salaff, J., Dimitrova, D., Garton, L., Gulia, M., \& Haythornthwaite, C. (2000). Computer Networks as Social Networks: Collaborative Work, Telework, and Virtual Community. (E. L. Lesser, M. A. Fontaine, \& J. A. Slusher, Edits.) Knowledge and Communities. Butterworth-Heinemann - Lesser.

Wenger, E. (1998a). Communities of Practice: Learning, Meaning and Identity. New York: Cambridge University Press.

Wenger, E. (2004). Knowledge management as a doughnut: Shaping your knowledge strategy through communities of practice (3 ed., Vol. 68). Ivey business journal.

311

Comunidad@Buenas Prácticas de Seguridad, Salud e Calidad de Vida en el trabajo INIAV

"Factores críticos de éxito" 
Doctorado en Salud, Discapacidad, Dependencia y Bienestar

Wenger, E. (2010). Communities Of Practice and social learning systems: the career of a concept. London: Uk, Springer.

Wenger, E., \& Snyder. (2001). California: Organically Grow.

Wenger, E., Mcdermott, R., \& Sny, W. M. (2002a). Cultivating communities of practice: a guide to managing knowledge. Boston: Harvard Business School Press.

Wenger, E.; Snyder, W. M. (2001). Communities of Practice: The Organizational Frontier . Boston: Harvard Business Review.

Wenger, Etienne. (2000a). Communities of practice and social learning systems (2 ed., Vol. 7). Organization.

Wenger, Etienne. (2000b). Communities of practice: The key to knowledge strategy. USA: In Heinemann, B. (Ed.) Knowledge and Communities.

Wenger, Etienne. (2004). Knowledge management as a doughnut: Shaping your knowledge strategy through communities of practice (3 ed., Vol. 68). Ivey business journal.

Wenger, E.; Trayner, B.; Laat, M. (2011). Promoting and assessing value creation in communities and networks: a conceptual framework. http://www.open.ou.nl/rslmlt/Wenger_Trayner_DeLaat_Value_creation.pdf. Obtido em 22 de junho de 2016

Yin, R. (1993). Applications of case study research. Beverely Hills,CA: Sage Publishing.

Yin, R.K. (2005). Estudo de caso: planejamento e métodos (3 ed.). Porto Alegre: Bookman.

Zboralski, K. (2009). Antecedents of knowledge sharing in communities of practice (3 ed., Vol. 13). Journal of Knowledge Management.

Zboralski, K.; Gemuenden, H. G. \& Letti, C. (2004). A members perspective on the sucess of communities of practice - Preliminary empirical results. Proceedings of 5th European conference on Organizational knowledge, learning, and capabilities, OKLC, (pp. 2-5). Innsbruck, Austria.

Zboralski, K.; Gemuenden, H. G. \& Letti, C. (2004). A members perspective on the sucess of communities of practice - Preliminary empirical results. Proceedings of 5th European conference on Organizational knowledge, learning, and capabilities, OKLC, (pp. 2-5). Innsbruck, Austria.

Zhang, W. \& Watts, S. (2008). Online commmunities of practice: A case study. Journal of Knowledge Management, $12,55-71$.

312

Comunidad@Buenas Prácticas de Seguridad, Salud e Calidad de Vida en el trabajo INIAV

"Factores críticos de éxito" 


\section{UNIVERSIDAD DE LEÓN \\ DEPARTAMIENTO DE ENFERMERIA Y FISIOTERAPIA}

Programa de Doctorado titulado "Salud, Discapacidad, Dependencia y Bienestar"

Comunidad@Buenas Prácticas de Seguridad, Salud e Calidad de Vida en el trabajo INIAV

"Factores críticos de éxito"

\section{Comunidade@boas práticas segurança, saúde e qualidade de vida no trabalho INIAV}

"Fatores críticos de sucesso"

\section{Élia Cristina de Sousa Figueiredo}

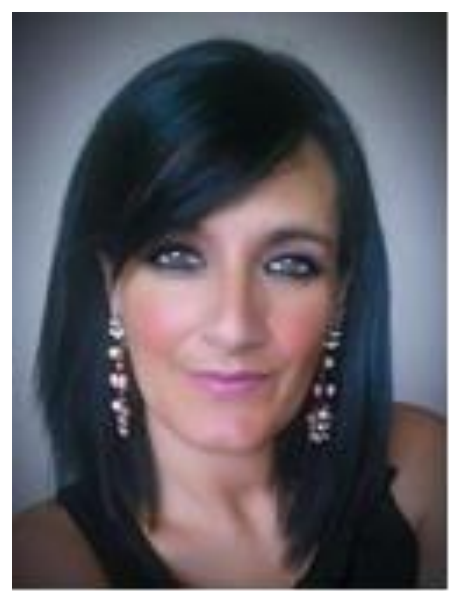

Tags: Comunidades de Prática; CoP; Práticas essenciais; Práticas inibidoras; Trabalho colaborativo; SST; Partilha de conhecimento; CoPV

Contatos:

http://wiki.iniav.pt/

Email: esousf00@estudiantes.unileon.es

Mobile: 0351925229960

Mobile: 0351987291000

Universidad de Léon

Campus de Vegazana $\mathrm{S} / \mathrm{N}$

24071 Léon 


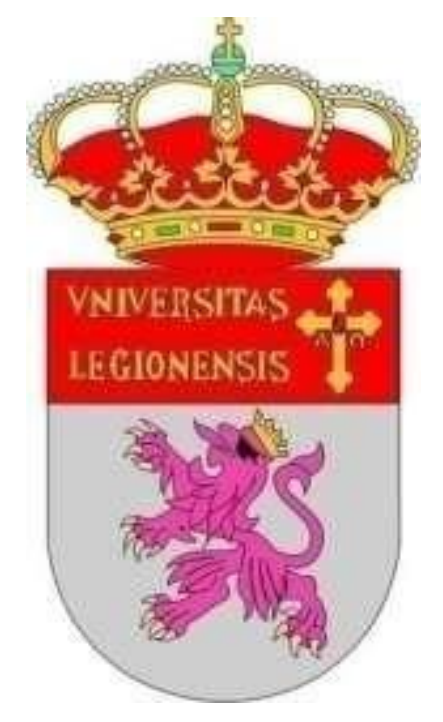

UNIVERSIDAD DE LEÓN
Comunidad@ Buenas Prácticas de Seguridad, Salud e Calidad de Vida en el trabajo INIAV
"Factores críticos de éxito"

Programa de Doctorado titulado "Salud Discapacidad, Dependencia y Bienestar"

\section{ANEXOS}

Tutor: Dr. D. Jesús Angel Seco Calvo

Directores: Dr. D. Jesús Angel Seco Calvo

Doutora Casimira Flor da Costa Santos

Dr. D. Óscar Seco Calvo

Élia Cristina de Sousa Figueiredo

León, 2019 


\section{Anexos grupo A \\ $\checkmark$ Instrumentos de Avaliação}

\section{Anexos grupo B}

$\checkmark$ Análise de conteúdo dos instrumentos aplicados 
Doctorado en Salud, Discapacidad, Dependencia y Bienestar

A- Instrumentos de avaliação

Comunidad@ Buenas Prácticas de Seguridad, Salud e Calidad de Vida en el trabajo INIAV

“Factores críticos de éxito" 

(CoPGAPEAN)

\section{Introdução}

Atendendo a que Coordenadora da Comunidade de Prática dos Animadores de Prevenção, acompanhou e foi ativa em todo o estudo desde 2004 até 2019, entendemos que reunia o know how necessário para o desenvolvimento da nossa entrevista semiestrurada.

\section{Dados de identificação:}

Nome: Casimira Flor da Costa Santos

Função: Coordenadora da CoPGAPEAN

Tempo de duração: $1 \mathrm{~h}$

\section{Guião de Entrevista}

1. Quando nasceu a CoPGAPEAN?

a) Como?

b) Onde?

c) Porquê?

2. Após escolhida a organização para o estudo o que aconteceu?

3. Quais foram as organizações que deram apoio ao projeto?

4. INA | EAN | ISCTE qual foi o papel de cada um deles?

5. No seu entender sem esta parceria o projeto teria dificuldade em avançar?

$$
\text { AI }-\mathbf{1 / 3}
$$


6. Como se desenrolou o projeto que teve início em 2004?

7. Foi importante terem a perceção que a Gestão de Topo, Gestão intermédia e Técnicos Profissionais num grupo diverso de profissionais estavam envolvidos?

8. Escolhidos os elementos cruciais no processo de mudança, qual foi a vossa estratégia de intervenção?

9. Em 2004, o grupo de técnico-profissionais de laboratório inicia a sua formação, como nasce a comunidade presencial?

10. Uma questão que levanto, está relacionada com o papel da Gestão de Topo, pois as CoP devem ser deixadas soltas e há o risco de a gestão poder interferir na sua dinâmica. O que aconteceu neste caso?

11. Essa dinâmica continuou a ter o apoio do líder da organização?

12. Que tipo de eventos criaram?

13. A comunidade abriu a sua fronteira?

14. Na sua opinião foi importante o papel do líder da Organização, na manutenção da CoPGAPEAN?

15. Mas as CoP têm um tempo de vida. Ao fim de um tempo correm o risco de ficar inativas ou até mesmo desparecer?

16. Após termos falado no líder da organização, também percecionamos que o líder da comunidade teve grande papel na dinâmica do grupo, confirma?

17. Sentiu que a CoPGAPEAN corria o risco de se perder ou de se transformar?

18. Em 2009 - 2010 começa uma dinâmica virtual?

19. A CoP presencial transformou-se na CoP virtual?

20. Essa dinâmica manteve-se?

21. O que aconteceu depois?

$$
\text { AI }-2 / 3
$$


Doctorado en Salud, Discapacidad, Dependencia y Bienestar

22. No seu entender, quais os fatores críticos de sucesso desta CoPGAPEAN?

23. O que foi mais valorizado? As interações síncronas ou assíncronas?

24. Quais foram os maiores desafios da CoPGAPEAN?

25. No seu entender qual(is) as vantagens das CoP?

\section{Agradeço desde já a sua disponibilidade e vontade em participação nesta entrevista}




\section{ANEXO AII - Entrevista semiestruturada à Comunidade embrionária (CoPGAPEAN)}

\section{Introdução}

Foram entrevistados 5 elementos que correspondeu a uma amostra de $30 \%$ da comunidade embrionária.

\section{Dados de identificação:}

Função: 30\% CoPGAPEAN

Tempo de duração: 40 minutos

\section{Guião de Entrevista}

1. Pertenceram a uma comunidade embrionária nesta organização. Qual foi o domínio?

2. O que para vós foi mais importante para que a comunidade se formasse?

3. No vosso entender qual foi a grande preocupação da liderança organizacional que a obrigou a repensar a dinâmica da gestão de conhecimento?

4. Para que os membros se juntassem para formar a CoP o que foi necessário?

5. Como foi legitimada a participação dos membros?

6. Como foi reconhecida?

7. Que tipo de suporte foi dado à CoP pela organização?

8. Quais foram os lugares onde se deu a partilha de conhecimento?

9. Para além do incentivo dado pela gestão da organização, o que se destaca no sucesso desta CoP?

10. Lembra-se de como se desenvolveu a fase inicial desta CoP?

11. E a etapa seguinte como foi o seu crescimento?

12. Quando atingiu a fase de maturidade?

13. Como foi a fase de sustentação?

14. Como foi a fase de transformação? 


\section{ANEXO AIII- Tipologia dos documentos avaliados da CoPGAPEAN}

$\checkmark \quad$ Documentos produzidos em eventos internos

$\checkmark \quad$ Documentos produzidos para eventos externos

$\checkmark \quad$ Análise de eventos presenciais CoPGAP

$\checkmark \quad$ Fichas técnicas elaboradas pela CoPGAP

$\checkmark \quad$ Guias de boas práticas elaborados pela CoPGAP

$\checkmark \quad$ Brochuras elaboradas pela CoPGAP

$\checkmark \quad$ Cartazes elaborados pela CoPGAP

\section{ANEXO AIII - Guião de avaliação das mensagens elaboradas pela CoPGAP}

1. Quais os temas abordados nas mensagens divulgadas pelo GAP?

2. Qual o formato das mensagens?

3. Qual o tipo de interações?

\section{ANEXO AIII - Guião de avaliação das interações da comunidade CoPGAPEAN}
$\checkmark \quad$ Que tipos de interações
$\checkmark \quad$ Documentos observados 


\section{ANEXO AIV Questões do inquérito surveys 2-8}

Este questionário foi aplicado por (For,C.2015)

Link: http://surveys.inrb.pt/index.php?sid=15799

\section{Caraterização da amostra}

$\checkmark$ Por sexo;

$\checkmark$ Categoria profissional e função

\section{Objetivo geral}

Demonstrar a importância das comunidades de prática como recurso do conhecimento produzido pelo INIAV e com o propósito de agilizar a comunicação entre elementos das equipas de trabalho inter e intraorganizacional, partilhando informações e também na resolução de problemas e melhorando ambientes de trabalho.

\section{Objetivos específicos:}

$\checkmark$ Verificar os instrumentos mais utilizados na troca de informação;

$\checkmark$ Analisar quais os fatores que favorecem a partilha de informação;

Para a realização deste trabalho contamos com a sua colaboração, de todas as equipas de investigação do INIAV, realçamos que as respostas são anónimas e os dados foram tratados de forma totalmente confidencial.

\section{Inquérito}

2. Quando necessita de uma informação ligada à sua área de trabalho / especialização de que forma e onde procura encontrar o conhecimento necessário para resolver o problema? Ordene as respostas selecionando os itens da lista à esquerda de acordo com o seu grau de importância/ relevância, sabendo que o item 1 corresponde ao que maior importância para si representa e o item 6 , aquele que menor importância tem

Clique num item na lista à esquerda, começando com o item de maior classificação, e percorrendo os itens até ao menor. 


\begin{tabular}{|l|}
\hline As suas escolhas: \\
\hline Conversa com pessoas de sua equipa \\
\hline Conversa com pessoas de outras Organizações \\
Documentação Técnica \\
Fóruns de discussão \\
Consulta ao Fabricante \\
Outros \\
\hline
\end{tabular}

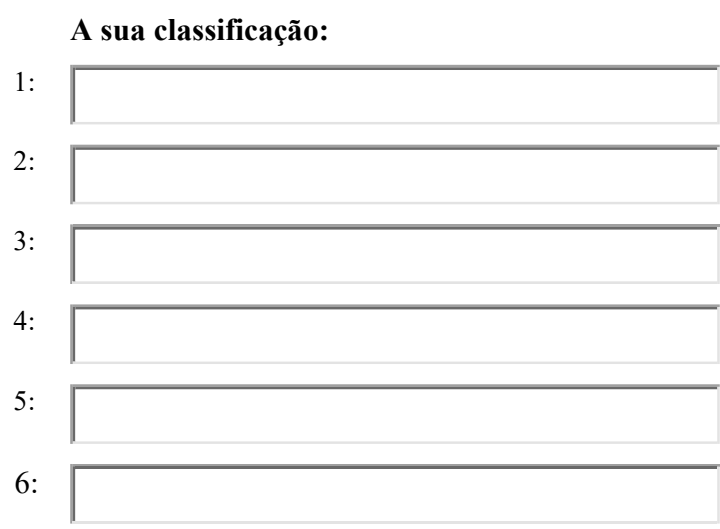

Carregue na tesoura próxima de cada item à direita para remover o último registo da sua lista de classificação

8. Quais os fatores que contribuem para que as pessoas partilhem informações e experiências? Enumere as respostas selecionando os itens da lista à esquerda de acordo com o seu grau de importância/ relevância, sabendo que o item 1 corresponde ao que maior importância para si representa e o item 4, aquele que menor importância tem.

Clique num item na lista à esquerda, começando com o item de maior classificação, e percorrendo os itens até ao menor.

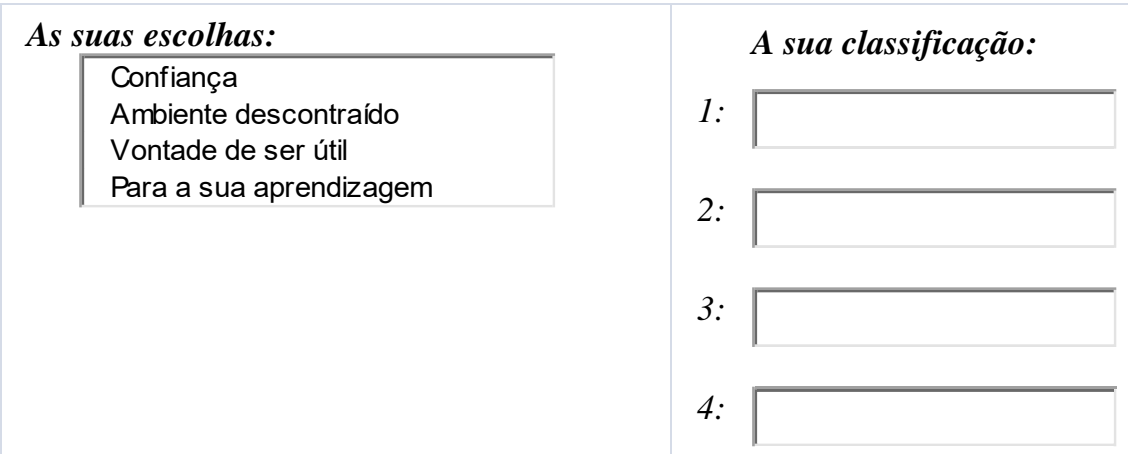

Carregue na tesoura próxima de cada item à direita para remover o último registo da sua lista de classificação

AIV - 2/2

Comunidad@ @uenas Prácticas de Seguridad, Salud e Calidad de Vida en el trabajo INIAV

"Factores críticos de éxito" 


\section{ANEXO AV -Inquérito da ação presencial}

\section{Introdução}

Do inquérito de ação presencial em auditório selecionamos as questões 2, 3, 6 e 9, para posterior analise combinatória.

2. $\mathrm{Na}$ sua opinião a plataforma de trabalho colaborativo, poderá minimizar problemas relacionados com: a perda de tempo na procura da informação; a perda do conhecimento tácito e ultrapassar distâncias?.

Sim Não

(Coloque um círculo na sua escolha)

3. Gostaria de ser membro de uma Comunidade de prática que partilhasse o conhecimento sobre uma temática da prevenção de riscos laborais?

Sim Não

(Coloque um círculo na sua escolha)

6. Gosta do formato da ferramenta de trabalho colaborativo?

Sim Não

(Coloque um círculo na sua escolha)

9. Necessita de uma ação de treino/ formação na ferramenta de trabalho colaborativo?

Sim Não

(Coloque um círculo na sua escolha)

$$
\text { AV }-1 / 1
$$


Doctorado en Salud, Discapacidad, Dependencia y Bienestar

ANEXO B - Análise de conteúdo dos Instrumentos de Avaliação 


\section{ANEXO BI - Análise da Entrevista semiestrurada Coordenadora da Comunidade de Prática CoPGaPeAn E COPSSQVTINIAV - Análise de conteúdo}

1. $\quad$ Em 2005.

a) Inicia devido a uma lacuna na AP sobre a Gestão da Prevenção de Riscos Laborais integrada num projeto dinamizado pelo INA (Instituto Nacional de Administração). Projeto com o tema "Cultura de Segurança | Um caminho com futuro na Administração Pública".

b) A realização do estudo de caso foi numa organização do setor público a ex Estação Agronómica Nacional (EAN) pertencente ao Ministério da Agricultura.

c) A escolha desta organização esteve relacionada com a diversidade de atividades profissionais: Administrativa; Laboratórios (químicos) biológicos. Atividades de campo (Agricultura) e atividades de manutenção.

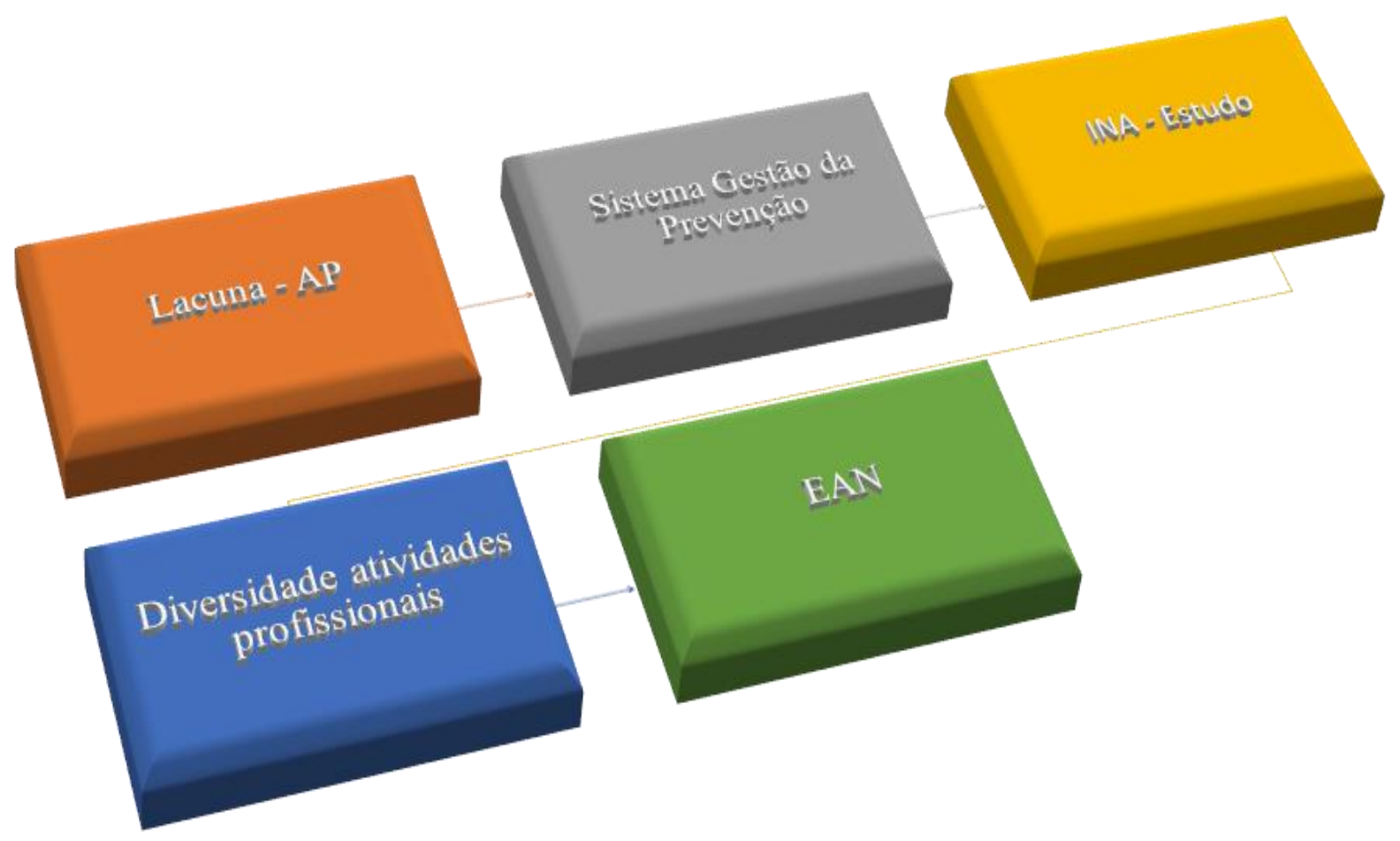

Fonte: Elaboração Própria

$$
\text { BI - 1/9 }
$$

Comunidad@ @uenas Prácticas de Seguridad, Salud e Calidad de Vida en el trabajo INIAV 
Doctorado en Salud, Discapacidad, Dependencia y Bienestar

2. A investigadora deu o primeiro passo que foi envolver a gestão de topo da organização em estudo. Sem o envolvimento da gestão de topo o projeto à partida não teria pernas para andar. A partir do momento em que a gestão de topo aceita que o projeto se desenvolva na organização também decide envolver-se na dinâmica.

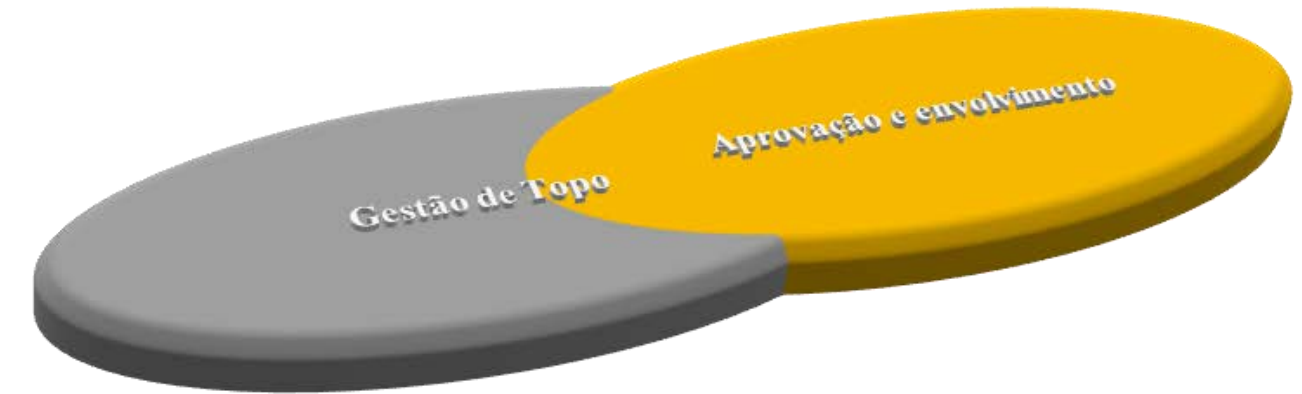

Fonte: Elaboração Própria

\section{INA | EAN | ISCTE}

4. O papel de cada um no projeto:

INA: Departamento de Investigação e Desenvolvimento no âmbito do Programa sabáticas para a AP aprova e apoia o projeto na temática da HSST, recentemente alterada a nomenclatura para SST.

EAN: A organização onde se realiza o estudo foi uma organização do setor público com diversidade de atividades profissionais, tinha tudo o que o projeto precisava.

ISCTE: O centro de investigação social do ISCTE (Instituto Universitário de Lisboa) colaborou aplicando instrumentos de diagnóstico da cultura de segurança e organizacional.

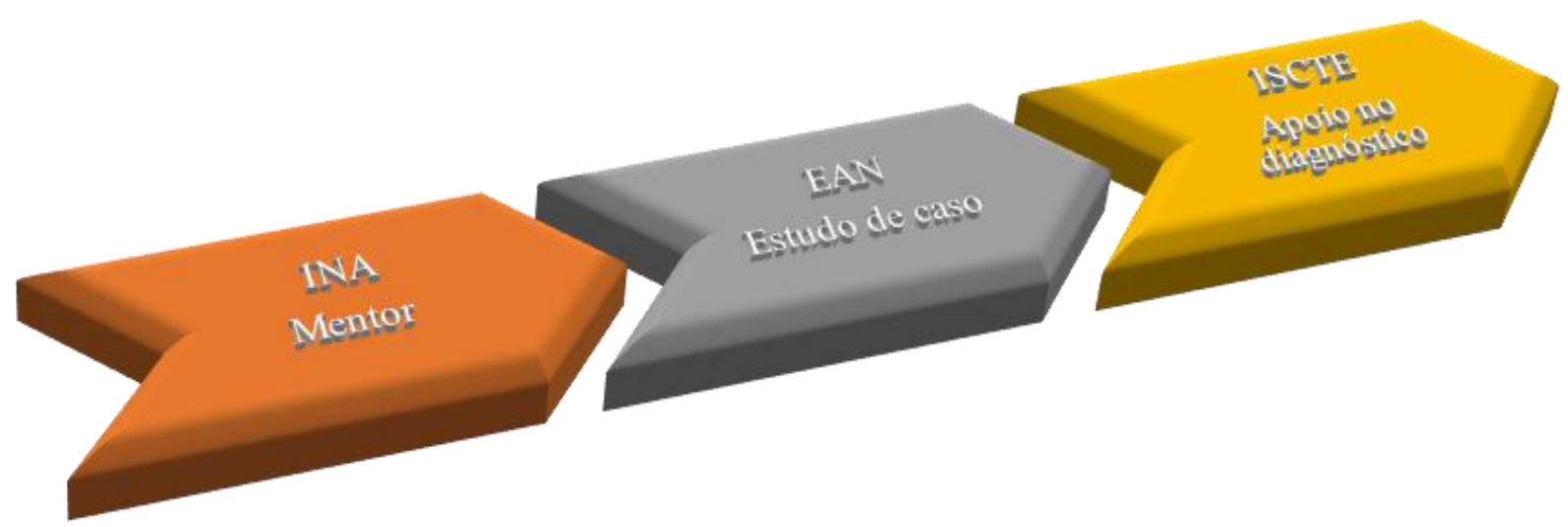

Fonte: Elaboração Própria

BI $-2 / 9$

Comunidad @ Buenas Prácticas de Seguridad, Salud e Calidad de Vida en el trabajo INIAV 
5. Sim, sem dúvida. O INA ao aprovar um projeto nesta temática desencadeia uma grande preocupação para a implementação do sistema de Gestão de Prevenção de Riscos Laborais na AP. Volvidos 15 anos (2004 - 2019), após este primeiro estudo, vemos agora sair em deliberação de Conselho de Ministros aquilo que há muito esperamos. Este estudo não foi em vão.
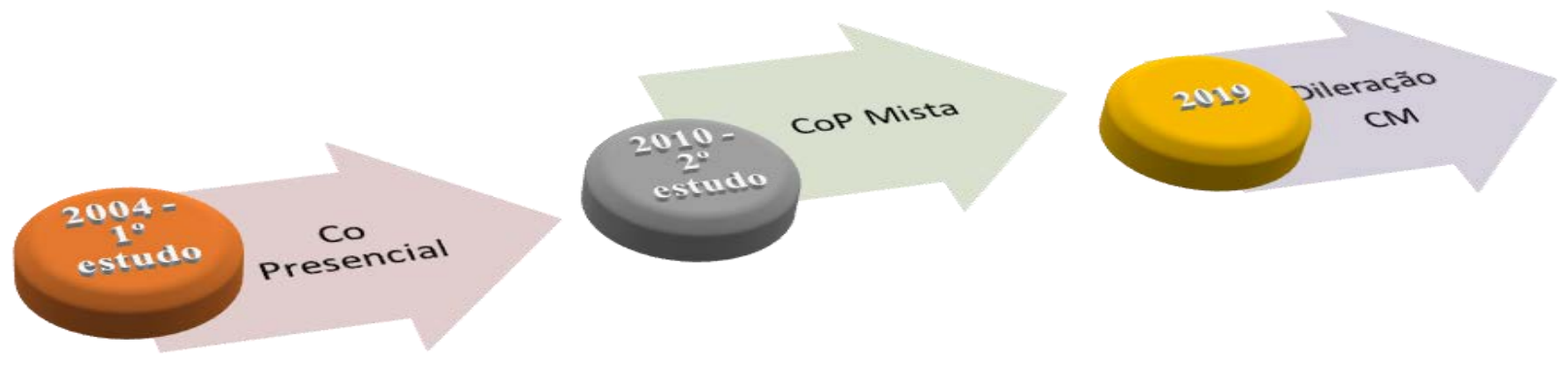

Fonte: Elaboração Própria

6. Após o envolvimento do gestor de topo da organização, fizemos uma parceria com o ISCTE, pois no CIS (Centro de Investigação Social) já existiam instrumentos de diagnóstico da Cultura de Segurança e Organizacional que seriam facilitadores para num processo de intervenção após análise dos instrumentos aplicados compatibilizaram a Cultura de Segurança e Organizacional. Após o diagnóstico feito através da metodologia qualiquantitativa (Entrevistas semiestruturadas e o Inquérito ICOS (Inquérito de Cultura Organizacional e Segurança) tivemos acesso à realidade da situação e conseguimos, envolvendo a gestão de topo, percecionar qual/s os grupos mais favoráveis à mudança. Assim percecionamos quer a gestão de topo quer a gestão intermédia seria parceira no projeto assim o grupo técnico-profissional.

$$
\text { BI }-3 / 9
$$


Doctorado en Salud, Discapacidad, Dependencia y Bienestar

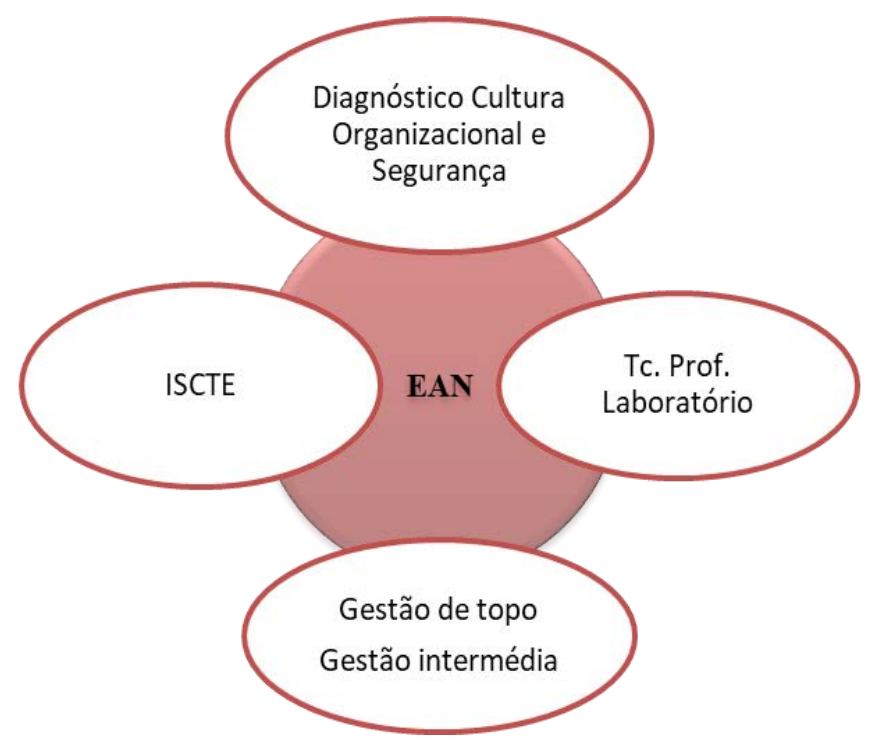

Fonte: Elaboração Própria

7. Sim. Isso verificou-se logo nas entrevistas. A gestão de topo com todos os riscos que poderiam advir da aceitação de um projeto destes na sua organização, assumiu correr os riscos a favor da mudança e a relação com chefias intermédias era muito favorável. Em relação a todos os grupos profissionais, os técnicos profissionais de laboratório que mais vibraram com a temática.

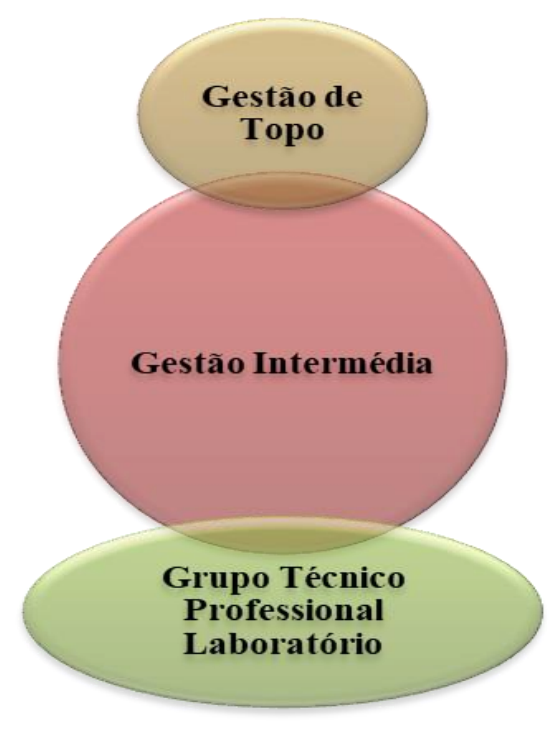

Fonte: Elaboração Própria

BI $-4 / 9$

Comunidad@Buenas Prácticas de Seguridad, Salud e Calidad de Vida en el trabajo INIAV

"Factores críticos de éxito" 
8. A estratégia foi envolver a Gestão de Topo na mudança e o Diretor apresentar publicamente o projeto a todos os trabalhadores como projeto da organização de e para a mudança face a prevenção. Nesta sessão de apresentação o Diretor escolheu o grupo facilitador e propôs de imediato a sua formação na temática da Prevenção de Riscos Laborais o grupo técnico-profissional de laboratório. O grupo tem acesso a muitas horas de formação e o clima criado entre os elementos é de confiança e muita entrega à temática. No segundo semestre do ano de 2004 organizaram-se como comunidade de partilha de todo o conhecimento quer formal quer informal adquirido ao longo do tempo em que se encontram quer em sala com formadores profissionais quer no terreno partilhando a sua experiência.

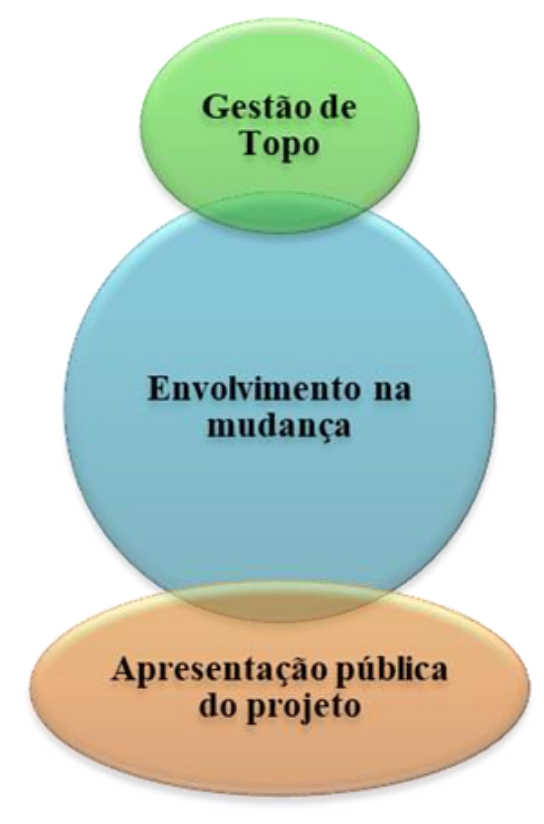

Fonte: Elaboração Própria

9. Nasce a CoPGAPEAN, apoiada fortemente e valorizada pelo gestor de topo. Aqui foi muito importante a abertura da Gestão de Topo, valorizando as atividades do grupo e criando condições para que a comunidade se desenvolvesse e mantivesse viva, num tempo que permitisse mudanças efetivas no comportamento e atitudes dos colaboradores face à prevenção.

10. O papel da gestão de topo foi sempre crucial para o desenvolvimento do projeto CoP. Nas questões seguintes entendemos porquê.

\section{BI $-5 / 9$}

Comunidad@Buenas Prácticas de Seguridad, Salud e Calidad de Vida en el trabajo INIAV

"Factores críticos de éxito" 


\section{Doctorado en Salud, Discapacidad, Dependencia y Bienestar}
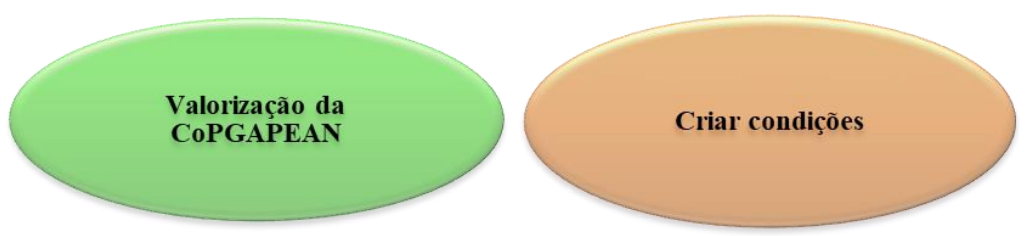

Fonte: Elaboração Própria

11. Sim, o líder da organização apoia todas as iniciativas desta comunidade embrionária, cedendo tempo para as atividades e apoiando as mesmas. Cedência de espaços da organização, como salas e auditórios para a realização de eventos e envolve-se na dinâmica sempre que é solicitado valorizando o esforço.

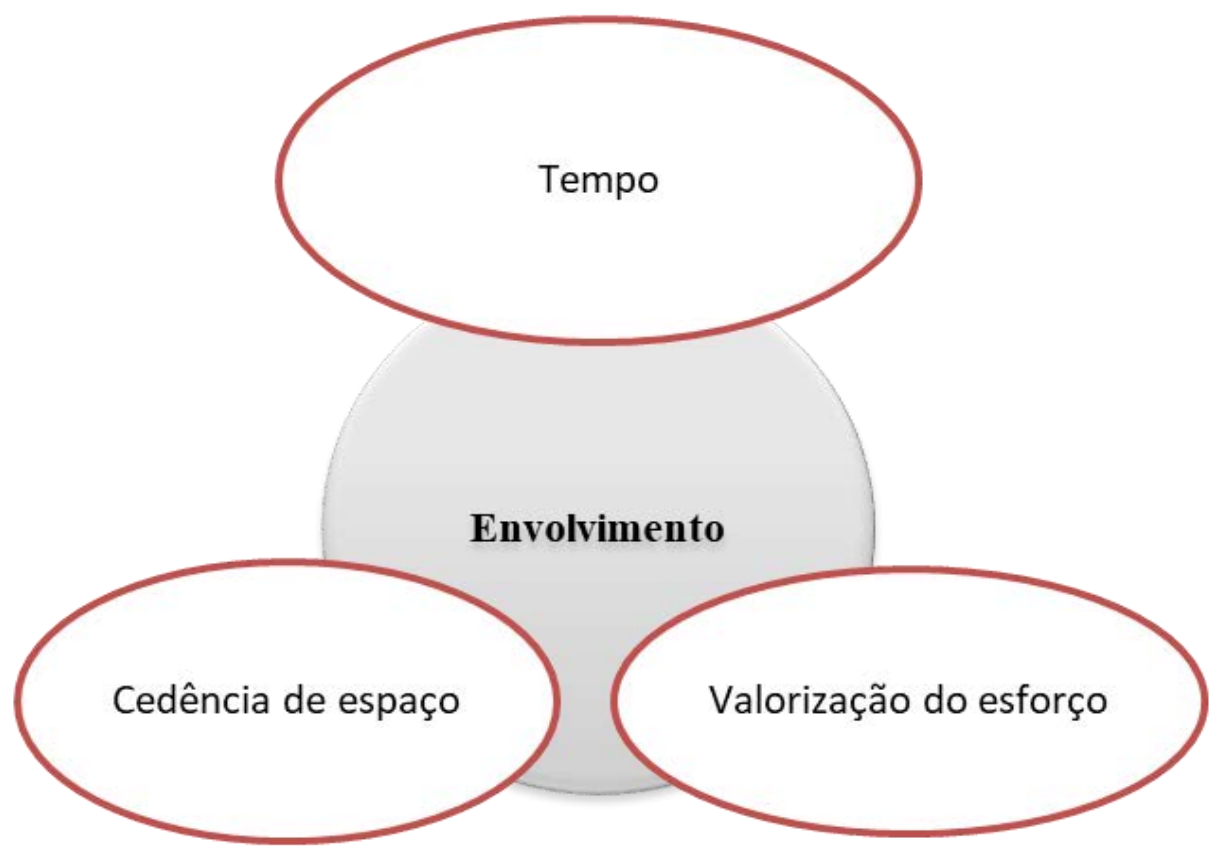

Fonte: Elaboração Própria

BI $-6 / 9$

Comunidad@Buenas Prácticas de Seguridad, Salud e Calidad de Vida en el trabajo INIAV

"Factores críticos de éxito" 
Doctorado en Salud, Discapacidad, Dependencia y Bienestar

12. Eventos internos e externos

$\checkmark$ Seminários

$\checkmark$ Workshops

13. Sim. Abriu a fronteira a outras organizações do setor público e privado.

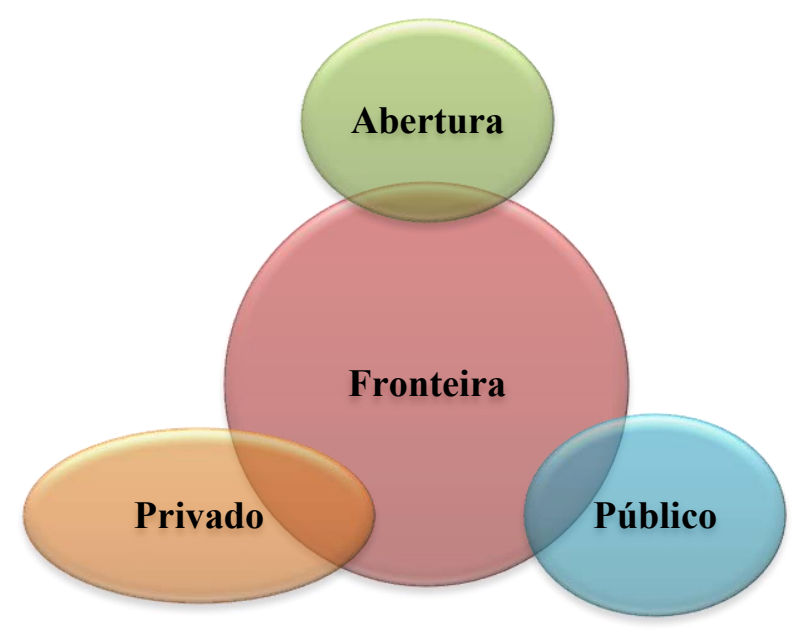

Fonte: Elaboração Própria

14. Sim, não tenho qualquer dúvida que o "combustível" não se esgotou porque o líder alimentou sempre o grupo, incentivando e colaborando.

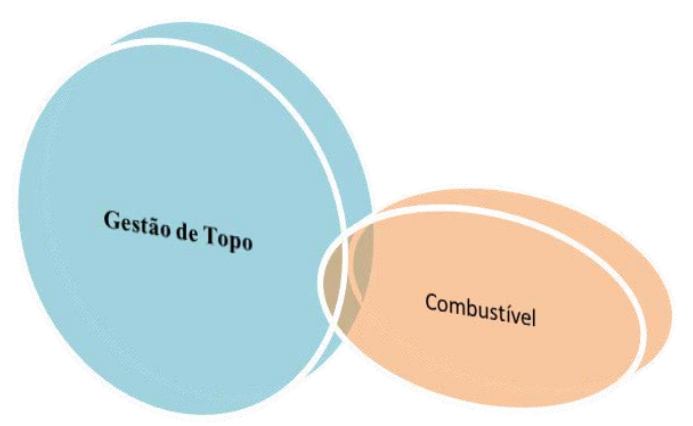

Fonte: Elaboração Própria

BI $-7 / 9$

Comunidad @ Buenas Prácticas de Seguridad, Salud e Calidad de Vida en el trabajo INIAV

"Factores críticos de éxito" 


\section{Doctorado en Salud, Discapacidad, Dependencia y Bienestar}

15. Sim, é verdade e isso sentiu-se com a saída deste líder. A comunidade fica sem combustível para desempenhar o seu papel e acaba por declinar.

16. Sim, foi a enzima, o catalisador para que tudo acontecesse.

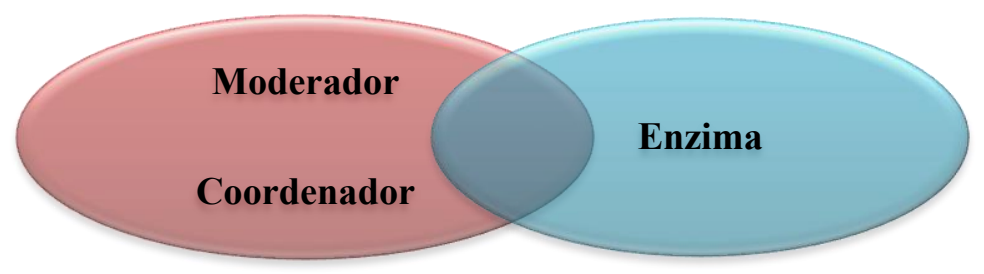

Fonte: Elaboração Própria

17. A CoP manteve-se ativa mesmo sem o líder organizacional, mas como prova do seu agradecimento, um sentimento que os mantinha unidas e ainda lutando. E em 2008, já sem o líder organizacional a CoPGAP manteve-se ativa devido à sua coesão e em 2009 transformou-se quando tem a oportunidade de a convite do INA se transformar numa CoP virtual. Se este convite não acontecesse corria o risco de se perder.

$$
2004-2005-2006-2007-2008-2009-2010
$$

18. Sim, através da comunidade INA cria-se a comunidade de partilha de boas práticas de SST.

19. Sim. Moderadores do grupo entraram em formação e criou-se uma nova dinâmica.

$$
\text { BI }-8 / 9
$$

Comunidad@Buenas Prácticas de Seguridad, Salud e Calidad de Vida en el trabajo INIAV

"Factores críticos de éxito" 
20. Sim a dinâmica manteve-se nesta plataforma até 2011 .

21. Mais uma vez as mudanças na AP, muda serviços e plataforma de suporte encerrou. A única possibilidade de continuidade era criar uma ferramenta de suporte para que esta dinâmica não se perdesse. E isso aconteceu no INRB com a criação da Wikiniav.

22. - Apoio da liderança da organização;

$\checkmark$ Sentido de pertença;

$\checkmark$ Abertura da fronteira;

$\checkmark \quad$ Líder da CoP

23. Foram as interações síncronas.

23. Participantes ativos e motivados, criação de um ambiente colaborativo, domínio claro, tinham um plano de ação bem definido. As necessidades dos participantes da CoP foram acompanhadas, assim como foram definidas estratégias de suporte ao longo do ciclo de vida.

24. Alavancar a criação e partilha de conhecimento.

25. Permitem em espaço de partilha de ideias e opiniões, as Organizações devem aprender a cultivar este tipo de estrutura.

$$
\text { BI - 9/9 }
$$




\section{ANEXO BII - Análise da Entrevista semiestrurada a membros da CoPGAPEAN}

\section{Caraterização da entrevista:}

Entrevistamos 30\% dos elementos ativos na CoPGAPEAN.

A entrevista durou 40 minutos.

1. Todos os elementos entrevistados pertenceram à CoPGAPEAN e o domínio da CoP era a partilha de boas praticas de SHST.

2. Os 5 elementos referiram que o que foi importante na formação desta comunidade foi em primeiro lugar o apoio da alta direção, em segundo lugar o domínio da CoP alta importância e por último a confiança.

3. O grande problema da nossa organização detentora de muito conhecimento na investigação agrária foi que grande parte do conhecimento é perdido quando os funcionários se aposentam. A aposta da gestão organizacional deve-se ao conhecimento tácito, que vai com o funcionário quando se aposenta e não se dedicou a atenção em passar a explicito.

4. Para que os membros da CoP se juntassem foi necessário, em primeiro lugar conhecer o domínio, em segundo lugar o relacionamento entre eles e por último a confiança mútua.

5. A participação foi legitimada tendo a Direção da Organização reservado tempo para as nossas atividades e outro aspeto não menos importante, cedeu-nos um espaço físico, onde as nossas atividades se desenvolveram, Centro de Aprendizagem Propedêutica.

$$
\text { BII }-\mathbf{1 / 3}
$$




\section{Doctorado en Salud, Discapacidad, Dependencia y Bienestar}

6. O reconhecimento foi público e dado o testemunho da alta direção no reconhecimento da comunidade, valorizando a cultura colaborativa na avaliação de desempenho.

7. Fomos beneficiados com alguns recursos como exemplo: peritos externos à organização, comunidades para nos apoiarem e cedência de instalações para reuniões e eventos.

8. Trocas??? Presenciais semiestruturadas via brainstorming em sala, meios presenciais estruturados como workshops e seminários.

Conversais informais (café e chá). Trocas virtuais simples (emails, documentos legislativos, vídeos, páginas web)

9. O respeito, a confiança, desafio, a valorização das singularidades e práticas profissionais e o envolvimento de um especialista na temática como membro líder da Comunidade assim como a abertura e visibilidade da fronteira da comunidade para o exterior.

10. Na fase inicial a comunidade foi lançada publicamente pelo gestor de topo e a coordenadora da CoP que foi muito importante, pois estimulou a nossa participação e colaboração, atendendo a que era especialista no domínio.

11. Na fase de crescimento a CoP tornou-se muito ativa, todos nós começamos a identificar e a valorizar o nosso envolvimento nas atividades de aprendizagem. O balanço entre o grau de confiança existente e o valor que retirávamos do nosso envolvimento e participação foi crucial.

BII $-2 / 3$

Comunidad@Buenas Prácticas de Seguridad, Salud e Calidad de Vida en el trabajo INIAV

“Factores críticos de éxito" 


\section{Doctorado en Salud, Discapacidad, Dependencia y Bienestar}

12. Esta fase permitiu construir a confiança entre nós. O líder da organização legitimou o papel importante da nossa comunidade e o entusiasmo e sentido de pertença foram crescendo, pois estávamos reunidos em torno de um interesse comum.

13. Os desafios que a nossa comunidade, na fase de maturidade, atravessou foram muitos, pois o "combustível" que alimentou este barco, ou melhor o Diretor da organização saiu e passamos por uma fase complicada em termos organizacionais e aqui ou a comunidade se desagregava ou juntos continuávamos com o barco mesmo na tempestade. Nesta fase foi o líder da CoP que comandou o barco e o levou para águas calmas, motivando todos os membros e mantendo a participação ativa dos mesmos. Nesta fase o desafio já era bem visível para as TIC perspetivavam a nossa CoP se formasse mista.

14. A fase de sustentação - o grande desafio foi manter o ritmo, passando por mudanças várias na relação com a organização e também mudanças tecnológicas. Os membros já não possuíam um envolvimento tão intenso, mas a CoP continuava viva. Nesta fase o importante foi manter os encontros, motivando-nos e conseguindo em termos virtuais um suporte organizacional.

15. Fase de transformação, dá-se quando após várias mudanças de liderança, não se reconhece na CoP o papel na partilha de conhecimento, que foi reconhecida anteriormente. Para nós se um líder da organização não valorizar o trabalho colaborativo a vida da CoP termina.

BII $-\mathbf{3} / \mathbf{3}$ 


\section{ANEXO BIII Tipologia de documentos analisados da CoPGAPEAN}

Atas de reuniões;

Apresentações em workshops internos;

Apresentações em workshops externos

$\checkmark$ Produtos elaborados e partilhados pela comunidade

$\checkmark$ Cartazes;

$\checkmark$ Brochuras;

$\checkmark$ Fichas técnicas

\section{ANEXO BIII - Análise de documentos - Atas de reuniões}

Tivemos acesso ao livro de atas das reuniões da CoPGAPEAN e verificamos vários tipos de reuniões:

$\checkmark$ Reuniões com o gestor de topo para definição do tipo de apoio que o mesmo poderia dar à comunidade;

$\checkmark$ Reuniões da comunidade para a preparação dos eventos internos e externos;

$\checkmark$ Reuniões da comunidade para a elaboração de produtos a partilhar com os colaboradores da organização;

$\checkmark$ Reuniões da comunidade com o responsável do centro de apoio aos eventos;

$\checkmark$ Reuniões da comunidade para avaliação das tarefas dos membros;

$\checkmark$ Reuniões da comunidade para gestão do orçamento das atividades em curso;

$\checkmark$ Reuniões da comunidade com a coordenadora/ líder;

$\checkmark$ Reuniões da comunidade para gestão dos convites a organizações e especialistas externos.

$$
\text { BIII - 1/29 }
$$

Comunidad@ Buenas Prácticas de Seguridad, Salud e Calidad de Vida en el trabajo INIAV

"Factores críticos de éxito" 


\section{ANEXO BIII - Produtos elaborados pela CoPGAPEAN}

Tivemos acesso a muitos produtos elaborados pela CoPGAPEAN e fomos informados que todos os desenhos foram elaborados por um desenhador que pertencia à comunidade, são desenhos testados pelo grupo com a técnica da elaboração de mensagens.

Os cartazes incidiam em mensagens certas e apostavam acima de tudo em mensagem de boas práticas assim como alertava para situações de risco.

Também observamos fichas técnicas, que resumidamente incidiam numa temática relacionada com a prevenção e que tinham uma saída quinzenal.

Assim, apresentamos alguns exemplos:

\section{Fichas técnicas:}

Exemplos

- Computador - 136

- Levantamento manual de cargas - 137

- Ginástica laboral - 138

- Armazenamento - Gases -

BIII - 2/29

Comunidad @ Buenas Prácticas de Seguridad, Salud e Calidad de Vida en el trabajo INIAV

"Factores críticos de éxito" 
Doctorado en Salud, Discapacidad, Dependencia y Bienestar

\begin{abstract}
ANEXO BIII - Análise das mensagens de Prevenção de Riscos Laborais elaboradas pela CoPGAPEAN
\end{abstract}

\title{
Temas abordados
}

$\checkmark$ Mudança de atitude fase à prevenção

$\checkmark$ Envolvimento das chefias

$\checkmark$ Formação

$\checkmark$ Proteção coletiva

$\checkmark$ Proteção individual

$\checkmark$ Perigos

$\checkmark$ Avaliação de riscos

\section{Formato das mensagens}
$\checkmark$ PowerPoint
$\checkmark$ Cartaz
$\checkmark$ Brochuras
$\checkmark$ Fichas técnicas

\section{Qual o tipo de interações?}

As interações foram síncronas e assíncronas

BIII - 3/29 


\section{Anexo BIII-Análise de Produtos elaborados e interações da CoPGAPEAN}

$\checkmark$ Produtos elaborados pelo Grupo de Animadores de Prevenção (Comunidade embrionária e presencial)

$\checkmark$ Reuniões com a Direção

$\checkmark$ Partilha de conhecimento com Especialistas

\section{Guias e Manual de Prevenção}

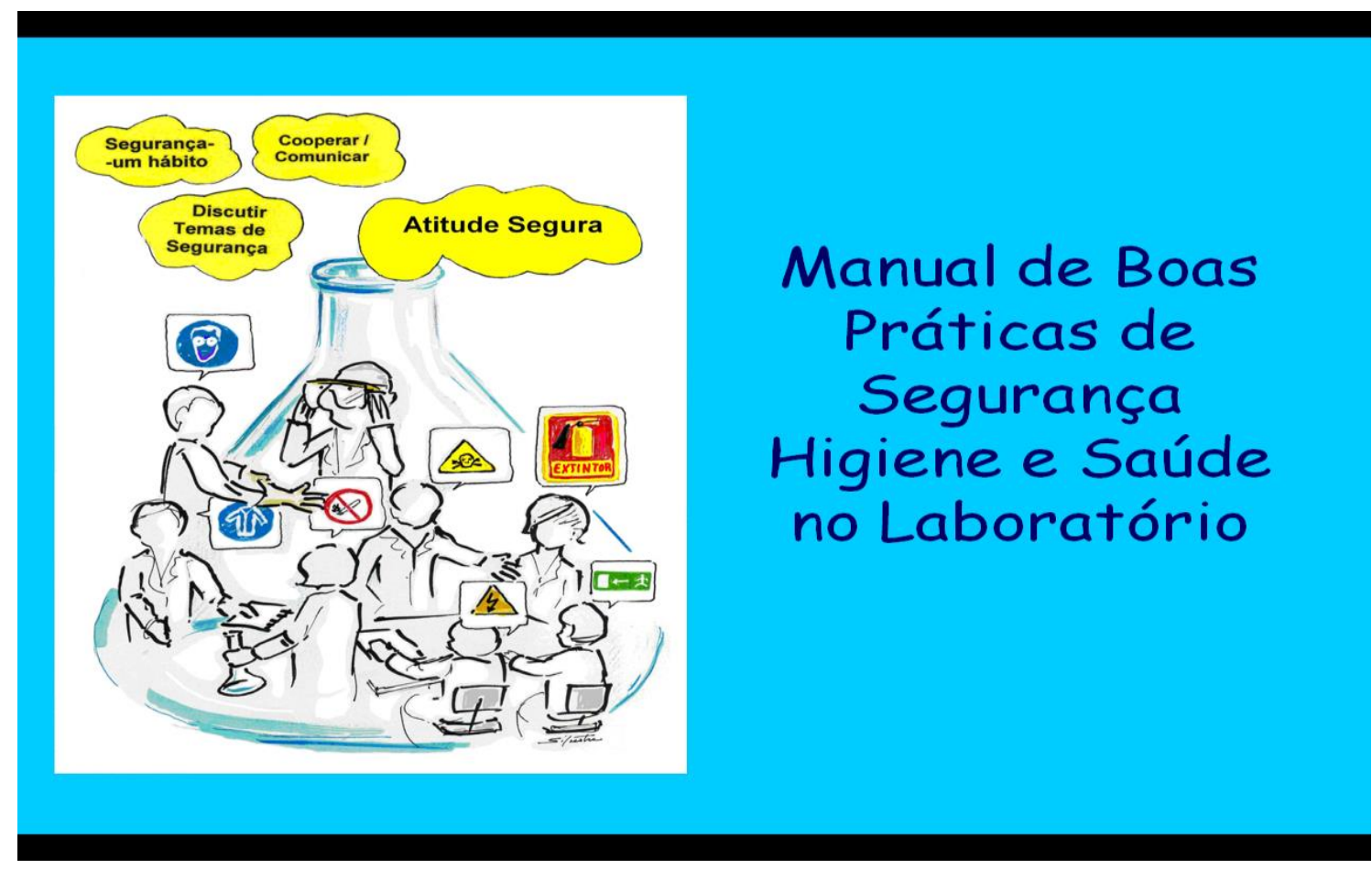

Manual de Boas Práticas (elaborado pelo GAP) partilhado em encontros presenciais e partilhado na plataforma da WIKINIAV na categoria fórum SHST

$$
\text { BIII }-4 / 29
$$

Comunidad @ Buenas Prácticas de Seguridad, Salud e Calidad de Vida en el trabajo INIAV 
Doctorado en Salud, Discapacidad, Dependencia y Bienestar

\section{Guia de Primeiros Socorros}

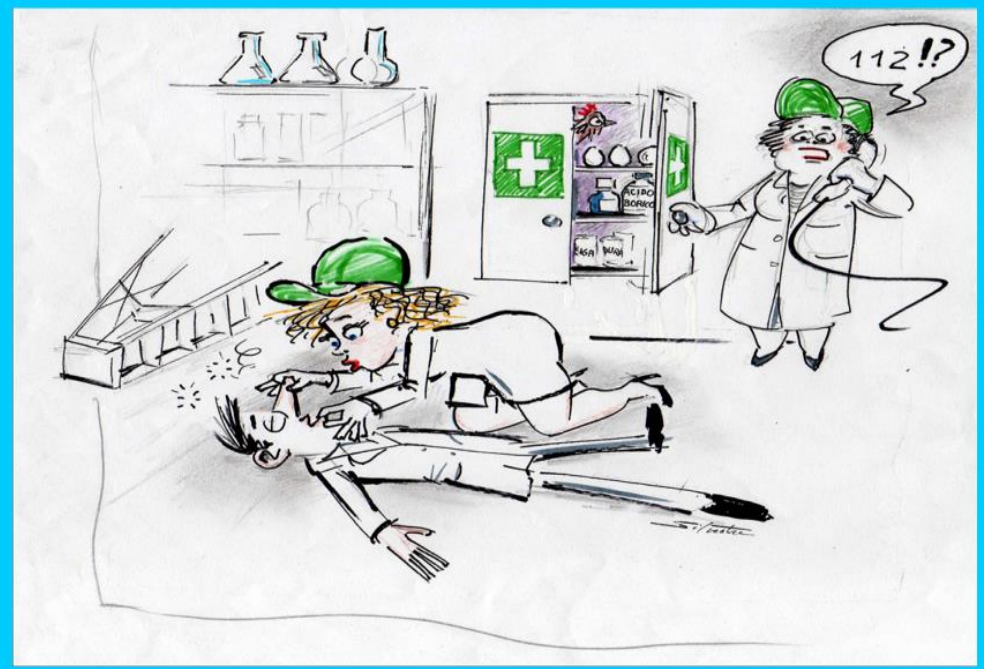

Guia de $1^{\circ} \mathrm{S}$ socorros n laboratório (elaborado pelo GAP) e partilhado na plataforma da WIKINIAV na categoria Fórum SST

\section{Guia de Partilha de Acidentes}

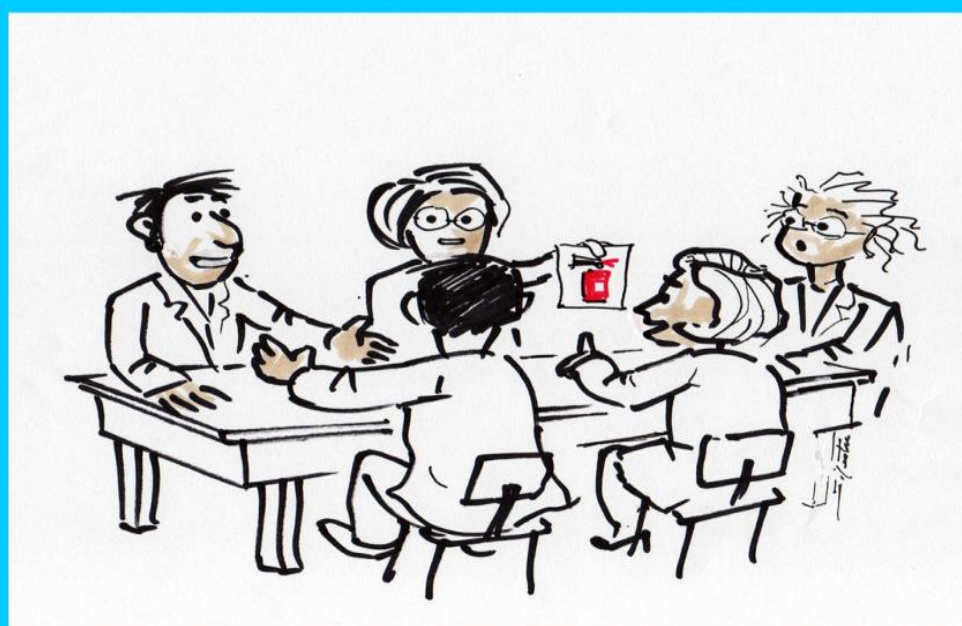

Guia de partilha de acidentes (Elaborado elo GAP) e partilhado na plataforma da WIKINIAV na categoria Fórum SST

$$
\text { BIII - 5/29 }
$$

Comunidad @ Buenas Prácticas de Seguridad, Salud e Calidad de Vida en el trabajo INIAV

"Factores críticos de éxito" 


\section{Guia de Atitudes Seguras}

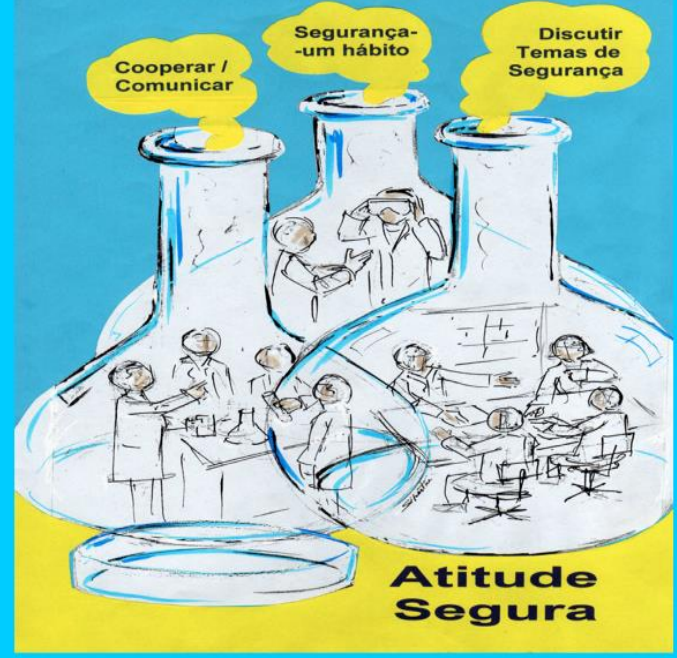

Guia de atitudes seguras (elaborado pelo GAP) e partilhado na plataforma da WIKINIAV na categoria Fórum SST

\section{Guia de Actuação em Caso de Emergência}

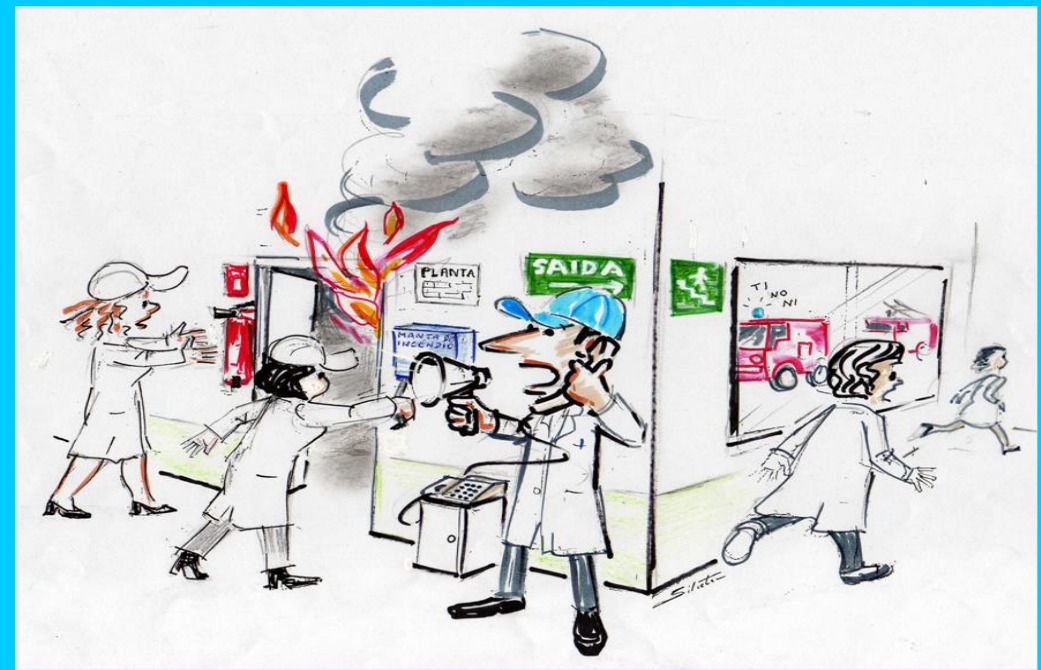

Guia de atuação em caso de emergência (elaborado pelo GAP) e partilhado na plataforma da WIKINIAV na categoria Fórum SST

$$
\text { BIII - 6/29 }
$$

Comunidad @ Buenas Prácticas de Seguridad, Salud e Calidad de Vida en el trabajo INIAV

"Factores críticos de éxito" 


\section{Doctorado en Salud, Discapacidad, Dependencia y Bienestar}

\section{Cartazes e Fichas Técnicas}

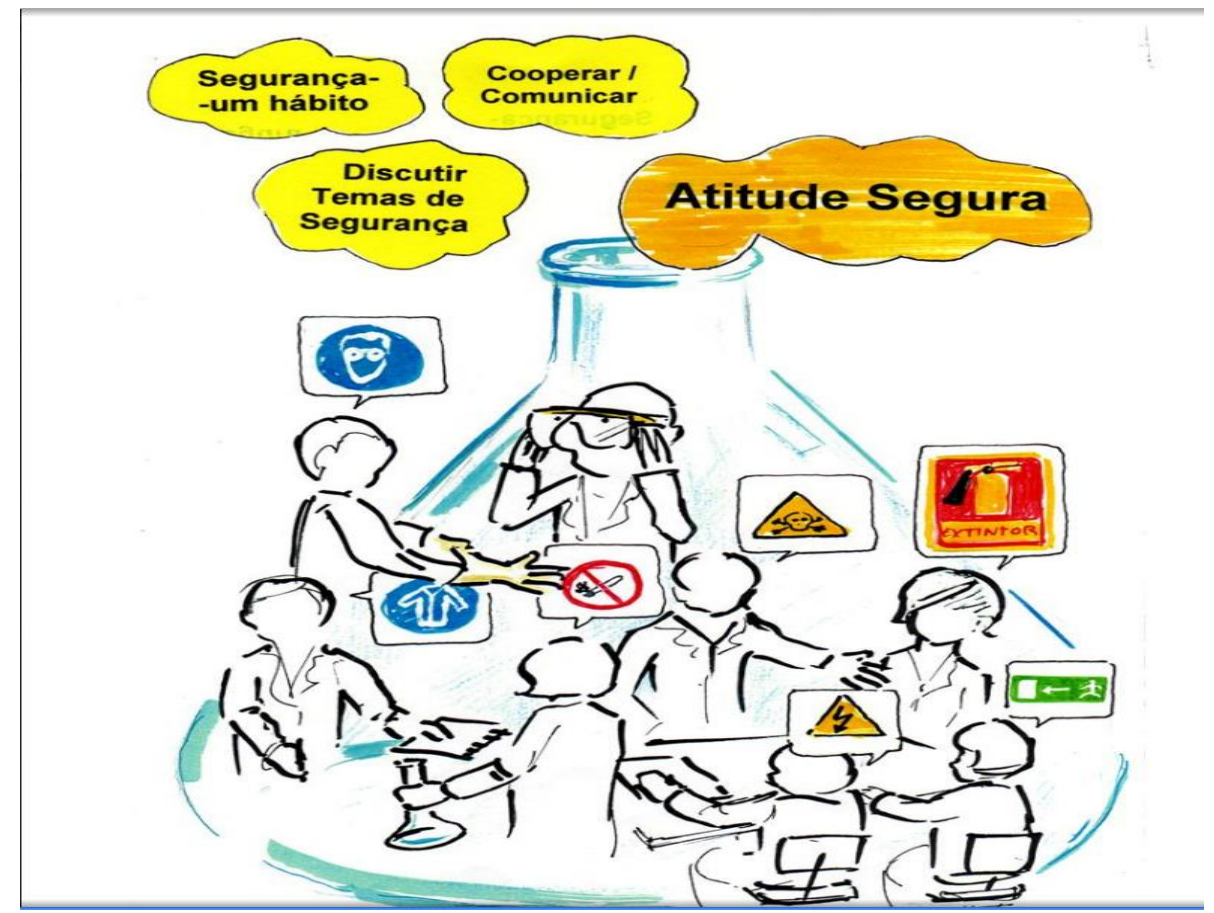

Cartaz: atitude Segura (elaborado pelo GAP) e partilhado na plataforma da WIKINIAV na categoria Fórum SST

\section{CONSCIÊNCIA DOS RISCOS NO \\ LOCAL DE TRABALHO E PREOCUPAÇÃO COM O BEM ESTAR}

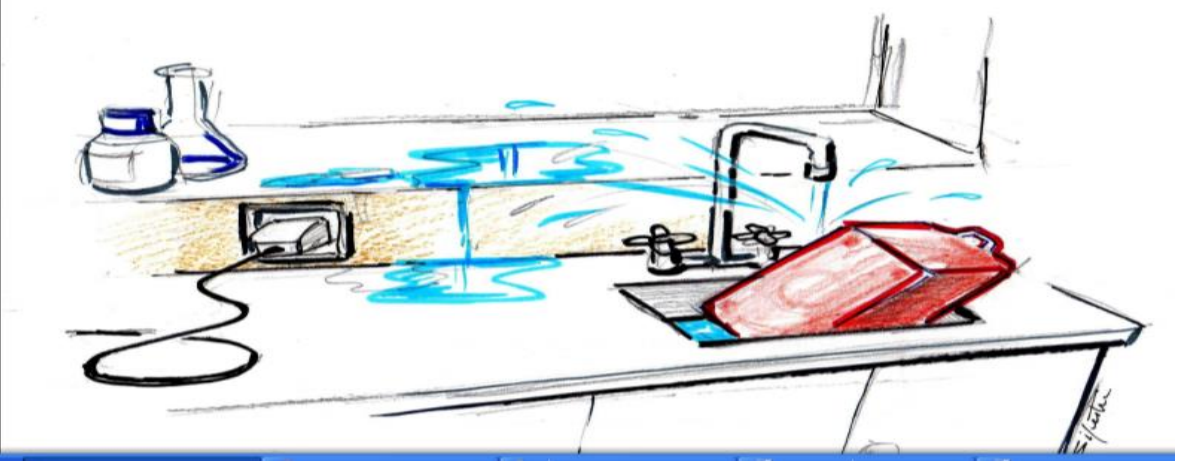

Cartaz: consciência de risco (elaborado pelo GAP) e partilhado na plataforma da WIKINIAV na categoria Fórum SST

$$
\text { BIII - 7/29 }
$$

Comunidad @ Buenas Prácticas de Seguridad, Salud e Calidad de Vida en el trabajo INIAV

"Factores críticos de éxito" 
Doctorado en Salud, Discapacidad, Dependencia y Bienestar

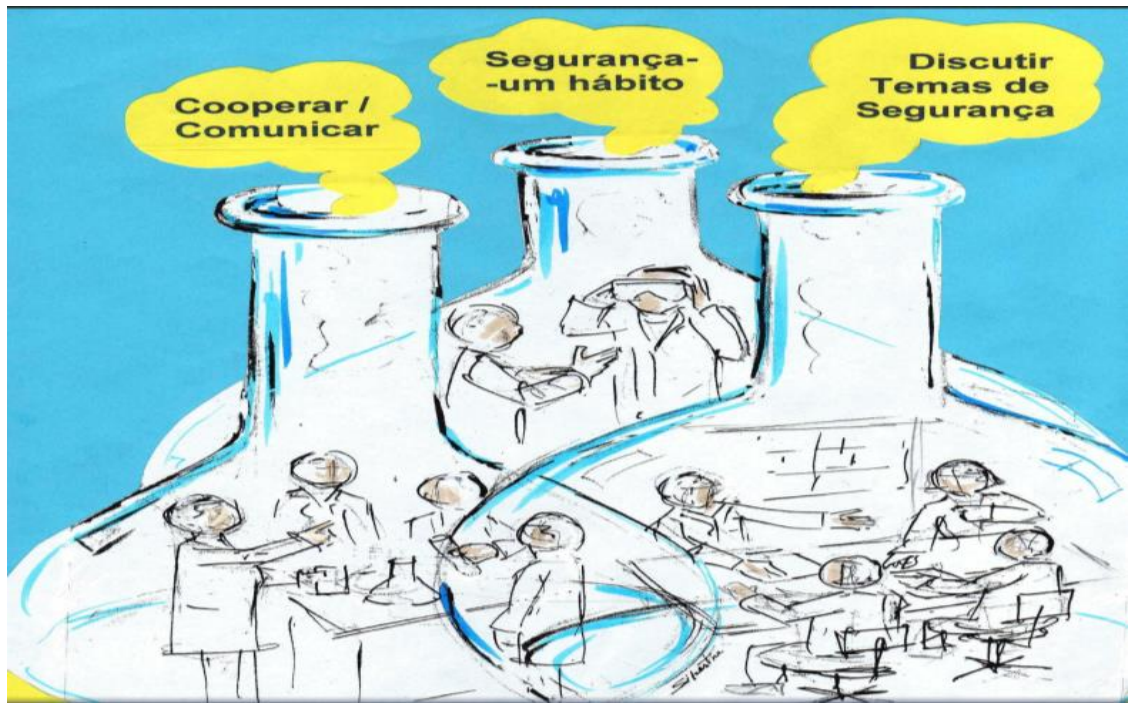

Cartaz: (elaborado pelo GAP) e partilhado na plataforma da WIKINIAV na categoria Fórum SST Atitude segura

\section{SAIBA COMO ACTUAR}

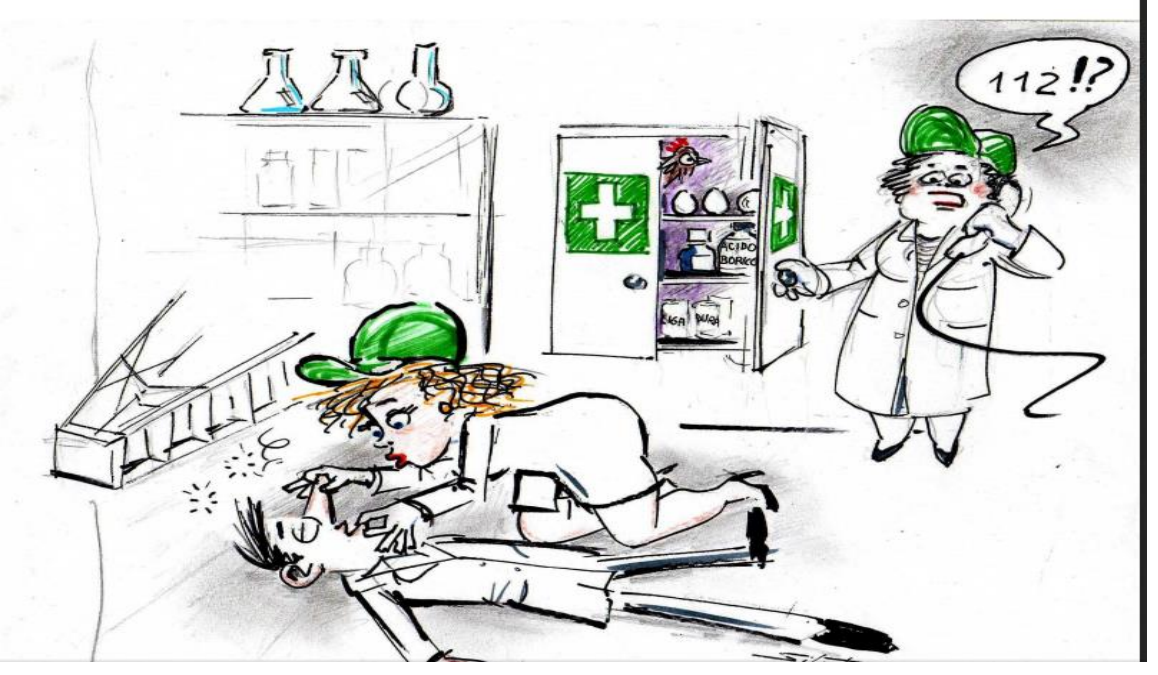

Cartaz: como atuar em caso de emergência (elaborado pelo GAP) e partilhado na plataforma da WIKINIAV na categoria Fórum SHST

$$
\text { BIII - 8/29 }
$$

Comunidad@Buenas Prácticas de Seguridad, Salud e Calidad de Vida en el trabajo INIAV

"Factores críticos de éxito" 
Doctorado en Salud, Discapacidad, Dependencia y Bienestar

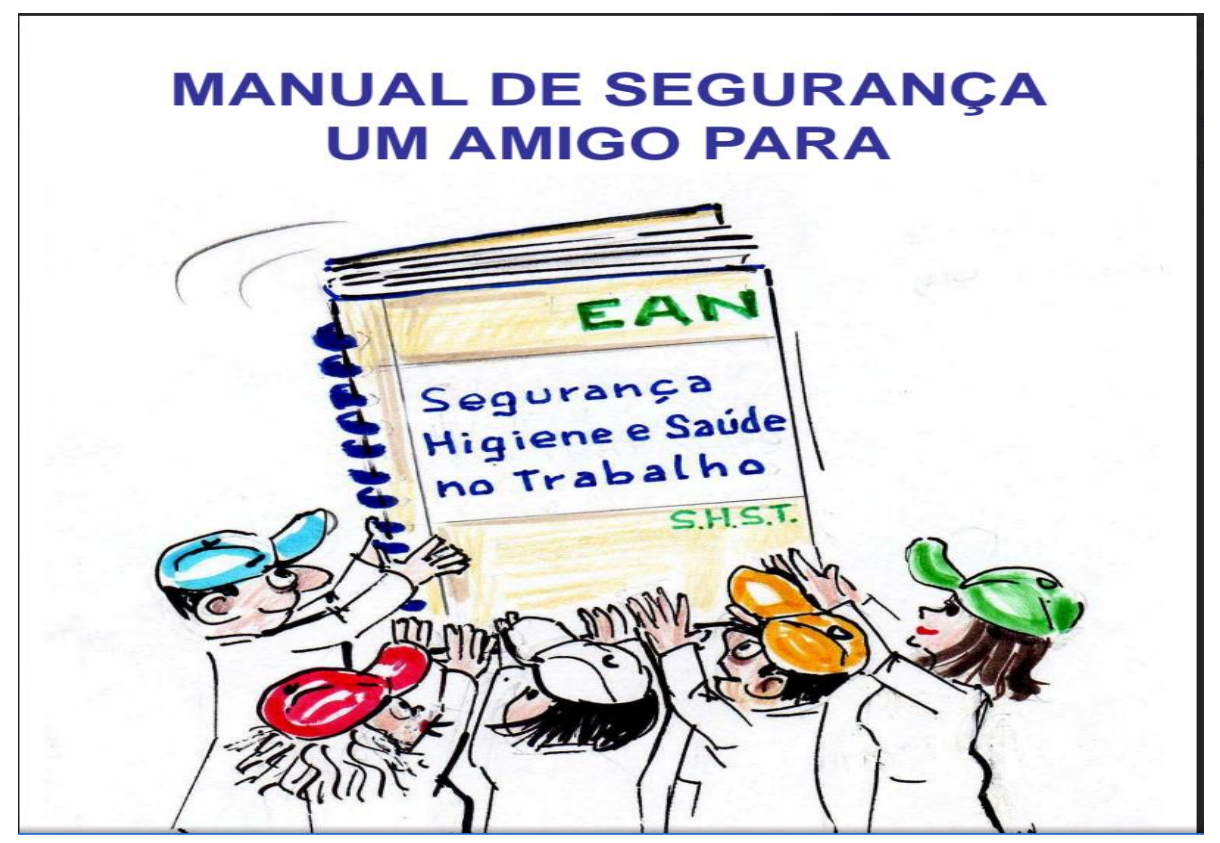

Cartaz: Manual de Segurança-(elaborado pelo GAP) e partilhado na plataforma da WIKINIAV na categoria Fórum SST

\section{HIGIENE E LIMPEZA NA HORA CERTA}

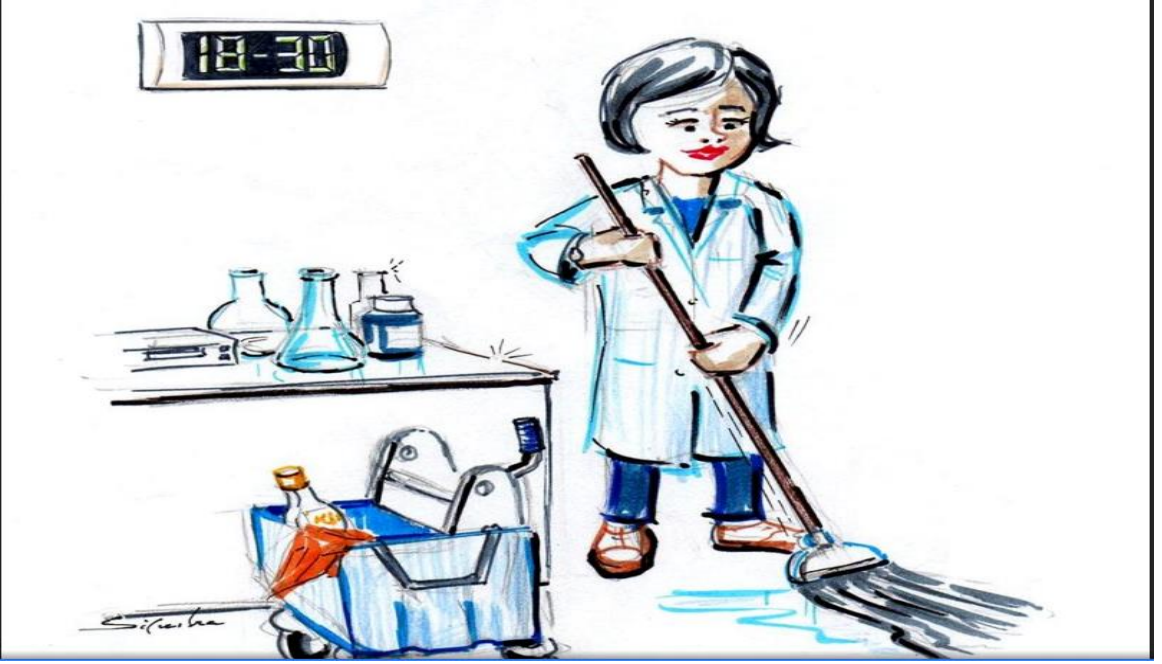

Cartaz: regras de higiene e limpeza nos laboratórios (elaborado pelo GAP) e partilhado na plataforma da WIKINIAV na categoria Fórum SST

$$
\text { BIII - 9/29 }
$$

Comunidad @ Buenas Prácticas de Seguridad, Salud e Calidad de Vida en el trabajo INIAV

"Factores críticos de éxito" 
Doctorado en Salud, Discapacidad, Dependencia y Bienestar

\section{O SEU PLANO DE EMERGÊNCIA DEVE SER:}

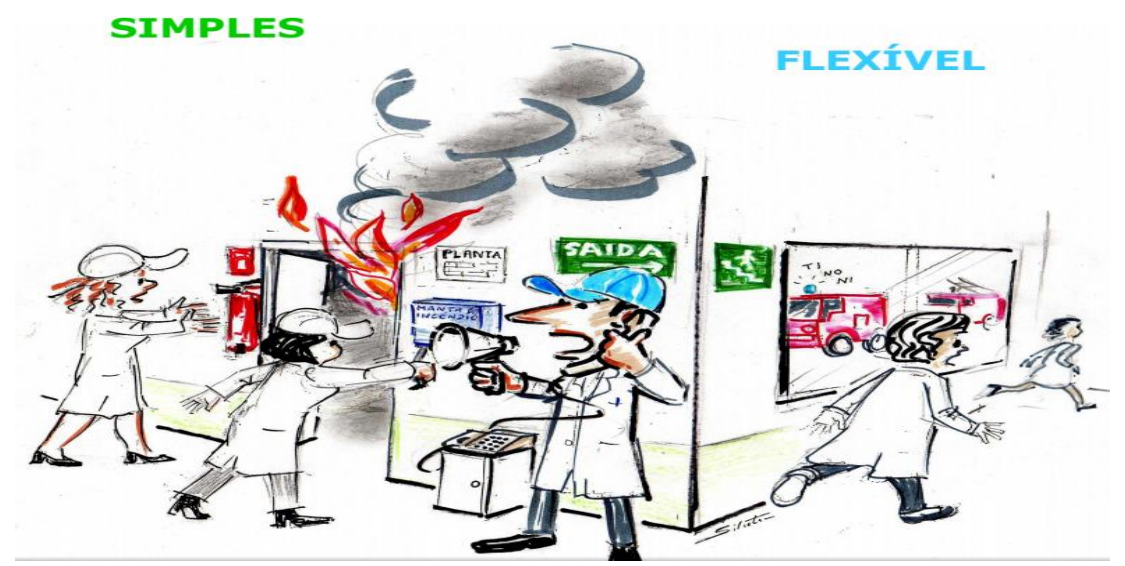

Cartaz: PEI (elaborado pelo GAP) e partilhado na plataforma da WIKINIAV na categoria Fórum SST

\section{SEGURANÇA O EXEMPLO A SEGUIR}

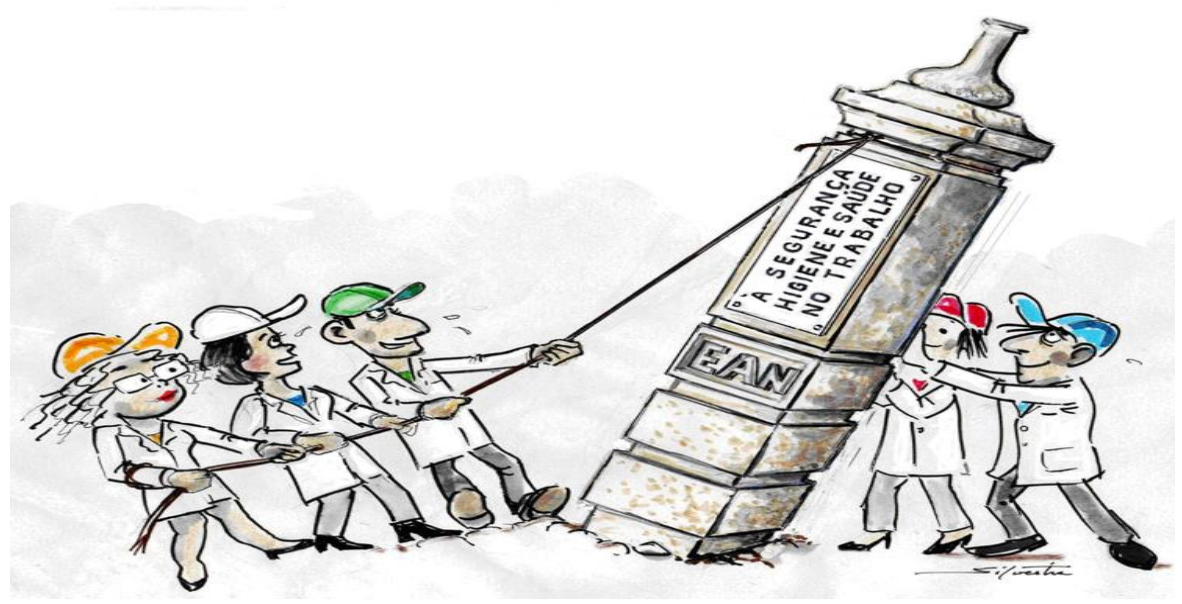

Cartaz (elaborado pelo GAP) e partilhado na plataforma da WIKINIAV na categoria Fórum SST

$$
\text { BIII - 10/29 }
$$

Comunidad@ Buenas Prácticas de Seguridad, Salud e Calidad de Vida en el trabajo INIAV

"Factores críticos de éxito" 


\section{O ACIDENTE}

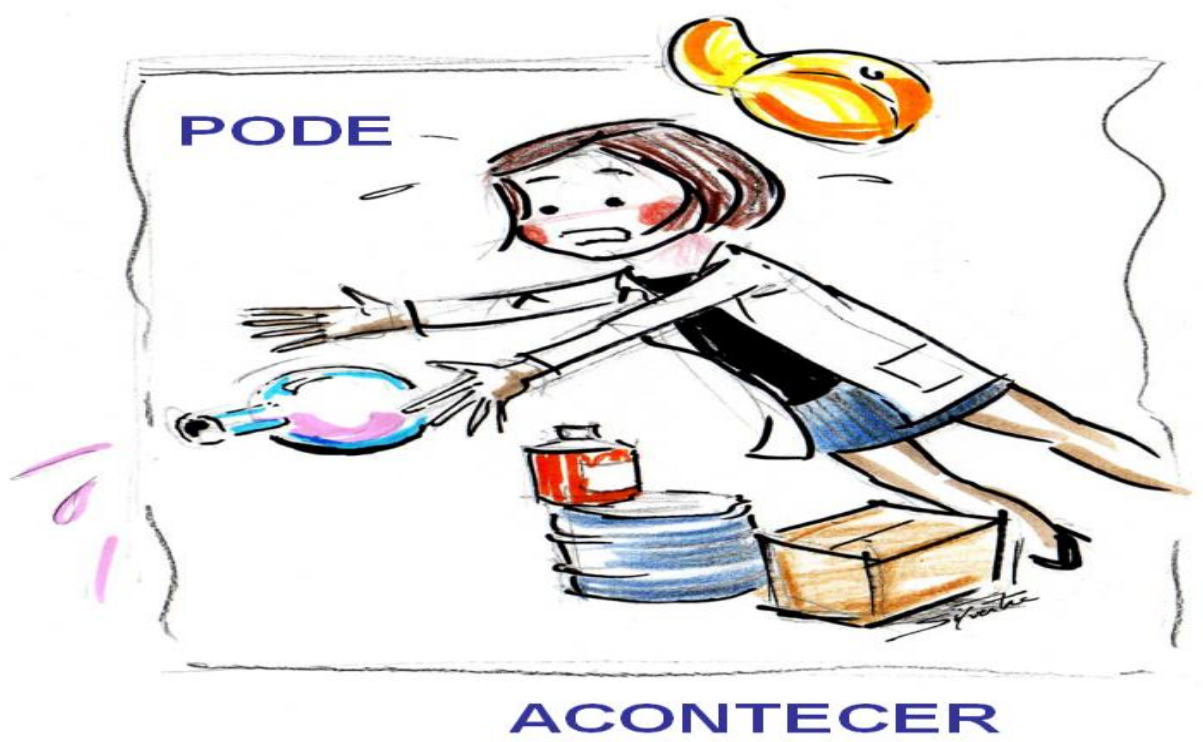

Cartaz: Período de incubação de acidentes . (elaborado pelo GAP) e partilhado na plataforma da WIKINIAV na categoria Fórum SST
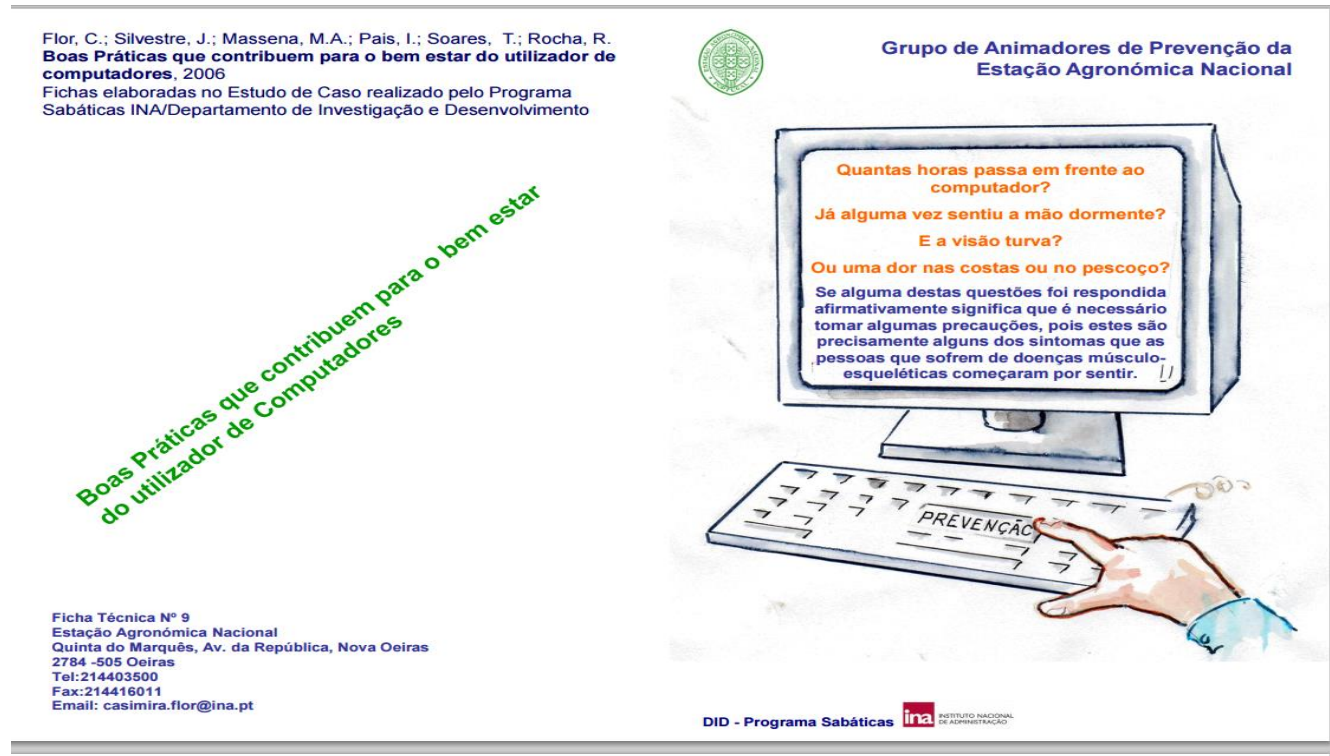

Ficha técnica: Computador-uso-Boas Práticas

$$
\text { BIII - 11/29 }
$$

Comunidad @ Buenas Prácticas de Seguridad, Salud e Calidad de Vida en el trabajo INIAV

"Factores críticos de éxito" 


\section{Doctorado en Salud, Discapacidad, Dependencia y Bienestar}
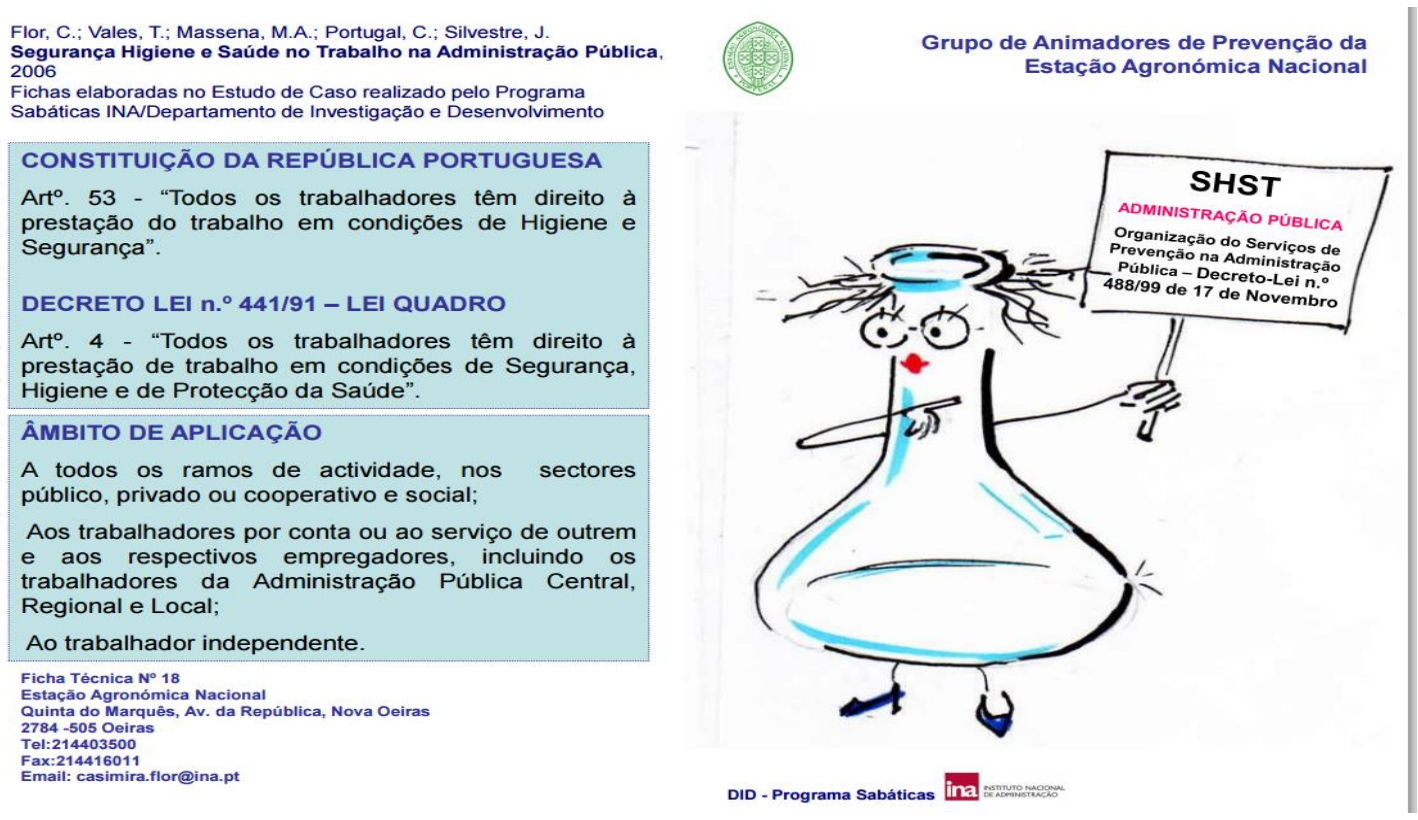

Ficha técnica: Administração Pública SST

Cravo, L.: Massena, M.A.; Portugal, C.; Pals, l.; Silvestre, J.; Hor, C.
Levantamento de Cargas, 2006 Grupo de Animadores de Prevenção da
Fichas elaboradas no Estudo de Caso realizado pelo Programa Sabáticas
INAVDepartamento de Investigaçăo e Desenvolvimento
Estação Agronómica Nacional

\section{Alegria}

Segurança

Higiene

e

Saúde no trabalho!

CULTIVE-AS!
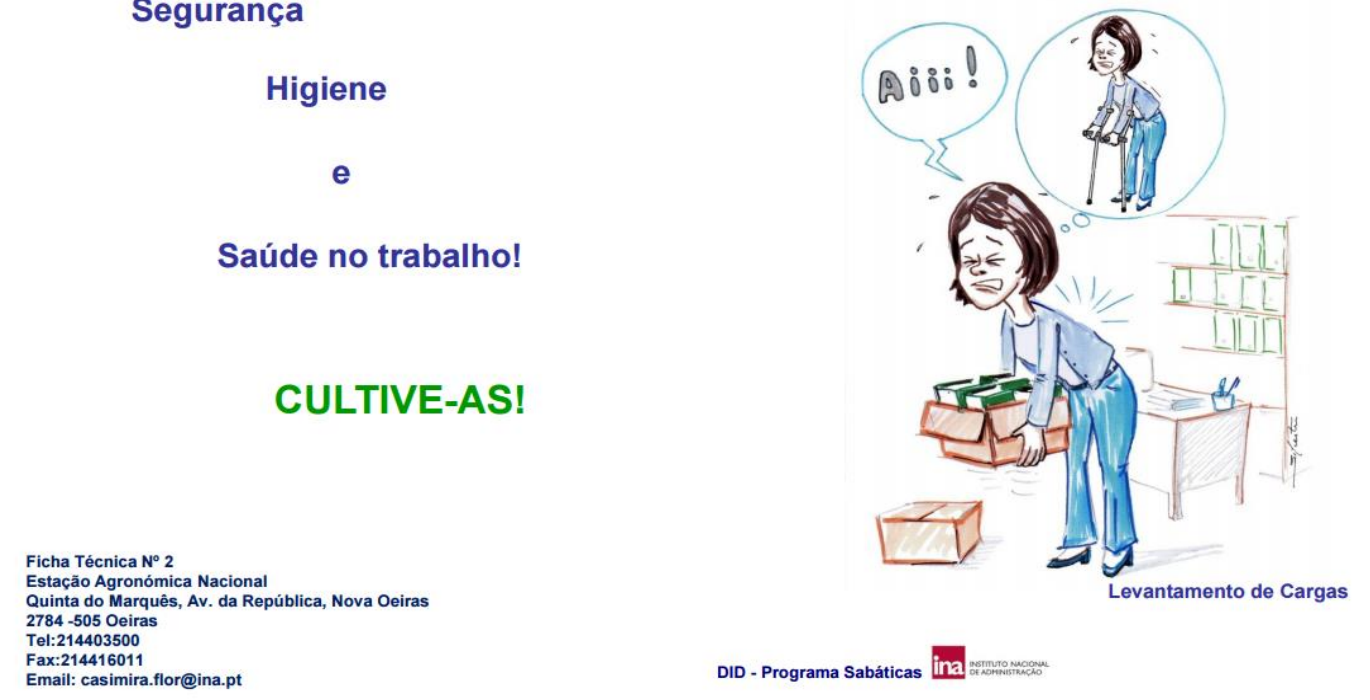

Ficha técnica: Levantamento manual de cargas

BIII - 12/29

Comunidad@ @uenas Prácticas de Seguridad, Salud e Calidad de Vida en el trabajo INIAV

"Factores críticos de éxito" 


\section{Doctorado en Salud, Discapacidad, Dependencia y Bienestar}

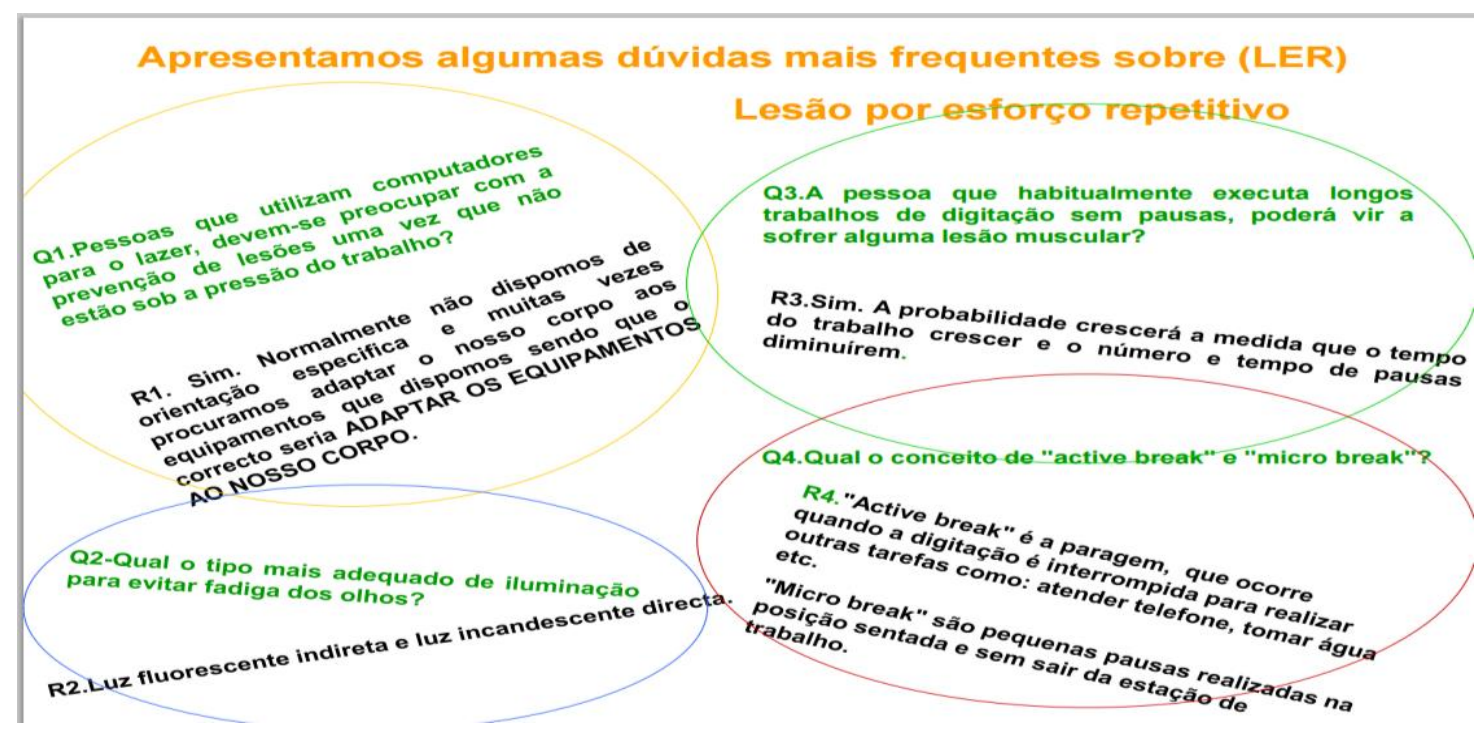

Ficha técnica: Lesões por esforço repetitivo

\section{EXERCICIOS DE ALONGAMENTO E} RELAXAMENTO

Estes exercícios podem ser executados no trabalho. Eles ajudam a evitar ou minimizar os efeitos das dores causadas pelas posiçōes inadequadas. É importante fazer deles uma rotina. As sugestőes abaixo devem ser repetidas no mínimo três vezes por dia. Permaneça alguns segundos em cada posição.

\section{COLUNA CERVICAL}

Alongue o pescoço para a frente, para trás e para os lados. Faça uma rotação completa do pescoço sobre os ombros de forma lenta e o mais acentuado possivel, num sentido e depois no outro.
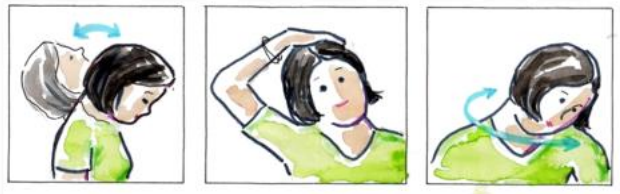

REGIÃO LOMBAR

Separe as duas pernas, flexione levemente os joelhos e solte o corpo para a frente. Relaxe os ombros, procurando chegar com as måos o mais próximo possivel do chăo. Volte à posiçăo inicial endireitando o corpo, vértebra por vértebra.

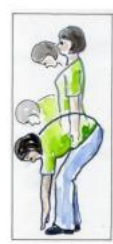

Ficha técnica: Ginástica laboral

\begin{abstract}
OMBROS
Eleve um dos braços na lateral da cabeça e segure-o na região do cotovelo. Repita o exercício com o outro membro.

Cruze a frente do tórax com um dos braços e pressione 0 cotovelo junto ao peito. Repita o movimento com o outro braço. Estique o braço para a frente apoie a palma de uma das mâos na parede. Gire o tronco para o lado oposto. Mantenhase nessa posiçăo até sentir o ombro alongado. Depois, faça uma rotaçåo simultânea nos dois ombros nos dois sentidos.
\end{abstract}
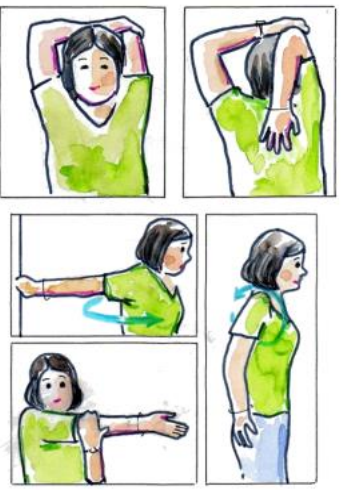

PUNHOS

Estique um dos braços para a frente e puxe o dorso da mão no sentido do antebraço. Em seguida, puxe a palma da mão em direç̧ão ao antebraço. Repita os dois movimentos com o outro braço.
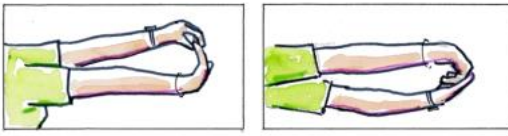

O Grupo de Animadores de SHST da Estação Agronómica Nacional está aqui para vos ajudar. Conte connosco!

BIII - 13/29

Comunidad @ Buenas Prácticas de Seguridad, Salud e Calidad de Vida en el trabajo INIAV 


\section{Doctorado en Salud, Discapacidad, Dependencia y Bienestar}

\section{Interações}

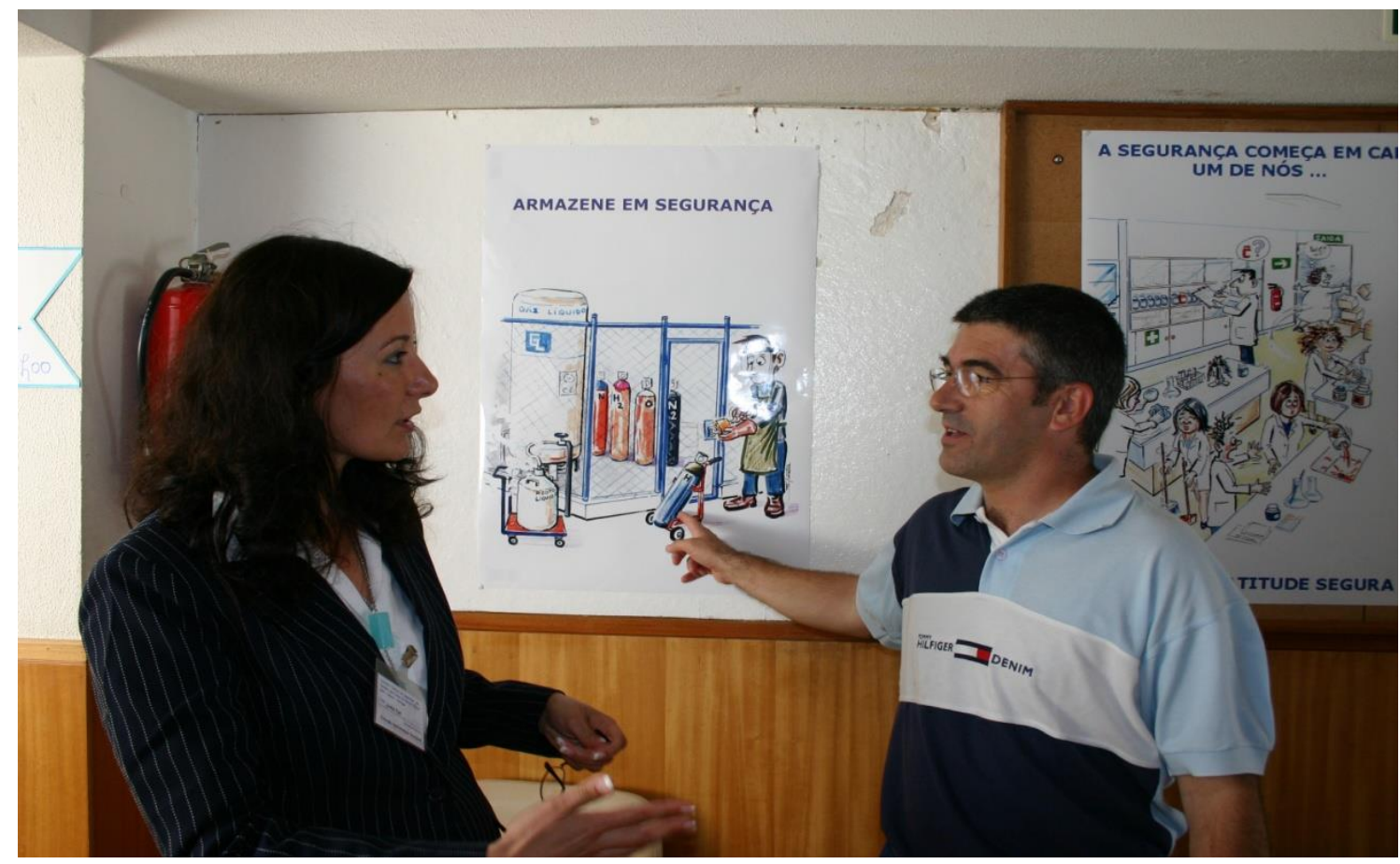

Posters -comunicação síncrona (facilitadora do GAP)

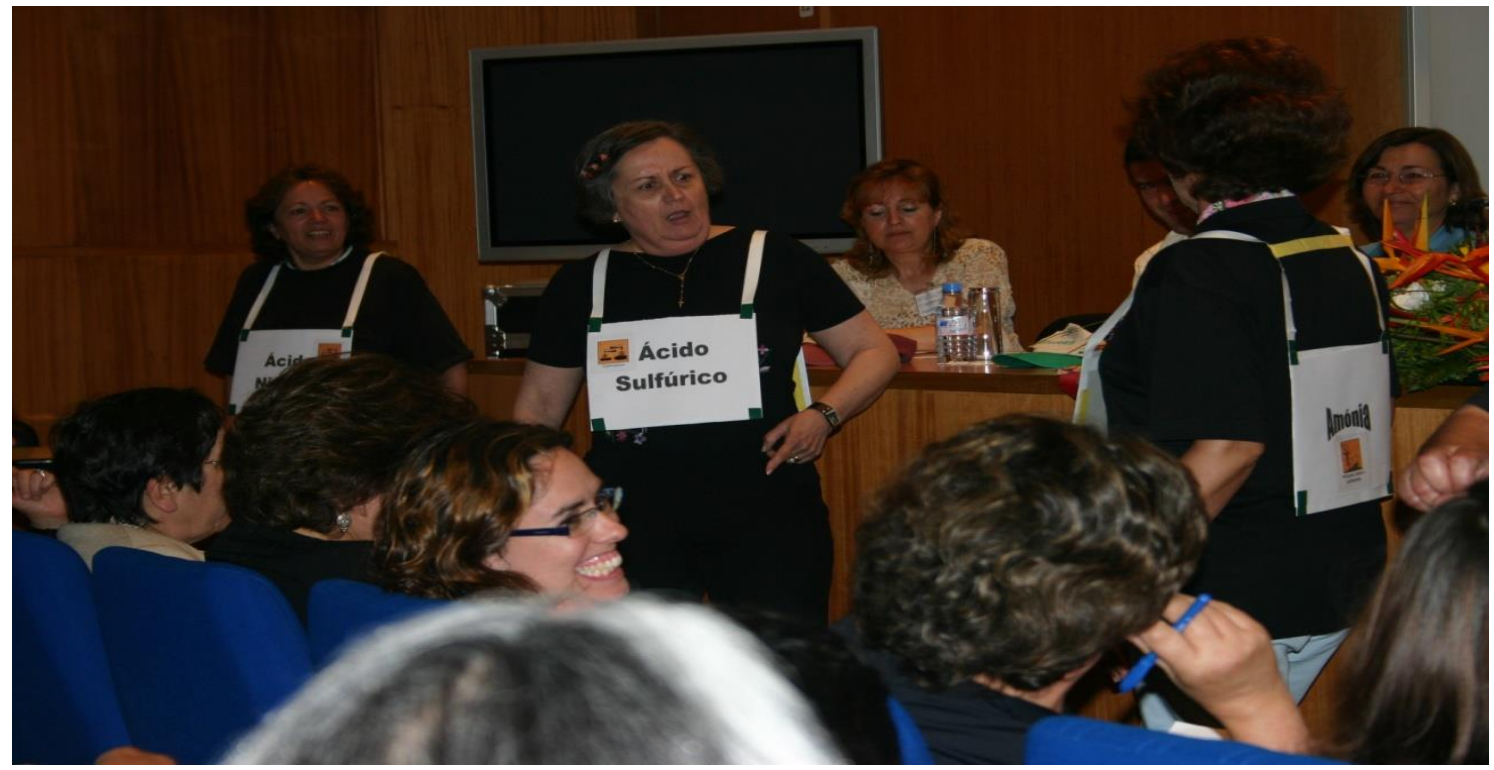

Dramatização, interação com o público | Prevenção Químicos (Gap-interação síncrona) BIII - 14/29

Comunidad @ Buenas Prácticas de Seguridad, Salud e Calidad de Vida en el trabajo INIAV

"Factores críticos de éxito" 


\section{露}

Doctorado en Salud, Discapacidad, Dependencia y Bienestar

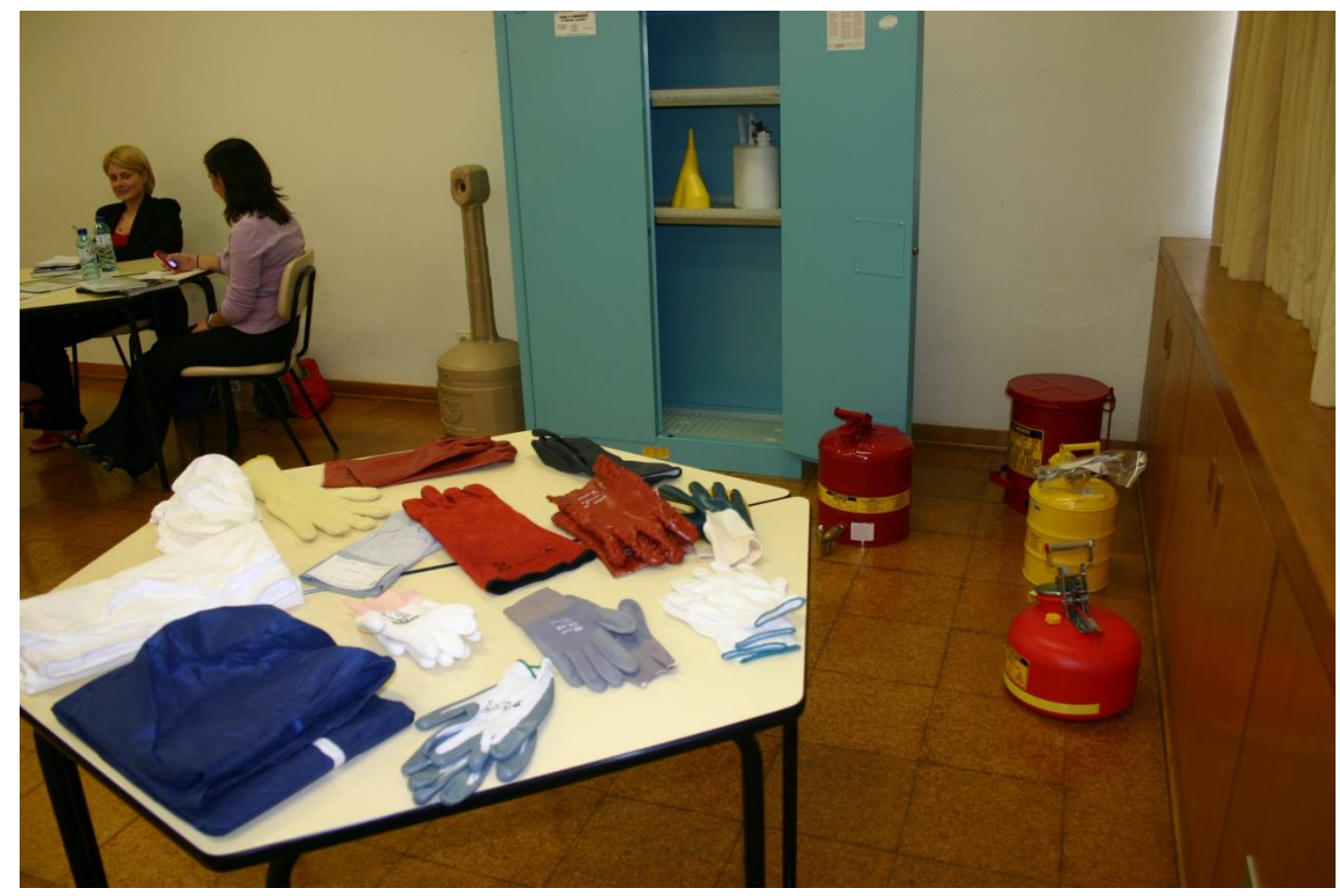

Exposição de Equipamentos de proteção na sala de apoio à interação

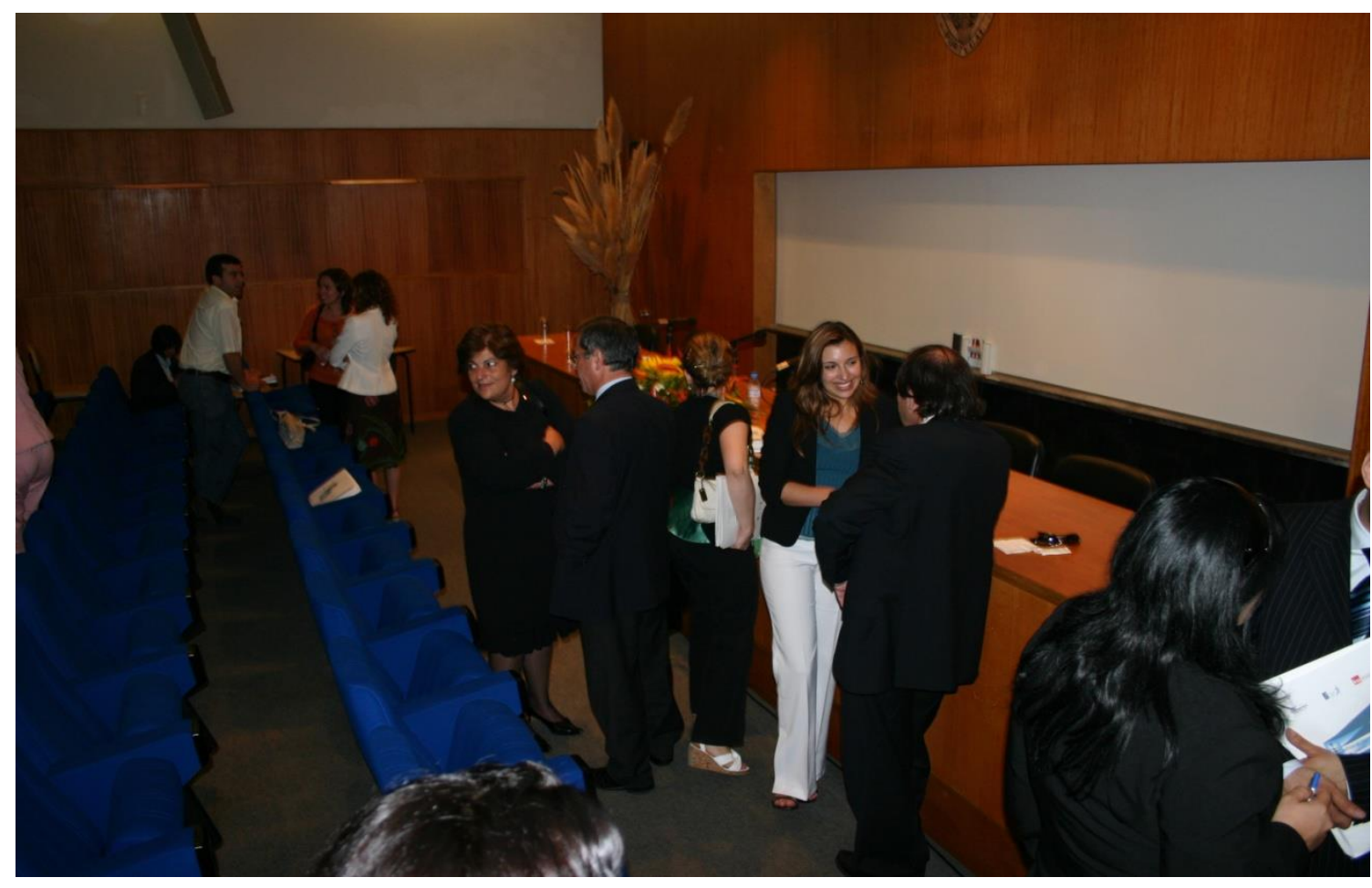

Pausa para partilha de tácito

$$
\text { BIII - 15/29 }
$$

Comunidad @ Buenas Prácticas de Seguridad, Salud e Calidad de Vida en el trabajo INIAV

"Factores críticos de éxito" 
Doctorado en Salud, Discapacidad, Dependencia y Bienestar

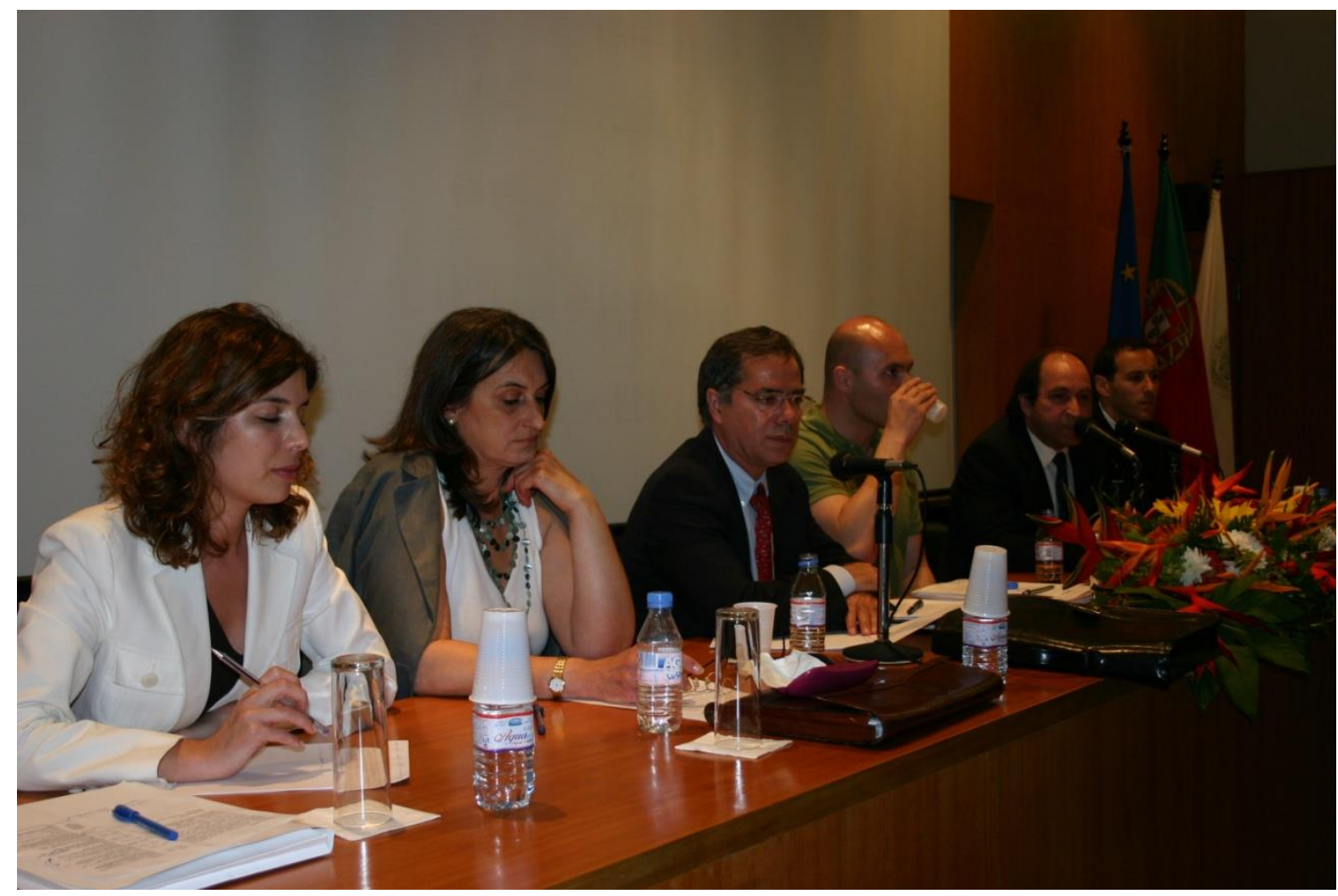

Convite a especialistas SHST - encontro face-to-face

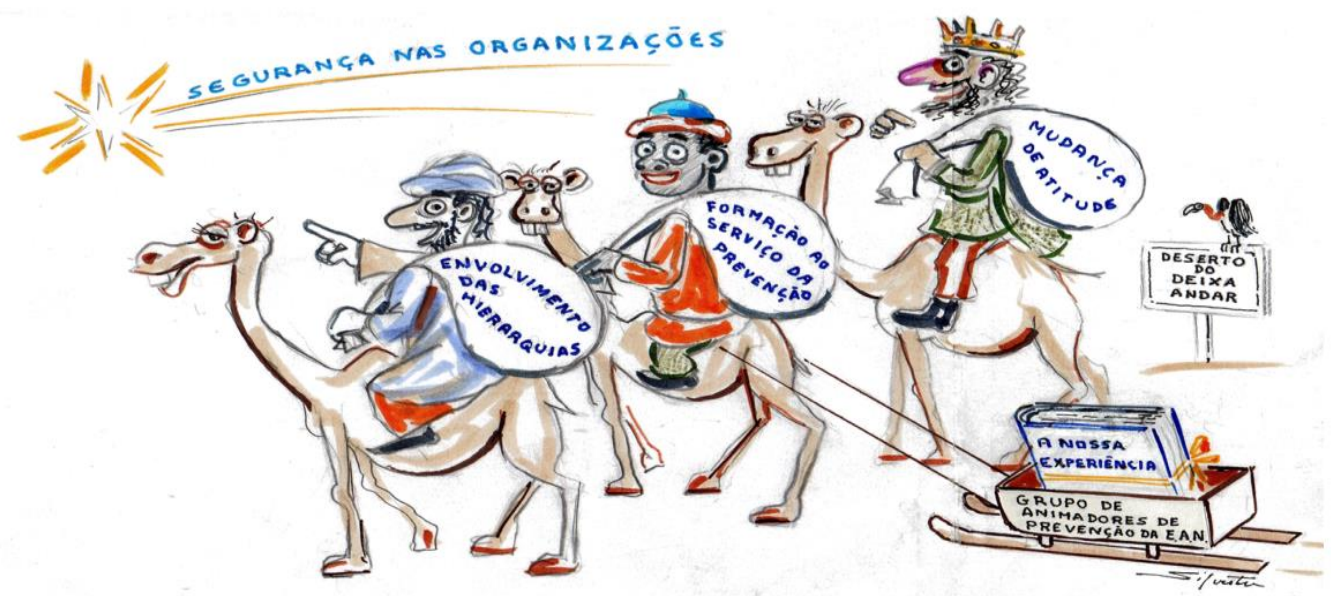

Postal de Natal enviado a todas as chefias para divulgação e a outras Organizações da AP Elaborado pelo GAP

$$
\text { BIII - 16/29 }
$$

Comunidad @ Buenas Prácticas de Seguridad, Salud e Calidad de Vida en el trabajo INIAV

"Factores críticos de éxito" 


\section{Doctorado en Salud, Discapacidad, Dependencia y Bienestar}

Mensagens partilhadas em reuniões /encontros face-to-face

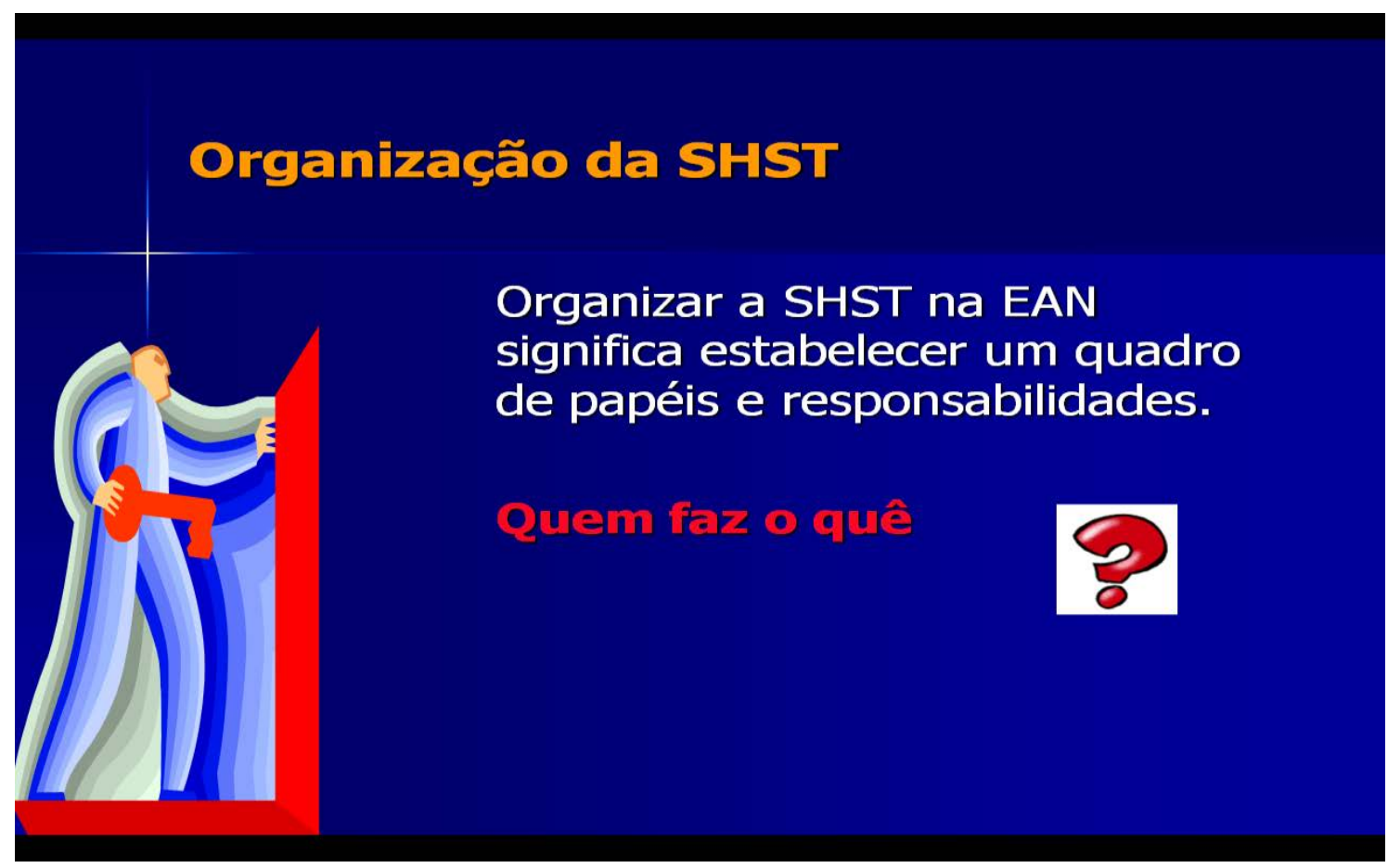

\section{Organização da SHST}

Criar uma rede de relações que permita uma permanente absorção e interpretação dos problemas.

\section{Fazer o quê e com que resultado}

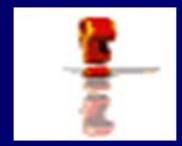

BIII - 17/29

Comunidad @ Buenas Prácticas de Seguridad, Salud e Calidad de Vida en el trabajo INIAV

"Factores críticos de éxito" 
Objectivo Geral da Intervenção

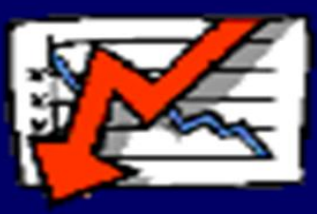

assegurar o "comprometimento da Direcção" na definiç̧ão da Política de Segurança e na sua implementação.

\section{Sucesso irá depender de uma acção concertada a vários níveis}

Empenhamento da alta direcção face à segurança;

Partilha da preocupação dos perigos;

Normas e regras de segurança realistas e flexíveis;

Uma contínua reflexão sobre as práticas de segurança através de mecanismos de monitorização;

Análises e "feed back".

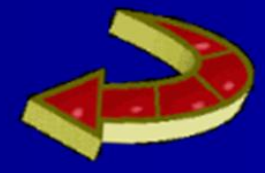

$$
\text { BIII - 18/29 }
$$

Comunidad @ Buenas Prácticas de Seguridad, Salud e Calidad de Vida en el trabajo INIAV 


\section{Realçar a vigilância, promoção} da informaçâo e formação dos trabalhadores equacionando:

(c) Que necessidades existem;

e Quando e para quem;

( Que objectivos de formação se devem identificar;

e Que programas de formação se vão estruturar;

e Como se vão estruturar;

• Como se vão concretizar;

e E qual a eficácia obtida.

\section{Conhecer a Cultura de Segurança}

A cultura de segurança deve ser mudada de forma evolucionária sendo determinante conhecer a cultura organizacional e existir uma compatibilidade entre ambas.

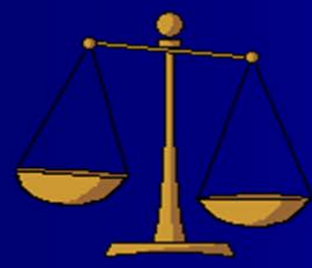

$$
\text { BIII - 19/29 }
$$

Comunidad @ Buenas Prácticas de Seguridad, Salud e Calidad de Vida en el trabajo INIAV 
Doctorado en Salud, Discapacidad, Dependencia y Bienestar

\section{Reuniões com a Direção}

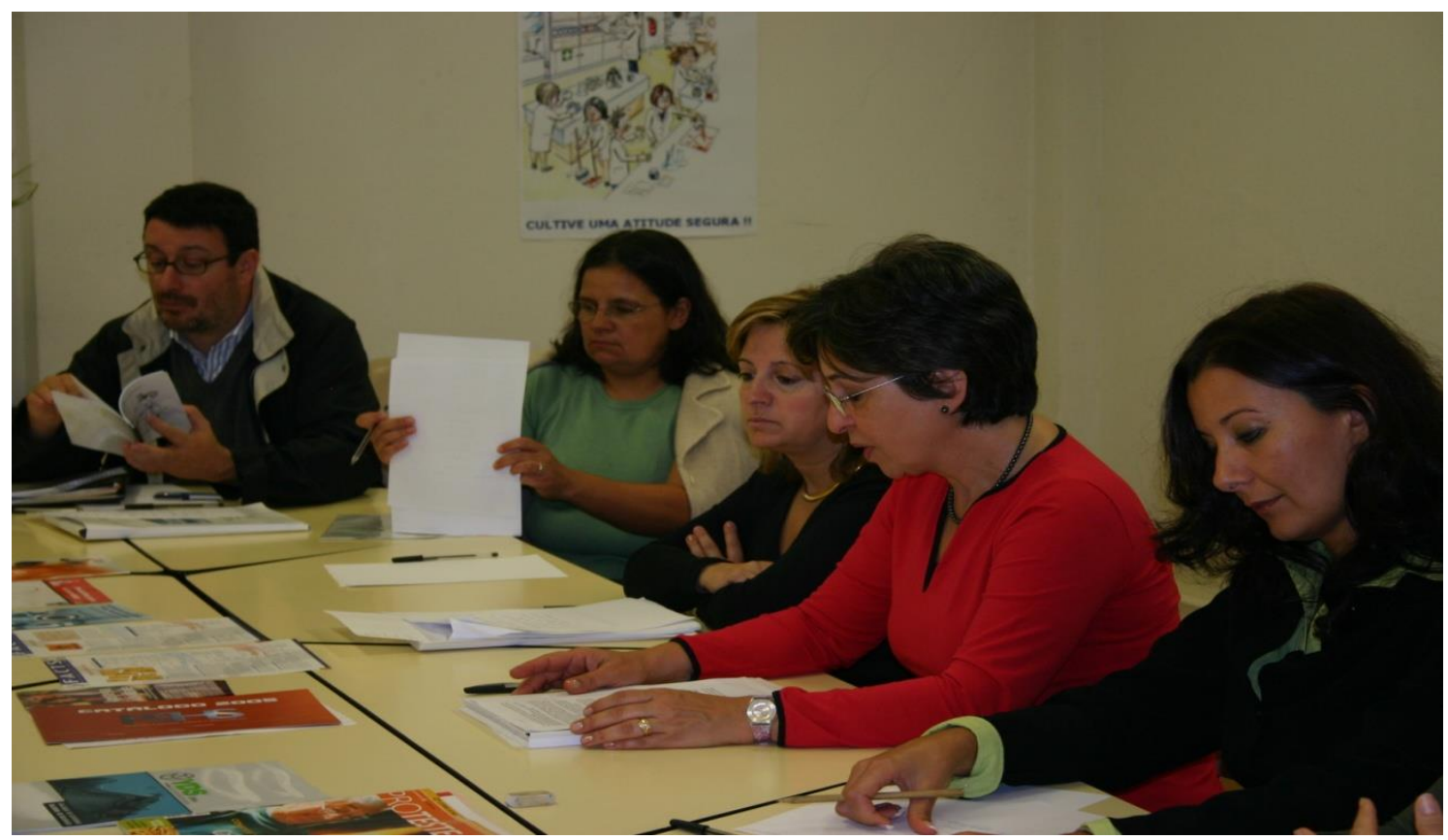

Interação com a Direção da EAN -reunião de trabalho-análise dos materiais elaborados pelo GAP

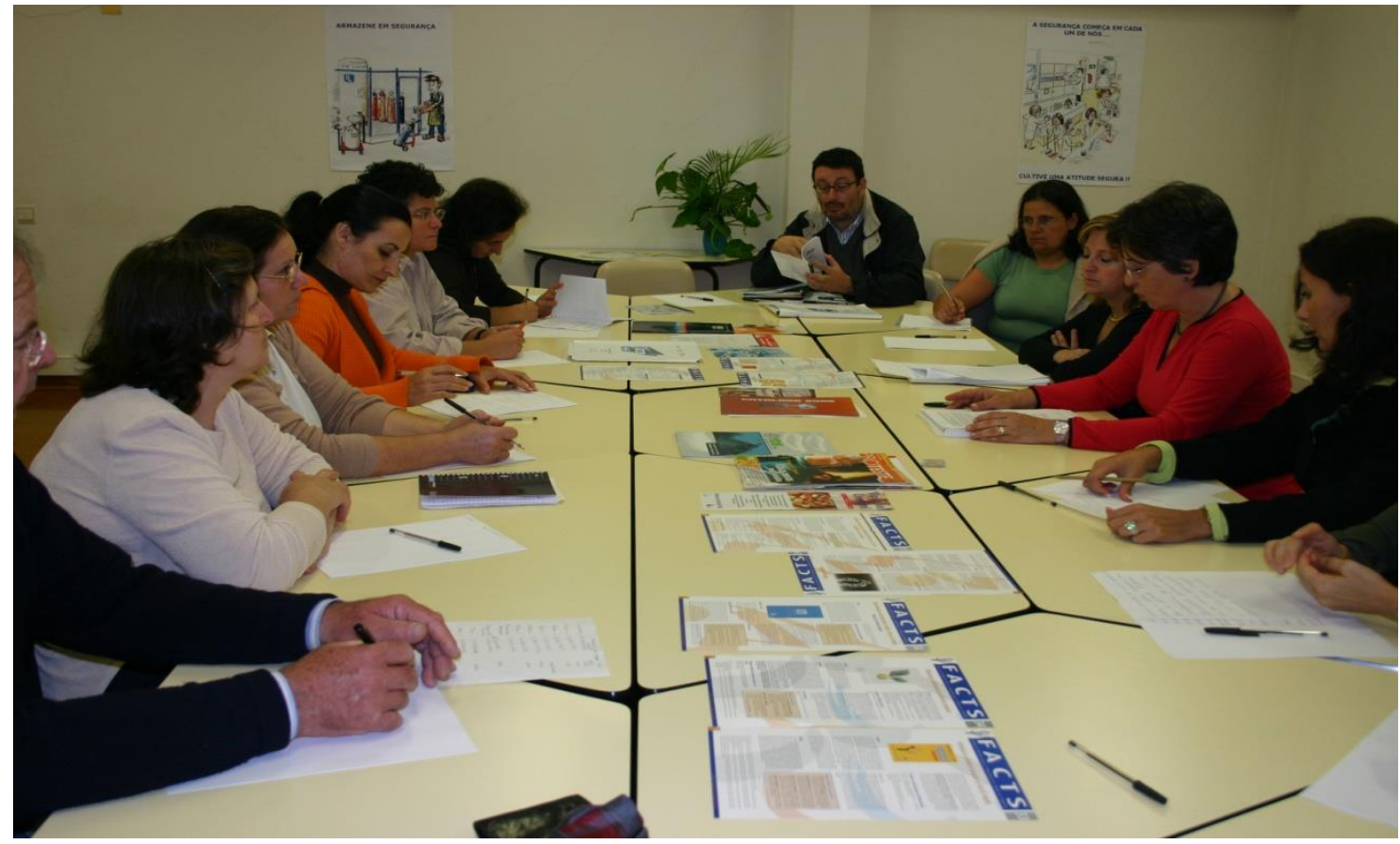

Interação com a Direção da EAN -reunião de trabalho-análise dos materiais elaborados pelo GAP

BIII - 20/29

Comunidad @ Buenas Prácticas de Seguridad, Salud e Calidad de Vida en el trabajo INIAV

"Factores críticos de éxito" 
Doctorado en Salud, Discapacidad, Dependencia y Bienestar

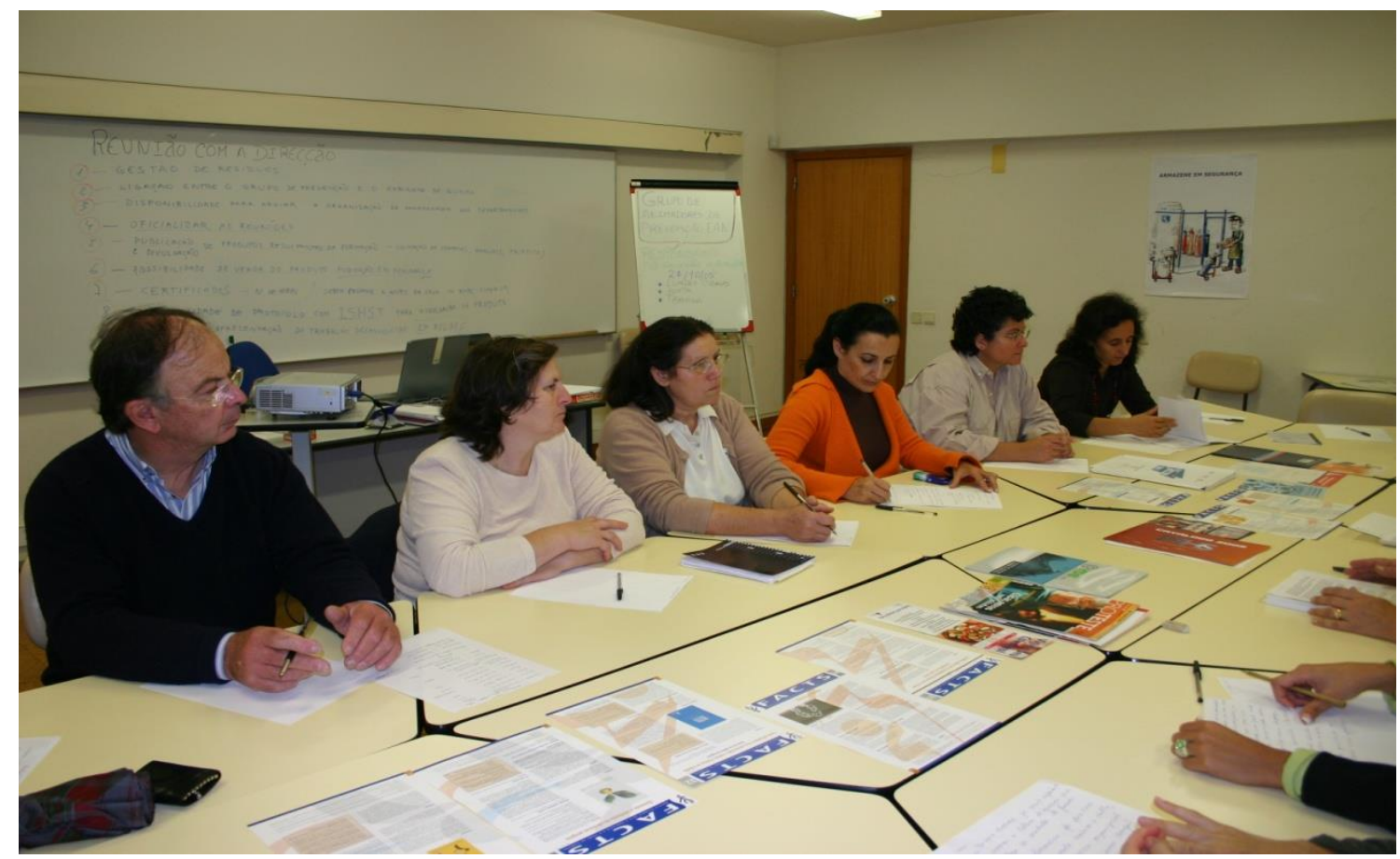

Interação com a Direção da EAN -reunião de trabalho-análise dos materiais elaborados pelo GAP

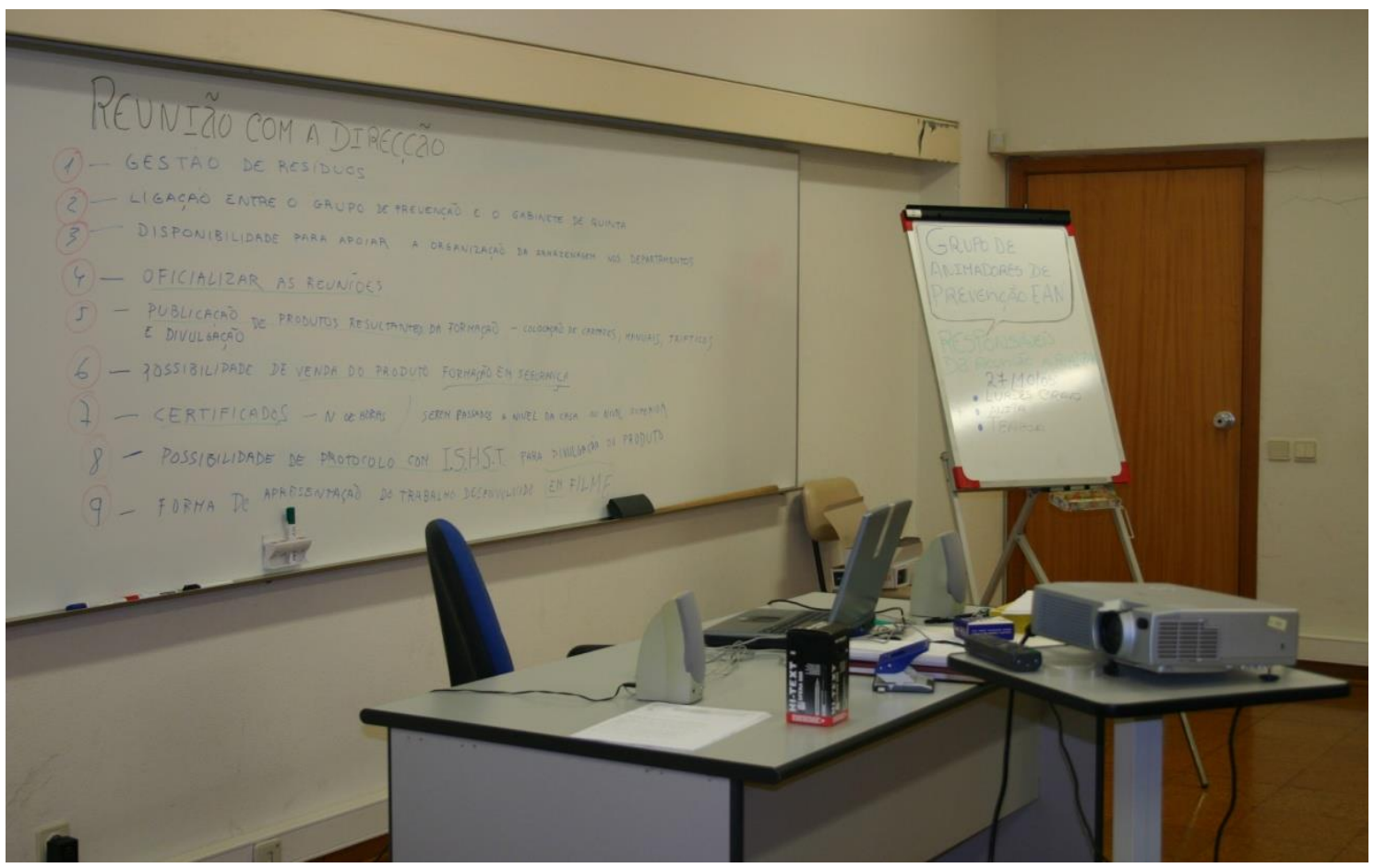

Envolvimento da chefia de topo

BIII - 21/29

Comunidad @ Buenas Prácticas de Seguridad, Salud e Calidad de Vida en el trabajo INIAV

"Factores críticos de éxito" 
Doctorado en Salud, Discapacidad, Dependencia y Bienestar

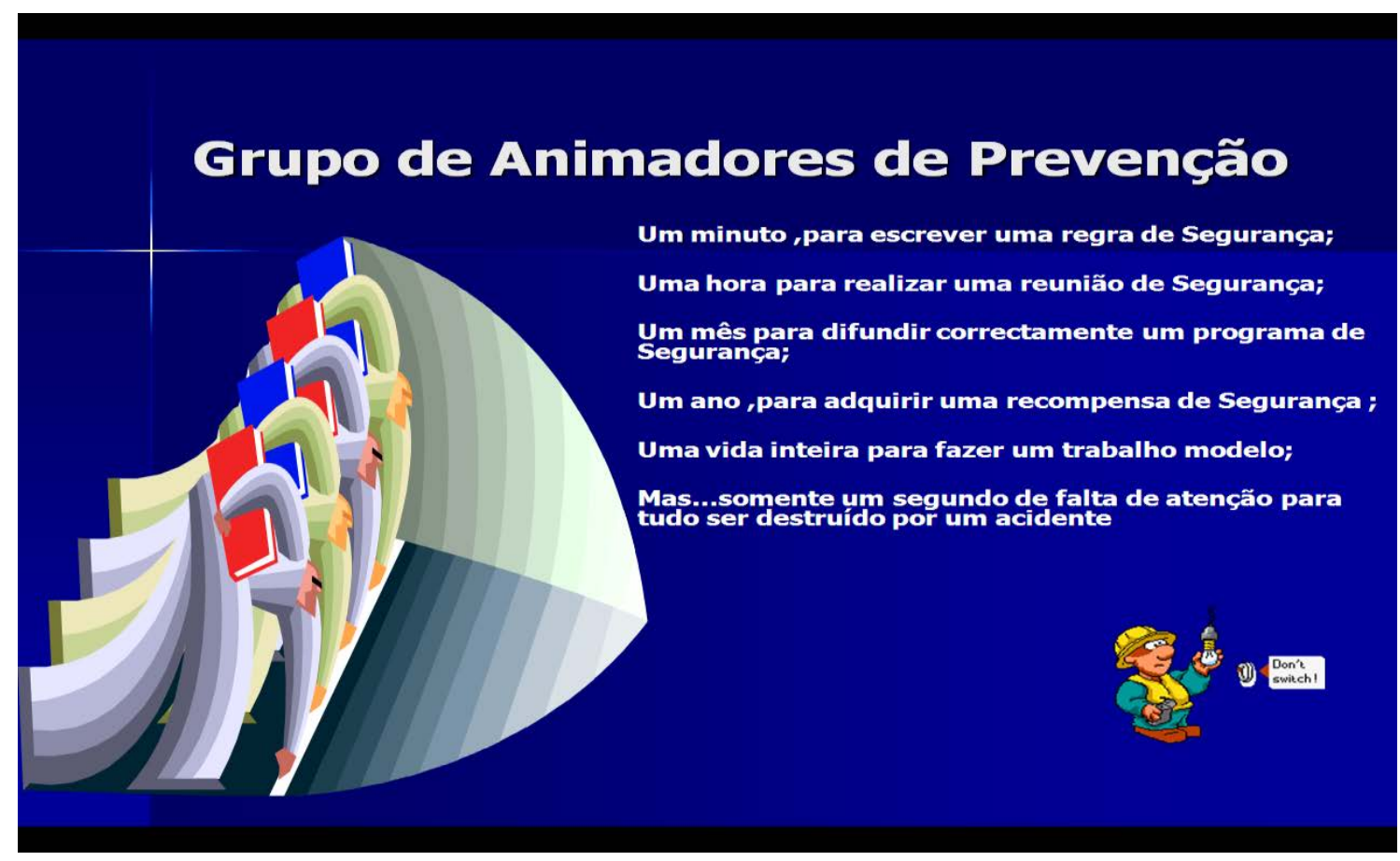

Interações nos eventos presenciais

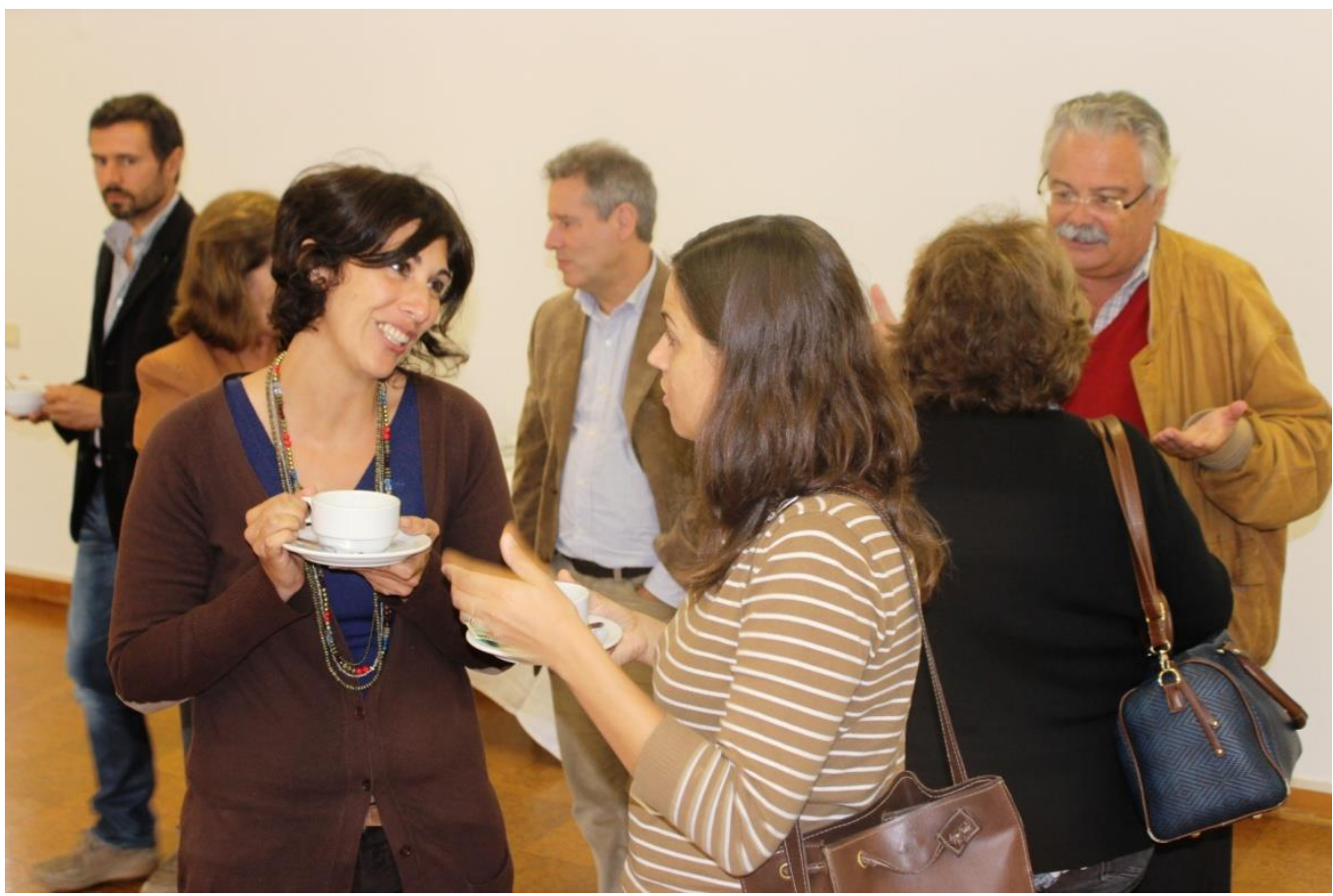

BIII - 22/29

Comunidad @ Buenas Prácticas de Seguridad, Salud e Calidad de Vida en el trabajo INIAV

"Factores críticos de éxito" 


\section{का}

Doctorado en Salud, Discapacidad, Dependencia y Bienestar

\section{Interações nos eventos presenciais}
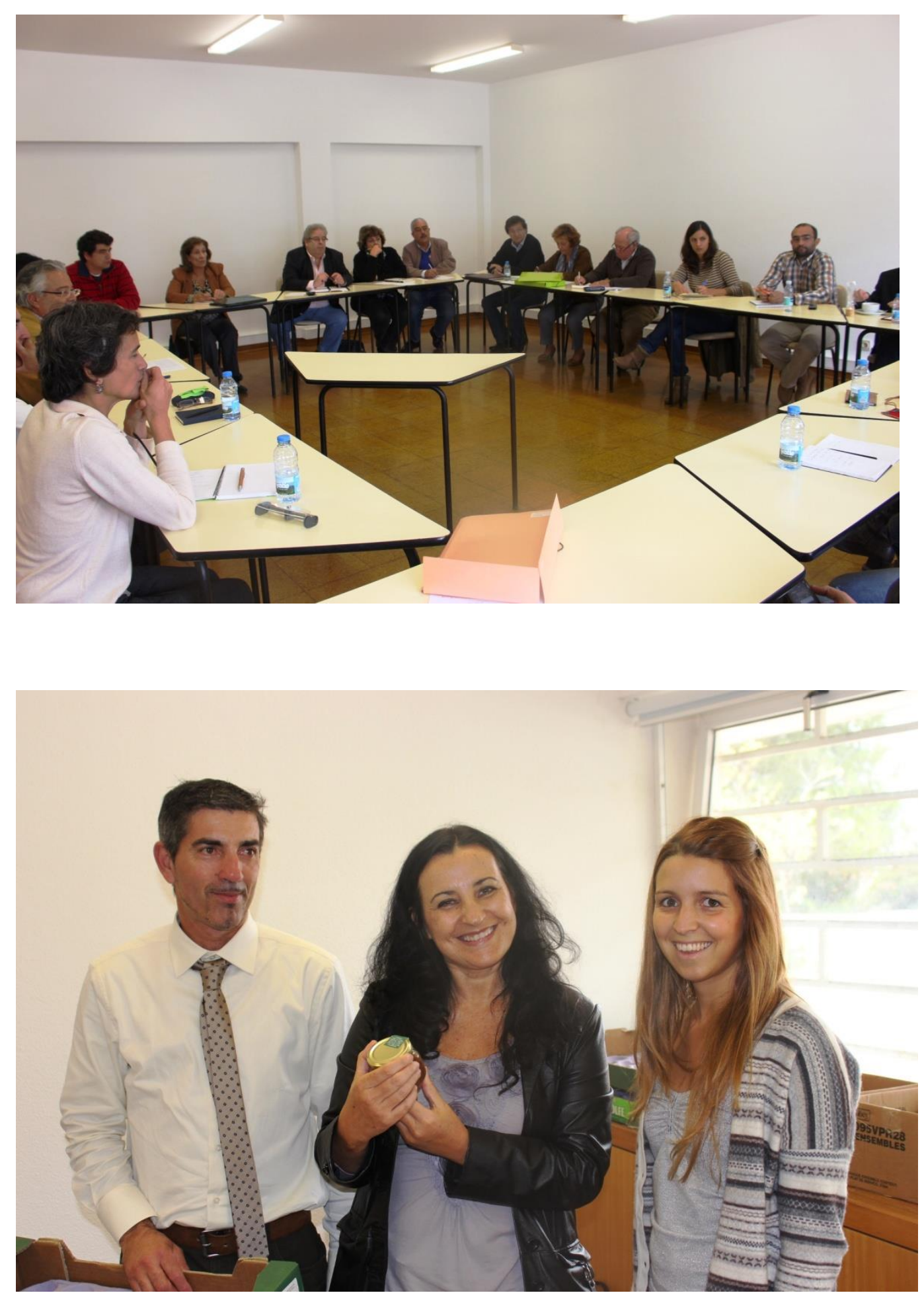

$$
\text { BIII - 23/29 }
$$

Comunidad@ Buenas Prácticas de Seguridad, Salud e Calidad de Vida en el trabajo INIAV "Factores críticos de éxito" 


\section{要}

Doctorado en Salud, Discapacidad, Dependencia y Bienestar
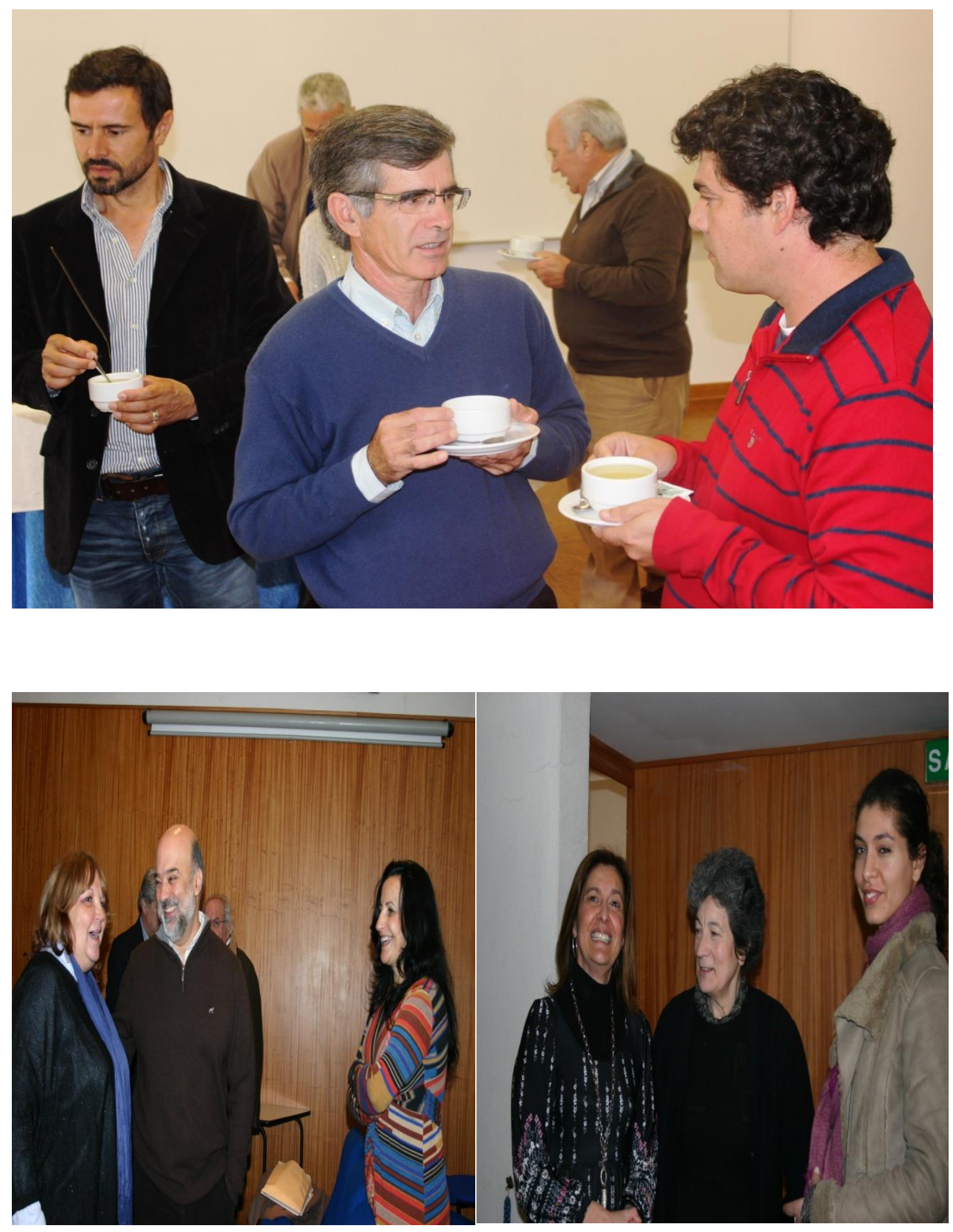

BIII - 24/29

Comunidad@ Buenas Prácticas de Seguridad, Salud e Calidad de Vida en el trabajo INIAV

"Factores críticos de éxito" 


\section{Doctorado en Salud, Discapacidad, Dependencia y Bienestar}

\section{Especialistas -convites}

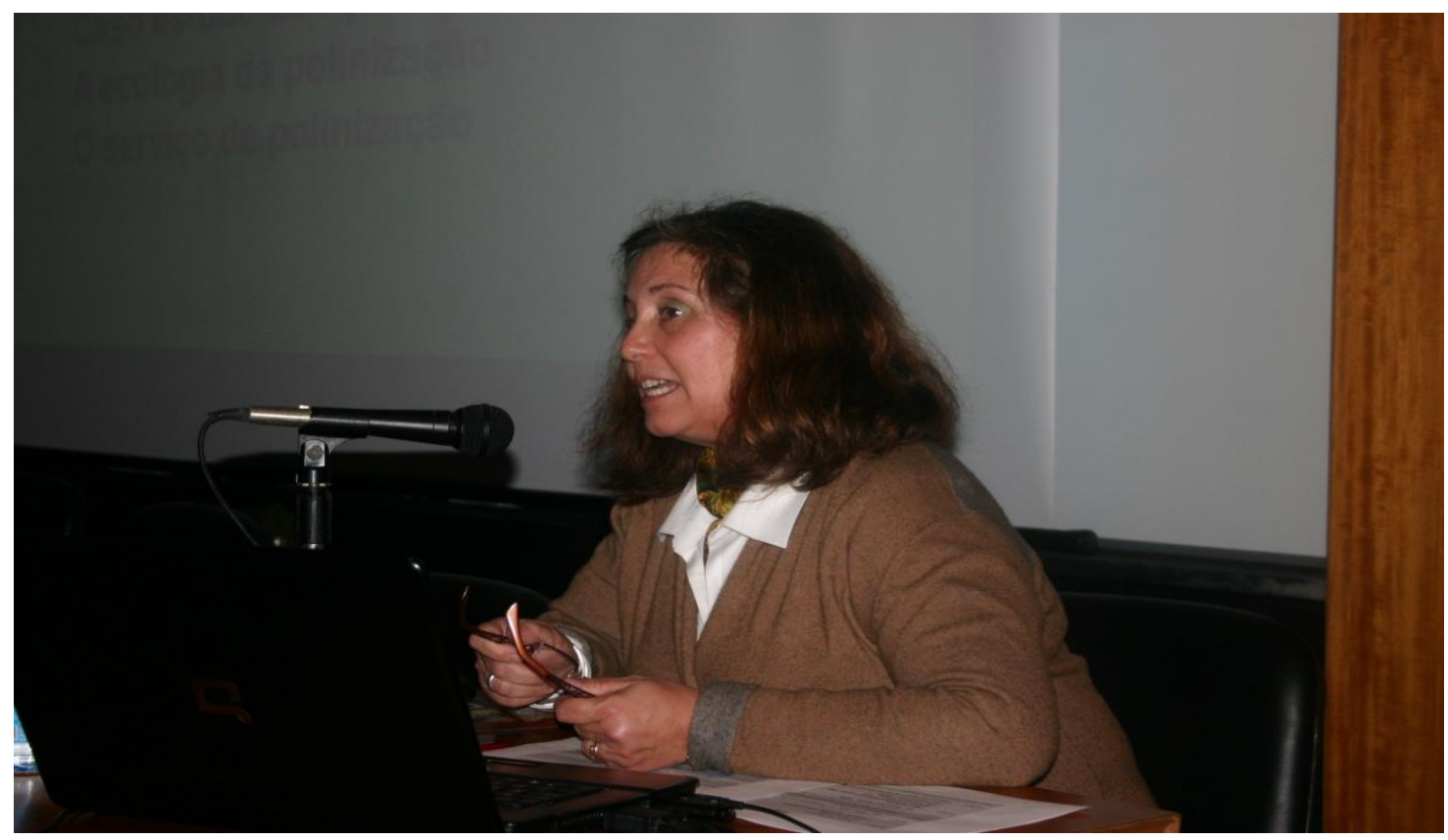

Joana Godinho - Apicultura

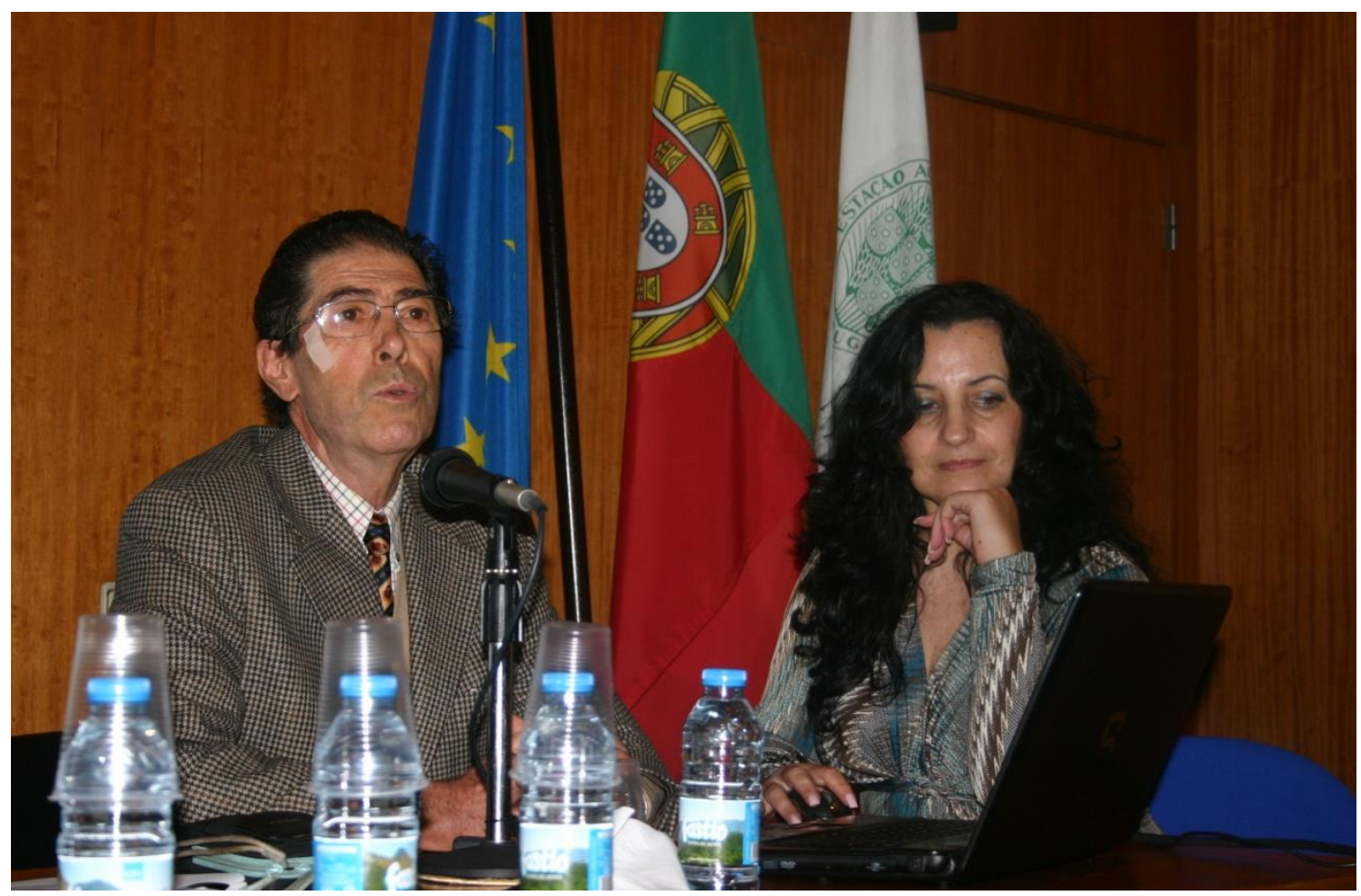

Nuno Costa e Casimira Flor-Apicultura

$$
\text { BIII - 25/29 }
$$

Comunidad @ Buenas Prácticas de Seguridad, Salud e Calidad de Vida en el trabajo INIAV

"Factores críticos de éxito" 
Doctorado en Salud, Discapacidad, Dependencia y Bienestar
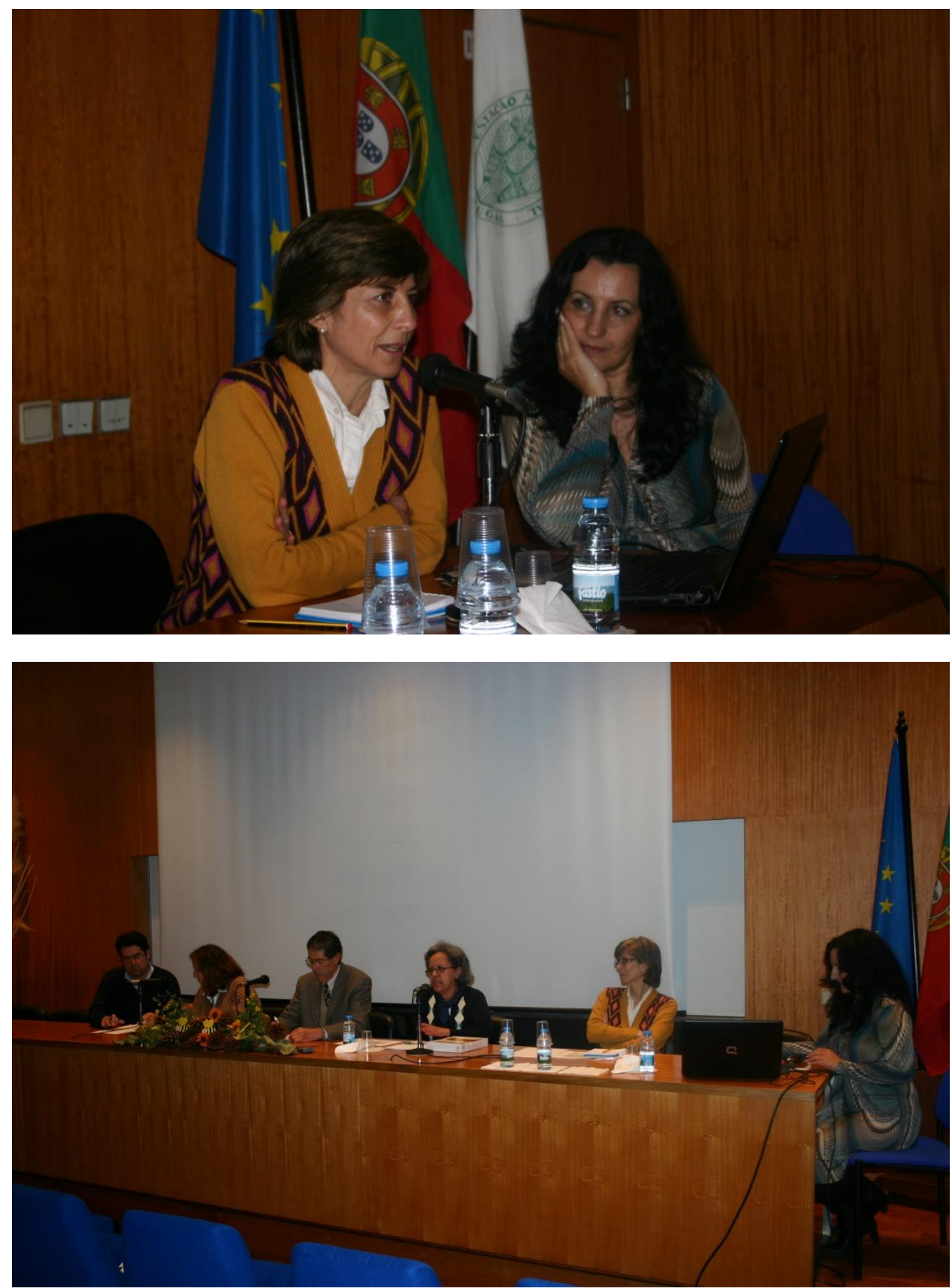

Intervenção da ACT

BIII - 26/29

Comunidad @ Buenas Prácticas de Seguridad, Salud e Calidad de Vida en el trabajo INIAV

"Factores críticos de éxito" 


\section{Doctorado en Salud, Discapacidad, Dependencia y Bienestar}

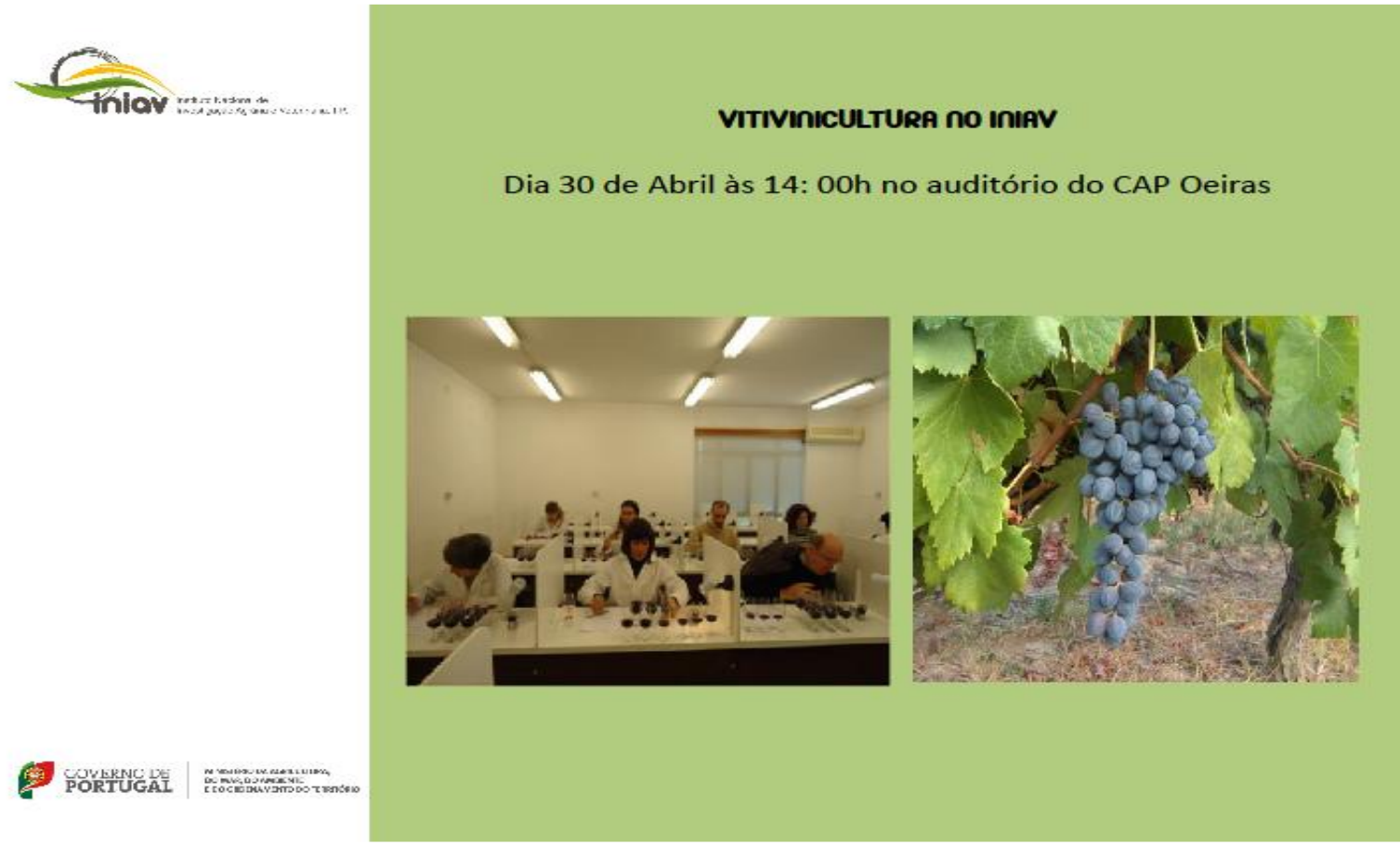

Intervenção de Chefias

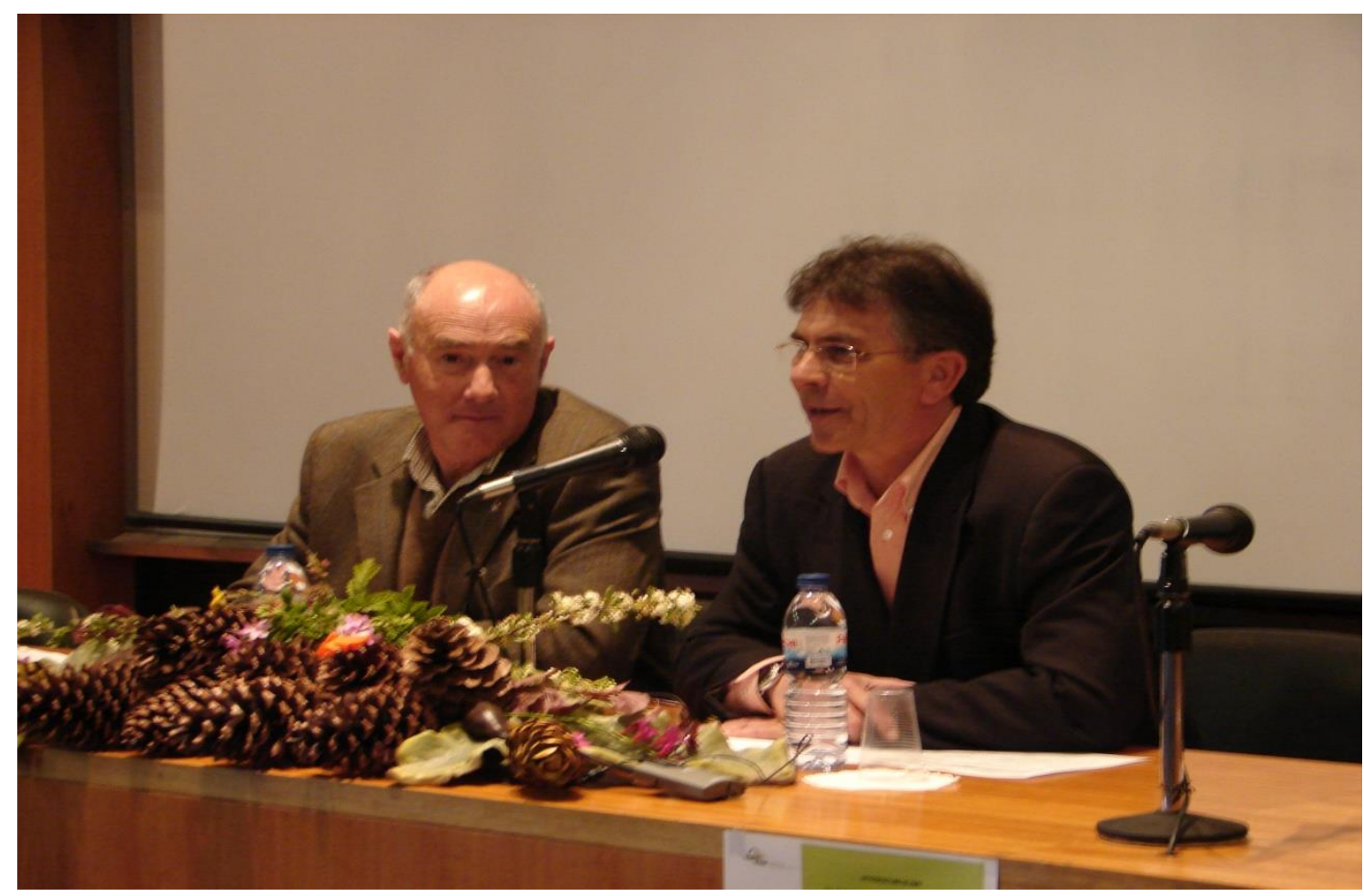

Intervenção de Chefias

BIII - 27/29

Comunidad @ Buenas Prácticas de Seguridad, Salud e Calidad de Vida en el trabajo INIAV

"Factores críticos de éxito" 


\section{妾}

Doctorado en Salud, Discapacidad, Dependencia y Bienestar

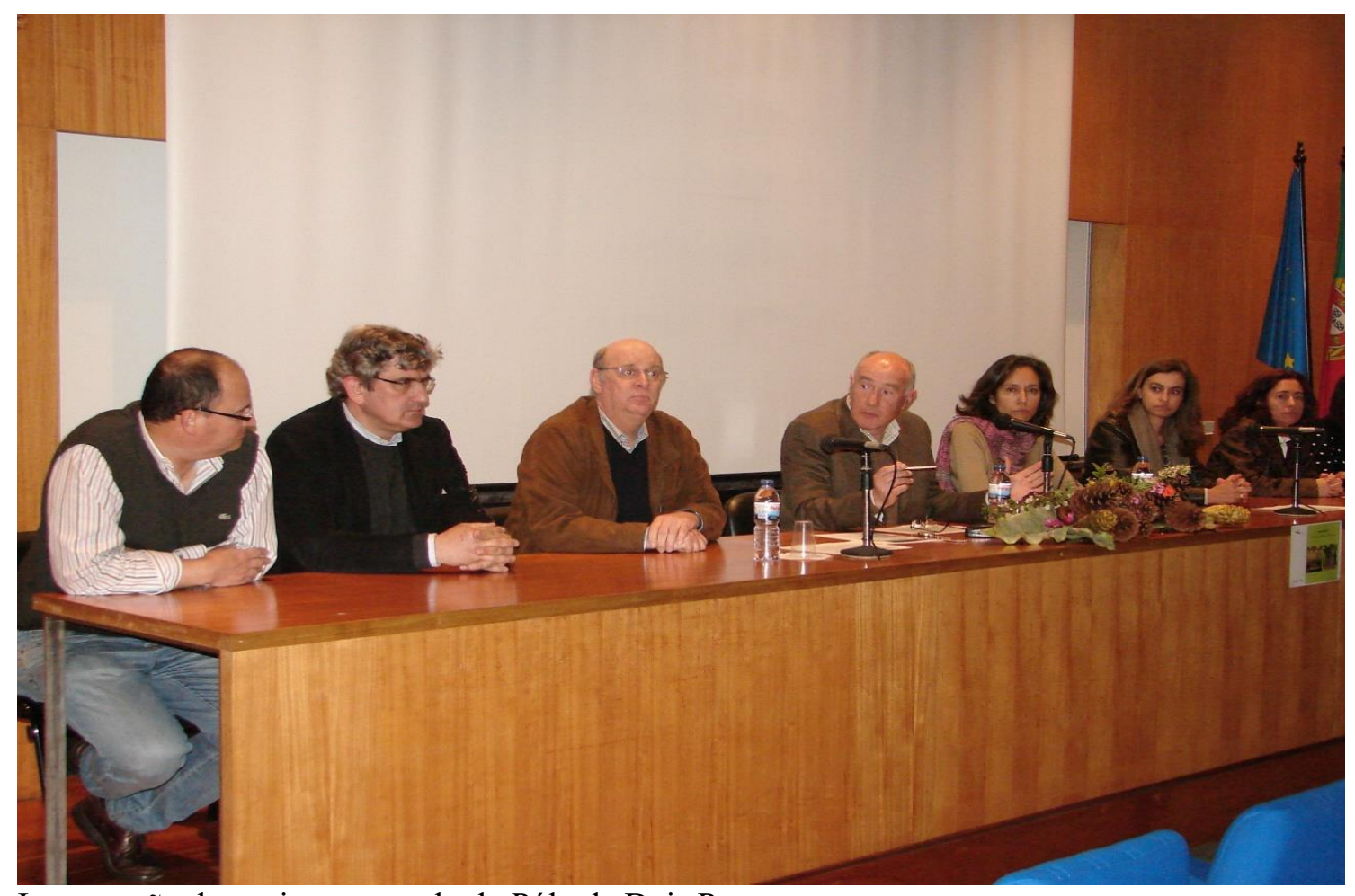

Intervenção da equipa num todo do Pólo de Dois Portos

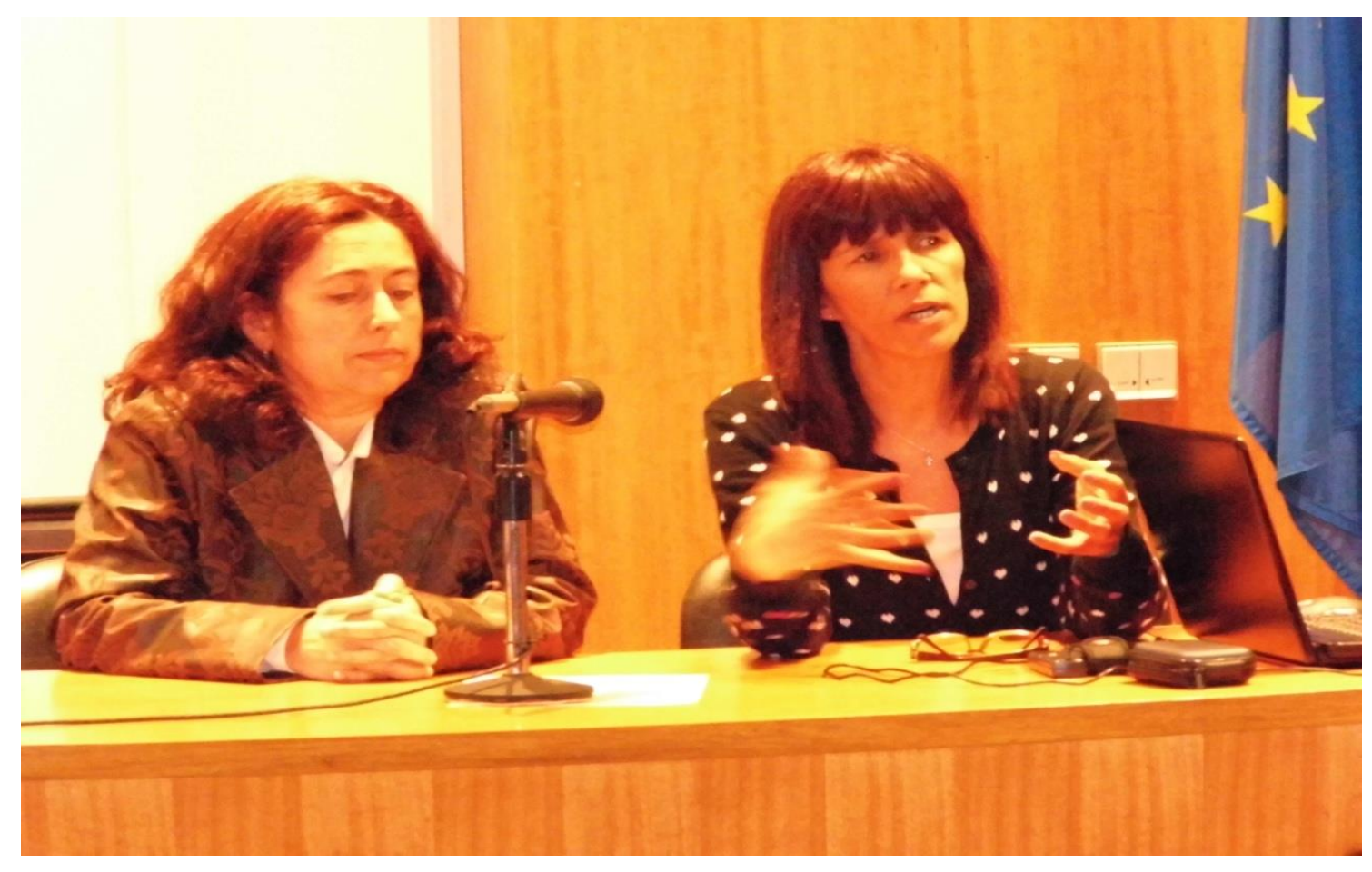

BIII - 28/29

Comunidad@Buenas Prácticas de Seguridad, Salud e Calidad de Vida en el trabajo INIAV

"Factores críticos de éxito" 
Doctorado en Salud, Discapacidad, Dependencia y Bienestar

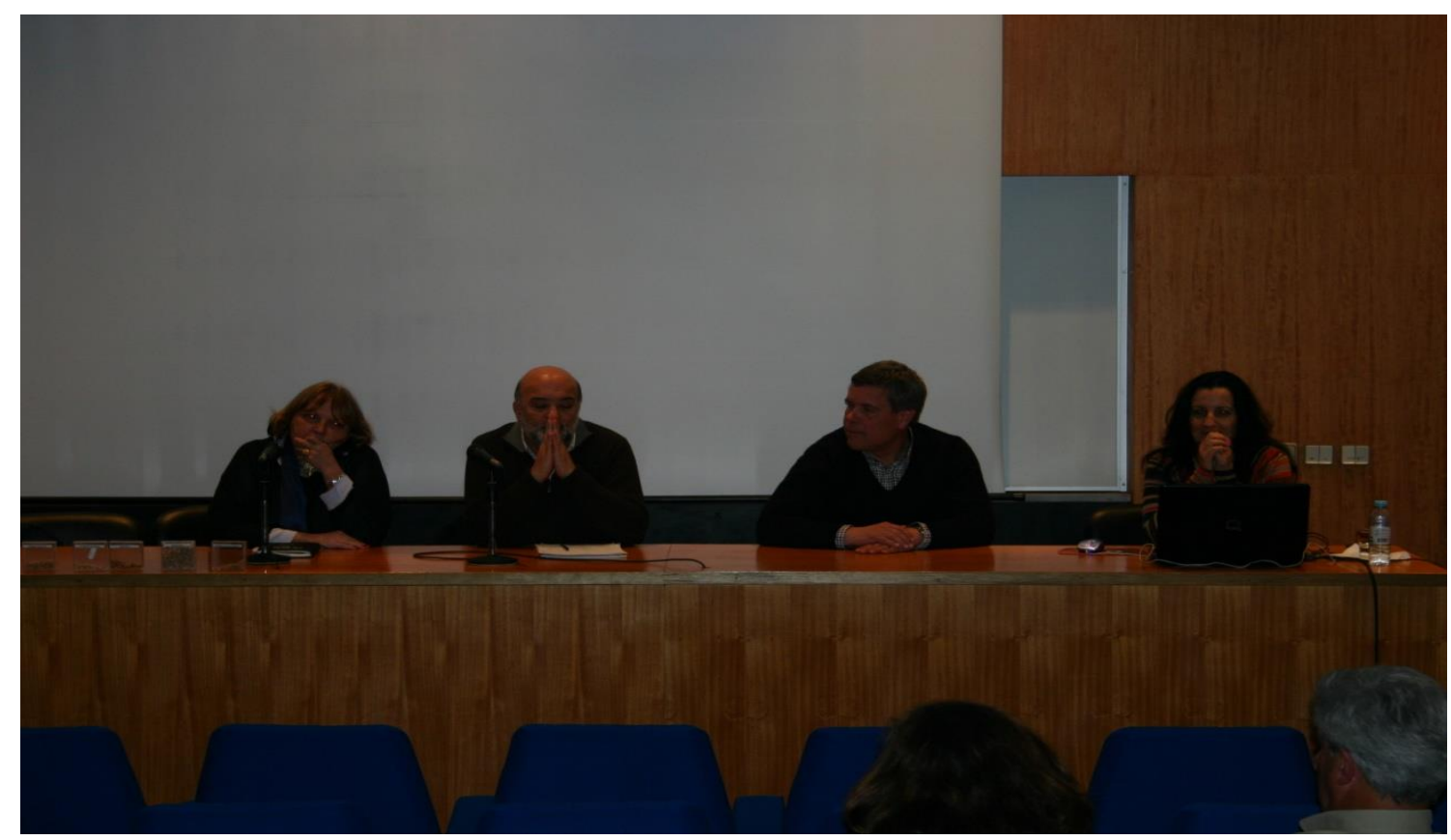

Participação de especialistas

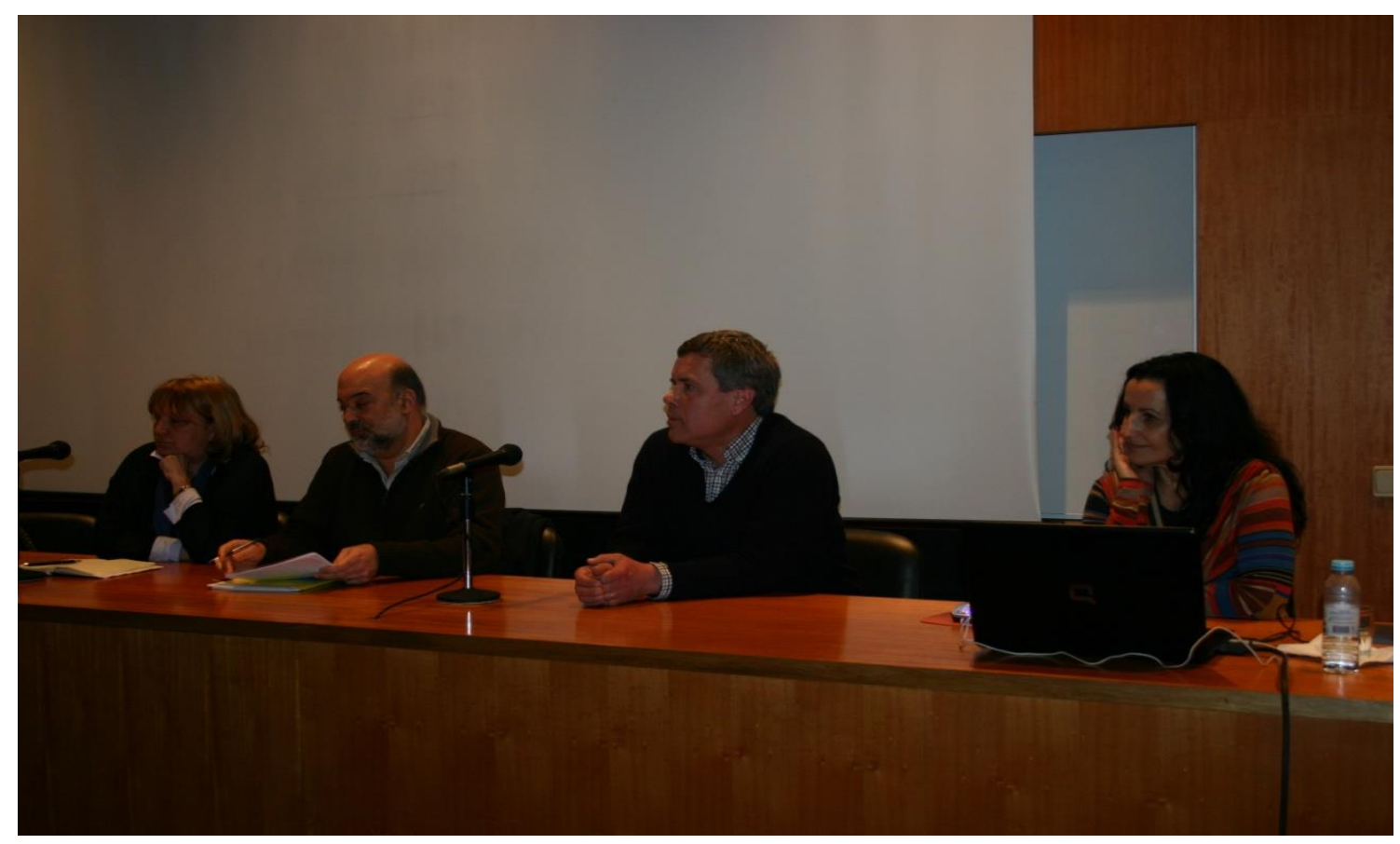

Olivicultura

BIII - 29/29

Comunidad@Buenas Prácticas de Seguridad, Salud e Calidad de Vida en el trabajo INIAV

"Factores críticos de éxito" 


\section{Doctorado en Salud, Discapacidad, Dependencia y Bienestar}

\section{ANEXO BIV - Análise Combinatória Questões analisadas do Questionário Surveys online}

2 - Quando necessita de uma informação ligada à sua área de trabalho / especialização de que forma e onde procura encontrar o conhecimento necessário para resolver o problema?

8 - Quais os fatores que contribuem para que as pessoas partilhem informações e experiências?

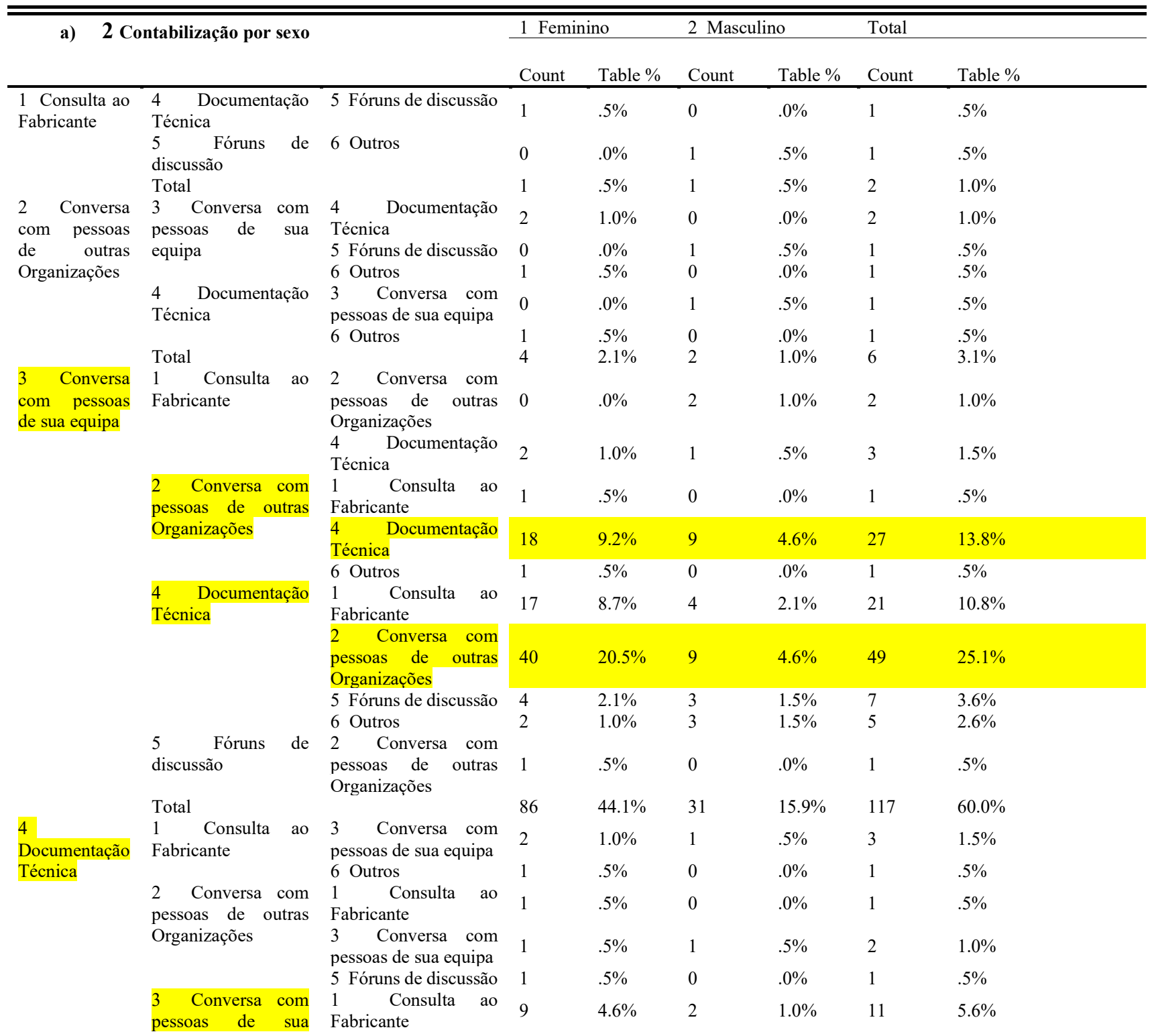

Comunidad@ @uenas Prácticas de Seguridad, Salud e Calidad de Vida en el trabajo INIAV

"Factores críticos de éxito" 


\section{Doctorado en Salud, Discapacidad, Dependencia y Bienestar}

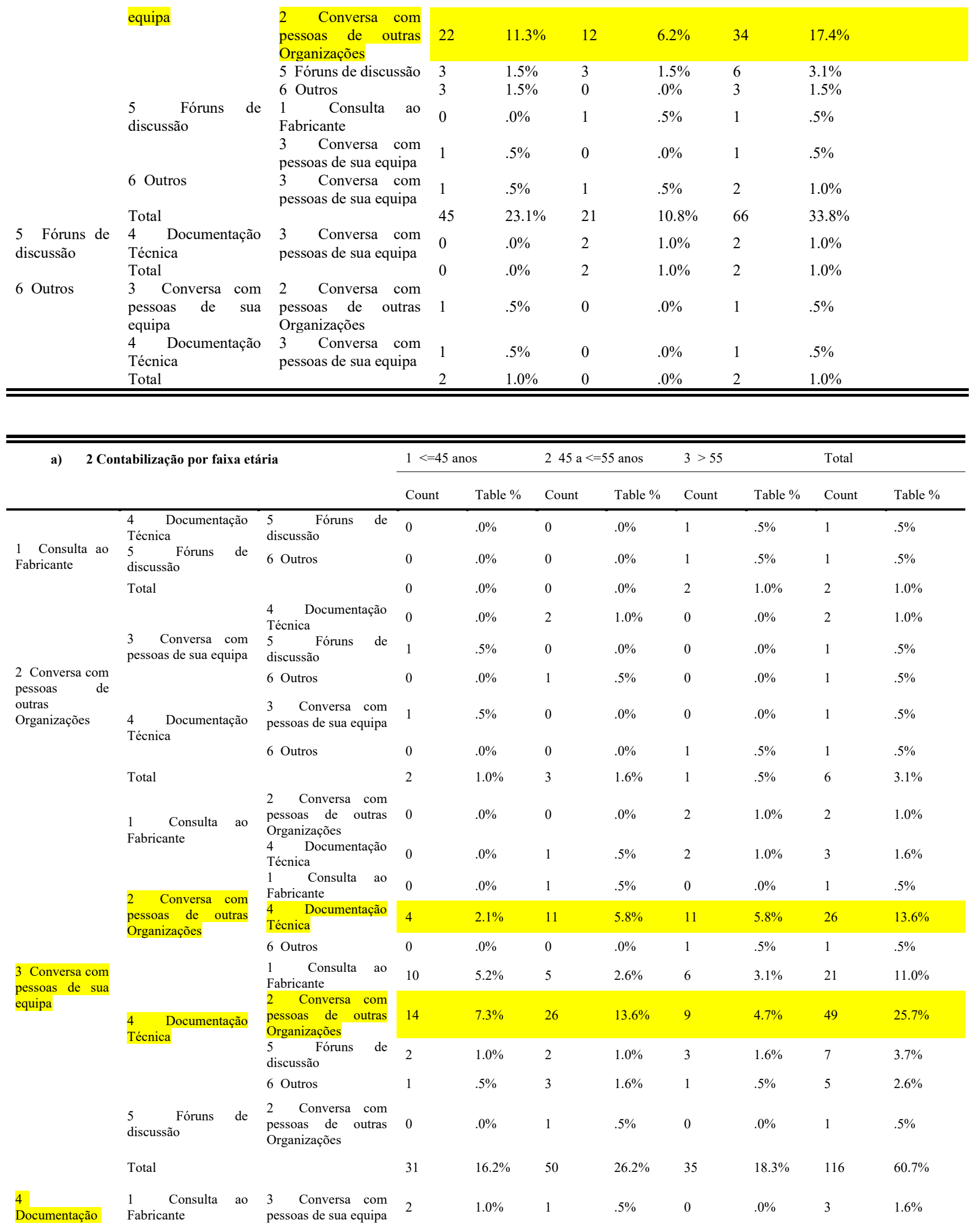

Comunidad @ Buenas Prácticas de Seguridad, Salud e Calidad de Vida en el trabajo INIAV 


\section{Doctorado en Salud, Discapacidad, Dependencia y Bienestar}

\begin{tabular}{|c|c|c|c|c|c|c|c|c|c|c|}
\hline \multirow[t]{11}{*}{ Técnica } & & 6 Outros & 0 & $.0 \%$ & 1 & $.5 \%$ & 0 & $.0 \%$ & 1 & $.5 \%$ \\
\hline & \multirow{4}{*}{$\begin{array}{l}2 \text { Conversa com } \\
\text { pessoas de outras } \\
\text { Organizações }\end{array}$} & $\begin{array}{l}1 \text { Consulta ao } \\
\text { Fabricante }\end{array}$ & 0 & $.0 \%$ & 1 & $.5 \%$ & 0 & $.0 \%$ & 1 & $.5 \%$ \\
\hline & & $\begin{array}{l}3 \quad \text { Conversa com } \\
\text { pessoas de sua equipa }\end{array}$ & 1 & $.5 \%$ & 1 & $.5 \%$ & 0 & $.0 \%$ & 2 & $1.0 \%$ \\
\hline & & $\begin{array}{l}5 \text { Fóruns de } \\
\text { discussão }\end{array}$ & 0 & $.0 \%$ & 1 & $.5 \%$ & 0 & $.0 \%$ & 1 & $.5 \%$ \\
\hline & & $\begin{array}{l}1 \text { Consulta ao } \\
\text { Fabricante }\end{array}$ & 5 & $2.6 \%$ & 4 & $2.1 \%$ & 2 & $1.0 \%$ & 11 & $5.8 \%$ \\
\hline & \multirow[t]{3}{*}{$\begin{array}{l}3 \text { Conversa com } \\
\text { pessoas de sua equipa }\end{array}$} & $\begin{array}{l}2 \text { Conversa com } \\
\text { pessoas de outras } \\
\text { Organizações }\end{array}$ & 5 & $2.6 \%$ & 19 & $9.9 \%$ & 8 & $4.2 \%$ & 32 & $16.8 \%$ \\
\hline & & $\begin{array}{l}5 \text { Fóruns de } \\
\text { discussão }\end{array}$ & 2 & $1.0 \%$ & 4 & $2.1 \%$ & 0 & $.0 \%$ & 6 & $3.1 \%$ \\
\hline & & 6 Outros & 0 & $.0 \%$ & 0 & $.0 \%$ & 3 & $1.6 \%$ & 3 & $1.6 \%$ \\
\hline & $\begin{array}{l}5 \quad \text { Fóruns de } \\
\text { discussão }\end{array}$ & $\begin{array}{lr}3 & \text { Conversa } \\
\text { pessoas de sua equipa }\end{array}$ & 1 & $.5 \%$ & 0 & $.0 \%$ & 0 & $.0 \%$ & 1 & $.5 \%$ \\
\hline & 6 Outros & $\begin{array}{l}3 \text { Conversa com } \\
\text { pessoas de sua equipa }\end{array}$ & 0 & $.0 \%$ & 2 & $1.0 \%$ & 0 & $.0 \%$ & 2 & $1.0 \%$ \\
\hline & Total & & 16 & $8.4 \%$ & 34 & $17.8 \%$ & 13 & $6.8 \%$ & 63 & $33.0 \%$ \\
\hline \multirow{3}{*}{$\begin{array}{l}5 \quad \text { Fóruns de } \\
\text { discussão }\end{array}$} & $\begin{array}{l}4 \quad \text { Documentação } \\
\text { Técnica }\end{array}$ & $\begin{array}{l}3 \text { Conversa com } \\
\text { pessoas de sua equipa }\end{array}$ & 0 & $.0 \%$ & 1 & $.5 \%$ & 1 & $.5 \%$ & 2 & $1.0 \%$ \\
\hline & Total & & 0 & $.0 \%$ & 1 & $.5 \%$ & 1 & $.5 \%$ & 2 & $1.0 \%$ \\
\hline & $\begin{array}{l}3 \text { Conversa com } \\
\text { pessoas de sua equipa }\end{array}$ & $\begin{array}{l}2 \text { Conversa com } \\
\text { pessoas de outras } \\
\text { Organizações }\end{array}$ & 1 & $.5 \%$ & 0 & $.0 \%$ & 0 & $.0 \%$ & 1 & $.5 \%$ \\
\hline \multirow[t]{2}{*}{6 Outros } & $\begin{array}{l}4 \quad \text { Documentação } \\
\text { Técnica }\end{array}$ & $\begin{array}{lr}3 \quad \text { Conversa com } \\
\text { pessoas de sua equipa }\end{array}$ & 1 & $.5 \%$ & 0 & $.0 \%$ & 0 & $.0 \%$ & 1 & $.5 \%$ \\
\hline & Total & & 2 & $1.0 \%$ & 0 & $.0 \%$ & 0 & $.0 \%$ & 2 & $1.0 \%$ \\
\hline
\end{tabular}

\begin{tabular}{|c|c|c|c|c|c|c|c|c|c|c|c|}
\hline $\begin{array}{l}\text { 2-Contabili } \\
\text { número de }\end{array}$ & $\begin{array}{ll}\text { zação por } \\
\text { casos }\end{array}$ & função em & $\begin{array}{l}1 \\
\text { Assistent } \\
\text { e Técnico }\end{array}$ & $\begin{array}{l}2 \\
\text { Investigaçã } \\
\text { o } \\
\text { (Assistente } \\
\text { de) }\end{array}$ & $\begin{array}{l}3 \\
\text { Investigad } \\
\text { or } \\
\text { (Bolseiro) }\end{array}$ & $\begin{array}{l}4 \\
\text { Investigad } \\
\text { or Auxiliar }\end{array}$ & $\begin{array}{l}5 \\
\text { Investigad } \\
\text { or } \\
\text { Principal }\end{array}$ & $\begin{array}{l}6 \text { Técnico } \\
\text { de } \\
\text { Informátic } \\
\text { a }\end{array}$ & $\begin{array}{l}7 \\
\text { Técnic } \\
\text { o } \\
\text { Superio } \\
\mathrm{r}\end{array}$ & $\begin{array}{l}8 \\
\text { Omiss } \\
\mathrm{o}\end{array}$ & Total \\
\hline \multirow[t]{3}{*}{$\begin{array}{l}1 \text { Consulta } \\
\text { ao } \\
\text { Fabricante }\end{array}$} & $\begin{array}{l}4 \\
\text { Documentaç } \\
\text { ão Técnica }\end{array}$ & $\begin{array}{l}5 \text { Fóruns de } \\
\text { discussão }\end{array}$ & 0 & 0 & 0 & 0 & 0 & 0 & 1 & 0 & 1 \\
\hline & $\begin{array}{l}5 \text { Fóruns de } \\
\text { discussão }\end{array}$ & 6 Outros & 0 & 0 & 0 & 0 & 0 & 0 & 1 & 0 & 1 \\
\hline & Total & & 0 & 0 & 0 & 0 & 0 & 0 & 2 & 0 & 2 \\
\hline \multirow{6}{*}{$\begin{array}{l}2 \text { Conversa } \\
\text { com } \\
\text { pessoas de } \\
\text { outras } \\
\text { Organizaçõ } \\
\text { es }\end{array}$} & $\begin{array}{l}3 \text { Conversa } \\
\text { com pessoas } \\
\text { de sua equipa }\end{array}$ & $\begin{array}{l}4 \\
\text { Documentaç } \\
\text { ão Técnica }\end{array}$ & 0 & 0 & 0 & 2 & 0 & 0 & 0 & 0 & 2 \\
\hline & & $\begin{array}{l}5 \text { Fóruns de } \\
\text { discussão }\end{array}$ & 0 & 0 & 0 & 1 & 0 & 0 & 0 & 0 & 1 \\
\hline & & 6 Outros & 0 & 0 & 0 & 0 & 0 & 0 & 1 & 0 & 1 \\
\hline & $\begin{array}{l}4 \\
\text { Documentaç } \\
\text { ão Técnica }\end{array}$ & $\begin{array}{l}3 \text { Conversa } \\
\text { com pessoas } \\
\text { de sua equipa }\end{array}$ & 1 & 0 & 0 & 0 & 0 & 0 & 0 & 0 & 1 \\
\hline & & 6 Outros & 0 & 0 & 0 & 1 & 0 & 0 & 0 & 0 & 1 \\
\hline & Total & & 1 & 0 & 0 & 4 & 0 & 0 & 1 & 0 & 6 \\
\hline
\end{tabular}




\section{Doctorado en Salud, Discapacidad, Dependencia y Bienestar}

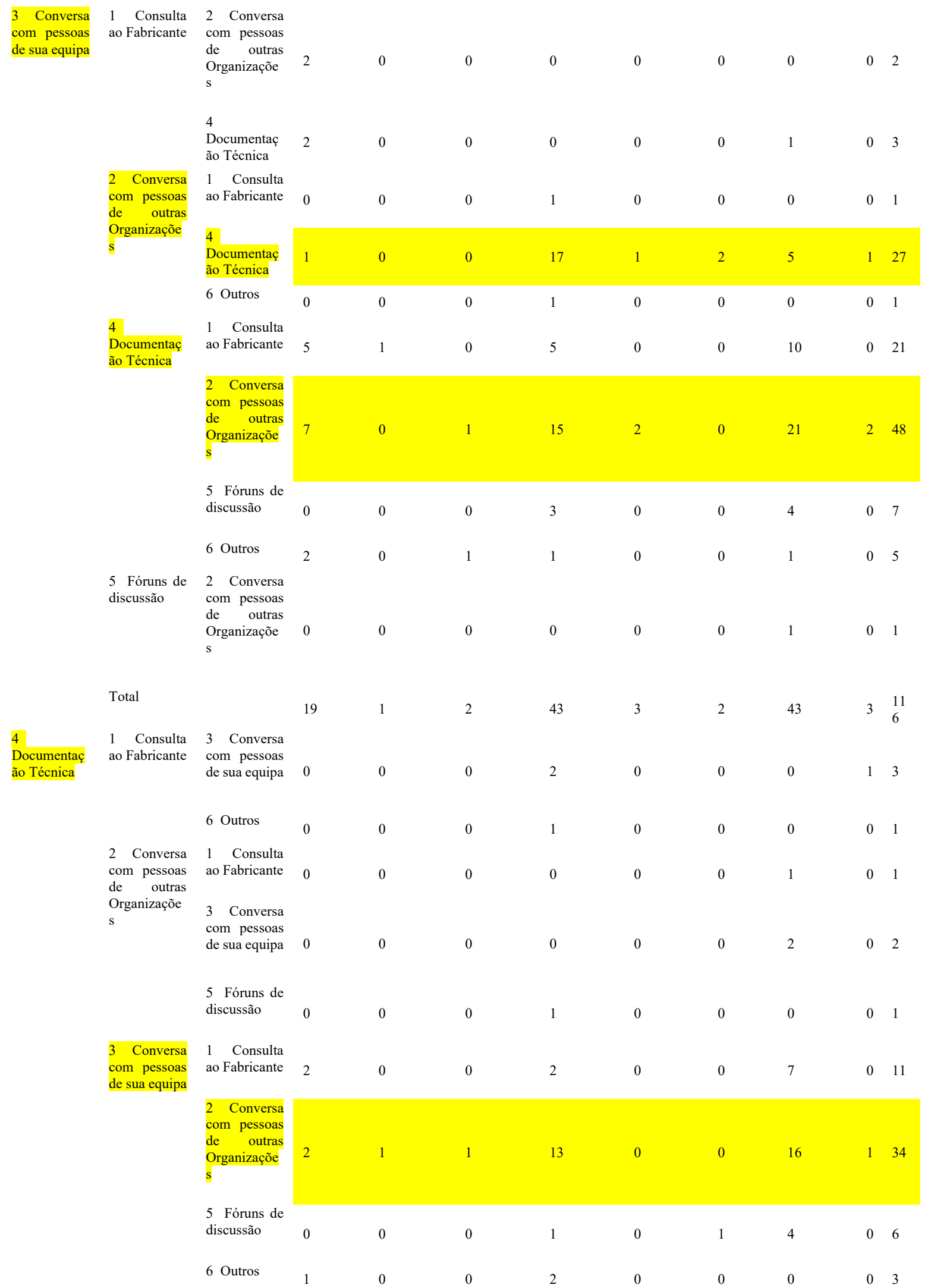

Comunidad @ Buenas Prácticas de Seguridad, Salud e Calidad de Vida en el trabajo INIAV 


\section{Doctorado en Salud, Discapacidad, Dependencia y Bienestar}

\begin{tabular}{|c|c|c|c|c|c|c|c|c|c|c|c|}
\hline & $\begin{array}{l}5 \text { Fóruns de } \\
\text { discussão }\end{array}$ & $\begin{array}{l}1 \text { Consulta } \\
\text { ao Fabricante }\end{array}$ & 0 & 0 & 0 & 0 & 0 & 0 & 0 & 1 & 1 \\
\hline & & $\begin{array}{l}3 \text { Conversa } \\
\text { com pessoas } \\
\text { de sua equipa }\end{array}$ & 0 & 0 & 0 & 0 & 0 & 0 & 1 & 0 & 1 \\
\hline & 6 Outros & $\begin{array}{l}3 \text { Conversa } \\
\text { com pessoas } \\
\text { de sua equipa }\end{array}$ & 0 & 0 & 0 & 2 & 0 & 0 & 0 & 0 & 2 \\
\hline & Total & & 5 & 1 & 1 & 24 & 0 & 1 & 31 & 3 & 66 \\
\hline \multirow[t]{2}{*}{$\begin{array}{l}5 \text { Fóruns de } \\
\text { discussão }\end{array}$} & $\begin{array}{l}4 \\
\text { Documentaç } \\
\text { ão Técnica }\end{array}$ & $\begin{array}{l}3 \text { Conversa } \\
\text { com pessoas } \\
\text { de sua equipa }\end{array}$ & 0 & 0 & 0 & 0 & 0 & 0 & 2 & 0 & 2 \\
\hline & Total & & 0 & 0 & 0 & 0 & 0 & 0 & 2 & 0 & 2 \\
\hline \multirow[t]{3}{*}{6 Outros } & $\begin{array}{l}3 \text { Conversa } \\
\text { com pessoas } \\
\text { de sua equipa }\end{array}$ & $\begin{array}{l}2 \text { Conversa } \\
\text { com pessoas } \\
\text { de outras } \\
\text { Organizaçõe } \\
\text { s }\end{array}$ & 0 & 0 & 0 & 1 & 0 & 0 & 0 & 0 & 1 \\
\hline & $\begin{array}{l}4 \\
\text { Documentaç } \\
\text { ão Técnica }\end{array}$ & $\begin{array}{l}3 \text { Conversa } \\
\text { com pessoas } \\
\text { de sua equipa }\end{array}$ & 0 & 0 & 0 & 0 & 0 & 0 & 1 & 0 & 1 \\
\hline & Total & & 0 & 0 & 0 & 1 & 0 & 0 & 1 & 0 & 2 \\
\hline
\end{tabular}

\begin{tabular}{|c|c|c|c|c|c|c|c|c|c|c|c|}
\hline & $\begin{array}{l}\text { 2-Contabilização } \\
\text { em percentagem }\end{array}$ & por função & $\begin{array}{l}1 \\
\text { Assisten } \\
\text { te } \\
\text { Técnico }\end{array}$ & $\begin{array}{l}2 \\
\text { Investigaç } \\
\text { ão } \\
\text { (Assistent } \\
\text { e de) }\end{array}$ & $\begin{array}{l}3 \\
\text { Investigad } \\
\text { or } \\
\text { (Bolseiro) }\end{array}$ & $\begin{array}{l}4 \\
\text { Investigad } \\
\text { or } \\
\text { Auxiliar }\end{array}$ & $\begin{array}{l}5 \\
\text { Investigad } \\
\text { or } \\
\text { Principal }\end{array}$ & $\begin{array}{l}6 \\
\text { Técnico } \\
\text { de } \\
\text { Informáti } \\
\text { ca }\end{array}$ & $\begin{array}{l}7 \\
\text { Téenic } \\
\text { o } \\
\text { Superi } \\
\text { or }\end{array}$ & $\begin{array}{l}8 \\
\text { Omiss } \\
0\end{array}$ & Total \\
\hline \multirow[t]{2}{*}{$\begin{array}{l}1 \text { Consulta } \\
\text { ao } \\
\text { Fabricante }\end{array}$} & $\begin{array}{l}4 \\
\text { Documentaç } \\
\text { ão Técnica }\end{array}$ & $\begin{array}{l}5 \text { Fóruns de } \\
\text { discussão }\end{array}$ & $.0 \%$ & $.0 \%$ & $.0 \%$ & $.0 \%$ & $.0 \%$ & $.0 \%$ & $.5 \%$ & $.0 \%$ & $.5 \%$ \\
\hline & $\begin{array}{l}5 \text { Fóruns de } \\
\text { discussão } \\
\text { Total }\end{array}$ & 6 Outros & $\begin{array}{l}.0 \% \\
.0 \%\end{array}$ & $\begin{array}{l}.0 \% \\
.0 \%\end{array}$ & $\begin{array}{l}.0 \% \\
.0 \%\end{array}$ & $\begin{array}{l}.0 \% \\
.0 \%\end{array}$ & $\begin{array}{l}.0 \% \\
.0 \%\end{array}$ & $\begin{array}{l}.0 \% \\
.0 \%\end{array}$ & $\begin{array}{l}.5 \% \\
1.0 \%\end{array}$ & $\begin{array}{l}.0 \% \\
.0 \%\end{array}$ & $\begin{array}{l}.5 \% \\
1.0 \%\end{array}$ \\
\hline \multirow[t]{6}{*}{$\begin{array}{l}2 \text { Conversa } \\
\text { com pessoas } \\
\text { de outras } \\
\text { Organizaçõe } \\
\text { s }\end{array}$} & $\begin{array}{l}3 \text { Conversa } \\
\text { com pessoas } \\
\text { de sua } \\
\text { equipa }\end{array}$ & $\begin{array}{l}4 \\
\text { Documentaç } \\
\text { ão Técnica }\end{array}$ & $.0 \%$ & $.0 \%$ & $.0 \%$ & $1.0 \%$ & $.0 \%$ & $.0 \%$ & $.0 \%$ & $.0 \%$ & $1.0 \%$ \\
\hline & & $\begin{array}{l}5 \text { Fóruns de } \\
\text { discussão }\end{array}$ & $.0 \%$ & $.0 \%$ & $.0 \%$ & $.5 \%$ & $.0 \%$ & $.0 \%$ & $.0 \%$ & $.0 \%$ & $.5 \%$ \\
\hline & & 6 Outros & $.0 \%$ & $.0 \%$ & $.0 \%$ & $.0 \%$ & $.0 \%$ & $.0 \%$ & $.5 \%$ & $.0 \%$ & $.5 \%$ \\
\hline & $\begin{array}{l}4 \\
\text { Documentaç } \\
\text { ão Técnica }\end{array}$ & $\begin{array}{l}3 \text { Conversa } \\
\text { com pessoas } \\
\text { de sua } \\
\text { equipa }\end{array}$ & $.5 \%$ & $.0 \%$ & $.0 \%$ & $.0 \%$ & $.0 \%$ & $.0 \%$ & $.0 \%$ & $.0 \%$ & $.5 \%$ \\
\hline & & 6 Outros & $.0 \%$ & $.0 \%$ & $.0 \%$ & $.5 \%$ & $.0 \%$ & $.0 \%$ & $.0 \%$ & $.0 \%$ & $.5 \%$ \\
\hline & Total & & $.5 \%$ & $.0 \%$ & $.0 \%$ & $2.1 \%$ & $.0 \%$ & $.0 \%$ & $.5 \%$ & $.0 \%$ & $3.1 \%$ \\
\hline
\end{tabular}

Comunidad @ Buenas Prácticas de Seguridad, Salud e Calidad de Vida en el trabajo INIAV 


\section{Doctorado en Salud, Discapacidad, Dependencia y Bienestar}

\begin{tabular}{|c|c|c|c|c|c|c|c|c|c|c|c|}
\hline \multirow[t]{4}{*}{$\begin{array}{l}3 \text { Conversa } \\
\text { com pessoas } \\
\text { de sua } \\
\text { equipa }\end{array}$} & \multirow[t]{2}{*}{$\begin{array}{l}1 \text { Consulta } \\
\text { ao } \\
\text { Fabricante }\end{array}$} & \multicolumn{2}{|c|}{$\begin{array}{l}2 \text { Conversa } \\
\text { com pessoas } \\
\text { de outras } \\
\text { Organizaçõe } \\
\text { s }\end{array}$} & $.0 \%$ & $.0 \%$ & $.0 \%$ & $.0 \%$ & $.0 \%$ & $.0 \%$ & $.0 \%$ & $1.0 \%$ \\
\hline & & $\begin{array}{l}4 \\
\text { Documentaç } \\
\text { ão Técnica }\end{array}$ & $1.0 \%$ & $.0 \%$ & $.0 \%$ & $.0 \%$ & $.0 \%$ & $.0 \%$ & $.5 \%$ & $.0 \%$ & $1.5 \%$ \\
\hline & \multirow{3}{*}{$\begin{array}{l}2 \text { Conversa } \\
\text { com pessoas } \\
\text { de outras } \\
\text { Organizaçõe } \\
\text { s }\end{array}$} & $\begin{array}{l}1 \text { Consulta } \\
\text { ao } \\
\text { Fabricante }\end{array}$ & $.0 \%$ & $.0 \%$ & $.0 \%$ & $.5 \%$ & $.0 \%$ & $.0 \%$ & $.0 \%$ & $.0 \%$ & $.5 \%$ \\
\hline & & $\begin{array}{l}4 \\
\text { Documentaç } \\
\text { ão Técnica }\end{array}$ & $.5 \%$ & $.0 \%$ & $.0 \%$ & $8.8 \%$ & $.5 \%$ & $1.0 \%$ & $2.6 \%$ & $.5 \%$ & $\begin{array}{l}13.9 \\
\%\end{array}$ \\
\hline & & 6 Outros & $.0 \%$ & $.0 \%$ & $.0 \%$ & $.5 \%$ & $.0 \%$ & $.0 \%$ & $.0 \%$ & $.0 \%$ & $.5 \%$ \\
\hline & \multirow[t]{4}{*}{$\begin{array}{l}4 \\
\text { Documentaç } \\
\text { ão Técnica }\end{array}$} & $\begin{array}{l}1 \text { Consulta } \\
\text { ao } \\
\text { Fabricante }\end{array}$ & $2.6 \%$ & $.5 \%$ & $.0 \%$ & $2.6 \%$ & $.0 \%$ & $.0 \%$ & $5.2 \%$ & $.0 \%$ & $\begin{array}{l}10.8 \\
\%\end{array}$ \\
\hline & & $\begin{array}{l}2 \text { Conversa } \\
\text { com pessoas } \\
\text { de outras } \\
\text { Organizaçõe } \\
\text { s }\end{array}$ & $3.6 \%$ & $.0 \%$ & $.5 \%$ & $7.7 \%$ & $1.0 \%$ & $.0 \%$ & $10.8 \%$ & $1.0 \%$ & $\begin{array}{l}24.7 \\
\%\end{array}$ \\
\hline & & $\begin{array}{l}5 \text { Fóruns de } \\
\text { discussão }\end{array}$ & $.0 \%$ & $.0 \%$ & $.0 \%$ & $1.5 \%$ & $.0 \%$ & $.0 \%$ & $2.1 \%$ & $.0 \%$ & $3.6 \%$ \\
\hline & & 6 Outros & $1.0 \%$ & $.0 \%$ & $.5 \%$ & $.5 \%$ & $.0 \%$ & $.0 \%$ & $.5 \%$ & $.0 \%$ & $2.6 \%$ \\
\hline & $\begin{array}{l}5 \text { Fóruns de } \\
\text { discussão }\end{array}$ & $\begin{array}{l}2 \text { Conversa } \\
\text { com pessoas } \\
\text { de outras } \\
\text { Organizaçõe } \\
\text { s }\end{array}$ & $.0 \%$ & $.0 \%$ & $.0 \%$ & $.0 \%$ & $.0 \%$ & $.0 \%$ & $.5 \%$ & $.0 \%$ & $.5 \%$ \\
\hline & Total & & $9.8 \%$ & $.5 \%$ & $1.0 \%$ & $22.2 \%$ & $1.5 \%$ & $1.0 \%$ & $22.2 \%$ & $1.5 \%$ & $\begin{array}{l}59.8 \\
\%\end{array}$ \\
\hline \multirow[t]{8}{*}{$\begin{array}{l}4 \\
\text { Documentaç } \\
\text { ão Técnica }\end{array}$} & \multirow[t]{2}{*}{$\begin{array}{l}1 \text { Consulta } \\
\text { ao } \\
\text { Fabricante }\end{array}$} & $\begin{array}{l}3 \text { Conversa } \\
\text { com pessoas } \\
\text { de sua } \\
\text { equipa }\end{array}$ & $.0 \%$ & $.0 \%$ & $.0 \%$ & $1.0 \%$ & $.0 \%$ & $.0 \%$ & $.0 \%$ & $.5 \%$ & $1.5 \%$ \\
\hline & & 6 Outros & $.0 \%$ & $.0 \%$ & $.0 \%$ & $.5 \%$ & $.0 \%$ & $.0 \%$ & $.0 \%$ & $.0 \%$ & $.5 \%$ \\
\hline & \multirow{3}{*}{$\begin{array}{l}2 \text { Conversa } \\
\text { com pessoas } \\
\text { de outras } \\
\text { Organizaçõe } \\
\text { s }\end{array}$} & $\begin{array}{l}1 \text { Consulta } \\
\text { ao } \\
\text { Fabricante }\end{array}$ & $.0 \%$ & $.0 \%$ & $.0 \%$ & $.0 \%$ & $.0 \%$ & $.0 \%$ & $.5 \%$ & $.0 \%$ & $.5 \%$ \\
\hline & & $\begin{array}{l}3 \text { Conversa } \\
\text { com pessoas } \\
\text { de sua } \\
\text { equipa }\end{array}$ & $.0 \%$ & $.0 \%$ & $.0 \%$ & $.0 \%$ & $.0 \%$ & $.0 \%$ & $1.0 \%$ & $.0 \%$ & $1.0 \%$ \\
\hline & & $\begin{array}{l}5 \text { Fóruns de } \\
\text { discussão }\end{array}$ & $.0 \%$ & $.0 \%$ & $.0 \%$ & $.5 \%$ & $.0 \%$ & $.0 \%$ & $.0 \%$ & $.0 \%$ & $.5 \%$ \\
\hline & \multirow{3}{*}{$\begin{array}{l}3 \text { Conversa } \\
\text { com pessoas } \\
\text { de sua } \\
\text { equipa }\end{array}$} & $\begin{array}{l}1 \text { Consulta } \\
\text { ao } \\
\text { Fabricante }\end{array}$ & $1.0 \%$ & $.0 \%$ & $.0 \%$ & $1.0 \%$ & $.0 \%$ & $.0 \%$ & $3.6 \%$ & $.0 \%$ & $5.7 \%$ \\
\hline & & $\begin{array}{l}2 \text { Conversa } \\
\text { com pessoas } \\
\text { de outras } \\
\text { Organizaçõe } \\
\text { s }\end{array}$ & $1.0 \%$ & $.5 \%$ & $.5 \%$ & $6.7 \%$ & $.0 \%$ & $.0 \%$ & $8.2 \%$ & $.5 \%$ & $\begin{array}{l}17.5 \\
\%\end{array}$ \\
\hline & & $\begin{array}{l}5 \text { Fóruns de } \\
\text { discussão }\end{array}$ & $.0 \%$ & $.0 \%$ & $.0 \%$ & $.5 \%$ & $.0 \%$ & $.5 \%$ & $2.1 \%$ & $.0 \%$ & $3.1 \%$ \\
\hline
\end{tabular}

Comunidad @ Buenas Prácticas de Seguridad, Salud e Calidad de Vida en el trabajo INIAV 


\section{Doctorado en Salud, Discapacidad, Dependencia y Bienestar}

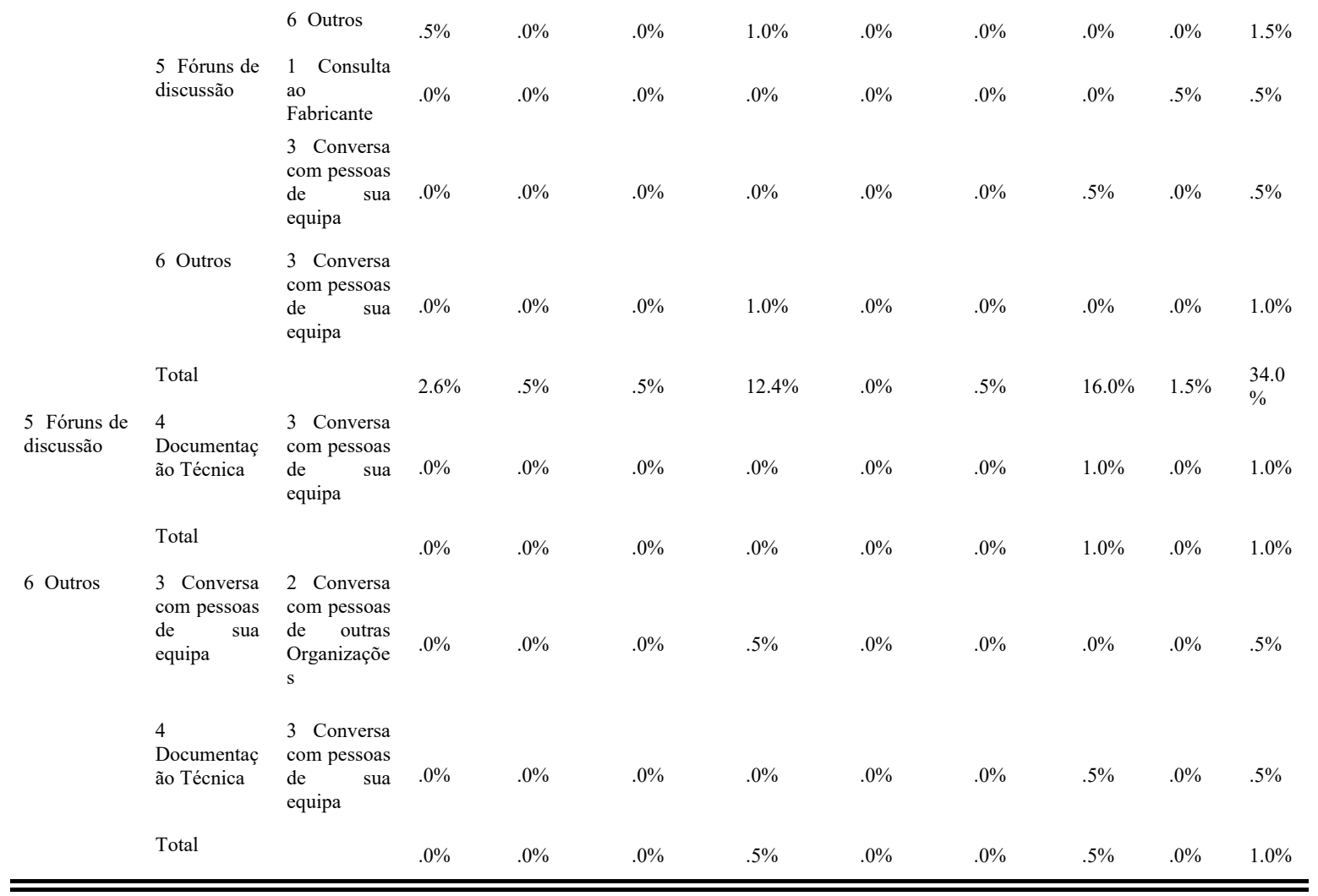

Comunidad @ Buenas Prácticas de Seguridad, Salud e Calidad de Vida en el trabajo INIAV 


\section{Doctorado en Salud, Discapacidad, Dependencia y Bienestar}

8-Contabilização por sexo em $\mathrm{n}^{\mathrm{o}}$ de casos

\begin{tabular}{|c|c|c|c|c|c|c|c|}
\hline & & & & & $\begin{array}{l}1 \\
\text { Feminino } \\
\end{array}$ & $\begin{array}{l}2 \\
\text { Masculino } \\
\end{array}$ & Total \\
\hline \multirow[t]{23}{*}{1} & $\begin{array}{l}1 \text { Ambiente } \\
\text { descontraído }\end{array}$ & 2 Confiança & $\begin{array}{l}3 \quad \text { Para a sua } \\
\text { aprendizagem }\end{array}$ & 4 Vontade de ser útil & 2 & 0 & 2 \\
\hline & & & 4 Vontade de ser útil & $\begin{array}{l}3 \quad \text { Para a sua } \\
\text { aprendizagem }\end{array}$ & 2 & 1 & 3 \\
\hline & & $\begin{array}{l}3 \quad \text { Para a sua } \\
\text { aprendizagem }\end{array}$ & 2 Confiança & 4 Vontade de ser útil & 2 & 1 & 3 \\
\hline & & 4 Vontade de ser útil & 2 Confiança & $\begin{array}{l}3 \quad \text { Para a sua } \\
\text { aprendizagem }\end{array}$ & 4 & 3 & 7 \\
\hline & & & $\begin{array}{l}3 \quad \text { Para a sua } \\
\text { aprendizagem }\end{array}$ & 2 Confiança & 2 & 1 & 3 \\
\hline & 2 Confiança & $\begin{array}{l}1 \text { Ambiente } \\
\text { descontraído }\end{array}$ & $\begin{array}{l}3 \quad \text { Para a sua } \\
\text { aprendizagem }\end{array}$ & 4 Vontade de ser útil & 6 & 1 & 7 \\
\hline & & & 4 Vontade de ser útil & $\begin{array}{l}3 \quad \text { Para a sua } \\
\text { aprendizagem }\end{array}$ & 16 & 11 & 27 \\
\hline & & $\begin{array}{l}3 \quad \text { Para a sua } \\
\text { aprendizagem }\end{array}$ & $\begin{array}{l}1 \text { Ambiente } \\
\text { descontraído }\end{array}$ & 4 Vontade de ser útil & 2 & 2 & 4 \\
\hline & & & 4 Vontade de ser útil & $\begin{array}{l}1 \text { Ambiente } \\
\text { descontraído }\end{array}$ & 20 & 5 & 25 \\
\hline & & 4 Vontade de ser útil & $\begin{array}{l}1 \text { Ambiente } \\
\text { descontraído }\end{array}$ & $\begin{array}{l}3 \quad \text { Para a sua } \\
\text { aprendizagem }\end{array}$ & 12 & 5 & 17 \\
\hline & & & $\begin{array}{l}3 \quad \text { Para a sua } \\
\text { aprendizagem }\end{array}$ & $\begin{array}{l}1 \text { Ambiente } \\
\text { descontraído }\end{array}$ & 19 & 10 & 29 \\
\hline & 3 Para a sua & $1 \quad$ Ambiente & 2 Confiança & 4 Vontade de ser útil & 2 & 1 & 3 \\
\hline & & & 4 Vontade de ser útil & 2 Confiança & 4 & 1 & 5 \\
\hline & & 2 Confiança & $\begin{array}{l}1 \text { Ambiente } \\
\text { descontraído }\end{array}$ & 4 Vontade de ser útil & 3 & 0 & 3 \\
\hline & & & 4 Vontade de ser útil & $\begin{array}{l}1 \text { Ambiente } \\
\text { descontraído }\end{array}$ & 8 & 2 & 10 \\
\hline & & 4 Vontade de ser útil & $\begin{array}{l}1 \text { Ambiente } \\
\text { descontraído }\end{array}$ & 2 Confiança & 1 & 1 & 2 \\
\hline & & & 2 Confiança & $\begin{array}{l}1 \text { Ambiente } \\
\text { descontraído }\end{array}$ & 10 & 1 & 11 \\
\hline & $\begin{array}{l}4 \text { Vontade de } \\
\text { ser útil }\end{array}$ & $\begin{array}{l}1 \text { Ambiente } \\
\text { descontraído }\end{array}$ & 2 Confiança & $\begin{array}{l}3 \quad \text { Para a sua } \\
\text { aprendizagem }\end{array}$ & 1 & 1 & 2 \\
\hline & & & $\begin{array}{l}3 \quad \text { Para a sua } \\
\text { aprendizagem }\end{array}$ & 2 Confiança & 1 & 0 & 1 \\
\hline & & 2 Confiança & $\begin{array}{l}1 \text { Ambiente } \\
\text { descontraído }\end{array}$ & $\begin{array}{l}3 \quad \text { Para a sua } \\
\text { aprendizagem }\end{array}$ & 4 & 1 & 5 \\
\hline & & & $\begin{array}{l}3 \quad \text { Para a sua } \\
\text { aprendizagem }\end{array}$ & $\begin{array}{l}1 \text { Ambiente } \\
\text { descontraído }\end{array}$ & 6 & 4 & 10 \\
\hline & & $\begin{array}{l}3 \quad \text { Para a sua } \\
\text { aprendizagem }\end{array}$ & $\begin{array}{l}1 \text { Ambiente } \\
\text { descontraído }\end{array}$ & 2 Confiança & 2 & 0 & 2 \\
\hline & & & 2 Confiança & $\begin{array}{l}1 \text { Ambiente } \\
\text { descontraído }\end{array}$ & 9 & 5 & 14 \\
\hline Total & & & & & 138 & 57 & 195 \\
\hline
\end{tabular}

Comunidad@Buenas Prácticas de Seguridad, Salud e Calidad de Vida en el trabajo INIAV 


\section{Doctorado en Salud, Discapacidad, Dependencia y Bienestar}

8-Contabilização por sexo em percentagem

\begin{tabular}{|c|c|c|c|c|c|c|c|}
\hline & & & & & $\begin{array}{l}1 \\
\text { Feminino }\end{array}$ & $\begin{array}{l}2 \\
\text { Masculino }\end{array}$ & Total \\
\hline & & & & & $\begin{array}{l}\text { Subtable } \\
\%\end{array}$ & $\begin{array}{l}\text { Subtable } \\
\% \\
\end{array}$ & $\begin{array}{l}\text { Subtable } \\
\% \\
\end{array}$ \\
\hline \multirow[t]{23}{*}{1} & $\begin{array}{l}1 \text { Ambiente } \\
\text { descontraído }\end{array}$ & 2 Confiança & $\begin{array}{l}3 \quad \text { Para a sua } \\
\text { aprendizagem }\end{array}$ & 4 Vontade de ser útil & $1.0 \%$ & $.0 \%$ & $1.0 \%$ \\
\hline & & & 4 Vontade de ser útil & $\begin{array}{l}3 \quad \text { Para a sua } \\
\text { aprendizagem }\end{array}$ & $1.0 \%$ & $.5 \%$ & $1.5 \%$ \\
\hline & & $\begin{array}{l}3 \quad \text { Para a sua } \\
\text { aprendizagem }\end{array}$ & 2 Confiança & 4 Vontade de ser útil & $1.0 \%$ & $.5 \%$ & $1.5 \%$ \\
\hline & & 4 Vontade de ser útil & 2 Confiança & $\begin{array}{l}3 \quad \text { Para a sua } \\
\text { aprendizagem }\end{array}$ & $2.1 \%$ & $1.5 \%$ & $3.6 \%$ \\
\hline & & & $\begin{array}{l}3 \quad \text { Para a sua } \\
\text { aprendizagem }\end{array}$ & 2 Confiança & $1.0 \%$ & $.5 \%$ & $1.5 \%$ \\
\hline & 2 Confiança & $\begin{array}{l}1 \text { Ambiente } \\
\text { descontraído }\end{array}$ & $\begin{array}{l}3 \quad \text { Para a sua } \\
\text { aprendizagem }\end{array}$ & 4 Vontade de ser útil & $3.1 \%$ & $.5 \%$ & $3.6 \%$ \\
\hline & & & 4 Vontade de ser útil & $\begin{array}{l}3 \quad \text { Para a sua } \\
\text { aprendizagem }\end{array}$ & $8.2 \%$ & $5.6 \%$ & $13.8 \%$ \\
\hline & & $\begin{array}{l}3 \quad \text { Para a sua } \\
\text { aprendizagem }\end{array}$ & $\begin{array}{l}1 \text { Ambiente } \\
\text { descontraído }\end{array}$ & 4 Vontade de ser útil & $1.0 \%$ & $1.0 \%$ & $2.1 \%$ \\
\hline & & & 4 Vontade de ser útil & $\begin{array}{l}1 \text { Ambiente } \\
\text { descontraído }\end{array}$ & $10.3 \%$ & $2.6 \%$ & $12.8 \%$ \\
\hline & & 4 Vontade de ser útil & $\begin{array}{l}1 \text { Ambiente } \\
\text { descontraído }\end{array}$ & $\begin{array}{l}3 \quad \text { Para a sua } \\
\text { aprendizagem }\end{array}$ & $6.2 \%$ & $2.6 \%$ & $8.7 \%$ \\
\hline & & & $\begin{array}{l}3 \quad \text { Para a sua } \\
\text { aprendizagem }\end{array}$ & $\begin{array}{l}1 \text { Ambiente } \\
\text { descontraído }\end{array}$ & $9.7 \%$ & $5.1 \%$ & $14.9 \%$ \\
\hline & 3 Para a sua & 1 Ambiente & 2 Confiança & 4 Vontade de ser útil & $1.0 \%$ & $.5 \%$ & $1.5 \%$ \\
\hline & & & 4 Vontade de ser útil & 2 Confiança & $2.1 \%$ & $.5 \%$ & $2.6 \%$ \\
\hline & & 2 Confiança & $\begin{array}{l}1 \text { Ambiente } \\
\text { descontraído }\end{array}$ & 4 Vontade de ser útil & $1.5 \%$ & $.0 \%$ & $1.5 \%$ \\
\hline & & & 4 Vontade de ser útil & $\begin{array}{l}1 \text { Ambiente } \\
\text { descontraído }\end{array}$ & $4.1 \%$ & $1.0 \%$ & $5.1 \%$ \\
\hline & & 4 Vontade de ser útil & $\begin{array}{l}1 \text { Ambiente } \\
\text { descontraído }\end{array}$ & 2 Confiança & $.5 \%$ & $.5 \%$ & $1.0 \%$ \\
\hline & & & 2 Confiança & $\begin{array}{l}1 \text { Ambiente } \\
\text { descontraído }\end{array}$ & $5.1 \%$ & $.5 \%$ & $5.6 \%$ \\
\hline & $\begin{array}{l}4 \text { Vontade de } \\
\text { ser útil }\end{array}$ & $\begin{array}{l}1 \text { Ambiente } \\
\text { descontraído }\end{array}$ & 2 Confiança & $\begin{array}{l}3 \quad \text { Para a sua } \\
\text { aprendizagem }\end{array}$ & $.5 \%$ & $.5 \%$ & $1.0 \%$ \\
\hline & & & $\begin{array}{l}3 \quad \text { Para a sua } \\
\text { aprendizagem }\end{array}$ & 2 Confiança & $.5 \%$ & $.0 \%$ & $.5 \%$ \\
\hline & & 2 Confiança & $\begin{array}{l}1 \text { Ambiente } \\
\text { descontraído }\end{array}$ & $\begin{array}{l}3 \quad \text { Para a sua } \\
\text { aprendizagem }\end{array}$ & $2.1 \%$ & $.5 \%$ & $2.6 \%$ \\
\hline & & & $\begin{array}{l}3 \quad \text { Para a sua } \\
\text { aprendizagem }\end{array}$ & $\begin{array}{l}1 \text { Ambiente } \\
\text { descontraído }\end{array}$ & $3.1 \%$ & $2.1 \%$ & $5.1 \%$ \\
\hline & & $\begin{array}{l}3 \quad \text { Para a sua } \\
\text { aprendizagem }\end{array}$ & $\begin{array}{l}1 \text { Ambiente } \\
\text { descontraído }\end{array}$ & 2 Confiança & $1.0 \%$ & $.0 \%$ & $1.0 \%$ \\
\hline & & & 2 Confiança & $\begin{array}{l}1 \text { Ambiente } \\
\text { descontraído }\end{array}$ & $4.6 \%$ & $2.6 \%$ & $7.2 \%$ \\
\hline Total & & & & & $70.8 \%$ & $29.2 \%$ & $100.0 \%$ \\
\hline
\end{tabular}

Comunidad @ Buenas Prácticas de Seguridad, Salud e Calidad de Vida en el trabajo INIAV 


\section{Doctorado en Salud, Discapacidad, Dependencia y Bienestar}

8-Contabilização por faixa etária em $\mathrm{n}^{\circ}$ de casos

\begin{tabular}{|c|c|c|c|c|c|c|c|c|}
\hline & & & & & $\begin{array}{l}1<=45 \\
\text { anos }\end{array}$ & $\begin{array}{l}2 \quad 45 \text { a } \\
<=55 \\
\text { anos }\end{array}$ & $3>55$ & Total \\
\hline & & & & & Count & Count & Count & Count \\
\hline \multirow[t]{23}{*}{1} & $\begin{array}{l}1 \text { Ambiente } \\
\text { descontraído }\end{array}$ & 2 Confiança & $\begin{array}{l}3 \quad \text { Para a sua } \\
\text { aprendizagem }\end{array}$ & $\begin{array}{l}4 \text { Vontade de ser } \\
\text { útil }\end{array}$ & 0 & 1 & 1 & 2 \\
\hline & & & $\begin{array}{l}4 \text { Vontade de ser } \\
\text { útil }\end{array}$ & $\begin{array}{l}3 \quad \text { Para a sua } \\
\text { aprendizagem }\end{array}$ & 0 & 1 & 2 & 3 \\
\hline & & $\begin{array}{l}3 \quad \text { Para a sua } \\
\text { aprendizagem }\end{array}$ & 2 Confiança & $\begin{array}{l}4 \text { Vontade de ser } \\
\text { útil }\end{array}$ & 2 & 0 & 1 & 3 \\
\hline & & $\begin{array}{l}4 \text { Vontade de ser } \\
\text { útil }\end{array}$ & 2 Confiança & $\begin{array}{l}3 \quad \text { Para a sua } \\
\text { aprendizagem }\end{array}$ & 1 & 2 & 4 & 7 \\
\hline & & & $\begin{array}{l}3 \quad \text { Para a sua } \\
\text { aprendizagem }\end{array}$ & 2 Confiança & 2 & 1 & 0 & 3 \\
\hline & 2 Confiança & $\begin{array}{l}1 \text { Ambiente } \\
\text { descontraído }\end{array}$ & $\begin{array}{l}3 \quad \text { Para a sua } \\
\text { aprendizagem }\end{array}$ & $\begin{array}{l}4 \text { Vontade de ser } \\
\text { útil }\end{array}$ & 3 & 3 & 1 & 7 \\
\hline & & & $\begin{array}{l}4 \text { Vontade de ser } \\
\text { útil }\end{array}$ & $\begin{array}{l}3 \quad \text { Para a sua } \\
\text { aprendizagem }\end{array}$ & 5 & 15 & 5 & 25 \\
\hline & & $\begin{array}{l}3 \quad \text { Para a sua } \\
\text { aprendizagem }\end{array}$ & $\begin{array}{l}1 \text { Ambiente } \\
\text { descontraído }\end{array}$ & $\begin{array}{l}4 \text { Vontade de ser } \\
\text { útil }\end{array}$ & 1 & 2 & 1 & 4 \\
\hline & & & $\begin{array}{l}4 \text { Vontade de ser } \\
\text { útil }\end{array}$ & $\begin{array}{l}1 \text { Ambiente } \\
\text { descontraído }\end{array}$ & 4 & 15 & 5 & 24 \\
\hline & & $\begin{array}{l}4 \text { Vontade de ser } \\
\text { útil }\end{array}$ & $\begin{array}{l}1 \text { Ambiente } \\
\text { descontraído }\end{array}$ & $\begin{array}{l}3 \quad \text { Para a sua } \\
\text { aprendizagem }\end{array}$ & 3 & 8 & 6 & 17 \\
\hline & & & $\begin{array}{l}3 \quad \text { Para a sua } \\
\text { aprendizagem }\end{array}$ & $\begin{array}{l}1 \text { Ambiente } \\
\text { descontraído }\end{array}$ & 12 & 11 & 6 & 29 \\
\hline & $\begin{array}{l}3 \text { Para a sua } \\
\text { aprendizagem }\end{array}$ & $\begin{array}{l}1 \text { Ambiente } \\
\text { descontraído }\end{array}$ & 2 Confiança & $\begin{array}{l}4 \text { Vontade de ser } \\
\text { útil }\end{array}$ & 0 & 1 & 1 & 2 \\
\hline & & & $\begin{array}{l}4 \text { Vontade de ser } \\
\text { útil }\end{array}$ & 2 Confiança & 0 & 3 & 2 & 5 \\
\hline & & 2 Confiança & $\begin{array}{l}1 \text { Ambiente } \\
\text { descontraído }\end{array}$ & $\begin{array}{l}4 \text { Vontade de ser } \\
\text { útil }\end{array}$ & 1 & 2 & 0 & 3 \\
\hline & & & $\begin{array}{l}4 \text { Vontade de ser } \\
\text { útil }\end{array}$ & $\begin{array}{l}1 \text { Ambiente } \\
\text { descontraído }\end{array}$ & 5 & 3 & 2 & 10 \\
\hline & & $\begin{array}{l}4 \text { Vontade de ser } \\
\text { útil }\end{array}$ & $\begin{array}{l}1 \text { Ambiente } \\
\text { descontraído }\end{array}$ & 2 Confiança & 0 & 2 & 0 & 2 \\
\hline & & & 2 Confiança & $\begin{array}{l}1 \text { Ambiente } \\
\text { descontraído }\end{array}$ & 5 & 2 & 4 & 11 \\
\hline & $\begin{array}{l}4 \text { Vontade de } \\
\text { ser útil }\end{array}$ & $\begin{array}{l}1 \text { Ambiente } \\
\text { descontraído }\end{array}$ & 2 Confiança & $\begin{array}{l}3 \quad \text { Para a sua } \\
\text { aprendizagem }\end{array}$ & 1 & 1 & 0 & 2 \\
\hline & & & $\begin{array}{l}3 \quad \text { Para a sua } \\
\text { aprendizagem }\end{array}$ & 2 Confiança & 1 & 0 & 0 & 1 \\
\hline & & 2 Confiança & $\begin{array}{l}1 \text { Ambiente } \\
\text { descontraído }\end{array}$ & $\begin{array}{l}3 \quad \text { Para a sua } \\
\text { aprendizagem }\end{array}$ & 0 & 4 & 1 & 5 \\
\hline & & & $\begin{array}{l}3 \text { Para a sua } \\
\text { aprendizagem }\end{array}$ & $\begin{array}{l}1 \text { Ambiente } \\
\text { descontraído }\end{array}$ & 2 & 4 & 4 & 10 \\
\hline & & $\begin{array}{l}3 \quad \text { Para a sua } \\
\text { aprendizagem }\end{array}$ & $\begin{array}{l}1 \text { Ambiente } \\
\text { descontraído }\end{array}$ & 2 Confiança & 1 & 0 & 1 & 2 \\
\hline & & & 2 Confiança & $\begin{array}{l}1 \text { Ambiente } \\
\text { descontraído }\end{array}$ & 2 & 7 & 5 & 14 \\
\hline Total & & & & & 51 & 88 & 52 & 191 \\
\hline
\end{tabular}

Comunidad @ Buenas Prácticas de Seguridad, Salud e Calidad de Vida en el trabajo INIAV 


\section{Doctorado en Salud, Discapacidad, Dependencia y Bienestar}

8-Contabilização por faixa etária em percentagem

\begin{tabular}{|c|c|c|c|c|c|c|c|c|}
\hline & & & & & $\begin{array}{l}1<=45 \\
\text { anos }\end{array}$ & $\begin{array}{l}2 \quad 45 \text { a } \\
<=55 \\
\text { anos }\end{array}$ & $3>55$ & Total \\
\hline & & & & & $\begin{array}{l}\text { Subtable } \\
\%\end{array}$ & $\begin{array}{l}\text { Subtable } \\
\%\end{array}$ & $\begin{array}{l}\text { Subtable } \\
\%\end{array}$ & $\begin{array}{l}\text { Subtable } \\
\%\end{array}$ \\
\hline \multirow[t]{23}{*}{1} & $\begin{array}{l}\text { 1 Ambiente } \\
\text { descontraído }\end{array}$ & 2 Confiança & 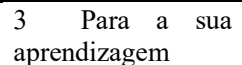 & $\begin{array}{l}4 \text { Vontade de ser } \\
\text { útil }\end{array}$ & $.0 \%$ & $.5 \%$ & $.5 \%$ & $1.0 \%$ \\
\hline & & & $\begin{array}{l}4 \text { Vontade de ser } \\
\text { útil }\end{array}$ & $\begin{array}{l}3 \quad \text { Para a sua } \\
\text { aprendizagem }\end{array}$ & $.0 \%$ & $.5 \%$ & $1.0 \%$ & $1.6 \%$ \\
\hline & & $\begin{array}{l}3 \text { Para a sua } \\
\text { aprendizagem }\end{array}$ & 2 Confiança & $\begin{array}{l}4 \text { Vontade de ser } \\
\text { útil }\end{array}$ & $1.0 \%$ & $.0 \%$ & $.5 \%$ & $1.6 \%$ \\
\hline & & $\begin{array}{l}4 \text { Vontade de ser } \\
\text { útil }\end{array}$ & 2 Confiança & $\begin{array}{l}3 \text { Para a sua } \\
\text { aprendizagem }\end{array}$ & $.5 \%$ & $1.0 \%$ & $2.1 \%$ & $3.7 \%$ \\
\hline & & & $\begin{array}{l}3 \quad \text { Para a sua } \\
\text { aprendizagem }\end{array}$ & 2 Confiança & $1.0 \%$ & $.5 \%$ & $.0 \%$ & $1.6 \%$ \\
\hline & 2 Confiança & $\begin{array}{l}1 \text { Ambiente } \\
\text { descontraído }\end{array}$ & $\begin{array}{l}3 \quad \text { Para a sua } \\
\text { aprendizagem }\end{array}$ & $\begin{array}{l}4 \text { Vontade de ser } \\
\text { útil }\end{array}$ & $1.6 \%$ & $1.6 \%$ & $.5 \%$ & $3.7 \%$ \\
\hline & & & $\begin{array}{l}4 \text { Vontade de ser } \\
\text { útil }\end{array}$ & $\begin{array}{l}3 \quad \text { Para a sua } \\
\text { aprendizagem }\end{array}$ & $2.6 \%$ & $7.9 \%$ & $2.6 \%$ & $13.1 \%$ \\
\hline & & $\begin{array}{l}3 \quad \text { Para a sua } \\
\text { aprendizagem }\end{array}$ & $\begin{array}{l}1 \quad \text { Ambiente } \\
\text { descontraído }\end{array}$ & $\begin{array}{l}4 \text { Vontade de ser } \\
\text { útil }\end{array}$ & $.5 \%$ & $1.0 \%$ & $.5 \%$ & $2.1 \%$ \\
\hline & & & $\begin{array}{l}4 \text { Vontade de ser } \\
\text { útil }\end{array}$ & $\begin{array}{l}1 \text { Ambiente } \\
\text { descontraído }\end{array}$ & $2.1 \%$ & $7.9 \%$ & $2.6 \%$ & $12.6 \%$ \\
\hline & & $\begin{array}{l}4 \text { Vontade de ser } \\
\text { útil }\end{array}$ & $\begin{array}{l}1 \text { Ambiente } \\
\text { descontraído }\end{array}$ & $\begin{array}{l}3 \quad \text { Para a sua } \\
\text { aprendizagem }\end{array}$ & $1.6 \%$ & $4.2 \%$ & $3.1 \%$ & $8.9 \%$ \\
\hline & & & $\begin{array}{l}3 \text { Para a sua } \\
\text { aprendizagem }\end{array}$ & $\begin{array}{l}1 \text { Ambiente } \\
\text { descontraído }\end{array}$ & $6.3 \%$ & $5.8 \%$ & $3.1 \%$ & $15.2 \%$ \\
\hline & $\begin{array}{l}3 \text { Para a sua } \\
\text { aprendizagem }\end{array}$ & $\begin{array}{l}1 \quad \text { Ambiente } \\
\text { descontraído }\end{array}$ & 2 Confiança & $\begin{array}{l}4 \text { Vontade de ser } \\
\text { útil }\end{array}$ & $.0 \%$ & $.5 \%$ & $.5 \%$ & $1.0 \%$ \\
\hline & & & $\begin{array}{l}4 \text { Vontade de ser } \\
\text { útil }\end{array}$ & 2 Confiança & $.0 \%$ & $1.6 \%$ & $1.0 \%$ & $2.6 \%$ \\
\hline & & 2 Confiança & $\begin{array}{l}1 \text { Ambiente } \\
\text { descontraído }\end{array}$ & $\begin{array}{l}4 \text { Vontade de ser } \\
\text { útil }\end{array}$ & $.5 \%$ & $1.0 \%$ & $.0 \%$ & $1.6 \%$ \\
\hline & & & $\begin{array}{l}4 \text { Vontade de ser } \\
\text { útil }\end{array}$ & $\begin{array}{l}1 \text { Ambiente } \\
\text { descontraído }\end{array}$ & $2.6 \%$ & $1.6 \%$ & $1.0 \%$ & $5.2 \%$ \\
\hline & & $\begin{array}{l}4 \text { Vontade de ser } \\
\text { útil }\end{array}$ & $\begin{array}{l}1 \text { Ambiente } \\
\text { descontraído }\end{array}$ & 2 Confiança & $.0 \%$ & $1.0 \%$ & $.0 \%$ & $1.0 \%$ \\
\hline & & & 2 Confiança & $\begin{array}{l}1 \text { Ambiente } \\
\text { descontraído }\end{array}$ & $2.6 \%$ & $1.0 \%$ & $2.1 \%$ & $5.8 \%$ \\
\hline & $\begin{array}{l}4 \text { Vontade de } \\
\text { ser útil }\end{array}$ & $\begin{array}{l}1 \text { Ambiente } \\
\text { descontraído }\end{array}$ & 2 Confiança & $\begin{array}{l}3 \quad \text { Para a sua } \\
\text { aprendizagem }\end{array}$ & $.5 \%$ & $.5 \%$ & $.0 \%$ & $1.0 \%$ \\
\hline & & & $\begin{array}{l}3 \quad \text { Para a sua } \\
\text { aprendizagem }\end{array}$ & 2 Confiança & $.5 \%$ & $.0 \%$ & $.0 \%$ & $.5 \%$ \\
\hline & & 2 Confiança & $\begin{array}{l}1 \text { Ambiente } \\
\text { descontraído }\end{array}$ & $\begin{array}{l}3 \text { Para a sua } \\
\text { aprendizagem }\end{array}$ & $.0 \%$ & $2.1 \%$ & $.5 \%$ & $2.6 \%$ \\
\hline & & & $\begin{array}{l}3 \quad \text { Para a sua } \\
\text { aprendizagem }\end{array}$ & $\begin{array}{l}1 \text { Ambiente } \\
\text { descontraído }\end{array}$ & $1.0 \%$ & $2.1 \%$ & $2.1 \%$ & $5.2 \%$ \\
\hline & & $\begin{array}{l}3 \quad \text { Para a sua } \\
\text { aprendizagem }\end{array}$ & $\begin{array}{l}1 \text { Ambiente } \\
\text { descontraído }\end{array}$ & 2 Confiança & $.5 \%$ & $.0 \%$ & $.5 \%$ & $1.0 \%$ \\
\hline & & & 2 Confiança & $\begin{array}{l}1 \text { Ambiente } \\
\text { descontraído }\end{array}$ & $1.0 \%$ & $3.7 \%$ & $2.6 \%$ & $7.3 \%$ \\
\hline Total & & & & & $26.7 \%$ & $46.1 \%$ & $27.2 \%$ & $100.0 \%$ \\
\hline
\end{tabular}

Comunidad @ Buenas Prácticas de Seguridad, Salud e Calidad de Vida en el trabajo INIAV 


\section{Doctorado en Salud, Discapacidad, Dependencia y Bienestar}

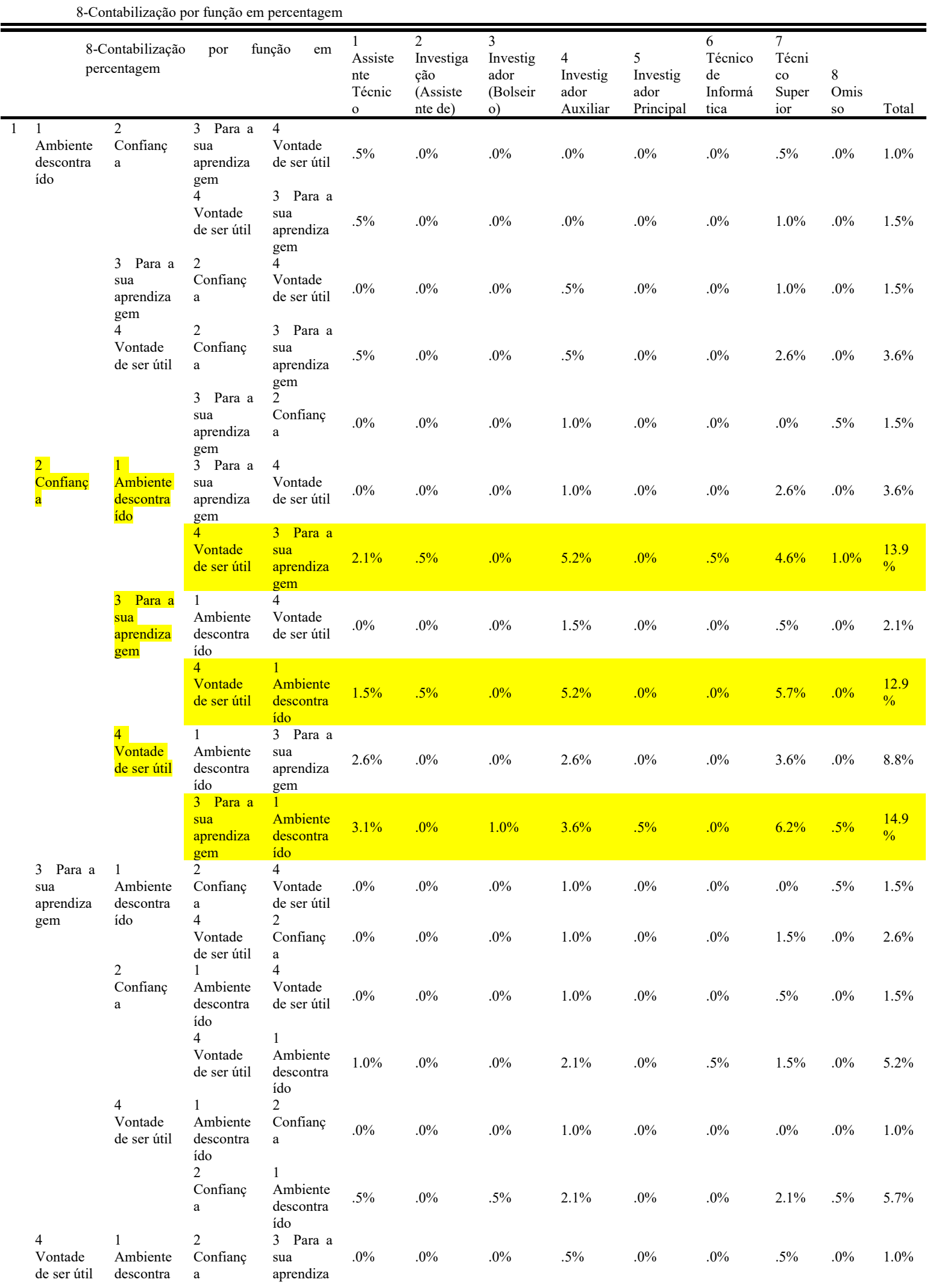

Comunidad @ Buenas Prácticas de Seguridad, Salud e Calidad de Vida en el trabajo INIAV 


\section{Doctorado en Salud, Discapacidad, Dependencia y Bienestar}

\begin{tabular}{|c|c|c|c|c|c|c|c|c|c|c|c|c|}
\hline \multirow{2}{*}{\multicolumn{2}{|c|}{ ído }} & & gem & & & & & & & & & \\
\hline & & $\begin{array}{l}3 \text { Para a } \\
\text { sua } \\
\text { aprendiza } \\
\text { gem }\end{array}$ & $\begin{array}{l}2 \\
\text { Confianç } \\
\mathrm{a}\end{array}$ & $.0 \%$ & $.0 \%$ & $.0 \%$ & $.0 \%$ & $.0 \%$ & $.0 \%$ & $.5 \%$ & $.0 \%$ & $.5 \%$ \\
\hline & $\begin{array}{l}2 \\
\text { Confianç } \\
\text { a }\end{array}$ & $\begin{array}{l}1 \\
\text { Ambiente } \\
\text { descontra } \\
\text { ído }\end{array}$ & $\begin{array}{l}3 \text { Para a } \\
\text { sua } \\
\text { aprendiza } \\
\text { gem }\end{array}$ & $.5 \%$ & $.0 \%$ & $.0 \%$ & $1.5 \%$ & $.0 \%$ & $.0 \%$ & $.5 \%$ & $.0 \%$ & $2.6 \%$ \\
\hline & & $\begin{array}{l}3 \text { Para a } \\
\text { sua } \\
\text { aprendiza } \\
\text { gem }\end{array}$ & $\begin{array}{l}1 \\
\text { Ambiente } \\
\text { descontra } \\
\text { ído }\end{array}$ & $.0 \%$ & $.0 \%$ & $.0 \%$ & $3.1 \%$ & $.0 \%$ & $.5 \%$ & $1.5 \%$ & $.0 \%$ & $5.2 \%$ \\
\hline & $\begin{array}{l}3 \text { Para a } \\
\text { sua } \\
\text { aprendiza } \\
\text { gem }\end{array}$ & $\begin{array}{l}1 \\
\text { Ambiente } \\
\text { descontra } \\
\text { ído }\end{array}$ & $\begin{array}{l}2 \\
\text { Confianç } \\
\text { a }\end{array}$ & $.0 \%$ & $.0 \%$ & $.0 \%$ & $.5 \%$ & $.0 \%$ & $.0 \%$ & $.5 \%$ & $.0 \%$ & $1.0 \%$ \\
\hline & & $\begin{array}{l}2 \\
\text { Confianç } \\
\text { a }\end{array}$ & $\begin{array}{l}1 \\
\text { Ambiente } \\
\text { descontra } \\
\text { ído }\end{array}$ & $.0 \%$ & $.0 \%$ & $.0 \%$ & $2.1 \%$ & $1.0 \%$ & $.0 \%$ & $3.6 \%$ & $.0 \%$ & $6.7 \%$ \\
\hline Total & & & & $12.9 \%$ & $1.0 \%$ & $1.5 \%$ & $37.1 \%$ & $1.5 \%$ & $1.5 \%$ & $\begin{array}{l}41.2 \\
\%\end{array}$ & $3.1 \%$ & $\begin{array}{l}100 . \\
0 \%\end{array}$ \\
\hline
\end{tabular}

Comunidad @ Buenas Prácticas de Seguridad, Salud e Calidad de Vida en el trabajo INIAV 


\section{ANEXO BIV - Análise de dados do Questionário surveys - 2012}

Análise de resultados do inquérito surveys aplicado no início da fase experimental sendo respondido através da plataforma surveys do INIAV num total de 195 respondentes estando aberta a plataforma por um período de 15 dias para resposta.

A caraterização da nossa amostra num total de 195 funcionários que responderam voluntariamente através da plataforma surveys do INIAV com a seguinte mensagem e enviada pelo email geral: "Caros colegas, contamos com a vossa colaboração. Já temos disponível Link para responder ao inquérito Gestão do conhecimento e Comunidades de prática clique e responda através do link” Link:http://surveys.inrb.pt/index.php?sid=15799

Pela análise da tabela verificamos que o sexo feminino é maioritário na nossa amostra de respondentes: tendo obtido 138 respostas do sexo feminino e 57 respostas do sexo masculino num total de 195 respondentes. Também caracterizamos as faixas etárias da amostra. A faixa etária maioritária situa-se entre 45-54 anos de idade com 88 de 191 respondentes conforme tabela abaixo apresentada, o que nos permite concluir que o INIAV tem uma população ativa já a envelhecer e que não está a ser reposta quando algum elemento se reforma.

Também caracterizamos a amostra consoante a categoria que desempenha no INIAV, sendo a maioria dos respondentes das carreiras técnica superior e de investigação.

\section{Caraterização da amostra}

\begin{tabular}{|lr|}
\hline Sexo & \\
\hline 1 Feminino & 138 \\
\hline 2 Masculino & 57 \\
\hline Total & 195 \\
\hline
\end{tabular}

Contabilização por sexo

BIV $-1 / 4$

Comunidad @ Buenas Prácticas de Seguridad, Salud e Calidad de Vida en el trabajo INIAV

"Factores críticos de éxito" 


\section{Doctorado en Salud, Discapacidad, Dependencia y Bienestar}

\begin{tabular}{|lr|}
\hline Faixa etária & \\
\hline $1<=45$ anos & 51 \\
\hline 245 a $<=55$ anos & 88 \\
\hline $3>55$ & 52 \\
\hline Total & 191 \\
\hline
\end{tabular}

Contabilização por faixa etária

\begin{tabular}{|lr|}
\hline Categoria/função & 25 \\
\hline 1 Assistente Técnico & 2 \\
\hline 2 Investigação (Assistente de) & 3 \\
\hline 3 Investigador (Bolseiro) & 72 \\
\hline 4 Investigador Auxiliar & 3 \\
\hline 5 Investigador Principal & 3 \\
\hline 6 Técnico de Informática & 80 \\
\hline 7 Técnico Superior & 6 \\
\hline 8 Omisso & 194 \\
\hline Total & 2 \\
\hline
\end{tabular}

Contabilização por Categoria/função

\section{Questões 2 e 8 foram as questões por nós escolhidas para análise:}

2 -Apresentamos as combinações e o número de casos ocorridos referentes à questão que colocámos aos funcionários quando necessitam de uma informação ligada à área de trabalho / especialização de que forma procuram encontrar o conhecimento necessário para a resolução do problema.

Chegámos pois à conclusão que o número de casos ocorrido e a combinação mais escolhida foi:

Conversam com Pessoas da sua Equipa - Apoiam-se em Documentação Técnica -Conversam com pessoas de outras Organizações.

$$
\text { BIV }-2 / 4
$$

Comunidad@Buenas Prácticas de Seguridad, Salud e Calidad de Vida en el trabajo INIAV 
Doctorado en Salud, Discapacidad, Dependencia y Bienestar

\begin{tabular}{|ccc|}
\hline Classificação & Combinações & $\mathbf{N}^{\mathbf{o}}$ casos \\
\hline $\mathbf{1}^{\mathbf{0}}$ & 342 & 49 \\
\hline $\mathbf{2}^{\mathbf{o}}$ & 432 & 34 \\
\hline $\mathbf{3}^{\mathbf{o}}$ & 324 & 27 \\
\hline $\mathbf{4}^{\mathbf{0}}$ & 341 & 21 \\
\hline $\mathbf{5}^{\mathbf{0}}$ & 431 & 11 \\
\hline
\end{tabular}

Forma como procuram encontrar o conhecimento para a resolução do problema - combinações/número de casos

3-4-2:Conversam com Pessoas da sua Equipa - apoiam-se em Documentação Técnica -Conversam com pessoas de outras Organizações

4-3-2:Documentação Técnica - Conversa com Pessoas da sua Equipa -Conversa com Pessoas de outras Organizações

3-2-4:Conversa com Pessoas da sua equipa -Conversa com pessoas de outras Organizações Documentação Técnica

3-4-1: Conversa com Pessoas da sua equipa -Documentação Técnica - Consulta ao fabricante 4-3-1:Documentação Técnica-Conversa com pessoas da sua equipa -Consulta ao fabricante $2^{\mathrm{a}}$ ) Especificaram Internet e bibliotecas; Documentos científicos, laboratórios nas áreas de referência; estágios e formação.

8- Nesta questão procurámos saber quais os fatores que mais contribuem para a partilha de informações por parte dos funcionários e as combinações que encontramos que estão relacionadas com o grau de importância/ relevância dada pela amostra inquirida foi:

\begin{tabular}{|c|c|c|c|}
\hline Combinação & $\mathrm{N}^{0}$ de casos & q & $\hat{0}$ \\
\hline 2431 & 29 & 19 & 10 \\
\hline 2143 & 27 & 16 & 11 \\
\hline 2314 & 25 & 20 & 5 \\
\hline
\end{tabular}

Tabela 1: Fatores que contribuem para a troca de informação/sexo

$$
\text { BIV }-3 / 4
$$

Comunidad@Buenas Prácticas de Seguridad, Salud e Calidad de Vida en el trabajo INIAV

"Factores críticos de éxito" 
Doctorado en Salud, Discapacidad, Dependencia y Bienestar

\begin{tabular}{|ccccc|}
\hline Combinação & $\mathbf{N}^{\mathbf{0}}$ de casos & $\mathbf{4 4 5}$ & $\mathbf{4 5 a} \leq \mathbf{5 5}$ & $\mathbf{> 5 5}$ \\
\hline $\mathbf{2 4 3 1}$ & 29 & 12 & 11 & 5 \\
\hline $\mathbf{2 1 4 3}$ & 25 & 5 & 15 & 5 \\
\hline $\mathbf{2 3 1 4}$ & 24 & 4 & 15 & 5 \\
\hline
\end{tabular}

Tabela 2: Fatores que contribuem para a troca de informação/faixa etária

\begin{tabular}{|cccccc|}
\hline Combinação & $\begin{array}{c}\mathbf{N}^{\mathbf{0}} \text { de } \\
\text { casos }\end{array}$ & Assistente tc & Investigação & Tc Superior & Omisso \\
\hline $\mathbf{2 4 3 1}$ & 29 & 6 & 10 & 12 & 1 \\
\hline $\mathbf{2 1 4 3}$ & 27 & 4 & 11 & 10 & 2 \\
\hline $\mathbf{2 3 1 4}$ & 25 & 2 & 4 & 13 & \\
\hline
\end{tabular}

Tabela 3: Fatores que contribuem para a troca de informação/categoria

1-Ambiente descontraído;

2-Confiança,

3-Para a sua aprendizagem;

4-Vontade de ser útil;

Tendo em conta o maior número de casos ocorridos a combinação escolhida foi:

Confiança - vontade de ser útil - Para sua aprendizagem e Ambiente descontraído

BIV $-4 / 4$

Comunidad@Buenas Prácticas de Seguridad, Salud e Calidad de Vida en el trabajo INIAV

"Factores críticos de éxito" 


\section{ANEXO BV -Análise do Inquérito em suporte de papel aplicado numa ação presencial-2012}

\section{Instrumento de avaliação: um inquérito aplicado numa ação presencial da Wikiniav aplicado no período experimental.}

O inquérito foi distribuído no início da ação em formato de papel e recolhido à saída do auditório.

Participaram nesta ação um total de 62 funcionários do Pólo Oeiras, responderam 45 funcionários e 17 não entregaram o inquérito.

Seguidamente faremos a apreciação global de cada uma das respostas ao inquérito das questões por nós escolhidas:2-4-6-9

$\mathrm{Na}$ opinião dos funcionários que participaram na ação em auditório, a maioria concordou totalmente com as seguintes afirmações de acordo com os resultados da tabela número:

$\checkmark$ A maioria dos RH perde muito do seu tempo a procurar a informação que necessita;

$\checkmark$ O saber fazer essencial está apenas disponível na mente de algumas pessoas;

$\checkmark$ Informação valiosa está dissimulada em imensos conjuntos de dados e documentos;

$\checkmark$ Erros dispendiosos são repetidos devido à não consideração de experiências anteriores;

$\checkmark$ Atrasos, produtos e serviços com pouca qualidade resultam de um insuficiente fluxo de informação entre os diversos agentes organizacionais.

\begin{tabular}{|r|r|r|r|}
\hline Afirmação & Discordo Totalmente & Concordo & \multicolumn{2}{|c|}{$\begin{array}{c}\text { Concordo } \\
\text { Totalmente }\end{array}$} \\
\hline a) & 0 & 6 & 39 \\
\hline b) & 0 & 5 & 40 \\
\hline c) & 0 & 3 & 42 \\
\hline d) & 0 & 1 & 43 \\
\hline e) & 0 & 6 & 39 \\
\hline
\end{tabular}

BV $-\mathbf{1 / 3}$

Comunidad@Buenas Prácticas de Seguridad, Salud e Calidad de Vida en el trabajo INIAV

"Factores críticos de éxito" 


\section{Doctorado en Salud, Discapacidad, Dependencia y Bienestar}

2-Na perspetiva dos funcionários que assistiram à ação o desenvolvimento de Comunidades de Prática no INIAV a plataforma de trabalho colaborativo para o desenvolvimento de Comunidades de Prática $(\mathrm{CoP})$ poderá minimizar e resolver parte dos problemas atrás referidos $(72,5 \%)$. As CoP poderão ser propositadamente desenvolvidas e fomentadas, fazendo parte integrante da estratégia organizacional, como forma de estimular a partilha de conhecimento de acordo com os resultados da tabela abaixo apresentada.

\begin{tabular}{|l|l|c|}
\hline & Sim & Não \\
\hline $\mathbf{N}^{\mathbf{0}}$ de respondentes & 45 & 0 \\
\hline
\end{tabular}

3-Questionados se gostariam de ser membros de uma Comunidade de Prática que partilhasse o conhecimento sobre uma temática da prevenção de riscos laborais, $62 \%$ dos funcionários que respondeu ao inquérito como podemos observar pelo gráfico 1 abaixo apresentado.

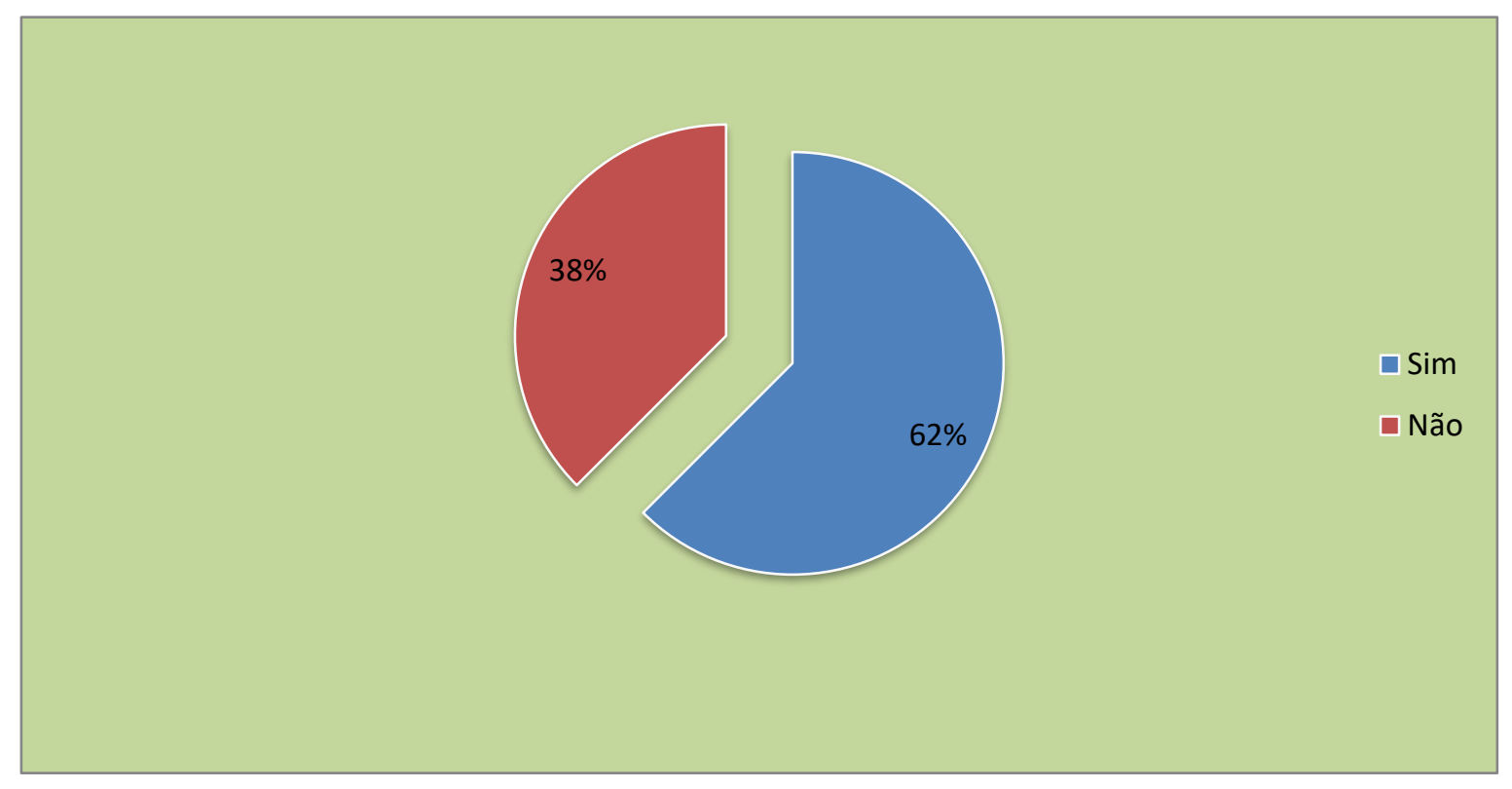

BV $-2 / 3$

Comunidad @ Buenas Prácticas de Seguridad, Salud e Calidad de Vida en el trabajo INIAV

"Factores críticos de éxito" 


\section{Doctorado en Salud, Discapacidad, Dependencia y Bienestar}

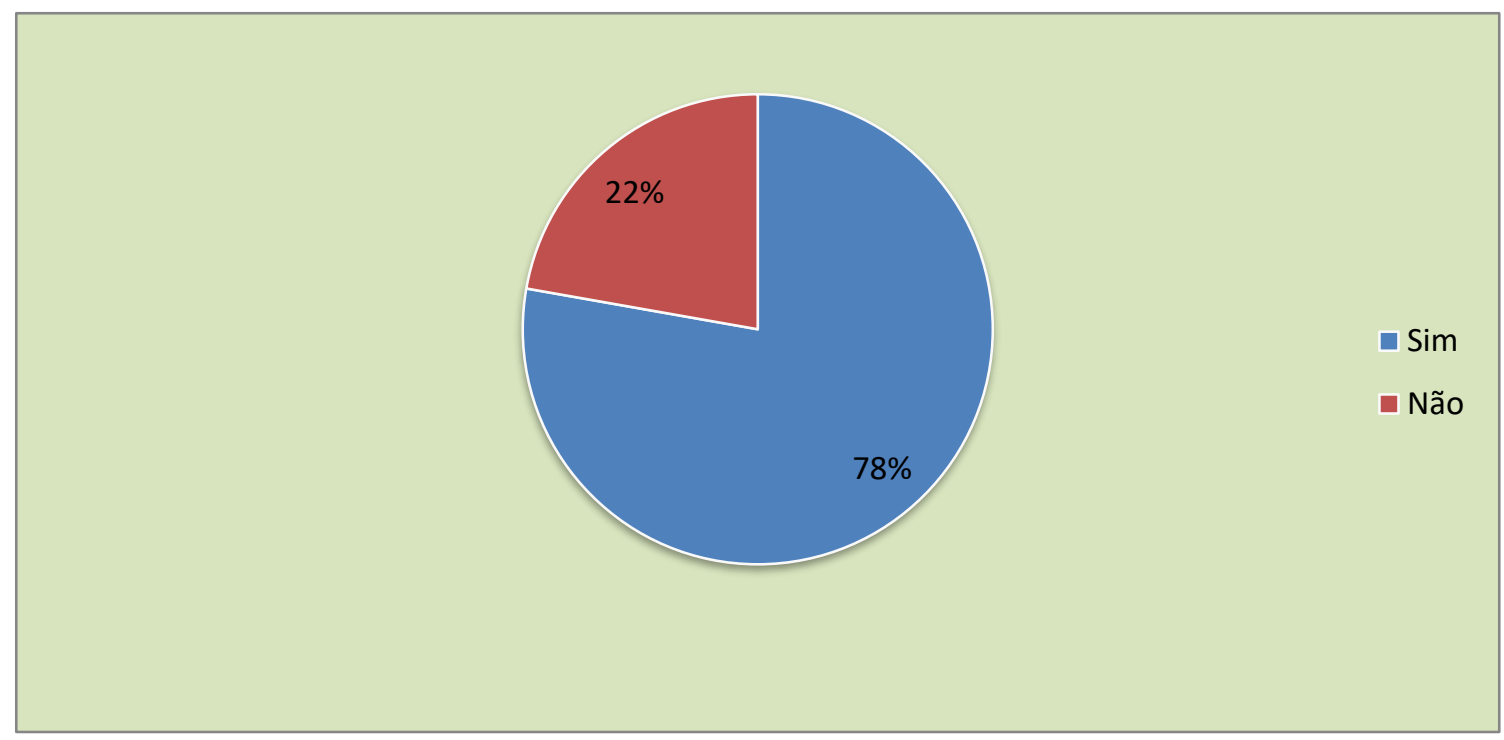

6- $78 \%$ dos funcionários que participaram na ação gosta do formato da apresentação desta ferramenta de apoio de trabalho colaborativo como podemos observar no gráfico 3 abaixo apresentado.

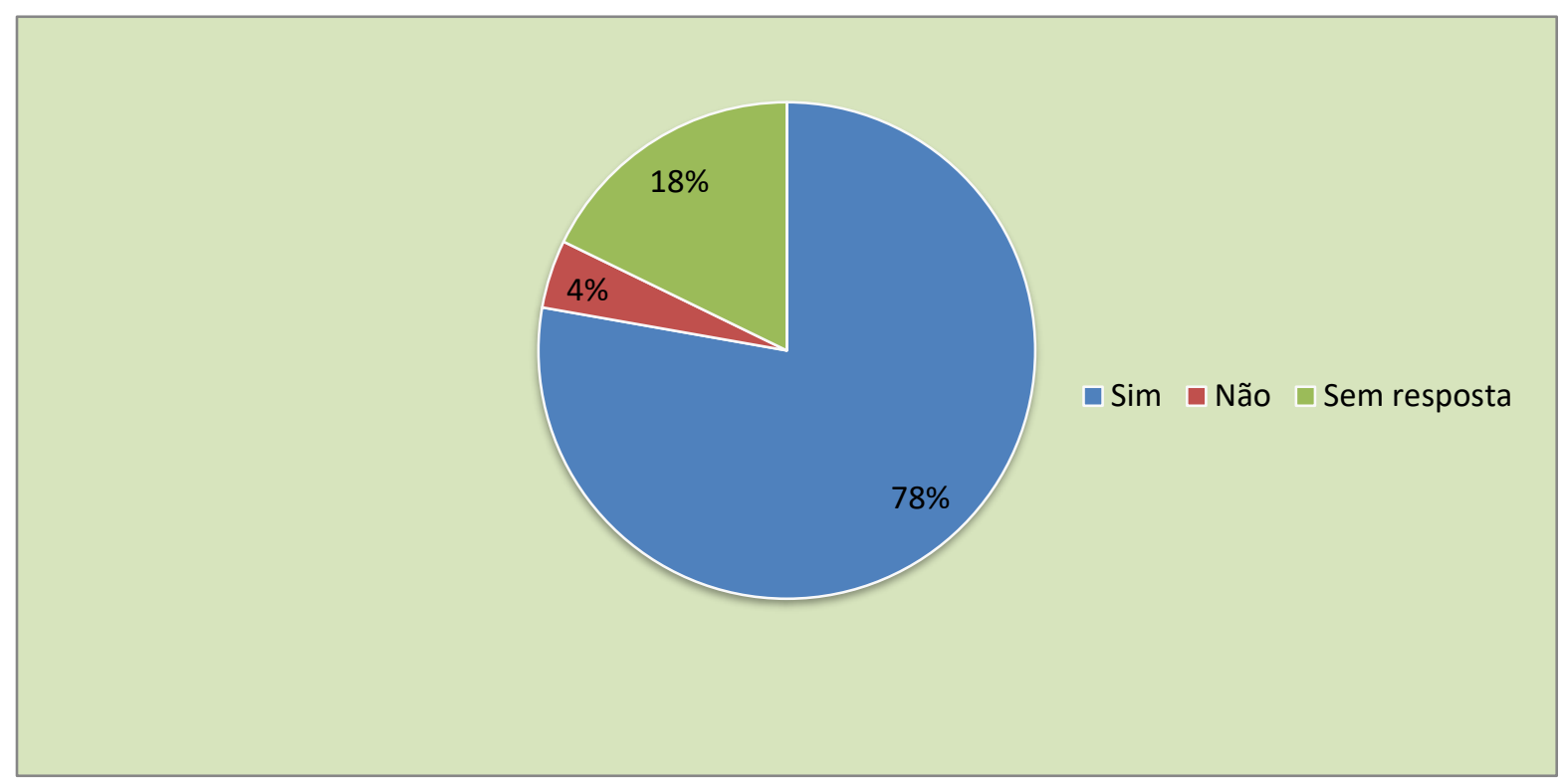

9-A maioria dos funcionários que assistiram a ação, manifestou vontade de ter uma ação treino sobre a ferramenta WIKINIAV, como poderemos observar

$$
\text { BV }-\mathbf{3 / 3}
$$


Doctorado en Salud, Discapacidad, Dependencia y Bienestar

\section{ANEXO BVI - Análise dos quadros de resultados ICOS}

Quadro 1-caraterização da amostra

\begin{tabular}{|c|c|c|c|c|c|c|c|}
\hline & & Departamento & Sexo & Idade & Escolaridade & $\begin{array}{c}\text { Tempo na } \\
\text { organização }\end{array}$ & $\begin{array}{l}\text { Desempenha } \\
\text { cargos de chefia }\end{array}$ \\
\hline 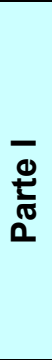 & $\begin{array}{l}\text { N } \\
\text { Missing } \\
\text { Média } \\
\text { Mediana } \\
\text { Desvio Padrão } \\
\text { Mínimo } \\
\text { Máximo } \\
\end{array}$ & $\begin{array}{c}213 \\
0\end{array}$ & $\begin{array}{c}180 \\
33 \\
-\end{array}$ & \begin{tabular}{|c|}
184 \\
29 \\
3,3370 \\
4,0000 \\
1,06383 \\
1,00 \\
5,00 \\
\end{tabular} & $\begin{array}{c}182 \\
31 \\
3,6593 \\
4,0000 \\
1,73505 \\
1,00 \\
6,00 \\
\end{array}$ & $\begin{array}{c}185 \\
28 \\
4,3730 \\
5,0000 \\
1,17322 \\
1,00 \\
5,00 \\
\end{array}$ & $\begin{array}{c}173 \\
40 \\
-\end{array}$ \\
\hline \multirow{7}{*}{ 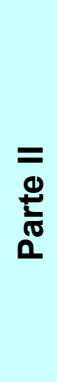 } & $\mathrm{N}$ & 121 & 105 & 116 & 113 & 115 & 114 \\
\hline & Missing & 0 & 16 & 5 & 8 & 6 & 7 \\
\hline & Média & & - & 3,3621 & 4,0708 & 4,4609 & - \\
\hline & Mediana & & & 4,0000 & 4,0000 & & 1,0000 \\
\hline & Desvio Padrão & & & ,99036 & 2,12853 & & - \\
\hline & Mínimo & & 1,00 & 1,00 & 1,00 & 1,00 & 1,00 \\
\hline & Máximo & & 2,00 & 5,00 & 7,00 & 5,00 & 2,00 \\
\hline
\end{tabular}

NOTA: Escalas de resposta de cada variável:

Sexo: 1 - Masculino, 2 - feminino; Escolaridade: 1 - até $4^{\mathrm{a}}$ classe, 2 - entre o $6^{\circ}$ ano e $9^{\circ}$ ano, 3 - entre $\circ 10^{\circ}$ e $12^{\circ}$ ano, 4 - bacharelato ou licenciatura, 5 - mestrado, 6 - doutoramento; Tempo da organização: 1- até 2 anos, 2 - 3-5 anos, 3- 6 -10 anos, 4- 11 -16 anos, 5 - mais de 17 anos; Desempenha cargos de chefia -1 - não, 2 - sim; Idade: 1- até 30 anos, 2 - 31-45 anos, 3- 46-50 anos, 4-51-60 anos, 5-mais de 60 anos.

BVI - 1/13

Comunidad@Buenas Prácticas de Seguridad, Salud e Calidad de Vida en el trabajo INIAV

"Factores críticos de éxito" 
Quadro 2 - Departamento

\begin{tabular}{|l|c|c|c|c|}
\cline { 2 - 5 } \multicolumn{1}{c|}{} & \multicolumn{2}{c|}{ Parte I } & \multicolumn{2}{c|}{ PARTE II } \\
\cline { 2 - 5 } \multicolumn{1}{c|}{} & Frequência & $\%$ & Frequência & $\%$ \\
\hline Apoio à Direção & 4 & 1.9 & 0 & 0 \\
\hline Administrativo & 12 & 5.6 & 5 & 4.11 \\
\hline CDI & 9 & 4.2 & 8 & 6.6 \\
\hline Ciência do Solo & 26 & 12.2 & 19 & 15.7 \\
\hline Contabilidade & 8 & 3.8 & 4 & 3.3 \\
\hline Entomologia & 11 & 5.2 & 1 & .8 \\
\hline Fitopatologia & 19 & 8.9 & 12 & 9.9 \\
\hline Fisiologia & 25 & 11.7 & 8 & 6.6 \\
\hline Gabinete de Apoio e Manutenção & 7 & 3.3 & 0 & 0 \\
\hline Produção Agrícola & 16 & 7.5 & 13 & 10.7 \\
\hline Recursos Genéticos & 24 & 11.3 & 20 & 16.5 \\
\hline $\begin{array}{l}\text { Serviços Sociais Jardim de } \\
\text { Infância }\end{array}$ & 14 & 6.6 & 11 & 9.1 \\
\hline $\begin{array}{l}\text { Serviços Sociais Pessoal de } \\
\text { Apoio }\end{array}$ & 3 & 1.4 & 0 & 0 \\
\hline Estatística & 15 & 7.0 & 6 & 5.0 \\
\hline Tecnologia de Produção Agrária & 19 & 8.9 & 14 & 11.6 \\
\hline Total & 213 & 100.0 & 121 & 100.0 \\
\hline
\end{tabular}

Quadro 3 - Sexo

\begin{tabular}{|l|c|c|}
\hline \multirow{2}{*}{} & \multicolumn{2}{|c|}{ PARTE II } \\
\cline { 2 - 3 } & Frequência & $\%$ \\
\hline 1, masculino & 33 & 31.4 \\
\hline 2, feminino & 72 & 68.6 \\
\hline Total & 105 & 100.0 \\
\hline Missing & 16 & \\
\hline Total & 121 & \\
\hline
\end{tabular}

Quadro 4 - Escolaridade

\begin{tabular}{|c|c|c|}
\hline & \multicolumn{2}{|c|}{ PARTE II } \\
\hline & Frequência & $\%$ \\
\hline 1 , até $4^{a}$ classe & 16 & 14.2 \\
\hline 2 , entre $6^{\circ}$ e $9^{\circ}$ anos & 17 & 15.0 \\
\hline $\begin{array}{l}3 \text {, entre } 10^{\circ} \text { e } 12^{\circ} \text { ano } \\
\text { anos }\end{array}$ & 18 & 15.9 \\
\hline $\begin{array}{l}\text { 4, bacharelato ou } \\
\text { licenciatura }\end{array}$ & 33 & 29.2 \\
\hline 5 , mestrado & 1 & .9 \\
\hline 6 , doutoramento & 28 & 24.8 \\
\hline Total & 113 & 100.0 \\
\hline Missing & 8 & \\
\hline Total & 121 & \\
\hline
\end{tabular}

Comunidad@Buenas Prácticas de Seguridad, Salud e Calidad de Vida en el trabajo INIAV

"Factores críticos de éxito" 


\section{Doctorado en Salud, Discapacidad, Dependencia y Bienestar}

Quadro 5 - Tempo na Organização

\begin{tabular}{|l|c|c|}
\cline { 2 - 3 } \multicolumn{1}{c|}{} & \multicolumn{2}{c|}{ PARTE II } \\
\cline { 2 - 3 } \multicolumn{1}{c|}{} & Frequência & $\%$ \\
\hline 1, até 2 anos & 5 & 4.3 \\
\hline 2, 3-5 anos & 3 & 2.6 \\
\hline 3, 6-10 anos & 11 & 9.6 \\
\hline $4,11-16$ anos & 11 & 9.6 \\
\hline 5, mais de 17 anos & 85 & 73.9 \\
\hline Total & 115 & 100.0 \\
\hline Missing & 6 & \\
\hline Total & 121 & \\
\hline
\end{tabular}

Quadro 6-Chefia

\begin{tabular}{|c|c|c|}
\cline { 2 - 3 } \multicolumn{1}{c|}{} & \multicolumn{2}{c|}{ PARTE II } \\
\cline { 2 - 3 } \multicolumn{1}{c|}{} & Frequência & $\%$ \\
\hline 1, não & 101 & 88.6 \\
\hline 2 , sim & 13 & 11.4 \\
\hline Total & 114 & 100.0 \\
\hline Missing & 7 & \\
\hline Total & 121 & \\
\hline
\end{tabular}

Quadro 7 - Idade

\begin{tabular}{|c|c|c|}
\hline & \multicolumn{2}{|c|}{ PARTE II } \\
\hline & Frequência & $\%$ \\
\hline 1 , até 30 anos & 1 & .9 \\
\hline $2,31-45$ anos & 31 & 26.7 \\
\hline $3,46-50$ anos & 18 & 15.5 \\
\hline $4,51-60$ anos & 57 & 49.1 \\
\hline 5 , mais de 60 anos & 9 & 7.8 \\
\hline Total & 116 & 100.0 \\
\hline Missing & 5 & \\
\hline Total & 121 & \\
\hline
\end{tabular}

BVI - 3/13

Comunidad@Buenas Prácticas de Seguridad, Salud e Calidad de Vida en el trabajo INIAV

"Factores críticos de éxito" 
Doctorado en Salud, Discapacidad, Dependencia y Bienestar

Quadro 8 - Experiência de acidentes de trabalho

\begin{tabular}{|c|c|c|c|c|c|c|}
\hline & $\begin{array}{l}\text { experiência } \\
\text { com } \\
\text { acidentes } \\
\text { individual }\end{array}$ & $\begin{array}{c}\mathrm{N}^{\circ} \mathrm{de} \\
\text { acidentes }\end{array}$ & $\begin{array}{l}\text { experiência com } \\
\text { incidentes } \\
\text { individual } \\
\text { (pequenas } \\
\text { quedas, cortes, } \\
\text { queimaduras)?" }\end{array}$ & $\begin{array}{c}\mathrm{N}^{0} \text { de } \\
\text { incidentes }\end{array}$ & 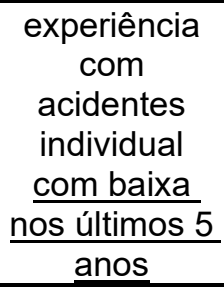 & $\begin{array}{l}\text { quantos } \\
\text { acidentes } \\
\text { com baixa }\end{array}$ \\
\hline $\bar{N}$ & 175 & 27 & 170 & 25 & 173 & 7 \\
\hline Missing & 38 & 186 & 43 & 188 & 40 & 206 \\
\hline Média & - & 1,5926 & - & 2,4000 & - & 1,2857 \\
\hline Mediana & 1,0000 & 1,0000 & 1,0000 & 2,0000 & 1,0000 & 1,0000 \\
\hline $\begin{array}{l}\text { Desvio } \\
\text { padrão }\end{array}$ & - & 1,00992 & - & 1,68325 & - & 48795 \\
\hline Mínimo & 1,00 & 1,00 & 1,00 & 1,00 & 1,00 & 1,00 \\
\hline Máximo & 2,00 & 5,00 & 2,00 & 8,00 & 2,00 & 2,00 \\
\hline
\end{tabular}

Quadro 9 - experiência com acidentes individual

\begin{tabular}{|l|c|c|}
\cline { 2 - 3 } \multicolumn{1}{c|}{} & Frequência & Percentagem (\%) \\
\hline 1, não & 137 & 78,3 \\
2, sim & 38 & 21,7 \\
Total & 175 & 100,0 \\
Missing & 38 & \\
Total & 213 & \\
\hline
\end{tabular}

Quadro $10-\mathrm{N}^{\mathrm{o}}$ de acidentes

\begin{tabular}{|c|c|c|}
\cline { 2 - 3 } \multicolumn{1}{c|}{} & Frequência & $\begin{array}{c}\text { Percentagem } \\
(\%)\end{array}$ \\
\hline 1,00 & 17 & 63,0 \\
2,00 & 7 & 25,9 \\
3,00 & 1 & 3,7 \\
4,00 & 1 & 3,7 \\
5,00 & 1 & 3,7 \\
Total & 27 & 100,0 \\
Missing & 186 & \\
Total & 213 & \\
\hline \multicolumn{3}{|c}{ BVI $-\mathbf{4 / 1 3}$} \\
\hline
\end{tabular}

Comunidad@Buenas Prácticas de Seguridad, Salud e Calidad de Vida en el trabajo INIAV

"Factores críticos de éxito" 


\section{Doctorado en Salud, Discapacidad, Dependencia y Bienestar}

Quadro 11 - Experiência com incidentes individual

1 (pequenas quedas, cortes, queimaduras)

\begin{tabular}{|l|c|c|}
\cline { 2 - 3 } \multicolumn{1}{c|}{} & Frequência & $\begin{array}{c}\text { Percentage } \\
\mathrm{m}(\%)\end{array}$ \\
\hline não & 125 & 73,5 \\
sim & 45 & 26,5 \\
Total & 170 & 100,0 \\
Missing & 43 & \\
Total & 213 & \\
\hline
\end{tabular}

Quadro $12-\mathrm{N}^{\mathrm{o}}$ de incidentes

\begin{tabular}{|c|c|c|}
\cline { 2 - 3 } \multicolumn{1}{c|}{} & $\begin{array}{c}\text { Frequênci } \\
\mathrm{a}\end{array}$ & $\begin{array}{c}\text { Percentage } \\
\mathrm{m}(\%)\end{array}$ \\
\hline 1,00 & 5 & 71,4 \\
2,00 & 2 & 28,6 \\
Total & 7 & 100,0 \\
Missing & 206 & \\
Total & 213 & \\
\hline
\end{tabular}

Quadro 13 - Experiência com acidentes individual com baixa nos últimos 5 anos

\begin{tabular}{|l|c|c|}
\cline { 2 - 3 } \multicolumn{1}{c|}{} & Frequência & Percentagem (\%) \\
\hline 1, não & 164 & 94,8 \\
2, sim & 9 & 5,2 \\
Total & 173 & 100,0 \\
Missing & 40 & \\
Total & 213 & \\
\hline
\end{tabular}

BVI $-\mathbf{5} / \mathbf{1 3}$

Comunidad @ Buenas Prácticas de Seguridad, Salud e Calidad de Vida en el trabajo INIAV

"Factores críticos de éxito" 


\section{Clima de Segurança - Nível Organizacional/Institucional}

Quadro 14 - Existência de normas ou regras de segurança

\begin{tabular}{|ll|c|c|}
\hline & & & \\
& & Frequência & Percentagem (\%) \\
\hline Valid & 1, não & 136 & $\mathbf{7 9 , 1}$ \\
& 2, sim & 36 & 20,9 \\
& Total & 172 & 100,0 \\
Missing & & 41 & \\
Total & & 213 & \\
\hline
\end{tabular}

Quadro 15- Existência de objetivos de segurança

\begin{tabular}{|ll|c|c|}
\hline & & & \\
Valid & 1, não & 128 & $\mathbf{7 6 , 2}$ \\
& 2, sim & 40 & 23,8 \\
& Total & 168 & 100,0 \\
Missing & & 45 & \\
Total & & 213 & \\
\hline
\end{tabular}

Quadro 16 - Existência de equipamento de segurança

\begin{tabular}{|ll|c|c|}
\hline & & \multicolumn{2}{|l|}{$\begin{array}{l}\text { Frequênci } \\
\text { a }\end{array}$} \\
\hline Valid & 1, não & 72 & 44,2 \\
& 2, sim & 91 & $\mathbf{5 5 , 8}$ \\
& Total & 163 & 100,0 \\
Missing & & 50 & \\
Total & & 213 & \\
\hline
\end{tabular}

Quadro 17- Existência de formação sobre segurança

\begin{tabular}{|c|c|c|c|}
\hline & Frequência & Percentagem (\%) \\
\hline Valid & 1 , não & 164 & $\begin{array}{l}94,8 \\
4\end{array}$ \\
\hline & $2, \mathrm{sim}$ & 9 & 5,2 \\
\hline & Total & 173 & 100,0 \\
\hline Missin & & 40 & \\
\hline Total & & 213 & \\
\hline
\end{tabular}

Comunidad @ Buenas Prácticas de Seguridad, Salud e Calidad de Vida en el trabajo INIAV

"Factores críticos de éxito" 
Quadro 18- Existência de departamento de segurança

\begin{tabular}{|ll|c|c|}
\hline & & & \\
& & Frequência & Percentagem (\%) \\
\hline Valid & 1, não & 150 & $\mathbf{8 9 , 3}$ \\
& 2, sim & 18 & 10,7 \\
& Total & 168 & 100,0 \\
Missing & System & 45 & \\
Total & & 213 & \\
\hline
\end{tabular}

Quadro 19 - Variáveis organizacionais de segurança

\begin{tabular}{|l|r|r|r|r|r|}
\hline & $\mathrm{N}$ & Minimo & Maximo & Média & Desvio-padrão \\
\hline $\begin{array}{l}\text { Clima geral de apoio à segurança } \\
\text { (e.g., as pessoas ajudam-se umas às outras a } \\
\text { trabalhar de forma segura) }\end{array}$ & 153 & 1,00 & 7,00 & 3,3873 & 1,28789 \\
$\begin{array}{l}\text { Ações da Direção de apoio à segurança } \\
\text { (e.g., a Direção mostra preocupação pela } \\
\text { segurança mesmo sem ocorrerem acidentes) }\end{array}$ & 160 & 1,00 & 7,00 & 4,3333 & 1,52547 \\
$\begin{array}{l}\text { Qualidade da Comunicação sobre } \\
\text { segurança } \\
\text { (e.g., é dada informação adequada sobre o } \\
\text { que se passa sobre segurança na instituição) }\end{array}$ & 163 & 1,00 & 7,00 & 2,9243 & 1,99839 \\
$\begin{array}{l}\text { Eficácia da Segurança (apenas 2 itens) } \\
\text { (e.g., é dada atenção à manutenção de boas } \\
\text { condiç̃̃es de segurança nas nossas } \\
\text { instalações) }\end{array}$ & 167 & 1,00 & 7,00 & 3,6766 & 1,29884 \\
$\begin{array}{l}\text { Trabalho em segurança mesmo sob } \\
\text { pressão } \\
\text { (e.g., Trabalho em segurança mesmo quando } \\
\text { tenho pouco tempo para fazer as minhas } \\
\text { tarefas) }\end{array}$ & 154 & 1,00 & 7,00 & 4,9221 & 1,38252 \\
$\begin{array}{l}\text { Implicação na segurança } \\
\text { (e.g., nesta instituição todos os indivíduos } \\
\text { partilham a responsabilidade pela segurança) }\end{array}$ & 157 & 1,00 & 7,00 & 3,9066 & 1,57429 \\
$\begin{array}{l}\text { Internalização da segurança } \\
\text { (e.g., As pessoas trabalham de forma segura } \\
\text { mesmo quando o chefe não está a } \\
\text { supervisionar) }\end{array}$ & 96 & 1,00 & 7,00 & 3,8594 & 1,40432 \\
$\begin{array}{l}\text { Orgulho na segurança } \\
\text { (e.g., as pessoas têm orgulho por se trabalhar } \\
\text { de forma segura) }\end{array}$ & 152 & 1,00 & 7,00 & 3,5811 & 1,32752 \\
\hline
\end{tabular}

Escala de concordância: 1= Discordo totalmente; 2= Discordo bastante; 3= Discordo em parte; 4= Não concordo nem discordo; $5=$ Concordo em parte; $6=$ Concordo bastante ; $7=$ Concordo totalmente

BVI - 7/13

Comunidad @ Buenas Prácticas de Seguridad, Salud e Calidad de Vida en el trabajo INIAV

"Factores críticos de éxito" 


\section{Clima de Segurança - Nível do Grupo/equipa de trabalho}

Quadro 20 - Variáveis grupais relativas à segurança

\begin{tabular}{|c|c|c|c|c|c|}
\hline & $\mathrm{N}$ & Minimo & Maximo & Média & $\begin{array}{l}\text { Desvio- } \\
\text { padrão }\end{array}$ \\
\hline $\begin{array}{c}\text { Ações dos supervisores } \\
\text { Risco } \\
\text { (e.g., o meu chefe não mostra grande preocupação } \\
\text { com a segurança até existir um acidente) } \\
\text { Segurança } \\
\text { (e.g. o meu chefe faz um elogio quando vê um } \\
\text { trabalho executado de acordo com as normas de } \\
\text { segurança) }\end{array}$ & 158 & 1,00 & 7,00 & 4,3059 & 1,38550 \\
\hline $\begin{array}{c}\text { Ações dos colegas } \\
\text { Risco } \\
\begin{array}{c}\text { (e.g., os meus colegas não mostram grande } \\
\text { preocupação com a segurança até existir um } \\
\text { acidente) } \\
\text { Segurança } \\
\text { (e.g., os meus colegas fazem sugestões com o } \\
\text { objetivo de melhorar a segurança) }\end{array}\end{array}$ & 159 & 1,00 & 7,00 & $\begin{array}{l}3,2222 \\
4,2474\end{array}$ & $\begin{array}{l}1,56093 \\
1,65320\end{array}$ \\
\hline
\end{tabular}

Escala de concordância: 1= Discordo totalmente; 2= Discordo bastante; 3= Discordo em parte; 4= Não concordo

nem discordo; $5=$ Concordo em parte; $6=$ Concordo bastante $; 7=$ Concordo totalmente

BVI $-8 / 13$

Comunidad @ Buenas Prácticas de Seguridad, Salud e Calidad de Vida en el trabajo INIAV

"Factores críticos de éxito" 


\section{Comportamentos da equipa e do indivíduo}

Quadro 21- Variáveis grupais e individuais relativas a comportamentos de segurança

\begin{tabular}{|c|c|c|c|c|c|}
\hline & $\mathrm{N}$ & Minimo & Maximo & Média & $\begin{array}{l}\text { Desvio- } \\
\text { padrão }\end{array}$ \\
\hline $\begin{array}{l}\text { Comportamentos da sua Equipa } \\
\text { Participação na segurança (papel ativo) } \\
\text { (e.g., no último ano o meu grupo de trabalho fez } \\
\text { sugestões ao nosso chefe com o objetivo de } \\
\text { melhorar a segurança no local de trabalho) }\end{array}$ & 153 & 1,00 & 7,00 & 4,2222 & 1,73247 \\
\hline $\begin{array}{c}\text { Cumprimento de Normas de segurança (papel } \\
\text { passivo) } \\
\text { (e.g., no último ano o meu grupo de trabalho } \\
\text { cumpriu as regras de segurança) } \\
\text { Risco/negligência } \\
\text { (e.g., no último ano o meu grupo de trabalho } \\
\text { modificou equipamento/máquinas para ganhar } \\
\text { tempo) }\end{array}$ & 148 & 1,00 & 4,00 & 1,4481 & 1,57289 \\
\hline $\begin{array}{l}\text { Comportamentos do Indivíduo } \\
\text { Participação e cumprimento de normas na } \\
\text { segurança } \\
\text { (e.g., no último ano eu utilizei todo o equipamento } \\
\text { de proteção individual necessário para o } \\
\text { desempenho do meu trabalho) }\end{array}$ & 148 & 1,00 & 7,00 & 4,7662 & 1,49291 \\
\hline $\begin{array}{c}\text { Negligência } \\
\text { (e.g., no último ano eu modifiquei } \\
\text { equipamento/máquinas para ganhar tempo) } \\
\text { Risco } \\
\text { (e.g., no último ano eu corri riscos para despachar o } \\
\text { trabalho mais rapidamente) }\end{array}$ & $\begin{array}{l}157 \\
156\end{array}$ & 1,00 & 4,00 & $\begin{array}{l}1,3631 \\
2,6795\end{array}$ & $\begin{array}{r}, 71300 \\
1,57393\end{array}$ \\
\hline
\end{tabular}

BVI - 9/13

Comunidad @ Buenas Prácticas de Seguridad, Salud e Calidad de Vida en el trabajo INIAV

"Factores críticos de éxito" 
$\underline{\text { Relativamente às variáveis psicossociais estudadas, encontram-se no Quadro } 22 \text { as médias, }}$ desvios-padrão e valores mínimos e máximos respetivos.

\section{Quadro 22 - variáveis psicossociais}

\begin{tabular}{|c|c|c|c|c|c|}
\hline VARIÁVEIS ESTUDADAS & $\mathrm{N}$ & Mínimo & Máximo & Média & $\begin{array}{l}\text { Desvio- } \\
\text { padrão }\end{array}$ \\
\hline \multicolumn{6}{|l|}{ IMAGEM ORGANIZACIONAL } \\
\hline Imagem percebida & 106 & 1,00 & 7,00 & 3,9198 & 1,19749 \\
\hline Prestígio percebido & 98 & 1,00 & 7,00 & 4,1388 & 1,09973 \\
\hline \multicolumn{6}{|l|}{$\begin{array}{l}\text { INTERDEPENDÊNCIA NO EXERCÍCIO DA } \\
\text { FUNCÃO }\end{array}$} \\
\hline Interdependência recíproca & 107 & 1,00 & 6,75 & 4,5210 & 1,22095 \\
\hline \multicolumn{6}{|l|}{$\begin{array}{l}\text { PERCEPÇÃO DE SUPORTE NO LOCAL DE } \\
\text { TRABALHO }\end{array}$} \\
\hline Perceção de suporte organizacional & 103 & 1,00 & 6,38 & 3,6735 & 1,30154 \\
\hline \multicolumn{6}{|l|}{ IDENTIFICAÇÃO } \\
\hline Identificação com a organização & 107 & 2,00 & 7,00 & 5,0748 & 1,27221 \\
\hline Identificação com a profissão & 110 & 1,00 & 7,00 & 5,3782 & 1,05286 \\
\hline \multicolumn{6}{|l|}{ IMPLICAÇÃO ORGANIZACIONAL } \\
\hline Implicação afetiva & 111 & 1,00 & 7,00 & 4,8198 & 1,32509 \\
\hline Implicação normativa & 105 & 1,00 & 7,00 & 4,0643 & 1,34942 \\
\hline Implicação continuidade & 102 & 1,00 & 6,75 & 3,4975 & 1,31701 \\
\hline \multicolumn{6}{|l|}{$\begin{array}{l}\text { CONFLITO ENTRE O TRABALHO E A } \\
\text { FAMÍLIA }\end{array}$} \\
\hline conflito trabalho-família & 107 & 1,00 & 6,25 & 2.9486 & 1,20618 \\
\hline conflito família-trabalho & 104 & 1,00 & 4,75 & 2,1082 & ,93785 \\
\hline \multicolumn{6}{|l|}{ AJUSTAMENTO DO INDIVÍDUO } \\
\hline Ajustamento pessoa-organização & 104 & 1,00 & 7,00 & 3,8654 & 1,46334 \\
\hline Ajustamento pessoa-trabalho & 109 & 1,00 & 7,00 & 4,9778 & 1,15290 \\
\hline \multicolumn{6}{|l|}{ ATITUDE FACE À MUDANÇA } \\
\hline $\begin{array}{l}\text { Atribuição situacional das consequências da } \\
\text { mudança }\end{array}$ & 108 & 1,33 & 7,00 & 3,5000 & 1,27399 \\
\hline Pessimismo relativamente à mudança & 107 & 1,00 & 7,00 & 3,2033 & 1,17669 \\
\hline \multicolumn{6}{|l|}{$\begin{array}{l}\text { COMPORTAMENTOS DE CIDADANIA } \\
\text { ORGANIZACIONAL }\end{array}$} \\
\hline Dedicação ao trabalho & 112 & 3,00 & 7,00 & 5,9487 &, 78710 \\
\hline Dedicação ao trabalho extra-horário & 106 & 1,00 & 7,00 & 4,2075 & 1,45384 \\
\hline \multicolumn{6}{|l|}{ INTENÇÃO DE SAÍDA } \\
\hline Intenção de turnover & 112 & 1 & 7 & 2.0804 & 1.55898 \\
\hline
\end{tabular}

Escala: 1= Discordo totalmente; 2= Discordo bastante; 3= Discordo em parte; 4= Não concordo nem discordo; 5=

Concordo em parte; 6= Concordo bastante; $7=$ Concordo totalmente

BVI - 10/13

Comunidad @ Buenas Prácticas de Seguridad, Salud e Calidad de Vida en el trabajo INIAV

"Factores críticos de éxito" 
Doctorado en Salud, Discapacidad, Dependencia y Bienestar

\section{$\underline{\text { Resultados de clima organizacional }}$}

\section{Variáveis organizacionais}

\begin{tabular}{|l|r|r|r|r|r|}
\hline & $\mathrm{N}$ & Mínimo & Máximo & Média & \multicolumn{1}{c|}{$\begin{array}{c}\text { Desvio- } \\
\text { padrão }\end{array}$} \\
\hline Objetivos & 111 & 1,33 & 7,00 & 5,0450 & 1,33370 \\
Inovação & 108 & 1,00 & 7,00 & 4,6537 & 1,32456 \\
Apoio & 107 & 1,00 & 6,80 & 4,7402 & 1,37778 \\
Regras & 109 & 2,00 & 7,00 & 4,9235 & 1,16943 \\
\hline
\end{tabular}

Escala: 1= nada importante ou nada frequente; 7 = muitíssimo importante ou muitíssimo frequente

\section{ANÁLISE E DISCUSSÃO DOS RESULTADOS - Características da amostra de participantes:}

Neste estudo, um total de 213 indivíduos responderam ao primeiro questionário e 121 indivíduos responderam ao segundo questionário (Quadro 1). Há a registar algumas diferenças importantes entre o número de funcionários que responderam ao primeiro questionário e os que responderam ao segundo. Assim, os departamentos de Ciência do Solo, Entomologia, Estatística, Fisiologia e Serviços Sociais, foram os que registaram as maiores diferenças (Quadro 2). Dos 121 participantes no segundo questionário, 33 eram do sexo masculino e 72 do sexo feminino, sendo que 16 pessoas não responderam à questão relativa a este item (Quadro 3). O nível de escolaridade destes participantes, esteve na sua maioria acima do $12^{\circ}$ ano de escolaridade, sendo que $24.8 \%$ possui um grau equivalente ao doutoramento (Quadro 4), e 73.9\% encontra-se já há mais de 17 anos na instituição (Quadro 5) e a maioria não desempenha cargos de chefia(Quadro 6) e apresenta idades entre os 51 e 60 anos (Quadro 7).

No que se refere à experiência com acidentes de trabalho, verifica-se que a maior parte dos 213 funcionários não indica ter tido experiência com acidentes individuais (78.3\%) . 63,0\% teve um acidente de trabalho e $26,5 \%$ relata ter tido experiência com um incidente de trabalho, 94,8\% admite não ter tido acidentes de trabalho que motivaram baixa nos últimos cinco anos.

No que se refere à existência de normas ou regras de Segurança a maior parte dos 213 funcionários $79,1 \%$ (quadro 14) afirma a não existência de normas escritas e o seu desconhecimento, assim como76,2 \% (quadro 15) afirma a inexistência de objetivos de Segurança. Dos 213 funcionários -89,3\%

BVI - 11/13

Comunidad @ Buenas Prácticas de Seguridad, Salud e Calidad de Vida en el trabajo INIAV

"Factores críticos de éxito" 


\section{Doctorado en Salud, Discapacidad, Dependencia y Bienestar}

(quadro 18) declara a não existência do departamento de Segurança. No quadro 17 podemos observar que a grande maioria dos funcionários assume que não teve acesso a ações de formação no âmbito da Higiene, Saúde e Segurança no Trabalho. Podemos também observar que 55,8\% dos funcionários afirmam a existência de equipamento de Segurança ao contrário de 44,2\% que não tem equipamento de Segurança (quadro 16).

O quadro 19 apresenta-nos os resultados das variáveis organizacionais de Segurança e da análise da escala de concordância apresentada, há a salientar que a dimensão que se refere à perceção dos trabalhadores sobre as ações da direção da organização em estudo ao nível da Higiene, Saúde e Segurança no Trabalho tem aqui um valor positivo que é uma referência a termos em consideração no envolvimento da Direção num processo de mudança face à Higiene, Saúde e Segurança no Trabalho.

A qualidade da comunicação sobre a Segurança enfatiza até que ponto as Comunicações funcionam na organização, nomeadamente se é eficiente e se abrange todos os Trabalhadores, o valor apresentado nesta dimensão é um valor negativo e há que investir numa comunicação eficaz num processo interventivo.

$\mathrm{O}$ efeito do ritmo de trabalho sobre a Segurança refere-se às perceções que os trabalhadores têm sobre os efeitos da pressão para a produção e pressão de tempo na Segurança. Esta dimensão apresenta um valor de concordância acima do meio da escala que é um fator positivo.

A eficácia da Segurança avalia o modo como a importância atribuída à Segurança se reflete nas práticas das rotinas diárias da organização, apresentando um valor neutro havendo necessidade de o inverter no sentido positivo cativando as chefias de departamento e chefias intermédias.

Outra variável analisada avalia a perceção da internalização das normas de Segurança organizacionais e aparece com um valor neutro o que manifesta que a Segurança ainda não é um valor da organização em estudo.

A implicação pessoal da Segurança avalia a perceção do envolvimento dos trabalhadores na Segurança através da partilha da responsabilidade pela Segurança na organização e por optarem por uma conduta segura no trabalho apresentando aqui um valor também neutro que nos leva a pensar também no investimento em termos de sensibilização e ações de formação direcionadas para a mudança comportamental.

BVI - 12/13

Comunidad @ Buenas Prácticas de Seguridad, Salud e Calidad de Vida en el trabajo INIAV

"Factores críticos de éxito" 


\section{Doctorado en Salud, Discapacidad, Dependencia y Bienestar}

Outra variável estudada é o orgulho na Segurança que avalia a perceção dos sentimentos de satisfação pessoal, com o desempenho em Segurança, quer pelos indivíduos, quer pela organização e o valor apresentado pode ser melhorado se investirmos seriamente na formação de um grupo animador de Segurança.

Vamos agora analisar o clima de Segurança ao nível do grupo/equipa de trabalho. O quadro 20 apresentanos valores numa escala de concordância das variáveis grupais relativas à Segurança e os valores apresentados ao nível da perceção que os trabalhadores têm sobre Acão dos seus supervisores, ao nível quer do risco quer da Segurança são valores positivos e aos quais teremos que atender como facilitadores num processo de mudança, o mesmo acontece nas ações dos colegas ao nível da perceção que o trabalhador tem sobre os seus colegas de trabalho apesar desta perceção ser mais positiva em relação aos supervisores.

No quadro 21 numa escala de frequência dá-nos as variáveis grupais e individuais relativas a comportamentos de Segurança e o que podemos observar são valores favoráveis quer ao nível do comportamento do indivíduo quer ao nível dos comportamentos da sua equipa de trabalho. $\mathrm{O}$ valor apresentado revela que não há negligência quer a nível do comportamento individual ou de equipa. Os comportamentos da sua equipa de trabalho são tidos como um papel ativo ao nível da Segurança e que pode ainda ser melhorado.

O clima organizacional é avaliado através do modelo dos valores contrastantes e verificamos que os valores se situam todos acima do ponto médio da escala ao nível dos objetivos, inovação, apoio e regras, o que significa um clima positivo. Os trabalhadores partilham a perceção de que a organização valoriza mais os objetivos e as regras revelando os resultados a existência de uma preocupação em definir uma missão e objetivos claros para a organização.

Relativamente às variáveis psicossociais estudadas que se encontram no quadro 22 as médias, desvios padrão e valores mínimos e máximos observados numa escala de concordância podemos recolher dados muito favoráveis para a implementação de mudanças. Verificamos uma identificação positiva com a organização e com a profissão, uma implicação afetiva. Também verificamos que o valor médio apresentado na relação trabalho-família é favorável, há também um valor médio positivo em relação ao ajustamento pessoa-trabalho. Ao nível de comportamentos de cidadania organizacional temos um valor positivo em relação à dedicação ao trabalho e um valor positivo em relação à continuidade na organização.

BVI - 13/13

Comunidad @ Buenas Prácticas de Seguridad, Salud e Calidad de Vida en el trabajo INIAV

"Factores críticos de éxito" 
Doctorado en Salud, Discapacidad, Dependencia y Bienestar

\author{
UNIVERSIDAD DE LEÓN
}

DEPARTAMIENTO DE ENFERMERIA Y FISIOTERAPIA

Programa de Doctorado titulado "Salud, Discapacidad, Dependencia y Bienestar" Comunidad@Buenas Prácticas de Seguridad, Salud e Calidad de Vida en el trabajo INIAV "Factores críticos de éxito"

\title{
Comunidade@boas práticas segurança, saúde e qualidade de vida no trabalho INIAV \\ "Fatores críticos de sucesso" \\ Élia Cristina de Sousa Figueiredo
}

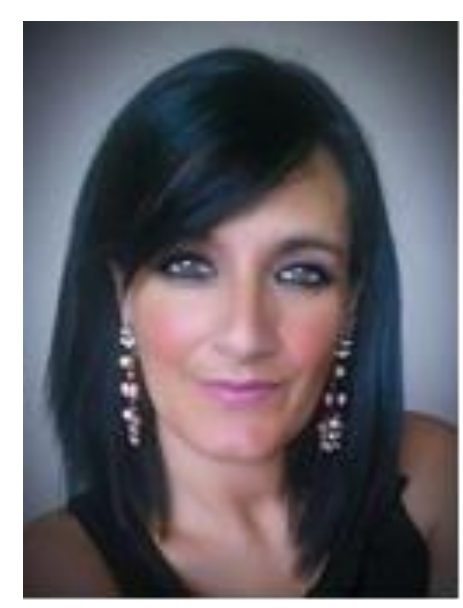

Tags: Comunidades de Prática; CoP; Práticas essenciais; Práticas inibidoras; Trabalho colaborativo; SST; Partilha de conhecimento; CoPV

Contatos:

http://wiki.iniav.pt/

Email: esousf00@estudiantes.unileon.es

Mobile: 0351925229960

Mobile: 0351987291000

Universidad de Léon

Campus de Vegazana $\mathrm{S} / \mathrm{N}$

24071 Léon

Comunidad@Buenas Prácticas de Seguridad, Salud e Calidad de Vida en el trabajo INIAV

"Factores críticos de éxito" 